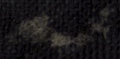

1

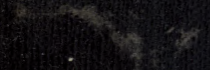

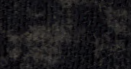

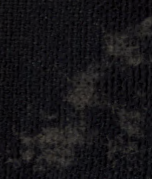

bat?

37.<smiles>C1=C[As]2CC[N+]2=C1</smiles>
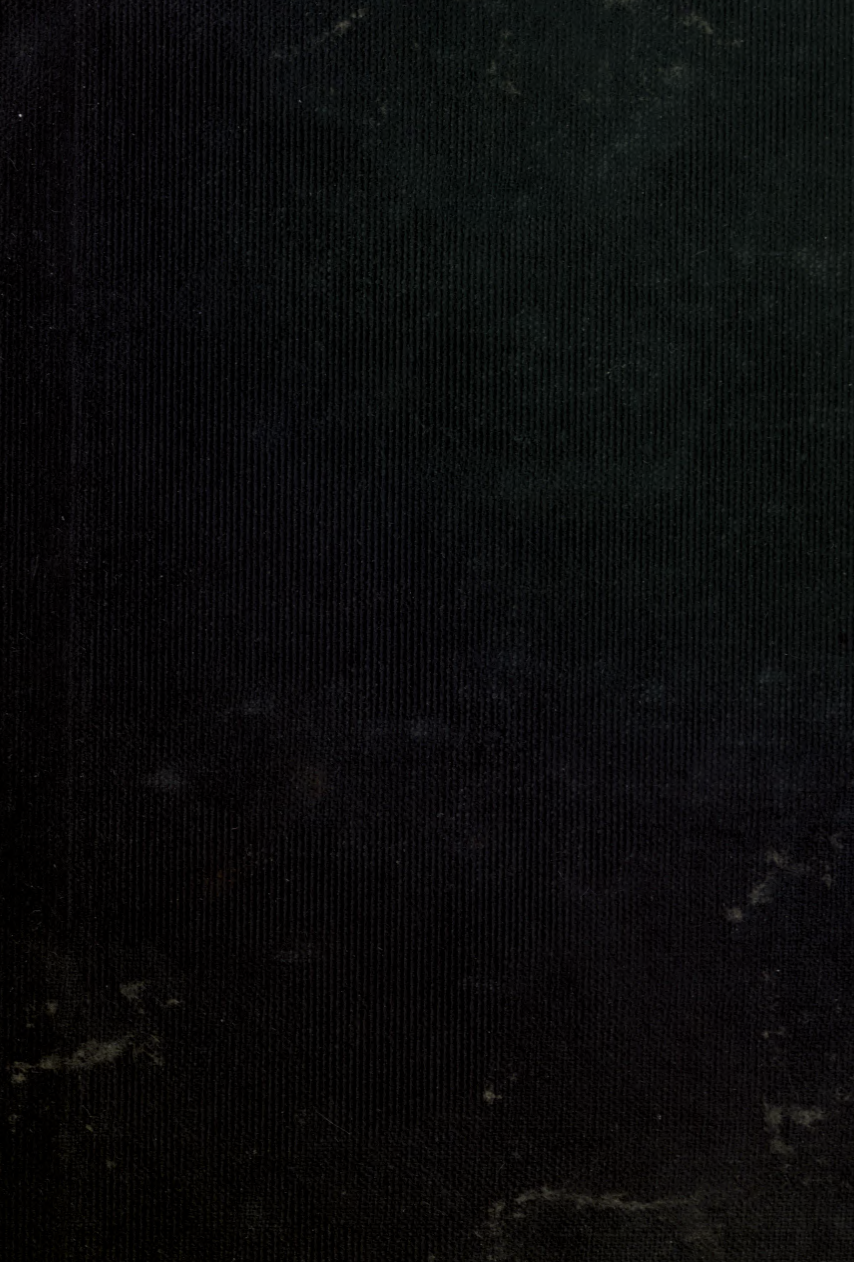

(x) 



\section{FOUNDATIONS OF BIOLOGY}




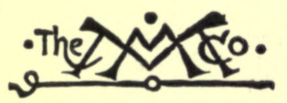

THE MACMILLAN COMPANY

NEW YORK - BOSTON - CHICAGO DALLAS - ATLANTA - SAN FRANCISCO

MACMILLAN \& CO., LIMITED

LONDON - BOMBAY - CALCUTTA MELBOURNE

THE MACMILLAN CO. OF CANADA, LTB. TORONTO 


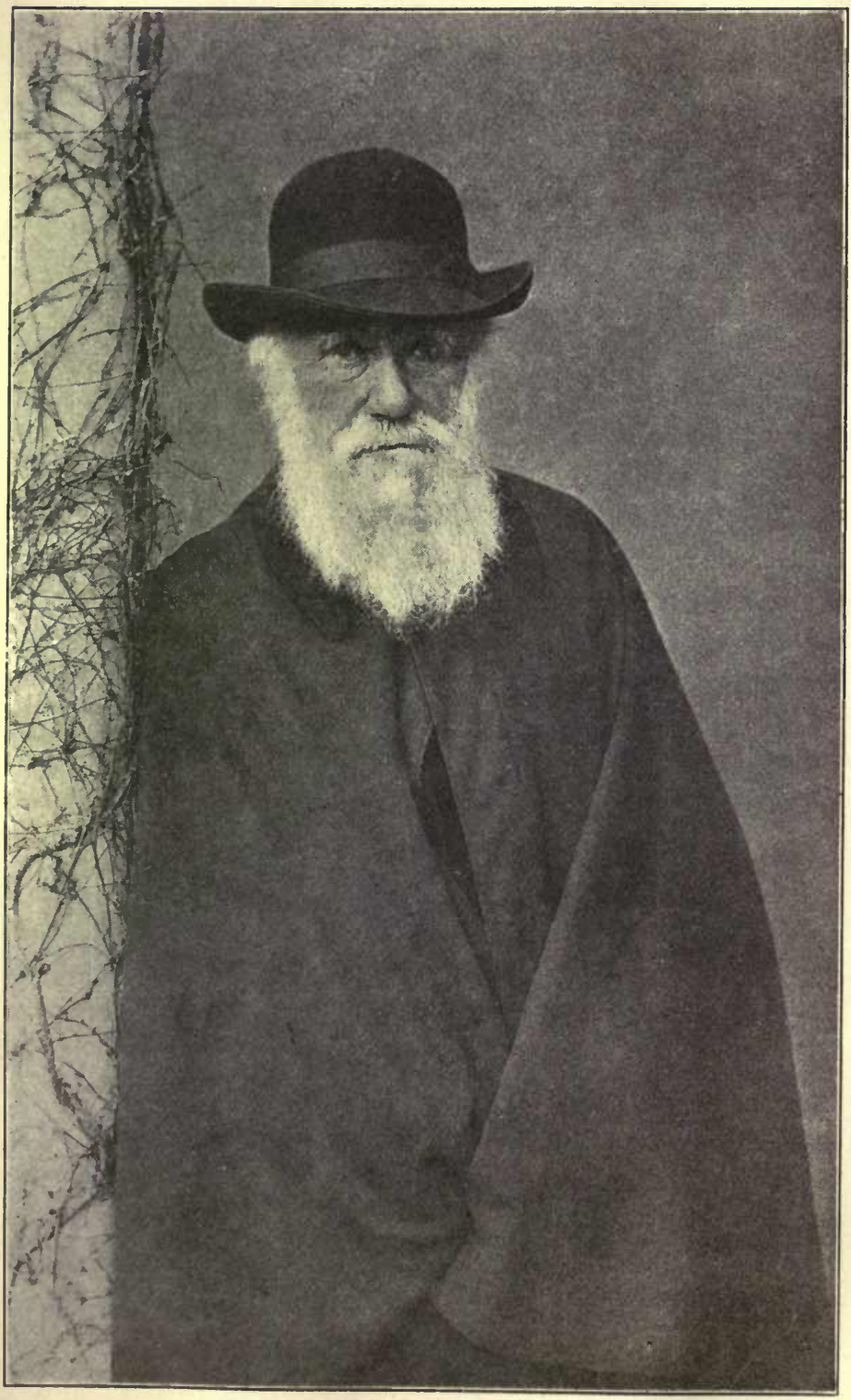

Ch. Danwin 


\title{
FOUNDATIONS OF BIOLOGY
}

BY

\section{LORANDE LOSS WOODRUFF}

\author{
PROFESSOR OF BIOLOGY IN YALE UNIVERSITY
}

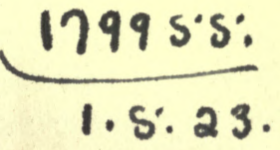

\section{止ew 勛ork \\ THE MACMILLAN COMPANY \\ 1922}

All rights reserved 
PRINTED IN THE UNITED STATES OF AMERICA

Copyright, 1922,

BY THE MACMILLAN COMPANY

Sot up and electrotyped. Published June, 1922 


\section{PREFACE}

The present volume brings together in brief form the fundamental principles of biology for the college student and the general reader.

It is well recognized that there is no adequate substitute for detailed laboratory work on the structure and physiology of representative organisms as a means of affording a firsthand knowledge of the facts and methods of biology. However, the author has realized with increasing force that the student's correlation of the laboratory data from day to day and accordingly his appreciation of the broader aspects of the subject are greatly enhanced by a synchronous 'running account' of the underlying principles. The material in this volume has proved to be of great value for this purpose in a course on General Biology elected each year by several hundred Yale undergraduates.

The large problems of life are common to both zoölogy and botany, and therefore both animals and plants have been drawn upon for illustration and discussion. This method of presentation accords with the author's conviction that the general biological viewpoint is the most favorable means of approach both to a broad knowledge of living phenomena as a part of a 'liberal' education, and to more advanced studies in zoölogy and botany which are prerequisite for 
medicine, forestry, etc. As is natural, however, the zoölogical aspect has been emphasized since it affords indispensable data for the interpretation of Man himself. For courses in general zoölogy, therefore, the book will be found adequate in its treatment of animals, while chapters VIII and IX on plants may readily be omitted, without breaking the continuity of the discussion.

The author is indebted, of course, to innumerable sources for the facts and principles outlined. The content has grown by accessions year by year. Nearly all the standard treatises have been drawn upon, but those which have been most generally suggestive are listed in the bibliographies of the respective chapters. Specific mention, however, should be made here of Professor Wilder's History of the Human Body, Professor Conklin's Heredity and Environment in the Development of Men, Professor Ganong's Text-book of Botany, and Professor Coulter's Evolution of Sex in Plants.

The author has availed himself of the constructive criticism generously given by Professor B. W. Kunkel of Lafayette College, Professor E. H. Cameron of the University of Illinois, and his colleagues at Yale, Professors R. G. Harrison, W. R. Coe, A. Petrunkevitch, F. P. Underhill, Henry Laurens, G. A. Baitsell, W. W. Swingle, and Dr. J. W. Buchanan, who have read the book either in manuscript or in the mimeographed form in which it has been used by the Yale classes. And Professor Baitsell's interest in the work of the course has made it possible to impose upon him the added task of reading the book at each stage of its development. Miss Hope Spencer of the Yale Laboratory has assumed with enthusiasm a considerable portion of the editorial work involved in seeing the book through the press. Finally, the author's indebtedness to the criticism and 
coöperation of his wife, Margaret Mitchell Woodruff, must not remain unmentioned, though it cannot be adequately expressed.

The original illustrations as well as those from other sources which have been modified or merely redrawn are, with a few exceptions, the work of Mr. R. E. Harrison, Yale, 1923. In most cases these figures have been selected because of their proved pedagogic value. Acknowledgments are due to the authors and publishers of the following works, from which illustrations have been reproduced by permission: Coulter, Barnes, and Cowles' Textbook of Botany, Coulter's Plant Life and Plant Uses (American Book Co.); Kellicott's Social Direction of Human Evolution, Jordan and Kellogg's Evolution and Animal Life, Darwin's Life and Selected Letters, Huxley's Life and Letters (D. Applẹton \& Co.); Folsom's Entomology, Gager's Fundamentals of Botany (P. Blakiston's Sons \& Co.); Jennings' Behavior of the Lower Organisms (Columbia University Press); Bergen's Foundations of Botany, Bergen and Caldwell's Practical Botany, Bergen and Davis' Principles of Botany, Densmore's General Botany, Hough and Sedgwick's The Human Mechanism, Linville and Kelly's General Zoölogy (Ginn \& Co.); Kellicott's General Embryology, Sedgwick and Wilson's General Biology (Henry Holt \& Co.); Morgan's Physical Basis of Heredity (J. P. Lippincott \& Co.); Romanes' Darwin and After Darwin (Open Court Publishing Co.); Conklin's Heredity and Environment in the Development of Men (Princeton University Press); Conn and Budington's Physiology and Hygiene (Silver, Burdett \& Co.); Coulter's Evolution of Sex in Plants (University of Chicago Press); Abbott's General Biology, Buchanan and Buchanan's Bacteriology, Campbell's University Textbook of Botany, Ganong's Textbook of Botany for Colleges, Hegner's College Zoölogy, and 
Introduction to Zoölogy, Holmes' Biology of the Frog, Huxley's Physiology, Lankester's Treatise on Zoölogy, Lull's Organic Evolution, Packard's Textbook of Entomology, Parker's The Elementary Nervous System, Parker and Haswell's Textbook of Zoölogy, Parker and Parker's Practical Zoölogy, Scott's The Theory of Evolution, Shipley and McBride's Zoölogy, Verworn's General Physiology, Walter's Genetics, and The Human Skeleton, Wiedersheim's Comparative Anatomy of Vertebrates, Wilson's The Cell (The Macmillan Co.). To The Macmillan Company is also due the author's appreciation of the liberal attitude which they have assumed in all the arrangements attendant upon the publication of the book.

L. L. Woodruff.

Yale University,

May, 1922. 


\section{CONTENTS}

CHAPTER

I. The Scope of Biology . . . . . . .

II. The Physical Basis of life . . . . . . . . 6

A. Protoplasm . . . . . . . . . . . . 7

B. Characteristics of Living Matter . . . . . 10

1. Chemical Composition . . . . . . . 11

2. Metabolism . . . . . . . . . 15

3. Growth . . . . . . . . . . . 16

4. Reproduction . . . . . . . . . 17

5. Adaptation . . . . . . . . . . . . 17

6. Organization . . . . . . . . . . 18

III. Organizational Units of Plants and Animals . 21

A. The Cell . . . . . . . . . . . 23

1. Cytoplasm . . . . . . . . . . 24

2. Nucleus . . . . . . . . . . . 27

B. Origin of Cells . . . . . . . . . . . 28

IV. Metabolism of Green Plants . . . . . . . 30

A. Structure and Life History of Sphaerella . . . 30

B. Metabolism in Sphaerella . . . . . . . 34

1. Food Making . . . . . . . . . . 35

2. Respiration . . . . . . . . . . 37

V. Metabolism of Animals . . . . . . . . . . 39

A. Structure and Life History of Paramecium . . 39

B. Metabolism in Paramecium . . . . . . 41

1. Food Taking . . . . . . . . . . . . . 42

2. Respiration and Excretion . . . . . 43

Vi. Metabolism of Colorless Plants . . . . . 44

A. The Bacteria . . . . . . . . . . . 44

B. Cycle of the Elements in Nature . . . . . 46

C. The Hay Infusion Microcosm . . . . . . 50

VII. The Multicellular Organism . . . . . . 54

VIII. The Plant Body . . . . . . . . . . . 61

A. Gross Structure . . . . . . . . . . 65

1. Root . . . . . . . . . . . 65

2. Stem . . . . . . . . . . . $\quad$. 69

3. Leaf . . . . . . . . . . 71 
VIII. The Plant Body-Continued

B. Histology . . . . . . . . . . . . 75

1. Root . . . . . . . . . . . 78

2. Stem . . . . . . . . . . . . 81

3. Leaf . . . . . . . . . . . . 82

C. Physiology . . . . . . . . . . . . . . $\quad$. 84

1. Circulation Paths . . . . . . . . . 85

2. Dynamics of Circulation . . . . . . . 88

3. Food Utilization . . . . . . . . . . 89

IX. Reproduction in Plants . . . . . . . . . . 91

A. Spore Formation . . . . . . . . . . . . . 92

B. Gamete Formation . . . . . . . . . 94

C. Sex Differentiation . . . . . . . . . . 96

D. Reproductive Organs . . . . . . . . . . $\quad .98$

E. Alternation of Generations . . . . . . 100

1. The Moss . . . . . . . . . . 100

2. The Fern . . . . . . . . . . 103

3. Higher Ferns . . . . . . . . . 105

4. Flowering Plants . . . . . . . . 107

X. The Animal Body . . . . . . . . . . . . 115

A. The Chief Groups of Animals . . . . . . 116

B. Hydra . . . . . . . . . . . . . 118

C. Earthworm . . . . . . . . . . . 121

D. Crayfish . . . . . . . . . . . 129

E. Vertebrates . . . . . . . . . . . 135

1. Body Plan . . . . . . . . . . 136

2. Skin . . . . . . . . . . . . 138

3. Muscles . . . . . . . . . . . . 138

4. Coelom . . . . . . . . . . . 140

5. Skeleton . . . . . . . . . . 140

F. Diagnostic Vertebrate Characters . . . . . 146

XI. Nutrition in Animals . . . . . . . . . 154

A. The Alimentary Canal . . . . . . . . . 154

B. Digestion . . . . . . . . . . . . 157

XII. Circulation and Respiration in Animals . . 161

A. Circulation in the Lower Vertebrates . . . . 162

B. Respiration . . . . . . . . 168

C. Circulation in the Higher Vertebrates . . . . 170

XIII. Excretion in Animals . . . . . . . . . 175

XIV. Coördination in Animals . . . . . . . . 181

A. Chemical Coördination . . . . . . . . 181

B. Coördination by the Nervous System . . . . 183 
XIV. Coördination in Animals-Continued

C. Sense Organs

1. Cutaneous Senses . . . . . . . . . 195

2. Sense of Taste . . . . . . . . . . . .

3. Sense of Smell . . . . . . . . . . . 196

4. The Ear . . . . . . . . . . . 196

5. The Eye . . . . . . . . . . . 198

XV. Reproduction in Animals . . . . . . . . 203

XVI. Origin of the Individual . . . . . . . . 209

A. Origin of Life . . . . . . . . . . . . . 209

B. Reproduction . . . . . . . . . 212

C. Origin of the Germ Cells . . . . . . . . 223

1. Mitosis . . . . . . . . . . . 224

2. Gametes . . . . . . . . . . 228

3. Spermatogenesis . . . . . . . . . 230

4. Oögenesis . . . . . . . . . . . . 232

5. The Chromosome Cycle . . . . . . . 233

6. Fertilization . . . . . . . . . 237

D. Significance of Fertilization . . . . . . . . 242

1. Protista . . . . . . . . . 243

2. Metazoa . . . . . . . . . . 249

E. Organization of the Zygote . . . . . . . 251

XVII. Herttage of the Individual . . . . . . . 261

A. Heritability of Variations . . . . . . . . 264

1. Modifications . . . . . . . . . 265

2. Combinations . . . . . . . . . . . 268

3. Mutations . . . . . . . . . . 269

B. Galton's 'Laws' . . . . . . . . . . 269

C. Mendelism . . . . . . . . . . . 271

1. Monohybrids . . . . . . . . . 272

2. Dihybrids . . . . . . . . . . 276

3. Trihybrids . . . . . . . . . . 280

4. General Principles . . . . . . . : 280

D. Neo-Mendelism . . . . . . . . . . 282

E. Mechanism of Mendelian Inheritance . . . . 287

1. Sex Determination . . . . . . . 291

2. Linkage . . . . . . . . . . . 293

F. Nature versus Nurture . . . . . . . . 296

G. Selection . . . . . . . . . . . 299

Pure Lines . . . . . . . . . 303

Summary 
A. Adaptations to the Physical Environment . 308

1. Adaptations Essentially Functional . . . 308

Food . . . . . . . . . . . 308

Temperature . . . . . . . . . 311

Pressure . . . . . . . . . . . 313

2. Adaptations Essentially Structural . . . 313

Adaptive Radiation of Mammals . . . 313

Animal Coloration . . . . . . . . 319

The Legs of the Honey Bee. . . . . . 324

B. Adaptations to the Living Environment . . . 330

1. Communal Associations . . . . . . . 331

2. Symbiosis . . . . . . . . . . 331

3. Parasitism . . . . . . . . . . 334

4. Immunity . . . . . . . . . . 338

C. Individual Adaptability . . . . . . . . . 339

XIX. The Origin of Species . . . . . . . . . . 345

A. Evidences of Organic Evolution . . . . . 347

1. Taxonomy . . . . . . . . . 348

2. Comparative Anatomy . . . . . . . 351

3. Paleontology . . . . . . . . . 356

4. Embryology . . . . . . . . . 364

5. Physiology . . . . . . . . . . 367

6. Distribution . . . . . . . . . 368

B. Factors of Organic Evolution . . . . . . 372

XX. Epochs in Biological History . . . . . . 379

A. Greek and Roman Science . . . . . . . . 379

B. Medieval and Renaissance Science . . . . 382

C. The Microscopists . . . . . . . . . 386

D. The Development of the Subdivisions of Biology 389

1. Taxonomy . . . . . . . . . . 390

2. Comparative Anatomy . . . . . . . 392

3. Physiology . . . . . . . . . . 394

4. Histology . . . . . . . . . . 398

5. Embryology . . . . . . . . . 401

6. Genetics . . . . . . . . 403

7. Organic Evolution . . . . . . . . 406

APPENDIX

I. Classification . . . . . . . . . . 413

A. Plants . . . . . . . . . . . 413

B. Animals . . . . . . . . . . . . 414

II. Bibliography . . . . . . . . . . . . . 417

III. Glossary . . . . . . . . . . . . . . . 429 


\section{LIST OF ILLUSTRATIONS}

FIGURE

TITLE

PAGE

Charles Darwin

1 The divisions of biology

Frontispiece

2 Amoeba proteus. .

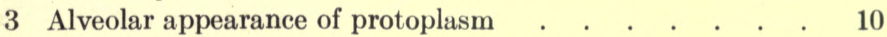

4 Cells . . . . . . . . . . . . . . . . 21

5 Section of a leaf . . . . . . . . . . . . . . . . . 22

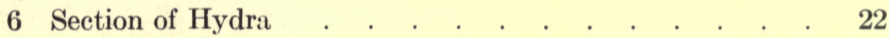

7 Types of cells . . . . . . . . . . . . . . . . . . . . 25

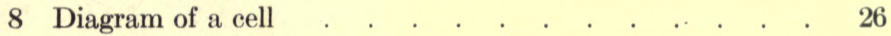

9 Life cycle of Sphaerella . . . . . . . . . . . . . . . . . . 32

10 Paramecium calkinsi . . . . . . . . . . . . . . . 40

11 Paramecium aurelia, dividing . . . . . . . . . . . . . . 41

12 Paramecia conjugating . . . . . . . . . . . . . . . 42

13 Types of Bacteria . . . . . . . . . . . . . . . 45

14 Types of flagellation in Bacteria . . . . . . . . . 46

15 The carbon cycle . . . . . . . . . . . . . 48

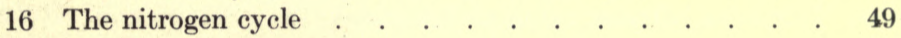

17 Spondylomorum . . . . . . . . . . . . . 55

18 Volvox globator . . . . . . . . . . . . . . . 56

19 Cleavage of Sea Urchin's egg . . . . . . . . . . . 58

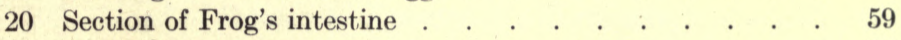

21 Cross section of a plant stem . . . . . . . . . . . . 60

22 Spirogyra . . . . . . . . . . . . . . . . . . 61

23 Common Seaweed (Fucus)

24 Giant Kelp . . . . . . . . . . . . . . 63

25 Gulfweed (Sargassum) . . . . . . . . . . . 64

26 Types of roots . . . . . . . . . . . . . . . . . . 65

27 Seasonal history of an annual plant . . . . . . . 66

28 Seasonal history of a biennial plant . . . . . . . 67

29 Aerial roots of English Ivy . . . . . . . . . . 67

30 Haustoria of Dodder . . . . . . . . . . . 68

31 Strawberry runners . . . . . . . . . . . . 69

32 Hyacinth bulb . . . . . . . . . . . . . 70

33 'Smilax' (Myrsiphyllum) . . . . . . . . . . 71

34 Leaf of a Flowering Plant . . . . . . . . . . 71 
35 Winter buds

36 Onion leaf

37 Pitcher Plant (Sarracenia purpurea) . . . . . . . 73

38 Sundew . . . . . . . . . . . . . . . 73

39 Sensitive Fern (Onoclea sensibilis) . . . . . . . . 74

40 Floral parts of Azalea (Loiseleuria) . . . . . . . . 75

41 Ideal vertical section of a Flowering Plant . . . . . 76

42 Generalized plant cell . . . . . . . . . . . 77

43 Root tip . . . . . . . . . . . . . . . 79

44 Root hair . . . . . . . . . . . . . . . 80

45 Cross section of a stem . . . . . . . . . . . 81

46 A bud of Elodea canadensis . . . . . . . . . . 82

47 Cross section of a leaf . . . . . . . . . . . . . 83

48 Diagram illustrating the physiology of a plant . . . . 87

49 Ulothrix . . . . . . . . . . . . . . 95

50 Oedogonium, filamentous form . . . . . . . . . 97

51 Oedogonium, zygote . . . . . . . . . . . . . . 98

52 A Brown Alga (Ectocarpus) . . . . . . . . . . 99

53 Life history of a Moss . . . . . . . . . . . 101

54 Life history of a Fern . . . . . . . . . . . 104

55 Decline of gametophyte and increase of sporophyte . . . 105

56 Life history of a higher Fern . . . . . . . . 106

57 Megaspore and microspore . . . . . . . . . 107

58 Typical flower . . . . . . . . . . . . . 107

59 Transition between petals and stamens . . . . . 108

60 Union of carpels to form the ovule case . . . . . . 108

61 The life history of a higher Flowering Plant . . . . . 110

62 Seed of Violet . . . . . . . . . . . . 111

63 Diagram of comparative morphology of plants . . . . 112

64 Hydra, longitudinal section . . . . . . . . . 119

65 Hydra, transverse section . . . . . . . . . . 120

66 Earthworm, body plan . . . . . . . . . . 122

67 Dissection of Earthworm (Lumbricus terrestris) . . . . 123

68 Earthworm transverse section .

69 Stages in development of the Earthworm . . . . . 126

70 Structure of a primitive Arthropod . . . . . . 130

71 Dissection of Crayfish (Cambarus affinis) . . . . . . 131

72 Appendages of Crayfish . . . . . . . . . . 132

73 Nervous system of Earthworm and Crayfish . . . . 134

74 Sagittal section of an ideal Vertebrate . . . . . 137

75 Cross section of an ideal Vertebrate . . . . . . 137

76 Section of human skin . . . . . . . . . . . . . . . 139

77 Skeleton of a bony Fish (Perca fluviatilis). . . . . . 141 
78 Relation of the notochord to vertebrae

79 A typical human vertebra

80 Plan of the Vertebrate limb skeleton

81 Skeleton of a Mammal (Felis domestica)

82 Dissection of Yellow Perch (Perca flavescens)

83 Dissection of Green Frog (Rana clamitans)

84 Dissection of Pine Lizard (Sceloporus undulatus)

85 Dissection of domestic Pigeon (Columba livia)

86 Dissection of Gray Squirrel (Sciurus carolinensis)

87 Sagittal section of human body

88 Human alimentary canal and derivatives

89 Chemical activities of the digestive tract .

90 A gland

91 Vascular system of a Shark

92 Plan of the circulatory system of a Fish, Amphibian, and Mammal

93 Paths of absorbed food

94 Food and respiratory paths

95 Transformations of the aortic arches . . . . . . . 171

96 Nephridium of an Earthworm . . . . . . . . 177

97 Evolution of the urogenital system

98 Section of human kidney and ureter

99 Simple receptor-effector system

100 More complex receptor-effector system

101 Simple reflex arc .

102 Differentiation of nerve cells

103 Nervous organization of intestinal wall . . . . . . 186

104 Development of the Vertebrate brain .

105 Types of Vertebrate brains .

106 Nervous system of the Frog

107 Paths of nervous impulses

108 Differentiation of sense cells

109 Membranous labyrinth of the ear .

110 Human ear

111 Development of the eye

112 Vertebrate eye (human)

113 Uterus (human)

114 Yeast cells

115 Reproductive cell cycles

116 Hydra, dividing

117 Flatworm, dividing .

118 Obelia . 
120 Regeneration and grafting in Hydra

121 Regeneration and grafting in an Earthworm .

122 Regeneration and grafting in a Flatworm

123 Typical stages in Mitosis

124 Period of chromosome reduction in animals and plants

125 Spermatogenesis and oögenesis in animals 231

126 Chromosome cycle in an animal . . . . . . . . 235

127 Egg and sperm of Lamprey . . . . . . . . . 236

128 Hen's egg . . . . . . . . . . . . . . . 238

129 Human egg and sperm . . . . . . . . . . . . 239

130 Conjugation in Paramecium . . . . . . . . . 245

131 Endomixis in Paramecium . . . . . . . . . . 248

132 Development of Dentalium . . . . . . . . . 255

133 Comparison of the development of Dentalium and Amphioxus 257

134 Relation of cytoplasmic differentiation to development $\quad$. 259

135 Continuity of the germ plasm . . . . . . . . . 265

136 Alternative, mosaic, and blending inheritance . . . . 269

137 I aw of filial regression . . . . . . . . . . . 270

138 Inheritance of size in Peas . . . . . . . . . . . 273

139 Mendelian monohybrid . . . . . . . . . , 275

140 Mendelian dihybrid . . . . . . . . . . . 277

141 Inheritance of human hair characters . . . . . . . 278

142 Possible types of zygotes in a dihybrid . . . . . . 279

143 Mendelian trihybrid . . . . . . . . . . 281

144 Color inheritance in the Four-o'clock (Mirabilis jalapa) . 284

145 Color inheritance in mulattoes . . . . . . . . . 285

146 Chromosome cycle in an animal . . . . . . . . . . 289

147 Chromosomes or genes at fertilization and maturation . . 290

148 The X chromosome in fertilization . . . . . . . 293

149 Inheritance of color-blindness from the male . . . . . 294

150 Inheritance of color-blindness from the female . . . . 295

151 Crossing-over at synapsis . . . . . . . . . 296

152 Nature and nurture . . . . . . . . . . 298

153 Population and pure lines in Beans . . . . . . 300

154 Model to illustrate the law of probability . . . . . 301

15.j Normal frequency curve . . . . . . . . . 302

156 Selection and filial regression . . . . . . . . 303

157 Relation of pure lines to a population . . . . . 305

158 Sulfur Bacteria (Beggiotoa) . . . . . . . . . 309

159 Yeast . . . . . . . . . . . . . 310

160 Spore formation in Bacteria . . . . . . . . . 312

161 Adaptive radiation in Eutherian Maınmals . . . . . 314

162 Gymnura. 
163 Foot postures of Mammals .

164 Sloth (Choloepus hoffmanni) .

165 Mole (Talpa europea)

166 Porpoise (Phocaena communis)

167 'Flying Lemur' (Galeopithecus volans).

168 Bat (Vespertilio noctula)

169 Katydid (Microcentrum laurifolium)

170 Underwing Moth (Catocala lacrymosa)

171 Dead-leaf butterfly (Kallima paralecta)

172 Walking-stick (Diapheromera femorata)

173 Larva of a Geometrid Moth

174 Drone Bee and Bee Fly (Eristalis tenax)

175 Bees

176 Head of Bee

177 Legs of Bee

179 Formation of a Lichen

180 Ants and Aphids .

181 Life cycle of a Malarial Parasite

182 Trypanosoma theileri

183 Avoiding reaction of Paramecium .

184 Rotation of Paramecium

185 Vertebrate fore-limbs

186 Skeleton of Man and Gorilla

187 Vestigial hind-limbs of a Snake

188 Archaeopteryx

189 Evolution of the Horse

190 Evolution of the Camel .

191 Comparison of embryos of Fish, Bird, and Man

193 Evolution of the head of Elephants

194 Varieties of domestic Pigeons

195 Aristotle

196 Theophrastus of Eresus . . . . . . . . . 381

197 Andreas Vesalius . . . . . . . . . . . 384

198 William Harvey . . . . . . . . . . . 386

199 Antony van Leeuwenhoek . . . . . . . . 387

200 Marcello Malpighi . . . . . . . . . . . 389

201 Carolus Linnaeus . . . . . . . . . . . 391

202 Georges Cuvier . . . . . . . . . . . 392

203 Thomas Henry Huxley . . . . . . . . . . 393

204 Stephen Hales . . . . . . . . . . . 397

205 Matthias Jacob Schleiden . . . . . . . . 399 


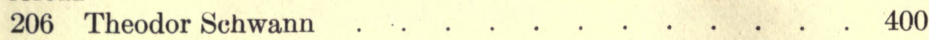

207 Karl Ernst von Baer . . . . . . . . . . . 402

208 Gregor Johann Mendel . . . . . . . . . . 405

209 Comte de Buffon . . . . . . . . . . . . 407

210 Erasmus Darwin . . . . . . . . . . . . . 408

211 Jean-Baptiste Lamarck . . . . . . . . . . 409 


\section{FOUNDATIONS OF BIOLOGY}





\section{FOUNDATIONS OF BIOLOGY}

\section{CHAPTER I \\ THE SCOPE OF BIOLOGY}

Science is, in its source, eternal; in its scope, unmeasurable; in its problem, endless; in its goal, unattainable. - von Baer.

The oldest and the most obvious classification of the materials of our environment is into non-living and living; and the accumulation of knowledge in regard to the former is represented in the so-called physical sciences, while that of the latter comprises the content of BIOLOGY, the science of matter in the living state. Biology, like all science, has as its ultimate object the explanation of its phenomena in terms of the basic concepts - matter and energy acting in space and time; but it is needless to say that the realization of this object is not imminent in any department of knowledge, and least of all in the science of living things which exhibit a condition of matter which altogether transcends the classifications of physicist and chemist to-day - a condition which expresses in its highest manifestations what we call 'our life.'

Whether the 'riddle of life' will ultimately be solved is a question which every one would like to answer but only the rash would attempt to predict. Suffice it to say that biologists who are on the firing line of progress to-day are directing their attention solely to an attempt to elucidate life phenomena in terms which the chemist and physicist offer. Our present interest, however, is not in discussing the theoretical goal of biology, but in drawing in bold strokes an outline picture of the present-day knowledge of the subject which 
represents the cumulative results of the application, to problems of life, of the scientific method - a method which is not peculiar to science but merely a perfected concentration of our human resources of observation, experimentation, and reflection. Thus far this has been a most productive method and certainly has given no evidence that its usefulness is being exhausted. To follow any other course would be to abandon the method of science. "In ultimate analysis everything is incomprehensible, and the whole object of science is simply to reduce the fundamental incomprehensibilities to the smallest possible number."

The foundations of the scientific study of living nature were laid by Aristotle and Theophrastus over 2000 years ago. On the basis of collecting, dissecting, classifying, and pondering they reached generalizations, many of which have but recently been put on a firm basis of fact. Indeed these pioneers asked nearly all the broad questions which are fundamental to-day; but from the Greeks until about the fifteenth century there is little to record. There were many additions to the body of knowledge during this long slumber period, but fact and fancy were'so amalgamated that the truth was obscured.

The feeling that though Man is of nature, he is still apart, was expressed at the revival of learning in the broad classification of all knowledge as history of nature and history of Man; the former having as its content the record or "history of such facts or effects of nature as have no dependence on Man's will, such as the histories of metals, plants, animals, regions, and the like"; the latter treating of the voluntary actions of men in communities. Thus all record of facts was either natural history or civil history. From this more or less nebulous natural history the present-day sciences of astronomy, physics, chemistry, geology, and biology were thrown off as relatively independent bodies of facts as each 
gained content, clearness, and individuality. Astronomy, physics or natural philosophy, and chemistry were emancipated first owing to the fact that their material was more readily susceptible to mathematical and experimental treatment, thus leaving the histories of the Earth, animals and plants, or so-called observational sciences, as the residue for natural history. It is in this restricted sense that natural history still lingers.

It remained, however, for Lamarck and Treviranus during the opening years of the nineteenth century to attain a vision of the unity of animal and plant life - the unity of zoöLOGY and BотANY - and to express it in the term biology. But biology is something more than a union of botany and zoölogy under one name - for it endeavors, in addition to describing the characteristics of animals and plants, to unfold the general principles underlying both.

Thus the biologist has as his field the study of living things - what they are, what they do, and how they do it. He asks, how this animal or that plant is constructed and how it works - and this he attempts to answer. He would like to ask, why it is so constructed and why it works the way it does - but this is beyond the scope of science.

These queries of the biologist reflect the two primary viewpoints from which biological phenomena may be approached: the morphological in which interest centers upon the form and structure of living things, and the physiological in which attention is concentrated upon the functions performed - the mechanical and chemical engineering of living machines. Clearly, however, it is impossible to draw a hard and fast distinction between morphology and physiology because in the final analysis structure must be interpreted in terms of function, and vice versa. But again, 
the fields of morphology and physiology naturally resolve themselves into special departments of study, depending on the level of analysis of structure or of function which is emphasized. Thus MORPHOLOGY stresses the general form of the animal or plant; АNAтомy, the gross structure of individual parts, or organs; HISTOLOGY, the microscopic

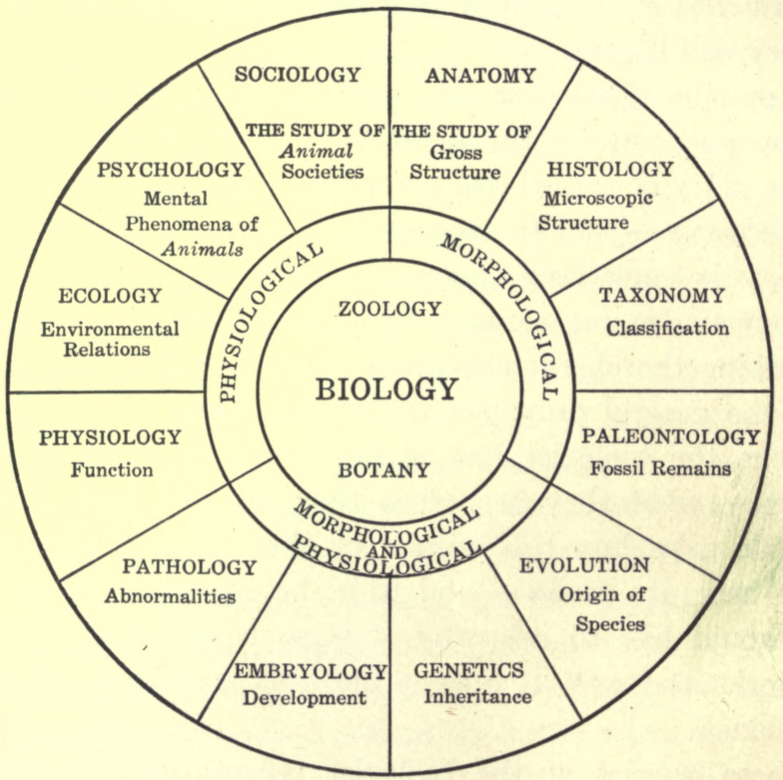

Fig. 1. - The chief divisions of Biology.

structure of organs, or tissues; CYтоLоGY, the component elements of tissues, or cells, and the physical basis of life, or protoplasm. Similarly, PHYsiology investigates the activities of animals and plants, the functions of organs, the properties of tissues, the phases of cell life, and finally the physico-chemical characteristics of protoplasm. So much for the study of the adult individual animal or plant - but this is not all. The origin and development of the individual, 
GENETICS and EMBRYology; and the origin and development of species, ORGANIC EVOLUTION, are other wide fields, sciences in themselves, which must be approached from both the structural and functional aspect if any real advance is to be made toward a comprehensive appreciation of life. (Fig. 1.)

Thus, just as the various physical sciences have expanded and become specialized until they are beyond the grasp of a single man, so biology and its subdivisions, or the вIоLOGICAL SCIENCES, are now distributed among many specialists. Although specialization results in a narrowing and isolating of the fields of study, as deeper levels of investigation have been reached in all the sciences there has been a tendency for the basic phenomena to meet on the common ground of the fundamental sciences, physics and chemistry - for in the last analysis the biologist must assume as a working hypothesis that the properties of protoplasm are the resultant of the properties and interrelationships of the chemical elements which compose it. "In one direction, supported by chemistry and physics, biology becomes biochemistry and biophysies. In a contrary direction it forms a connection with the psychical sciences which relate to human nature, with psychology and sociology, with ethics and religion." 


\section{CHAPTER II}

\section{THE PHYSICAL BASIS OF LIFE}

Science never destroys wonder, but only shifts it, higher and deeper. - Thomson.

THE old saying that the materials forming the human body change completely every seven years is a tacit recognition that lifeless material, in the form of food, is gradually transformed into similar living matter under the influence of the body. Indeed, just as a geyser retains its individuality from moment to moment though it is at no two instances composed of the same molecules of water identically placed, so the living individual is a focus into which materials enter, play a part for a time, and then emerge to become dissipated in the environment. But here the analogy stops. For in the living organism the materials which enter as food, endowed with POTENTIAL energy, are arranged and rearranged until specific molecular aggregates result, which in turn are transformed into integral parts of the organization of life itself. However, to live is to work, and to work means expenditure - the transformation of the potential into KINETIC energy with the result that materials in relatively simple form and largely or entirely devoid of energy are returned to the realm of the non-living.

Thus we reach a fact of prime importance: so far as we know, living matter is merely ordinary matter which has assumed, for the time being, a peculiar condition in which it displays the remarkable series of phenomena which we recognize as LIFE. 
The body of Man in common with that of all animals and plants is composed of living and non-living matter closely associated, though totally distinct. For example, the visible parts of hair and nails, a large part of bone and the liquid part of blood is non-living material. But, the nonliving is not confined to gross structures, for the dead among the living is still revealed until the resolving power of the microscope fails us.

\section{A. Protoplasm}

Although there is a continuous stream of matter and energy flowing through the living individual, nevertheless the physical and chemical study of living matter from whatever source we take it - Mold or Elm, Amoeba or Man reveals a remarkable similarity in its fundamental factors, and it is to a consideration of what the concept PROTOPLASM holds for the biologist that we now turn.

As the finer structure of animals and plants came within the range of vision through improvements in microscope lenses, it was gradually recognized that the ultimate living part appeared to be a granular, slime-like material. Thus Dujardin, in 1835, designated as sarcode the material forming the bodies of microscopic animals. Purkinje, in 1840, named the formative substance of the developing animal protoplasm, and compared it with the granular material of the growing region of certain plants. Six years later, von Mohl similarly named the contents of the finer structural units of plants. Confirmatory observations came from many sources during the following decade and culminated in the classical studies of Max Schultze and de Bary which established the full physiological significance of protoplasm as the essentially similar, fundamental, living material of both animals and plants. This reduction of all life phenomena 
to a common denominator was the final justification of the prevision of the earlier workers in recognizing a life-science biology.

Although we speak of a common 'physical basis of life,' it is of paramount importance to bear in mind that the protoplasm of no two animals or plants or, indeed, of different parts of the same animal or plant is exactly the same. Identity of protoplasm would mean identity of structure and function - identity of life itself. The concept protoplasm merely emphasizes that, after allowances are made for all the variations, we still have the similarities far outnumbering the dissimilarities in the 'agent of vital manifestations.'

The physical chemists tell us that matter in the living state represents a type of COLLOIDAL CONDITION of matter known as an emulsoid which, in turn, may exist either as a sol - the apparently homogeneous liquid state of living matter; or as a gel - the apparently amorphous semi-solid state. Protoplasmic sols appear, as a rule, homogeneous because of the exceedingly small size of the molecular aggregates which form them, while protoplasmic gels reveal either a homogeneous or heterogeneous molar structure because of the relatively large particles which set to form the gel. In other words, living matter holds an intermediate position between true solids and true liquids, and has many properties of both, as well as many peculiar to itself.

But this leaves the reader without any clear conception of the appearance of protoplasm. As a matter of fact it is as difficult to describe the appearance of, as it is to define, protoplasm. It must be seen under the microscope to be appreciated. With a moderate magnification, protoplasm presents a fairly characteristic picture, appearing like a translucent, colorless, viscid fluid containing many minute 
granules as well as clear spaces or vacuoles. (Fig. 2.) If it is examined in water it exhibits no tendency to mix with the surrounding medium, though investigations show that osmotic interchanges are constantly going on. For this reason it is impossible to consider protoplasm except in connection with its surroundings whatever they may be-

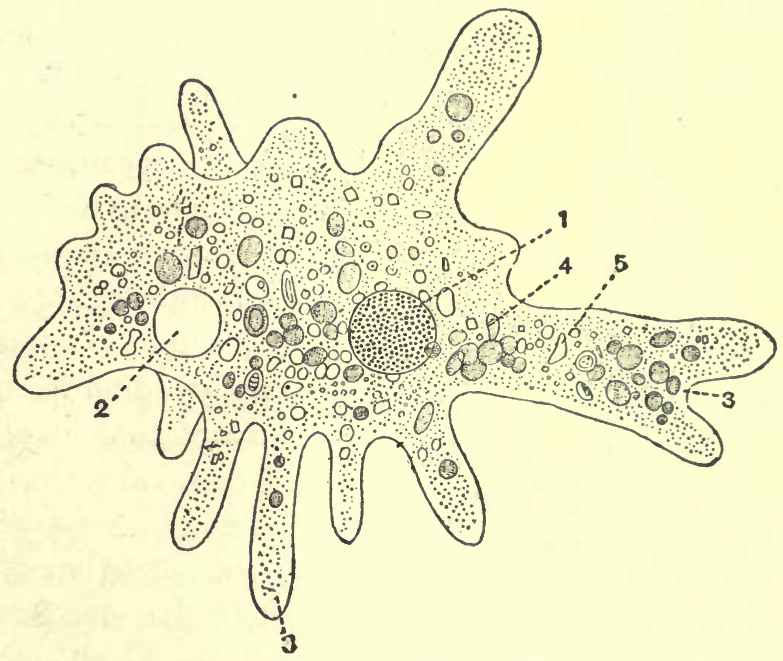

Frg. 2. - A simple animal (Amoeba proteus) which consists of a single unit mass of protoplasm (highly magnified). 1, nucleus; 2, contractile vacuole; 3, pseudopodia; 4 , food material in process of digestion (food vacuole); 5 , sand particle or other indigestible inclusion. (From Shipley and McBride, after Gruber.)

variations in its environment and variations in its activities being reflected directly or indirectly in its appearance. Under the highest magnifications, not only does the finer structure of protoplasm differ in various specimens, but also in the same living unit mass under slightly different physiological conditions. At one time it presents the appearance of a fairly definite net-like structure, or reticulum, the meshes of which enclose a more fluid substance; at another, a frothy 
appearance in which the alveoli, or 'bubbles,' represent a more liquid substance emulsified in a less liquid medium. Again, at other times, the denser portion seems to take the form of

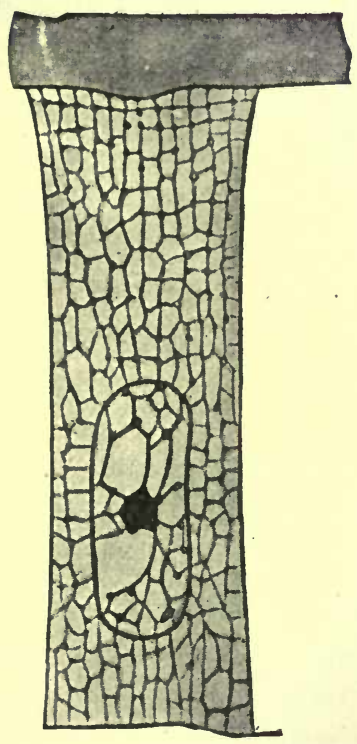

Fıg. 3. - Alveolar appearance of the protoplasm of a cell from the skin (epidermis) of an Earthworm. (From Verworn, after Bütschli.) minute rods, or fibers, distributed in a somewhat fluid matrix. (Fig. 3.)

These appearances have given rise to various theories which emphasize one or another as the universal formula for the physical structure of protoplasm, from which the other appearances are merely secondarily derived. But the trend of recent work has been to indicate that although the general similarity of protoplasmic activity, wherever we find it, might lead us to expect to find also a visible fundamental structural basis, such does not exist within the range of magnifications at our command. Reticular, alveolar, and fibrillar structures which our microscopes reveal are, as it were, merely surface ripples from underlying physico-chemical changes which, thus far, have proved unfathomable.

\section{B. Characteristics of Living Matter}

Since the phenomena of life are without exception the results of protoplasmic activity, it is obvious that we must look to protoplasm for the primary attributes of living matter. The properties which are absolutely diagnostic of living matter are its chemical composition, metabolism including the power of waste and repair, growth by intus- 
susception, the power of reproduction, the power of adaptation, and specific form and organization.

\section{Chemical Composition}

It is impossible to make an analysis of living matter because the disturbance of its molecular organization by chemical reagents kills it. Therefore our knowledge of its chemical composition has of necessity been derived from a study of dead protoplasm. However, since in the transformation from the living to the non-living state there is clearly no loss of weight, it follows that the complete material basis of life is still present for examination. In other words, the death of protoplasm is a result of disorganization.

Chemical analysis of protoplasm shows that it invariably comprises the elements carbon, oxygen, hydrogen, nitrogen, sulfur, and phosphorus; and usually also chlorine, potassium, sodium, magnesium, calcium, and iron. Occasionally a number of other elements are found normally in the protoplasm of certain parts of various species of animals and plants.

The average composition of the human body is about as follows:

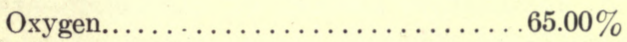

Carbon .......................... 18.00

Hydrogen . . . . . . . . . . . . . . . . 10.00

Nitrogen. . . . . ............. 3.00

Calcium..................... 2.00

Phosphorus.................... 1.00

Potassium..................... 0.35

Sulfur..................... 0.25

Sodium..................... 0.15

Chlorine..................... 0.15

Magnesium......................... 0.05

Iron ...................... 0.004

Iodine ......................traces

Fluorine................... traces

Silicon......................traces 
At first glance there is nothing very striking about this list of elements. They are all common ones with which the chemist is familiar in the non-living world. But it is the combination of the elements which is significant, and this results from the capacity of carbon, hydrogen, and oxygen, or carbon and hydrogen together, to form the numerous complex compounds which in turn supply the basis for intimate associations with other elements. As a matter of fact, the bulk of protoplasm is composed of carbon, oxygen, hydrogen, and nitrogen associated with each other in an apparently infinite series of relationships, in which the carbon seems to play the leading rôle. Some of these compounds are relatively simple, such as water $\left(\mathrm{H}_{2} \mathrm{O}\right)$ which is quantitatively the most important constituent of all protoplasm, but the majority consist of elaborate atomic arrangements and not a few represent molecular complexes of hundreds and even thousands of atoms.

The compounds of carbon which are characteristic of protoplasm fall into three chief groups: proteins, carbohydrates, and fats.

Proteins invariably consist of the elements carbon, oxygen, hydrogen, nitrogen, and sulfur, and frequently phosphorus and iron. Examples are albumin of the white of egg, casein of milk, gluten of cereals, and myosin of lean meat. The nitrogen particularly distinguishes proteins from the other compounds of the living complex and, as we shall see later when considering the chemical processes in animals and plants, is largely responsible for their commanding position as "the chemical nucleus or pivot around which revolve a multitude of reactions characteristic of biological phenomena." Study of the relationship of nitrogen to the other chemical elements of proteins long since revealed the fact that the protein molecule is a huge complex of linked 
AMINO ACIDS - an amino acid being an organic acid in which one hydrogen atom is replaced by the amino group, $\mathrm{NH}_{2}$. But at the present time it is becoming increasingly patent that the amino acids are, as it were, the nitrogenous units with which organisms deal physiologically, rather than the proteins themselves. An animal, for example, with various proteins available in its food, chemically disrupts these into their amino acid constituents, and then takes an amino acid here and another there and synthesizes the specific proteins it demands. And further, if individual amino acids are supplied, the animal employs them. So it seems highly probable that the specific structure of an organism depends upon the chemical specificity of its proteins.

Although the presence of proteins and the power of forming them is the chief diagnostic chemical characteristic of living matter, at the present stage of our knowledge it is impossible to define proteins satisfactorily on the basis of chemical or physiological properties. The most we can say is that the biochemist describes proteins as "huge molecules, complex in structure, labile in character, and therefore prone to chemical change" - and the latter characteristic undoubtedly is closely associated with the perennial plasticity and responsiveness of the protoplasmic system itself.

CARBohydrates consist of various combinations of carbon, hydrogen, and oxygen, the latter elements invariably being present in the proportion found in water $\left(\mathrm{H}_{2} \mathrm{O}\right)$. Though more simple in chemical structure than proteins, they range in complexity from the simple sugars, or monosaccharids, such as glucose and fructose, to polysaccharids such as dextrins, starches, and cellulose.

FATs are composed of the same elements as the carbohydrates, but in quite different arrangements. The proportion of oxygen is always less, and therefore they are more 
oxidizable and richer in potential energy. Fats represent a synthesis of an acid (fatty acid) and glycerine. Examples are butter and all oils of plant or animal origin.

Thus proteins, carbohydrates, and fats represent large classes of substances which are distinctly characteristic of living matter, not being found in nature except as the result of protoplasmic activity; although biochemists now can artificially synthesize certain fats and carbohydrates as well as the amino acid constituents of some proteins. Proteins undoubtedly play the most important part in the organization of protoplasm, while the carbohydrates and fats contribute largely to the supply of available energy. However, it is impossible to draw a hard and fast distinction in regàrd to their respective contributions because, for example, as we shall see later, carbohydrates form the foundation upon which proteins are synthesized by green plants.

Proteins, carbohydrates, and fats are frequently referred to as the foodstuffs, but it will be recognized that while, in a way, they constitute the chief groups, all the constituents of protoplasm must be available. Accordingly, inorganic salts, water, and free oxygen are really foodstuffs. Furthermore, recent investigation has disclosed another class of organic substances which are absollutely necessary for the constructive phases of protoplasmic activity. These are termed vitamines and must be classified as accessory food substances, although as yet little is known in regard to their chemical structure or mode of action. And then, finally, on the border line of food substances may be mentioned a great group of organic catalyzers, called ENzymes, which play a major rôle in metabolism. But, when all is said, our knowledge of the chemical complexities of protoplasm affords no adequate conception of how they are related to the phenomena of life. This is beyond present-day biology. 


\section{Metabolism}

We have emphasized that living matter is continually changing, and this fundamental fact is reflected in nearly all attempts to define life. Aristotle described life as "the assemblage of operations of nutrition, growth, and destruction"; deBlainville, as a "twofold internal movement of composition and decomposition"; and Spencer, as "the continuous adjustment of internal relations to external relations."

This interaction consists of chemical and physical processes in which combustion or oxidation plays the chief rôle. Lavoisier and Laplace in 1780 showed that animal heat results from a slow burning of the materials of the body, involving the consumption of oxygen and the liberation of carbon dioxide; and further, that for a given consumption of oxygen and liberation of carbon dioxide, about the same amount of heat is produced by an animal as by a burning candle. This was an important discovery, because it went far toward establishing the fact that at least certain characteristic vital phenomena are amenable to the laws which hold in the nonliving world.

But the processes involved in life are not so simple as perhaps might be imagined from the results just mentioned. Heat represents but one of the many energy transformations within the organism. Indeed the living organism, like a steam engine, is a machine for transforming energy - transforming the potential energy stored in chemical complexes of its own substance into the various vital processes of living - into work performed. In these processes many complex substances rich in potential energy, which have entered as food and have in whole or part added to the protoplasmic complex, are reduced to simpler and simpler conditions and 
finally, with their energy content nearly or entirely exhausted, are eliminated as ExCRETIONs. This continual waste must, if life is to persist, be counterbalanced by a proportionate intake of food in order to renew the supply of energy and afford the materials which, after preliminary changes, are made into an integral part of the living organism. Thus in living the animal or plant is partially consuming and rebuilding itself continually. This dual process is METABOLISM. When constructive metabolism, ANABOLISM, keeps pace with destructive metabolism, КАтАвоLISM, the individual remains essentially unchanged and this is the normal condition of adult life. During youth the anabolic phases are in the ascendency and growth occurs, while old age is characterized by a predominance of katabolic processes.

\section{Growth}

The results of metabolism force themselves upon our attention chiefly as growth, or permanent increase in the size of the individual. As a rule growth in plants continues more or less rapidly throughout life, while in animals it is confined mainly to the early part of the individual's existence, or youth. Indeed, at birth a child is about a billion times larger than the egg from which it has developed.

Growth means that the organism makes over the materials which it receives in the form of food from its environment and fits them into the protoplasmic organization here and there throughout as needed. This method of addition of materials, which is termed growth by INTUSSUSCEPTION, is highly characteristic of life. When growth occurs in the non-living world, it is typically by accretion; as, for example, in crystals where new material of the same kind is superimposed upon the surface. But protoplasm, with materials 
and energy taken from its environment, constructs more protoplasm and, if the available materials are adequate, the specifically organized living substance tends to increase indefinitely. Thus it is not only the method of growth which is diagnostic of animals and plants, but also the fact that when the individual body has reached a certain physiological balance, or maturity, in which it ceases to increase in size, under normal conditions it expresses the inherent growth power of living matter by setting free certain living units, which go through a cycle of growth phenomena that result in re-productions of the parent individual.

\section{Reproduction}

So far as is known, living matter never arises except under the direct influence of preëxisting living matter. We have seen that this transformation is continually going on in the constructive phase of metabolism in the animal or plant, and brings about repair and growth of the individual; but it is in reproduction that what may be termed the overgrowth of the individual results in the production of a new one. A larger or smaller part of the parent generation is detached and becomes the new generation, so that in ultimate analysis reproduction is division. This is a highly unique characteristic of living things which provides for the continuation of the race.

\section{Adaptation}

The discussion of metabolism has emphasized the close interrelationship between the living complex and its surroundings, and the dependence of life upon the interplay and interchange between protoplasm and its environment. As a matter of fact the plant or animal retains its individuality - lives - solely by its powers of developing and main- 
taining exquisite adjustments to its surroundings. This results from the IRRITABILITY of living substance: its inherent capacity of reacting to environmental changes by changes in the equilibrium of its matter and energy. The inciting changes, known as stimul, may be chemical, electrical, thermal, photic, or mechanical, but the nature of the response is determined rather by the fundamental character of the protoplasmic system itself than by the nature of the stimulus. Muscle protoplasm contracts however it is stimulated. The reaction of living matter by virtue of its intrinsic irritability implies not only response to a stimulus but also conduction so that the protoplasmic system as a whole is directly or indirectly influenced. It responds as a coördinated unit-an individual. It adapts itself structurally and functionally to the exigencies of its existence. . This power of adaptation, as exhibited in active adjustment between internal and external relations, overshadows every manifestation of life and contributes, more than any other factor, to the "enormous gap that separates even the lowest forms of life from the inorganic world."

\section{Organization}

Finally, adaptation implies that living things are not homogeneous, but exhibit reciprocal structural and physiological organization. Accordingly animals and plants are referred to as organisms. Indeed a major part of the present volume is devoted to the organization of organisms.

The characteristics which we have described - chemical composition, metabolism including waste and repair, growth by intussusception, reproduction, adaptation, and specific organization - individually and collectively are diagnostic of living matter. It is possible, to be sure, to take exception to one or another; e.g., to say that growth by intussusception 
occurs in non-living things when a salt is dissolved in water; but such formal objections only emphasize the unique conditions which obtain in life.

The reader may be surprised to note that the power of movement has not been mentioned as a characteristic of life, but a moment's thought will make it apparent that visible movement is not confined to living matter. Though this is so, movement is one of the most obvious manifestations of life and depends, of course, in every instance, upon molar changes resulting from tumultuous ultramicroscopic chemical changes of protoplasm itself.

And it is to these changes that, in the last analysis, we must turn for the energy which brings about the visible movements in animals and plants, such as the contraction of the muscles of animals, the streaming movement (amoeboid movement) of the simple animals known as Amoebae, the rotation and circulation of the protoplasm in certain of the living units of plants and, finally, the lashing of threads of cytoplasm (cilia) which not only enables many a tiny plant and animal to swim, but also aids in numerous ways in certain parts of the bodies of higher organisms. The phenomena of life are quite generally expressed in visible movements, but the latter are not peculiar to living things.

In our discussion thus far we have endeavored to describe the characteristics of matter in the living state on the basis of the fundamental vehicle of life manifestations - protoplasm. We have not attempted formally to define 'life' or 'protoplasm' because they are so unique that it is impossible to resort to the lexicographer's trick of comparing them with something else; and because the expressions 'protoplasm' and 'life' are abstractions; one indicating that all individual animals and plants have to a large extent a common organizational foundation, and the other that they exhibit certain 
characteristic actions and reactions. The living organism is a microcosm which exhibits a permanence and continuity of individuality correlated with specific behavior, and this it transmits to other matter which it makes a part of itself, and to its offspring in reproduction. 


\section{CHAPTER III}

\section{ORGANIZATIONAL UNITS OF PLANTS AND ANIMALS}

Over the structure of the chemical molecule rises the structure of the living substance as a broader and higher kind of organization. Over the structure of the cell rises again the structure of plants and animals, which exhibit the yet more complicated, elaborate combinations of millions and billions of cells coördinated and differentiated in the most extremely different ways. - Hertwig.

Since living matter is only known to us in the form of individual animals and plants, individuals are the only

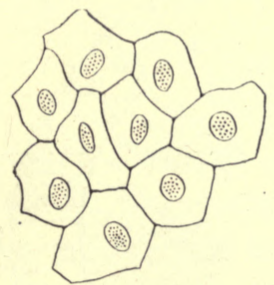

A

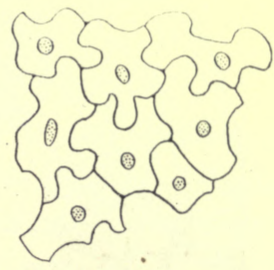

B

Fig. 4. - Cells, highly magnified, from the surface of the Frog's skin (A), and a plant leaf (B).

realities in living nature, and we turn now to a consideration of the organization of the individual.

A thin slice of material from the surface of the skin of a Frog or the leaf of a Buttercup shows under the microscope the same general structure. Each appears to be a mosaic of innumerable small bodies, no two of which are exactly alike even in the same piece, though all are similar enough to be one and 
the same type of unit. And if we extend our study to other parts of the Buttercup or the Frog or, indeed, to any part of

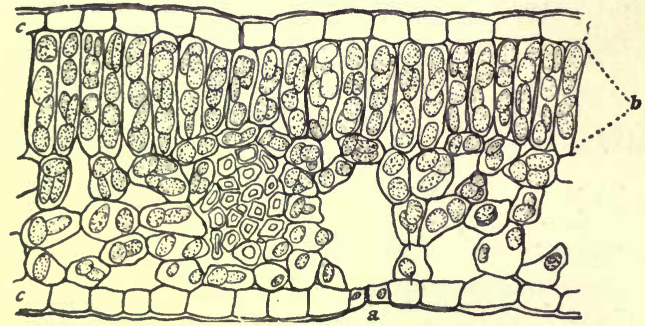

FIG. 5. - Vertical section (highly magnified) of a leaf to show its cellular structure. $a$, guard cells, at opening (stoma) through epidermis; $b$, cells containing chlorophyll; $c$, upper and lower epidermal cells. (From Abbott, after Bailey.)

any familiar plant or animal, we find essentially similar units of structure in every case. In fact, the bodies of all living

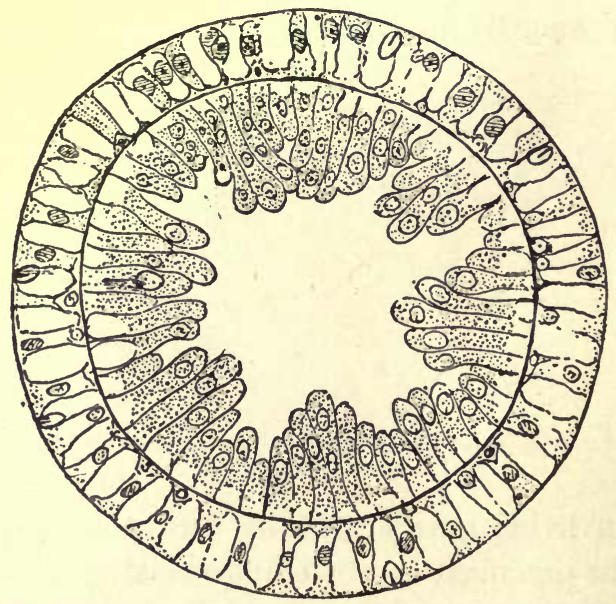

Fra. 6. - Transverse section (highly magnified) of a simple animal (Hydra) to show the cellular structure. Outer layer, ectoderm; inner layer, endoderm; central cavity, enteron. (After Shipley and McBride.)

things either consist of a single organic unit or are congeries of millions of essentially similar units called cELLs. (Fig. 4.) 
Such being the case we reach another great generalization: all organisms have the same clementary structure, just as we have seen that all organisms are composed of a similar fundamental life-stuff, protoplasm. Therefore a cell may be described as a small mass of protoplasm, either living apart as a microscopic plant or animal, or forming a building block, as it were, in the architecture of one of the higher organisms. Indeed, organisms are organisms because of specific local differentiations in the living material - this differentiation being possible largely because the protoplasm is disposed in microscopic unit masses, or cells. (Figs. 5, 6.)

The appreciation of this dual similarity - protoplasmic basis and cellular organization - of all living things, which was finally attained about the middle of the last century, firmly established the fact that all living nature is one, the corner stone of modern biology.

\section{A. The Cell}

Having taken a general survey of the building materials of living nature, microscopic unit masses of protoplasm, termed cells, we are now in a position to consider in some detail the structure of a typical cell. With the diversity of gross structure of animals and plants in mind; one is not surprised that there are considerable, even great, variations in their component elements. In fact the characteristics of an organism or part of an organism are determined by those of its cells. But there are certain generalized cell characters which are common to all cells - by virtue of which they are cells - and it is important to emphasize these.

In its simplest form a cell is a small spherical mass of protoplasm. Such are the eggs of various animals and the complete body of some of the lowest plants and animals. 
Cells forming the units of multicellular organisms, however, frequently exhibit more or less hexagonal surfaces on account of stresses and strains incident to their position among other cells, while specializations and differentiations, for one purpose or another, produce forms which are characteristic of different parts of the organism, as, for example, the long spindleshaped cells of smooth muscle, and the widely branching cells of parts of the brains of animals. Broadly speaking, the greater diversity of cell form is found in animals, while in plants, owing to the more general presence of rigid cell walls about the protoplasm, the units more frequently present symmetrical, angular outlines. (Figs. 7,42 .)

The term cell is a relic of the time when the cell wall was regarded as the more important part, and its protoplasmic contents, if observed at all, were considered as only of secondary importance, if not a waste product. Now we recognize many cells which are merely naked masses of protoplasm, such as certain types of blood cells. In other words, the protoplasm is the essential living part - the cell wall frequently being a non-living accessory which more or less sharply delineates one unit mass of protoplasm from another and lends rigidity and form to the group of cells as a whole.

\section{Cytoplasm}

The protoplasm of all typical cells is differentiated into two parts: the CYTOPLASM, or general groundwork which makes up the bulk of the cell; and the NUCLEUs, a restricted, clearly defined area, usually situated near the center of the cytoplasmic mass.

The cytoplasm may be considered the more generalized protoplasm of the cell, and its appearance and other characteristics are those which have been outlined in our discussion of protoplasm. With that in mind, for the sake of definiteness, 
A

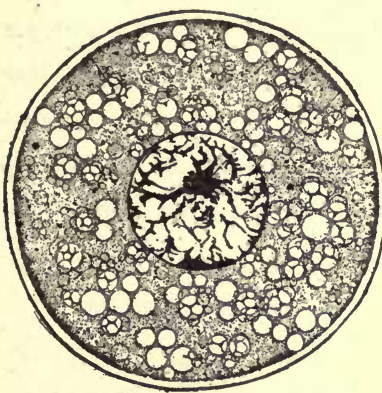

B
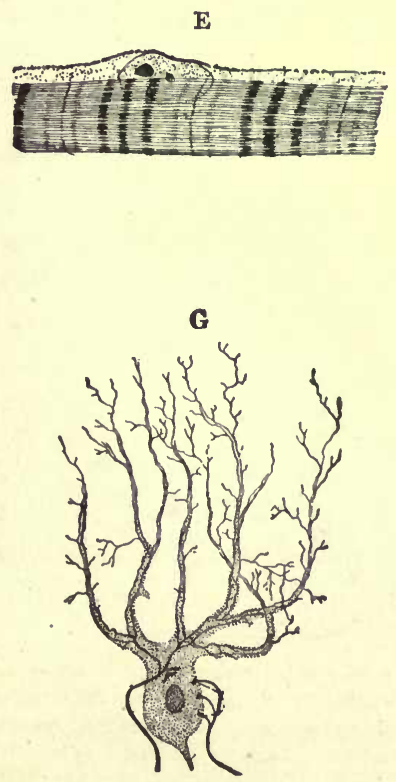

C
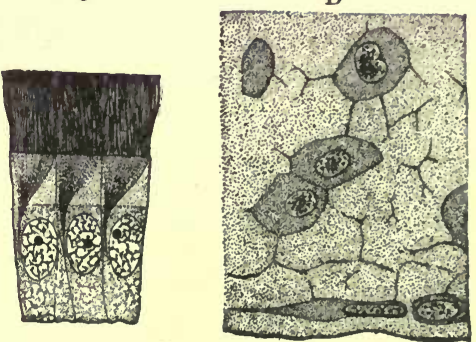

F

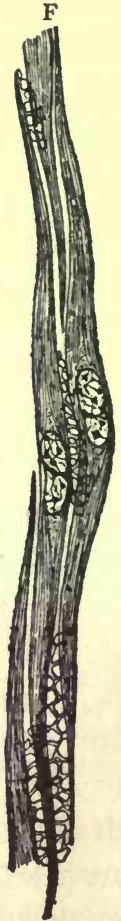

Fig. 7. - Various types of cells, highly magnified: $A$, female germ eell, egg of a Cat. $B$, male germ cell, sperm of a Snake. $C$, three ciliated epithelial cells from the digestive tract of a Clam. D, supporting tissue (cartilage) of a Squid. $E$, voluntary (striated) muscle fiber from an Insect. $F$, involuntary (smooth) muscle fibers from the bladder of a Calf. $G$, nerve cell from the brain of Man. (From Hegner, after Dahlgren and Kepner.) 
we may consider its basis as consisting of a meshwork, composed of innumerable, minute granules which permeate an apparently homogeneous hyaline ground-substance. Distributed throughout the cytoplasm are usually various lifeless inclusions such as granules of food, droplets of water or oil, vacuoles of cell sap, crystals, etc., representing materials

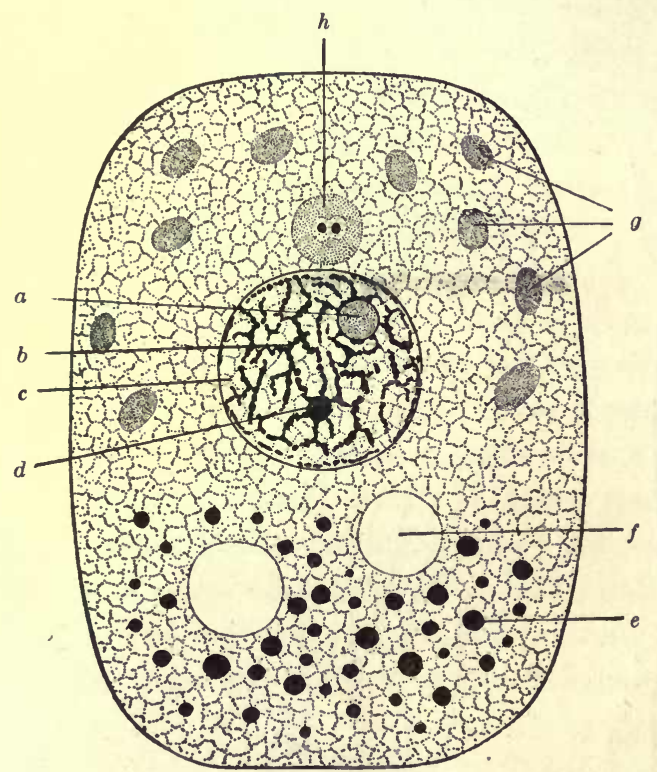

Fra. 8. - Diagram of a cell. $a-d$, nucleus; $a$, nucleolus; $b$, chromatin 'network'; $c$, linin meshwork; $d$, karyosome, or chromatin knot; $e$, metaplasmic inclusions in cytoplasmic meshwork; $f$, vacuole; $g$, plastids in cytoplasm; $h$, centrosome, recently divided. (From Wilson.)

which are to be, or have been, a part of the living complex, or are by-products of the vital processes. This passive material is frequently referred to as METAPLASM, but it is quite evident that such a term stands for no essential morphological part of the cell, and we have no absolute criterion to distinguish between some granules which are regarded as 
metaplasmic in nature and others which are ordinarily considered active elements of the cytoplasm. Specialized living cytoplasmic bodies, known as PLASTIDs, are sometimes also present. Finally, within the cytoplasm in the vicinity of the nucleus, there is frequently visible a differentiated area containing a centrosome, an important cell organ which is especially active during cell reproduction. (Fig. 8.)

The cytoplasm, since it forms the general groundwork, is that part of the cell which comes most closely into relations with the environment, and accordingly near the surface it is frequently modified somewhat in texture and consistency so that an outer region, or ECTOPLASM, may be distinguished from an inner, or ENDOPLASM. Again, the cell may form about itself a definite membrane or a heavy cell wall. Nearly all gradations exist between highly differentiated cytoplasm (ectoplasm) and definite membranes and cell walls. The ectoplasm is certainly a part of the living protoplasm, while certain types of membranes and cell walls must be regarded as non-living, though in many cases they are direct transformations of the living materials which grow and play an important, indeed a crucial, part in controlling directly or indirectly the flow of matter and energy to and from the cell and its surroundings.

\section{Nucleus}

Within the cytoplasmic mass there is a restricted area of clearly differentiated material, which typically has a rounded form, bounded by a membrane, so that it appears as a definite body of protoplasm called the nucleus. The structural basis of the nucleus appears to be essentially similar to that of the cytoplasm - the so-called LININ meshwork and KARYOLYMPH being comparable respectively to the granular meshwork and hyaline ground substance of the 
cytoplasm. But superimposed upon this, as it were, is the highly characteristic nuclear material, or chromatis, which takes various forms during different phases of cell activity but generally, in a 'resting' cell, gives the appearance of a network of tiny granules with one or more dense ' $k$ nots' of chromatin (KARYosomes). Later we shall describe some of the important changes in chromatin arrangement, but it is sufficient at this time to emphasize that the nucleus is a differentiated area of the cell protoplasm which is the arena of the chromatin. Frequently there is a conspicuous round achromatic body within the nucleus known as the NUCLEOLUS.

Cytoplasm and nucleus, looked at from the functional viewpoint, represent a physiological division of labor within the confines of the cell. Experiments have shown that they are mutually necessary for cell life; the removal of the nucleus putting an end to anabolic processes - assimilation, repair, and growth - and thus leading rapidly to death. Accordingly the nucleus may be considered as the center of the synthetic activities of the cell, and the cytoplasm, if not as the area in which destructive processes are chiefly involved, at least as a neutral region which translocates material toward and away from the nucleus. All the evidence points to the nucleus as the "controlling center in cell activity, and hence a primary factor in growth, development, and transmission of specific qualities from cell to cell, and so from one generation to another."

\section{B. Origin of Cells}

With regard to the origin of life on the Earth absolutely nothing is known. But all the evidence at hand tends to show that, at the present time at least, living matter never arises except under the influence of preëxisting living matter. That is, protoplasm grows - cells grow and, having attained 
a certain size, reproduce by dividing into two more or less equal parts. The process of cell division involves the division of both cytoplasm and nucleus, and therefore we must enlarge our conception of a cell as a small mass of protoplasm differentiated into cytoplasm and nucleus, by adding that both cytoplasm and nucleus arise through the division of the corresponding elements of a preëxisting cell.

We shall later have occasion to make a study of the details of cell division, known as MiTosis, but from what has been said it must occur to the reader that, since cells arise only by division, those of the present day, whether complete free living organisms or units composing the bodies of higher animals and plants, are actually lineal descendants in unbroken series from the beginning of life on the Earth. The bond of discontinuity between parent and offspring is typically a single cell division. (Fig. 123.) 


\section{CHAPTER IV}

\section{METABOLISM OF GREEN PLANTS}

Matter and force are the two names of the one Artist who fashions the living as well as the lifeless. - Huxley.

IT has been emphasized that life is only known to us in the form of individuals, and we turn now to concrete examples of unicellular plants and animals which present, in relatively simple form within the confines of a cell, an epitome of all the fundamental life processes which we shall later have occasion to review in their complex expressions in the higher animals and plants.

Unicellular green plants are distributed all over the world and adapted to a great variety of conditions. We find them, for example, forming green coatings on the bark of trees, scums on puddles and ponds, or being blown about as dust by winds. Of the many hundreds of species we select Sphaerella lacustris because it can readily be obtained and kept for observation, and because its life history has been carefully studied.

\section{A. Structure and Life History of Sphaerella}

A single Sphaerella is invisible or barely visible to the naked eye, but, like many another microscopic form, it makes up in numbers for the small size of the individual, and sometimes gives a stagnant pool of rain-water a bright green or red color. Sphaerella has a complicated LIFE CYCLE, or series of forms which it assumes under different conditions, chiefly environmental. We shall take as the initial stage for descrip- 
tion the so-called DORMANT Form which may be assumed when the water in which it has been living dries up. In this condition the organism consists of a spherical mass of protoplasm near the center of which is a rather large nucleus. The protoplasm, which appears greenish or reddish for reasons to be discussed later, is enclosed within a distinct, rigid cell wall. This has been secreted by the cell and is composed of CELLulOse, a carbohydrate which is especially characteristic of plant cells. It is evident that the organism is a single cell. (Fig. 9.)

Sphaerella in this phase is able to withstand unfavorable conditions for several years at least. All the life processes of the protoplasm are reduced to the lowest ebb; so low that it is difficult to demonstrate any chemical change whatsoever going on. Life in a dormant condition is not peculiar to Sphaerella, but is quite a characteristic phase in the life of many animals and plants, being most familiar to us in the case of plant seeds, some of which are known to retain their vitality for nearly a century under proper conditions.

When dormant specimens of Sphaerella are placed in rain water in the sunlight active life shortly is resumed. The cell wall swells up and the protoplasm within divides twice, with the result that four smaller but otherwise essentially similar cells, known as spores, take the place of the original cell and are set free by the rupture of its wall. The four daughter cells soon become more or less oval in outline and secrete cellulose walls of their own. The cell walls do not fit closely about the body of protoplasm, termed the PRoTOPLAST, but are separated from it by a liquid-filled space, or vacuole, except where cytoplasmic strands extend through the vacuole to the wall. But a more remarkable change occurs at the same time - two long slender cytoplasmic strands are developed from the more pointed end of the cell, and these, 


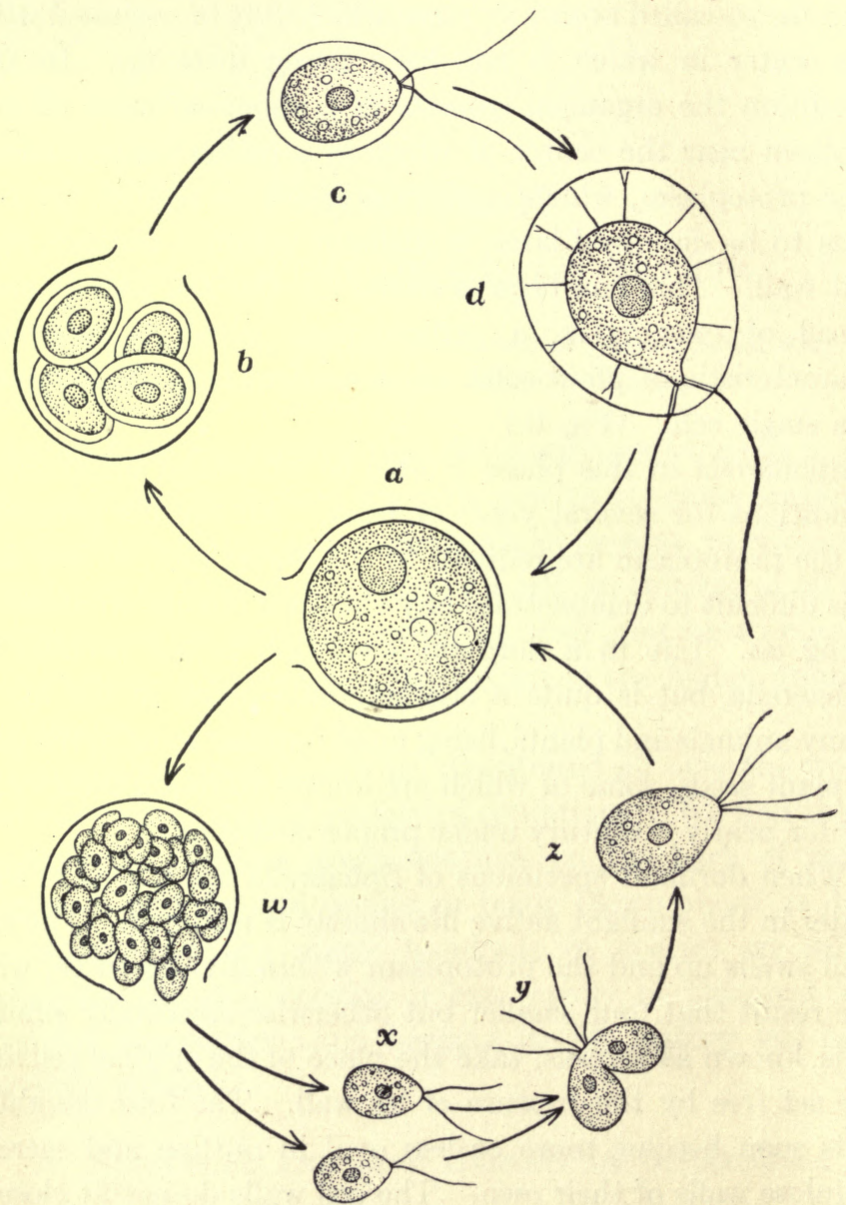

Fig. 9. - Life history of Sphaerella lacustris. $\quad a, b, c, d$, asexual cycle; $a, w, x, y, z$, sexual cycle. $a$, dormant cell enclosed within'a protective cyst wall which has ruptured to allow the enclosed protoplast to escape; $b$, division of the protoplast to form four spores $(c)$ each of which grows, develops two flagella, and assumes the typical 'adult' free living form of Sphaerella $(d)$. This may divide many times, but each cell eventually assumes the dormant form (a) again. Under other circumstances the protoplast from the dormant form may divide until 32 or 64 small cells $(w)$ are formed. These make their escape and are gametes $(x)$ since they fuse in pairs $(y)$. The composite cell resulting from fertilization is a zygote $(z)$ which soon forms a cyst wall and assumes the dormant phase. 
passing through the cellulose wall, extend for some distance into the surrounding water. These threads of cytoplasm, or FLAGELLA, lash vigorously and pull the cell rapidly through the water. The activity of the flagella is one expression of a fundamental property of protoplasm, conTractility, which is exhibited in its most specialized form in the muscles of the higher animals.

Returning now to the life-history of Sphaerella. The four free-swimming individuals, which have arisen from the parent dormant phase, may each divide many times so that instead of four there may be, before long, thousands of flagellated cells, all direct lineal descendants of the original resting cell. If this number seems high, one only has to determine how many cells there would be at, say, the twenty-fifth generation by raising 2 to the 25 th power. Sooner or later, however, these active cells withdraw their flagella and again become dormant forms.

But Sphaerella is still more versatile. Now and then, probably influenced by environmental conditions, the protoplasm within the wall of a spherical dormant form divides rapidly into 32 or 64 relatively small cells which, when set free, are termed GAMETES. These differ structurally from the active form already described chiefly by the absence of the prominent cell wall and vacuole. But it is the behavior rather than the structure of these small cells which is characteristic. After swimming about for a time by means of their flagella, they come together in pairs, the two cells of a pair completely fusing - nucleus with nucleus and cytoplasm with cytoplasm - to form a single cell, or zYGOTE, with four flagella. Soon the individual absorbs its flagella and, secreting about itself a heavy cell wall, enters upon a dormant stage with the characteristics and potentialities described above. 
It is clear that the various forms which follow one another arise by cell division in every case, though this is interrupted once by just the opposite process - the complete cytoplasmic and nuclear fusion of two distinct cells to form one cell. This is the process of FERTILIzation, an expression of a fundamental phenomenon of protoplasm at the basis of sex and sexual reproduction, which we shall consider at length later.

Such is the history of Sphaerella. It is apparent that the sequence of divesse forms which arise from one another constitute a life cycle, and although each individual cell in the cycle is a Sphaerella, nevertheless the plant called Sphaerella lacustris comprises all the forms assumed. From one viewpoint we may look upon the cycle as forming an individual of a different or higher order - an individual the component cells of which are separate.

\section{B. Metabolism in Sphaerella}

We now turn our attention from the structure and life history of Sphaerella to the point it was chosen especially to illustrate - the metabolism of green plants. It may appear to the reader that a tree or shrub might with more propriety be taken as the example of a typical plant, but, since the fundamental distinction between animals and plants is chiefly a question of metabolism, there are advantages in studying it in a single cell, where one's attention is not distracted by root, stem, and leaf.

Since Sphaerella lives, grows, and multiplies in pools of water exposed to sunlight, it is to this environment that we must look for the materials which it turns into protoplasm, and the energy by which it makes the transformation. And further, since the organism is enclosed in a cell wall, its income and outgo of materials must be in solution in order to pass through. 


\section{Food Making}

In short, Sphaerella takes materials from its surroundings in the form of simple compounds, as carbon dioxide, water, and mineral salts, which are relatively stable and therefore practically devoid of energy, and, through the radiant energy of sunlight, shifts and recombines their elements in such a way that products rich in potential energy result. Sphaerella thus exhibits the prime diagnostic characteristic of green plants - the power to construct its own foodstuffs.

The key to this power of chemical synthesis by light PHOTOSYNTHESIS - resides in a complex chemical substance called chlorophyLL. ${ }^{1}$ This pigment, which is segregated in special cytoplasmic bodies known as CHLOROPLAstids, gives to Sphaerella during its active phases and to the foliage of plants in general their characteristic green color. The chlorophyll arrests and transforms a small part of the energy of the sunlight, which impinges upon it, in such a way that the protoplasm can employ this energy for food synthesis.

The first great step in the constructive process is a combination of carbon with hydrogen and oxygen to form a carbohydrate. Sphaerella gets these elements from carbon dioxide and water by a process of molecular disruption. We know that when charcoal, for instance, is burned, carbon and oxygen unite to form carbon dioxide, and energy in the form of light and heat is liberated. Obviously Sphaerella must employ an equal amount of energy in separating the carbon and oxygen of carbon dioxide; that is, in overcoming their chemical affinity. And this kinetic energy which the plant employs is then represented in the chemical potential which exists between the oxidizable carbon and free oxygen - it is

${ }^{1} \mathrm{~A}$ rough approximation of the formula of chlorophyll has been given as: ( $\mathrm{MgN}_{\mathrm{k}}$ $\left.\mathrm{C}_{32} \mathrm{H}_{30} \mathrm{OO}\right)\left(\mathrm{COOCH}_{3}\right)\left(\mathrm{COOC}_{20} \mathrm{H}_{39}\right)$. A slight chemical modification of chlorophyll results in hematochrome, which gives at certain times the reddish tinge to Sphaerella. 
potential energy. Thus the plant in sunlight is continually separating the carbon from the oxygen of carbon dioxide. The oxygen is liberated as free oxygen while the carbon which has been separated from the oxygen is combined with molecules of water to form carbohydrates - grape sugar (glucose) and fruit sugar (fructose).

The conventional equation for this reaction is:

$\underset{\text { (carbon dioxide) }}{6 \mathrm{CO}_{2}}+\underset{\text { (water) }}{6 \mathrm{H}_{2} \mathrm{O}} \underset{\text { (glucose or fructose) }}{=} \underset{\text { (free oxygen) }}{\mathrm{C}_{6} \mathrm{H}_{12} \mathrm{O}_{6}}+\underset{2}{6 \mathrm{O}_{2}}$

It should be emphasized, however, that the processes involved are by no means so simple as is implied above; but since there is little conclusive data in regard to the details, the equation as stated affords a formal explanation which is adequate for the present discussion.

The first great step in food synthesis, the formation of a sugar, having been accomplished, the green plant transforms the sugar and stores it as starch for future use as fuel or as the basis of further synthesis. Starch is the first visible product of photosynthesis.

We have seen that the characteristic of proteins as compared with carbohydrates (sugars, starches) is the presence of nitrogen, and this element must be added to the $\mathrm{CHO}$ basis already constructed as the next step toward protein synthesis. The green plant not only can, but must employ nitrogen in such simple combinations as nitrates, and this is a fact of prime importance, for typically, as will appear later, animals and most colorless plants require nitrogen in more complex combinations. By the addition, then, of nitrogen to the carbohydrate basis a very simple nitrogen compound, such as an amine (e.g., asparagine $=\mathrm{C}_{4} \mathrm{H}_{8} \mathrm{~N}_{2} \mathrm{O}_{3}$ ), is built up, which may be transformed into a protein by the addition of sulfur and other elements secured from sulfates, phosphates, etc. Again, we do not know how this is done, 
or, after it is done, how the protein becomes an intrinsic part of the living material itself. So we attribute it to synthesizing enzymes. These are chemical bodies which are only known as products of living protoplasm and are the activating agents (catalytic agents) for chemical transformations in which, however, they themselves take no integral part. The chemical composition and constitution of enzymes is undetermined.

Sphaerella thus takes the raw elements, so to speak, of living matter and by the radiant energy of sunlight, which its chlorophyll traps, constructs carbohydrate, protein, protoplasm. In other words, the green plant is a synthesizing agent, building up highly complex and unstable molecular aggregates brimming over with the energy received from the Sun.

\section{Respiration}

So the green plant, whether Sphaerella or Elm, manufactures its own food and itself! But, as we have said before, protoplasm is always at work - to live is to work - and this means expenditure of energy, the same energy which chlorophyll has secured for the plant and stored away in its food. In other words, the food must be oxidized in order to release the energy, and for this the plant must have available a supply of free oxygen. Sphaerella obtains this oxygen dissolved in the water and, incidentally, in sunlight, from that liberated through photosynthesis. The process involved, for the sake of simplicity, may be represented by the equation:

$$
\mathrm{C}_{6} \mathrm{H}_{12} \mathrm{O}_{6}+6 \mathrm{O}_{2}=6 \mathrm{CO}_{2}+6 \mathrm{H}_{2} \mathrm{O}
$$

which, it will be noted, is the reverse of the equation for photosynthesis. This intake of free oxygen by the cell and outgo of carbon dioxide and water, the chief products of combustion, is known as Respiration. It is an interchange 
of gases between the living matter and its surroundings which is not only characteristic of Sphaerella and all green plants, but of all living things. Plants breathe just as truly as animals, though the active life of most of the latter requires a more or less elaborate respiratory apparatus in order that an adequate gaseous interchange may be effected with the necessary rapidity.

Thus the green plant may be regarded as a chemical machine for the transformation of energy - the radiant energy from the Sun - into lifework; the matter and energy which enters, forms, and leaves the organism obeying, to the best of our knowledge, the fundamental laws of matter and energy of the non-living world.

We have now obtained some idea of one living organism, Sphaerella lacustris, a green plant reduced to the simplest terms - a single cell provided with chlorophyll. And we have seen that this chlorophyll is the key to the photosynthetic activity of the green plant. In other words, the expression 'green plant' does not refer specifically to the color of a plant (in some cases it may appear red, as in Sphaerella under certain conditions), but to the fact that there is present a complex pigment functionally similar to chlorophyll by virtue of which the plant is a constructive agent in nature. It has the power to manufacture its own foodstuffs from relatively simple compounds largely devoid of energy and, in particular, is able to utilize nitrogen in the form of nitrates.

We pass now from the essentially constructive agents in nature to the chiefly destructive; from the collectors of energy to the energy dissipators; from the green plants to animals and to 'colorless' plants. 


\section{CHAPTER V \\ METABOLISM OF ANIMALS}

The most important discoveries of the laws, methods, and progress of Nature have nearly always sprung from the examination of the smallest objects which she contains, and from apparently the most insignificant enquiries. - Lamarck.

There is probably no better introduction to the study of the biology of an animal than that afforded by PARAMECIUM, a common organism of ponds, ditches, and decaying vegetable infusions. Paramecium is a representative of some 10,000 kinds of single-celled animals, or РвотоzoA. Members of this group are found in almost every niche in nature and, like the Рвоторнута, as the unicellular plants are sometimes called, are important because in numbers there is strength.

\section{A. Structure and Life History of Paramecium}

Paramecium is a giant among the Protozoa, though just visible to the naked eye as a whitish speck if the water in which it is swimming is properly illuminated. But to make out the details of structure it is necessary to magnify it several hundred times. This done, it appears as a more or less cigar-shaped organism which one would not consider, at first glance, a single cell because it shows highly differentiated parts. However, careful study reveals the fact that the organism really consists of a single protoplasmic unit differentiated into cytoplasm and nucleus, though each of these regions shows specializations. The nuclear material, instead 
of forming a single body as it does in most cells, in Paramecium is distributed in two parts: a larger body, or MACroNuCleus, and a smaller body, or Micronucleus. ${ }^{1}$ Strictly

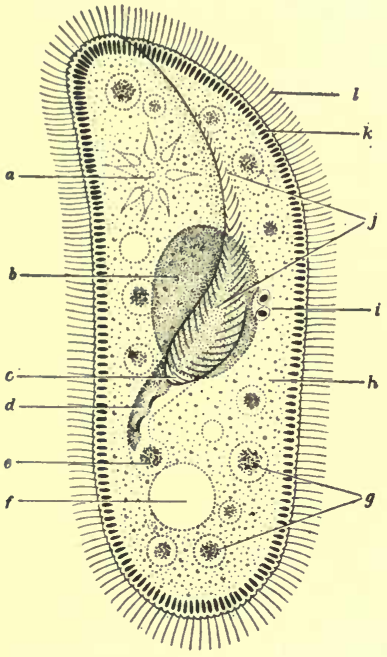

Fig. 10. - Paramecium calkinsi. Diagrammatic. $a$, contractile vacuole surrounded by radiating canals; $b$, macronúcleus; $c$, mouth; $d$, undulating membrane extending lengthwise in gullet; $e$, gastric vacuole in process of formation, at end of gullet; $f$, contractile vacuole, fully formed; $g$, gastric vacuoles; $h$, endoplasm; $i$, micronuclei; $j$, peristome and peristomial cilia; $k$, trichocysts in ectoplasm; $l$, cilia. speaking, the macronucleus and micronucleus together constitute the nucleus of the cell, and represent a sort of physiological division of labor in the chromatin complex. But it is in the cytoplasm that specialization is most conspicuous. Not only are there general differentiations into ectoplasm and endoplasm, but these regions also have local specializations such as CILIA for locomotion, TRICHOCYSTs for defense, PERISTOME, MOUTH, and GULLET for the intake of solid food, GASTRIC VACUOLES for digestion, and CONTRACTILE vacuoles for excretion. And withal, recent investigations indicate that various parts of the cell are coördinated by a 'neuromotor' apparatus. (Fig. 10.)

Paramecium, under favorable conditions, grows rapidly and, when it has attained the size limit characteristic of the species, cell division takes place, with the result that from the single large cell there are formed two smaller individuals which soon become complete in all respects. These, in turn,

1 The several species of Paramecium differ in regard to micronuclear number; e.g., $P$. caudatum has one micronucleus, and $P$. aurelia and $P$. calkinsi have two micronuclci. 
grow and repeat the process in about ten hours so that, as in the case of Sphaerella, within a few days the original Paramecium has divided its individuality, so to speak, among a multitude of descendants. (Fig. 11.)

This process of multiplying by dividing can go on indefinitely under optimum environmental conditions. But periodically Paramecium undergoes an internal nuclear reorganization process (ENDOMIXIs). Also now and then individuals temporarily fuse in pairs and interchange nuclear material (CONJUGation) - an expression of the same fundamental sex phenomenon which is exhibited in Sphaerella. (Figs. 12, 130, 131.)

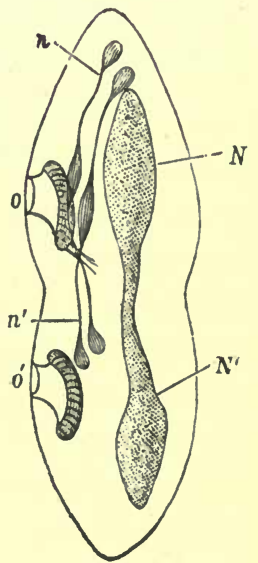

Fig. 11. - Paramecium aurelia, dividing. $N, N^{\prime}$, macronucleus; $n, n^{\prime}$, the two dividing micronuclei ; $o, o^{\prime}$, mouth. (After Hertwig.)

\section{B. Metabolism in Paramecium}

Paramecium thus affords some idea of the complexities of structure and function which a cell may exhibit when it forms

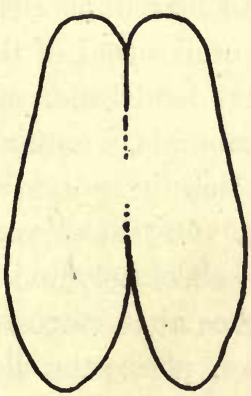

Fig. 12. - Position assumed by conjugating Paramecia. the whole animal organism. The Protozoa are the simplest, though by no means simple, animals. But the great structural differences between Sphaerella and Paramecium, though to a certain extent representative of plants on the one hand and animals on the other, are not essentially diagnostic, because, as we have suggested before, in the last analysis it is a matter of metabolism. And it is largely for this reason that Sphaerella and Paramecium, organisms shorn of all, or nearly all, non-essentials, have been selected as illustrations. 


\section{Food Taking}

The food of Paramecium is chiefly microscopic, colorless plants known as BACTERIA which are present in countless numbers in decaying vegetable infusions. As Paramecium swims about by means of its cilia, a current of water laden with Bacteria is whirled down the peristome on one side of the animal and some passes through the mouth and gullet into the endoplasm. Here the Bacteria, surrounded by a droplet of water, form a gastric vacuole, into which the endoplasm secretes chemical substances (enzymes, etc.) which gradually break down - that is, digest - the complex proteins, carbohydrates, etc., of the plant cells. Finally, this material which shortly before was Bacteria protoplasm is incorporated into Paramecium protoplasm - matter and energy is supplied and the animal lives and grows.

This is, in most regards, a strikingly different condition from that which we have seen in Sphaerella. In Paramecium solid particles of food - Bacteria - are taken into the cell, and since the chief organic constituents of protoplasm are proteins, associated with carbohydrates and fats, it is clear that the income of the animal organism is, unlike that of the green plant, chiefly ready-made complex foodstuffs. In other words, Paramecium, like all animals, requires relatively complex chemical compounds rich in potential energy: proteins, carbohydrates, and fats. Of these, proteins or their constituent amino acids are absolutely indispensable because it is only from this source that nitrogen is available for the animal. But the green plant, through its chlorophyll apparatus, is able to take materials largely devoid of energy and to rearrange them and endow them with potential energy which it has received in the kinetic form from sunlight. 


\section{Respiration and Excretion}

Of course, during life, the animal, like the green plant, is continually breaking down its food and its own protoplasm by a process of combustion which involves an intake of free oxygen and the liberation of carbon dioxide and water. Nitrogenous wastes, chiefly UREA, as well as inorganic salts, are also excreted. So the animal, like the plant, returns to its environment the elements in simple combinations which are devoid or nearly devoid of energy. We have stated that green plants are essentially constructive and animals essentially destructive agents in nature. It is now apparent that green plants are both constructive and destructive, while animals are essentially destructive.

A little consideration of the income and outgo of green plants and animals will show that, although the animals are dependent on the plants for their complex foodstuffs, they do not return, for example, the nitrogen to the outer world in a form simple enough to be available for green plants. In other words the urea, $\left(\mathrm{NH}_{2}\right)_{2} \mathrm{CO}$, which still has a little energy left which the animal is unable to extract, must be transformed into nitrates.

Furthermore, since plants die, which are not consumed by animals, and animals die, which are not devoured by other animals, large stores of matter and energy are locked up in the complex compounds of their dead tissues. Clearly, there must be some way of completing the cycle of the elements, for if there were not, life, as we know it, could not have continued long on the Earth. This gap is filled by the so-called colorLESS PLANTS, that is plants which, because chlorophyll is not present, lack the power of photosynthesis and so in most cases are dependent for food on more complex substances than green plants demand, though not so complex as animals require. 


\section{CHAPTER VI}

\section{METABOLISM OF COLORLESS PLANTS}

Nature, which governs the whole, will soon change all things which thou seest, and out of their substance will make other things and again other things from the substance of them, in order that the world may be ever new.-Marcus Aurelius.

As representative of the diverse types of colorless plants which, lacking chlorophyll or a functionally similar pigment, are without the power of photosynthesis, we select the vast group known as the BACTeria. For reasons that will appear later, it is not practical to focus attention on one particular species of Bacteria, as we have just done in considering green plants and animals. Instead we shall discuss in very general terms the group as a whole, referring now and then to special kinds of Bacteria to illustrate particular points.

\section{A. The Bacteria}

The wide distribution of the Protozoa is exceeded by the Bacteria. Representatives are literally found everywhere: floating with dust particles in the air; in salt and fresh water; in the water of hot springs; frozen in ice; in the upper layers of the soil; and in the bodies of plants and animals. Bacteria have received a considerable notoriety under the names of 'microbes' and 'germs,' owing to the fact that certain types get a living within the human body as parasites and bring about disturbances, chiefly chemical, which we interpret as disease. But aside from these forms, which are relatively few in number, human life and life in general on the Earth 
could not long continue without their services. It is this aspect of the Bacteria which concerns us at present.

Among the Bacteria are the smallest organisms known. Some species are less than one fifty-thousandth of an inch in length and much less in breadth. None of the typical forms comes within the range of unaided vision, - indeed there is room and to spare for thousands of millions of Bacteria to live in a thimble-full of sour milk. The small size and similarity of structure of many of the Bacteria render their study particularly difficult, and accordingly

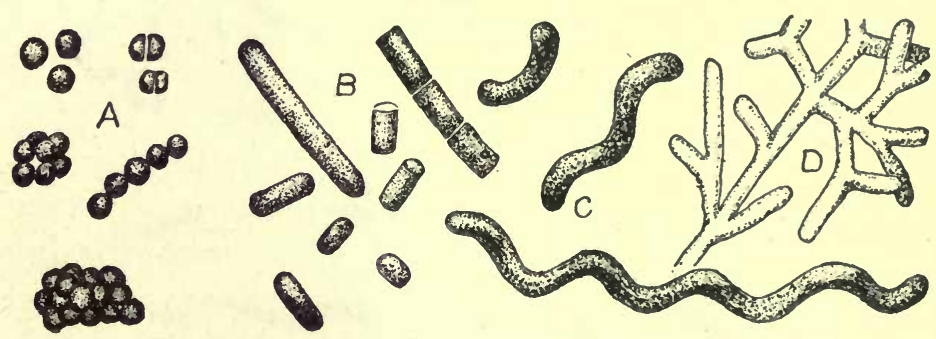

Fig. 13. - Chief types of Bacteria. $A$, cocci; $B$, bacilli; $C$, spirilla; $D$, branched filamentous form. (From Buchanan.)

they are grouped and classified largely on the basis of chemical changes which they produce, rather than on structural characteristics. However, there are three chief morphological types: the rod-like forms or BACILLI; the spherical forms or COCCI; and the spiral forms or SPIRILLA. Bacilli or cocci may be associated in linear, branching, or plate-like series, or grouped together in colonies. (Fig. 13.)

The individual bacterium is generally regarded as a single cell though in most species there is no definite nuclear body; the chromatin material being distributed in the form of granules throughout the cytoplasm. A cell wall chemically similar to protein is usually present. Some forms show active movements by means of prolongations of the cytoplasm, 
or flagella, as in the case of the common Spirillum of decaying vegetable infusions. (Fig. 14.)

Reproduction is by a process of cell division which, under favorable conditions, may occur as often as every half hour. The vast multitude of cells thus produced before long exhaust the food supply and contaminate with excretion products the medium in which they are living, so that further growth is inhibited. Under these circumstances the protoplasm within the cell wall ordinarily assumes a spherical form and secretes

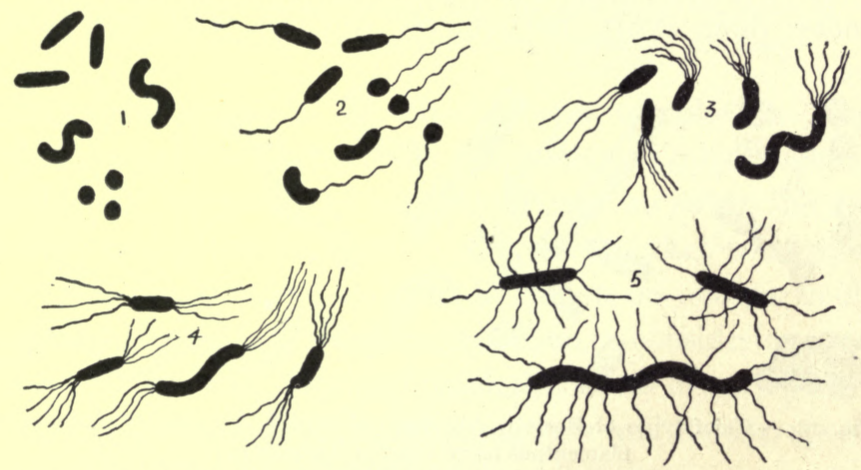

FIg. 14. - Types of flagellation in Bacteria. 1, without flagella (atrichous forms); $2,3,4,5$, with flagella (trichous forms). (From Buchanan.)

a protecting coat about itself, and thus enters upon a resting state. In this spore form the Bacteria can withstand drying and variations in temperature to which in the active state they would readily succumb, and thereby the organisms tide over periods of unfavorable conditions and are ready to start active life again when the opportunity presents itself. (Fig. 160.)

\section{B. Cycle of the Elements in Nature}

We have seen that carbon dioxide is the source from which green plants derive the carbon which they synthesize into carbohydrates, fats, and proteins. Animals directly or in- 
directly feed on plants so that the ultimate source of the carbon of animals is likewise the carbon dioxide of the atmosphere. Although both plants and animals by their respiratory process are continually returning to the outer world some of this carbon as carbon dioxide, it is evident that relatively enormous amounts of carbon are nevertheless being taken out of circulation and locked up in the bodies of the plants and animals. For example, it has been estimated that about one half the weight of a dried tree trunk is contributed by carbon.

The same general segregation is going on in regard to nitrogen. The green plants take it in the form of nitrates, for instance, and store it away in the proteins; and again animals get their nitrogen from plant proteins, so that the ultimate source of the animal nitrogen is the same. In a somewhat similar manner we might trace the fate of the other chemical elements necessary for protoplasm, but that of carbon and nitrogen is particularly striking and instructive, and is sufficient to illustrate the fact that although both green plants and animals are continually taking elements from and returning them to their environment, nevertheless more is taken away than is returned. (Figs. 15, 16.)

The agents which restore to the inorganic world the elements removed by green plants and animals are the colorless plants, chief among which are the Bacteria. As we know, when an animal or plant dies, decay sets in almost immediately; that is, the complex chemical compounds are slowly but surely reduced to simpler and simpler forms until 'dust' remains. Although undoubtedly many of these compounds would automatically, so to speak, tend to simplify, nevertheless this is not only hastened, but chiefly carried out by organisms of decay such as the Bacteria. Through enzymes, or ferments, which they form, FERMENTATIon occurs. The 
carbohydrates and fats are resolved into carbon dioxide and water, and the proteins are reduced to carbon dioxide, water, and ammonia $\left(\mathrm{NH}_{3}\right)$ or free nitrogen, while the nitrogenous waste (urea, etc.) of animals is similarly broken down. Practically all of these long series of chemical reactions are carried on by different kinds of Bacteria. Most green plants, however, take their nitrogen chiefly in the form of nitrates and

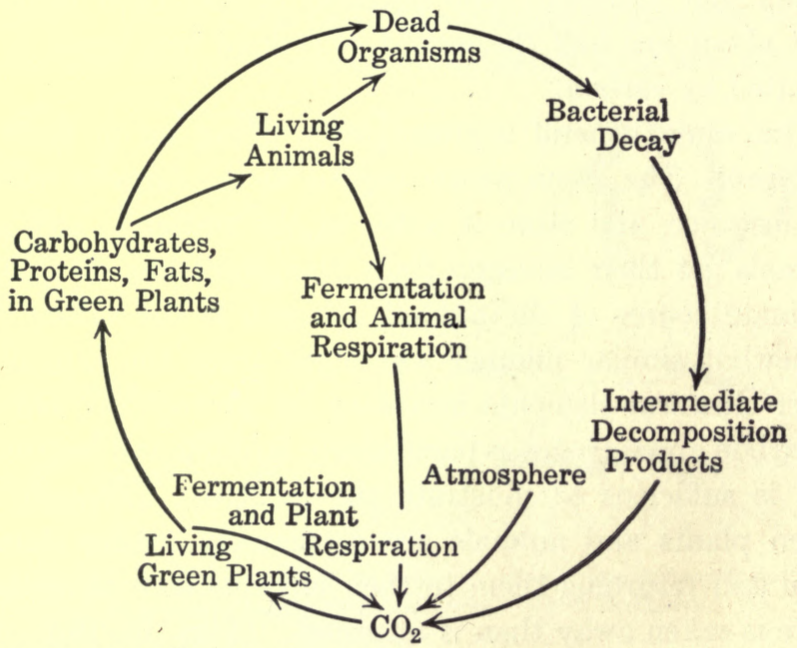

Fra. 15. - The Carbon Cycle. A schematic representation of the circulation of carbon in nature.

accordingly we find that another type of Bacteria (NITRITE BACTERIA) acts upon the ammonia and transforms it into nitrous acid $\left(\mathrm{HNO}_{2}\right)$. After certain chemical reactions in the soil, forming, e.g., potassium nitrite or ammonium nitrite, still another type (NITRATE BACTERIA) oxidizes the nitrites into nitrates (e.g., $\mathrm{KNO}_{3}$ or $\mathrm{NH}_{4} \mathrm{NO}_{3}$ ), so that again this nitrogen is in a form which is available for green plants.

But, still confining our attention to the nitrogen, it is obvious that there is a leak from this cycle, since some of the 
nitrogen in the form of ammonia or free nitrogen escapes to the atmosphere. The greatest loss, however, is brought about by a group of DENITRIFYING BACTERIA whose activities are largely spent in changing nitrates into gaseous nitrogen which escapes into the air, and so putting it beyond the reach of green plants and animals. Fortunately there is also a special group of NITROGEN-FIXING BACTERIA which rescue

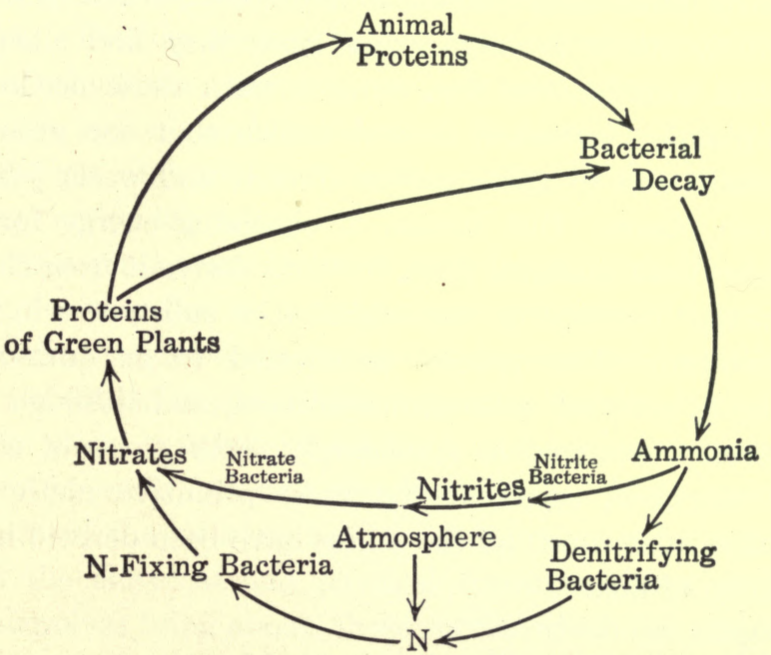

Fig. 16. - The Nitrogen Cycle. A schematic representation of the circulation of nitrogen in nature.

the nitrogen from the atmosphere and return it to the cycle of elements in living nature. These organisms inhabit the soil or little nodules which they produce on the rootlets of leguminous plants, such as beans, clover, and alfalfa; and this accounts for the fact, long known but not understood, that these plants when plowed under are particularly efficient in enriching the soil. In brief, there is a cycle of the elements in nature through green plants and animals and back again to the inorganic world through the 
Bacteria and other colorless plants. Such is the reciprocal nature of the nutritive processes of living organisms.

It is hardly necessary to state that the chemical changes produced by the Bacteria are either the direct results of, or are incidental to, the process of nutrition in these organisms. Therefore the material taken as food by certain groups is relatively complex, for example, by those which bring about the early putrefactive changes in proteins; while that employed by others is very simple since they find adequate chemical combinations less complex than those needed by green plants. Indeed, it is now known that one group of Bacteria is able to utilize carbon dioxide and water just as do green plants. But instead of obtaining energy for the synthesis from sunlight, these Bacteria derive it from chemical energy liberated by the oxidation of substances in their environment. This process is referred to as CHEMosynTHESIs, in contrast with photosynthesis, and although it is apparently restricted to a relatively small group of organisms, may well represent the most primitive method of nutrition from which all the others have been derived in the evolution of life.

\section{The Hay Infusion Microcosm}

The importance of the complex nutritional interdependence of organisms in general and the cosmical function of green plants - the link they supply in the circulation of the elements in nature - may be emphasized and summarized by a brief description of a 'hay infusion.'

Probably nowhere is the 'web of life' more conveniently or convincingly exhibited than in the kaleidoscopic sequence of events - physical, chemical, and biological - which are initiated when a few wisps of hay are added to a beaker of water. Apparently the chief components of a hay infusion 
are hay and water, but these merely supply the matter and energy for the interplay of various forms of life. Most of these are beyond the scope of unaided vision though chiefly responsible for the obvious changes which occur from day to day in their environment.

Ordinary tapwater, for instance, contains free oxygen and various inorganic salts in solution, and not infrequently different species of Bacteria, unicellular green plants, and Protozoa. The hay soaking in the water contributes soluble salts, carbohydrates, proteins, etc. It also supplies many microscopic animals and plants which have adhered to it in dormant form and are only awaiting suitable surroundings to assume active life again.

A microscopical examination of an infusion when it is first made shows very few active organisms, but within a day or so, depending largely on the temperature, it reveals countless numbers of Bacteria which have arisen by division from the relatively small number of dormant and active specimens originally present. At first the Bacteria are fairly evenly distributed in the infusion, but as conditions change, largely through the chemical and physical transformations which they themselves bring about, those species which can employ oxygen in combined form (that is, in chemical compounds) find existence possible and competition less keen at the bottom of the beaker, while those types of Bacteria which are dependent upon free oxygen gather nearer the surface where the supply is being replenished constantly from the atmosphere.

Up to this point the life of our microcosm is largely bacterial - unicellular sAPROPHYTIC plants which employ as food the complex decomposition products of the proteins, etc., of the hay. The process is essentially destructive and the simplified products are represented in the relatively simple excretions of the Bacteria. 
But during bacterial ascendency another factor has been gradually intruding itself almost imperceptibly into the drama. This is the microscopic animal life which has been multiplying with increasing rapidity as conditions became more favorable, and forthwith assumes the dominant life phase in the infusion. Among the animal forms, the first to appear are exceedingly minute flagellated Protozoa, known as Monads, many species of which absorb products of organic disintegration brought about by the Bacteria, while others ingest solid food - the Bacteria themselves. Then tiny ciliated animals, close relatives of Paramecium, appear in untold numbers and feed upon the Bacteria. The dominance of these smaller ciliates is brought to an end after a few days by the ascendency of larger ciliates, which, though feeding to a certain extent upon the already greatly depleted bacterial population, obtain most of their food by eating the smaller ciliates. And so the cycle of life continues - saprophytic forms gradually being replaced in dominance by herbivorous and these in turn by carnivorous organisms.

But obviously this chain of events must sooner or later come to an end through the dissipation of energy brought about by the metabolic processes of the colorless plants and animals. Sooner or later the supply of potential energy stored up in the chemical compounds of the hay will have become nearly or completely exhausted - transformed into the kinetic form and expressed in the life activities of the plant and animal population.

Thus, after a few weeks, the hay infusion world has reached a standstill - extermination faces the population and inevitably occurs unless microscopic green plants, possibly Sphaerella, find their opportunity to develop in the energyexhausted environment and proceed to entrap the kinetic energy of sunlight, store it up in carbohydrates and proteins, 
and thus restore energy in the potential form to the hay infusion.

If this occurs, the hay infusion world is a microcosm indeed - green plants, colorless plants,and animals gradually become reciprocally adjusted so that a self-perpetuating condition of practically stable equilibrium subvenes; in other words, what is termed a 'balanced aquarium.' The crescendo and diminuendo of teeming populations, made possible by the rapidly changing environmental conditions which the bringing together of hay and water initiated, is replaced by an apparently harmonious interdependence of organisms demandịng different food conditions, such as we are familiar with in the world at large. 


\section{CHAPTER VII \\ THE MULTICELLULAR ORGANISM}

The student of Nature wonders the more and is astonished the less, the more conversant he becomes with her operations; but of all the perennial miracles she offers to his inspection, perhaps the most worthy of admiration is the development of a plant or animal from its embryo. - Huxley.

IT has been pointed out that all organisms consist of one free living cell or of many cells, and some idea has been gained of unicellular forms from Sphaerella, Paramecium, and the Bacteria which were selected to illustrate various types of nutrition. We are now in a position to consider the origin and organization of the individual in the Metazos and Metaphyta, as the multicellular animals and plants are sometimes called.

Every individual, with exceptions to be noted later, begins its existence as a single cell which has been set free as such from the parent; or which has been formed at fertilization by the fusion of two cells, or GAMETEs, each typically derived from a separate parent individual. The former is known as UNIPARENTAL, or ASEXUAL, reproduction and the latter as BIPARENTAL, or SEXUAL, reproduction. Both asexual and sexual methods are widespread among plants and animals, frequently alternating in regular sequence in the same species to give what is termed an ALTERNATION of GENERATIONS.

The most remarkable fact about the reproductive cells is the inherent power of each to develop into a replica of the parent 
species from which it has separated. Both the spore and the zygote (fertilized egg) are set, one may say, to go through a series of changes which transform an apparently simple cell into an obviously complex multicellular plant or animal with all the tissues and organs characteristic of the species. It is important, at this point, to review the general method by which the development of the adult is accomplished.

Briefly, the modus operandi of development is cell division accompanied by differentiation. The spore (asexual) or the fertilized egg (sexual) by a succession of cell divisions, termed CLEAVAGE, passes from the single-cell stage to a twocell stage and then, with more or less regularity, to four-cell, eightcell, sixteen-cell stages, etc. If these cells separated after each division, the same general condition would obtain here which has been seen in the Protophyta and Protozoa, where each organism is a complete free-living cell. Or again, if cleavage merely resulted in a group

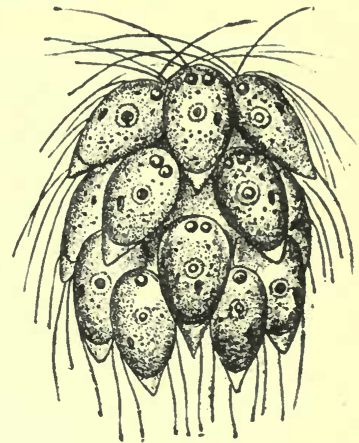

Fig. 17. - A simple colony of unicellular organisms (Spondylomorum) each of which carries on all the functions of nutrition and reproduction. Highly magnified. (From Hegner, after Oltmanns.) of so many exactly similar cells, there would arise a colony of unicellular individuals rather than a multicellular organism. Such colonial forms are, in fact, numerous among the lower plants and animals, and show nearly all grades of complexity from simple associations of a few identical cells, as for example in Spondylomorum, to groups of many thousands in which some of the individuals are specialized for certain functions. (Fig. 17.) Volvox affords an instructive example of the latter condition. The majority of the cells, ten thousand or more, which form the relatively large spherical colony are 
flagellated individuals each of which lives a practically independent existence in organic union with its fellows. The chief contribution of each of these cells to the economy of the

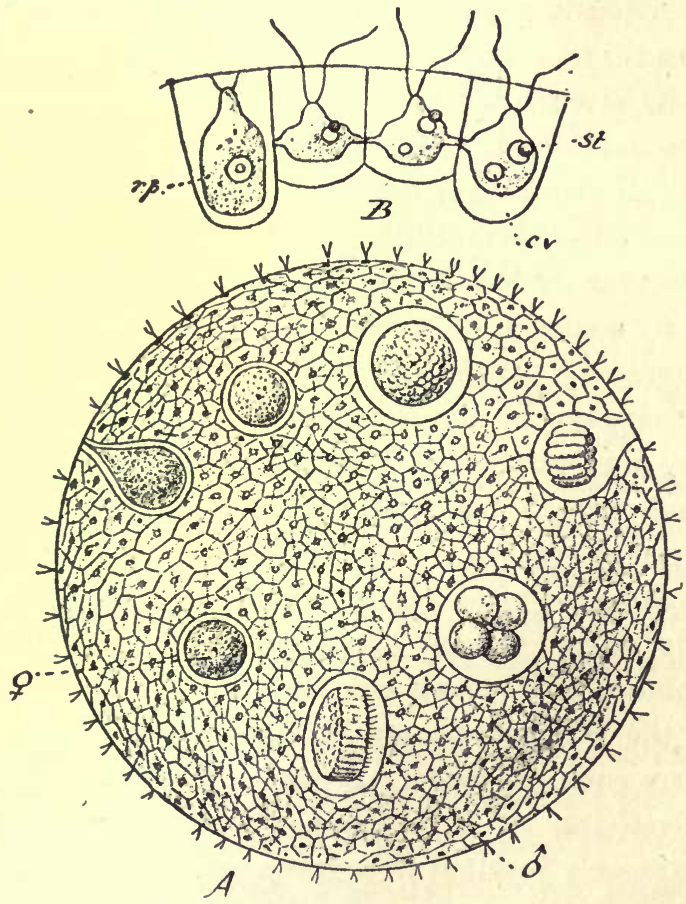

Fig. 18. - Volvox globator, a large colony of flagellated unicellular organisms in which the various cells have become organically connected, and certain cells specialized for reproduction. $A$, mature colony (highly magnified) showing sperm, $\delta$, and eggs, $\$$, in various stages of development. $B$, four cells (more highly magnified) showing the connections between three 'somatic' cells, and the early differentiation of a reproductive cell, $r p$; $c v$, contractile vacuole; st, 'eyespot' or stigma. (From Hegner, after Kölliker.)

whole results from the lashing of its flagella, which helps to propel the colony through the water. But, under certain conditions, some of the cells become specialized for reproduction and form new colonies which sooner or later are set 
free. Thus we have a foreshadowing of that differentiation and physiological division of labor between cells which is the most characteristic feature of the Metaphyta and Metazoa. (Figs. 18, 115.)

However, in the developing multicellular organism cleavage results, sooner or later, in a body composed of cells which possess differentiations of one kind or another that adapt them for the special part they are destined to play in the economy of the individual. Thus cell division, involving differentiation, is the keynote of development in the higher plants and animals.

Among animals, for example, the cells which arise from the cleaving egg frequently become arranged so that they form the surface of a hollow sphere of cells known as a BLASTULA. All the cells at first appear essentially similar, but soon those at one side of the blastula become invaginated until the central cavity, termed the BLASTOCOEL, is largely obliterated. Accordingly there results the GASTRULA stage, which may be roughly compared to a sack, with an opening to the exterior termed the BLASTOPORE, composed of two layers of cells. The outer layer is known as the EcToDERM, and the inner, which lines the gastrula cavity (ENTERIC CAVITY), as the ENDODERM. The ectoderm comprises cells which are already somewhat differentiated among themselves for special purposes, but which, as a whole, form a primary tissue with general functions of its own, chiefly sensory and locomotor. Similarly the endoderm consists of cells which, as a group, form the nutritive cells of the embryonic animal. (Fig. 19.)

In the gastrula stage of most animals, a third layer of cells arises typically from the endoderm and becomes disposed between the ectoderm and endoderm. This new middle layer is the MESODERM. In this way the so-called three 
PRIMARY GERM LAYERS are established which are characteristic of the developing animal, and from these the specialized tissues which compose the various systems of organs of the

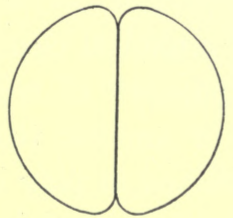

A

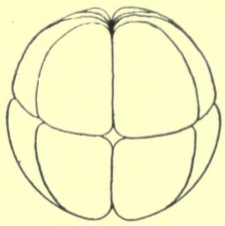

D

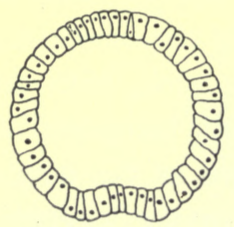

G

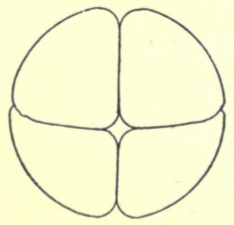

B

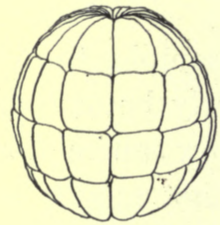

E

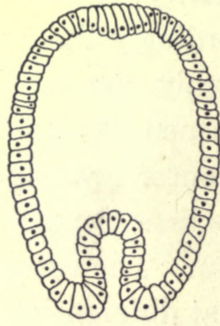

H

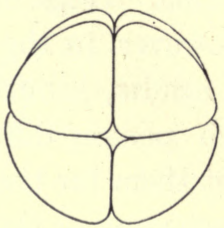

C

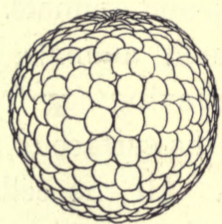

F

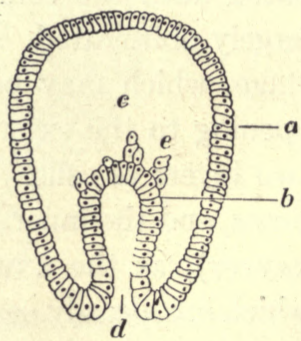

I

Frg. 19. - Early stages in the development of the egg of a Sea Urchin. A-F, cleavage and formation of the blastula; $G$, section of blastula showing the beginning of gastrulation; $H-I$, early and later gastrula stages. $a$, ectoderm; $b$, endoderm; $c$, blastocoel; $d$, blastopore, leading into the enteric cavity; $e$, cells, arising from the endoderm, destined to form the mesoderm.

adult are derived. For example, the ectoderm by cell division and differentiation gives rise to the outer skin and central nervous system; the mesoderm to muscular, connective, and supporting tissues and the blood vascular system; while the 
endoderm forms the layer of cells which lines the alimentary canal of the adult organism.

This grouping of more or less similar cells into functional systems, or tissues, is at the basis of the architecture of multicellular organisms, and thus we have now reached another level in the analysis of their structure. Although the unit of organization is the cell, these are associated in groups, or tissues, which represent a morphological unit of a

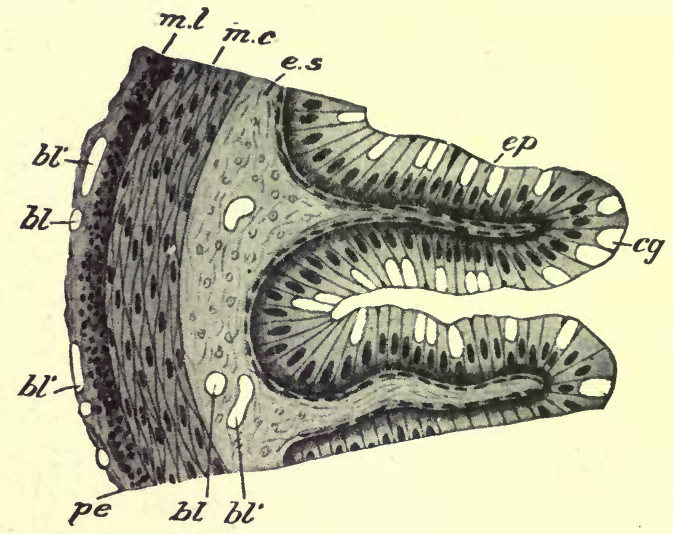

Frg. 20. - Portion of a cross section of the small intestine of the Frog, highly magnified to show cellular differentiation and tissues. $b l$, blood vessels; $c q$, unicellular glands; $e p$, ordinary absorptive epithelial cells lining the intestine; es, connective tissue; m.c., circular muscle cells; $m$. $l$., longitudinal muscle cells; pe, peritoneum. (From Holmes, after Howes.)

higher order. A tissue may be defined as a group of essentially similar cells specialized to perform a certain function. Examples are bone, muscle, and nerve in animals; and wood and bark in plants. (Figs. 20,21.)

Since the similar cell components of multicellular organisms are grouped to form tissues, it follows that the major working units, or oRgans, of the animal or plant body as a whole are formed of tissues. In other words an organ is a complex of 
tissues which has assumed a definite form for the performance of a certain function: for example, the human hand composed of bone, muscle, nerve, etc.; or the plant leaf with its chlorophyll-bearing tissue, epidermal covering, etc.

As one would naturally expect, among the lowest Metaphyta and Metazoa there are forms in which the body is relatively simple, without highly specialized tissues and organs, but in most animals specialization is carried still another step forward by the grouping of organs devoted to

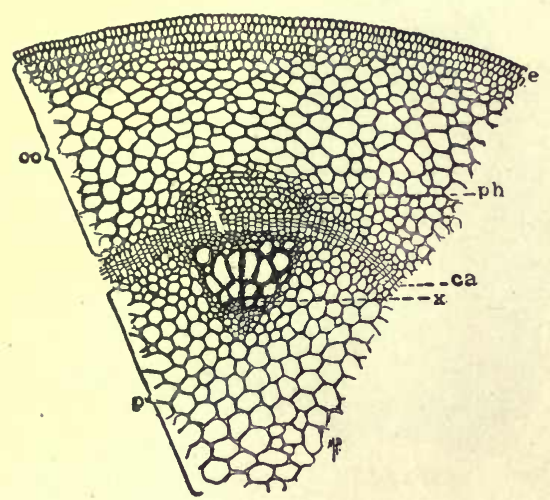

Fia. 21. - Portion of a cross section of a young plant stem, magnified to show cellúlar differentiation and tissues. $c a$, cambium; $c o$, cortex; $e$, epidermis; $p$, pith; $p h$, phloem; $x$, xylem. (From Gager.)

the performance of some one general function into an ORGAN sYSTEM. An animal has many muscles, each of which is an organ but which collectively constitute a working unit, the muscular system; or it has stomach, intestine, liver, etc., forming the digestive system. On the other hand, even in the highest plants, differentiation has proceeded neither in just the same way, nor so far, since the body is composed of TISSUE SYSTEMS rather than organ systems. This point will be clear when the structure of the plant and animal body has been considered. 


\section{CHAPTER VIII \\ THE PLANT BODY}

The evidence seems to show beyond question that our present species of plants have descended by gradual evolution from simpler and fewer species which formerly existed-back, it is possible, to a single kind which throve in remotest antiquity.

- Ganong.

NearLy all stages exist between the simplest unicellular plant body such as is exhibited by Sphaerella, and the highly complex condition which obtains in the familiar Flowering Plants, technically known as Seed Plants or SpermaTOPHYTES. A simple type is found among the filamentous green Algae commonly called pond scums. In forms such as

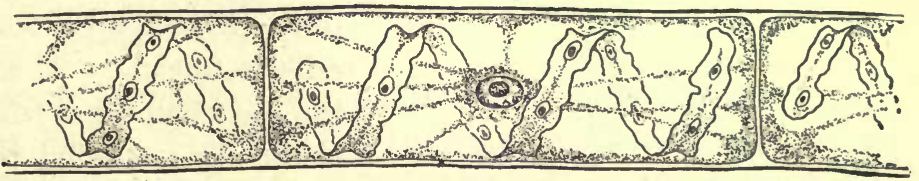

Fig. 22. - Spirogyra. Portion of a filament, highly magnified, showing cell wall, cytoplasm, nucleus, vacuole of cell sap, and spiral chloroplastid. (From Coulter.)

Spirogyra the body of the plant consists of a series of similar cells placed end to end and, therefore, from one point of view, may be looked upon as a colony of cells since the individual cells of the filament are essentially independent. (Fig. 22.) In Ulothrix, another simple form, the filament instead of floating free is attached by a more $\cdot$ or less specialized cell devoid of chlorophyll. (Fig. 49, A.) Still more common are plant bodies composed of branching filaments of cells. The branches may all be similar, or there may be a chief axis 
with lateral branches of different form. Frequently the branches, though still composed merely of filaments of cells placed end to end, may show, for example, larger chloroplastids and thus be more active in photosynthesis. This is essentially the same general division of labor that occurs

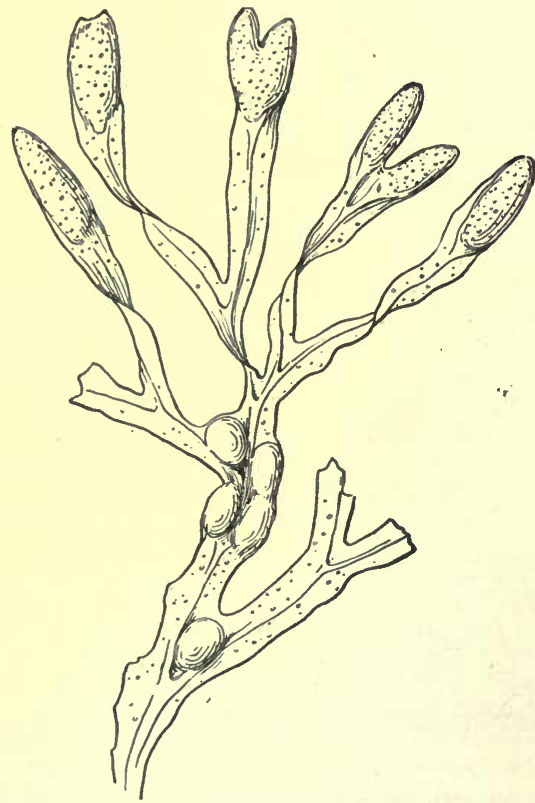

Fic. 23. - A common Seaweed (Fucus). One of the Brown Algae, showing comparatively simple thallus structure. (From Coulter.)

between the stem and leaves of higher plants, but without the attendant structural differentiation of the parts into tissues. (Cf. p. 413.)

The next specialization we find is in regard to the character of the growth. Whereas, in simple unbranched filamentous forms, growth takes place as a rule by the division of all of the cells composing it, in the branched types this is usually restricted to one or more cells near the end of each filament. Thus, depending on the character of the growth from the apical cells, various complex forms of massive branching structures arise as, for instance, in many of the Red Seaweeds. In these plants the chloroplastids are chiefly developed in the cells on the surface; which again indicates the physiological division of labor referred to above and suggests that many, if not all, of the modifications of the simple plant bodies thus far considered are provisions for the purpose of 
bringing about the most favorable exposure to light of the photosynthetic apparatus.

Another method of attaining the same object is found in other Seaweeds. In the common Sea Lettuce (Ulva) and the Rockweed (Fucus) the plant body takes the form of a plate of cells, as a result of cell division occurring in two planes, and then this THALLUs usually becomes thicker by division of the cells in a third plane also. As a result of further modifications of the thallus, the single attaching cell of the simple filamentous types is replaced in the larger Sea-

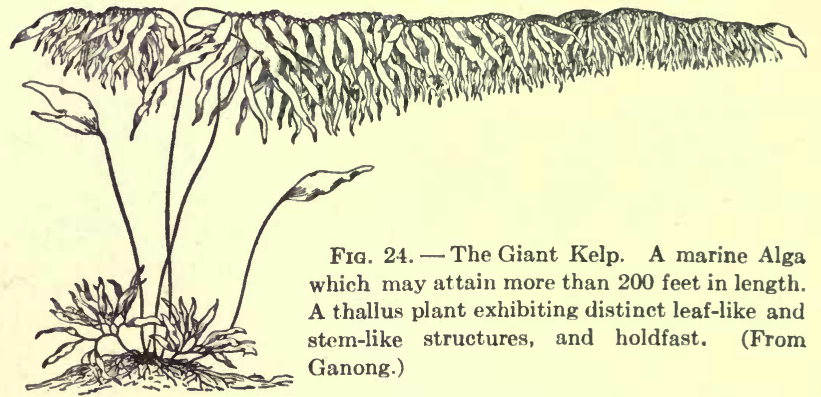

weeds by massive HOLDFASTs which anchor them securely to rocks. Still there is no marked differentiation in the cellular components of the holdfasts because they perform only this one function of the roots of higher forms; the absorption of food materials dissolved in the water being carried on by the individual cells of the whole plant. Although among the most complex Seaweeds, for example in the Kelps and Gulfweed, the form of the thallus is highly modified into divisions which serve certain of the functions of root, stem, and leaf of higher plants, still none of the fundamental tissue differentiations so characteristic of the higher forms occur. Similarity of function has given rise to ANALOGous structures. (Figs. 23, 24, 25.) 
It is among the so-called vascular PLANTS - the Ferns and Flowering Plants - that the most highly specialized plant body occurs. As will be explained in more detail later, these plants exhibit in their life history an alternation of generations: a sexual plant (GAметорнутE) bearing gametes gives rise to a non-sexual spore-bearing plant (sPOROPHYTE)

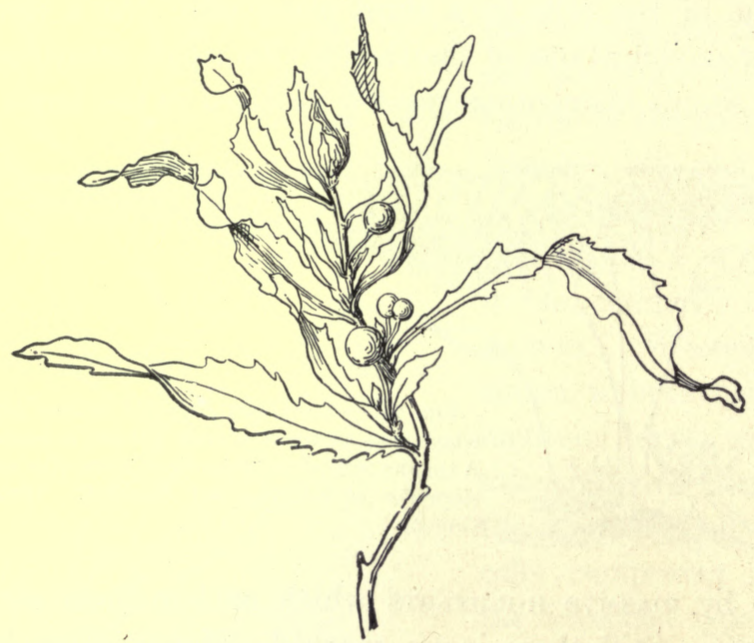

Frg. 25. - Gulfweed (Sargassum) showing the 'stem,' 'leaves,' and the berry-like floats of the thallus. (From Coulter, Barnes, and Cowles.)

which in turn produces a gametophyte. These two generations exhibit marked differences in structure. The gametophyte body is relatively very simple, consisting merely of a few cells, the main function of which is to develop male and female gametes. On the other hand, the sporophyte is composed of a number of specialized tissues and organs, and is the conspicuous generation which is recognized by everyone as a 'Fern' or a 'Flowering Plant.' 


\section{A. Gross Structure}

The body of the sporophyte of a typical Flowering Plant is clearly differentiated into two parts, воот and sноот. The root is the organ of attachment, as well as of absorption of food material in solution. The shoot consists of sTEM and LEAVES. The stem is largely a passive structure and forms the connecting link between the root and the photosynthetic

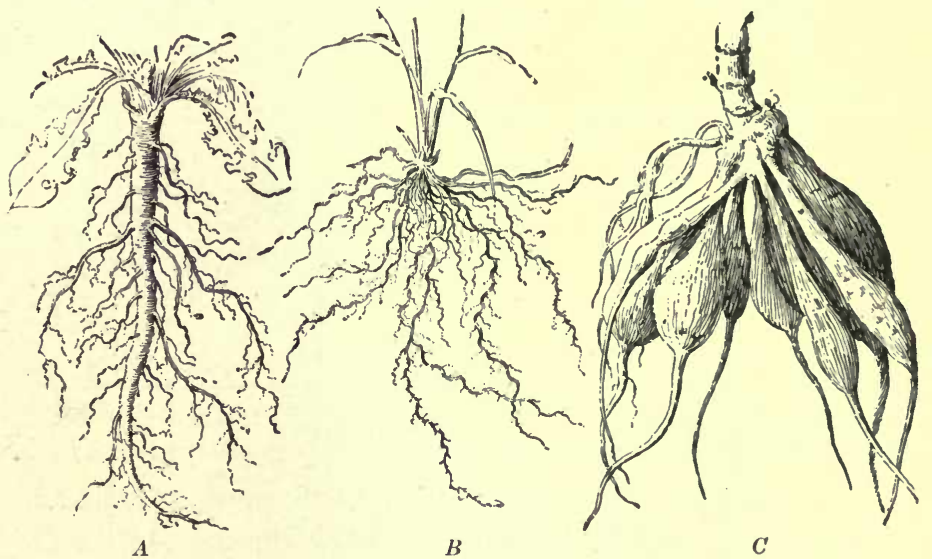

Fig. 26. - $A$, tap root of the Dandelion; $B$, fibrous roots of a grass; $C$, clustered and fleshy roots of the Dahlia. (From Bergen and Davis.)

apparatus of the leaf. The reproductive organs (SPORANGIA) are usually developed as appendages of modified leaves (SPOROPHYLLS).

\section{Root}

The PRIMARY root of a young plant, which is usually a continuation downward from the shoot, may persist throughout the life of the plant as the chief root and merely give off laterally small secondary roots. Such a root system, known as a TAP root, is common in many herbs, as for example the Dandelion. More often the primary root is entirely replaced 
by the SECONDARY roots which radiate and branch in all directions from the main axis of the plant until they form a complex underground structure. This may equal in size the part of the plant body which is developed above the surface by the shoot system.

In plants which live through two years (BIENNIALs), often

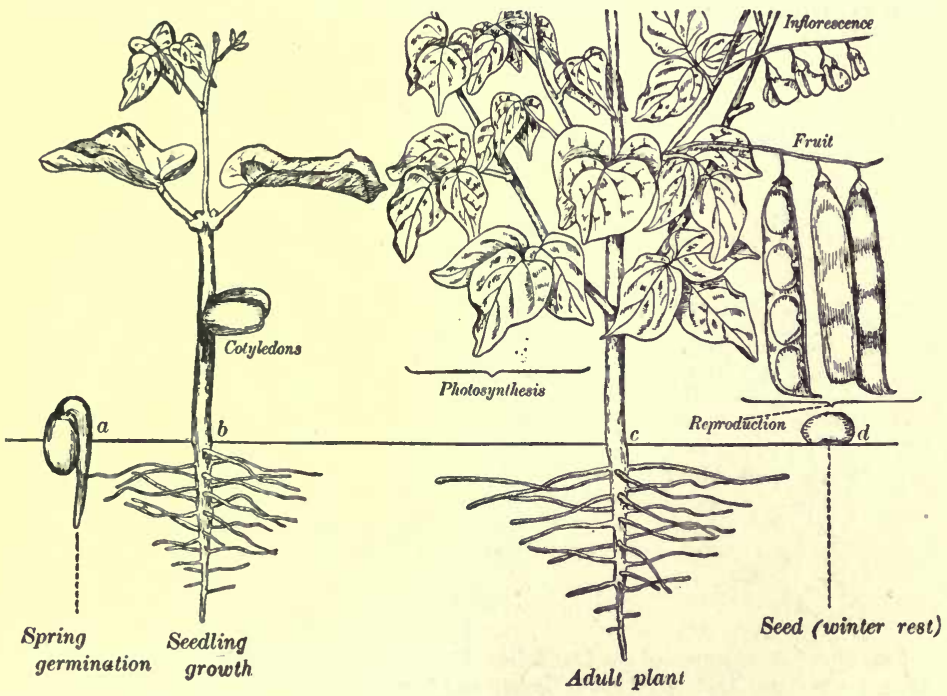

Fig. 27. - The seasonal history of an annual plant, a Bean.

(From Densmore.)

the first year is spent in storing up food. Sometimes this is in the roots, in which case they are greatly enlarged to form a reservoir of material, at the expense of which during the second season the plant rapidly develops flowers and seeds. These storage roots may be tap roots as in the Turnip, or lateral roots as in the Dahlia and Sweet Potato. (Figs. 26, 27,28.)

Although the contact of the plant with its environment through its roots is ordinarily underground, tropical plants in particular frequently develop AERIAL roots from the stem or 

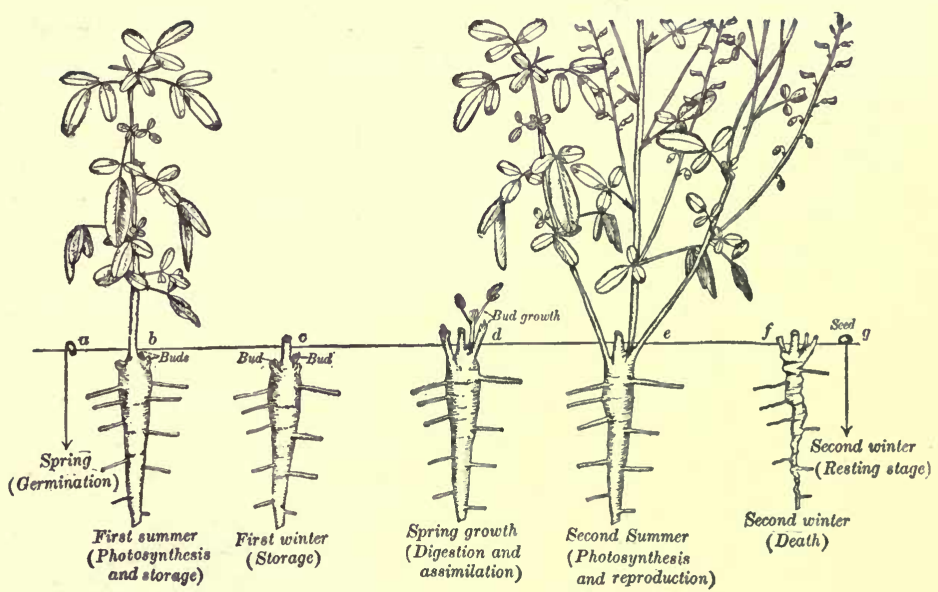

FIg. 28. - The seasonal history of a biennial plant, White Sweet Clover (Melilotus).

(From Densmore.)

its branches. Roots which rise from such unusual places are called ADVENTITIOUs roots. In certain species the aerial roots hang free in the air and absorb moisture from the atmosphere. In addition, such roots may develop chlorophyll and so perform the characteristic function of leaves. In the Fig tree the aerial roots grow from the branches down to the earth where they become attached and eventually form a stout trunk which functions as a stem. Comparable to these roots are the so-called BUTTRESS roots of some Palms and of the familiar Indian Corn. (Fig. 29.)

Many plants depend chiefly or entirely on other plants for their food materials. The roots of such

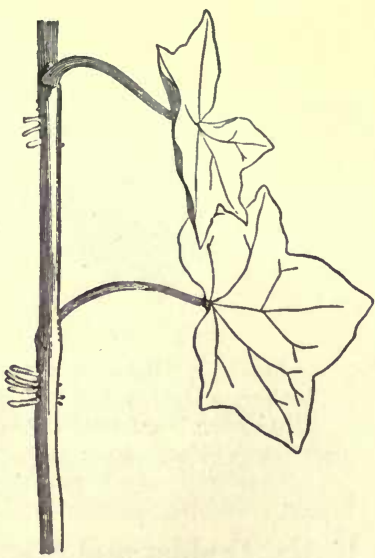

FIG. 29. - English Ivy, showing the aerial roots which enable it to cling to walls. (From Ganong, after LeMaout and Decaisne.) 
parasitic species frequently grow into the tissues of the host, and become more or less modified into suckers, or HAUSTORIA.

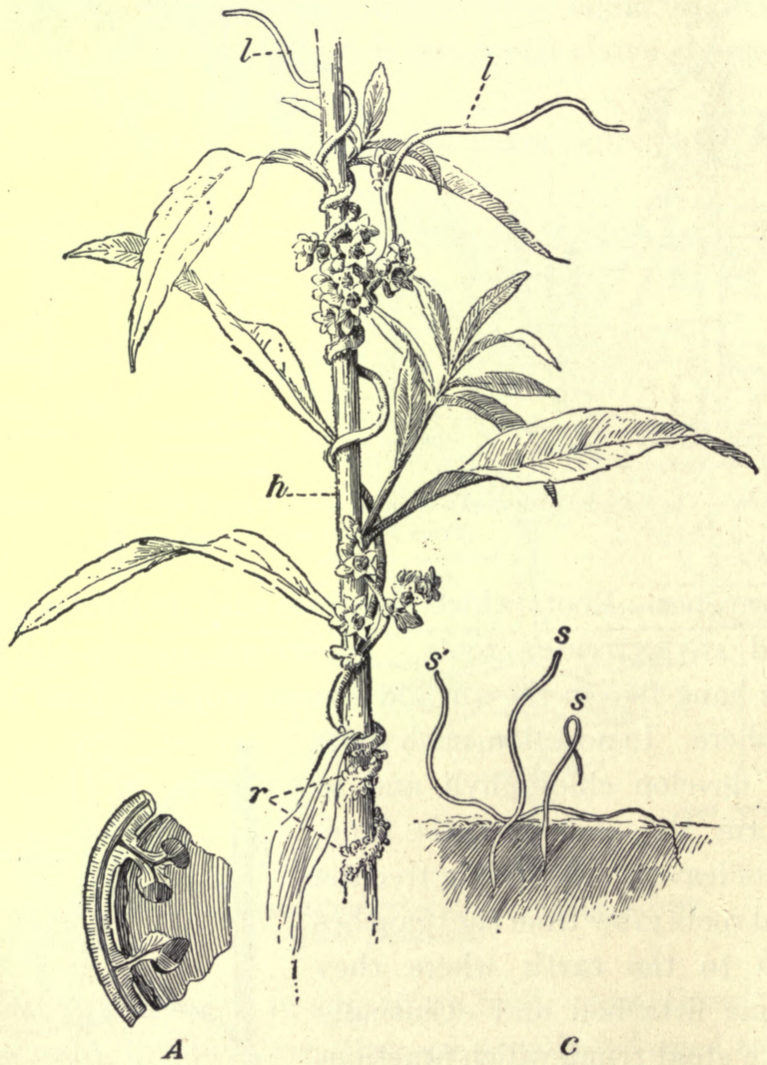

Fig. 30. - Dodder, a parasitic Flowering Plant, entwined about the stem of its host, a Golden Rod. $A$, cross section of stem of host to show its penetration by the Dodder rcots (haustoria). $C$, several Dodder seedlings growing in the soil before attachment to a host. $h$, stem of host; $l$, scale-like leaves; $r$, haustoria; $s$, seedlings. (From Bergen and Davis.)

In the Dodder and Mistletoe, the haustoria enter the tissues of the stem of the host, while in many of the false Foxgloves (Gerardia) they enter the tissues of the roots. In some 
aquatic and parasitic plants roots are absent, their function being taken over by other parts of the body such as stem or leaves. (Fig. 30.)

Without multiplying examples, it is clear that the part of a plant which the botanist calls a root, and which typically anchors the plant to the earth and takes water with food materials in solution from the soil, frequently is highly modi-

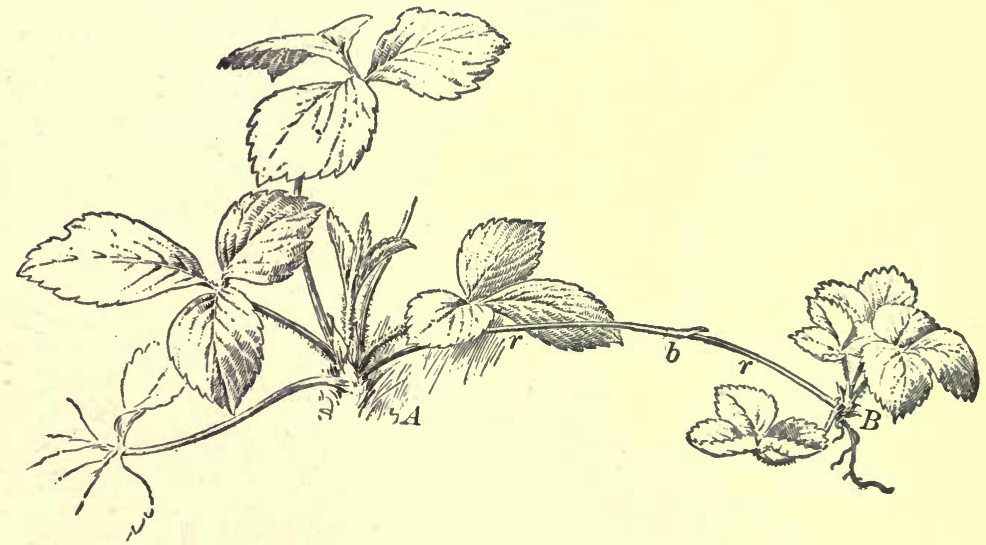

FIG. 31. - Propagation of the Strawberry plant by runners. $A$, parent plant; $B$, young plant; $b$, modified leaf; $r$, runner or stem. (From Bergen and Caldwell.)

fied and even assumes the duties of other organs in certain plants which are adapted for special places in the economy of nature.

\section{Stem}

The stem of the vascular plants is the axis of the shoot and has two primary functions. First, to support and raise the leaves into a position of vantage with respect to light; and, second, to act as the medium of communication between the absorbing organs, or roots, and the photosynthetic organs, or leaves. But, like the root, it may be modified and diverted 
from its typical structure and take over more or less of the functions of other parts.

For the purpose of propagation, creeping stems occur such as the surface RunNers of the Strawberry, and the underground RHIzomes of many Sedges, Grasses, and common Ferns. Sometimes the stem to a large extent re-

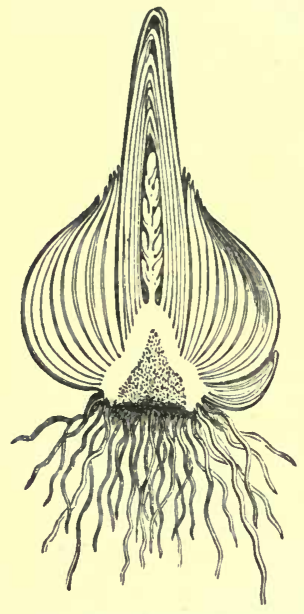

Fig. 32.-Bulb of a Hyacinth, in section, showing roots, stem, bases of leaves of previous year stored with food, and new foliage leaves about the flower cluster. (After Figurier.) places the root system, but more often it acts as an underground reservoir in which food material is stored up during the short growth period for the rapid development of the flowering shoot. This is well seen in some of the early spring Flowering Plants of New England such as Bloodroot and Trillium. (Figs. 31, 39.)

Again, the stem is greatly shortened to form a BULB or a coRM; types particularly common in plants adapted to dry soil. (Fig. 32.) Extremely arid regions are characterized by plants, such as the Cacti, in which the leaves are completely suppressed to prevent rapid evaporation; their function being taken over by the stem which is provided with well-developed chlorophyllbearing tissue. Sometimes parts (branches) of the stem may superficially resemble a leaf by being flattened or otherwise modified, as in the Prickly Pear, the apparent leaves of the so-called Smilax (Myrsiphyllum), and the filamentous 'leaves' of Asparagus. (Fig. 33.) Finally, the versatility of the stem is illustrated by the thorns of the Honey Locust, the twining tendrils of the Grape, and the tuber of the Potato which is essentially a 'concentrated rhizome.' 


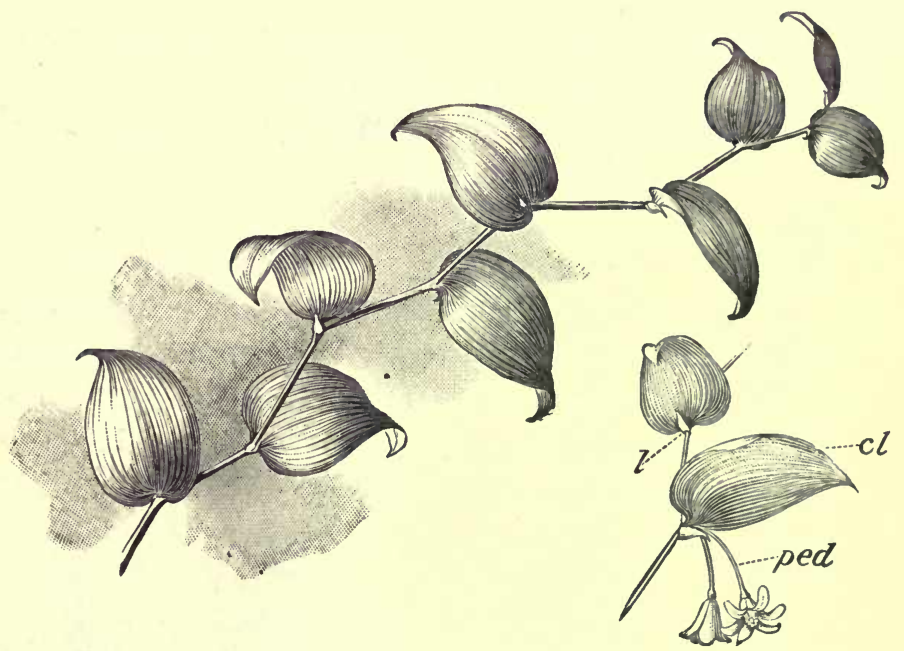

Fig. 33. - Stem of Smilax (Myrsiphyllum). cl. leaf-like branch, or cladophyll, situated in the axil of a leaf; $l$, leaf; ped, flower stalk. (After Bergen.)

\section{Leaf}

Although the leaves of the higher plants exhibit much diversity in form, they agree in their essential features. The fundamental functions of leaves are to expose to the sunlight the chlorophyll apparatus and to afford a surface for evaporation and the exchange of gases with the environment. Accordingly the principal part of a typical leaf is a broad blade, or LAMINA, which affords the optimum conditions for exposure. The leaf is usually attached to the stem by a stalk, or PETIOLE, which is some-

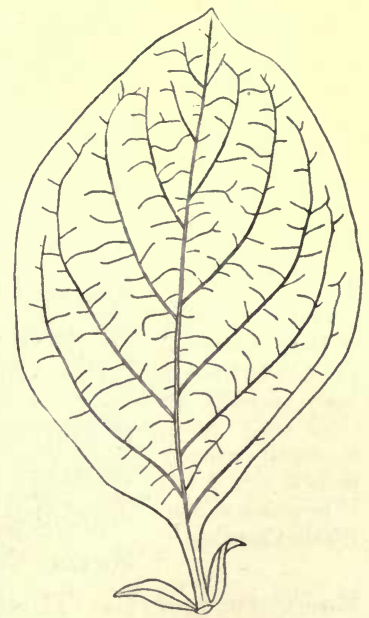

Fig. 34. - Leaf of a Flowering Plant, showing blade, or lamina, petiole, and $t$ wo stipules at the leaf base. (From Ganong, after Gray.) 
what modified at the point of union with the stem into a LEAF BASE from which arise leaf-like appendages, or sTIPULEs. When the petiole is absent the lamina of such a sessile

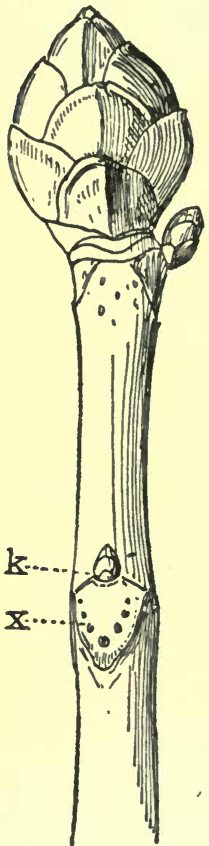

Fra. 35. - Shoot of Horse Chestnut showing winter buds enclosed by thick scale leaves; $k$, small axillary bud; $x$, scar of leaf of previous season. (From Campbell.)

leaf appears to arise directly from the stem. (Fig. 34.)

The leaf, like the root and the stem, exhibits numerous modifications in adaptation to other functions. The chlorophyll-bearing tissue may be nearly or completely suppressed, as in the SCALEs which enclose winter buds in a protective case. These are conspicuously developed in the Horse Chestnut and the Hickory. (Fig. 35.) Or the scale leaves, in addition to affording protection, may act as reservoirs in which food materials are stored, an example of which is the familiar Onion. (Fig. 36.) All transitions between scale leaves and typical foliage leaves may frequently be seen in an unfolding leaf bud. Still more marked departures from the usual leafform are the TENDRILS of some climbing plants such as the Sweet Pea, the spines of the

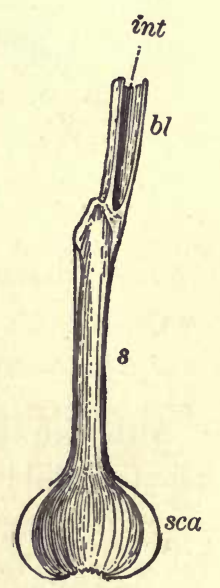

Frg. 36.-Onion leaf, cut longitudinally. $b l$, blade; int, hollow interior of blade; 8 , thin sheath of leaf; sca, thickened base of leaf. (From Bergen and Davis, after Sachs.)

Barberry and the Thistle, and the 'insect traps' of Pitcherplants and Sundews which capture small living animals. (Figs. 37, 38.)

Leaf modification in another direction occurs in the spore- 


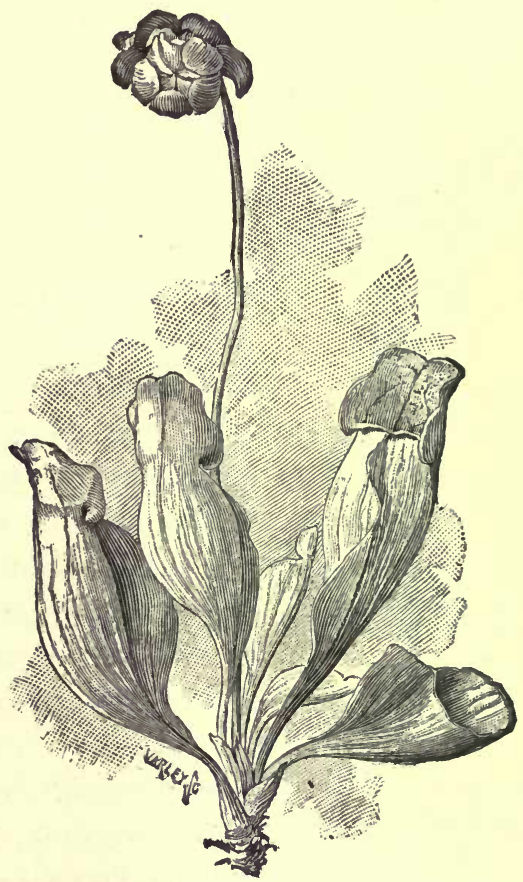

Frg. 37. - Common Pitcher-plant (Sarracenia purpurea). At the right, one of the pitcher-like leaves is shown in cross section. (From Bergen.)
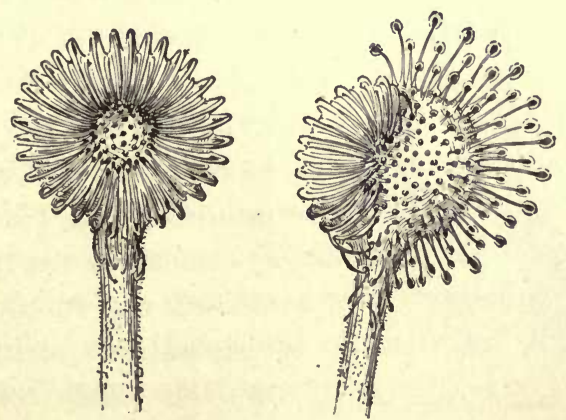

Fra. 38.- Leaves of Sundew during digestion of captured prey. The one at the left has all the tentacles closed; the one at the right, only half of them closed over the prey. (From Bergen.) 


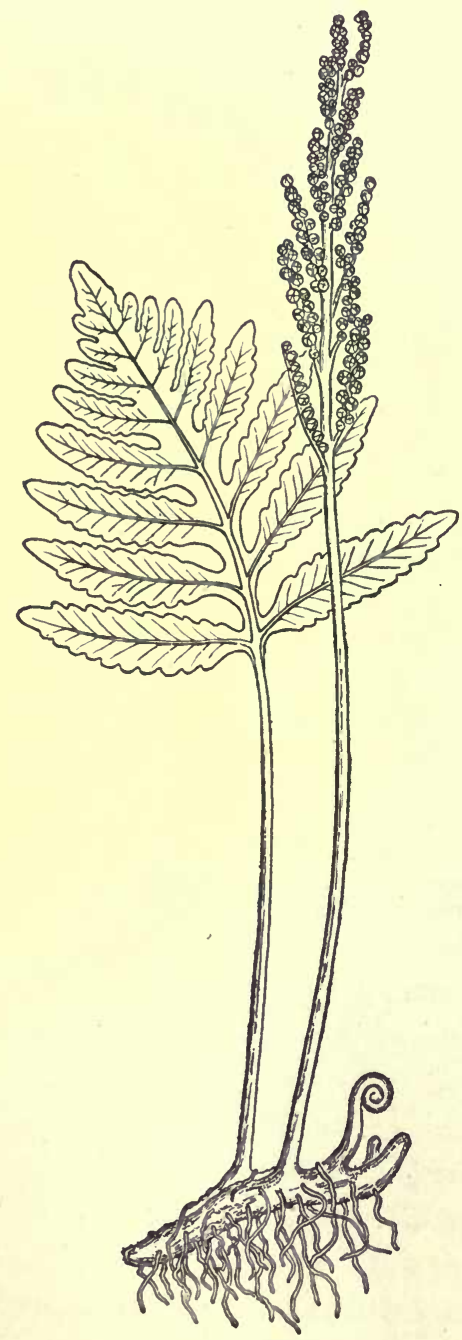

FIg. 39. - The Sensitive Fern (Onoclea sensibilis), showing vegetative leaf, and spore leaf, or sporophyll, arising from the rhizome. (From Bergen and Davis.) bearing structures of Ferns and Flowering Plants. In some Ferns the spore cases (sporangia) are borne upon typical leaves, while in others they arise on special leaves with chlorophyll-bearing tissue partly or completely suppressed. Such leaves which are given over to the production of spores, as in the Sensitive Fern, are known as SPOROPHYLLS. (Fig. 39.) In the Flowering Plants, the FLOwER is a group of sporophylls, known as CARPELS and stamens, associated in most cases with certain sterile leaf structures, termed SEPALS and PETALS, which afford protection to the sporophylls and offer attraction to insect visitors. (Figs. 40, 58.)

We shall consider the structure of the flower in more detail in discussing reproduction in plants, but it is essential now, having considered the fundamental divisions (root, stem, and leaf) of the body of vascular plants, and some of the adaptive modifications of these 


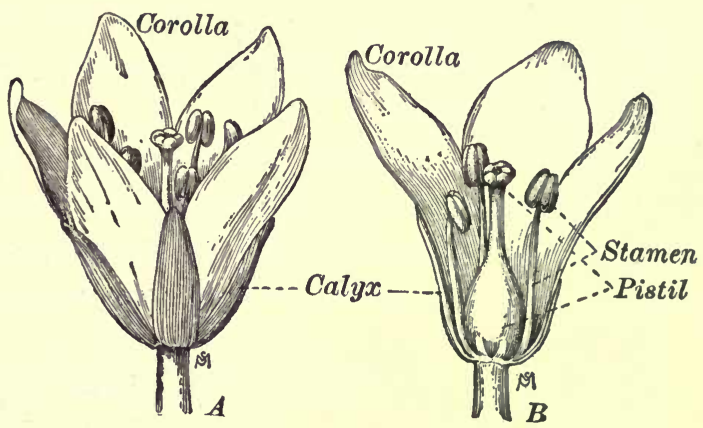

Fig. 40. - The Floral parts of the Alpine Azalea (Loiseleuria). Collectively the sepals constitute the calyx, and the petals, the corolla. The pistil represents several united carpels. (From Bergen and Caldwell, after Müller.)

parts that fit plants for different modes of life, to obtain some insight into the tissue organization, or HISTOLOGY, of a typical plant.

\section{B. Histology}

As we have seen, the functions of organisms are performed by their protoplasm which constitutes the structural units, or cells. The cells, when specialized for a particular duty in the economy of the organism, are usually associated in more or less homogeneous groups, or tissues. Tissues, in turn, are grouped to form tissue systems and organs; that is, major divisions of the body which allow the tissues and, therefore, the cells devoted to a special function to play their part under the most suitable relations to internal or external conditions. It is important, however, as we resolve the individual plant (or animal) into its component cells, tissues, or organs, not to lose sight of the fact that these parts are all at work for the good of either the individual or the race. The many different kinds of work which are being carried on by the organism, whether it is simple or complex, must provide in the final analysis for two things: the support or nutrition of the 


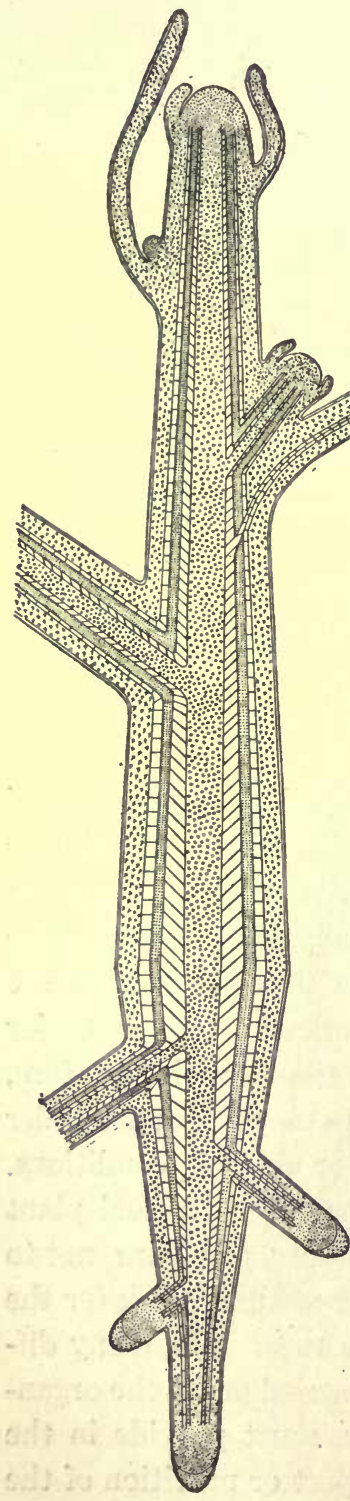

individual and the production of other similar individuals, reproduction.

In order to obtain a mental picture of the essential working plan of the tissue distribution in the body of a higher Flowering Plant, we shall con-

FIg.41. - Ideal vertical section through a generalized plant, showing the typical distribution of the systems of tissues. The central cylinder, or stele, comprises the pith (coarse dotted), xylem (diagonally lined), phloem (cross lined), with cambium (fine dotted) between and extending to growing points of root and shoot. The cortical system (crosses) forms the 'hollow' cylinder which surrounds the central cylinder and is, in turn, enclosed by the outer hollow cylinder (double lined), or dermal system. (From Ganong.)

sider first an ideal vertical section through a generalized plant. (Figs. 41,43 , a.)

The root and shoot system together constitute a continuous body, which may be regarded as forming a long narrow cylinder of cells, the bottom of which is the growing point of the primary root, and the top, the growing point of the shoot. This primary cylinder, in turn, is made up of a solid central cylinder of cells, surrounded by two concentric 'hollow' cylinders. The inner of these concentric hollow cylinders surrounds the central cylinder, and in turn is surrounded by 
the outer cylinder. The latter forms the surface of the primary cylinder, or the outer layer of cells of the plant. These three cylinders comprise the primary tissue systems.

The central cylinder, known as the STELE, runs continuously throughout root and stem, and sends bifurcations into the branches by which certain of its elements enter the leaves to form the veins. It provides the PITH, or primary axial tissue, and the vascular BUndles. The latter include the food-conducting tissue (PHLOEM), the water-conducting tissue (XYLEM), and between them the actively growing tissue

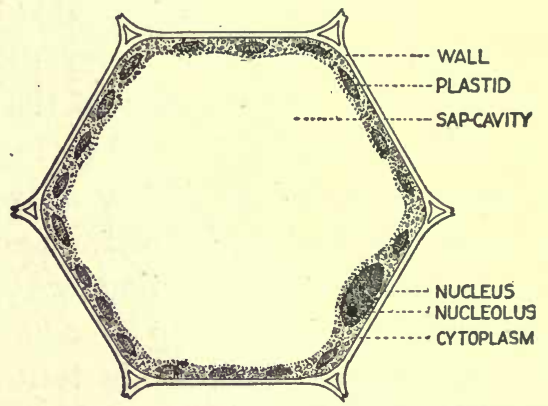

FrG. 42. - Optical section (highly magnified) of a generalized plant cell. (From Ganong.)

(CAMbium). The cambium becomes continuous with the tissues at the growing points of stem and roots, and together these embryonic tissues, called MERISTEM, may be regarded as the growth system of the plant.

The hollow cylinder immediately surrounding the solid central cylinder comprises the CORTICAL system which provides the CHLORENCHYMA, or chlorophyll-bearing tissue of the young stem and of the leaves, and also the cortex of bark and root.

The outside cylinder forms the DERMaL system which supplies the hair layer of the surface of the young root and the protective EPIDERMIS covering the stem and leaf. 
With this diagrammatic arrangement of the tissue systems of the plant in mind, we are in a position to consider the histology of a typical root, stem, and leaf of the higher Flowering Plants; in other words, to resolve the cylinders or tissue systems of the plant into their component parts by the study of transverse and longitudinal sections cut at various levels, and so to determine the general character and distribution of the cells as seen under the microscope.

\section{Root}

An examination of the tip of a root shows that it is covered with a large number of cells which form the ROOT CAP. These cells are gradually rubbed away as the root works through the soil and continually replaced by new ones from the GROwING POINT which is immediately above. The numerous, small, densely-packed cells constituting the growing point represent the region of cell formation for the entire root tip, since near the center is a group of cells from which smaller cells are divided off, and these in turn absorb food materials and attain the normal size. It will be recalled that the growing point is continuous with the cambium region above; and it thus represents the growth system (meristem) at the root tip. (Fig. 43.)

Just above the growing point is the GROwTH zONE which includes cells recently formed by the tip in its growth downward. In this region the cells enlarge rapidly, especially in length, and at the same time retain relatively thin cell walls. The cytoplasm of these cells, by the development and coalescence of large vacuoles of cell sap (water, sugar, and other substances in solution), soon forms merely a lining closely applied to the wall; a condition characteristic of many plant cells in contrast with those of animals. In the growth zone also is clearly seen on the surface the protective layer, or epidermis, 
and, just within, the cortex made up of several layers of cells. Still further toward the center of the root, the central cylinder appears, which shows differentiating vascular bundles.

Passing now to a point a little above, we find the growth zone merging imperceptibly into a region in which many of the

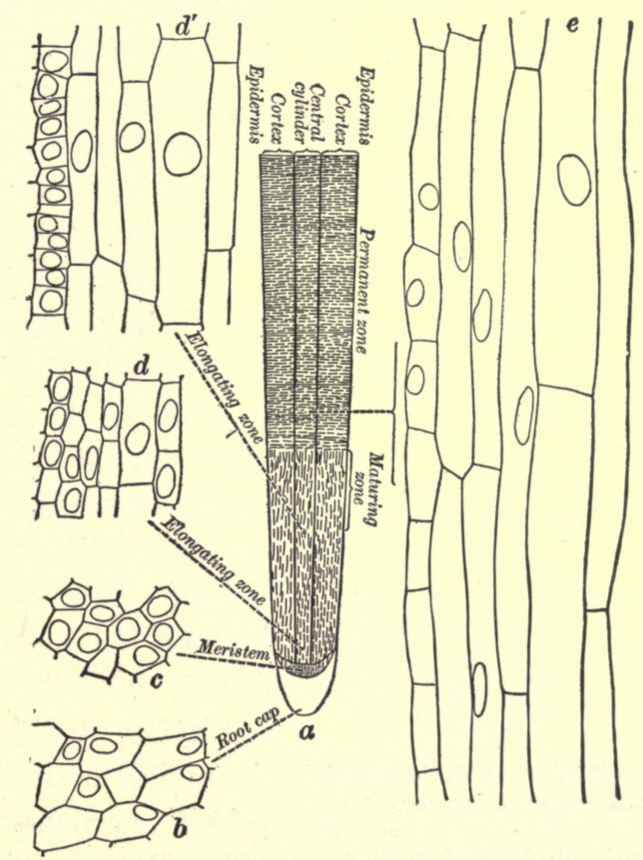

FIG. 43. - Cell division and tissue differentiation in a growing root tip. Diagram of root $(a)$ shaded to show the several regions from which the highly magnified sections $\left(b, c, d, d^{\prime}, e\right)$ are taken. (From Densmore.)

epidermal cells on the outer surface of the root are modified into RoOT HAIRs. It has been emphasized above that the primary function of the root is the intake of certain of the elements of food in solution. This function is performed almost entirely by osmosis through the extensive area afforded by the surface of the root hairs, and accordingly cells 
of this type form the vital point of contact between the root and its environment. The root hairs exhibit the selective power of protoplasm to a remarkable degree. For example, Red Clover plants and Barley plants when burned yield about the same proportion of mineral matter as ash. But the

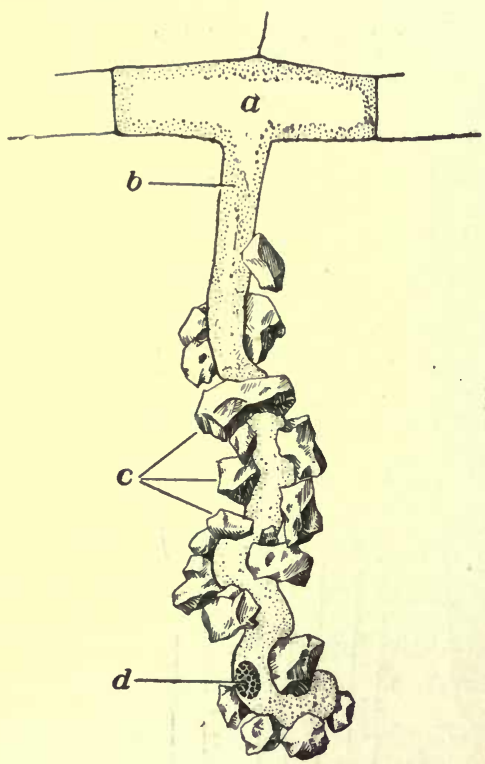

Frg. 44. - Root hair (very highly magnified) showing its relation to adjoining cells of the root and to particles of the soil. $a$, vacuole filled with cell sap; $b$, cytoplasm (dotted); $c$, soil particles; $d$, nucleus within the cytoplasm lining the cell wall.

Barley ash contains nearly twenty times as much silica as the Clover, while the latter contains nearly six times as much lime as the Barley. (Fig. 44.)

In the zone in which root hairs are present the central cylinder of the root shows still more cellular specialization. The young vascular bundles are differentiated into the phloem tissue, characterized by its small angular ducts; while the developing xylem, with its large ducts, has obliterated the primitive ground tissue, or pith. Between the xylem and the phloem appears the developing cambium, but this begins its characteristic growth contribution somewhat above the hair zone. Indeed, as we pass upward from the region where the root hairs are developed, the cellular structure becomes more and more similar to that of the stem; the older woody roots of trees and shrubs being, from the standpoint of both structure and function, stems. 


\section{Stem}

Just as cell division in the meristem tissue of the growing tip of the root proceeds in such a way that the direction of growth is typically downward, so in the similar region at the growing point (BUD) of the shoot (stem and leaves) cell multiplication results in progress upward. In other words, from the region where root and shoot merge, the growth of the plant is in opposite directions.

The general character of the embryonic tissue is essentially the same in both the root and shoot regions, being composed of densely packed, more or less cubical cells which are completely filled with protoplasm. At this stage the cells have not become modified for special functions by the

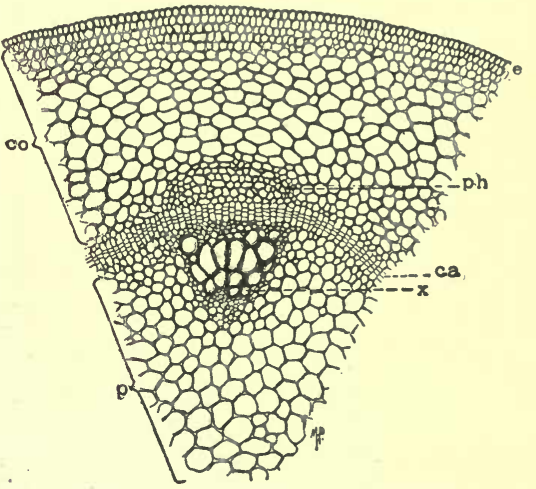

FrG. 45. - Portion of a cross section of the stem of a young plant (Ricinus). ca, cambium; co, cortex; $e$, epidermis; $p$, pith; $p h$, phloem; $x$, xylem. (From Gager.)

formation of vacuoles of cell sap, or in other ways. But all the tissues of the stem are derived from the cells of the growing point, so that slightly below this region three areas are to be noted in which differentiations are in progress. These result in the formation of the outer cylinder (epidermis), the intermediate cylinder (cortex), and the central cylinder (stele) in which the ground tissue (pith) is gradually encroached upon by the developing vascular bundles. The general arrangement of these fundamental tissue systems may be seen in a transverse section of the young stem of a Bean which affords an excellent working plan of stem anat- 
omy in one of the main divisions (Dicotyledons) of Flowering Plants. (Fig. 45.)

\section{Leaf}

The embryonic cells forming the growing point, or bud, of the shoot comprise, as we have seen, the fundamentals of both stem and leaves; that is to say, stem and leaves arise together in buds. The method of formation of stem and leaves is well seen in the buds of a common water plant,

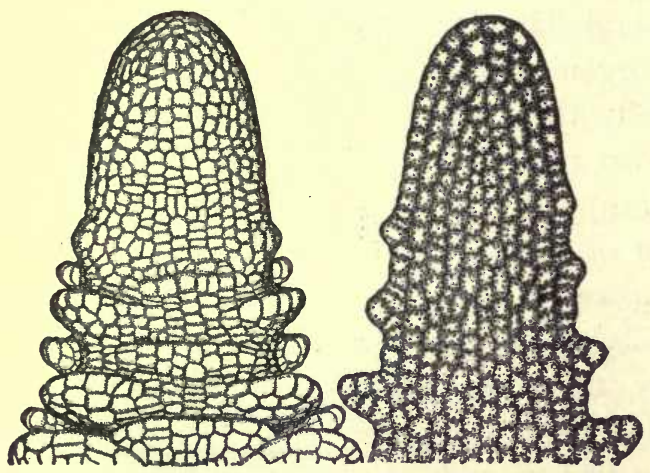

Fig. 46. - A bud, of unusually elongated form, of Elodea canadensis, in exterior view and section, showing the development of leaves; $\times 150$. (From Ganong, after Kny.)

Elodea. Here the rounded end of the stem is composed of the characteristic embryonic tissue. The rudiment of each individual leaf is first visible on the surface as an enlarged cell which by division and differentiation gradually develops into a flat projection of epidermal, cortical, and vascular tissue, constituting the fully formed leaf. (Fig. 46.)

Bearing in mind that the leaf is the chief organ for the intake and utilization of the energy of sunlight and for the interchange of gases, it is evident that it forms the second of the two chief points of contact of the plant with its surroundings. This intimate relationship is manifest in the in- 
numerable adaptations in the form of leaves, but the fundamental structure of all can be reduced to a common plan which may be illustrated by a transverse section of a leaf. (Fig. 47.) The essential features of a leaf consist of upper and Lower, limiting membranes (epidermis) which are continuous at the edges of the blade, and thus enclose the supporting and conducting tissues consisting of vascular bundles (veins), and

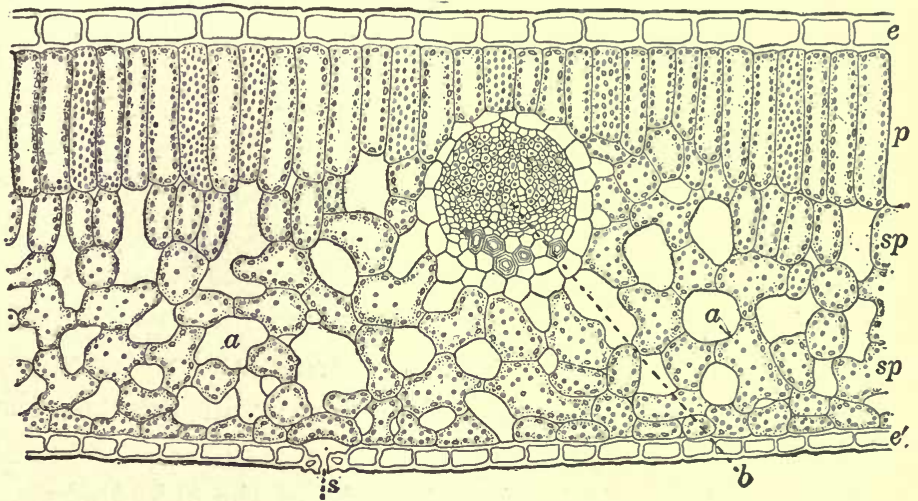

FIG. 47. - Cross section of a typical leaf, highly magnified. $a$, air spaces; $b$, vein; $e_{\text {。 }}$ $e^{\prime}$, upper and lower epidermis; $p$, palisade layer of chlorenchyma; $s$, stoma $s p$, irregularly arranged 'spongy' chlorenchyma cêlls. (From Bergen and Davis.)

the chlorophyll-bearing cells (chlorenchyma) which carry on the work of photosynthesis.

The walls of the epidermal cells are impervious to water and gases, and therefore the epidermis is perforated with tiny pores (stomata) which lead into air spaces among the chlorenchyma cells. It is estimated that the number of stomata in the epidermis of common leaves averages about 500 per square millimeter, so there is ample provision for the exchange of water vapor, carbon dioxide, and oxygen with the atmosphere. Each stoma is enclosed by two specialized epidermal cells, termed GUARD CELLS, which regulate the size of the opening according to varying internal and external conditions. 
The veins, as we have seen, are merely the extensions into the leaf of the chief elements of the vascular bundles of the stem. They form the framework of the leaf, as well as the system of ramifying highways for the transportation of materials between the blade as a whole and the stem. In cross-section the larger veins show the essential features of the vascular bundles seen in the stem, lacking, however, the cambium.

The chief tissue of the leaf is the chlorenchyma, consisting of chlorophyll-bearing cells. Immediately under the upper epidermis these cells are arranged in a definite layer known as the PALISADE LAYER. Below this region the cells are more or less irregularly disposed so that there are larger and smaller AIR SPACES between them. These air spaces form a practically continuous system of passages and thereby facilitate the interchange of oxygen, carbon dioxide, and water vapor between the leaf cells and the outer world through the stomata.

The cytoplasm within the thin walls of the chlorenchyma cells forms merely a lining in which are situated the nucleus and numerous specialized, disc-shaped, cytoplasmic bodies, the chloroplastids, which bear the chlorophyll and therefore appear green. It will be recalled that these are the essential agents of photosynthesis. The center of the cell is occupied by a large vacuole of cell sap. This sap is usually under considerable pressure, which accounts for the close application of the cytoplasm to the inside of the cell wall and produces the turgor characteristic not only of the chlorenchyma cells, but also of many other types of plant cells as well.

\section{Physiology}

We have now outlined the essential structure of a generalized Flowering Plant, with the exception of the parts modi- 
fied for reproduction. Before turning to the flower which in its function has to do with the race rather than the individual, it is important to consider the organism as a whole - how the various cells, tissues, and organs coöperate in the nutrition of the living plant; for nutrition, it will be recalled, is the function of primary importance to the individual.

The essentials of nutrition were readily described in the simple green plant Sphaerella, because the whole organism comprises but a single cell which directly interchanges matter and energy with its environment. But with the establishment of the complex plant body, an organization of many millions of highly specialized cells, the intricate interrelationship of these various parts to the nutrition of the whole the mechanical engineering of the plant-becomes a problem in itself.

\section{Circulation Paths}

The green plant, as we know, takes in the raw materials and builds them up into its foodstuffs. In the case of the higher plants, water in large amounts is taken in through the root hairs. Dissolved in this water are various substances nitrates, phosphates, sulfates, etc. - supplying most of the elements that are necessary for the make-up of protoplasm. The leaves admit carbon dioxide through the stomata. Thus the substances which are to be built up into foodstuffs enter at the opposite ends of the plant, and must be brought together in a chemical laboratory, as it were, in order that their union may be effected. The organ in which food construction takes place is the leaf, and, specifically, in the chloroplastids of the chlorenchyma cells. Accordingly we must consider the highways which bring the raw materials from the root hairs to the leaves and those which distribute the finished products to the various parts of the plant for their use. (Fig. 48.) 
The water which enters the root hairs is given a start up the stem by 'root pressure' due to osmotic phenomena in the multitude of cells of the root. This pressure in an actively growing tree in spring may be nearly forty pounds to the square inch. Passing from the xylem of the root the ascending water enters the similar region of the stem, Here the conducting vessels are of two kinds: namely, greatly elongated single cells, known as TRACHEIDS, and DUCTS. The latter are really tubes which have been formed by the absorption of the contiguous walls of many long cells arranged end to end. The mature tracheids and ducts, though originally derived from living cells, are devoid of protoplasm, and form a series of non-living tubes extending up the stem to the leaves, through which they are distributed in the veins. This is the fluid-conducting highway from root to leaf.

The supply of carbon which the plant needs is obtained from carbon dioxide which enters the leaves through the stomata. The water, containing various salts in solution, which has been taken in by the roots, meets the carbon dioxide in the chlorenchyma cells; and it is here that these raw materials are manufactured into food. Therefore, the leaves are the organs specialized for assembling the materials of the inorganic world and forming from them new chemical compounds of such a character that they can be utilized as building material for the plant body and as sources of energy for carrying on the vital functions. In other words, the new compounds are the food of the plant. As we know, through * the radiant energy of light a complicated series of chemical reactions are initiated by which carbon, oxygen, and hydrogen are united to form a sugar. In this process, free oxygen is evolved which may be used in respiration or liberated through the stomata. Part of the sugar thus formed is directly utilized by the plant as fuel, and part is employed as the basis for 
the manufacture of proteins and the living material itself by the addition of nitrogen and various other chemical elements.

In every case all types of food built up in the leaves must be distributed to the organism as a whole. This occurs

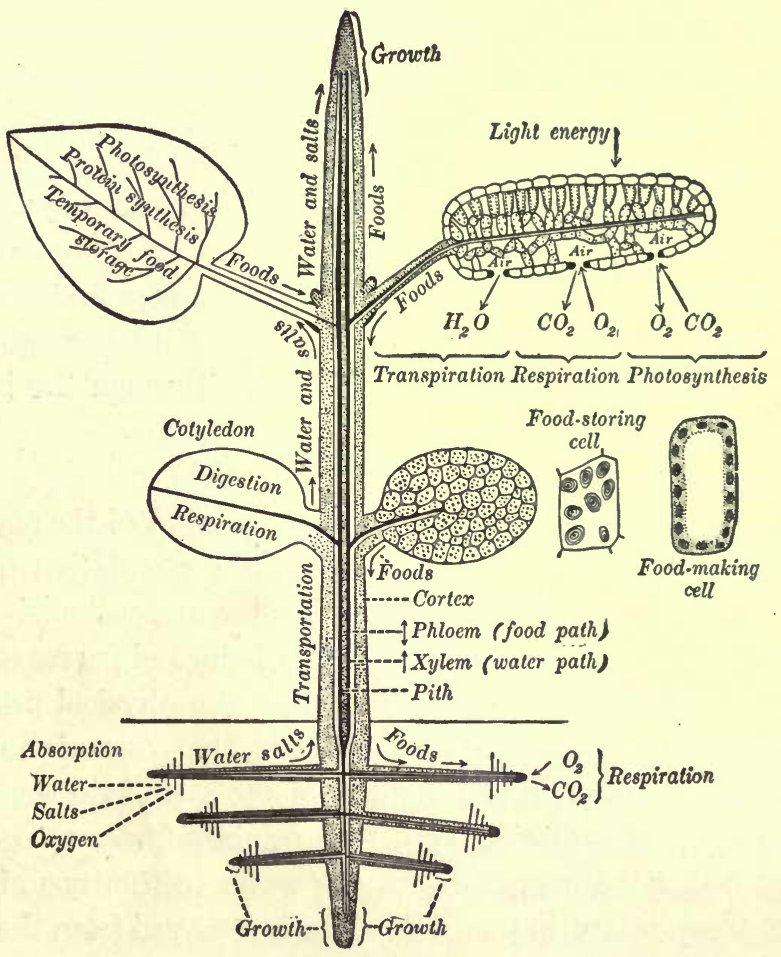

FIg. 48. -Diagrammatic presentation of the chief physiological activities of a Flowering Plant (Bean). The first leaves (seed leaves, or cotyledons) are richly stored with food but contribute only slightly to photosynthesis. (From Densmore.)

chiefly by diffusion in the form of soluble carbohydrates (e.g., grape sugar) or in soluble nitrogenous form (e.g., amines or soluble proteins) to the smallest veinlets and then on to larger and larger veins, which finally deliver it to the stem. 
In the stem, the course taken by the food depends upon the immediate needs of the plant. It may pass either up or down through the phloem, or some may be transferred to the xylem and carried to the growing tip or the developing flower and fruit for immediate use. When growth is not active, most of the food passes downward through the phloem to supply the cambium and to be stored, chiefly as starch, in stem and root. In brief, all the living cells of the plant directly or indirectly draw upon the supply of food circulating through the phloem, so we may look upon the phloem as primarily a food-distributing system from the leaf, just as we have seen that the xylem is the system for carrying water and solutes from root to leaf. The raw materials pass up through the wood and the finished products pass down through the bark.

\section{Dynamics of Circulation}

The question will naturally arise in the mind of the reader: what is the force which brings about the circulation of all these fluids in the plant body? We have mentioned that water containing solutes enters the root hairs and passes to the cortical cells and ducts of the xylem by the physical process known as osmosis. It is now believed that osmosis in the leaves draws water from the ducts of the stem into the cells of the leaf. It is also thought that osmotic forces operating in leaf cells are adequate to lift the water to the tops of the tallest trees, where, in turn, the water is removed from the leaf cells by evaporation through the stomata.

The outgo of water by evaporation is termed TRANSPIRATION, and is brought about by heat energy from the surrounding atmosphere. In the last analysis, if the explanation suggested above is correct, the energy of heat, resulting in evaporation from the leaves, is chiefly responsible for the movement of the column of water which is continually pass- 
ing through the plant-entering the root with various substances in solution and emerging through the stomata as water vapor. The fact that much more water usually is evaporated from a forest than from an equal area of a lake, affords some conception of the part played by vegetation not only in returning water to the atmosphere but also in 'consuming' heat energy - cooling the summer air. The dynamics of the circulation through the xylem, however, are probably by no means so simple as might appear from the theory just outlined; and, moreover, there is no satisfactory explanation of the causes of food distribution in the phloem, further than that osmotic phenomena play an important rôle.

\section{Food Utilization}

The food which the plant has constructed and distributed to the various parts of its body must be employed by the individual cells in supplying the material and energy for their life processes. It is important not to lose sight of the cell in the larger organization of which it is a part, for, in the final analysis, the life of the individual plant is but the life of the multitude of units which coöperate toward its make-up. Although the cells suppress their individuality in the corporate whole which they form, the life of the plant is as truly the life of the protoplasmic units which form it as is the life of a human community resident in the individual citizens.

The cells select from the food stream not only the materials essential for their individual life, but in addition those which they require for the performance of their particular part in the economy of the whole. But doing this implies work, and work means expenditure of energy - the same energy of sunlight which was stored in the food during its construction by the chlorenchyma cells of the leaf. In order to release this energy RESPIRATION must occur. Carbohydrates, fats, 
and proteins must be oxidized, that is, burned, and consequently free oxygen transmitted throughout the plant to the various cells, and carbon dioxide carried away. This is effected by an intercellular system of air spaces which ramifies throughout the plant and communicates with the surrounding atmosphere chiefly by way of the stomata.

We have now considered, in such detail as the scope of the present work requires, the structure and functions of a typical higher plant as a whole, and have indicated how the organism is specialized for the chief function which primarily concerns the individual; that is, nutrition, or the transformation of matter and energy into life and work. Since, however, the duration of the existence of the individual is relatively limited, it is obvious that some provision must exist for the continuation of the race. In other words new individuals must be formed. This brings us to the second great function of the organism, reproduction. 


\section{CHAPTER IX}

\section{REPRODUCTION IN PLANTS}

The synthetic act by which the organism maintains itself is fundamentally of the same nature as that by which it repairs itself when it has undergone mutilation, and by which.it multiplies and reproduces itself.-Bernard

Among the lowest members of the plant kingdom the body consists of but a single cell; the individual and the cell are identical. As has been seen in Sphaerella, all the life processes essential to the individual are exhibited in relative simplicity and without obviously complicated machinery. Moreover, the continuation of the race is provided for by the individual cell dividing to form two new cells. Neglecting for the time being the mechanism of cell division, it is clear that reproduction in Sphaerella, since it is not complicated by specialized organs for its performance, is a comparatively simple process.

We have considered briefly the gradual increase in complexity of the plant body from the unicellular condition, through colonies of essentially similar cells and the thallus type, to that of the higher vascular plants, placing emphasis on organs directly or indirectly associated with nutrition. It is necessary now to review in a similar manner the specializations of structure and function which exist in the plant kingdom for the multiplication of individuals.

It may be well to reiterate here that reproduction and growth are phenomena which are intrinsically the sameboth are the result of a preponderance of the constructive 
phase of metabolism. The single cell, whether a whole organism or a single unit of a complex body, increases in volume up to a certain limit and then divides. In the former case two new individuals replace the parent cell; in the latter, the complex body has been increased to the extent of one cell. In both cases cell division has resulted in cell reproduction. Thus cell division is always reproduction, though it is customary and convenient to restrict the term reproduction to cell divisions which result in the formation of new individuals - single cells or groups of cells which sooner or later separate from the parent organism.

It will be recalled that during the life cycle of Sphaerella there is associated with the reproductive act of cell division, the formation of cell individuals which exhibit in simple form the fundamental characteristics of spores and gametes. We shall now see that the development and specialization of these is at the basis of the elaborate reproductive processes of the higher plants.

\section{A. Spore Formation}

As already emphasized, cell division among unicellular plants results in the formation of new individuals, and, among multicellular plants, in the growth of the single individual. This is well illustrated by the familiar pond scums in which the plant body consists of a series of similar cells placed end to end to form a long thread-like body. In such cases, cell division results merely in an increase in the length of the filament constituting the plant body, unless the newly formed cell becomes detached from the parent plant. As a matter of fact, however, under certain conditions the protoplasmic content actually does make its escape from the cell wall and swims about in the surrounding water. This independent PROTOPLAST is a spore. 
Moreover, this spore now begins a series of cell divisions which result in a new filament, or individual. It will be noted that the potentialities of the spore and the protoplasts which continue to retain their stations in the parent body are intrinsically the same, but the opportunity of the spore is different. In brief, the fact that the spore has separated from the parent stock appears to be the reason why it reproduces. Therefore a SPORE may be defined as a cell, or the essential part of a cell, the protoplast, which has separated from one plant body and is capable of producing another plant body. This statement might, at first glance, seem to indicate that spore formation is restricted to plants with multicellular bodies, whereas we have seen that spore formation occurs in the life cycle of Sphaerella. This apparent contradiction is cleared away when we recall that in the latter the cell divisions which produce the spores do not involve the cell wall; merely the protoplast within divides and the daughter cells make their escape. (Fig. 9.)

Therefore spore formation is not a necessary result of the establishment of a multicellular body, but an inheritance from unicellular forms which makes possible one of the two effective types of asexual reproduction in the Metaphyta. The other type is FRAGMENTATION, which consists essentially in the separation from the body of larger or smaller parts, which later reproduce the whole plant. It is a familiar fact that, under proper conditions, cuttings, buds, bulbs, and sometimes pieces of leaves may reproduce or, as it is sometimes stated, REGENERATE a complete plant. This is just an expression of the same power which the spore, though a single cell, exhibits. It regenerates, as it were, a plant body similar to the one from which it has separated. 


\section{B. Gamete Formation}

In the life cycle of Sphaerella it was noted that under certain conditions the so-called dormant cell, instead of dividing twice to form four spores, divides five or six times and forms 32 to 64 small cells called gametes. Now it is not the structure but the behavior of the gametes which particularly distinguishes them from spores. From the standpoint of their origin, gametes may be regarded as spores which have developed the habit of fusing to form a zygote. Moreover, the origin of gametes is the origin of SEx, so that sexuality arose in plants when spores, instead of reproducing, developed the habit of pairing and thus became gametes. The act of fusing is FERTILIzATION and the cells which unite are sex cells.

A concrete example may emphasize this important point. The body of a filamentous Alga, Ulothrix, is composed of a linear series of cells all of which are essentially the same in structure and function. Under favorable conditions the cells divide and the plant grows in length. New individuals are not formed by this process, although the mechanical breaking of the filament into two parts, owing to the simplicity of the body, gives two individuals. When conditions become less favorable for vegetative growth, some of the cells cease to contribute to the elongation of the filament. Instead, the protoplasts begin to divide within their cell walls, and thus each forms from 2 to 64 or more spores of different sizes, depending upon the number of divisions the parent protoplast undergoes. (Fig. 49.)

The largest spores are provided with four, and the smallest with two, flagella by means of which they swim actively in the water when discharged from the parent plant body. However, the number of flagella is apparently of no im- 
portance since the cells of intermediate size may have either two or four. Nevertheless the behavior of the spores of different sizes is characteristic and significant. The largest spores soon settle down and, attaching themselves by the flagellated end, begin to develop into new filaments. The spores intermediate in size likewise form new individuals,
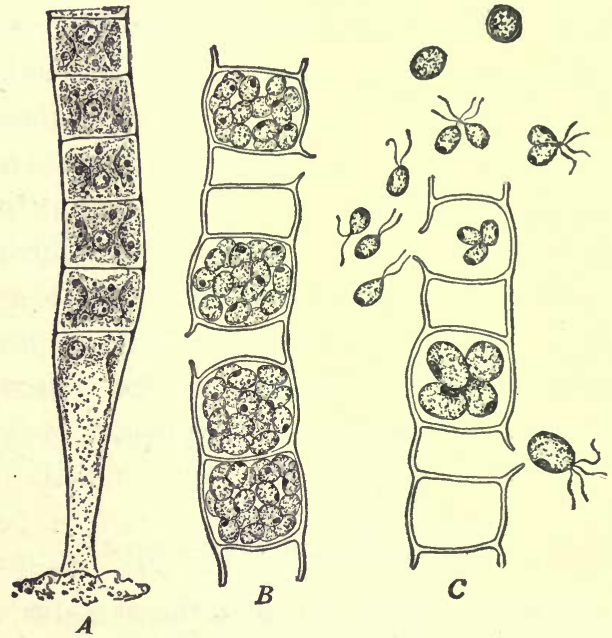

FIG. 49. - Ulothrix, a filamentous Green Alga. $A$, modified cell for attachment at the base of a filament. $B$, cells of a filament which have formed spores. From three cells the spores have been liberated. $C$, part of a filament liberating spores (below), and gametes (above) which pair to form zygotes. (From Coulter.)

but the process is much less rapid; while the smallest spores not only germinate very slowly, but give rise to dwarf filaments with vigor below the normal. As a matter of fact very few of the smallest spores germinate at all. Instead, they unite in pairs, each pair fusing to form a large single cell. It is apparent that the small spores by fusing, instead of feebly germinating, perform the sex act and, therefore, are gametes, while the product of this process of fertilization is a zygote. 
Nothing could indicate more clearly the primary relationship of gametes to spores than the origin of sex and sexual reproduction through the assumption by certain spores of the habit of pairing to form a zygote before germination.

It should be noted that sexual reproduction is not a different kind of reproduction, but merely reproduction preceded by the formation of a zygote; a fact very readily lost sight of in the higher forms where accessory phenomena connected with sexuality obscure the essential features, but quite apparent in Ulothrix because here the zygote does not form directly a new filament. Instead, after passing a longer or shorter time in a dormant condition protected by a heavy wall, the protoplast (zygote) within divides to form a number of spores, each of which then germinates into a new individual. Thus in Ulothrix, as in Sphaerella, reproduction is solely by spores, "sexual 'reproduction' not reproducing, but only protecting a spore-forming protoplast."

\section{Sex Differentiation}

So far we have seen that sex cells, the gametes, arose with the establishment of the habit of reduced spores uniting in pairs. This is obviously a statement of fact rather than an explanation of sex. Although the two cells which fuse show no morphological characters by which they can be distinguished from each other, there is certainly a physiological basis of sex which induces them to swim toward each other, to become oriented so that fusion begins at the flagellated ends, and to melt into a single cell, which culminates in a reorganized cell with the complicated structural and physiological equipment of the two cells which entered into its make-up. The zygote thus is a cell which combines the characteristics of both the contributing gametes, and to this 
significant fact must be attributed the profound importance of sex phenomena in the life history of plants as well as of animals.

Although sexuality is fundamentally a physiological difference between gametes which leads to their characteristic behavior (zygote formation), even among the lower plants structural differentiations appear. In fact, a series of plants can be arranged showing a gradual transition from gametes which are morphologically identical to those which differ so widely that they appear to have little in common. Oedogonium, an unbranched filamentous Alga, will suffice as an example, since it affords an excellent illustration of an intermediate stage in gamete differentiation. One form of Oedogonium gamete, representing an entire protoplast of a greatly enlarged cell, is richly supplied with food materials and chloroplastids and remains motionless within the cell wall. The
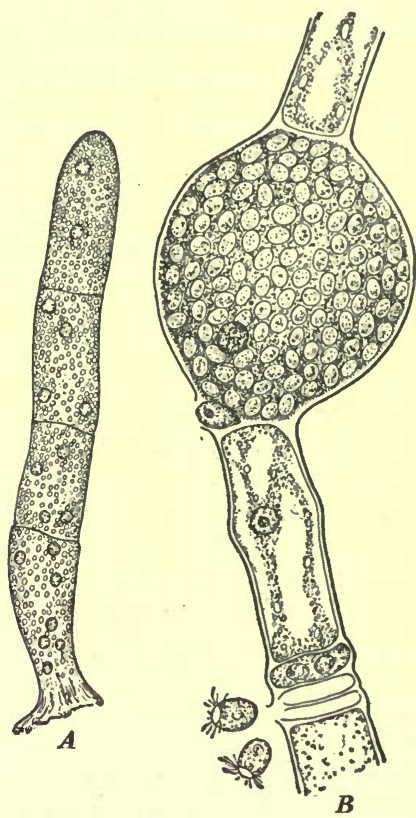

Frg. 50. - Oedogonium, a filamentous Green Alga. $A$, young filament. $B$, portion of a filament forming gametes (egg and sperm). Below are two sperm which have just been liberated; above is a large egg with a sperm just coming into contact with it to form a zygote. (From Coulter.) other type develops in pairs in small cells with greatly reduced chloroplastids and food content. Instead of being motionless, each cell is provided with a circlet of cilia by which it leaves its place of origin, swims actively in the 
water and, entering a cleft in the wall surrounding a large gamete, fuses with it to form a zygote. (Figs. 50, 51.)

In short, one gamete, designated the $\mathrm{EGG}$, is a large nonmotile cell stored with food materials, while the other gamete, or SPERM, is a small active cell largely devoid of food. This is typical of the conditions which are at the foundation of gamete differentiation throughout the plant and animal kingdoms - eggs and sperm expressing a physiologi-
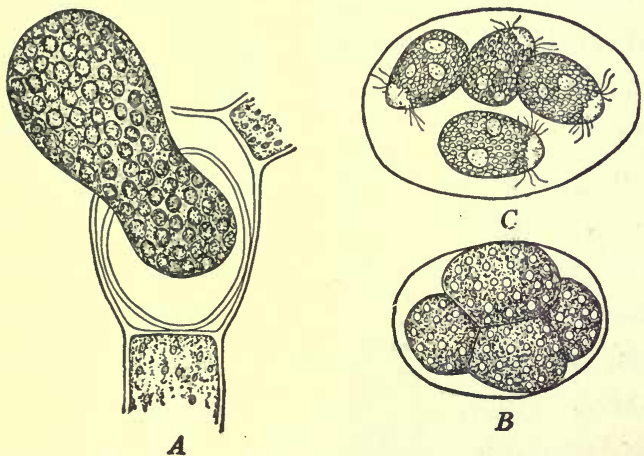

FIG. 51. - Oedogonium: $A$, zygote emerging from cell of parent filament. $B$, division of zygote into four spores. $C$, mature spores ready to escape and develop into new filaments. Note that the zygote does not directly give rise to a filament, but to spores. (From Coulter.)

cal division of labor which entails structural specialization in opposite directions.

In Oedogonium sexuality is apparent both in the behavior and in $\mathrm{the}$ structure of the gametes, so that it is possible to identify the sex cells as MALE gametes, or sperm, and FEMALE gametes, or eggs. It will be noted that this is not the origin of sex, for sex arose when spores by their behavior became gametes. In other words, the sex act is the fusion of two cells which reorganize as a single cell; and all modifications of these cells, which enable them to function as gametes, are secondary.

\section{Reproductive Organs}

Hand in hand with the specialization of spores and gametes there is a progressive modification of the cells or groups of 
cells which produce them, until highly developed REPRODUCTIVE ORGANS arise. The asexual reproductive cells are formed in SPORANGIA, which may be merely vegetative cells in which the protoplast becomes transformed into a spore, or elaborate multicellular structures set aside for this one function. Similarly, with the origin of sexuality, the sex cells arise in GAMETANGIA, which later are distinguished as ANTHERIDIA, or sperm-producing, and ARCHEGONIA, or egg-producing organs. Moreover, although the terms male and female are strictly applicable only to the sperm and eggs respectively, the antheridia and archegonia are called male and female organs; while a plant body which bears only male reproductive organs is designated as a male plant and one which bears female reproductive organs is known as
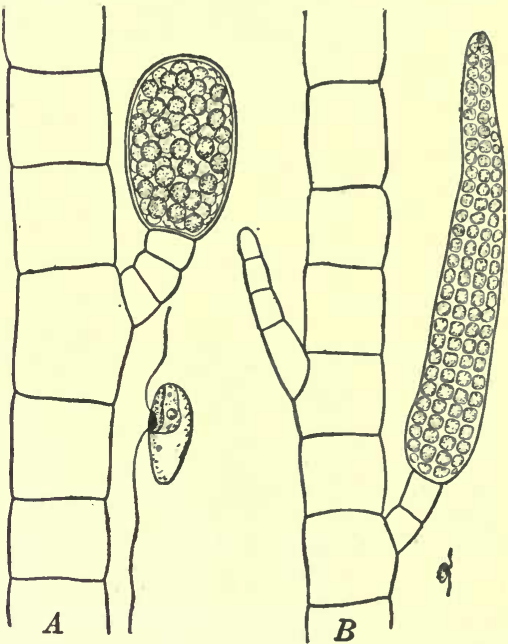

Frg. 52. - A Brown Alga, Ectocarpus. A, portion of a filament with a sporangium and a liberated spore; $B$, portion of a filament with a gametangium and a liberated gamete. (From Coulter.)

a female plant. In short, the sexuality of the gametes is reflected back, as it were, to the organs and then to the individual which bears them; although actually the gametes are the only sex cells. If this is kept clearly in mind it will obviate confusion in considering the remarkably specialized secondary features which sexuality imposes on the bodies of higher plants and animals. (Fig. 52.)

We may now recapitulate before proceeding to further 
complications. Reproduction, divested of its specialized features, is merely growth expressed in cell divisions. This primary potentiality of all cells may exist side by side with the development of cells specialized for asexual reproduction (spores) and sexual reproduction (gametes). In either case the products become separated from the parent body and develop new bodies. Furthermore, spores which at first are developed from any of the vegetative cells of the plant body, later arise in asexual reproductive organs (sporangia), while gametes are produced in sexual reproductive organs (gametangia). With the morphological differentiation of gametes into sperm and eggs, a further specialization of the gamete-forming organs results in male and female reproductive organs (antheridia and archegonia). When sporangia and gametangia are borne by separate individuals, asexual plants (SPorophytes) and sexual plants (GAMEToPHYTES) result. Finally, the sperm and eggs may be borne on separate gametophytes, in which case male and female gametophytes result.

\section{E. Alternation of Generations}

From the standpoint of the evolution of the higher plants the most significant fact stated above is that sporangia and gametangia may be borne by separate individuals, for this clearly involves an asexual, spore-bearing generation, and a sexual, gamete-bearing generation. We shall outline this alternation of generations in the life history of a typical Moss and Fern as an introduction to the problem of reproduction in the higher Flowering Plants.

\section{The Moss}

The common Mosses of woods, hillsides, and fields are a relatively inconspicuous but nevertheless an important part 
of our flora, since they form heavy growths or carpets of vegetation which hold back much of the rainfall so that it sinks into the soil. Although there are over 8000 species which botanists include in the order Bryales of the Phylum Bryo-
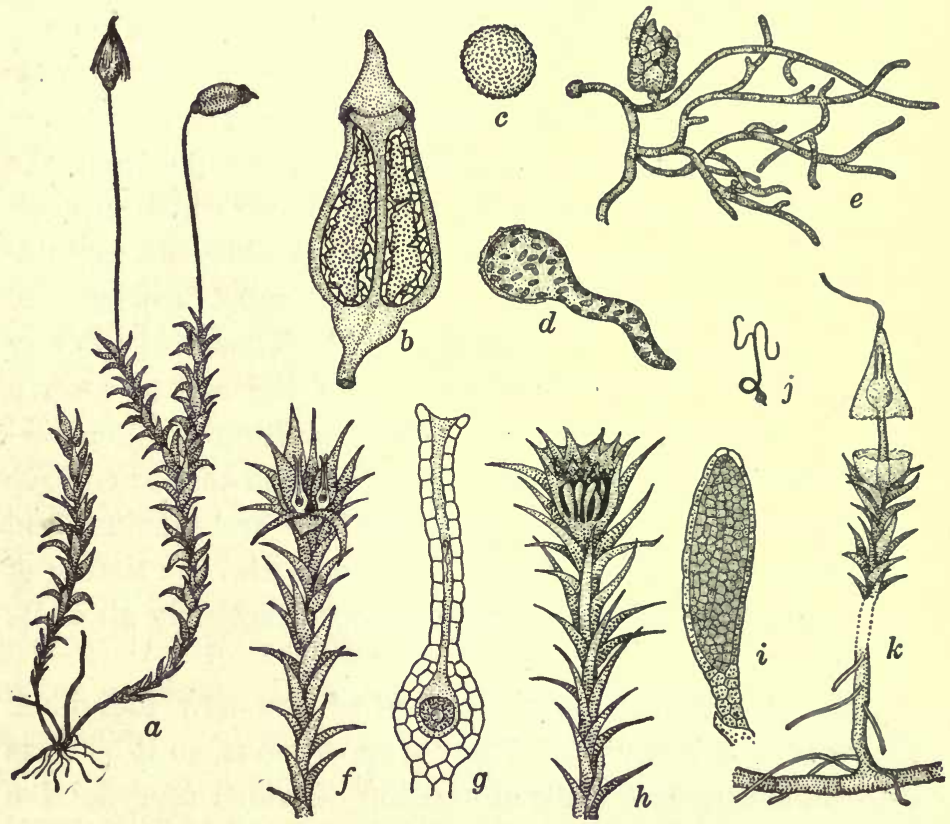

Frg. 53. - The life history of a Moss, chiefly Polytrichum. a, the entire plant (gametophyte and sporophyte), $\times \grave{b} . \quad b$, median vertical section of the capsule in which spores are formed, $\times 6$, with spore $(c)$ and germinating spore $(d), \times 300 ; e$, spore germinated to a protonema with a bud which forms leafy plant (gametophyte), $\times 75 ; f$, tip of gametophyte with two archegonia, $\times 2 ; g$, archegonium in section showing egg, $\times 16 ; h$, tip of gametophyte with antheridia, $\times 2 ; i$, antheridium, $\times 16$; $j$, a single liberated sperm, $\times 600 ; k$, gametophyte with sporophyte developing in enlarged and transformed archegonium. (After Ganong, Dodel-Port and others.)

PHYTA, a general description of a typical common Moss, such as Polytrichum communae, will suffice for the purpose at hand. (Fig. 53.)

The shoot of a moss plant is differentiated into stem and 
leaves which are of very simple construction compared with those of the Flowering Plant we have studied. True roots are not present, but their function is performed by filamentous outgrowths called RHIzords. At the top of the leafy moss plant, inconspicuous reproductive organs are developed. Some species bear both antheridia and archegonia on the same plant, while others have only one type. The leafy moss plant is thus a sexual individual, or gametophyte. When the reproductive organs are mature, sperm escape from the antheridia and, swimming about in moisture which has collected on the leaves, are attracted to the archegonia containing the eggs, apparently by a chemical substance secreted within these organs. A single sperm which has made its way down into an archegonium, fuses with the egg to form a zygote. The fertilized egg retains its position in the archegonium and germinates. The result is a rod-shaped embryo which grows not only upward through the archegonium and so out into the world, but also downward into the tissues of the gametophyte, from which it secures practically all of its food materials.

The essentially parasitic nature of the new individual renders the development of leaves superfluous, so it consists of a simple upright stalk at the top of which reproductive organs are borne. These are sporangia and accordingly the individual is a sporophyte. The ripe spores are liberated and, falling to the ground, each forms a filamentous outgrowth called a рRотоnema. Soon a bud arises on the protonema which develops into a leafy moss plant.

A common Moss thus exhibits in its life history an alternation of sexual and non-sexual generations. The leafy moss plant, with antheridia and archegonia, produces gametes and is the gametophyte. The leafless generation, which develops from the fertilized egg in the archegonium, produces 
spores and is the sporophyte. The gametophyte arises asexually, but is itself sexual; the sporophyte arises sexually but is itself asexual. The dominant generation from the viewpoint of both structure and nutrition - the plant one thinks of as a 'moss' - is the gametophyte.

\section{The Fern}

The common Ferns comprise the largest group of one of the major divisions of the plant kingdom known as the PTERIDoPHYTA. Although the forms of different species are remarkably varied, the ensemble of characters and in particular the foliage is quite distinctive, so that one would recognize practically any member of the group as a 'fern.' The stems may be short and close to the ground, or upright as in the Tree Ferns, though creeping and underground stems (rhizomes) are more common. The leaves, known as Fronds, either arise in clusters from the tip of the stem (Tree Ferns), or are distributed along the creeping and underground stems. Roots bring the stem into intimate contact with the food materials of the soil, though rhizomes function to a certain extent as roots. An examination of the cellular structure of a common Fern, such as Aspidium marginale, shows that it is much more complex than a Moss, the tissues of stem and leaves being essentially like those we have seen in the Flowering Plants, and accordingly Ferns and Flowering Plants are frequently referred to as vascular plants.

The leafy fern plant bears, on certain of its fronds, reproductive organs which are sporangia. These, of course, produce spores and therefore the plant commonly recognized as a Fern is a sporophyte. The spores when ripe are liberated from the sporangia and fall to the ground, where they germinate. From the spore arises a tiny body, about a quarter of an inch in diameter, called a PROTHALLUs, which is essentially 
a plate of chlorophyll-bearing cells with rhizoids attaching it to the ground. On its lower surface are developed reproductive organs, antheridia and archegonia, which form gametes. The prothallus therefore is a gametophyte. (Fig. 54.)

Sperm are liberated from the antheridia and swim in the moisture from dew or rain to the archegonia. A single sperm

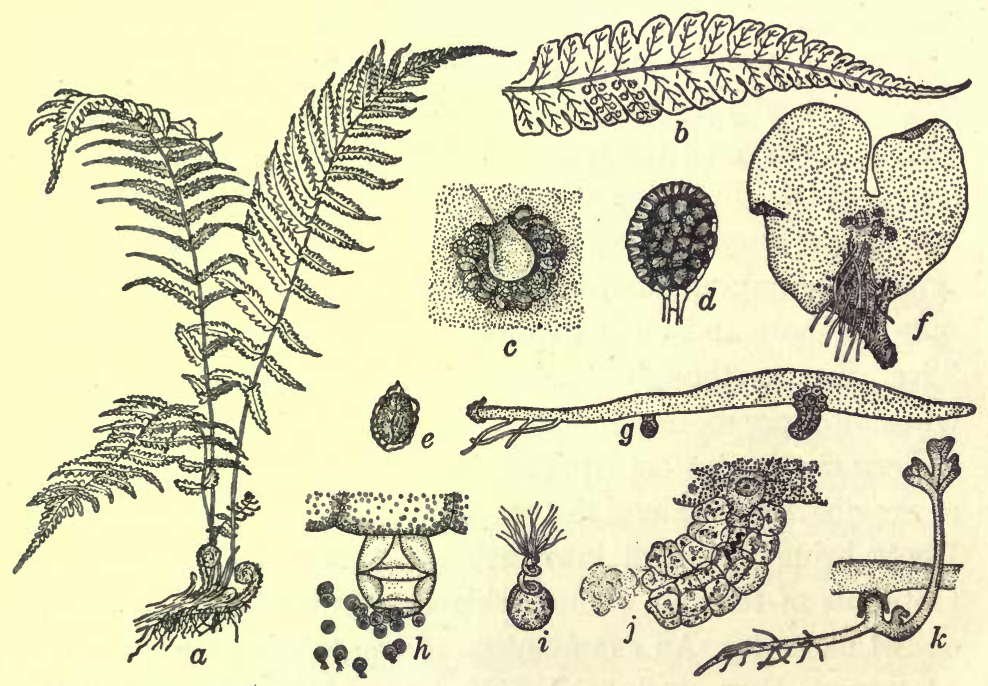

FIG. 34. - The life history of a common Fern, chiefly Aspidium. a, the entire sporophyte, $\times \frac{1}{10} ; b$, portion of a leaf showing groups of sporangia (sori), $\times \frac{1}{2} ; c, a$ sorus showing sporangia, $\times 10 ; d$, a sporangium, $\times 50 ; e$, a single spore, $\times 100$; $f$, ventral view, $\times 3$ and $g$, a median section, $\times 6$ of a prothallus showing rhizoids, antheridia, and archegonia; $h$, antheridium liberating sperm, $\times 120 ; i$, single sperm still attached to a remnant of 'mother cell', $\times 300 ; j$, open archegonium with sperm passing down to egg, $\times 120 ; k$, young sporophyte developing from zygote. (After Ganong.)

works its way down an archegonium and fuses with the egg to form a zygote. Then the zygote, which remains in the archegonium, proceeds to divide and forms at first a small plant, with stem and leaf which grows upward and root which seeks the soil. During the process of root and shoot development the plant retains its attachment to the parent 
prothallus from which its food is secured. Later, when direct communication with the environment has been established by its own root and leaf, the new generation becomes entirely independent of the prothallus, which then degenerates and dies. The young plant gradually grows into the typical asexual leafy fern plant, which itself in due time produces spores.

It is clear that in the Fern, as in the Moss, there is an alternation of generations. The leafy fern plant (sporophyte) gives rise to the prothallus (gametophyte). The leafy fern

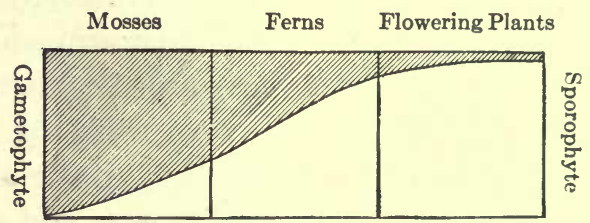

Frg. 55. - Diagram to illustrate the decline of the gametophyte generation and the advance of the sporophyte generation. (From Coulter.)

arises sexually, but is itself asexual; the prothallus arises asexually, but is itself sexual. The significant fact, however, is that the conspicuous leafy moss plant is a gametophyte, while the large leafy fern plant is a sporophyte; or, one may say, the 'moss' is a sexual plant and the 'fern' is an asexual plant. This ascendancy in dominance of the asexual and suppression of the sexual generation, which is so characteristic of the fern as compared with the moss life history, is carried still further in the higher Ferns and finally culminates in the Flowering Plants. (Fig. 55.)

\section{Higher Ferns}

As we have seen, the sporophyte of the common Ferns produces spores on ordinary vegetative fronds or, more rarely, on specialized sporophylls. (Figs. 39,54 .) In either case but one 
kind of spore is formed. Among the higher Ferns, however, spores of two kinds occur which, since they differ greatly in size, are called Microspores and MEGASPORES. The produc-

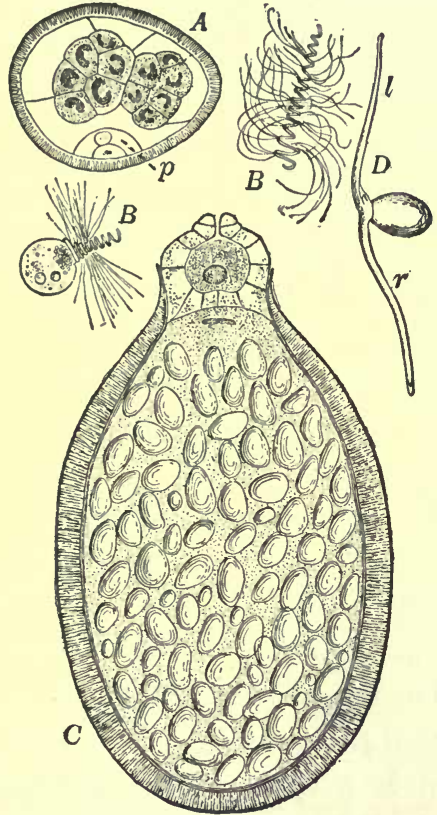

Fig. 56. - Stages in the life history of a higher Fern (Marsilia). A, microspore, enclosing the male gametophyte with two groups of sperm mother cells, and prothallial cells $(p) ; B$, sperm; $C$, megaspore, enclosing food material (starch grains), and female gametophyte comprising a single archegonium (with egg) at one end of the spore; $D$, a weekold embryo sporophyte, still attached to the megaspore, with first leaf $(l)$ and root $(r)$. (From Bergen and Davis.) tion of two kinds of spores is known as HETEROSPORY and leads to the differentiation of the sporophylls into MICROSPOROPHYLLS and MEGASPORophyLls. Moreover, the microspores on germination form gametophytes which produce sperm, and therefore are called MALE GAMETOPHYTES, while the megaspores develop into gametophytes bearing eggs, and accordingly are known as FEMALE GAMETOPHYTES. Finally, in these heterosporous forms, the gametophytes are no longer even small independent plants, such as the prothallus of the common Ferns, but both male and female gametophytes are so greatly reduced that they practically remain permanently in the parent microspore and megaspore, respectively, which supply them with food. This, it will be noted, is just the reverse of the condition which exists in the Moss, where it is the sporophyte which is the dependent generation. (Figs. 56, 57.) 


\section{Flowering Plants}

Passing to the Flowering Plants, we find that these are heterosporous sporophytes, and the FLOWER represents a greatly modified stem (branch), the leaves of which are specialized as sporophylls and accessory structures. In order to make this clear it is necessary to review the structure of a typical flower. (Figs. 40, 58.)

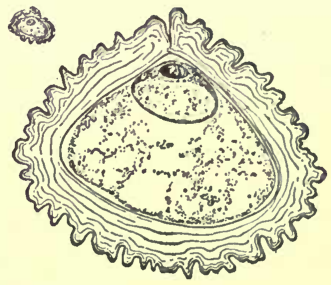

Fig. 57. - A microspore and megaspore of a 'higher Fern', Selaginella, magnified and drawn to the same scale. (From Coulter.)

A complete flower consists of four whorls of modified leaves. These arise near together at the tip of a PEDUNCLE, representing the floral branch, which connects the flower proper with the main tissue systems of the plant as a whole.

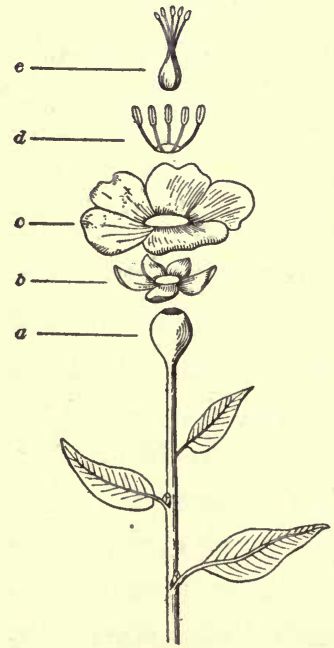

Frg. 58. - Diagram of a typical flower. $a$, tip of peduncle; $b$, calyx; c, corolla; $d$, stamens; $e$, pistil formed of fused carpels. (Modified from Gager.)
The outer and lower circle of leaves (CALYX) is composed of several parts (sEPALs) which usually are green and retain a leaf-like appearance. Just within and above the calyx is the second circle (COROLLA) formed of larger leaves (PETALs) which are usually brightly colored. The calyx and corolla together form the PERIANTH, or floral envelope which surrounds the primary floral organs, the STAMENS and CARPELS.

The stamens represent the third circle of leaves, but are so highly modified that their leaf origin is not immediately apparent. Each consists of a slender FILAMENT at the apex of which is a small case known 
as the ANTHER. Within the anther POLLEN GRAINs are formed. The pollen grains are microspores and, therefore, it is

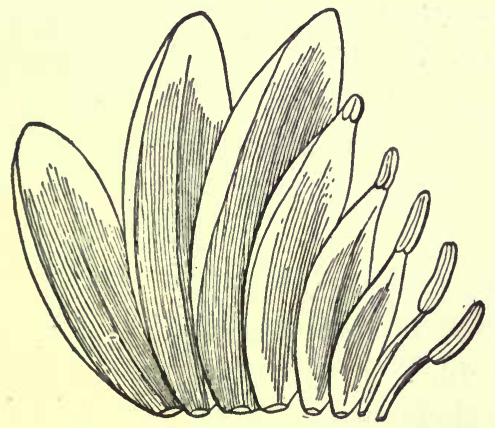

FIG. 59. - Transition between petals and stamens in a Water Lily. (After Gray.)

apparent that the pollen sacs of the anthers are Microsporan-

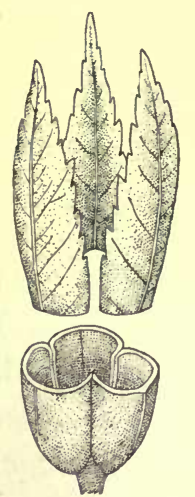

Fig. 60. - Diagram to illustrate the method of union of three carpels (megasporophylls) to form the ovule case of a pistil (coinpound). The edges which unite form the point of attachment of the ovales. (After Gray.)
GIA and the stamens are microsporophylls.

Finally, just within the circle of stamens is the fourth whorl of floral leaves, the carpels, in which specialization has gone so far that practically no suggestion of leaf structure remains. Each carpel consists of three parts: a lower, expanded portion termed the ovule Case, merging above into the elongated, slender STYLE, the tip of which is the stigma. Such a fully developed carpel is known as a PISTIL and when, as frequently happens, the various carpels fuse to form a composite structure, this is termed a compound pistil. Within the ovule case are developed the reproductive bodies known as ovULES which are essentially MEGASPORANGIA, for within each is formed a megaspore, commonly known as an EMbryo sac. A carpel, therefore, is a megasporophyll. (Fig. 60.) 
So far it is clear that a flower is a group of sporophylls which produce microspores and megaspores. Since, however, such reproductive bodies always form male and female gametophytes, their development must now be considered.

The first fact to have clearly in mind is that the megaspore is never liberated by the megasporangium. And further that the latter remains just where it arose in the ovule case of the pistil. Consequently the megaspore germinates within the pistil, and it forms there a female gametophyte composed of only a few cells, including the female gamete, or egg. Thus the female gametophyte generation of Flowering Plants is invisible except with the microscope.

The pollen grain is a typical microspore, a single cell enclosed within a protective wall. Germination starts, while the pollen is still in the anther, by the division of the spore nucleus into two, one of which divides again. Further development does not occur unless the pollen is transferred in some way, usually by insects or the wind, to the stigma of the pistil. The stigma secretes fluids suitable for the germination of the ripe pollen grain, which bursts its rigid wall and puts forth a cytoplasmic tube. This grows down through the tissues of the pistil until its tip enters the ovule case, and carries with it the nuclei, two of which represent sperm. The pollen has now completed its development and thus the contents of the pollen grain plus the tube itself constitute a greatly reduced male gametophyte.

By the time the pollen tube reaches the ovule case, the megaspore within has formed, as already described, the female gametophyte with its egg. One of the sperm nuclei unites with the egg and forms a zygote, which remains just where it is, surrounded by the tissues of the pistil base, and proceeds to divide to form an embryo sporophyte with rudimentary root, stem, and leaf. Concurrently, the ovule case 
and associated tissues of the base of the pistil undergo more or less profound changes ('ripen') and become transformed into a FRUIT. The young sporophyte within, together with food material for its further development, is hermetically sealed up in a special packet - it has become a sEED.

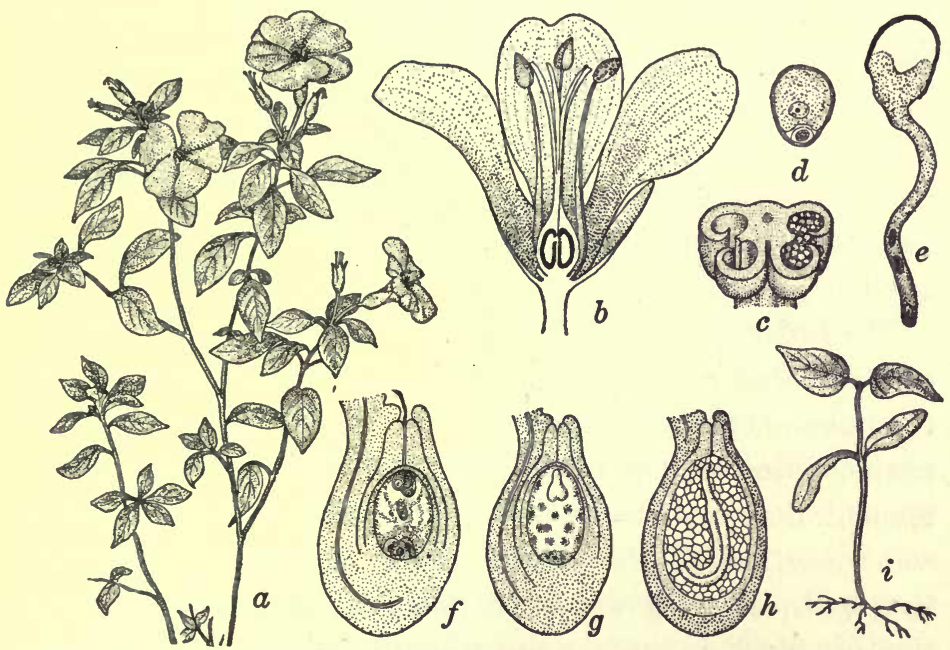

Frg. 61. - The life history of a higher Flowering Plant, from various species. $a$, shoot of a Flax with flowers, $\times \frac{1}{3} ; b$, vertical section of a flower, $\times 1 ; c$, an anther cut to show four mícrosporangia containing pollen grains (microspores), $\times 6$; $d$, an ungerminated pollen grain, and one, $e$, which has formed tube (male gametophyte), $\times 110 ; f$, longitudinal sections of an ovule enclosing megaspore and its contents (female gametophyte), $\times 20 ; g$, an ovule transformed into a seed with young embryo sporophyte and endosperm, $\times 10 ; h$, a mature seed, $\times 5 ; i$, young sporophyte from the germination of the seed, $\times \frac{1}{2}$. (After Ganong.)

In this form the new generation is prepared not only to leave the parent plant and withstand adverse conditions for a long time, but also to continue rapidly its development into an adult sporophyte when it falls upon favorable soil. Incidentally, it may be mentioned that the establishment of seed formation is probably chiefly responsible for the dominant position which the Flowering Plants hold in the flora of to-day. (Fig. 61.) 
Thus it is clear that the gametophyte generation of Flowering Plants is reduced to practically its lowest terms - a few nuclear divisions sufficient to form the gametes. The whole generation is telescoped, as it were, within the flower of the previous sporophyte generation, so that sporophyte seems to produce sporophyte; whereas, as a matter of fact, three distinct generations contribute directly to the formation of the seed. A seed is really a highly modified megasporangium with its contents. The seed coat comprises tissue from the megasporangium of the parent sporophyte bearing the flower (first generation). Certain nutritive tissues (endosperm) represent the female gametophyte (second generation). The product of the fertilized egg is a young sporophyte (third generation). (Fig. 62.)

The great reduction of the gametophyte generation in Flowering Plants is accompanied by a transference of some of the phenomena associated with sexuality to the sporophyte, so that the latter, though intrinsically asexual, comes secondarily to exhibit
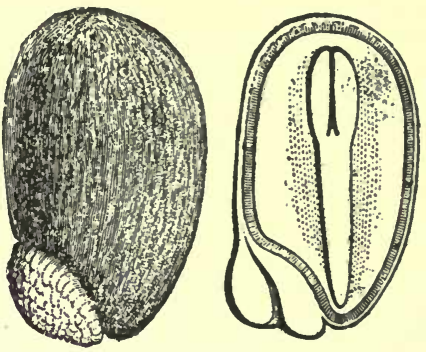

Fig. 62. - Seed of a Violet. At the left the hard seed coat; at the right, a section showing the abundant endosperm (female gametophyte) enclosing the embryo, or young sporophyte. (From Coulter.) certain sexual characters, chiefly in the flower. Thus, although the stamens and pistil (carpels) are actually sporophylls of the non-sexual generation, they are frequently referred to as the male and female organs of the flower. Likewise Pollination, or the transference of the pollen grains from anther to stigma, is often called the fertilization of the flower; whereas, as we have seen, it is merely a preliminary step which makes it possible for gametophytes to meet on common ground so that the sperm, which them- 
SPERMATOPHYTES P T ER I D O P H T T E B R Y P H T T S TH A L L O P T T E

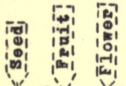

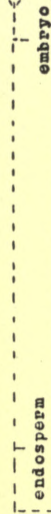
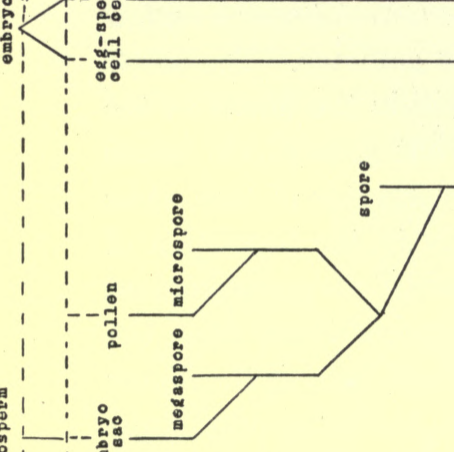

要品

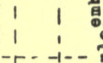

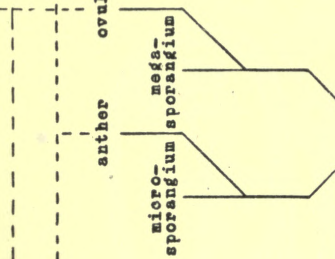

.

妾

-
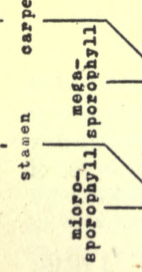

-

๓๐ํํㅇ.

햏
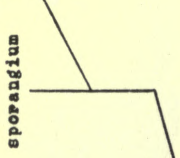

总

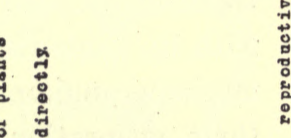

$\infty$
$\stackrel{4}{4}$
$\vdots$
0

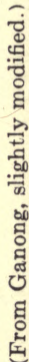

:

¿

$\therefore$ ॐ

:

离

:

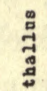


selves have suffered reduction and lost their motility, can reach the egg and perform the act of fertilization. Frequently this sexual differentiation extends to the flower as a whole, since some flowers bear only stamens and others only carpels and are known as male and as female flowers respectively. Moreover, male and female flowers may be borne on separate plants, in which case the plants themselves are called male and female. In brief, the terminology which rightly is applicable only to the sexual generation is, for convenience, transferred to the asexual generation, in consequence of the fact that vicarious sexual functions are reflected back to it through the almost complete suppression of the actual sexual generation itself.

If we glance back over the reproductive processes in plants, we are impressed with the fact that reproduction is, to a very large extent, asexual. The great masses of thallus vegetation, represented by Seaweeds and their allies, increase in bulk chiefly by vegetative cell division, and new individuals are formed in profusion by fragmentation and spore formation. In the Mosses, where the sexual generation is prominent, beds of moss are developed chiefly by the asexual budding of the sexual plant, while spore formation holds a prominent place in the increase and dissemination of individuals. In the Ferns and Flowering Plants, which are to all intents and purposes asexual plants, since the sexual phase is relegated to an increasingly obscure position in the life history, reproduction is not only by spores, but also by cuttings, bulbs, fragments of leaves, etc. In brief, reproduction, unaccompanied by sexual phenomena, is apparently amply sufficient for the propagation of plants.

However, it will be noted that sexuality has persisted from its simple origin when spores of unicellular plants performed the sexual act and became gametes. The gametophyte 
generation in the life history which it provoked wanes in importance as we proceed from the lower to the highest plants, but in spite of this the sex act itself is retained and shows its modifying powers even in the asexual generation. Obviously some advantages must be gained in the long run by fertilization, other than the establishment of another generation in the life history, or such devious methods culminating in the flower would not be elaborated for its preservation. We shall leave this large problem until we take up the question of sex in animals, since sexuality is a fundamental attribute of both plants and animals which profoundly affects their morphology and physiology. 


\section{CHAPTER X \\ THE ANIMAL BODY}

If we contemplate the method of Nature, we see that everywhere vast results are brought about by accumulating minute actions. - Spencer.

The most obvious characteristic which distinguishes familiar plants and animals is the power of locomotion of the latter. This criterion, however, fails among the lowest forms; for example, Sphaerella, as we have seen, swims as actively as Paramecium. Moreover, among multicellular animals there are innumerable sessile forms, such as the typical stages of the Sponges, Hydroids, Barnacles, etc. Although the power of locomotion is not a diagnostic character of animals as compared with plants (this, as has been explained, being chiefly a matter of metabolism), it is a fact that, taken by and large, the great dissimilarity between the bodies of multicellular plants and animals is a direct or indirect result of the loss by plants and the development by animals of the primitive power of locomotion which most unicellular organisms possess. At the basis of this difference is probably the fact that early in the evolution of plants comparatively rigid cell walls of cellulose were established, which directed the development of the body along relatively fixed lines. On the other hand, animal cells, unhampered by the limitations imposed by rigid confining walls, were free to respond in more ways to environmental conditions, and this made possible the extremely diverse forms of mobile bodies characteristic of the animal kingdom. This greater plasticity of the animal in compari- 
son with the plant is reflected again in the fact that the body of the higher plants is essentially a combination of a series of tissue systems and organs, each of which plays a particular part in the economy of the whole, while that of the higher animal is a coöperating series of organs, or ORGAN SYSTEMS.

The organ systems of animals may be classified as the INTEGUMENTARY AND SKELETAL SYSTEMS which constitute the covering and the framework of the individual; the ALIMENTARY, RESPIRATORY, CIRCULATORY, and EXCRETORY SYSTEMS which directly or indirectly are concerned with nutrition; the Nervous SYSTEM which, in coöperation with the system of SENSE ORGANS, the MUSCULAR SYSTEM, etc., not only coördinates the various parts of the individual, but also orients the whole with respect to its environment; and, finally, the REPRODUCTIVE SYSTEM which makes possible the continuation of the race. The fundamental life processes for which these systems provide must be carried on by all animals, and the chief differences in the structure of animals, from the lowest to the highest, is a resultant of the means adopted to serve these essential functions under different exigencies imposed by the environment and mode of life.

\section{A. The Chiff Groups of Animals}

The animal kingdom may be divided into two main groups; on the one hand, the unicellular animals, or ProtozoA, comprising about ten thousand known kinds, nearly all of which are microscopic, such as Amoeba, Paramecium, and their.allies; and on the other hand, multicellular forms, or MetazoA. The latter division includes animals ranging in size from those which are so small that hundreds can sport in a drop of water, to the present-day Whales and the Dinosaurs of the past. Although the actual stages in the transition from the Protozoa to the Metazoa are unknown, among 
the more complex colonial Protozoa there are forms, as already noted, in which the various cells become organically connected so that a primitive sort of body results, and, furthermore, certain cells are set aside for reproduction. In other words, coöperation involving a physiological division of labor takes place between the individuals of a group of cells, and this results in the establishment of an individual body of somatic cells associated with germ cells. (Fig. 18.)

The Metazoa proper may be divided into two large groups known as Invertebrates and Vertebrates. The former group, frequently referred to as the lower animals, comprises some five hundred thousand living species and exhibits an enormous variety of form and complexity of structure ranging from the Sponges and Hydroids to the Moliuses, Crustacea, and Insects. On the other hand, the Vertebrates, or higher animals, form a relatively homogeneous group of about thirtyfive thousand species, including the Fishes, Amphibia, Reptiles, Birds, and Mammals. The Birds and Mammals in contrast with all other animals are commonly referred to as warm-blooded, because their body temperature is practically constant and usually above that of their surroundings.

The highly complicated and varied organization of animals renders it impossible to present a concise and adequate plan of a typical animal body, and it is therefore necessary in the present work to select one group of animals as the basis of study and then to compare with this, in so far as comparisons are possible without confusion, a few of the most significant morphological and physiological variations presented by other groups. We naturally select the group of Vertebrates for chief consideration not only because its relative homogeneity renders it the most available, but because it includes Man. However, even before we focus attention on the Vertebrates, it is necessary to make a brief preliminary sur- 
vey of certain morphological principles as exhibited among the Invertebrates - selecting as types the Hydra, Earthworm, and Crayfish - in order to afford a background for the consideration of Vertebrate structure and function.

\section{B. HYDRA}

In discussing the development of animals, it was pointed out that the dividing egg typically forms a blastula which, in turn, becomes transformed by the invagination of its wall at one pole into the gastrula stage. This early gastrula is essentially a sac composed of two layers of cells: an outer or ectoderm and an inner or endoderm layer. Although no adult animal retains this simple gastrula form, the animals composing the group known as the Coelenterates are to all intents and purposes permanent gastrulae since their bodies are built on the plan of a two-layered sac. This is well exhibited in Hydra, an almost microscopic, fresh-water Coelenterate which is commonly found attached to submerged vegetation or stones in brooks and ponds. (See p. 414.)

The body of Hydra somewhat resembles a tube closed at one end, constituting the FоOT, and open at the other, forming the MOUTH. Surrounding the mouth is a circle of outpocketings of the body wall termed tentacles. The main axis of the body extends from foot to mouth, and every plane passing through this axis divides the body into symmetrical halves. In other words, the parts of the body are symmetrically disposed about, or radiate from, the main axis, and so Hydra affords an example of RAdial symmetry. (Fig. 64.)

The tubular body wall of Hydra is composed of two distinct cell layers, ectoderm and endoderm, separated by a thin non-cellular supporting layer of jelly-like material (MEsoGLOEA) secreted by the cells of both ectoderm and endoderm. Hydra thus illustrates a simple type of Metazoan structure 
in which but two primitive tissues exist; such specializations as are necessary for the performance of the essential life functions being confined to the more or less isolated cells of these layers. The majority of the cells of the endoderm which

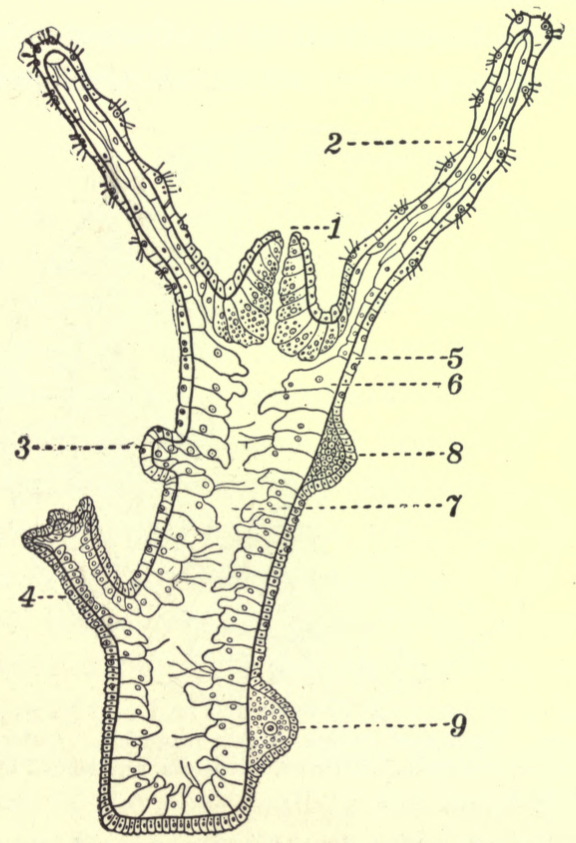

FIG. 64. - Hydra. Longitudinal section, magnified. 1, mouth; 2, tentacles; 3 , early stage in budding; 4 , older bud; 5 , ectoderm; 6 , endoderm; 7 , enteric cavity; 8, testis; 9, ovary. (From Linville and Kelly, after Parker.)

line the ENTERIC CAVITY are concerned with the digestion of solid food taken in through the mouth, while those of the ectoderm are variously modified for protection, and the other relations of the individual to its surroundings, as well as for reproduction.

In short, in the organization of Hydra the primary tissues (ectoderm and endoderm) have not become differentiated 
into secondary specialized tissues (muscular tissue, nerve tissue, etc.) for one function or another - the simple life processes of Hydra are adequately provided for by the specialization of isolated cells or small cell groups within ectoderm and endoderm. (Fig. 65.)

The bodies of all animals above the Coelenterates are built up of three primary layers, which, as development of the

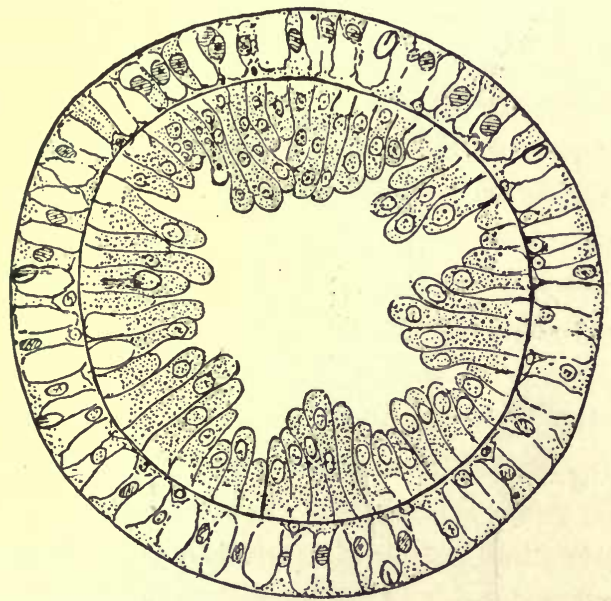

Fig. 65. - Hydra. Transverse section, highly magnified. Outer layer of cells, ectoderm; inner layer, endoderm. Between, mesogloea, represented by a line. (After Shipley and McBride.)

individual proceeds, give rise to the secondary tissues and thereby form a relatively complex body. This third primary layer, known as the mesoderm, typically is developed, as we have deseribed earlier, from the endoderm and comes to occupy the position held by the mesogloea of Hydra; that is, between the ectoderm and the endoderm.

The development of the mesoderm is the key to the advance in body organization of higher animals, because it makes possible a radical change in plan that involves the establishment of a body cavity, or COELOM, in which are dis- 
posed many of the chief organs and organ systems. Accordingly the Coelentrates, since they lack the coelom, are often referred to as Acozlomates, and the animals above the Coelenterates, since they possess the coelom, are known as the Coelomates. The difference in structure can best be made clear by comparing the body plan of a higher Invertebrate, such as the common Earthworm, with that of Hydra.

\section{Earthworm}

Whereas the Hydra body is essentially a single tube composed of two layers of cells surrounding the enteric cavity, the body of the Earthworm is built on the plan of a tube within a tube - the outer tube forming the body wall, and the inner, the wall of the ALIMENTARY CANAL. The walls of these tubes become continuous, or merge into each other at both ends, and thus together they enclose a space, the coelom. Or, to state it another way: the outer tube, or body wall, surrounds a space, the coelom: through the coelom runs a second tube, the alimentary canal, which opens to the exterior at either end forming the mouth and anus. (Fig. 66.)

The coelom of the Earthworm is divided by a large number of transverse partitions, called SEPTA, which extend from the inner surface of the body wall to the outer surface of the alimentary canal. The result is that the worm's body cavity is not a continuous space running from one end of the animal to the other, but consists of a linear series of chambers through the center of which runs the alimentary canal. The limits of these chambers are indicated on the outside of the worm by a series of grooves which encircle the body wall. In short, the body is made up of a series of essentially similar units known as METAMERES, and thus affords a simple example of METAMERISM, which is a characteristic of all the higher animals. (Fig. 67.) 
Many of the chief organs of the Earthworm are developed as outgrowths from the walls enclosing the coelom, so that it is in this cavity that we find, for example, the main parts of the organ systems devoted to circulation, excretion, and reproduction, as well as the nervous system. Moreover, the
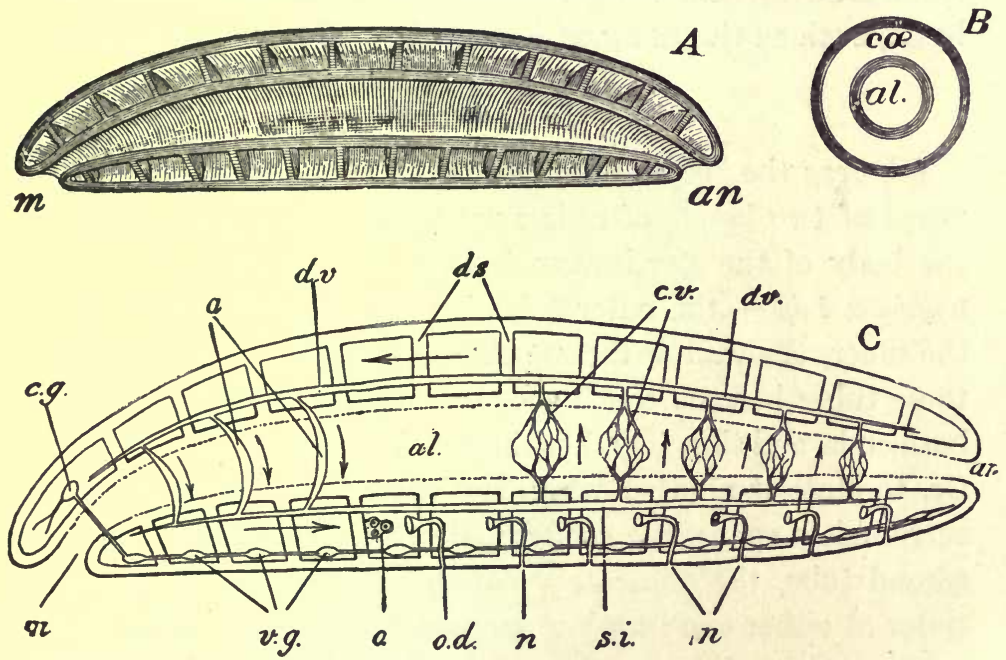

Fig. 66. - Diagrams of the body plan of the Earthworm. $A$ and $C$, longitudinal sections; $B$, transverse section. $a$, aortic loops of the blood vascular system; al, alimentary canal; $a n$, anus; c.g. brain (cerebral ganglion); coe, coelom; $c v$, blood vessels (parietal) to body wall; $d s$, partitions (septa) between the segments; $d . v$., dorsal blood vessel; $m$, mouth; $n$, nephridia; o, ovary; o.d., oviduct; s.i., ventral blood vessel. (From Sedgwick and Wilson.)

organs are symmetrically disposed with respect to the long axis of the body which passes from mouth to anus. For instance, the chief blood vessels and the nerve cord lie in the long axis and extend from end to end, while the organs of the excretory and reproductive systems are disposed in pairs on either side of this axis. Thus there may be passed through the main axis a single plane which divides the body into symmetrical halves, each of which is a 'mirror picture' of the 


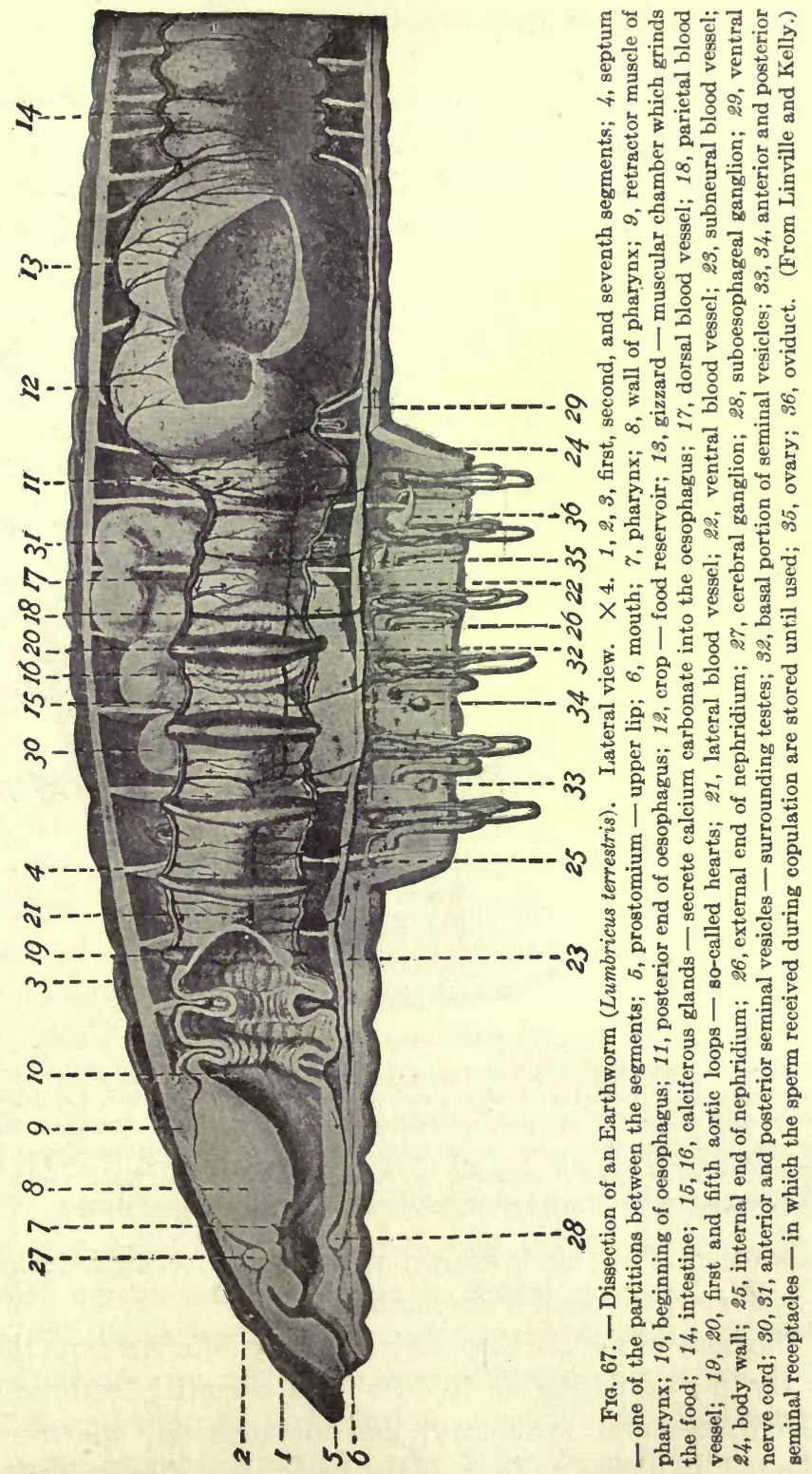


other. The main axis, therefore, extends from the mouth (ANTERIOR END) to the anus (POSTERIOR END), and the plane which divides the body into right and left sides passes through the upper (DORSAL) and lower (VEnTRAL) side. This general

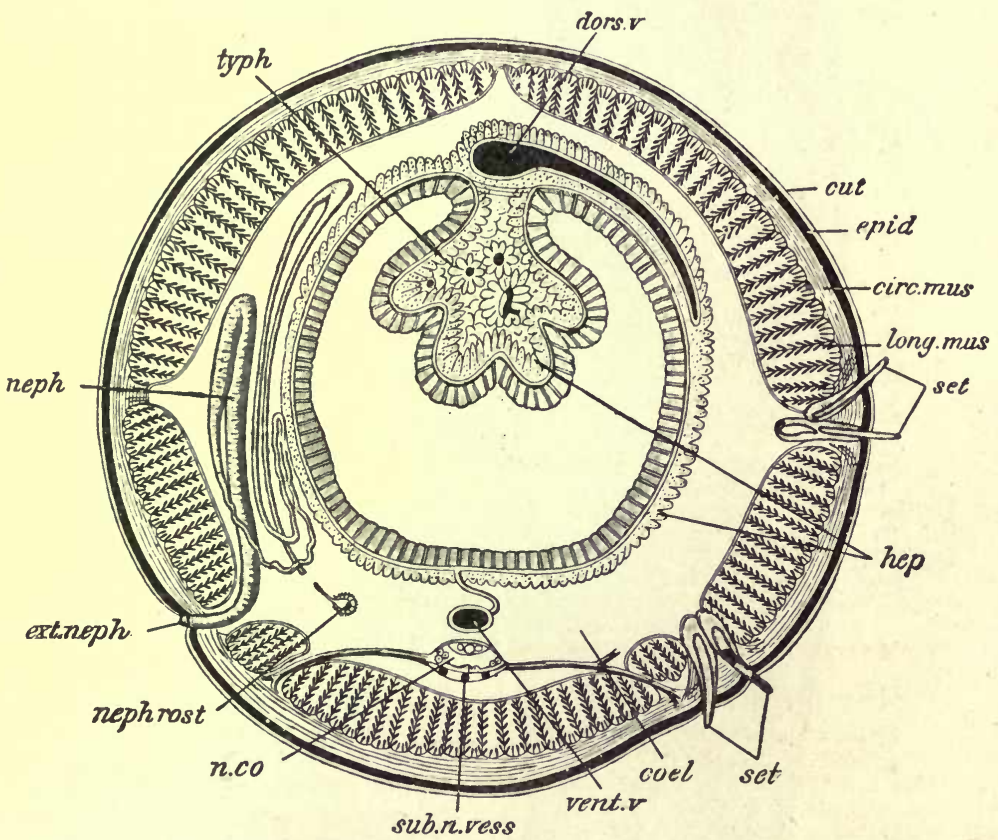

Fig. 68. - Transverse section through the middle region of the body of the Earthworm. circ. mus, circular muscle fibers; coel, coelom; cut, cuticle; dors. $v$, dorsal blood vessel; exid, epidermis; ext. neph, external opening of nephridium; hep, gland cells; long. mus, longitudinal muscles; neph, nephridium; nephrost, internal opening of nephridium; n. co, nerve cord; set, setae; sub. n. vess, subneural vessel; typh, typhlosole; vent. $v$, ventral vessel. (From Parker and Haswell, after Marshall and Hurst.)

disposition of organs is known as BILATERAL SYMMETRY and is characteristic of all higher animals.

The body of the Earthworm is radically different from that of Hydra, exhibiting as it does such essential features as coelom, bilateral symmetry, and metamerism, which are adopted by higher animals as the basic plan of organization. 
It is important in this connection to understand how these modifications are related to the third primary germ layer, or mesoderm, which, as we have stated, plays a part in the development of all forms above Hydra. For the sake of concreteness we shall describe the development of the Earthworm from the fertilized egg to the establishment of the general body plan, though it must be borne in mind that in no two species of animals is the process of development identical.

After fertilization, the egg of the worm proceeds to divide first into two cells, then four cells, eight cells, and so on, with more or less regularity, until a condition is attained in which many relatively small cells are arranged about a central cavity. This stage of the embryo will be recognized as the blastula. (Fig. 69.)

The various cells of the blastula appear essentially the same except that those at one end are somewhat larger than at the other. The larger cells now sink into and nearly obliterate the central cavity of the blastula, thus forming a typical gastrula stage composed of two layers of cells, ectoderm on the outside and endoderm on the inside. The infolded endoderm pouch (ENTERIC POUCH) enclosing the enteric cavity eventually becomes the main part of the alimentary canal of the worm, its present opening to the exterior (BLASTOPORE) forming the mouth. The ectoderm is destined to form the skin, or outer layer of the worm's body.

While these two primary germ layers are being established, the developing embryo shows the rudiments of the third primary germ layer (mesoderm) in the form of two cells (POLE CELLS) which leave their original position in the wall of the embryo and take up a place between the ectoderm and endoderm; that is, in the remnant of the cavity of the blastula which the invagination process during gastrulation has not completely obliterated. Here the pole cells, by di- 

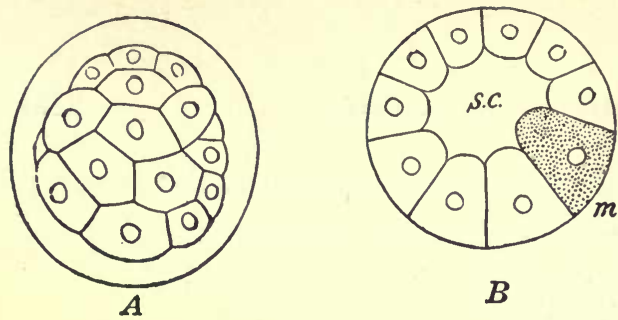

$B$

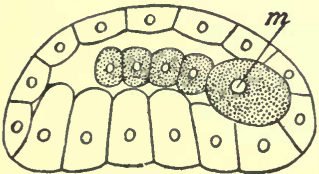

$D$

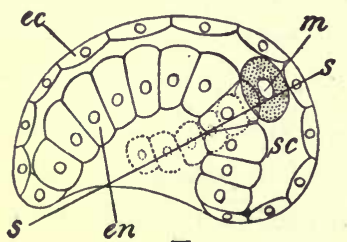

$E$
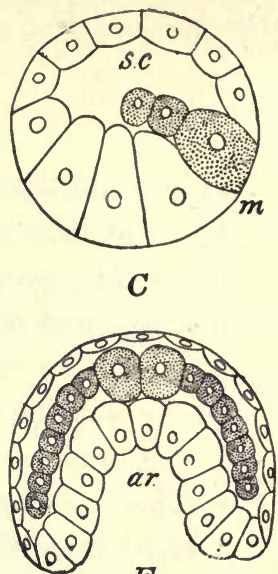

F
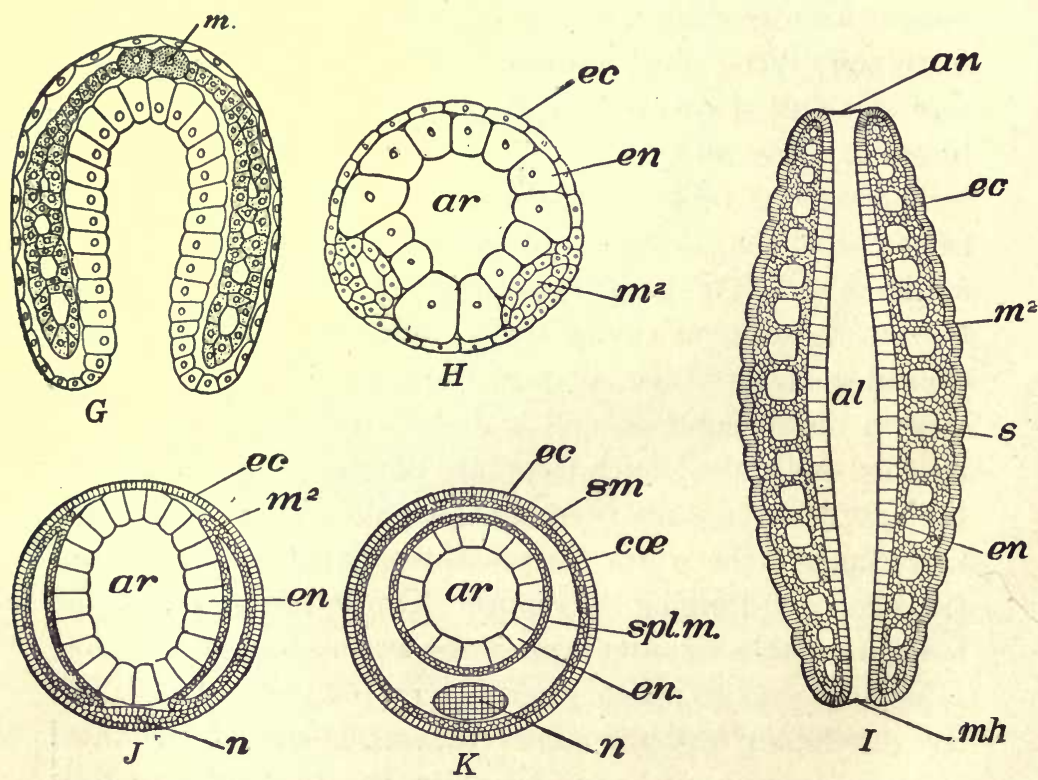

Frg. 69. - Diagrams of stages in the development of the Earthworm. A, blastula (surrounded by a membrane); $B$, section of a blastula showing blastocoel and one of the primary cells (pole cells) of the mesoderm; $C$, later blastula with developing mesoderm bands; $D$, start of gastrulation; $E$, lateral view of gastrula showing invagination, which as it proceeds leaves the mesoderm bands on either side of the body as indicated by the cells represented with dotted outline; $F$, section of $E$, along the line $S-S$ to show pole cells, mesoderm bands, and enteric cavity. $G$, later stage showing cavities in the mesoderm bands, $H$, the same $(G)$ in cross section; $I$, diagram of a longitudinal section of a young worm after formation of mouth and anus; $J$, the same in cross section; $K$, later stage in cross section. al, alimentary canal; an, anus; ar, enteric cavity; $c o e$, coelom; $e c$, ectoderm; $e n$, endoderm; $m$, primary mesoderm cells or pole cells; $m^{2}$, mesoderm; $m h$, mouth; $n$, nerve cord; 8 , cavity of segment; $8 c$, blastocoel; $s m$, somatic layer of mesoderm which with the ectoderm forms the body wall; splm, splanchnic layer of mesoderm which witb the endoderm forms the wall of the alimentary canal, (From Sedgwick and Wilson.) 
vision, form on either side of the enteric pouch a linear series, or band, of mesoderm cells. These MESODERM BANDS gradually increase in size and spread out until finally they unite above and below, that is encircle, the enteric pouch. Thus they form a continuous mesoderm layer between ectoderm and endoderm. Simultaneously with the growth of the mesoderm bands to form a definite middle layer, a linear series of spaces appears in each band which presages the future segmentation of the worm's body. These cavities increase in size and, when the bands unite around the enteric pouch, the corresponding cavities of each band also become continuous in the same regions.

In this way the mesoderm becomes divided up into what are essentially two cellular layers, an outer, or SOMATIC LAYER, next to the ectoderm, and an inner, or SPLANCHNIC LAYER, in contact with the endoderm. The space between these layers of the mesoderm is the body cavity, or coelom. The coelom, however, is not a continuous cavity from one end of the embryo to the other, because the mesodermal cells which separated the linear series of cavities in the respective mesodermal bands persist. These cells form a regular series of connecting sheets of tissue between the two mesoderm layers and thus divide the body of the worm into a series of essentially similar segments, or metameres, the limits of which are indicated on the outside by a series of grooves which encircle the worm's body.

While these processes are transforming the two-layered gastrula into an embryo composed of three primary layers, and exhibiting metameric segmentation, coelom, etc., - in short, the 'tube within a tube' body-plan characteristic of higher forms - the embryo is gradually increasing in size and elongating. The mouth, representing the blastopore, remains at one end, which is therefore designated as anterior, while 
growth is chiefly in the opposite direction or toward the posterior. At this end (the blind end of the enteric pouch formed at gastrulation) an opening to the exterior, the anus, is formed so that the enteric pouch now communicates with the exterior at both ends and becomes the alimentary canal. Thus antero-posterior differentiation is clearly established.

A cross section perpendicular to the main axis of the developing worm at this stage presents the appearance of a circle within a circle. The smaller circle surrounds the enteric cavity and is the wall of the alimentary canal. It is separated by a space, the coelom, from the larger circle, or body wall. Moreover, each of these circles is composed of two tissue layers: the alimentary canal, formed internally of endoderm and externally of mesoderm; and the body wall, internally of mesoderm and externally of ectoderm. Thus the coelomic cavity is entirely enclosed by mesoderm.

It is from these four layers of cells (ectoderm, somatic and splanchnic mesoderm, and endoderm) that all of the tissues and organs of the adult worm arise through thickenings, foldings, outgrowths, etc. For example, the nervous system is formed by the ingrowth of a thickened region of the ectoderm; the blood vascular system develops by a specialization of cells throughout the mesoderm; while the reproductive system first appears as thickenings of the somatic mesoderm which, as development proceeds, becomes largely separated from it as independent organs in the coelom. In general, it may be said that in all the higher animals the ectoderm forms the outer skin and nervous system; the endoderm supplies the lining membrane of the major part of the alimentary tract; while the mesoderm contributes muscles, blood vessels, reproductive organs, and the membrane lining the coelom. This similarity in origin of the organ systems throughout the animal series above Hydra and its allies is of the highest 
significance, because it indicates a basic structural identity in the body plan of all these forms. It is exhibited in the developmental process in each generation, even though the adult body in the various groups differs widely in form and arrangement of organs. Such a state of affairs clearly suggests a genetic relationship throughout the whole animal series - the origin of the diverse forms by evolution.

\section{Crayfish}

Bearing in mind the general plan of organization and development of the body of the Earthworm, we must next consider briefly the main principle underlying the changes in this plan which give rise to many of the diverse forms among the higher Invertebrates. This principle appears to be chiefly a specialization of the individual segments so that the body, instead of consisting of a large number of essentially similar metameres, is formed of a linear series of metameres, many of which are quite different from the rest. Moreover, by the partial or complete fusion of two or more metameres and the suppression of segmentation, definite regions of the body are delineated. This principle is well illustrated by animals of the group known as the ArTHroPODA, or 'jointed-footed' Invertebrates, such as Lobsters, Insects, Millipedes, and Spiders. Altogether the Arthropoda comprises nearly half a million living species.

The body of a primitive Arthropod differs from that of the Earthworm chiefly in the reduction of the number of segments and the development of paired jointed appendages as outgrowths from the body in each segment. (Fig. 70.) From such a type all the multitude of diverse forms of Arthropod bodies can be derived. For instance, in the Crayfish, which is essentially a fresh-water Lobster, the body consists of nineteen segments, of which segments 1 to 5 together form the 
HEAD; segments 6 to 13, the THORAX; and segments 14 to 19 , the ABDomen. In other words, by the coalescence or complete fusion of certain segments, the body has become divided into more or less distinct regions. (Fig. 71.) Also, the primitive locomotor appendages of the respective segments have become modified into organs for the performance of widely different functions: those of the head, as sensory organs, jaws, etc.; those of the thorax, as organs for grasping, offense and defense, and walking; and those of the abdomen for swimming, etc. Thus change in structure has gone on hand

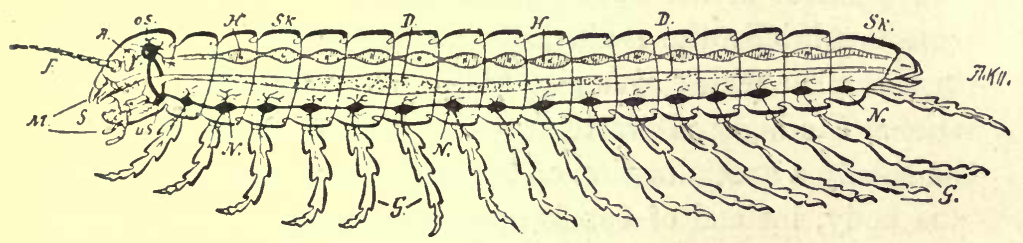

Fig. 70. - Diagrammatic representation of the structure of a primitive Arthropod in which very little specialization of the segments has occurred. $A$, eye; $D$, digestive tract; $F$, antenna; $G$, jointed appendages; $H$, dorsal blood vessel; $M$, mouth appendages; $N$, ventral nerve cord with ganglia; $S$, mouth; $S k$, chitinous exoskeleton; $O S$, cerebral ganglion; $U s$, suboesophageal ganglion. (After Schmeil.)

in hand with change in function, so that although there is no superficial resemblance between the jaws of the Crayfish and the legs employed for swimming, nevertheless a study of their development shows beyond doubt that they owe their origin to modifications of one primary type. Accordingly the various appendages are said to be Homologous, signifying a fundamental similarity of structure based on descent from a common antecedent form. (Fig. 72.)

On the other hand, organs of dissimilar fundamental structure, which nevertheless perform the same function, are called ANalogous. In the group of the Arthropods known as the Insects, the series of head appendages and the legs are homologous with those of the primitive Arthropod type, 


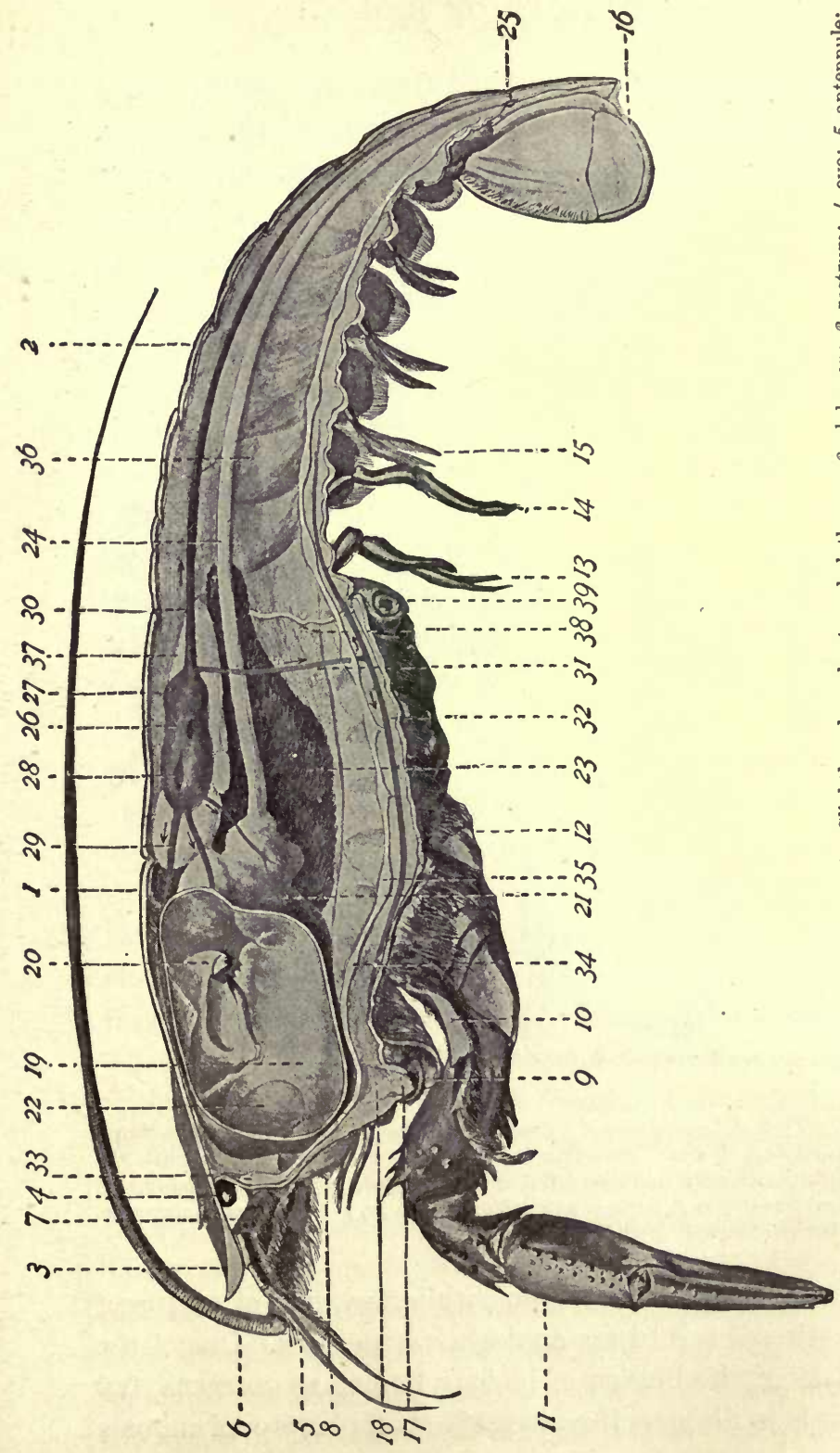

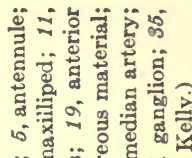
¿ छ

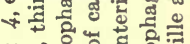
๕ี웡 क

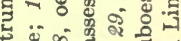
के

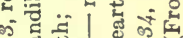
.. हु

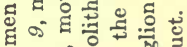

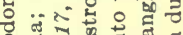
을... के 売 अं का रै

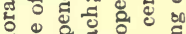
व 응 घี क क बै चี क ๘... 융 ठี

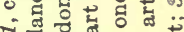

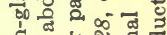
ช் ฮี

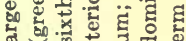
द्व क : خ 过 啳总㐘

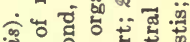

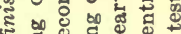
등.

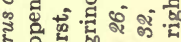
है क्ष के

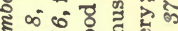
ช... ㄴำ

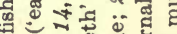

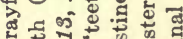
陆 क 월 ट्य के प द

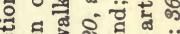
ช.ํำ . A \& 용ㄹ 人品范 -1... कै

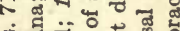

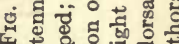
1 के में के 
while the wings are new, unrelated structures and not modifications of the primitive serial appendages of the ancestral form. However, as we shall see later, the wing of a Bird and

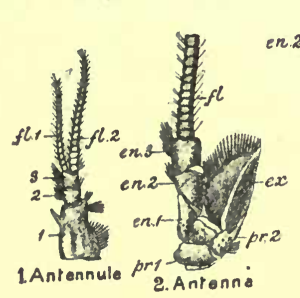

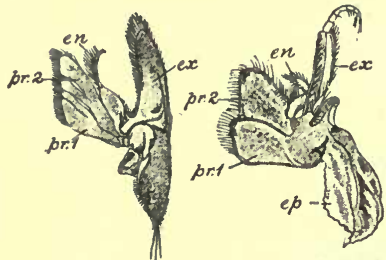

5. 2.: Maxilla
6. I? Maxilliped

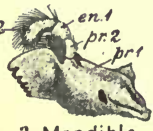

3. Mandible
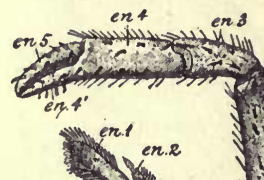

7. 3r: Maxilliped

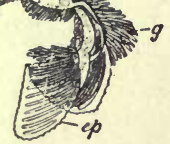

8. 3 ? $^{d}$ Lo 8

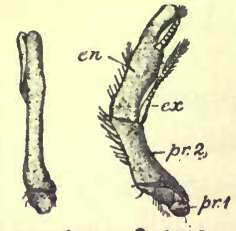

0. Copulatory Organs

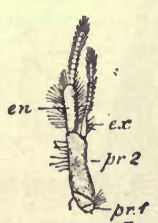

10.Swimming Foor

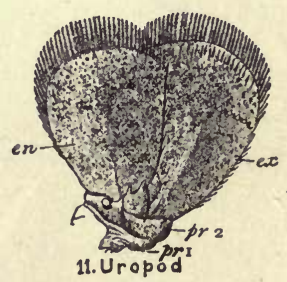

Fra. 72. - Typical appendages of a Crayfish. All have been derived from a simple biramous appendage similar to the swimming foot (10). Protopodite, endopodite, and exopodite are homologous throughout the series. en, 1-5, parts of endopodite; $e p$, epipodite; $e x$, exopodite; $f$, parts of antennule; $g$, gill; $p r, 1-2$, parts of protopodite. (From Parker and Haswell, after Huxley.)

the arm of Man are homologous, while the wing of an Insect and the wing of a Bird are analogous structures. One of the chief tasks of the branch of biology known as COMPARATIVE ANATOMY is to discover the various parts of plants or of animals 
which are homologous and to study the modifications which . are associated with change of function. (See p. 353.)

We have considered the principle of specialization and fusion of the segments of the higher Arthropods in so far as it affects external structures, but profound modifications of the internal organs also occur. In the first place, the partitions between the various segments which are present in the Earthworm have disappeared in the Crayfish. Again, the alimentary canal of the Earthworm is a nearly straight tube extending through the coelom, with relatively slight modifications in certain segments for the elaboration of the food material as it passes along from mouth to anus; while in the Crayfish we see the accentuation of such modified regions, and the development of large outpocketings which are specialized for the formation of chemical substances to DIGEST the food material. That is, to change the food into a soluble form so that it can pass through the cellular membrane which lines the digestive tract and thus actually pass to the circulatory system for distribution to the tissues of the animal.

As a final illustration we may take the nervous system. In the Earthworm this consists of a nerve cord which runs along the body in the mid-ventral line below the digestive tract. At the anterior end, it bifurcates into commissures which encircle the digestive tract and unite above in a relatively large body of nervous tissue which constitutes the cerebral ganglion, or BRAIN. In each segment the nerve cord also is somewhat enlarged to form masses of nerve tissue (GANGLIA) from which nerves pass to the organs in the vicinity. The nervous system of the Crayfish exhibits the same general plan as that of the Earthworm, but certain modifications have been brought about by the coalescence of segments in the region of the head and thorax. This process has resulted in the union of the segmental ganglia in this region into larger 
ganglionic masses. The brain of the Crayfish, for example, comprises the primitive ganglia of the segments which have. coalesced to form the head. (Fig. 73.)
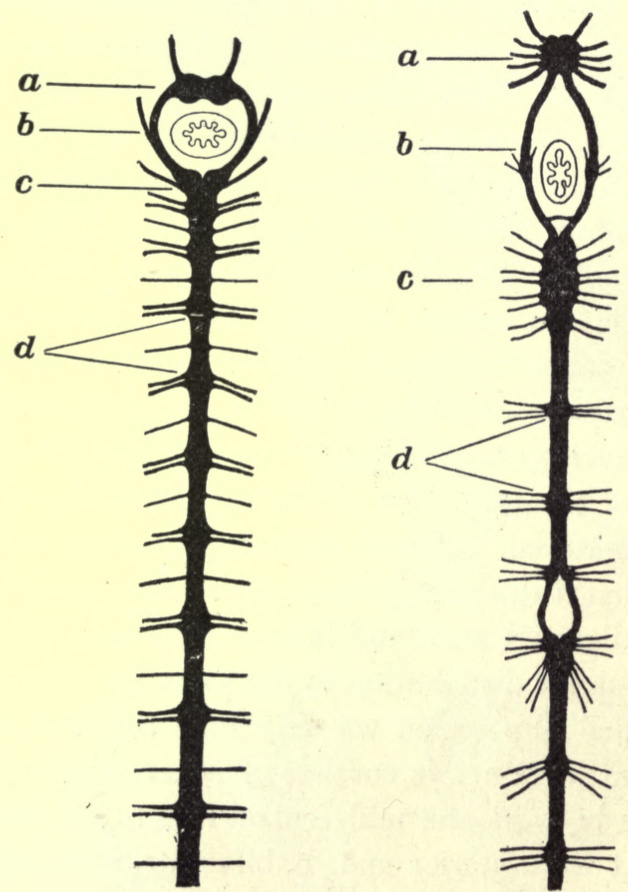

FIG. 73.- Diagram of the general plan of the anterior portion of the central nervous system of an Earthworm and a Crayfish. a, brain (cerebral, or supraoesophageal, ganglion); $b$, nerve commissures, encircling the pharynx (shown in section); $c$, suboesophageal ganglion; $d$, ganglia of the ventral nerve cord, with nerves emerging.

We have now considered the fundamental body plan of Hydra, Earthworm, and Crayfish. These Invertebrate types afford an excellent background for a proper understanding of the body structure of the Vertebrate groups. Hydra exhibits the simple two-layered condition (ectoderm and endoderm) which is a transient phase in the early develop- 
ment of higher forms. The Earthworm is of particular value since it illustrates bilateral symmetry, an alimentary canal opening to the exterior by an anterior mouth and a posterior anus, metameric segmentation, coelom, definite organ systems for various functions, and, finally, the part played in development by the mesoderm. The Crayfish shows, in simple form, certain general principles underlying the modification of the Earthworm type, which involve the specialization of various regions in connection with the change of functions of the parts to fulfil more complex life conditions.

The reader, however, must be cautioned against supposing that there is a sort of progression through all the series of lower animals up to the Vertebrates. We have selected from the groups of Invertebrates certain types which illustrate several of the fundamental structural principles which are to be found in the Vertebrate body, but there are other Invertebrate groups that exhibit body plans which depart widely from the types described. The consideration of the morphology of the groups which comprise such forms as the Tapeworms, Rotifers, Sea Urchins, Oysters, etc., would but tend to obscure those principles which are requisite for a proper interpretation of the structure and functions of the Vertebrates, including Man.

\section{E. Vertebrates}

The Vertebrates form one of the most clearly defined divisions of the animal kingdom and include all the larger and more familiar animals - Fishes, Amphibians, Reptiles, Birds, and Mammals - so that in the popular mind the words animal and Vertebrate are essentially synonymous. (Figs. 82-87.)

A Fish, as every one knows, is an aquatic backboned animal which breathes by means of gills and moves by fins. An 
Amphibian may be thought of as a Fish which early in life - at the end of the tadpole stage - discards its gills, develops lungs, substitutes five-toed limbs for fins, and takes up a terrestrial existence. In the same general way, a Reptile may be pictured as an Amphibian which has relegated, as it were, the tadpole stage to the egg, and therefore emerges with limbs and lungs. Birds and Mammals may be regarded as derivatives of the reptilian stock which have transformed the scales of the reptile into feathers and hair respectively, and have developed a special care for their young; the Birds by incubation of the eggs and the Mammals by retention of the young essentially as parasites within the body of the female until birth occurs. It will be appreciated, of course, that other important characteristics - some of which will be apparent as we proceed - delineate these chief Vertebrate groups; but there is, in fact, less diversity in structure among the Vertebrates as a whole than is present, for example, in the one subdivision of the Arthropods, the Crustacea, of which the Crayfish is a member. Accordingly we shall confine our attention largely to a description of the structure and physiology of an 'ideal' Vertebrate, and mention incidentally, so far as possible; the chief modifications of general significance which appear in the different groups.

\section{Body Plan}

The ideal Vertebrate body is more or less cylindrical in form, and is bilaterally symmetrical with respect to a plane passed vertically through the main axis which extends from the anterior to the posterior end. Three regions of the body may be distinguished, HEAD, TRUNK, and TAIL. The head forms the anterior end and contains the brain, eyes, ears, and nostrils, as well as the mouth and throat. On either side of the head is a series of openings, or GILL sLITs, leading into the 


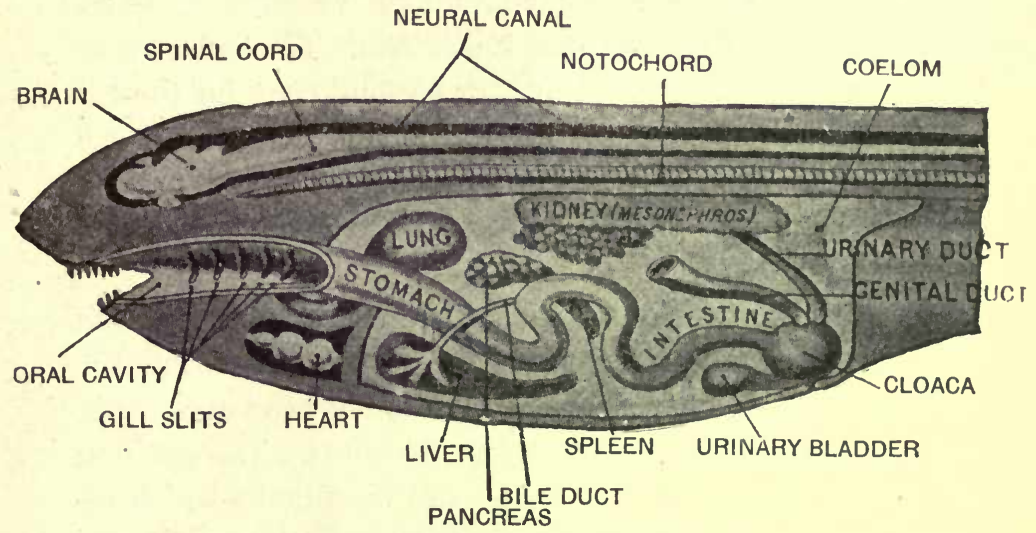

Fra. 74. - Diagrammatic longitudinal section of an ideal Vertebrate (female). (From Hegner, after Wiedersheim.)

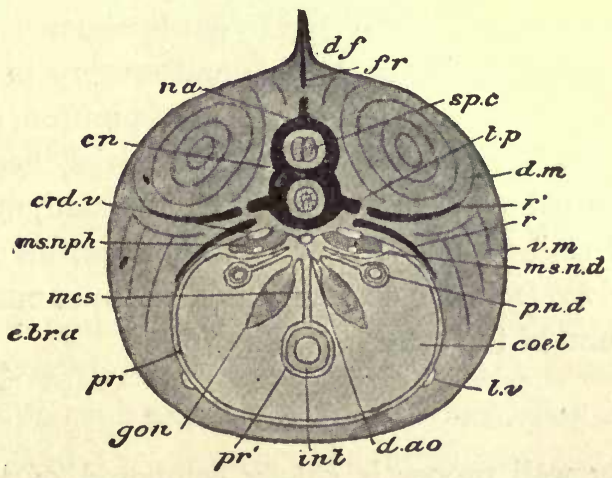

FIG. 75. - Diagrammatic transverse section through the trunk of an ideal Vertebrate. cn, centrum of vertebra; coel, coelom; crd. $v$, cardinal vein; d.a.o, dorsal aorta; d.f, dorsal fin; d.m, dorsal muscles; f.r, fin-ray; gon, gonad; int, intestine; $l . v$, lateral vein; mes, mesentery; ms.n.d, mesonephric düct; $m s . n p h$, mesonephros; na, neural arch; $p . n . d$, pronephric duct; $p r$, peritoneum, parietal layer; $p r^{\prime}$, peritoneum, visceral layer; $r$, subperitoneal rib; $r^{\prime}$, intermuscular rib; sp.c, spinal cord; t.p, transverse process; $v . m$, ventral muscles. (From Parker and Haswell.) 
throat, which, however, in air-breathing Vertebrates disappear before the adult condition is attained. The trunk forms the body proper and its cavity, or coelom, contains the alimentary canal, opening to the exterior by the anus, as well as the chief circulatory, excretory, and reproductive organs. The tail comprises the region posterior to the coelom and anus. (Figs. 74, 75.)

In aquatic forms thin extensions from the trunk and tail form median and paired FINs, the latter comprising the PECTORAL fins, situated near the junction of head and trunk, and the PELvic fins, just lateral to the anus. The pectoral and pelvic fins, or the fore-limbs and hind-limbs which replace them in all forms above the Fishes, are the only lateral appendages found in Vertebrates.

\section{Skin}

The surface of the body which comes in direct contact with the environment is covered by an integument, or skin, which, though primarily protective and sensory in function, takes part to a greater or less degree in respiration, excretion, and secretion. Scales, feathers, claws, horns, hoofs, nails, teeth, etc., are derivatives of the skin. The skin, unlike that of the Invertebrates, is formed of two layers; an outer EPIDERMIS derived from the ectoderm, and an inner DERMIs from the mesoderm of the embryo. (Fig. 76.)

\section{Muscles}

The body wall proper is chiefly composed of 'MUSCULAR TISsUE, commonly spoken of as 'flesh,' which varies in thickness in different regions of the body. In the mid-dorsal region it surrounds the CENTRAL NERvous SYSTEM and the axial supporting structure (NOTOCHORD), while ventrally it forms the wall of the coelom. In the lower Vertebrates and 
the embryonic stages of higher forms the muscular layer is composed of segments known as мүотомеs. But in the adult stage of the latter this evidence of Vertebrate segmentation largely disappears, since the muscular tissue for the most part assumes the form of highly complex longitudinal bands, extensions from which pass into the paired appendages.

A muscle consists of a very large number of muscle cells bound together by connective tissue and permeated with

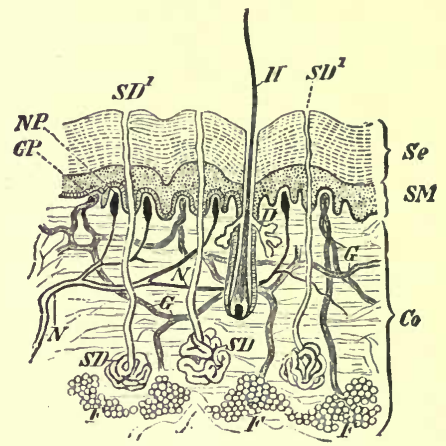

FIG. 76. - Vertical section of human skin, highly magnified, to show its composite structure. Co, dermis; $S M$, Malpighian layer of epidermis; $S e$, outer layer of epidermis; $G, G p$, blood vessels; $H$, hair with sebaceous glands $(D)$; $N$, nerves; $N P$, sensory endings of nerves; $S D$, sweat glands with ducts opening at $S D^{1}$. (From Wiedersheim.)

blood vessels and nerves. The muscle cells themselves have in a highly developed and specialized form a primary attribute of all protoplasm, contractility, which they exhibit by shortening and broadening when stimulated by impulses reaching them through the nervous system. Muscles, such as those attached to the bones, in which contraction can be brought about at will, are termed voluntaRY muscles, while those which cause most of the movements of the viscera are known as involuntary muscles. (Fig. 7, E, F.) 


\section{Coelom}

The Vertebrate coelom, in contrast with the condition in the Earthworm, essentially comprises only two chambers-a large ABDOMINAL cavity which contains most of the chief viscera, and a small, anterior, PERICARDIAL cavity in which the heart is situated. In the Mammals, including Man, however, the anterior chamber, known as the THORAX, contains the heart and lungs and is separated from the abdominal cavity by a muscular partition, or DIAPHRAGM. The lining membrane of the coelom is known as the PERITONEUM and forms the innermost layer of the body wall. (Figs. 74, 82-87.)

\section{Skeleton}

The form of the Vertebrate body is maintained by a system of supporting and protecting structures, termed the SKELETON. Although various outgrowths of the skin, such as scales, feathers, and hair, form a part of the skeletal system known as the EXoskeleton which is comparable to the protective coverings of the Invertebrates, it is a bony ENDOSKELETON which is characteristic of the higher animals. This internal skeleton which is largely mesodermal in origin exhibits such great diversity and complexity that its study, known as OSTEOLOGY, forms a most important subdivision of comparative anatomy. In the lower Fishes the endoskeleton is composed of a firm elastic tissue, CARTILAGE, or gristle, but from the 'bony' Fishes to Man most of the cartilage becomes ossified: that is, impregnated with lime salts and transformed into BONE. The human skeleton is formed of about 200 separate bones, but the number varies at different periods of life, because some bones which at first are distinct later become fused. (Figs. 77, 81, 186.)

While it is true that the bones constitute the main support- 


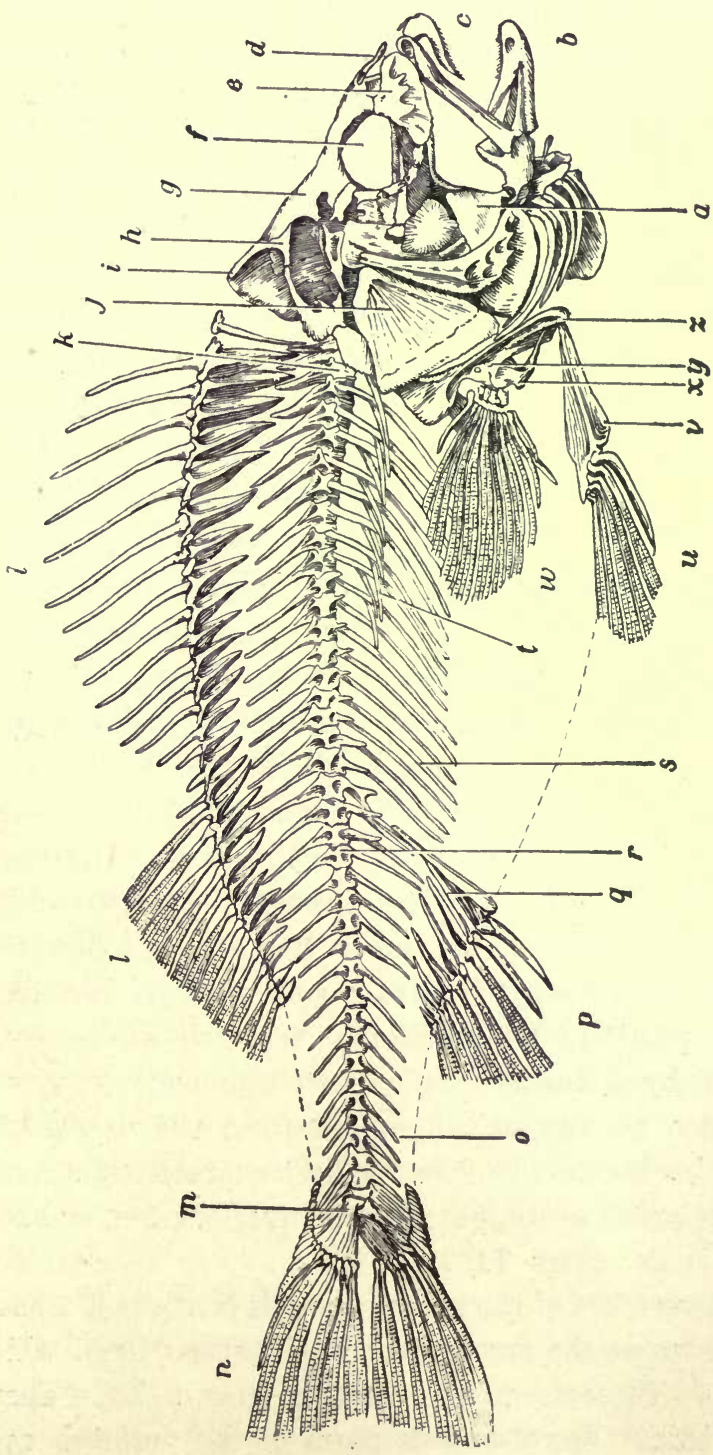

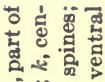

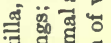

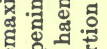
원 영

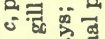
원. \& ำ 든 运范 요 䃬告 เ 으유월

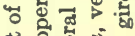
도요.

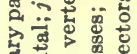
矛. 붕유요 $\therefore$ 팬

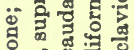
ㄴㄷㅇ ज़ ज़

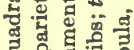
리을 o क्ष की

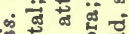
:

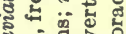
ड 5 8ำ ज़ के क्षे 2. 귱 क्ष 요요

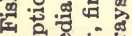
요몀 ํํㅇㅁㅇ

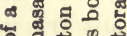

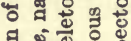
동ㅎㅇ 造范紫 政婴

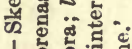
1 ڤ. $\therefore \approx 50$ N $\because$ 密它西 过 ⿷匚 
ing framework of the body, they are entirely inadequate to knit together the organism into a working unit We find therefore various kinds of CONNECTIVE TISSUE interwoven between the integral parts of the body. These tissues form sheaths about most of the organs and also supply the connecting links between muscle and muscle, muscle and bone, and bone and bone. Skeletal tissues, of which bone, cartilage, and connective tissue form the chief groups, are distinguished from the other body tissues by the development of large amounts of non-living material in or between the component cells themselves; the character of the skeletal tissue being

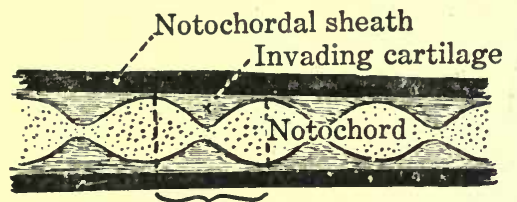

Extent of one vertebra

FIG. 78. - Diagram of a longitudinal section through a developing vertebral column to show the invasion of the notochord by cartilage to form the centra of the vertebrae. (From Walter.) determined chiefly by the nature of this matrix.

The primitive axis of the skeleton consists of a cylindrical cord or rod of cells (NOTOCHORD), which lies in the middorsal line of the body wall just below the dorsal nerve tube (sPINAL CORD) and above the coelom. In most Vertebrates, however, the notochord in its original form is only a temporary structure, being partially or completely replaced during later development by a linear series of cartilaginous or bony elements, known as vertebrae, which form the VERTEBRAL colums, or backbone. This is the most characteristic structure of Vertebrates as compared with Invertebrates, or backboneless animals. (Figs. 74, 78.)

A typical vertebra of the higher animals consists of a basal portion, known as the CENTRUM, and a NEURAL ARCH which it supports. These form a protecting ring of bone about the spinal cord. From various parts of the vertebra as a 
whole arise PROCESSES for movable articulation with its neighbors, the attachment of muscles, etc. Between the vertebrae of the Mammals are cushions of cartilage which absorb shock. (Fig. 79.)

In some forms, RIBs are attached to the transverse processes of certain vertebrae. These extend outward and downward within the body wall, and become attached in the midventral line to the breast bone (sTERNuM). Thus, in the adult of the higher Vertebrates, the series of centra of the vertebrae come to occupy the position formerly held by the notochord; while above, the neural arches encircle the NEURAL CANAL con-

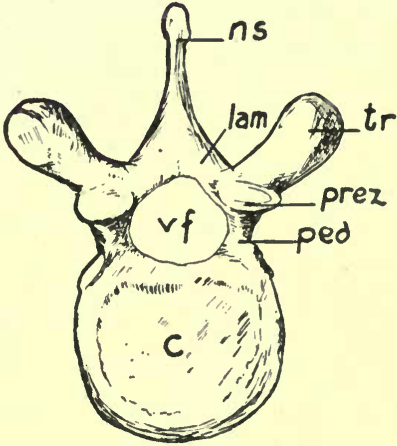

Fig. 79. - A typical human vertebra (tenth thoracic) viewed from the dorsal surface. $C$, centrum; lam, ped, neural arch; $n s$, neural spine; prez, anterior articulating process; $t r$, transverse process; $v f$, neural canal through which the spinal cord passes. (From Walter, after Spalteholz.)

taining the spinal cord; and below, the transverse processes, ribs, and sternum surround the anterior portion of the coelom. (Fig. 75.)

The Vertebrate head, containing the anterior end of the alimentary and neural canals, the brain, and the chief sense organs, is protected in the lower Fishes by a case of cartilage. In higher forms the cartilage is replaced by a bony sKULL which articulates with the first vertebra of the backbone. JAws, or supporting structures of the mouth, are attached to the skull.

The skull, vertebral column, ribs, and sternum together comprise the AXIAL skeleton, from which is suspended the APPENDICULAR skeleton, or bony frame-work of the paired appendages. This is relatively simple in the anterior (pec- 
toral) and posterior (pelvic) paired fins of Fishes, which merely act as paddles; but when these are modified into paired limbs for progression on land, the mechanical problems involve the development of complex limb skeletons to support the body, and to act as levers for the limb muscles to move in locomo-
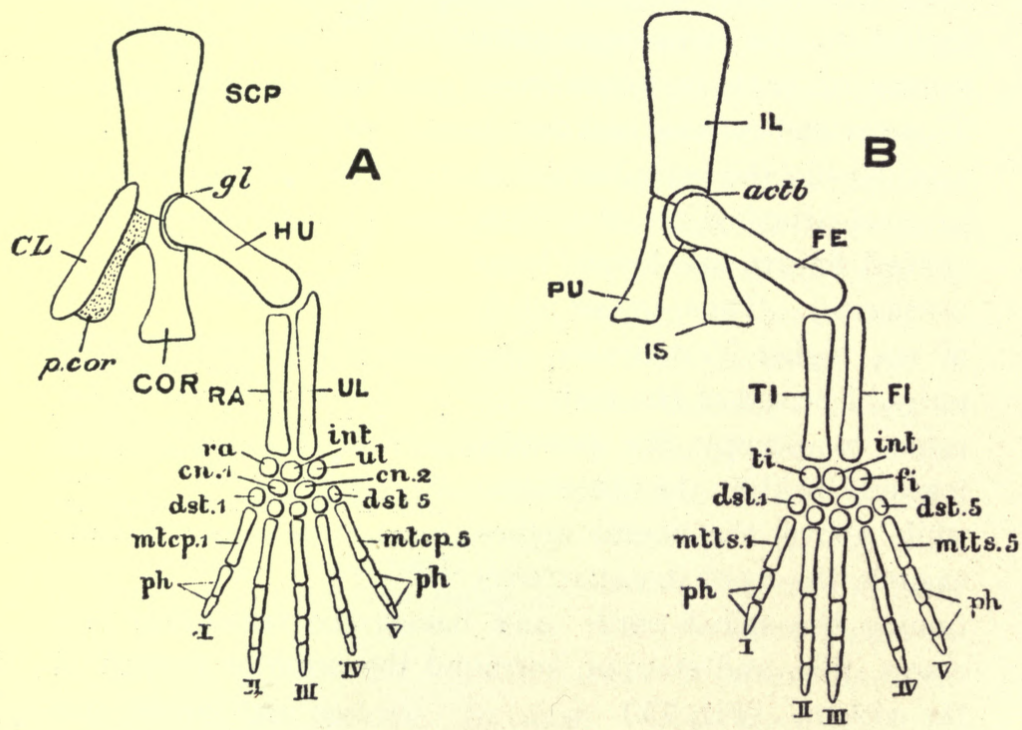

Fig. 80. - Diagram of the plan of the Vertebrate limbs. $A$, fore limb and pectoral girdle; $B$, hind limb and pelvic girdle; $a c t b$, socket for femur; $C L$, clavicle (collar bone); $c n, 1-2$, middle row of carpals and tarsals; $C O R$, coracoid; $d s t, 1-5$, distal row of carpals and tarsals; $F E$, femur (thigh bone); $F I$, fibula; $f$, fibulare (a tarsal); $g l$, socket for humerus; $H U$, humerus (upper arm bone); $I L$, ilium; int, intermedium (a tarsal); $I S$, ischium; mtcp, $1-5$, metacarpals; mtts, $1-5$, metatarsals; p.cor, procoracoid; $p h$, phalanges; $P U$, pubis; $R A$, radius; ra, radiale (a carpal); $S C P$, scapula; $T I$, tibia; $t i$, tibiale (a tarsal); $U L$, ulna; $u l$, ulnare (a carpal). (From Parker and Haswell.)

tion. In response to this need an elaborate series of bones is developed which, in all cases, however, may be referred to a common plan, known as the PENTADACTYL LIMB in allusion to the five digits (FINGERS and TOES) in which it usually terminates. The limbs are attached directly or indirectly to 


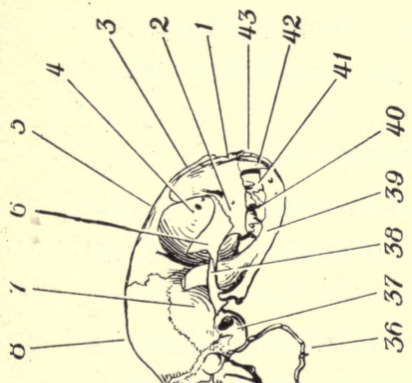

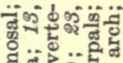
दू⿹

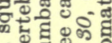
. i.을

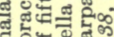
a o 0 क 元总密

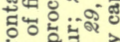

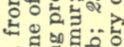
10. ำ

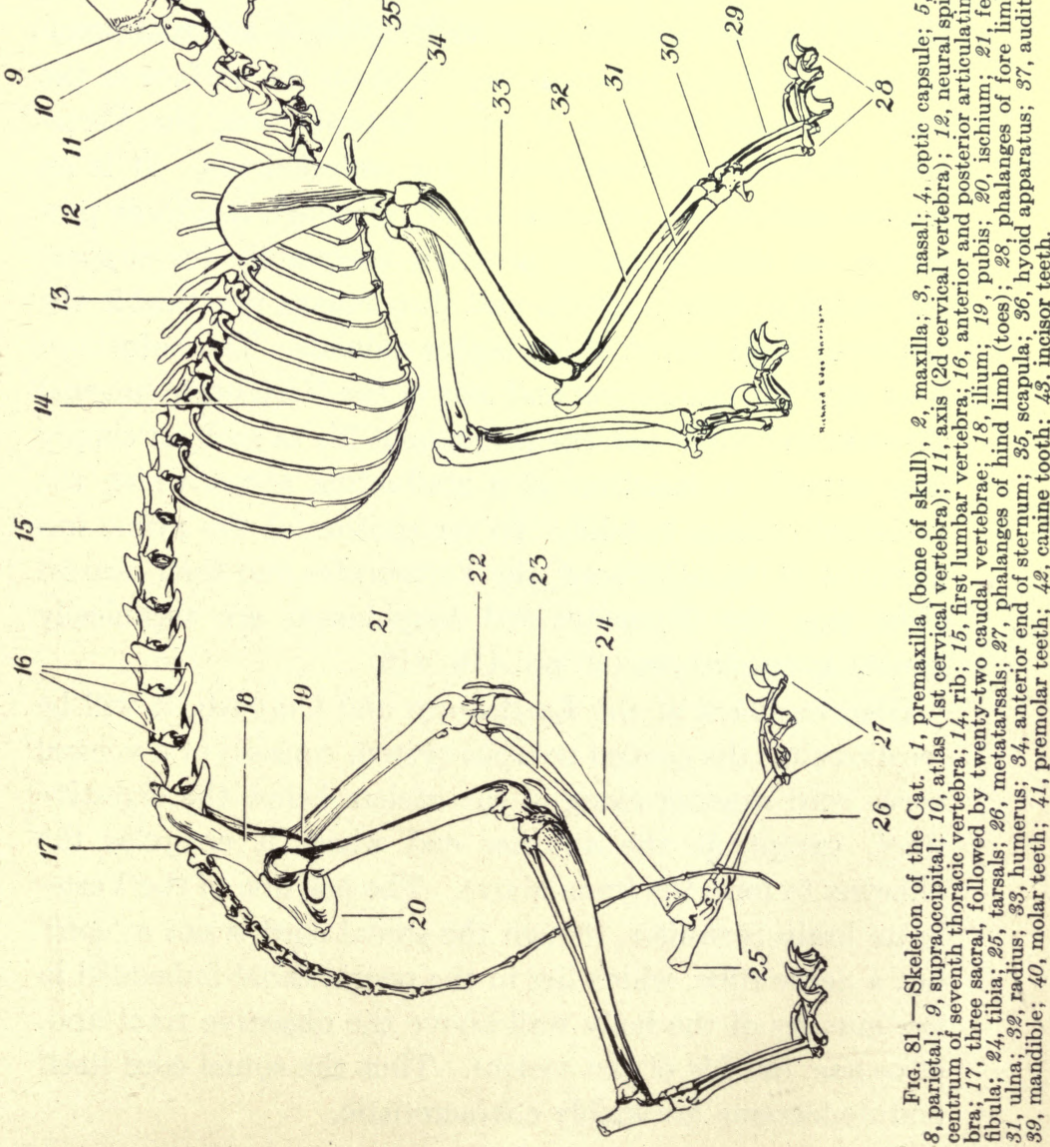


the axial skeleton by groups of bones which form respectively the PECTORAL and PELVIC GIRDLES.

(Figs. 80, 81, 185, 186.)

\section{F. Diagnostic Vertebrate Characters}

As a summary of this general outline of the structure of the Vertebrate body, we may emphasize three characters which are of prime diagnostic importance.

In the first place, whereas the skeletal structures of Invertebrates typically consist, as in the Crayfish, of an exoskeleton of hard non-living materials deposited on the surface of the body, the chief function of which is protection, the Vertebrate skeleton is primarily a living endoskeleton. It is an organic part of the organism which, although it affords protection for delicate parts, provides adequately for support and supplies muscle levers, and thus makes practicable the relatively large bodies of the higher animals. The notochord is at once the foundation and axis of the Vertebrate internal skeleton and either persists throughout life as such, or simply long enough to function as a scaffolding about which the vertebral column is built. In recognition of the prime importance of the notochord, the Vertebrates and their nearest allies (e.g., the Tunicates and Amphioxus) are technically known as cHordates (cf. pp. 415, 416)..

Glancing back at the Earthworm and Crayfish, it will be recalled that the central nervous system consists of a ventral nerve cord running along in the coelom below the digestive tract, except at the anterior end where it encircles the pharynx to form the brain above. The position of the Vertebrate brain is similar, though the spinal cord is not a 'cord' but a nerve tube, which lies in the neural canal imbedded in the muscles of the body wall above the digestive tract and, of course, outside of the coelom. Thus the spinal cord itself and its location are highly characteristic. 
A third fundamental peculiarity is a series of perforations or slits through the throat and body wall. In the lower forms the gill slits provide an exit for the current of water entering by the mouth and, being richly supplied with blood, afford the chief means of respiratory interchange between the animal and the surrounding medium. In the higher Vertebrates the gill slits are present merely during a transient phase in the development of the individual since the function of aerating the blood is taken over by the lungs. (Figs. 74, 75.) 


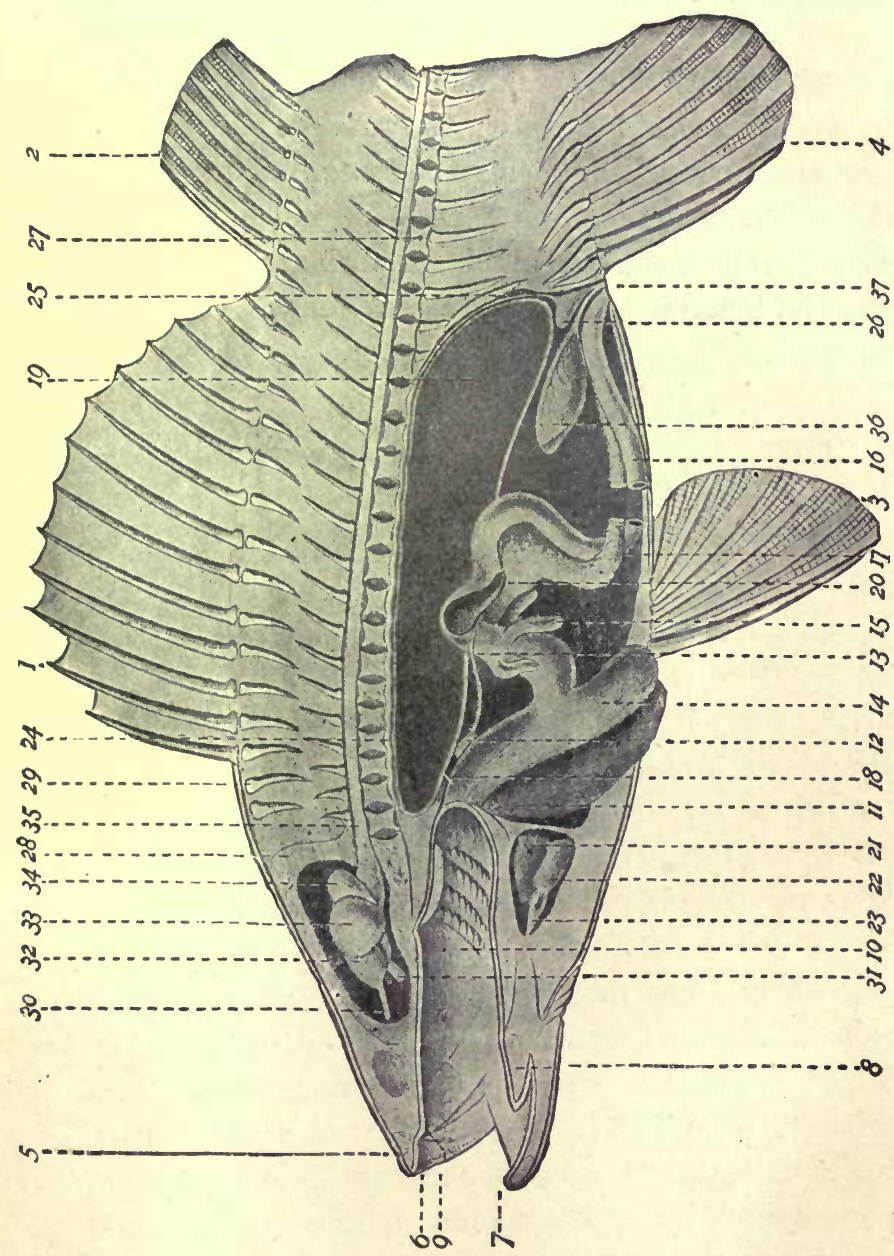

0 ํํำ

㟧 范藏

음

10 ₹ 0 응

¿-

4

สี

พ .क का

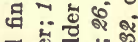
预 总 ญ. 긍

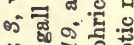
उ शं

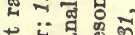
屯 จ $=$ ह

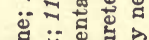

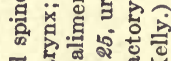
겸 궁ㅎํ ठ 을

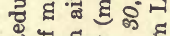
때 행 $\overrightarrow{0} \ddot{8}$ के

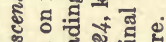
ङ

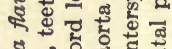

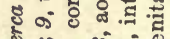
औ 영 유유. म $\infty$ हू है क

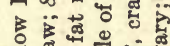
न

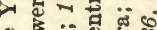

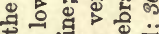

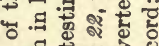

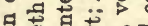

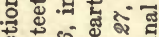
¿゙ษ

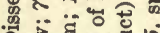

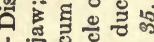
। 希 क

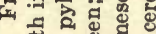
क्षे क्व के के 


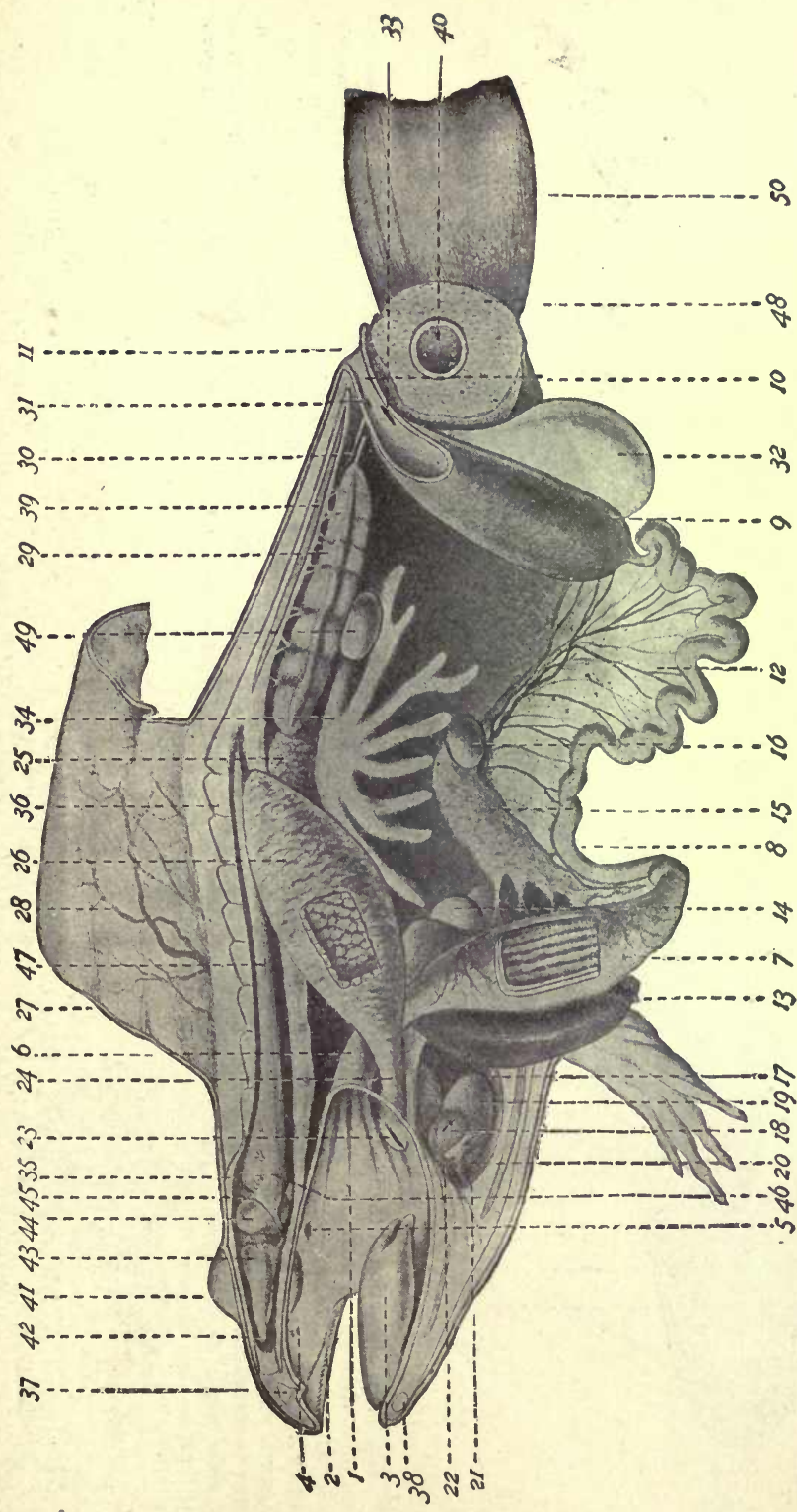

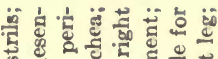
ถั वर्त की สี

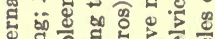

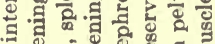
₹ 혬

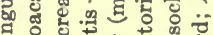
유율 क స 10 के खึं

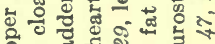
ณ 0 औ

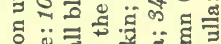
들

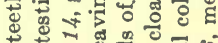
จ.

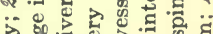

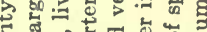

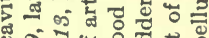

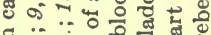

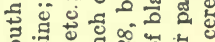
घั के

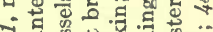

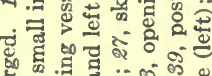
范 जี कि 药

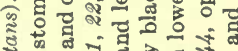

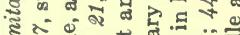

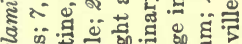
उั

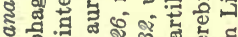
ट 융 की के गु हू

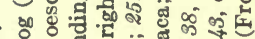
离 0 品 8

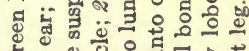
(5) द

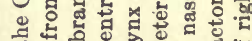

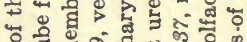
ङ व 영 ปึّ ग 일 คैं 红苾 ฌ $\infty$ ๖ 융 请 ०ू 


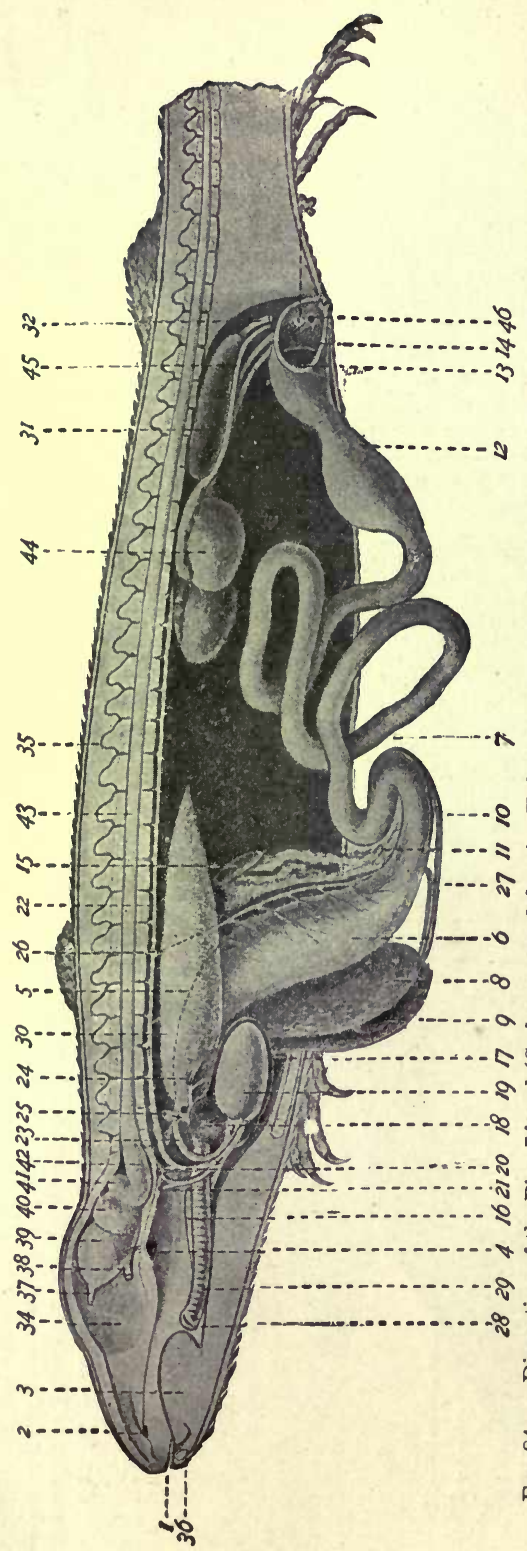

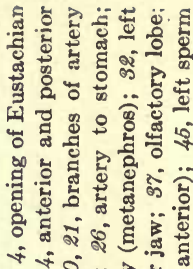

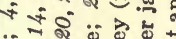

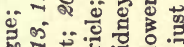
언

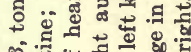
के क्षें के :

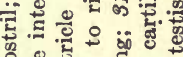
政 ง 군 ज्ञ. की के จ ङ

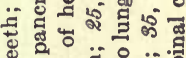
$\Phi \div$ 글 ชं

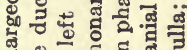

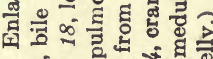
ऽ है है के की ङ उँ क्ष

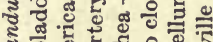
ङ

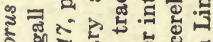
के

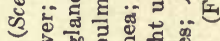

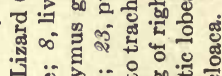

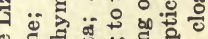
을

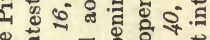

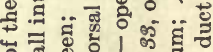
영 咅 政 . . 1 s. 의

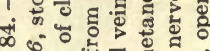
D.

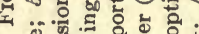

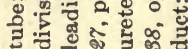




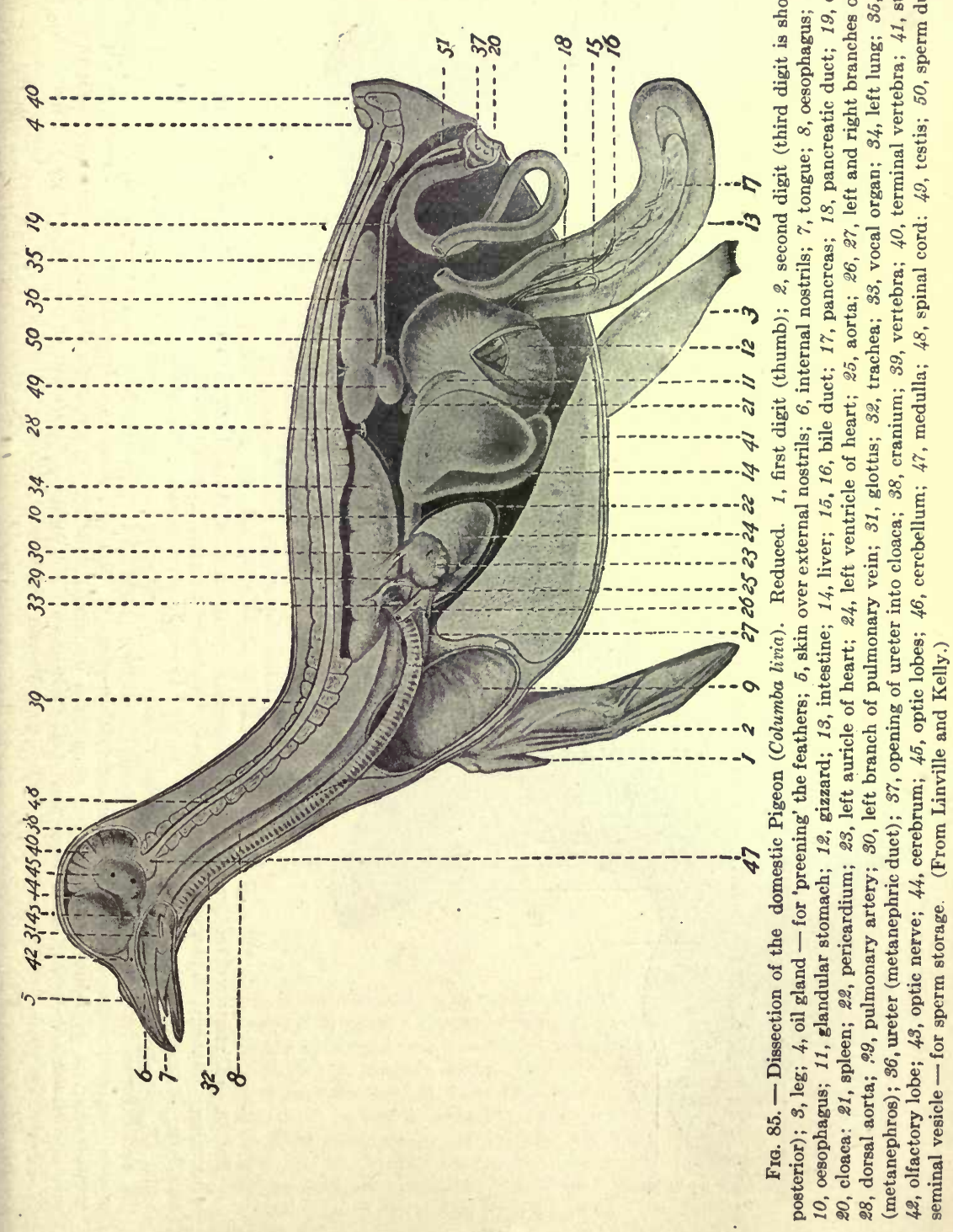




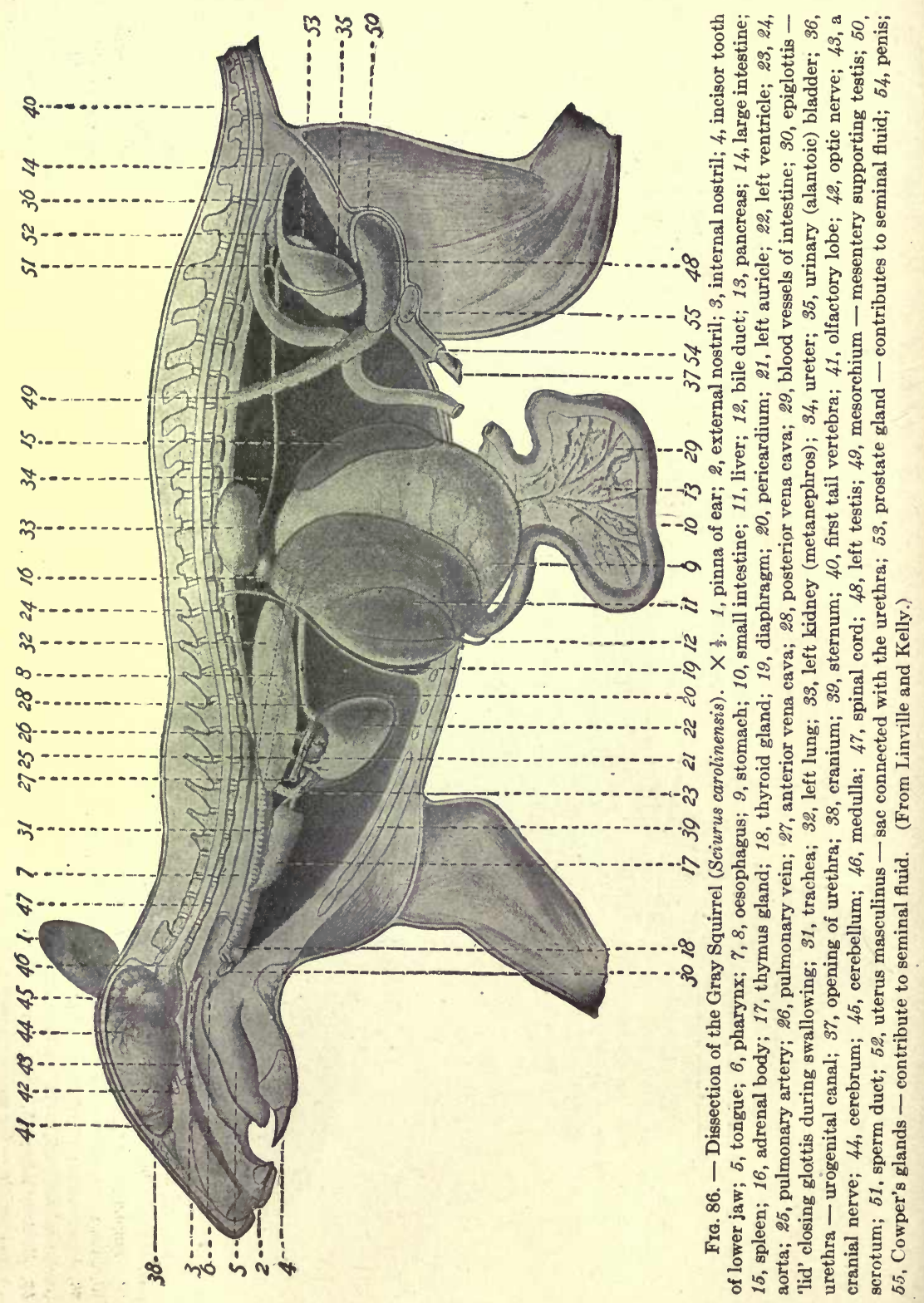




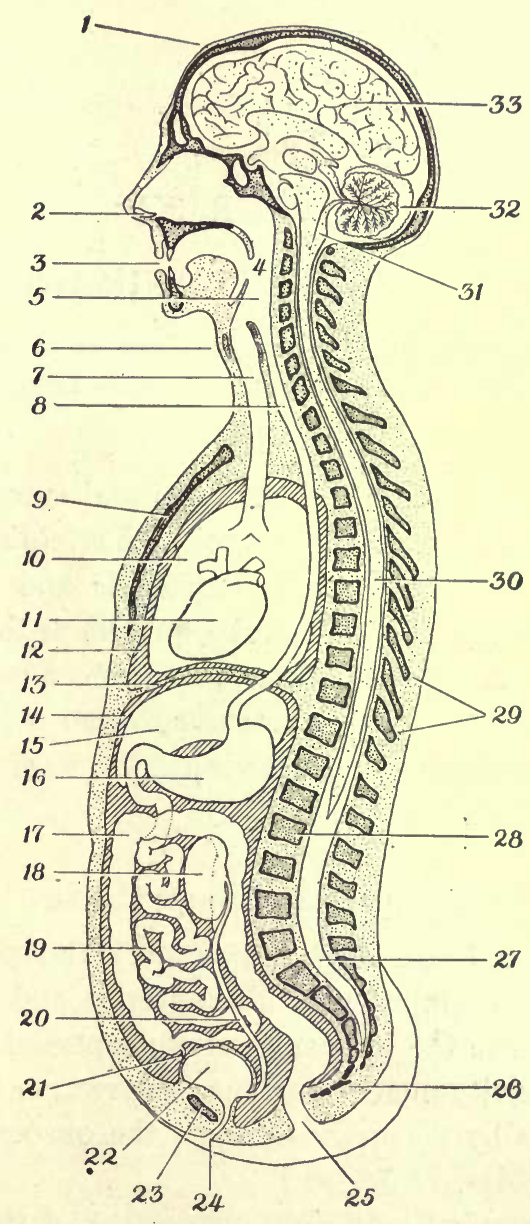

Frg. 87. - Diagrammatic median section of the human body. 1, cranium; 2, nostrils (external nares); 3 , mouth; 4, internal nostrils; 5 , pharynx; 6 , 'Adam's apple'; 7 , trachea (to lungs); 8 , oesophagus; 9 , sternum (breast bone) imbedded in body wall; 10 , lungs; 11 , heart; 12, thoracic cavity (part of coelom); 13 , diaphragm; 14, abdominal cavity (part of coelom); 15 , liver; 16 , stomach; 17 , large intestine; 18 , kidney; 19 , small intestine; 20 , ureter; 21 , vermiform appendix of large intestine; 22 , urinary bladder; 23 , pubis of pelvic girdle; 24, urethra; 25 , anus; 26 , coccyx; 27, posterior part of neural canal; 28 , centrum of vertebra; 29 , neural spines of vertebrae; 30 , spinal cord; 31 , medulla; 32 , cerebellum; 38 , cerebral hemisphere. 


\section{CHAPTER XI \\ NUTRITION IN ANIMALS}

The living body is the theatre of many chemical and physical operations in line with those of the inorganic domain.

- Thomson.

We have now considered the form and supporting structures of the body wall of a typical Vertebrate; in other words, the outer tube which surrounds and contains the viscera. Through this outer tube, just as in the case of the Earthworm and Crayfish, there runs from mouth to anus a second or inner tube, the alimentary canal, which has been mentioned incidentally in describing the various regions of the Vertebrate body.

\section{A. The Alimentary Canal}

The entrance to the alimentary canal is the mouth, a transverse ventral aperture near the anterior end of the head, which leads into the BUCCAL CAVITY supported by the jaws. The buccal cavity merges into the PHARYNX, or throat, which in turn leads by a narrow passage, the onsophagus, to the STOMACH. (Figs. 74, 82-88.)

In the aquatic Vertebrates the region of the alimentary canal from the mouth to the oesophagus acts as a common food and respiratory passage. The food passes on through the oesophagus to the stomach, while the water makes its exit by a series of perforations, or gill slits, through the pharynx and body wall directly to the exterior. During this passage the respiratory interchange of gases takes place. Among the 
air-breathing Vertebrates the gill slits persist merely as transient embryonic reminders of evolutionary history, their

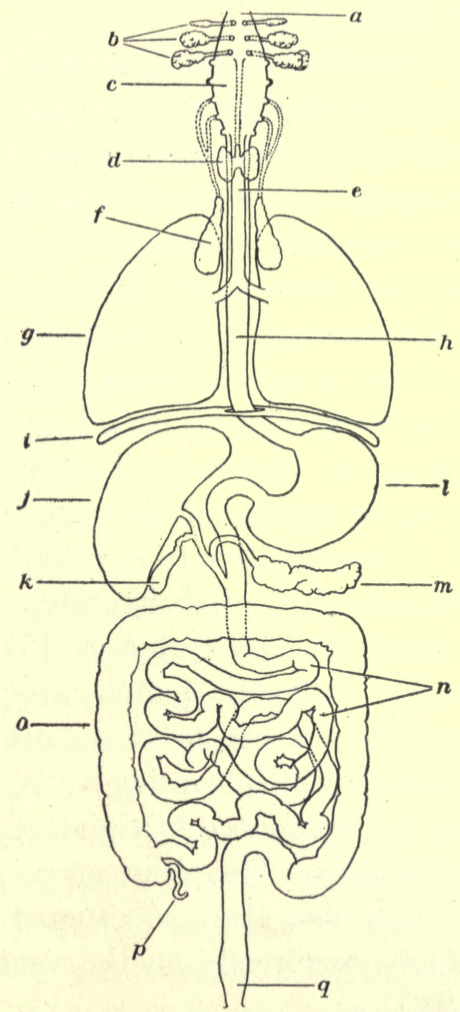

Fig. 88. - Diagram of the alimentary canal and its derivatives in Man. $a$, mouth; $b$, salivary glands; $c$, pharynx, showing the embryonic position of five pairs of gill pouches, the second pair probably giving rise to the tonsils, and the third and fourth to the thymus glands; $d$, thyroid gland; $e$, trachea; $f$, thymus gland; $g$, lungs; $h$, oesophagus; $i$, diaphragm - the muscular partition between the thorax and abdomen; $j$, liver; $k$, gall bladder; $l$, stomach; $m$, pancreas; $n$, small intestine; $o$, large intestine; $p$, vermiform appendix; $q$, rectum leading to exterior by the anus.

function being taken over by an outpocketing of the ventral wall of the pharynx into the body cavity, which forms the Lungs. Thus, even in Man, the respiratory membrane which 
lines the lungs is, from the standpoint of development, a specialized part of the epithelium of the alimentary canal. (Fig. 94.)

The stomach is the first stopping place of food which has been swallowed and where the work of the digestive tract (alimentary canal) essentially begins by the dissolving action of chemical substances (enzymes) secreted by its walls. The stomach leads by a constriction (PYLORIC VALVE) into a long and usually convoluted INTESTINE. The anterior portion of this is known as the SMALL INTESTINE, and it is here that the major part of digestion is accomplished directly or indirectly by means of chemical secretions supplied by its walls and by the PANCREAS and LIVER. In the small intestine ABSORPTION also begins; that is, the passage of the soluble food materials through the wall of the digestive tract into the body proper. The soluble proteins and carbohydrates are taken up directly by the blood vascular system and conveyed to the liver, while the fats enter the lymph vessels which later deliver it to the blood. A constriction marks the origin of the LARGE INTESTINE which continues the absorption of water and carries the undigested material, or FAECES, to the exterior through the anus. This either opens into a terminal sac, the CLOACA, in which also are situated the orifices of the urogenital ducts, or directly on the ventral surface, as in Man. (Fig. 93.)

The wall of the alimentary canal consists of three chief cellular layers: a lining epithelium, a connective tissue layer, and a muscular layer. The epithelium, however, together with its derivatives is the digestive tract proper in the sense that it is of prime functional importance; the other layers performing accessory functions such as support, conduction of blood vessels, and movements of the canal. (Figs. 20, 103.) 


\section{B. Digestion}

Among the single-celled animals such as Paramecium, digestion is reduced to its simplest terms. The food material enters the cell and is acted upon directly by substances formed by the protoplasm (endoplasm) in its vicinity. In Hydra a special layer of cells, the endoderm, is largely devoted to digestion. Although some of the endoderm cells actually engulf small particles of food and digest them within the cell (INTRACELlULAR Digestion), the major part of digestion is brought about within the enteric cavity by secretions from the endoderm cells. Digestion of the latter type (INTERCELLULAR) is characteristic of all higher animals and reaches its full development in the Vertebrates.

The alimentary canal is essentially a tubular chemical laboratory which passes the food on by its own muscular activity, known as PERISTALTIC CONTRACTIONs, from one compartment to another. Each of these compartments, in turn, supplies the chemical reagents which it uses for changing the food into a soluble form so that it can pass through the walls to be taken up by the circulatory system and finally distributed to the cells of the organism as a whole. The complex food materials which enter the human mouth run the gauntlet of a whole series of digestive fluids. The salivary glands in the mouth secrete an enzyme which chemically modifies the starches; the gastric glands of the stomach supply the gastric juice containing enzymes which act on proteins, and free hydrochloric acid which renders the stomach contents acid in reaction; while glands in the intestinal walls, and the pancreas collectively supply other enzymes which act on proteins, carbohydrates, and fats in a medium made alkaline chiefly by certain substances from the liver.

Turning now to the origin of the chemicals which bring 


\begin{tabular}{|c|c|c|c|c|c|}
\hline Location & Secretion & ENZYMES & $\begin{array}{l}\text { Substances } \\
\text { Changed }\end{array}$ & $\begin{array}{c}\text { INTER- } \\
\text { MEDIATE } \\
\text { PRODUCTS }\end{array}$ & $\begin{array}{c}\text { ProduCts } \\
\text { READY FOR } \\
\text { ABsoRPtion }\end{array}$ \\
\hline Mouth & Saliva & Ptyalin & Starch & Maltose & \\
\hline Stomach & $\begin{array}{r}\text { Gastric } \\
\text { juice }\end{array}$ & Pepsin & Protein & $\begin{array}{l}\text { Proteoses } \\
\text { and Pep- } \\
\text { tones }\end{array}$ & \\
\hline \multirow[t]{5}{*}{$\begin{array}{l}\text { Small } \\
\text { intestine }\end{array}$} & \multirow[t]{3}{*}{$\begin{array}{l}\text { Pancreatic } \\
\text { juice }\end{array}$} & Amylopsin & Starch & \multirow[t]{5}{*}{ Maltose } & \\
\hline & & Lipase & Fats & & $\begin{array}{c}\text { Fatty acid } \\
\text { and } \\
\text { Glycerine }\end{array}$ \\
\hline & & Trypsin & Proteins & & $\begin{array}{l}\text { Amino } \\
\text { acids }\end{array}$ \\
\hline & \multirow[t]{2}{*}{$\begin{array}{l}\text { Intestinal } \\
\text { juice }\end{array}$} & $\begin{array}{l}\text { Maltase } \\
\text { Sucrase } \\
\text { Lactase }\end{array}$ & $\begin{array}{l}\text { Maltose } \\
\text { Cane sugar } \\
\text { Milk sugar }\end{array}$ & & $\begin{array}{l}\text { Simple } \\
\text { sugars }\end{array}$ \\
\hline & & Erepsin & $\begin{array}{l}\text { Proteoses } \\
\text { and Pep- } \\
\text { tones }\end{array}$ & & $\begin{array}{l}\text { Amino } \\
\text { acids }\end{array}$ \\
\hline
\end{tabular}

FIg. 89. - Chemical activities of the human digestive tract.

about the solution of the food materials. Every cell of the body receives from the circulatory system the materials necessary for its own life, but some cells take in addition substances which they do not need and, after transforming them chemically, contribute the product as a SECRETION for the good of the whole organism. Such cells may act more or less independently as UNICELLULAR GLANDS, but generally, for economy of space and adequate blood supply, many cells are grouped together to form MULTICELLULAR GLANDS. This is usually brought about by sinking the glandular area below the level of the membrane to which it really belongs. Such is the origin of complex glands as the liver and pancreas, which are outpocketings of the wall of the digestive tract; the sole remaining connection in each case being a narrow tube, or DUCT, which delivers the products of the glands to the intestine. (Fig. 90.) 
Other glandular derivatives of the digestive tract in Man are the SALIVARY glands of the mouth, the THYRoID and THYMUs glands near the anterior end of the oesophagus, and the GASTRIC and INTESTINAL glands imbedded in the wall of the stomach and intestine respectively. As a matter of fact

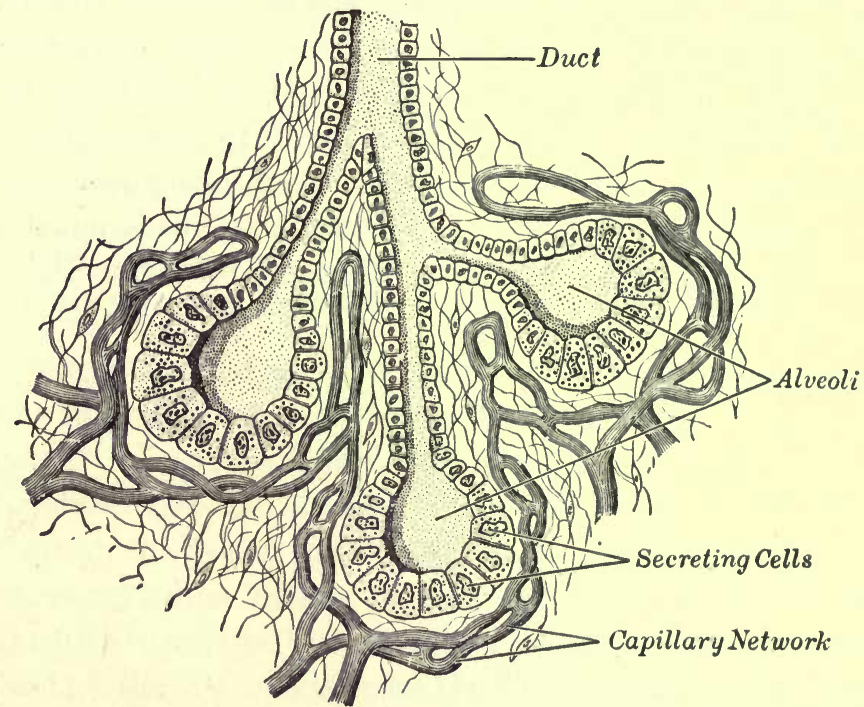

FrG. 90. - Diagram of a gland, in section, together with the surrounding connective tissue and blood vessels. Highly magnified. (From Hough and Sedgwick.)

the thymus degenerates, while the thyroid loses all connection with the alimentary canal and contributes its products directly to the blood. Accordingly the thyroid as well as a number of other similar glands, are known as DUCTLESS, or ENDOCRINE, glands, and their products as INTERNAL SECRETIONS. (Fig. 88.)

At first glance the complicated digestive system of the Vertebrate may seem to have little in common with that of the Earthworm, but as a matter of fact the fundamental plan is the same. The differences which are present are the result of an increase of the working area of the alimentary 
canal, not only to afford greater secretive and absorptive surface and a larger variety and amount of digestive substances, but also to prolong the length of time the food is subjected to treatment. This increase in area has been effected by folds and elevations of the inner surface of the tract; by outpushings of limited areas of the tube to form large glands which in most cases contribute their products to their point of origin through ducts; and by increasing the length of the inner tube as compared with the outer tube, or body wall, which results in throwing the intestine into various convolutions within the body cavity. Thus is met the increasingly complex nutritional demands of more highly organized animals. 


\section{CHAPTER XII}

\section{CIRCULATION AND RESPIRATION IN ANIMALS}

I finally saw that the blood, forced by the action of the left ventricle into the arteries, was distributed to the body at large, and its several parts, in the same manner as it is sent through the lungs, impelled by the right ventricle into the pulmonary artery, and that it then passed through the veins and along the vena cava, and so round to the left ventricle . . . which motion we may be allowed to call circular. - Harvey, 1628 .

THE crucial points of contact between the higher animal and its' environment, in so far as the intake of matter and energy is concerned, are the membranes which line the digestive tract and a large diverticulum from it, the lungs. Through the former must pass all the materials which are to be assembled as integral parts of the organism and the fuel which is to supply the energy for the vital processes, while through the latter must pass the oxygen which is to release this energy. Only when these membranes have been passed are the materials really within the body and at its disposal for distribution by the CIRCULATORY SYSTEM to the individual cells of the various organs which are to use them. In addition to carrying the fuel and the oxygen, the circulatory system must remove the waste products of metabolism from the cells and deliver them to the proper excretory organs, such as the lungs or kidneys, to be passed to the outside world. The circulatory system is therefore the essential connecting link between the points of intake, utilization, and outgo of materials - a distributing system which in coöperation with the nervous system unifies the organs into an organism. 


\section{A. Circulation in the Lower Vertebrates}

In the higher plants the movement of water and food in solution through the conducting systems is effected chiefly by physical forces which are, to a certain extent, independent of, though directed by, the activity of the plant cells. In the higher animals, on the other hand, circulation is brought about by an active system which forces as well as conducts throughout the body what is to all intents and purposes a fluid tissue.

Many stages in the evolution of this elaborate circulatory system can be traced from the lowest coelomate Invertebrates - in which it consists merely of a single cavity or several connected cavities filled with a fluid containing various types of cells - through forms in which more and more of the spaces are replaced by definite tubes for the conduction of the fluid. With the establishment of closed vessels, the contractions of various organs and the movements of the body as a whole can no longer be entirely depended on for the movement of the fluid, and accordingly, in certain regions, a muscular layer is developed in the walls of the tubes, which by rhythmic pulsation forces the fluid along. Thus, for exampie, in the Earthworm there is a fluid (coelomic fluid) within the body cavity which is forced about by the movements of the worm and bathes most of the internal organs; and also a system of vessels, a part of which contracts rhythmically and distributes the blood to the individual cells. (Figs. 66, 67.)

In the higher forms a closed vascular system gradually takes the ascendency and becomes what one ordinarily has in mind when speaking of 'the circulatory system,' but the primitive type of open system still functions as an auxiliary of no mean importance even in Man. The highly developed Vertebrate circulatory system, therefore, really consists of two parts. 
First, a closed system of vessels containing BLOOD. Blood is a lifeless liquid PLASMA in which float detached cells, the red and the white blood corpuscles. Second, a series of spaces, channels, and vessels, closely associated with the blood vascular system, which is filled with LYMPH. Lymph consists of some of the liquid plasma of the blood, with some white corpuscles, which has passed through the thin walls of the smallest blood vessels and bathes the individual tissue cells. The lymphatic system really acts as an intermediary between the blood and the tissues. It supplies the milieu of the cells, and finally returns the materials again to the blood vascular system.

The essential elements of the blood vascular system are first, a muscular organ for propulsion of the blood, the HEART, which lies, as has been mentioned, near the mid-ventral line in the anterior part of the coelom; and second, tubes which convey the blood to the heart, the verns, and away from the heart, the ARTERIES. The arteries divide and subdivide to form smaller and smaller vessels (ARTERIOLES) which finally merge into exceedingly delicate tubes (CAPILLARIES) that permeate the tissues of the body. The capillaries, in turn, deliver the blood to VEINLETs which pass it on through larger and larger veins to the heart. Consequently the blood flows in a circle from heart to heart again, through a closed system of vessels. (Figs. 91, 92.)

The heart represents that part of the vascular system in which the power of rhythmic contraction has concentrated, and can be regarded as a blood vessel whose walls have become highly modified by an excessive development of the muscular layer. In the lowest Vertebrates and in embryonic stages of higher forms the heart consists typically of two chief chambers, an AURICLE and a VENTRICLE, fitted with muscular flaps, or VALves, which allow the blood 


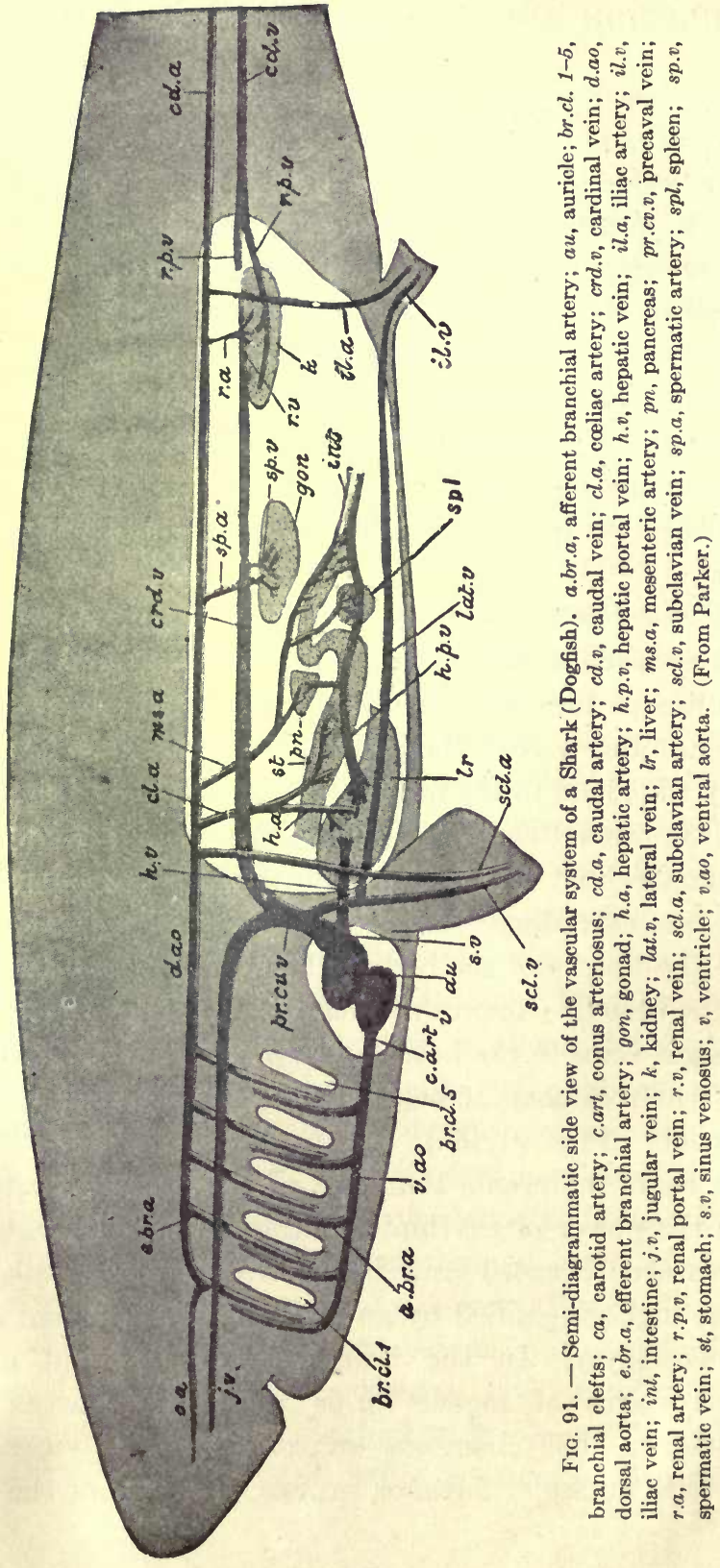




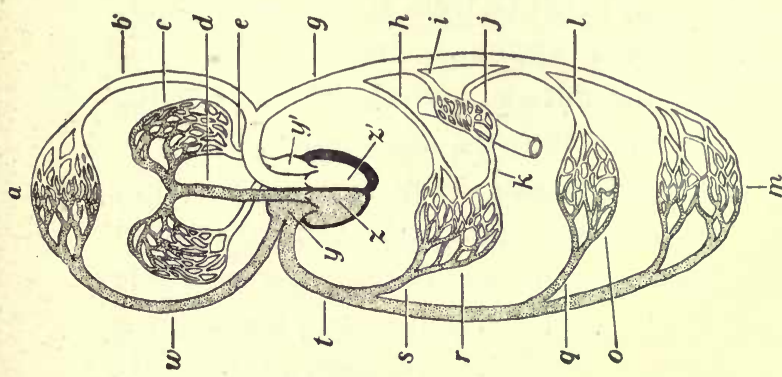

ठึ.

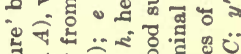

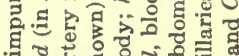

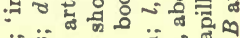
ט

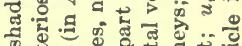

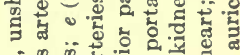

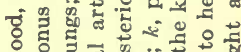
응 응. 원뎡

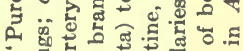
- 3 至

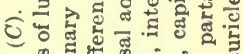

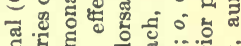

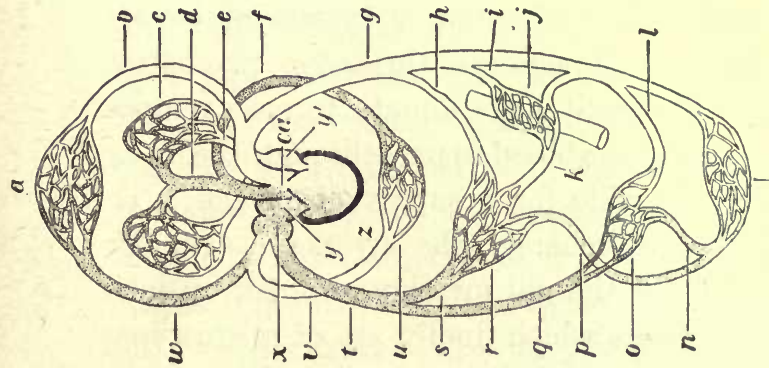
हू.

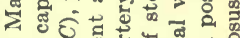
马ن ن ๘ี จํ. 1 5 क क

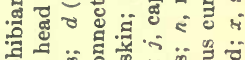

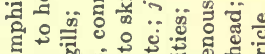
यक ड़ ( 要

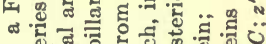

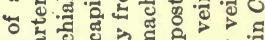

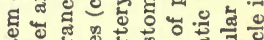

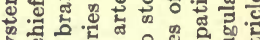

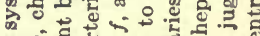

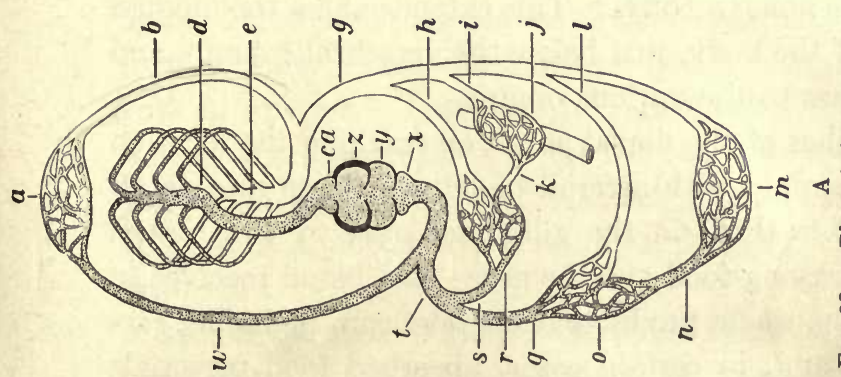

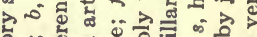

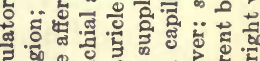
50 แํำ ‡.

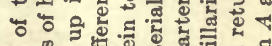
สี कि

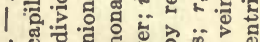
ช่

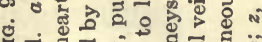

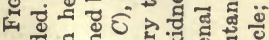

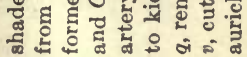


to flow in one direction only; that is, from auricle to ventricle. An enlargement, the sinus venosus, connects the veins (VEnous SYSTEM) with the auricle, and there is frequently another, called the cONUS ARTERIOSUs, in a similar position at the arterial end. The heart is thus essentially a linear series of chambers. The sinus venosus and auricle function mainly as reservoirs to fill rapidly the especially muscular ventricle. The latter, acting both as a suction and force pump, passes the blood on to the conus arteriosus and from there to the ARTERIAL SYSTEM as a whole. For our purposes, however, we may consider the heart in the lowest Vertebrates (Fishes) as composed of the two chambers, auricle and ventricle. (Fig.91.)

The arterial system is the distributing system of vessels which carries the blood to all regions of the body. Soon after its origin at the heart the circuit in the aquatic forms is temporarily interrupted to allow the blood to pass through the GILLS and exchange carbon dioxide for a supply of oxygen. < To facilitate this gaseous interchange, the arteries (AFFERENT BRANCHIAL) as they enter the gill membrane break up into smaller and smaller vessels which finally are of microscopic calibre and consist of but a single layer of cells. These capillaries, in turn, merge into larger vessels (EFFERENT BRANCHIAL ARTERIES) which finally lead into the chief artery of the body, the DORSAL AORTA. This extends along the median dorsal line of the body, just below the vertebral column, and sends branches to the various organs.

The branches of the dorsal aorta, on reaching the location which they supply with arterial blood, break up into capillaries similar to those in the gills, and pass to the tissues the blood carrying food and oxygen. The blood receives in return various waste products of metabolism, including carbon dioxide and, in certain cases, absorbed food materials from the intestine, and special secretions chiefly from ductless 
glands. The fine capillaries lead into veinlets and these into veins of constantly increasing calibre which sooner or later complete the circuit by returning the blood to the heart.

The return current, however, is not quite so simple as would appear from the above statement because, just as all the outgoing stream is interrupted for the respiratory interchange in the gills, so a part of the return current is temporarily side-tracked through the liver. The veins returning blood from the digestive organs merge to form the PORTAL VEIN which proceeds to the liver, where it resolves into capillaries to allow that organ to regulate certain of the blood constituents - in particular, to store up sugar after a meal and later dole it out to the blood as needed. These capillaries then pass the blood into the HEPATIC VEIN, which conveys it toward the heart. Thus the liver receives blood from two sources: an artery providing blood primarily for the use of the organ itself and a vein (portal vein) delivering blood containing a large amount of food material solely to receive special treatment before being sent back to the heart and then all over the body. This special arrangement for a venous blood supply to the liver is known as the HEPATIC PORTAL system. Moreover, in Vertebrates lower than the Birds, the venous blood from the posterior part of the body makes a detour through the capillaries in the kidneys on its way back to the heart. This constitutes what is termed the RENAL PORTAL SYstem. Therefore in these forms the kidneys as well as the liver receive blood from two sources, an artery and a vein. It will be noted that both the hepatic portal vein and the renal portal vein arise in capillaries and terminate in capillaries. (Figs. 91-93.)

Such is the general plan of the blood vascular system of the lower Vertebrates. The modifications of this which occur in higher forms are related chiefly to changes in the respiratory 
mechanism necessitated by abandoning the aquatic for the terrestrial mode of life, with the consequent dependence on

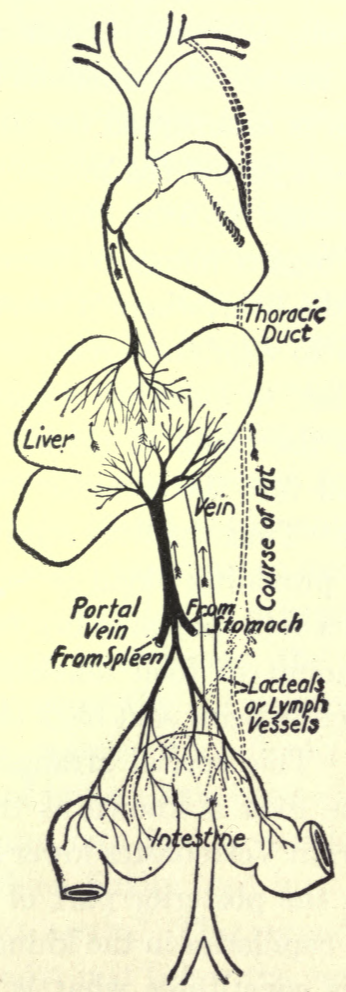

Fig. 93. - Diagram of paths of absorbed food from the digestive tract. Proteins and carbohydrates by: veins (in solid black); Fats by lymphatics (dotted). (From Conn and Budington.)

the free oxygen of the atmosphere instead of that dissolved in the water.

\section{B. Respiration}

As we have seen, the essential factor of respiration is an interchange of gases between protoplasm and the environ- 
ment: an intake of free oxygen for combustion, and an outgo of the waste products, chiefly carbon dioxide. In the unicellular organisms, such as Sphaerella and Paramecium, and in simple multicellular animals like Hydra, this appears to be a relatively simple process since an elaborate mechanism is not necessary to facilitate the interchange. But with the establishment of a highly differentiated multicellular body, fewer and fewer cells are in direct contact with the aerating medium and so various provisions are necessary to transfer the gases to and from the outer world and the individual cells themselves. In all forms the skin functions to some extent; in the Earthworm, in fact, it acts as the chief respiratory membrane since a profuse supply of blood vessels to the moist surface of the body effects a sufficiently rapid gaseous interchange for the relatively inactive life of the organism. The Crayfish meets the problem of respiration by finger-form out-pocketings of the body wall, the gills: a method of bathing a large area of the respiratory membrane in the respiratory medium, the surrounding water. The Insects, on the other hand, instead of bringing the blood to the surface, develop a network of tubes which ramify throughout the body and conduct the air directly to the various tissues. Among the lower Vertebrates, as has been indicated, the anterior end of the digestive tract functions as a common food and respiratory passage. In Fishes, the respiratory water current which enters the mouth makes its exit by way of the gill pouches and gill slits; the lining of the pouches - outpocketings of the lining of the alimentary canal - functioning as the respiratory membrane. (Fig. 94.)

Among the air-breathing Vertebrates there are the added problems of protecting and keeping moist the greatly increased respiratory surface which their active metabolism demands. Accordingly the gill pouches are replaced by a 
huge outpocketing from the alimentary canal into the anterior portion of the coelom, which constitutes the lungs. This entails, in turn,.a complex respiratory mechanism so that the air within the lungs may be changed at frequent
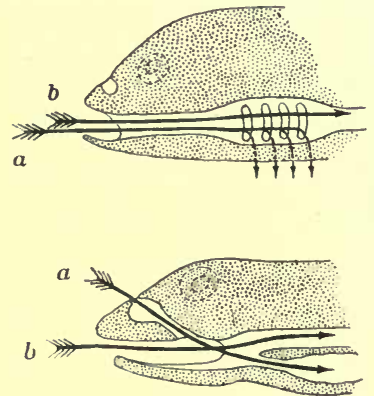

FIG. 94-Diagram of a vertical section through the head region of Fish (above) and Reptile or Bird (below) to show the paths of the respiratory currents $(a)$ and food (b). See Fig. 87 . intervals. As a matter of fact one ordinarily thinks of the movements involved in the renewal of the air in lungs as respiration, but from what has been said it is clear that neither the respiratory movements involved in inhalation and exhalation, nor the interchange of gases between blood and air through the lung membrane is respiration proper. The essential feature of respiration takes place throughout the body when the blood trades its oxygen supply for carbon dioxide with the tissue cells. Thus respiration in the final analysis is the securing of energy from food.

\section{Circulation in the Higher Vertebrates}

But to return to the blood vascular system, which necessarily undergoes far-reaching modifications as a result of the substitution of lungs for gills. In the first place the series of paired branchial arteries, which formerly supplied the gills, no longer break up into capillaries, but instead lead directly into the dorsal aorta, and accordingly are termed AORTIC ARCHES. Thus Fishes bequeath, as it were, to higher forms a series of pairs of aortic arches which, though they are no longer of use in their former capacity, appear in the developmental stages. Some disappear at that time and others are modified and diverted to various uses in the adult. (Fig. 95.) 
For our purpose it is sufficient to emphasize that in Man's body one branchial arch continues to carry blood directly from the heart to the dorsal aorta, while parts of another deliver blood from the heart to the lungs and back again to

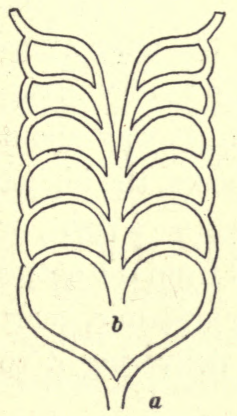

A

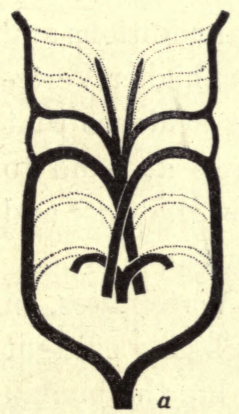

D

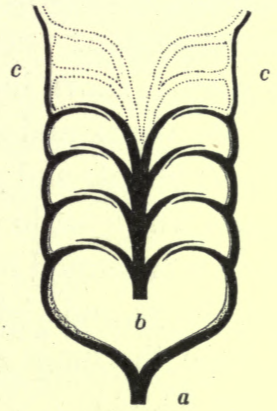

B

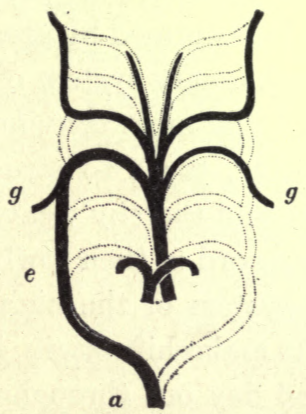

E

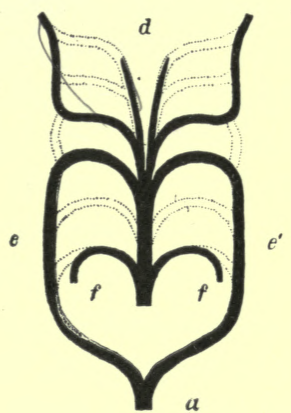

c)

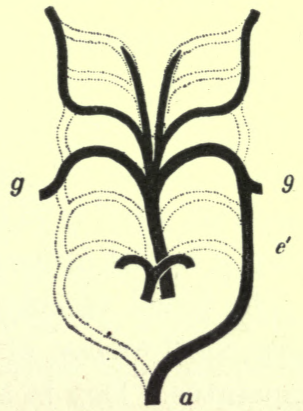

$\mathbf{F}$

Frg. 95. - Diagram to show the transformation of the six pairs of primitive gill slit arteries (aortic arches) in the ascending series of Vertebrates. $A$, primitive condition, embryonic; $B$, Fish; $C$, Amphibian (Frog); $D$, Reptile; $E$, Bird; $F$, Mammal. $a$, dorsal aorta; $b$, ventral artery from heart; $c$, internal carotids; $d$, external carotids; $e, e^{\prime}$, right and left aortic arches; $f$, pulmonary arteries; $g, g^{\prime}$, subclavian arteries to fore limbs.

the heart. Thus there is established a second current of blood through the heart, which necessitates a median partition in both the auricle and ventricle in order to keep the two currents separate. In this way a four-chambered heart arises 
which consists of right and left auricles and ventricles. The RIGHT AURICLE receives blood from the venous system of the body and passes it through the TRICUSPID VALVE into the right ventricle to be pumped through the PULMONARY ARTERY to the lungs. After traversing the capillaries of the lungs the blood is returned by the PULMONARY VEIN to the LEFT AURICLE, thence through the MITRAL VALVE into the LEFT VENTRICLE, which forces it into the AORTA and so on its way about the body as a whole. To all intents and purposes, the higher Vertebrates have two hearts which act in unison - a right, or pulmonary, heart receiving non-aerated blood from the entire body and pumping it to the lungs, and a left, or systemic, heart receiving aerated blood from the lungs and delivering it to the body as a whole. (Fig. 92, C.)

In this way the blood vessels of the primitive aquatic respiratory apparatus are transformed by gradual additions and subtractions into the pulmonary system of the higher Vertebrates, including Man - the most convincing evidence that nature, whenever possible, turns to structures at hand to construct what is to be, and thereby weaves in the woof and warp of higher forms a record of their lowly origin.

The blood vascular system of the higher Vertebrates, in spite, shall we say, of its makeshift origin, is a highly efficient apparatus. Day in and day out throughout life the human heart, beating rhythmically at an average rate of 70 times per minute, does about 175,000 foot-pounds of work. This power is expended in moving the weight of the blood, in imparting to it the velocity of its motion, and in raising the pressure in the aorta and pulmonary artery.

The RATE of flow is greatest when the blood leaves the heart and gradually diminishes until, in the capillaries of both the pulmonary and systemic systems, it is reduced to a minimum. On the return trip from the capillaries through the veins the 
rate of flow gradually increases though it reënters the heart at a slower rate than it departed. Thus of the 23 seconds which it takes a unit of blood to make the complete circuit in Man, about two seconds are spent in the capillaries - a relatively long time when it is realized that the average length of the capillary path is about one fiftieth of an inch. The principle underlying the change in rate is simple. The blood, driven throughout its course by the same force - the heart beat - varies in rate with the width of the bed through which it is flowing. Although the area afforded individually by the arteries and veins is greater than that by the single capillaries, nevertheless the total area afforded by the capillary system is enormously greater than that by either the arterial or venous system.

Moreover, since a liquid in a closed system of tubes must flow from a region of high to one of low pressure, the blood PRESSURE continuously diminishes from heart back to heart again. But, it should be noted, that although the pressure in the capillaries of any region as a whole is greater than in the veins which they supply, nevertheless the pressure in a single capillary is very low, as is demanded by its delicate wall.

Thus it is apparent that in the capillaries the blood moves very slowly under low pressure - for it is here that the blood does its work. All the rest of the vascular system - heart, arteries, and veins - is arranged to give the blood just this opportunity in the capillaries.

It is in the capillaries that the blood vascular system turns over the work of distribution to the lymphatic system. As has been said, lymph to all intents and purposes consists of plasma and white corpuscles from the blood which have passed through the thin capillary walls, carrying along food materials; oxygen, etc., to exchange for the various waste products of metabolism of the cells which it bathes. Thus 
there is a continuous drainage of lymph from the capillaries into intercellular lymph spaces. Some of the fluid, with waste products, etc., passes immediately into the capillaries again, but the excess passes from lymph spaces into small lymph vessels, and from these into large lymph vessels. The latter, in turn, empty into the venous system and so restore the materials to the blood. (Fig. 93.)

So much for the path and the duties of the liquid tissue which circulates through the body. But clearly some provision must exist for regulating the blood flow in order to meet the varying local demands of the organs of the body under different physiological conditions. This is attended to chiefly by nerve impulses which are conducted by a system of VAsoмотоR nerves and bring about the dilation or contraction of the smaller blood vessels (arterioles) leading to an organ, and thus increase or decrease the volume of the blood which it receives. The elaborate mechanism in homothermal animals, which maintains a practically constant body temperature, is largely dependent upon heat distribution, loss, and conservation by the blood vascular system. Since the total volume of blood in the body is practically constant, an extra supply to one part obviously necessitates a reduced supply to another. So it happens, for instance, that after a hearty meal more blood is concentrated where digestion is actively going on, leaving less for the other organs - the reduced supply to the brain resulting in the proverbial drowsiness at such times. 


\section{CHAPTER XIII \\ EXCRETION IN ANIMALS}

The mathematically accurate end-reaction of a chain of known and unknown causes and effects. - Noyes.

Provisions for eliminating from the organism the waste products of metabolism are only second in importance to those for supplying the matter and energy by which the vital processes are carried on. Accordingly we find the kidneys devoted solely to excretion; the gills or the lungs, largely to excretion; and the skin and liver acting in subsidiary capacities. In nearly every case the essential parts of the excretory organ are gland cells which select from the blood supply at their disposal one or another waste product. This material they secrete in more or less changed form so that it eventually leaves the body as an excretion. There is therefore an essential distinction between an EXCRETION, which represents chemical waste from the vital processes, and the major part of the material which is eliminated from the digestive tract as FAECES. The latter is almost entirely indigestible material taken in with the food which has not directly contributed to the metabolic processes of the organism. Accordingly the digestive tract is not included in the list of excretory organs, though as a matter of fact certain waste products excreted by the liver reach the outside world with the faeces.

We have already emphasized the elimination of carbon dioxide by the GILLS or the LUNGS. Here the cells of the RESPIRATORY MEMBRANES play essentially a passive rôle in excretion, since the carbon dioxide, which is under higher tension 
in the blood than in the water or air, follows the physical laws of diffusion of gases and passes from the blood. In addition to carbon dioxide, the blood of warm-blooded animals (Birds and Mammals) loses a large amount of water and heat; the amount depending on the temperature and moisture of the air which enters the lungs. When the air is exhaled its temperature is essentially that of the body and it is saturated with water vapor.

The skin in some of the lower Vertebrates, for instance the Frog, is an exceedingly important excretory organ, because more carbon dioxide is eliminated through the skin than through the lungs; but in higher forms, including Man, excretion by the skin is confined to the SwEAT GLANDS. These take from the blood, in addition to large quantities of water, traces of nitrogenous waste or urea, fatty acids, and salts, which form a residue on the surface of the skin when the PERSPIRATION evaporates. (Fig. 76.)

The LIVER, in addition to its various other functions, aids in no small way in excretion. On the one hand, the liver removes deleterious compounds of ammonia from the blood and transforms them into urea. Then it secretes the urea into the blood from which it is later removed by the kidneys. On the other hand, the liver collects other waste products etc., from the blood, which form the bile. This passes to the GaLL BLADDER for temporary storage or directly to the intestine.

The KIDNEYs are, in a way, the chief excretory organs of Vertebrates, and any serious interference with their activity rapidly leads to a poisoning of the body with its own waste products. Certain cells of the kidneys remove the urea from the blood stream which reaches them, while water and various solutes are drained from the blood. Aside from their functional importance, the kidneys are of considerable interest to the comparative anatomist because of their complicated 
evolutionary history - indeed the structure of the human kidneys is intelligible only in the light of the relatively simple excretory organs of Invertebrates, such as the Earthworm, and of lower Vertebrates. (Figs. 66, 67, 96.)

The chief excretory organs of the Earthworm consist of pairs of coiled tubes, or NEPHRIDIA, segmentally arranged in the coelom on either side of the alimentary canal. Each nephridium begins as an open funnel in the coelom of one segment, passes through the partition to the next posterior segment and there, after coiling, passes to the ventral surface and opens to the exterior by a pore. Thus, reduced to its simplest terms, a nephridium is a tube communicating between the coelom and the outer world, and affording a path of egress for the waste matter in the coelomic fluid. But the closed blood vascular system of the worm

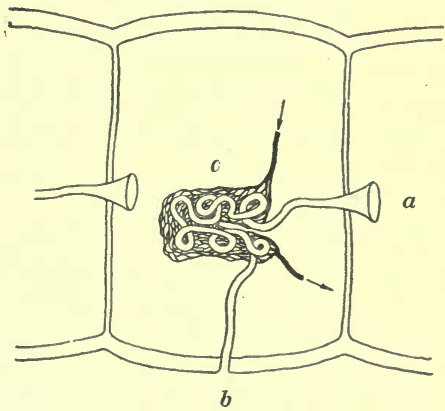

Fig. 96. - Diagram to show the general structural plan of a nephridium of an Earthworm, anterior end toward the right. $a$, internal opening of nephridium; $b$, external opening; $c$, capillary network about the coiled, glandular portion.

collects various waste products in addition to the carbon dioxide which it delivers to the skin. Nitrogenous waste, inorganic salts, etc., are carried to the coiled part of the nephridial tube where gland cells take them from the blood and deliver them to the interior of the tube to be passed out of the body. Now strange as it may seem, although the primitive segmentation of the coelom has disappeared in the Vertebrates, nevertheless there are good grounds for believing that the archaic, segmentally arranged nephridia have been taken over, as it were, and made the basis of the essential excretory elements of the kidneys. 
In the lowest Vertebrates the primitive type of kidney, or PRONEPHROS as it is called, consists of a series of segmentally arranged nephridia in the dorsal part of the anterior end of the coelom. These, however, instead of opening independently to the exterior, discharge their products into a common tube (PRONEPHRIC DUCT) which passes them to the outside. In higher forms the pronephros disappears, and its function is taken over by another series of nephridia which appear in the coelom posterior to the pronephros. This series constitutes the MEsonephros, and opens into the pronephric duct which accordingly now is called the Mesonephric DUCT. Finally, in still higher Vertebrates this second urinary organ is replaced by a third, the kidney proper (METANEPHROs) and its special duct, the URETER. Thus as we ascend the Vertebrate series three distinct kidney systems appear, in each case by the development and grouping of a number of nephridia into a definitive organ. In this process the primitive communication of the individual nephridia with the body cavity is lost and the activity of the glandular portion increased, until, in the higher forms, all the waste products are taken solely and directly from the blood.

(Fig. 97.)

It is therefore apparent that each of the relatively large, compact kidneys of the higher Vertebrates, including Man, is to all intents and purposes a large group of nephridia-like elements, the tubules, bound together by connective tissue and covered with a protective coat. The tubules within the kidney deliver the materials taken from the blood to the pelvis of the kidney, from which it passes down the ureter and on to the URINARY BLADDER and finally to the exterior. (Fig. 98.)

Such, in broad outline, is the historical viewpoint from which the kidneys of Man must be interpreted. As a matter of fact, however, the evolutionary transformation is still 


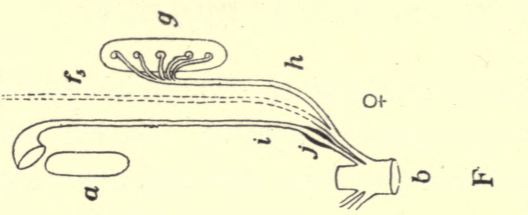

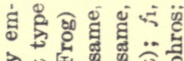

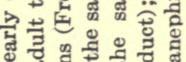

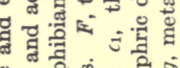

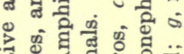

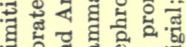

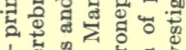

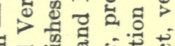

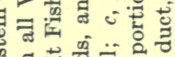

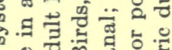
요 क्ष 5.

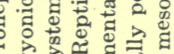
要 व द्व

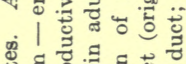
的

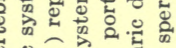
. 둥

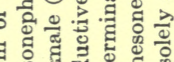
घू

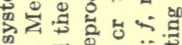

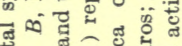

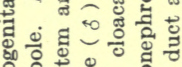

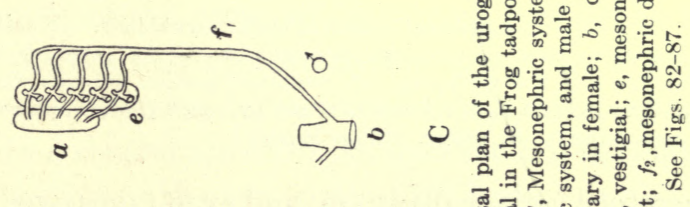

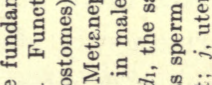
o

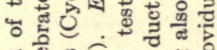
再 8 政 음 1.950 o क

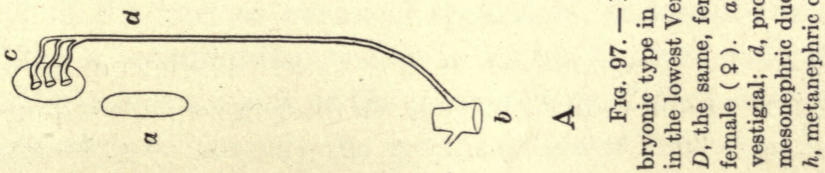


further complicated by anatomical, though not physiological, relations with the reproductive system. As will be pointed out later, this neighboring system now and again foists, as it were, some of its accessory responsibilities upon parts of the

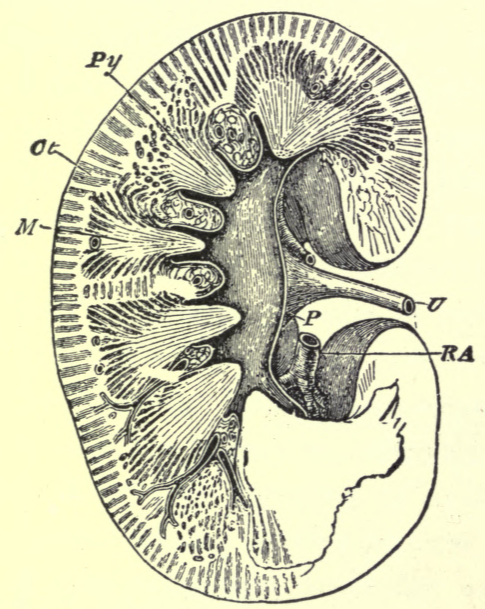

Fig. 98. - Longitudinal section of the human kidney. $C t$, cortex, or region in which the essential nephridial elements, the tubules, come into functional association with the capillaries; $M$, medullary portion, through which the tubules extend to open on the summits of the pyramids $(P y) ; P$, pelvis of kidney; $R a$, renal artery; $U$, ureter. (After Huxley.)

excretory (urinary) system, and even takes over portions and makes them integral parts of its own when they have been permanently abandoned by the urinary system in its evolutionary development. 


\section{CHAPTER XIV \\ COÖRDINATION IN ANIMALS}

It seems that Nature, after elaborating mechanisms to meet particular vicissitudes, has lumped all other vicissitudes into one and made a means of meeting them all. - Mathews.

SINCE a primary attribute of protoplasm is irritability the power of responding to environmental changes by changes in the equilibrium of its own matter and energy - it is not strange that the cells of an organism mutually modify each other's activities and reciprocal interrelationships have been established during their long evolutionary history. The various cells, tissues, organs, and organ systems are unified into an organism by what may be called the chemical interplay between its various parts, which is made possible by the facilities for distribution afforded by the circulatory system; and also by the directing influence of the nervous system which supplies a central station with lines for instantaneous intercommunication with every part of the body.

\section{A. Chemical Coördination}

It is only with the recent increase in knowledge of the general problem of metabolism that the far-reaching importance of the chemical control of bodily processes has gradually been brought to the fore. Although we may properly think of the various chemical regulators, or HORMONEs, as forming a coördinating system in so far as their collective action has such a result, in the present stage of our knowledge it is possible to cite only the specific action of individual hor- 
mones as examples of the general method of chemical regulation which their study, ENDOCRINOLOGY, is revealing.

Certain hormones are secreted by organs whose sole function is their production, such as the various endocrine glands which pour their secretion directly into the blood stream. Others are elaborated by special cells imbedded in organs, such as the pancreas and reproductive organs, of which they physiologically form no part. As a concrete example of an endocrine gland we may select the THYROID which, as has been seen, arises as an outpocketing of the digestive tract in the neck region and finally loses all connection with its point of origin and becomes a ductless gland. (Fig. 88.)

The general effect of the thyroid hormone on metabolism is a regulation of the rate of oxidation in the body. An excess of the substance results in such vigorous fuel consumption that no surplus remains in the body to be stored as fat; while a deficiency in the glandular secretion results in a tendency toward fat formation. Accordingly the administration of thyroid extract is often an efficient means of reducing flesh by increasing the oxidative processes of the body. A deficiency of the hormone during adult life frequently results in a type of mental deterioration called myXedema. Children in whom the development of the thyroid is suppressed become dwarfish idiots known as cretriss, while overdevelopment of the gland induces increased nervous activity and mental disorders. Feeding with thyroid material sometimes prevents the development of cretinism and cures myxedema, while a surgical removal of part of the gland may cure the nervous instability and other symptoms due to an excessive amount of the hormone. Goitre is a pathological enlargement of the thyroid.

Finally, as a further indication of the nicety of the reciprocal adjustments within the organism, it may be mentioned 
that the thyroid gland itself is subject to regulating stimuli reaching it through the nervous system, as well as by a hormone derived from the PITUITARY BODY which is another endocrine gland situated in conjunction with the lower part of the brain. Glimpses of such interrelationships are being gradually afforded as one hormone after another is discovered. But chemical coördination, indispensable as it is as a means of regulating many of the processes of the organism, especially the slower ones such as growth, is entirely inadequate for the instantaneous correlation of diverse parts of an animal and also for the adjustment of the whole animal to its surroundings. The nervous system supplies this need by a complicated arrangement of cellular elements in which irritability and conduction are highly developed. (Sec p. 206.)

\section{B. Coördination by the Nervous System}

In some unicellular organisms certain portions of the protoplasm are especially differentiated for receiving and conducting stimuli, and others for making effective such stimuli by contractions of the whole or parts of the cell. It is in the lower Metazoa, such as Hydra and its allies, however, that we find the establishment of definite NERVE CELLS some of which are specialized for receiving stimuli and others for conducting the excitation to cells specialized for contracting (muscle cells), etc. Thus a simple RECEPTOREFFECTOR system arises which may be regarded as the basis for the development of the elaborate NEURO-MUSCULAR MECHANISM of higher forms. Although from the functional point of view it is impossible to differentiate between the receiving and conducting elements and those which make them effective (muscular system) in the economy of the organism, from the standpoint of anatomy the former constitutes a definite entity, the Nervous sYstem proper. (Figs. 99, 100.) 
The structural elements of the nervous system of all animals consist of cells known as nerve cells, or NEURons.

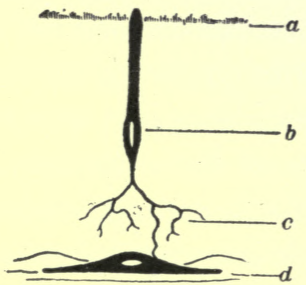

Fig. 99. - Diagram of a simple type of receptor-effector system, found in some Hydra-like animals. It comprises receptors $(b)$, or sense cells, reaching to the body surface $(a)$, with basal nerve net $(c)$ connecting with muscle cells $(d)$. (Slightly modified, after G. H. Parker.)

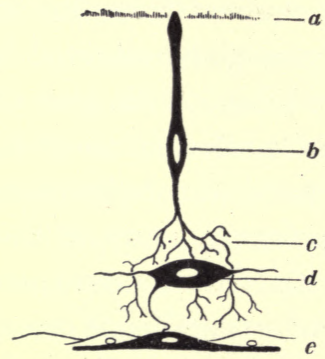

Fig. 100. - Diagram of a more complex type of receptor-effector system, found in some Hydra-like animals. It comprises, in addition to the receptor (b) with nerve net (c) and the muscle cells (e), another nerve (ganglion) cell (d) interpolated in the nerve net. $a$, body surface. (After G. H. Parker.)

In the lower forms these cells are permanently united so that they form NERVE NETS which surround and permeate the tissues which they stimulate to action. In more highly

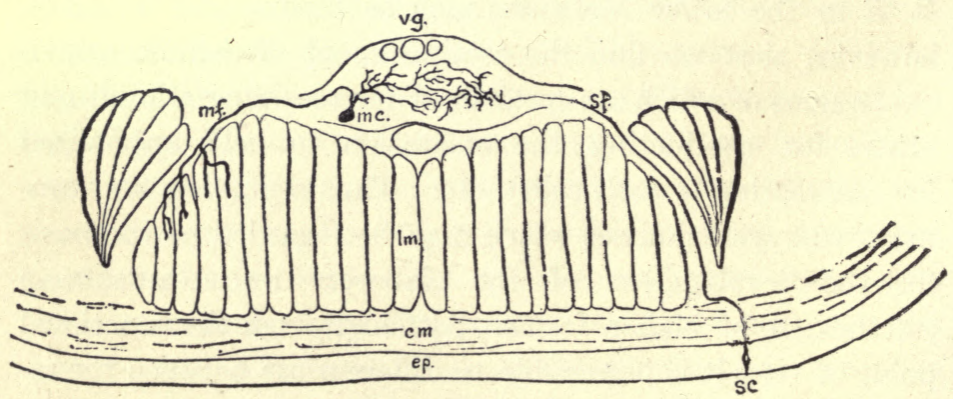

Fig. 101. - Diagram of a primary sensory $(s f)$ and motor $(m f)$ neuron of the ventral nerve cord of an Earthworm, showing their connections with the skin $(e p)$ and the muscles $(l m)$ to form a simple reflex arc. $\mathrm{cm}$, circular muscles; $e p$, epidermis; $l m$, longitudinal muscles; $m c$, motor neuron cell body (in a ventral ganglion), with fiber $(m f) ; s c$, sensory neuron cell body with fiber $(s f)$ entering ganglion to form synapses with processes of motor neuron. See Fig. 68. (After G. H. Parker, and Retzius.) 
developed animals the net arrangement is relegated to the control of relatively subsidiary functions (Fig. 103), while the main nervous system consists of neurons arranged in groups, or GANGLIA, and prolongations of the neurons, or nerve FIBERs, bound together into cables, or Nerves. The neurons, which are imbedded in protective sheaths of connective tissue in the ganglia, are in physiological continuity one with another by 'transmitting contacts,' or syNAPsEs, but each neuron, it is believed, preserves its structural integrity. (Figs. 101, 102.)

It will be recalled that the first great structural differentiation during the development of a multicellular animal establishes an outer ectoderm and inner endoderm, and thus segregates the functions of protection and general reactions to the environment from that of nutrition. It is natural therefore that the
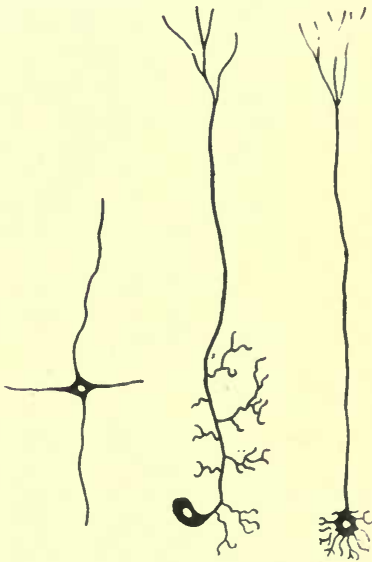

A
B

C

Fig. 102. - Diagram of stages in the differentiation of nerve cells (neurons). $A$, primitive neuron from the nerve net of Hydra-like animals; $B$, motor neuron of the Earthworm; $C$, a primary motor neuron of a Vertebrate. In $B$ and $C$ the nerve impulse passes from below upward. (After G. H. Parker.)

ectoderm should become the seat of those specializations which have evolved into the nervous system and sense organs. Such is the case in all forms from the lowest to the highest and thus the development and comparative anatomy of the nervous system of Vertebrates, in particular, affords the most cogent evidence of the genetic continuity of the whole series, including Man.

In the development of a Vertebrate the first evidence of 
the nervous system is a longitudinal groove in the ectoderm along the dorsal surface, which soon becomes converted into

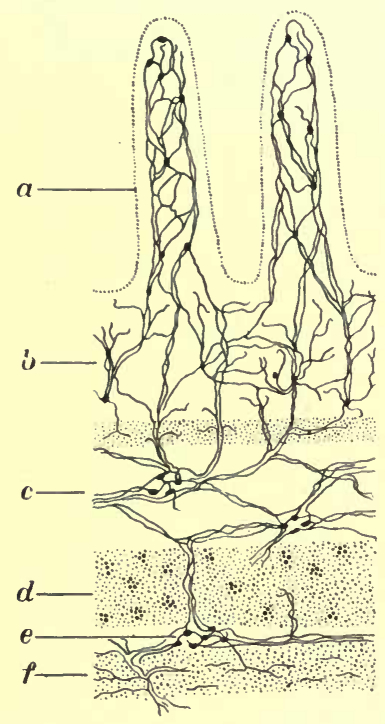

$g$

FIG. 103. - Diagram of a section (highly magnified) of the wall of the intestine of a Vertebrate to show its intrinsic nervous organization which brings about the movements of the tube. The two plexuses consist essentially of simple neurons arranged as nerve nets. $a$, food absorbing surface of the intestine; $b$, mucous layer; $c$, plexus of neurons (submucous); $d$, circular muscle; $e$, plexus of neurons (myenteric); $f$, longitudinal muscle; $g$, serous layer. (From Parker, after Lewis.) a tube by the apposition and, finally, the fusion of its edges. This NeUral tuBE then becomes separated from and sinks below the surface ectoderm, and in time forms the CENTraL nervous system consisting of the brain and spinal cord. As development proceeds, outgrowths from the central nervous system establish the PERIPHERAL and the AUTONOMIC (SYMPATHETIC) nervous systems, so that structurally as well as physiologically the whole nervous system represents a unit; a single organ, as it were, which secondarily becomes closely identified here and there with sense organ, muscle, or gland, as the case may be.

The first marked structural modifications in the developing central nervous system of Vertebrates are two constrictions of the enlarged anterior end of the neural tube, which delineate the three primary brain vesicles: FOREBRAIN, MID-BRAIN, and HIND-BRAIN. Thus very early in embryonic development, one end of the neural tube is molded into the brain, leaving the rest to form the spinal cord. (Fig. 104.) 
The three-vesicle brain now becomes transformed into one of five vesicles by a hollow outpocketing from the anterior end

A

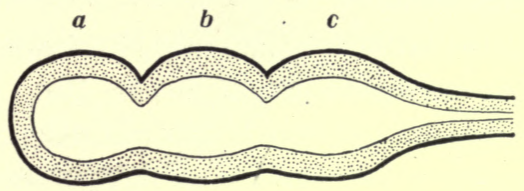

B
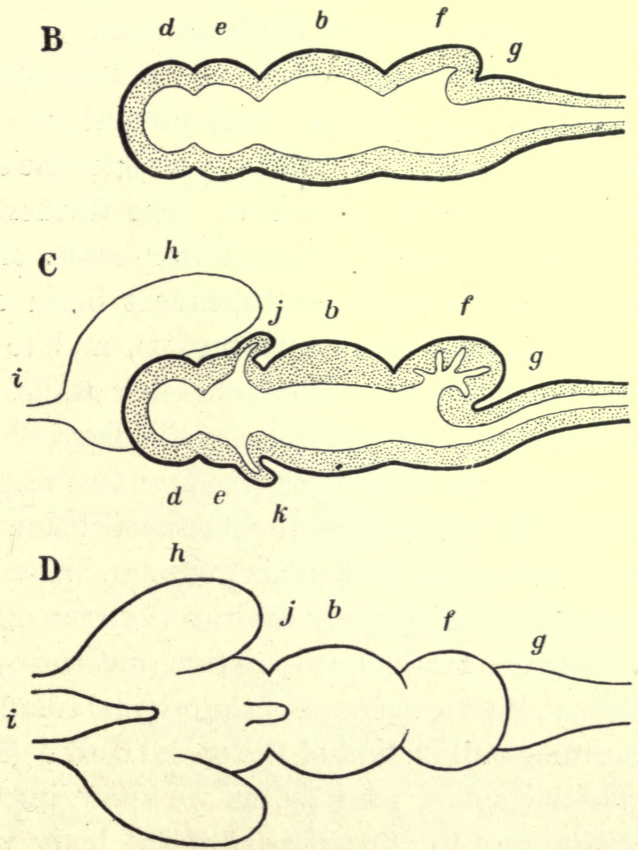

Fig. 104. - Diagrams to iilustrate the general method of transformation of the anterior end of the neural tube into the brain. $A, B, C$, median vertical sections; $D$, dorsal view of $C$. $a$, fore-brain; $b$, mid-brain; $c$, hind-brain; $d$, prosencephalon; $e$, diencephalon; $f$, cerebellum; $g$, medulla oblongata; $h$, cerebral hemispheres; $i$, olfactory lobes; $j$, pineal body; $k$, inf undibulum.

of the fore-brain and a dorsal outpocketing of the hind-brain. In some of the lower Vertebrates the brain throughout life 
consists of these divisions, known as PROSENCEPHALON, DIENCEPHALON, mid-brain or MESENCEPHALON, EPENCEPHALON Or CEREBELLUM, and METENCEPHALON or MEDULLA oBLONGATA, the latter merging into the spinal cord. Usually, however, the prosencephalon gives rise to a pair of PARENCEPHALA, or CEREBRAL HEMISPHERES, which are destined gradually to overshadow in development all the other parts of the brain and to become the seat of consciousness as well as of the higher mental life in general.

Finally, the development from the prosencephalon, or from the cerebral hemispheres when present, of a pair of RHINENCEPHALA, Or OLFACTORY LOBES, completes the establishment of the chief brain chambers. The further changes which transform the more or less linear series of vesicles into the increasingly complex and compact brain of higher forms are due to bendings, or FLEXUREs, and to unequal thickenings and outgrowths of the chamber walls. For instance, the upper and lower surfaces of the diencephalon give rise to the PINEAL BODY and the INFUNDIBULUM respectively, while from similar regions of the mesencephalon are developed the optic LOBES and CRURA CEREBri. Hand in hand with these changes the primary cavities (VENTRICLES) of the chambers undergo a gradual constriction, but throughout all there persists at least a remnant of the original tubular cavity which is continuous with that of the spinal cord.

(Fig. 105.)

The brain and spinal cord lie, as we know, imbedded in the muscles forming the dorsal part of the body wall, and are protected and isolated by a cartilaginous or bony tube formed by the skull and neural arches of the vertebrae. The sole paths of nervous communication between the central system and the rest of the organism and its surroundings are a series of pairs of CRANIAL and SPINAL NERVES. These arise at fairly regular intervals from one end of 


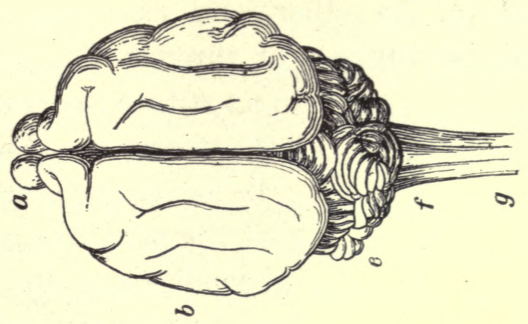

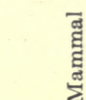

II

जे :

ถิ․ㅠ

舶

eे

호ํ 율

ค.
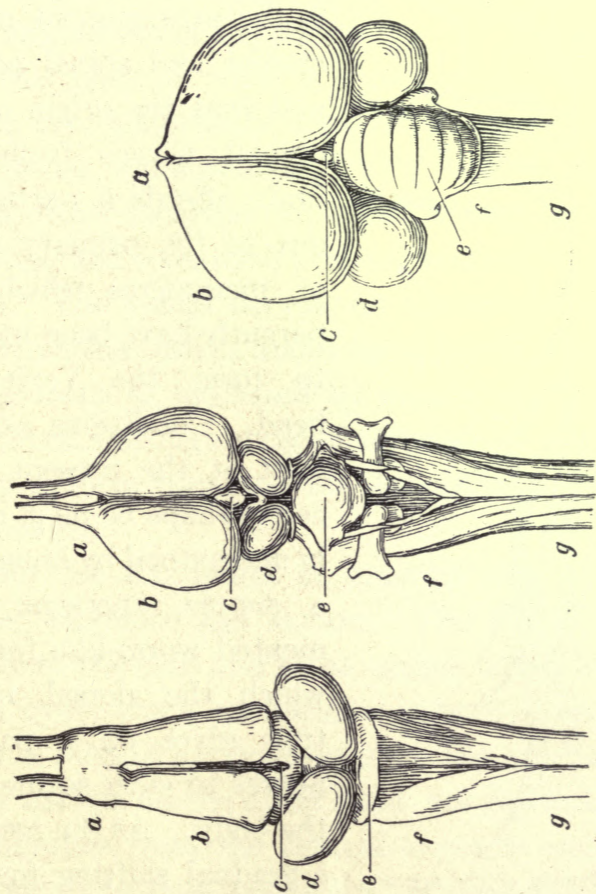

茖

ค 융

웡

की

$0 \div$

额宽

कृ

卺

要

的贯

(1) $\because 0^{\circ}$

डิ

ثै

क्ञ

语

ㅎํㅇ

ख छ

$\infty$.

蛋

응

낭 충

密

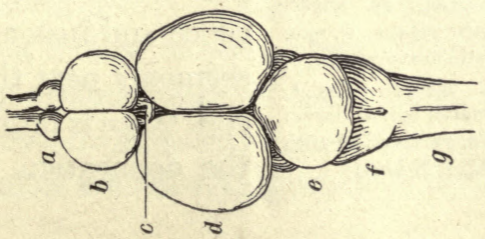

41 它

เి

品 
the brain and cord to the other, and pass out through openings in the skull and between or through the vertebrae

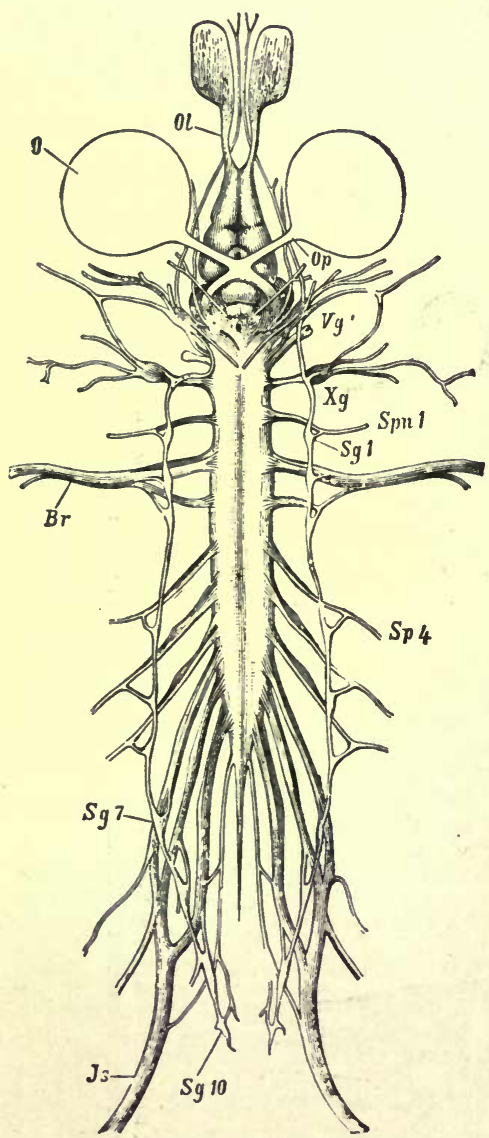

Fig. 106. - Ventral view of the nervous system of the Frog. $B r$, second and third spinal nerves (brachial plexus); $J_{8}$, sciatic nerve leading from the sciatic plexus; $O$, eye; $O l$, olfactory nerve; $O p$, optic nerve; $S g$ 1-10, ten ganglia of autonomic system; $S p n$ 1, first spinal nerve; $S p$ 4, fourth spinal nerve; $V g$, Gasserian ganglion; $X g$, ganglion of 10th cranial nerve (vagus), (After Ecker.) to constitute the peripheral nervous system. (Fig. 106.)

It is usually considered that the primitive segmental condition of the Vertebrate body is well exhibited in the arrangement of the cranial and spinal nerves, and that the origin of the cranial nerves from the brain affords a partial index to the primary series of metameres which apparently have been merged to form the Vertebrate head. Conditions as they exist at the present time can perhaps be most readily understood by imagining a simple, ancestral, segmented worm-like form in which the dorsal neural tube gives off a pair of nerves to each segment of the body. As the result of a gradual shifting forward and a consequent coalescence and fusion of certain segments near the anterior end, there is brought about the delineation of a head 
region, with its brain, battery of sense organs, and skull, from a trunk region with its spinal cord, vertebral column, paired limbs, etc. This naturally involves a corresponding shifting and modification of the primitive condition of the paired nerves; especially since the innervation of a group of cells in normal development is apparently rarely changed - a nerve following the part which it originally supplied through many of the transformations and even migrations of the latter.

If this point of view is accepted, the cranial and spinal nerves are, historically considered, similar structures. But the former, synchronously with the changes in the head region, have departed somewhat widely from their ancestral condition and have even been augmented by nerves of diverse origin. The spinal nerves, on the other hand, continue to issue from the cord at about equal intervals and in metameric arrangement as indicated by muscle segments and skeletal structures, although those of certain regions unite in the body cavity to form PLEXUSEs for the adequate innervation of the appendages.

From the standpoint of function the nerves are of two classes, sENsORY and мотоR. The former are distributed mainly to the skin and sense organs of the head, and are the paths over which excitations (NERvous IMPULSES) due to external stimuli are conducted to the cord and brain. The motor nerves, on the other hand, are the media for distributing impulses from the central organ to muscle cells, gland cells, etc., and thus induce the response of the organism.

In discussing nerves, it must be kept in mind that a nerve is actually a bundle of nerve fibers; the fibers themselves in turn being prolongations of nerve cells, the cell bodies of which are usually situated in groups or GANGLIA. Moreover, nerve impulses are not transmitted by nerves as a whole, but 
by one component cell process, the nerve fiber; that is, by way of a definite cell path through the nerve. The same is equally true of the cord and the brain, which differ from nerves largely in the circumstance that they comprise more cell processes and also the cell bodies themselves. In other words, the brain and cord comprise the elements of both ganglia and nerves.

A given nerve may conduct impulses both to and from the central organ if it contains afferent and efferent cell paths, or fibers. As a matter of fact all the peripheral nerves primarily are mixed nerves, because typically they arise by two roots from the central organ; the DORSAL ROOT containing only sensory (afferent) fibers and the VENTRAL ROOT only motor (efferent) fibers. This condition is preserved by the spinal nerves of higher forms since each arises by two roots. But some of the cranial nerves, in response to the profound modifications which have been wrought in the head region, have only one root, and so are either solely sensory, as those to the sense organs, or only motor, as those innervating the muscles which move the eye. (Fig. 107.)

So far we have considered the central system - the brain and spinal cord - and its lines of communication with the body as a whole, the peripheral system, or cranial and spinal nerves. In point of fact, however, the peripheral system gives rise to an auxiliary series of ganglia and nerves which are charged with the innervation of certain of the internal organs, particularly the alimentary canal and arteries, which are not directly under voluntary control. This AUTONOMIC SYSTEM in the higher Vertebrates consists essentially of a double nerve chain situated chiefly within the coelom just ventral to the spinal column. It communicates with the central system by way of the sensory roots of the spinal and some of the cranial nerves. (Fig. 106.) 
Such in essence are the ramifications throughout the body of the nervous system which, although it arises as an infolding of the ectoderm and therefore is primarily external, comes to be internal and so chiefly dependent upon more or less isolated groups of sensory cells for the reception of stimuli. Some of these, termed External Receptors, remain at the surface to receive stimuli from the outer world, while others,

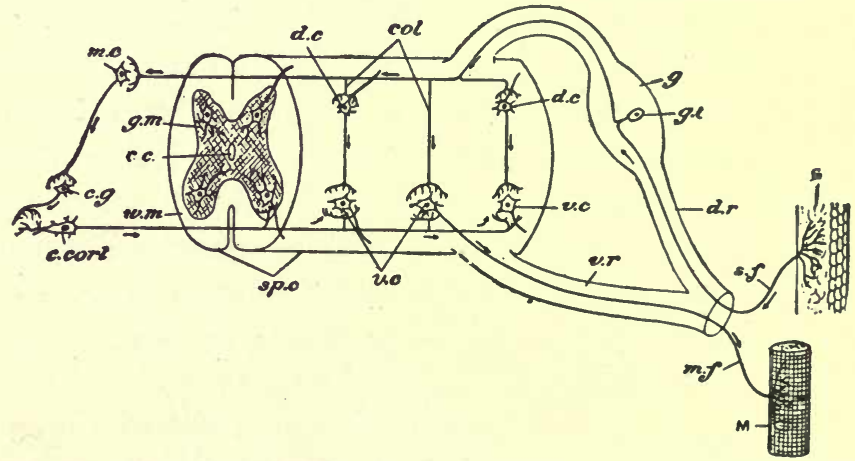

Fig. 107. - Diagram of a section of the spinal cord to show the paths of nerve impulses. c.c, central canal; col, collateral fibers; c. cort, cells of the cortex of the cerebral hemispheres of the brain; c.g, smaller cerebral cells; d.c, cells in dorsal part of gray matter; d.r, dorsal root of spinal nerve; $g$, ganglion of dorsal root; g.c, cell body of sensory neuron; g.m, gray matter of cord; $M$, muscle; m.c, nerve cell in medulla; $m . f$, fiber (axon) of motor neuron; $s$, sensory surface; s.f, fiber of sensory neuron; spc, spinal cord; $v . c$, cells in ventral part of gray matter; $v . r$, ventral root of spinal nerve; $w . m$, white matter of cord. The arrows indicate the direction of the impulses. (After Parker and Parker.)

known as INTERNAL RECEPTORS, are situated within the body for the reception of stimuli arising there. The external receptors are what one ordinarily thinks of as sense organs.

\section{Sense Organs}

Although among some of the Protozoa certain regions of the cell are specialized so that they are more sensitive to one or another kind of stimulation, the great majority show no trace of sense organs. Nevertheless all forms, in common with all protoplasm, possess the power of receiving and re- 
sponding to environmental changes. Thus Paramecium reacts to mechanical, thermal, chemical, and electrical stimulation: the entire surface of the cell is sensitive to stimuli, and

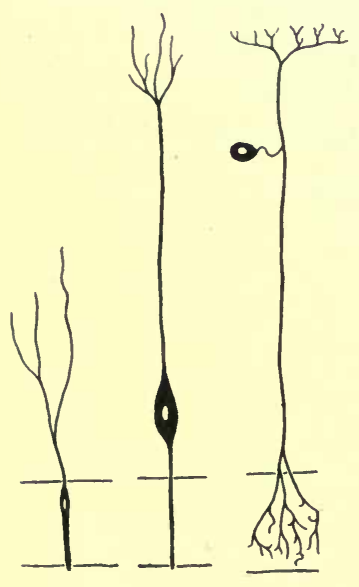

A $\quad$ B $\quad$ C

FIG. 108. - Diagram of stages in the differentiation of sense cells. $A$, primitive sensory neuron of Hydra-like animals; $B$, sensory neuron of a Mollusc; $C$, primary sensory neuron of a Vertebrate. In each case the sensory surface is represented below, and therefore the nerve impulse passes upward. (After G. H. Parker.) the excitations are conducted from one part to another essentially by the protoplasm as a whole. In some Invertebrates, such as Hydra and the Earthworm, the whole surface of the body is still depended upon as a receiving organ for all kinds of stimuli, and only simple sense cells are developed. In the majority of animals, however, although all the cells retain to some extent their pristine power of irritability, environmental changes exert their influence chiefly upon complex receptors, which are specialized to respond most readily to particular forms of energy. The energy, for example of heat or light, is transformed by appropriate mechanisms into the energy of a NERVE IMPULSE, and accordingly the sense organs constitute the outposts of the nervous system.

Since we necessarily gain our knowledge of the outside world solely through the data afforded by our sense organs, it follows that we judge the capacity of the sense organs of other animals merely by analogy with our own. This is a safe procedure only in the case of sense organs which more or less correspond in structure to those which we possess. In the Crayfish, for example, we find complex sense organs which, without doubt, are eyes, and others which are ears, or at least 
perform one of the functions of our ears, equilibration; while some of the head appendages are particularly adapted to receive sensations of touch. The senses of smell and taste are also probably present, but here we are on less certain ground. It is possible, perhaps probable, that environmental changes which are without effect on the sense organs of the human body, and so play no recognizable part in the 'world' of Man, may stimulate receptors in lower organisms.

The simplest form of sense organ in Vertebrates is a single epithelial cell for the reception of stimuli, connected with a nerve fiber for the conduction of the nerve impulse to a sensory center. Usually, however, many associated cells are arranged to respond and are aided by accessory structures for intensifying the stimulus, protection, etc, so that the whole forms a highly complex sense organ. (Figs. 108C, 112.)

\section{Cutaneous Senses}

Confining our attention to the Vertebrates we find that practically the entire surface of the body constitutes a sense organ, because the skin is permeated with a network of sensory nerves. Certain regions are supplied with special tactile organs, which may take the form of a regular system of sense organs, such as the LATERAL LINE ORGans of Fishes and Amphibians, or of groups of TACTILE CORPUSCLES as in Man. In addition to pressure receptors, the whole surface of the human body is provided with PAIN, HEAT, and COLD SENSE SPOTS.

\section{Sense of Taste}

In the higher Vertebrates the sense of taste is restricted to the cavity of the mouth, particularly to the tongue, where special receptors known as TASTE BUDS are in communication with the brain ky two of the cranial nerves; but in some Fishes they are scattered quite generally, so that the whole body surface is sensitive to such qualities as sweet, sour, and salt. 


\section{Sense of Smell}

The special sense organs of smell, or OLFACTORY BUDS, reside in the membrane which lines a pair of invaginations of the anterior end of the head, termed olfactory pouches.

The buds are in communication with the brain by the olfactory, or first pair of cranial nerves. The pouches constitute relatively simple sacs in the lower Vertebrates, but in the airbreathing forms, and especially in the Mammals, the walls of the pouches are thrown into folds, ridges, and secondary pouches. This is necessitated by the concentration of the olfactory surface to the air passages of the nose which lead to the lungs. On the other hand, in Man the olfactory apparatus has fallen somewhat from the complexity which it attains in the lower Mammals, as is attested not only by its structure in the adult but also by transient remnants in the human embryo.

\section{The Ear}

The ears, or organs of hearing and equilibration, arise as paired depressions of the ectoderm of the head, which, in all Vertebrates above the lower Fishes, lose their connection with the exterior and form the so-called INNER EAR, or LABYRINTH. This becomes divided into two chief parts, the sACCULUs and the UTRICULUs from which are developed three SEMICIRCULAR CANALS, one in each plane of space. The sacculus is largely devoted to the reception of vibrations of the surrounding medium, that is to hearing in the usual sense of the word. Accordingly the sacculus becomes progressively differentiated as we ascend the Vertebrate scale - a complex derivative in the mammalian ear being the COCHLEA. On the other hand, the utriculus and the semicircular canals provide for sensations of loss of equilibrium, or orientation of the body in space, and show far less change. It is probable 
that equilibration is the chief function of the entire labyrinth in Fishes, as it is of the so-called auditory organs of many Invertebrates, such as the Crayfish. With the progressive specialization of the labyrinth, the essential sensory cells, which are in communication with the brain by the eighth, or AUDITORY NERVE, become limited to a few definite areas. These sensory cells are provided with auditory hairs which project into the cavity of the labyrinth and so are stimulated by movements of the fluid which fills it. (Fig. 109.)

The ears of Fishes lie immediately below the skull roof, where they are readily accessible to vibrations transmitted by the water. But with the substitution of air for water as the surrounding medium, there arises the necessity of a more delicate method for conducting and also for collecting and augmenting the sound waves. The result is that, in ascending the Vertebrate

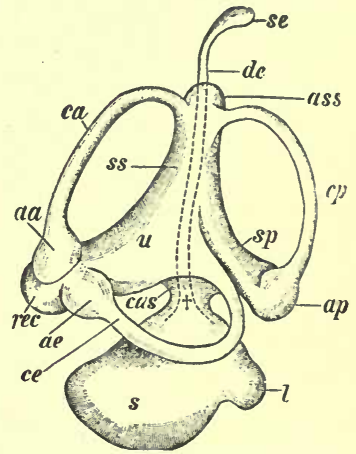

Frg. 109. - Semidiagrammatic figure of the left membranous labyrinth of a lower Vertebrate to show the sacculus $(s, l)$, utriculus $(u, r e c)$, and the three semicircular canals $(a a, c a$; $a e, c e$, and $a p, c p)$. l, lagena, a derivative of the sacculus which becomes the cochlea in higher Vertebrates; cus, utriculo-saccular canal; de, se, endolymphatic duct and sac; $a s s, s p$, ss, utricular sinuses. (After Wiedersheim.) series, we find the ear proper receding farther and farther below the surface.

Soon, between the inner ear and the surface of the head, a simple resonating chamber is added which is provided with a vibrating TYMPANIC membrane, or EAR DRUM, situated just under the skin. Then this is improved by the development of a bony transmitting mechanism between the tympanic membrane and the inner ear. This consists of a single bone until we reach the Mammals, when two more bones are added by being diverted from their earlier function of articulating 
the jaws with the skull! Finally, the resonating (tympanic) chamber recedes farther below the surface and becomes the

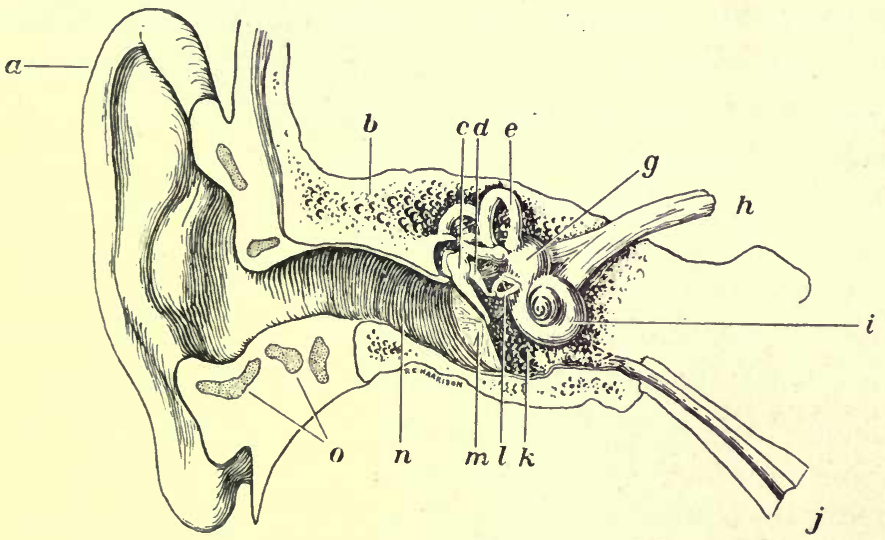

FiG. 110. - Front view of the human organ of hearing, right side. $a$, pinna of outer ear; $b$, bone of skull; $c, d, l$, transmitting mechanism of three bones-malleus, incus, and stapes; $e$, one of the three semicircular canals; $g$, vestibule; $h$, auditory nerve; $i$, cochlea; $j$, Eustachian tube leading to the throat; $k$, tympanic chamber or middle ear; $l$, stapes; $m$, tympanic membrane; $n$, external auditory passage, or outer ear; $o$, cartilage.

MIDDLE EAR to which sound waves are conducted through a tubular passage, the oUTER EAR. In some forms, as in Man, there is an external funnel-like collecting appendage, the PINNA. (Fig. 110.)

\section{The Eye}

The organs of sight are the most complex sense organs of animals and reach a very high degree of specialization even in some of the Invertebrate forms. Among the latter the essential sensory element (RETINA) of the eye usually arises by the invagination of a limited area of ectoderm, the cells of which become differentiated for receiving the photic stimuli that produce impulses to be transmitted to the central nervous system. Among Vertebrates the sensory cells are also of ectodermic origin, but only secondarily so, since the oPTIC 
VESICLES arise as lateral outpocketings directly from the forebrain. (Fig. 111.)

A retina alone such as exists in some of the lower Invertebrates can afford no visual sensations other than light and darkness, and perhaps in some cases the ability to distinguish light of one color from that of another. In order that not merely degrees of the intensity of light may be perceived, but that objects may be seen, many of the higher Invertebrates have developed various kinds of complicated apparatus for bringing the rays from a given point to a focus at one point on the retina, culminating on the one hand in the mosaic vision of the Arthropods, and on the other hand in the camera eye of the Cuttlefish. In the latter case the mechanism is quite similar to that found in the Vertebrates, but since it occurs in the group of Molluses which cannot be considered in the direct evolutionary line of the Vertebrates, it affords an example of similar responses of different organisms to similar needs giving rise to analogous structures. (Fig. 112.)

In the development of the Vertebrate eye, the hollow outgrowth or optic vesicle (one of which arises from either side of the diencephalon) gradually extends toward the outer surface of the head, where it becomes associated with an inpocketing of the ectoderm. The latter gradually becomes separated from the surface ectoderm as a sac, the very thick walls of which almost completely obliterate its cavity. This sac is destined to become the LENs, and as it enlarges it comes in contact with the optic vesicle, which now is connected with the point of origin from the diencephalon by a narrow isthmus (opTIC STALK). Apparently under the influence of the developing lens, the optic vesicle is invaginated and thereby transformed from a single-layered structure into a doublelayered cup (OPTIC CUP). These two layers form the retina, the inner layer becoming differentiated into the essential 

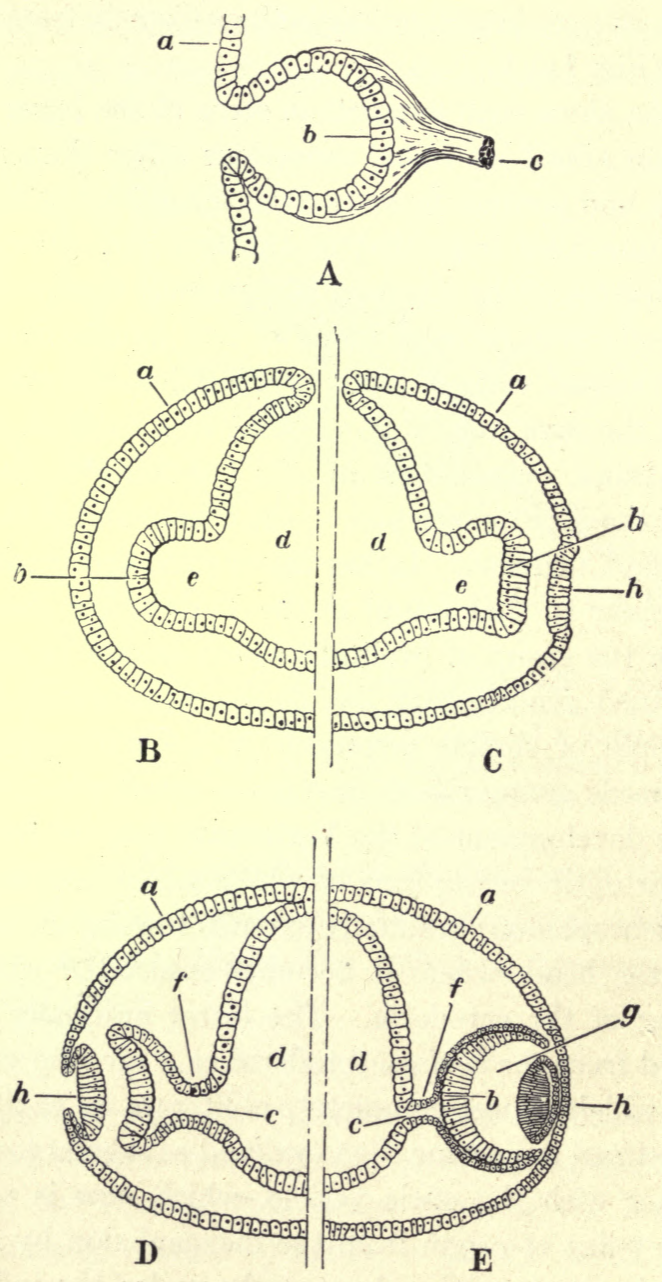

Fig. 111. - Diagrams illustrating the method of formation of the eye of an Invertebrate $(A)$ and a Vertebrate $(B, C, D, E,-$ successive stages). Note that the opposite surface of the retinal cells is exposed to the light rays in the Vertebrates as compared with the Invertebrate Eye. $a$, ectoderm; $b$, retinal area; $c$, future position of optic nerve; $d$, cavity of the diencephalon; $e$, optic vesicle; $f$, stalk of optic vesicle later replaced by the optic nerve; $g$, vitreous chamber within optic cup; $h$, developing lens. 
visual elements (RODS and CONES) of the eye, while the outer supplies the PIGMENTED LAYER. The nerve cells of the retina develop fibers which proceed to the brain through the path

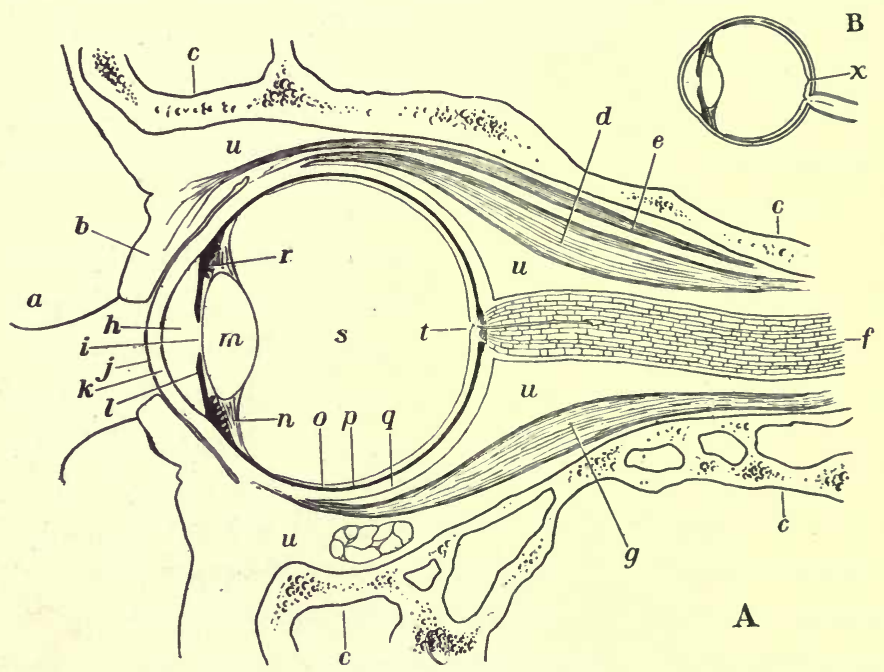

Fig. 112. - The Vertebrate eye (human). A, vertical section of the eye in situ. $B$, horizontal section to show relation of optic nerve to fovea centralis through which the optical axis passes. $a$, eyelash; $b$, lid; $c$, bony orbit; $d$, superior rectus, one of the six muscles which revolve the eyeball; $e$, muscle to upper lid; $f$, optic nerve (bundles of fibers cut obliquely); $g$, inferior rectus muscle of eyeball; $h$, anterior chamber filled with aqueous humor; $i$, pupil, opening to posterior chamber, also filled with aqueous humor, between iris and lens; $j$, conjunctiva, a transparent membrane, continuous with the lining of the eyelid; $k$, cornea; $l$, iris; $m$, lens; $n$, suspensory ligament of lens; $o$, retina; $p$, choroid coat; $q$, sclerotic coat; $r$, muscles to ligament suspending lens; $s$, vitreous chamber containing vitreous humor; $t$, point of entrance of optic nerve ('blind spot'); $u$, fatty connective tissue; $x$, fovea centralis at posterior end of axis of eyeball.

occupied by the optic stalk and so give rise to the opTIC NERVE.

To the optic cup and lens, the former indirectly and the latter directly of ectodermal origin, other portions largely of mesodermal origin are added - e. g., the CORNEA, CHOROID 
and SCLEROTIC COATS, the IRIS, and the vitREOUS HUMOR all of which contribute to the make-up of the eye-ball. The eye of Vertebrates is an optical apparatus which may be compared roughly with a camera. Light waves which pass through an outer transparent protective coating and an opening (PUPIL) in a regulating diaphragm (iris) reach the lens and are brought to a focus on the retina. The sensory stimulation thus brought about is transmitted by the optic or second cranial nerve to the brain.

A broad survey of the sense organs of Vertebrates impresses one with the fact that, taken by and large, the improvements, though considerable, are not so marked as one might expect when the great development of the nervous system, and the brain in particular, is considered. And so we must look chiefly to the cumulative influence of the sensory stimuli themselves for the underlying factor in the development of the brain during its long evolutionary history - the brain, in turn, being enabled to make more out of the same stimuli and create in Man the higher mental life with all that it implies. 


\section{CHAPTER XV}

\section{REPRODUCTION IN ANIMALS}

So careful of the type . . .

So careless of the single life. - Tennyson.

In addition to the organs devoted to the life of the individual animal, the Vertebrates in common with all forms of life necessarily are provided with means for the continuation of the life of the race. Reproduction, it will be recalled, is, in the last analysis, division; the setting free by the organism of cells with the power of going through a complex series of changes, involving cell division and differentiation, by which the relatively simple germ cell becomes transformed into the obviously complex individual, similar to the parent. In most plants and animals this process is complicated at the start by the fusion of two germ cells, the male and female gametes, to form the fertilized egg, or zygote. Disregarding for the time being the ultimate origin of the germ cells in the body, we find in the Metazoa special organs in which the germ cells reside and undergo changes preparatory to their liberation. Such reproductive organs, or GONADS, ordinarily contain germ cells of one kind, and accordingly are either ovaries (eggproducing organs) or TESTES (sperm-producing organs).

In many of the simpler animals, the gonads are merely temporary structures which appear during certain seasons of the year when conditions favor sexual reproduction. Frequently also the same individual produces both eggs and sperm, in which case the sexuality of the germ cells is not reflected back, so to speak, to the organism as a whole, which 
accordingly is known as a HERMAPHRODItE. Such is the condition in Hydra, where the testes appear as small swellings in the ectoderm a little below the circle of tentacles; and the ovary, which is usually single, is a somewhat larger projection near the opposite end of the animal. Both the testis and the ovary at first appear to be a heap of ectoderm cells, which in one case gives rise to many sperm and in the other to a single egg. The mature sperm are set free from the testis and swim about in the water. Sooner or later one enters the now ruptured covering of the ovary and fuses with the egg. With the conclusion of fertilization the zygote begins to divide and forms an embryo, which at an early stage becomes detached from the parent. Thus in Hydra there is no complicated apparatus for sexual reproduction; merely now and again the temporary development of the primary sex organs, cvaries and testes. (Fig. 64.)

The complex bodies of most animals, however, demand more or less permanent gonads as well as means for transferring the gametes directly or indirectly to the exterior. This is brought about by the fact that in coelomate animals the gonads come to lie, not on the outside of the body, but within the coelom. In the Earthworm, which also is hermaphroditic, the testes and ovaries are permanent organs attached to the partitions between certain somites. The sexual products are set free in the coelom, where they are taken up by SPERM DUCTs and oviducts and carried to the outside. Although each Earthworm possesses both male and female reproductive organs, two worms copulate and exchange sperm which are stored in the respective seminal receptacles. Later, when the eggs pass to the exterior, the 'foreign' sperm are shed on them. Thus cross-fertilization is insured in this hermaphroditic form. In the Crayfish the sexes are represented by separate individuals, and the appen- 
dages of the first and second abdominal segments of the male are modified into copulatory organs for the transfer of the sperm to the body of the female, where they are retained

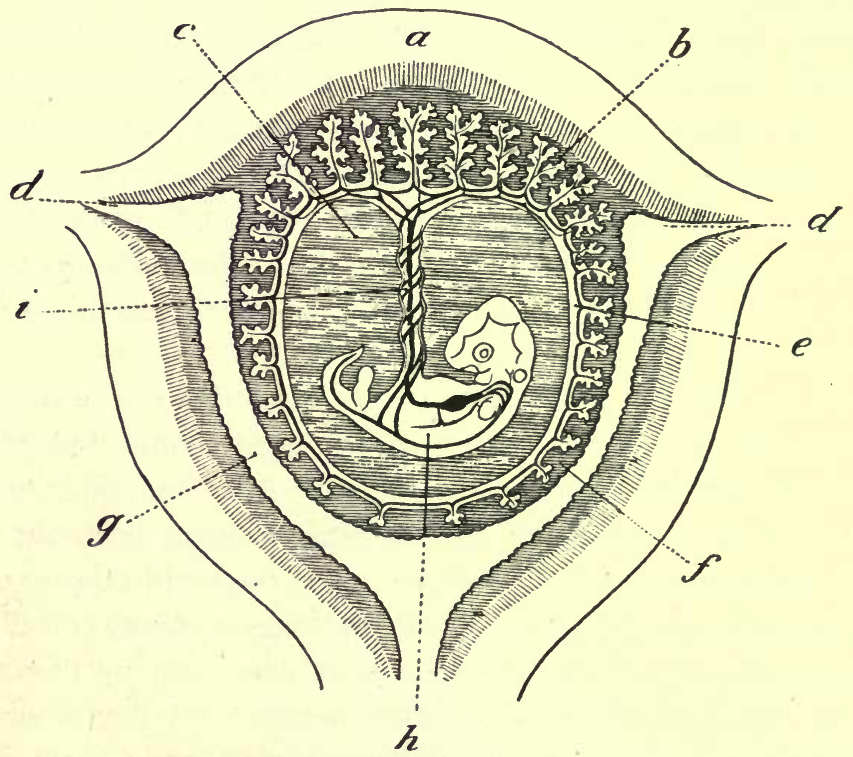

Fig. 113. - Diagrammatic section of the human uterus with developing embryo. The embryo $(h)$ is suspended in a fluid-filled cavity $(c)$ surrounded by the foetal membranes $(e)$ and by tissue $(f)$ from the uterus itself. The sole path of communication between embryo and mother is by blood in vessels passing up through the umbilical cord $(i)$, spreading out into capillaries in the placenta $(b)$ and there coming into close relations with the maternal blood supply. The openings of the oviducts $(d)$ into the uterus become closed during the development of the embryo. $a$, dorsal wall of uterus; $b$, placenta; $c$, fluid-filled cavity of amnion; $d$, openings of oviducts (Fallopian tubes); $e$, foetal membranes; $f$, uterine tissue; $g$, uterine cavity; $h$, embryo; $i$, umbilical cord.

until egg-laying. In most terrestrial Vertebrates, including Man, fertilization occurs while the eggs are still within the oviiducts, the copulatory organs transferring the sperm directly to the terminal portion of the ducts from which they make their way up to meet the descending eggs. (Figs. 67, $71,72,86$. 
When fertilization occurs within the body, the egg may soon pass to the exterior, usually after being wrapped up in nutritive and protective coats secreted about it during its passage down the oviduct. Or, as is the case sporadically among lower forms and the rule among the highest Vertebrates, the Mammals, the egg on reaching the lower part of the oviduct may become attached to the wall of an enlargement of the oviduct, or of a chamber formed by the union of the two oviducts, called the uTERus. Here the embryo derives nourishment from the maternal blood supply, and proceeds far along in development before it is expelled to the exterior, or born. (Fig. 113.)

Thus, except in the simplest animals, there is a special REPRODUCTIVE SYSTEM; a series of organs connected with the reproductive function. But it must be emphasized that the essential organs are the gonads themselves and all the rest are accessory. Furthermore, in relation to the sexual differentiation of male and female individuals, many so-called SECONDARY SEXUAL CHARACTERS arise which are not directly connected with the reproductive organs, but nevertheless depend very largely for their development upon hormones liberated by the gonads. For example, early castration of the Stag inhibits the growth of a distinctive male secondary sexual character, the antlers; while if performed later when the antlers are full grown, they are shed and abnormal ones take their place. Similarly, the development and functioning of the mammary glands during pregnancy in the human female is induced by hormones produced, not by the ovary itself, but by its product, the developing embryo within the uterus. Here at least two hormones are involved; one directly stimulates the development of the glands, while another inhibits their active functioning until it is removed by the birth of the offspring. (See p. 181.) 
Throughout all the chief Vertebrate groups the sexes are distinct, although in rare instances abnormal hermaphroditic individuals occur. The definitive primordial germ cells first appear as localized areas of the coelomic epithelium, on either side of the vertebral column. As the germ cells develop they become associated with connective tissue, blood vessels, and nerves and form the paired gonads. In the most primitive Vertebrates a condition more simple than in the Earthworm is found, for both male and female germ cells when ripe merely break out of the gonads and find their way to the exterior by a pair of minute ABDOMINAL PORES. In higher forms, however, the labor of conducting the products out of the body is foisted upon the urinary system, as was suggested when that system was under discussion. We now turn to a statement of the structural inter-relations of these two systems to form the UROGENITAL SYSTEM.

It has been pointed out that the nephridia, which combine to form the kidneys, in some of the lower Vertebrates retain their funnel-like openings into the coelom and therefore afford a direct exit for waste material in the coelomic fluid. It is some of these nephridia which are employed in the lower Fishes for the transfer of the germ cells to the outside. The testes of the male, which lie close to the kidneys, become connected with the nephridia (mesonephros) by a series of short delicate tubes. Through these tubes the SPERMatic FLUID, containing the sperm from the testes, is transferred to the nephridia and by them to the kidney. (mesonephric) ducts and so to the exterior with the urinary waste. In this way, during the period of sexual activity of the male, the kidney tubules satisfactorily perform two functions, and the mesonephric ducts become urogenital canals. (Fig. 97, C.)

Turning to the female, we find that the ovaries, which are situated in about the same position with relation to the kid- 
neys as the testes in the male, do not enter into communication with a set of nephridia of the kidneys (mesonephros); probably because the eggs are too large to pass through the tubules. Instead, what appears to be the coelomic opening, or NePHROSTOME, of a single nephridium on either side (which fails, so to speak, to enter the kidney complex) enlarges and becomes the funnel which connects up with a new duct opening into the cloaca. Thus there arises from the female urinary system a pair of entirely distinct oviducts. An egg, liberated from the ovary into the coelom, finds its way into one of the oviducts and descends directly to the outside, or into an enlargement (uterus) of the terminal portion of the duct where development proceeds until birth occurs. (Fig. 97, D.)

The female reproductive system, though derived from the mesonephric system, has become entirely independent of it. Accordingly the disappearance of the mesonephros and duct in higher Vertebrates, when it is replaced by the metanephros and the ureter as the functional urinary system, has little effect on the female reproductive system. As a matter of fact the abandoned mesonephros and duct degenerate and disappear in the female, while in the male the mesonephric duct remains and becomes completely appropriated by the reproductive system. The sperm now pass directly into the former mesonephric duct, which thereby becomes solely a sperm duct. Such is the historical origin of the foundations of the reproductive system as it occurs in the Reptiles, Birds, and Mammals. Naturally each of these groups, building on this foundation, has developed modifications and additions demanded by its special lines of evolution. (Fig. 97, E, F.) 


\section{CHAPTER XVI \\ ORIGIN OF THE INDIVIDUAL}

Owing to the imperfection of language the offspring is termed a new animal, but is in truth a branch or elongation of the parent. - Erasmus Darwin, 1794.

A GENERAL background of biological facts and principles has now been established and we are therefore in a position to take up from an advantageous viewpoint some of the broad questions relating to the origin of life and the origin of species, that is the origin of individuals since life and species are merely concepts, and individuals are the realities in living nature.

\section{A. Origin of Liffe}

It must seem strange to the reader, with some of the complexities of organisms before him, that the best minds up to the seventeenth century saw nothing more incongruous in the spontaneous origin of plants and animals of all kinds from mud and decaying matter, than does the boy of to-day who believes that horse hairs soaked in water are transformed into worms. As a matter of fact, we find that even Aristotle, who laid such broad foundations for the science and philosophy of the organism, believed that certain of the Vertebrates, such as Eels, arose spontaneously.

Naturally, with the increase of knowledge, the idea of SPONTANEOUS GENERATION was gradually restricted more and more to the lower forms. It remained, however, for Redi during the latter half of the seventeenth century to question seriously the general proposition and to substitute direct 
experimentation for academic discussion and hearsay. By the simple expedient of protecting decaying meat from contamination by flies, he demonstrated that these insects are not developed from the flesh and that the apparent transformation of meat into maggots is due solely to the development of the eggs deposited thereon by flies.

But the time-honored doctrine of spontaneous generation was not overthrown by this experiment nor the long series which Redi made. The presence of parasites within certain internal organs of the higher animals, as in the brains of sheep, baffled Redi himself. Also, the improvements of the microscope revealed an unknown microcosm whose origin seemed plausibly explained as spontaneous. Biogenesis, or all life from preëxisting life, was placed on a secure foundation only within the past half-century by the working out of the remarkably complex life histories of internal parasites, which showed that they all arise from parents like themselves, and by the classical demonstrations of Pasteur and others that microörganisms are not the result, but the cause of decay. The latter fact is at the basis of, and is attested by, the methods now universally used in food preservation and aseptic surgery - to mention but two instances.

At the present time, we may consider it as established that all known forms of life arise from preëxisting life by reproduction. But if we accept the testimony of astronomer and geologist, the Earth was at one time in a condition in which life as we know it could not exist, and so we are face to face with the problem of how it came to be established on the Earth in the past - the remote past, since the geological record affords convincing proof that life has existed continuously on the Earth for some hundreds of millions of years.

Unless one is willing to ascribe life's origin to SPECIAL CREATION - which at once removes it from the sphere of 
science and so beyond the present discussion - or to ANOTHER PLANET from whence it was transferred through space to the Earth - which removes it to a "conveniently inaccessible place where its solution is impossible" - there remains but one alternative: life arose through the graduol evolutionary complexification of matter when, ages ago, Earth conditions became favorable. Such living matter must have been relatively simple compared with protoplasm as we know it today; so simple, in fact, that we would not recognize it as such, because protoplasm as we see it even in the simplest organisms has had a long evolutionary history. Of course it is not, a priori, impossible that such simple life is even at the present time arising spontaneously under special environmental conditions, perhaps in the ocean depths, but is unable to come to fruition in competition with existing protoplasm of ancient pedigree and evolutionary specialization.

However that may be, during the past quarter century some biologists have now and then thought they were on the verge of artificially creating life in the test tube, only to leave the problem, like the alchemists of old, with more respect for the complexities of its organization and the "enormous gap which separates even the simplest forms of life from the inorganic world." And so we may more profitably turn to a consideration of the present-day manifestations of life in the reproduction of organisms, and dismiss the insolvable problem of the origin of life on the Earth with the conservative statement penned over forty years ago by Huxley:

"Looking back through the prodigious vista of the past, I find no record of the commencement of life, and therefore I am devoid of any means of forming a definite conclusion as to the conditions of its appearance. Belief, in the scientific sense of the word, is a serious matter, and needs strong 
foundations. To say, therefore, in the admitted absence of evidence, that $I$ have any belief as to the mode in which existing forms of life have originated, would be using words in a wrong sense. But expectation is permissible where belief is not; and if it were given to me to look beyond the abyss of geologically recorded time to the still more remote period when the Earth was passing through physical and chemical conditions, which it can no more see again than a man can recall his infancy, I should expect to be a witness of the evolution of living protoplasm from not living matter. . . . That is the expectation to which analogical reasoning leads me; but I beg you once more to recollect that I have no right to call my opinion anything but an act of philosophical faith."

Since so far as is known all life now arises from preëxisting life and has done so since matter first assumed the living state, it apparently follows that the stream of life is continuous from the remote geological past to the present and that all organisms of to-day have an ancient pedigree. It is to the establishment of this as the reasonable conclusion from the data accumulated during recent years, that from now on our attention is somewhat more particularly directed; and accordingly it is necessary first of all to consider in some detail the genetic connection of present-day forms as exhibited in reproduction.

\section{B. Reproduction}

The power of producing new individuals specifically similar to the parent is, as has been seen, one of the most important characteristics of living in contrast with lifeless matter, and is exhibited in its simplest form in the unicellular plants and animals. In Paramecium the nucleus and cytoplasm divide into two parts, so that by cell division, here called BINARY FISSION, the identity of the parent organism is merged into 
the two new cells. Simple as this seems, the fission of Paramecium, for instance, involves considerably more than the halving of the original cell, because, as a matter of fact, each half must reorganize into a complete new individual with all parts characteristic of the parent. (Fig. 11.)

Among some unicellular organisms (e.g., Sphaerella) the parent cell, instead of merely forming two cells by binary fission, becomes resolved into from four to several hundred cells by a series of practically simultaneous divisions known as MULTIPLE Fission, or sporulation. This is usually preceded by a considerable growth of the parent cell and its

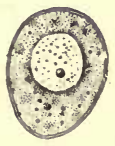

A

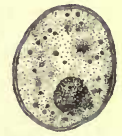

B

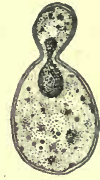

C

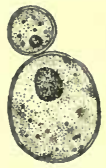

D

Fig. 114. - Yeast cells, very highly magnified. $A$, cell showing granular cytoplasm and a large vacuole; $B$, showing nucleus; $C$, cell budding; $D$, mother cell and bud after division is completed.

enclosure in a protective covering, or CYST, which ruptures to liberate the spores. Other unicellular forms, such as the Yeasts - colorless plants chiefly responsible for alcoholic fermentation-exhibit a modified form of fission, in which the parent cell forms one or several outgrowths, or BUDs, which, gradually assuming the characteristic adult structures, are usually detached as complete similar individuals. (Fig. 114.)

In a considerable number of instances, however, the cells arising by multiple fission or budding remain closely associated or organically connected so that they form a COLONY. In some colonial organisms the component cells are all alike and each retains its individuality, while in others certain cells are restricted more or less in their functions, so that a physiological division of labor is established which involves the 
shifting of individuality from the cells to the colony as a whole. This specialization is exhibited chiefly with regard to reproduction and reaches its highest expression among colonial Protista (Protozoa and Protophyta) in Volvox, where among ten thousand or so cells, perhaps a score are specialized for reproduction and the rest are vegetative. Usually each of the reproductive cells (germ cells) divides

A. Paramecium.

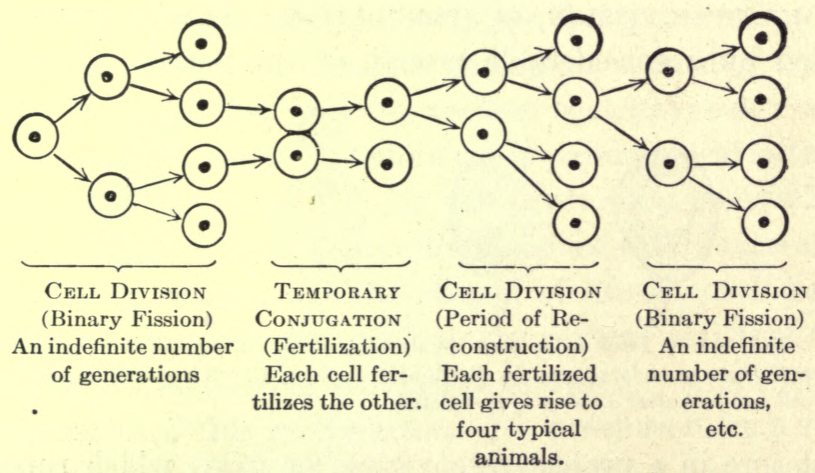

B. Volvox.

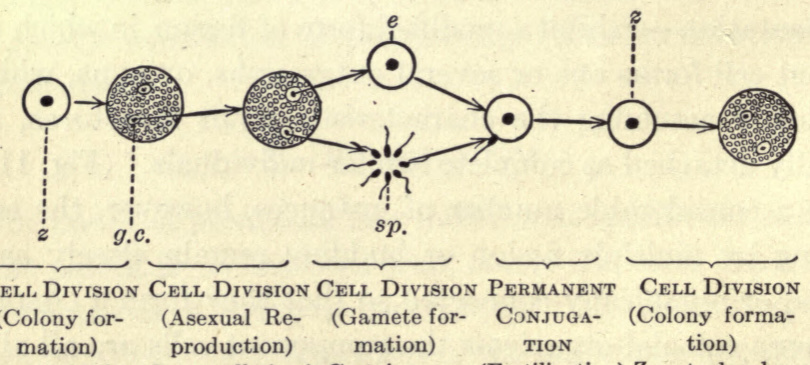

Zygote (z) de- Germ cells (g.c.) Certain germ (Fertilization) Zygote develops velops into a give rise to new cells produce One sperm into a colony, colony. colonies. eggs $(e)$; others fuses with one etc. sperm. (sp.) egg, forming a zygote (z). 


\section{Hydra.}

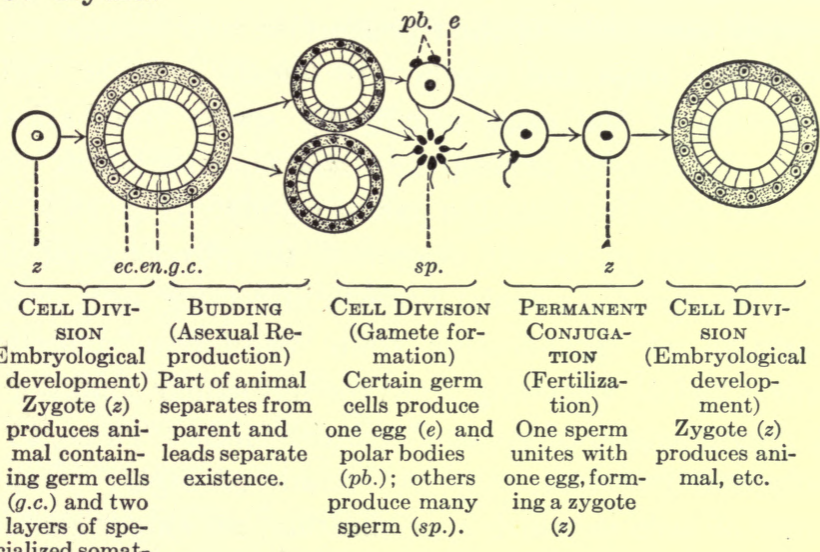

cialized somat-

ic cells, the

ectoderm (ec.)

and endoderm

(en.).

\section{Earthworm}

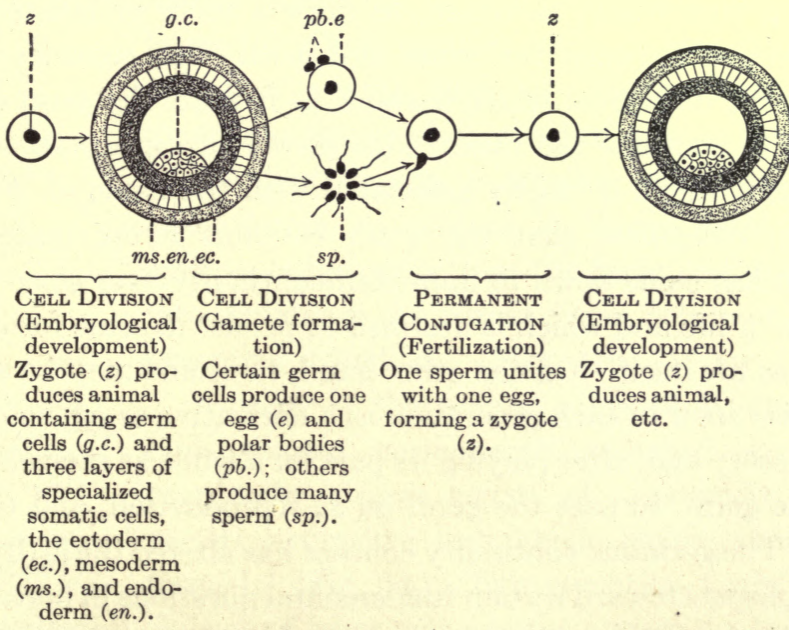

Fig. 115, - Diagrams to illustrate the general reproductive cell cycle in (A) a unicellular organism (Paramecium); (B) a colony of cells (Volvox); (C) a simple Metazoon (Hydra); and (D) a more complex Metazoon (Earthworm). (From Hegner.) 
to form a group which is set free as a miniature colony; but in certain cases some of the reproductive cells become transformed into male and others into female gametes. After fertilization of the eggs, usually by sperm from another colony, the zygotes develop into new colonies which eventually are liberated from the parent colony. (Fig. 18.)

As has been previously suggested, the physiological division of labor in the colonial Protista, involving, as it does, a segregation of reproductive from vegetative structures, affords a logical transition from the unicellular condition to that characteristic of the multicellular forms. These, to all intents and purposes, may be considered highly complex colonies of cells in which specialization, no longer confined merely to demarking germinal and vegetative regions, has transformed the latter into a complex of tissues and organs, the body (soma) of the individual, while the germinal tissue (GERM) is confined to the essential reproductive organs.

It is customary, therefore, to draw a more or less sharp distinction between the soma and germ - to consider the soma the individual which harbors, as it were, the germ destined to continue the race. This theory of GERMINAL CONTINUITY, which is chiefly associated with the name of Weismann, recognizes that the germ contains living material which has come down in unbroken continuity ever since the origin of life and which is destined to persist in some form as long as life itself. On the other hand, the soma may be said to arise anew in each generation as a derivative or offshoot of the germ; and, after playing its part for a while as the vehicle of the germ, to pass the germ on at reproduction, and then die. The germinal continuity concept has altered the attitude of biologists toward certain fundamental questions in heredity and evolution, as will be apparent when these subjects are considered. (Figs. 115, 135.) 
Though Volvox and other colonial forms afford a glimpse of the conditions which probably prevailed when the evolutionary bridge from unicellular to multicellular organisms was crossed, the varied methods of reproduction of the latter by no means indicate the early establishment of a hard and fast boundary between soma and germ. Many of the Invertebrates, such as Hydra and various types of worms,

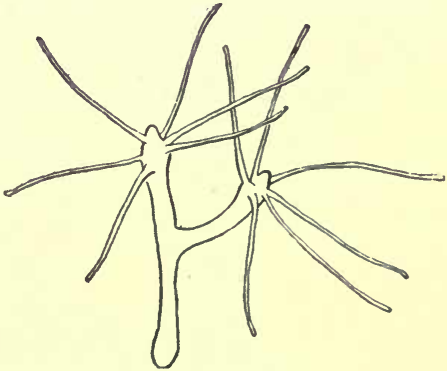

Fig. 116. - Hydra reproducing asexually by dividing lengthwise. (After Koelitz.) reproduce not only by germ cells, but also by strictly asexual

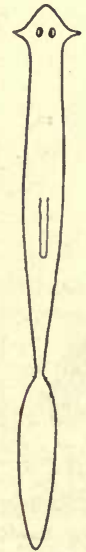

Frg. 117. -An unsegmented worm (Flatworm) in process of fission. (After Child.)

processes which are known as FIssion and BUDDING. These processes are comparable merely in a superficial way with the similarly named methods in the Protista. In some forms the whole complex body divides into two or more parts, each of which reformsREGENERATES - what was lost and so becomes a complete though a smaller individual. In other forms, as well as in Hydra itself, buds arise as outgrowths from the body and develop into replicas of the parent either before or after becoming detached. (Figs. 116, 117.)

In many of the nearest allies of Hydra the buds remain permanently attached so that eventually a large colony of organically connected hydra-like individuals (HYDRANTHS) is formed. (Fig. 64.) This condition leads to a physiological division of labor between the various hydranths which may become more or less modified in structure so that, 
for instance, feeding, protective, and reproductive individuals are established, and thereby the HydroId colony exhibits what is termed POLYMORPHISM. Our present interest is confined
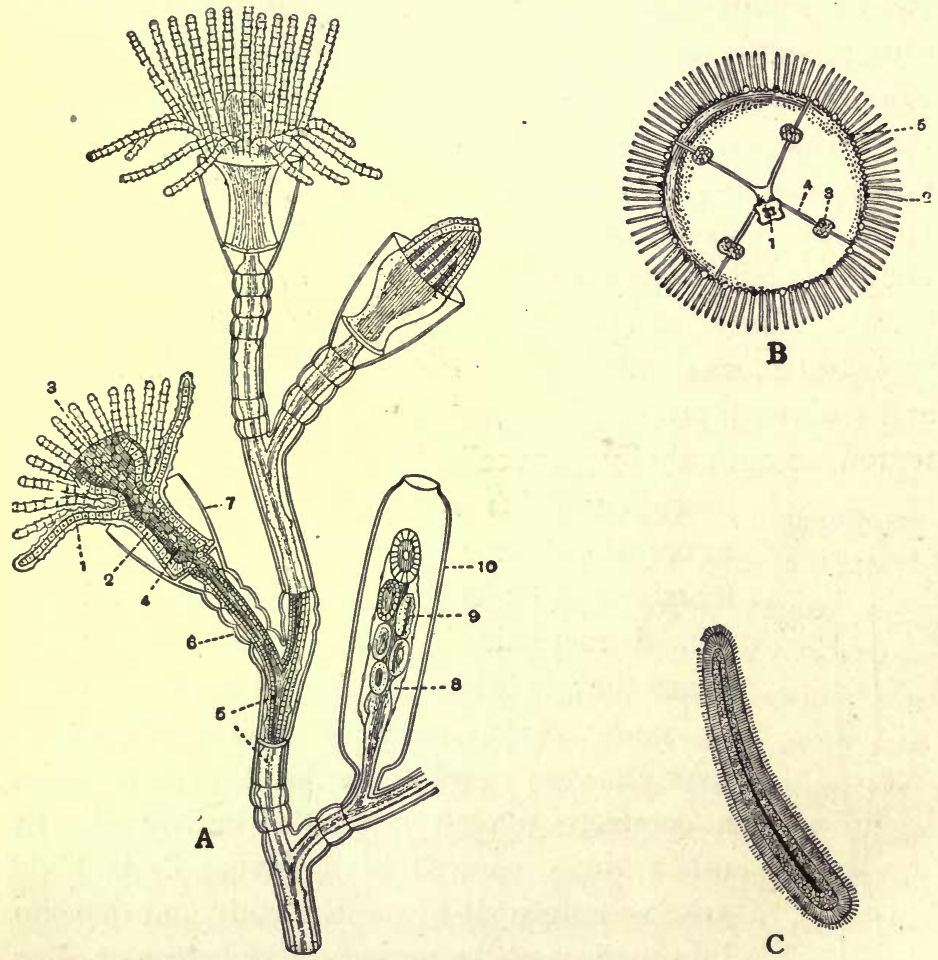

B

Frg. 118. - Life history of Obelia. A, portion of a colony: 1, ectoderm; 2 , endodarm; 3 , mouth; 4 , enteric cavity; 5 , stalk of colony; 6,7 , and 10 , exoskeleton; 8 , reproductive hydranth (blastostyle); 9 , medusa bud. $B$, free swimming medusa: 1 , mouth; 2 , tentacles; 3 , reproductive organs; 4 , radial canals; 5 , sense organ. $C$, ciliated larva of closely related species. (From Hegner, after Parker and Haswell, Shipley and MacBride, and Allman.)

to the reproductive hydranths, which in many of the Hydroids are so modified that they are dependent upon the colony as a whole for all the necessities of life and are merely bodies which form by budding other individuals known as MEDUSAE. 
The medusae, which become detached and swim away, usually bear no superficial resemblance to any of the other individuals of the colony on which they arose, but a study of their structure shows that they are built on the same fundamental plan and are, to all intents and purposes, freeswimming sexual hydranths, some of which produce sperm and others eggs. The medusae liberate their sexual products in the water where fertilization occurs, and the zygote gives

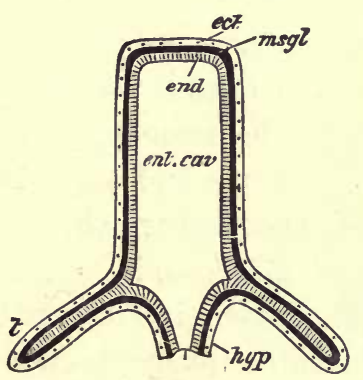

A

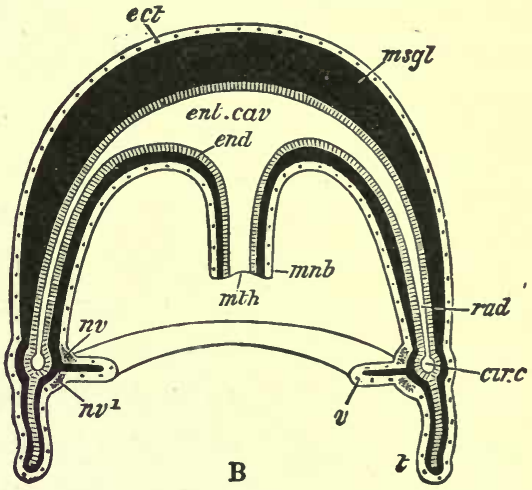

FIG. 119. - Diagrams to show the fundamentally similar structure of Hydra or of a hydranth of Obelia (A) and of a medusa (B). circ, circular canal; ect, ectoderm; end, endoderm; ent. cav, enteric cavity; hyp, mnb, region of mouth (mth); msgl, mesogloea; $n v, n v^{1}$, nerve rings; rad, radial canal; $v$, velum. (From Parker.)

rise to a free swimming embryo (LARVA). This soon becomes attached to some submerged object and develops into a $\mathrm{Hy}-$ droid colony. (Figs. 118, 119.)

Thus the common Hydroids, such as OBeLIA, exhibit two distinct phases, or generations, in their life history - the fixed, polymorphic colony of hydranths, or polypes, which is produced sexually but is itself asexual; and the free-swimming medusae which are produced asexually but are themselves sexual. The asexual and sexual generations alternate with each other in regular sequence, so that an alternation of 
generations known as metagenesis occurs, which, thougn it differs from, recalls the conditions which obtain in plants.

Alternation of asexual and sexual methods of reproduction, attended by more or less difference in structure of the individuals of the generations, is fairly widespread among the Invertebrate groups, particularly in forms which have adopted a parasitic mode of life. Frequently the life histories are exceedingly complicated: several asexual, sexual, and parthenogenetic generations succeeding one another in response to the exigencies imposed by adaptation to a life within another animal or series of animals.

It is clear from such life histories that the conception of special germ cells early set aside, as it were, from the somatic cells must not be taken too literally. The same point is emphasized by the power exhibited by plants and animals in restoring parts lost by mutilations of one kind or another. Among many plants, pieces of the root, stem, or, in special cases, of the leaf may give rise to individuals complete in every respect. Until the middle of the eighteenth century this was considered a property peculiar to plants, and accordingly soon after Hydra was discovered experiments were made to determine whether the organism was a plant or an animal. Specimens were cut into several pieces and it was found that each piece developed into a complete Hydra. This result, from the ideas of the time, should have led to the conclusion that Hydra is a plant, but additional characteristics were observed which outweighed all other considerations. Accordingly Hydra was recognized as an animal with the power of replacing lost parts. (Fig. 120.)

Since the classic work on Hydra the power of regeneration has come to be recognized as a fundamental property of all animals. It is exhibited to the greatest degree among the lower animals while in the higher Vertebrates it is confined 
chiefly to the replacement of cells which especially suffer from wear and tear, such as those forming the outer layer of the skin. It will be recognized that regeneration is but one phase of a fundamental property of protoplasm, namely growth, whether it consists in restoring a part of a Paramecium, transforming a bit of a Flatworm into a complete animal, or replacing half of an Earthworm, the head of a

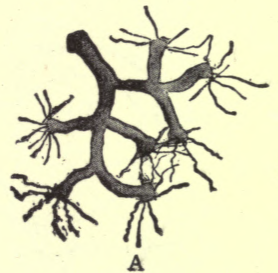

A
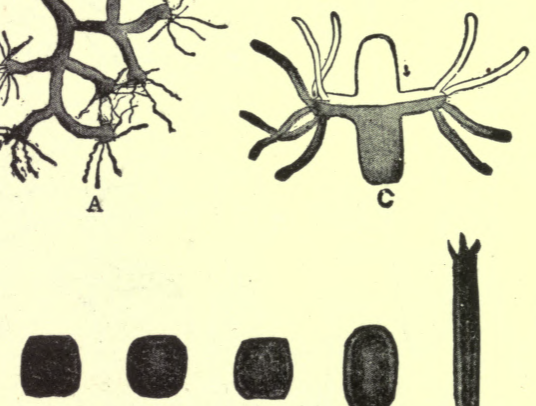

$\mathbf{I}$

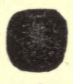

a

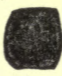

3

$\mathbf{B}$

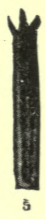

FIg. 120. - Regeneration and grafting in Hydra. A, an individual with seven 'heads' as a result of lengthwise cuts. $B$, stages in the regeneration of a complete individual from a small piece. $C$, Portions of two individuals grafted together. (From Hegner; $A$, after Trembley; $B$, after Morgan; $C$, after King.)

Snail, the claw of a Crayfish, or the leg of a Salamander. But the experimental study of regeneration phenomena has opened up a new vista of the regulatory powers of living things from Protist to Vertebrate and from egg to adult, and has afforded a means of approach to some fundamental biological problems. And withal it has a practical value. The surgeon now knows more of the regeneration of tissues in general and nerves in particular in wound healing, and the oysterman knows - or should know - that his attempt to destroy Starfish by tearing them up and throwing the pieces 
overboard, serves merely to increase many fold this enemy of the oyster. (Figs. 121, 122.)

The power of fragments of distinctively somatic tissue, as in the Earthworm and many plants, to form a complete organism including the reproductive organs and germ cells, indicates that we must postulate at least a potential supply
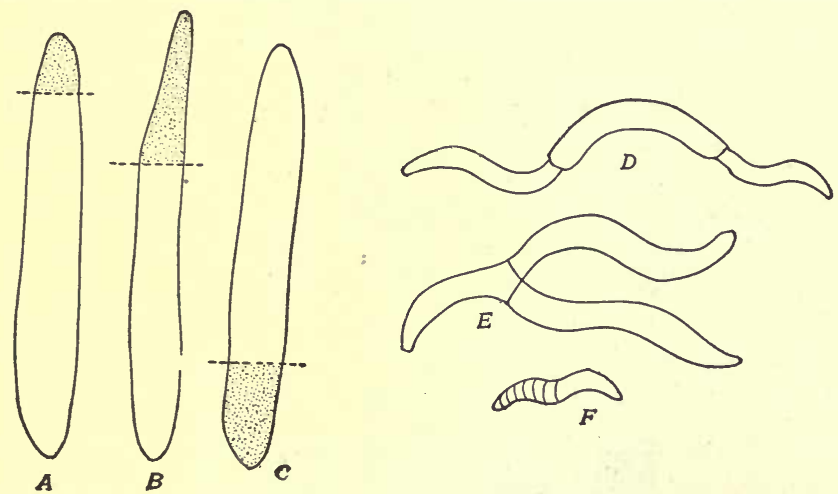

FIG. 121. - Regeneration and grafting in the Earthworm. $A$, regeneration of removed anterior segments by the posterior piece. $B$, regeneration of posterior segments by the posterior part, so that the worm has a 'tail' at either end. $C$, regeneration of removed posterior end by the anterior piece. $D$, three pieces grafted together to make a long worm; $E$, two pieces grafted to form a worm with two 'tails'; $F$, short anterior and posterior pieces grafted together. Regenerated portions are dotted. (From Hegner, after Morgan.)

of the germ residing in the somatic tissue, which can make good the definitive germ cells when they are lost. At first glance this may seem to be a far cry to save an idea, but it is a fact that there is a continuity of the nuclear complex (GERM PLASM) whether the germ cells are set aside early in individual development, or later by the transformation of what seem to be typical somatic cells. That this is really the crux of the question will be appreciated after the details of cell division have been described. 


\section{Origin of the Germ Cells}

Among the Vertebrates, as we know, the germ cells reside during adult life in definite organs, the ovaries and testes, and upon these cells the power of reproduction of the individual is solely dependent. It seems clear, however, that the

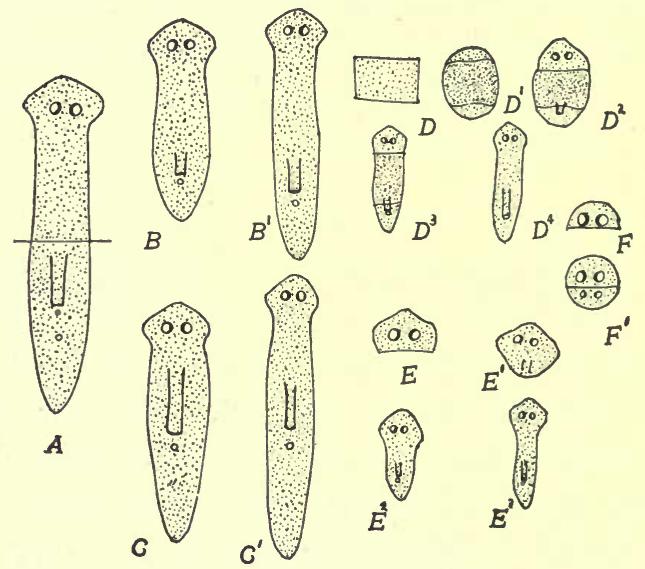

Fig. 122. - Regeneration of a Flatworm (Planaria maculata). A, normal worm; cut across at line indicated. $B, B^{\prime}$, and $C, C^{\prime}$, regeneration of anterior and posterior parts of $A$ to form complete worms. $D$, piece cut from a worm; $D^{1}, D^{2}, D^{3}, D^{4}$, successive stages in the regeneration of $D$. $E$, 'head' from which rest of animal has been cut off. $E^{1}, E^{2}, E^{3}$, successive stages in the regeneration by $E$ of a complete body. $F$, similar experiment to $E$, but a new 'head' in reversed position is regenerated instead of a body, $F^{1}$. (From Hegner, after Morgan.)

primordial germ cells do not arise as such by division in the tissues which during development form the ovaries and testes. Just when the germ cells are set aside in Vertebrates is uncertain, but it would seem to occur very early in embryonic life, perhaps during the cleavage of the egg. Then by shiftings of the tissues during growth, and possibly also by amoeboid movements of the germ cells themselves, they finally reach definite positions in the epithelium lining the 
dorsal wall of the coelom, which becomes an integral part of the gonads as development proceeds.

With regard to the fate of the PRIMORDIAL GERM CELLS, once they have reached testis or ovary, we are on surer ground and can trace with considerable exactness their divisions and transformations which give rise to the gametes, sperm and eggs. In the first place the primordial germ cells proceed to . multiply in the testis and ovary so that they produce a large number of relatively small germ cells known as SPERMAToGONIA and oöGONIA respectively.

\section{Mitosis}

Before taking up the origin of the gametes from the spermatogonia and oögonia, it will be necessary to describe in some detail the complicated internal process involved in all typical cell divisions, known as MITosis, which was dismissed when considering the origin of cells until the reader would be in a position to appreciate to the full its significance.

Reduced to its simplest terms, a typical resting cell, that is one which is not dividing, consists of a mass of cytoplasm surrounding a nucleus; the latter with its chromatin distributed so that it presents a net-like appearance. In addition to the nucleus, it will be recalled that there is present another important cell organ, the CENTROsome, which appears like a tiny granule situated in the cytoplasm near the nucleus of the resting cell. For all practical purposes we may consider the cytoplasm as the arena in which mitosis takes place, the centrosome as the dynamic agent, and the nucleus, or more specifically its chromatin, as the essential element which the complicated process is particularly designed to distribute with nicety to the daughter cells which are in process of formation. With this in mind we may proceed to an outline of the chief stages of mitosis, first cautioning the reader 
to remember that variations in the details are as numerous as the different types of cells, and that any general account can do no more than present the fundamental plan of operations.
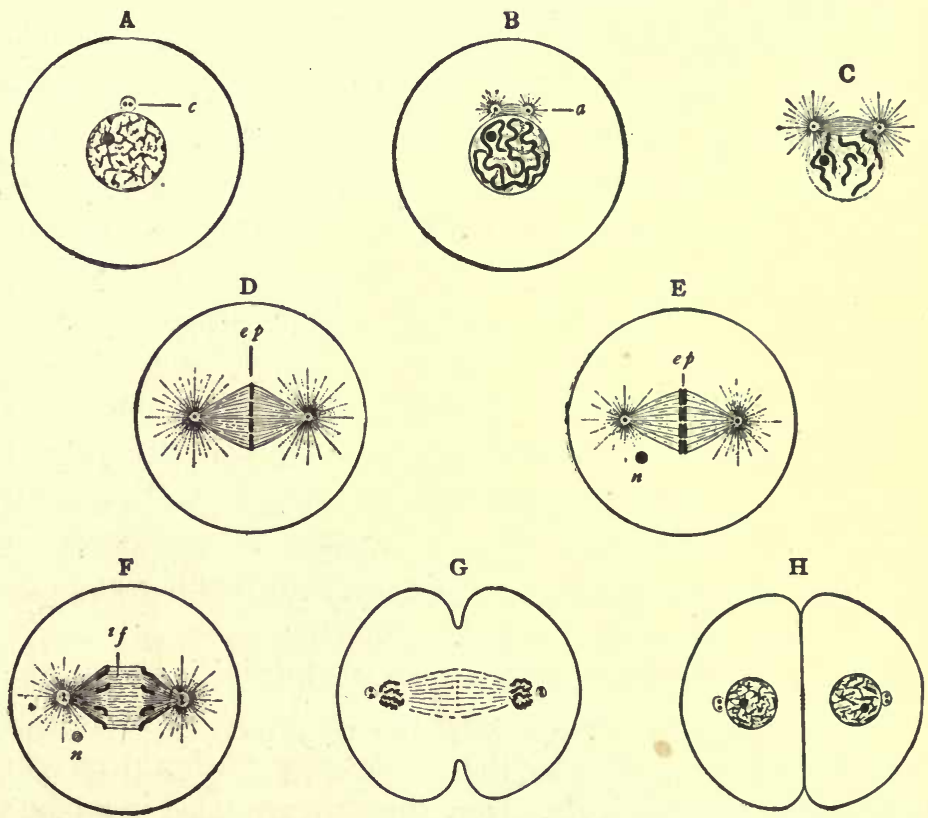

Frg. 123. - Diagrams of typical stages in mitosis. $A$, resting cell with chromatin presenting a net-like arrangement within the nuclear membrane; $c$, centrosome divided; $B$, Prophase (early): centrosomes, asters (a), and spindle; most of the chromatin material seems to assume the form of a long thread (spireme); $C$, prophase (later) involving the disappearance of the nuclear membrane, and the separation of the chromatin of the spireme stage into discrete bodies (chromosomes); $D$, prophase (final) with chromosomes arranged in the equatorial plate $(e p)$; $E$, metaphase; each chromosome splitting lengthwise; $F$, anaphase: the daughter sets of chromosomes moving toward the asters; if, 'inter-zonal fibers'; $G, H$, early and later telophase involving the gradual loss of visibility of chromosomes as they spin out into the resting net-like arrangement of the chromatin; division of the cytoplasm; $n$, nucleolus. (After Wilson.)

Broadly speaking, mitosis can be divided into four chief stages: PROPHASE, METAPHASE, ANAPHASE, and TELOPHASE, during each of which characteristic changes take place in the nucleus, cytoplasm, and centrosome. (Figs. 8, 123.) 
At the beginning of the prophase, or earlier, the centrosome divides to form two, each of which becomes surrounded by what appears to be a halo (ASTER) of radiating fibers which are possibly cytoplasmic currents - the visible expression of physico-chemical forces. The centrosomes and asters now proceed to move apart, take up positions at opposite sides of the nucleus, and the astral fibers between lengthen until they form a central spindle. While these changes are going on, the nucleus is not inactive. The nuclear membrane gradually disappears and the chromatin granules, originally in a net-like arrangement, seem to become rearranged in a more or less continuous thread of chromatin called the SPIREME. This, however, actually represents a number of definite chromatin entities, termed chromosomes, which gradually by chromatin concentration become distinctly individual. The number of chromosomes varies greatly in different species, but is typically an even number and the same for all the cells of a given species.

When the chromosomes have assumed definitive form, the preliminary events which constitute the prophase of mitosis are brought to a close by the chromosomes being drawn to the center of the spindle. Here they are arranged in a plane at right angles to the long axis of the central spindle, midway between the two centrosomes, and form the EQUATORIaL PLATE.

And now the stage is set for what is apparently the climax of mitosis, designated the metaphase. Each of the chromosomes separates into two parts along the line of a longitudinal split,in such a manner that each of the thousands of chromatin granules which make up a chromosome is equally divided. Two sets of similar daughter chromosomes are thus formed.

With chromosome division consummated, the metaphase merges into the anaphase which is devoted to a shifting of a 
daughter set of chromosomes along the fibers to either end of the spindle. In this way each centrosome becomes associated with one set of daughter chromosomes.

The last stage, or telophase, is one of nuclear reconstruction and division of the cytoplasm. The chromosomes become indistinct as they spin out to form the net-like arrangement of the chromatin in the nucleus of each daughter cell; a nuclear membrane arises; and the nucleus again assumes the form of a definite spherical body characteristic of the resting cell. It must be emphasized, however, that although the chromosomes usually disappear from view as definitive entities in the resting nucleus, nevertheless the individuality of each persists and the same chromosomes emerge from the nuclear complex at the next division period.

Simultaneously with these nuclear changes, and before the spindle and asters - the machinery of mitosis - disappear, the division of the cytoplasm is initiated as indicated by an indentation of the cell wall at the equator of the cell. This gradually extends through the cytoplasm in the same plane which the equatorial plate formerly occupied, until the cytoplasm is cut into two separate masses, each containing one of the daughter nuclei and centrosomes. And one cell has merged its individuality into two daughter cells by mitotic division.

A little thought will convince the reader that whereas the mitotic process apparently results in merely a mass division of the cytoplasm, the chromatin material is rearranged and distributed in a manner which makes it possible for each cell to receive a very definite share. Indeed this seems to be the primary object of mitosis. For in many cases there is a very great difference in the size of the resulting cells, but the number of chromosomes in each is the same. This, and other evidence which will presently appear, has clearly established 
the chromosomes as the chief factors in the transmission of characters from cell to cell, and therefore in inheritance.

\section{Gametes}

Returning now to the origin of gametes. The spermatogonia and oögonia in the reproductive organs are, together with all the cells forming the body proper, direct descendants by mitotic cell division from the fertilized egg which gave rise to the individual organism. This is equally true of the chromosomes themselves and accordingly every cell of the animal has the same number of chromosomes as the fertilized egg.

Fertilization, as we now know, always consists of the fusion of two gametes, whether it is in plants or animals; a fusion of nucleus with nucleus and cytoplasm with cytoplasm to form a zygote, which therefore is one cell reconstructed from two. Such being the case, one of two things must happen at fertilization. Either the fertilized egg must have double the chromosome number, that is a set contributed by both egg and sperm; or some method must exist by which the chromosomes of the gametes are reduced in number to one half that characteristic of the somatic cells.

As a matter of fact a reduction in the number of chromosomes always takes place sometime during the life history. In plants such as the Mosses, Ferns, and Flowering Plants, it occurs at the formation of the spores. Thus it follows that the gametophyte contains half as many chromosomes as the sporophyte, and the sporophyte number is restored by the union of the gametes. It must be borne in mind, however, that the familiar plants are sporophytes which, for all practical purposes, directly produce sporophytes because the gametophyte is reduced almost to the vanishing point. The chromosome number of the parent sporophyte and the sporophyte in the seed is the same. But we cannot digress 

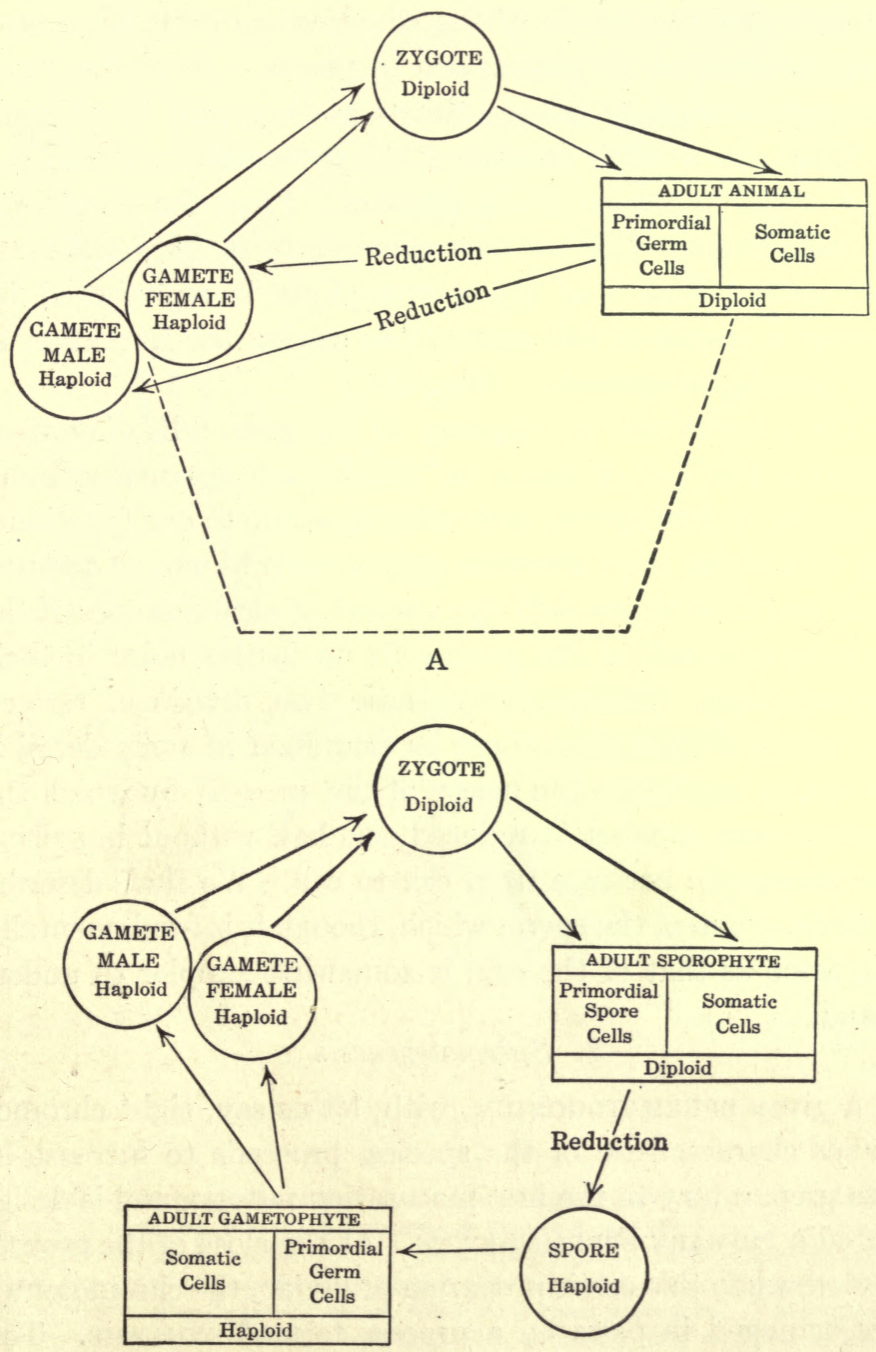

B

Frg. 124. - Schematic representation of the life history of an animal (A) and of a plant, e.g., Fern, (B) from the standpoint of the diploid and haploid condition of the chromosomes. 
to elaborate the details of the chromosome cycle associated with alternation of generations in plants - attention must be concentrated on the conditions as they exist in animals, in which the somatic number of chromosomes is reduced one half at the formation of the gametes. From the standpoint of chromosome number, the sporophyte is comparable to the animal soma and the gametophyte is represented by merely a couple of cell generations during the formation of the gametes in animals. (Fig. 124.)

The MATURA'TION or 'ripening' of the germ cells of animals involves two cell divisions by which each spermatogonium gives rise to four sperm, and each oögonium to one functional egg and three tiny, abortive eggs known as POLAR BODIEs; each and all with one half the number of chromosomes of the somatic cells and of the germ cells up to this point in their development. Consequently these two divisions, termed MATURATION DIVISIONS, must be examined in some detail if we are to appreciate the nicety of the process by which the chromosome number is reduced one half without impairing the chromatin heritage from cell to cell. We shall describe first the origin of the sperm which, though it is fundamentally the same as that of the egg, is somewhat simpler to understand.

\section{Spermatogenesis}

A given spermatogonium, with, let us say, eight chromosomes characteristic of the species, proceeds to increase in size preparatory to the first maturation mitosis, and is designated a PRIMARY SPERMATOCYTE. At the close of the growth period, when this cell is preparing to divide, the chromosomes are arranged in pairs by a process termed synapsis. The number of such pairs will obviously be half that of the chromosome number. The synaptic pairs are then distributed in the equator of the spindle exactly as the single chromosomes 


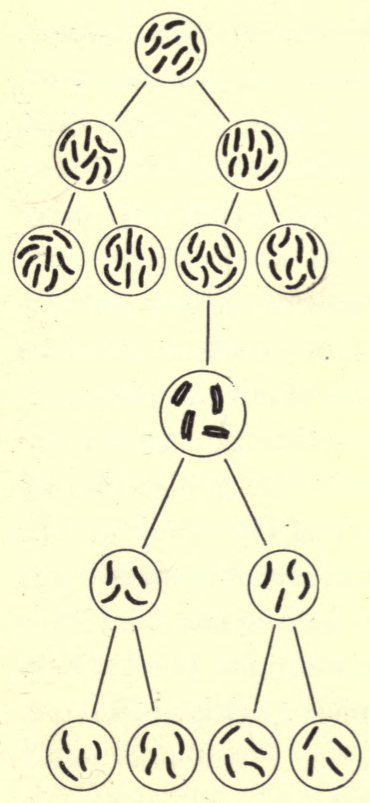

A

B
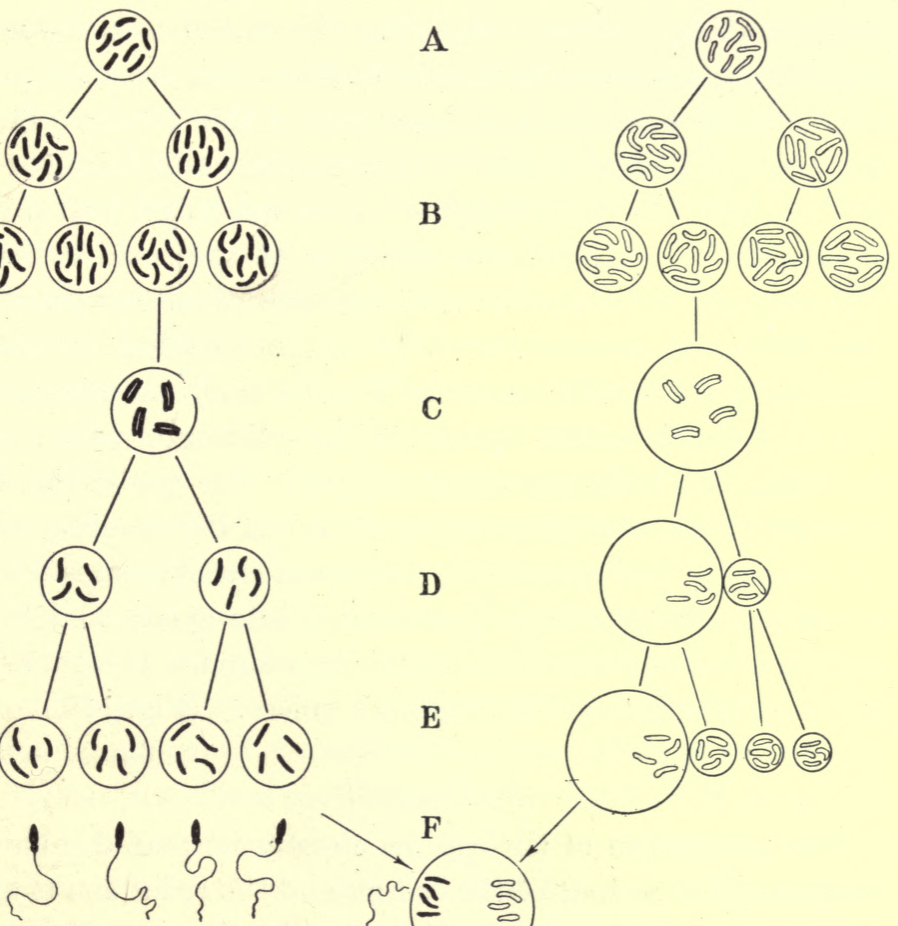

D

C

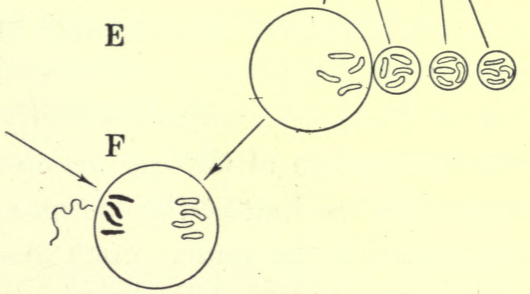

G

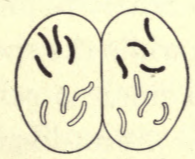

FIG. 125. - Diagram of the general plan of spermatogenesis and oögenesis in animals. The somatic, or diploid, number of chromosomes (duplex group) is assumed to be eight. Male, to the left; female, to the right. $A$, primordial germ cells; $B$, spermatogonia and oögonia, many of which arise during the period of multiplication; $C$, primary spermatocyte and oöcyte, after the growth period, with chromosomes in synapsis; $D$, secondary spermatocytes and oöcytes, with haploid number (simplex group) of chromosomes, which have arisen by the first maturation (reduction) division; $E$, spermatids (which become transformed into sperm) and egg and three polar bodies which have arisen by the second maturation (equation) division; $F$, union of sperm and egg (fertilization) to form zygote with diploid number (duplex group) of chromosomes; $G$, chromosome complex of cells after first division of the zygote, and of all subsequent somatic cells, and germ cells until maturation. 
are in ordinary mitosis. But, and this is the crucial point, in the early anaphase the members of each pair are separated, one synaptic mate going to each pole of the spindle. Thus each of the daughter cells - SECONDARY SPERMATOCYṬE receives half the total number of chromosomes that were present in the primary spermatocyte or the somatic cells. The essential difference between this type of mitosis (REDUCTION DIVISION) and that involved in other nuclear divisions (EQUATION DIVISIONS) lies in the separation of entire chromosomes (synaptic mates) instead of the splitting of each chromosome. Both the secondary spermatocytes now divide by typical mitosis, thus distributing to each of the resulting cells (spermatids) half the somatic number of chromosomes. The spermatids are presently transformed into sperm and thus each spermatogonium with eight chromosomes gives rise to four sperm with four chromosomes apiece. (Fig. 125.)

\section{Oögenesis}

The maturation of the egg, as already intimated, follows the same plan as that of the sperm, and the reduction of the chromosomes is the same. Such modifications as occur are related to the fact that the egg is usually a relatively large passive cell stored with nutritive materials for use during the developmental process, while the sperm is among the smallest of cells - essentially a nucleus surrounded with a delicate envelope of cytoplasm. Accordingly it is only necessary to emphasize that the growth period of egg formation, in which the oöGONIUM becomes transformed into the PRIMARY оÖсүте, is characterized by a much greater increase in size than is the case in the corresponding period in spermatogenesis; and that both of the ensuing cell divisions (one a reduction and the other an equation division) involve very unequal divisions of the cytoplasm. Thus one SEcondary 
OöCYTE is very large, while the other is a tiny cell termed the FIRST POLAR BODY. Both the large secondary oöcyte and first polar body now divide again; the former giving rise to a large cell, the mature EGG, and a tiny SECOND POLAR BODY; while the first polar body divides equally to form two polar bodies. In this way arise the four cells, comparable to the four sperm in spermatogenesis, each with half the somatic number of chromosomes. But only one of these, the egg, functions as a gamete. The three polar bodies, although possessing a similar chromosome complex, are sacrificed in providing one cell with its special cytoplasmic equipment. The polar bodies get just enough cytoplasm to be regarded as cells, and soon degenerate and disappear.

Such is the outline of the essentials of spermatogenesis and oögenesis in animals; processes which involve at one stage a modification of ordinary mitosis to give each gamete half the somatic number of chromosomes characteristic of the species. It is clear that this is not merely a mass reduction of chromatin material, but is a separating of definite chromatin entities, the chromosomes, so that the gametes receive the reduced number.

\section{The Chromosome Cycle}

Throughout the animal kingdom, wherever sexual reproduction occurs, phenomena which can be interpreted as nuclear reduction have been observed in the formation of gametes. In some of the Protozoa this seems to be merely an extrusion of a certain amount of chromatin, but since whenever chromosomes can be observed and counted the process has been found to follow in principle essentially the same lines described above, we have every reason to believe that it is never a haphazard mass reduction, and that the ripe gametes emerge with a definite chromatin heritage, relatively simple as this may be in the lowest forms. 
We have now surveyed the germ cell cycle from fertilized egg through the germ plasm in the adult to the gametes again, but before proceeding to consider the details of the fusion of egg and sperm - the fertilization process it may clarify matters to glance back to the chromosome condition in the fertilized egg at the beginning of the cycle which has just been considered. Obviously this fertilized egg (zygote) contained chromosomes, half of which belonged to the egg and therefore may be termed MATERNAL, and half of . which were derived from the sperm and thus are PATERNAL. When the zygote divided by mitosis to form the body and germ, every cell received a set of chromosomes, directly derived from this original set in the zygote. It logically follows, and all observations indicate, that each and every cell, both of the soma and of the germinal tissue, possesses a set of chromosomes, half of which are of maternal and half of paternal origin - in other words are direct lineal descendants of the combined set formed at fertilization. So it happens, that each body cell really has a double set (DUPLEX GROUP, DIPLOID NUMBER) of homologous chromosomes - and the same is true of the germ cells until maturation. Then at synapsis maternal and paternal chromosomes pair and, after the reduction division, the secondary spermatocytes and oöcytes and the gametes themselves have a single set (sImpLex GROUP, HAPLOID NUMBER). (Figs. 124A, 126.)

Thus far we have emphasized chromatin and, in particular, chromosome reduction as the main purpose of the complicated maturation phenomena. The question now arises: Is this chromatin distributed so that all the gametes receive the same heritage?

All the evidence at hand indicates not only that chromosomes differ qualitatively one from another but also that the various parts (chromomeres) of each chromosome are 

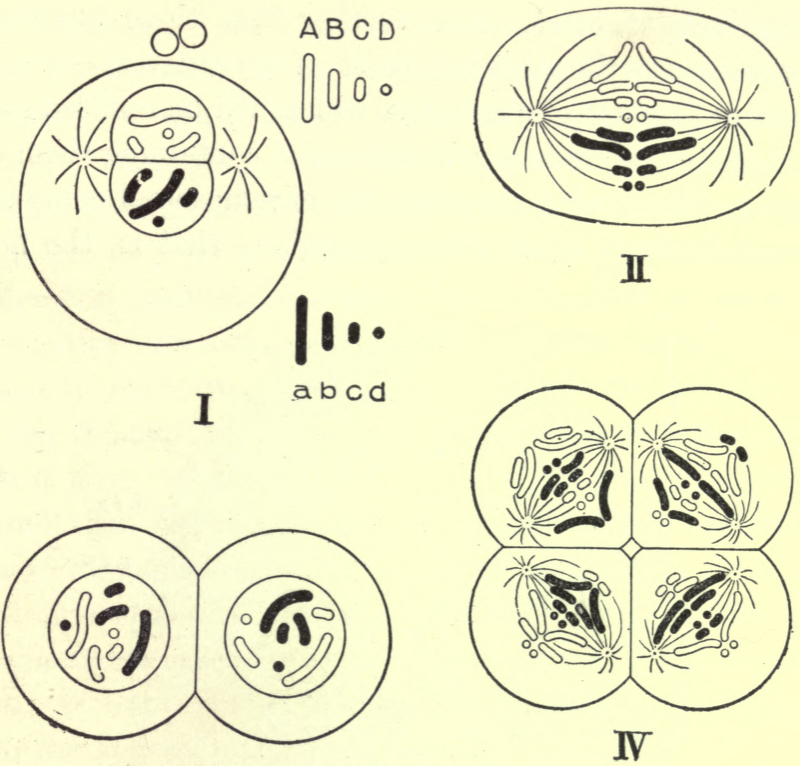

III

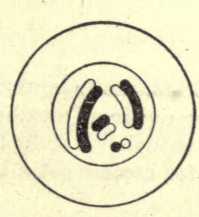

$\mathrm{AaBbCcDd}$

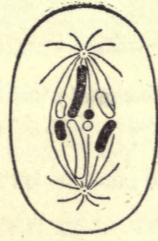

VI

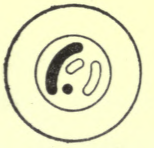

$\mathrm{aBCd}$.

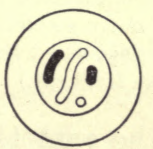

VII

FIG. 126. - Diagram of the chromosome cycle of an animal. Somatic (diploid) chromosome number assumed to be eight. Paternal chromosomes (from sperm) $=$ $A B C D$; maternal (from egg) $=a b c d$. I, union of nuclei of gametes, each with a simplex group (haploid number) of chromosomes, in the zygote at fertilization to form a duplex group (diploid number) of chromosomes. II, III, IV, somatic divisions or divisions of germ cells before maturation (duplex groups of chromosomes). V, synapsis, involving pairing of homologous paternal and maternal chromosomes to give the haploid number of paired chromosomes. VI, reduction division - separation of pairs into single chromosomes again. VII, two gametes, with simplex groups (haploid number) of chromosomes; there are 14 more possible combinations of the chromosomes, or types of gametes, which are not shown. (After Wilson, slightly modified.) 
qualitatively distinct. And further that these qualitative differences are the physical basis of inheritance - the determiners (GENES) of characters which will be realized in the individual or the race to which the cell containing them contributes. Such being the case, the chromosomal complex of the nuclei which arises after synapsis - that is, the nuclei

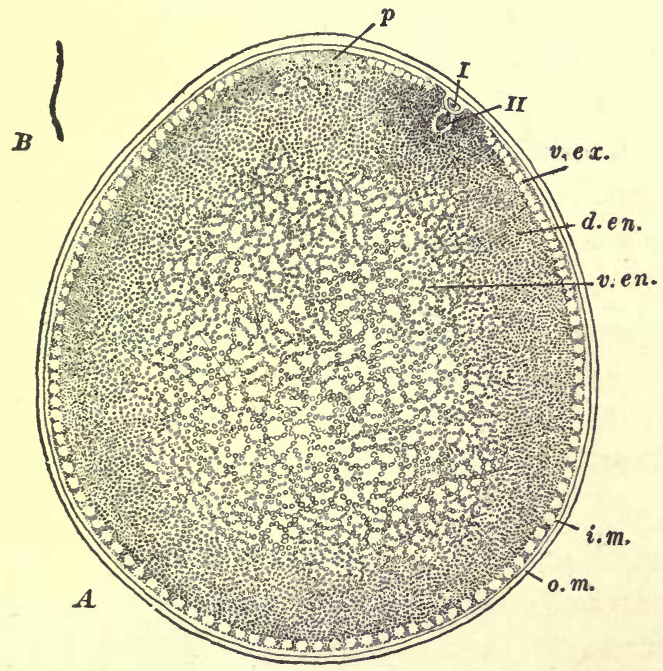

Fig. 127. $-A$, section through the egg of a primitive Vertebrate, the Lamprey. $B$, sperm of the same species, drawn to scale. d.en, dense endoplasm; i.m, inner membrane; o.m, outer membrane; $p$, granular 'polar' cytoplasm; v.en, vacuolated endoplasm; v.ex, vacuolated ectoplasm; $I$, first polar body; $I I$, spindle for second polar body. (From Kellicott.)

of the gametes - depends on how the various chromosomes happen to be distributed during the two maturation divisions. As a matter of fact all the chromosomal combinations occur which are mathematically possible with the available number of chromosomes in a given species, but with one limitatıon: every cell must receive one member of each synaptic pair of chromosomes, so that each and every gamete receives a complete simplex group of chromosomes, but rarely the same 
groups (maternal and paternal) which existed before maturation. For example, if the somatic (diploid) number of chromosomes is eight, sixteen different types of gametes are possible. In Man with 48 somatic chromosomes, and after synapsis 24 pairs of paternal and maternal chromosomes, there are $2^{24}$, or about twenty million possible types of gametes in each sex, and since these combine at random at fertilization, the number of possible different types of zygotes from one parental pair mounts far up in the trillions. No wonder the children of a family differ - there is variation!

In a way, therefore, fertilization is not consummated, so far as its influence on the race is concerned, until the maturation of the gametes in the new generation. We must defer until later the consideration of the significance of these facts in biparental inheritance, and take up now some necessary details of the gametes themselves and of how they unite to form the zygote.

\section{Fertilization}

The gametes, while exhibiting in certain cases peculiar adaptations to special conditions, are remarkably similar in general structure throughout the animal series. It is possible in animals, just as in plants, to arrange a series of lower forms which shows various stages in sex differentiation. Beginning with animals in which both gametes are structurally similar, we pass by slow gradations to others in which the egg is a relatively large, passive, food-laden cell and the sperm a minute, active, flagellated cell. As a matter of fact the egg is subject to somewhat more variation in size and general appearance than the sperm, for after fertilization it must be adapted to meet the special conditions of development peculiar to the species. Thus, for instance, the actual size of the egg in both plants and animals is determined chiefly by 
whether the developing embryo is in the main dependent upon food stored in the cytoplasm of the egg itself, or upon some outside source, such as the sea water in which it floats, or the tissues of the parent. The first case is well illustrated by a Bird's egg in which the so-called youK is the egg cell proper, hugely distended by stored food, and surrounded by nutritive

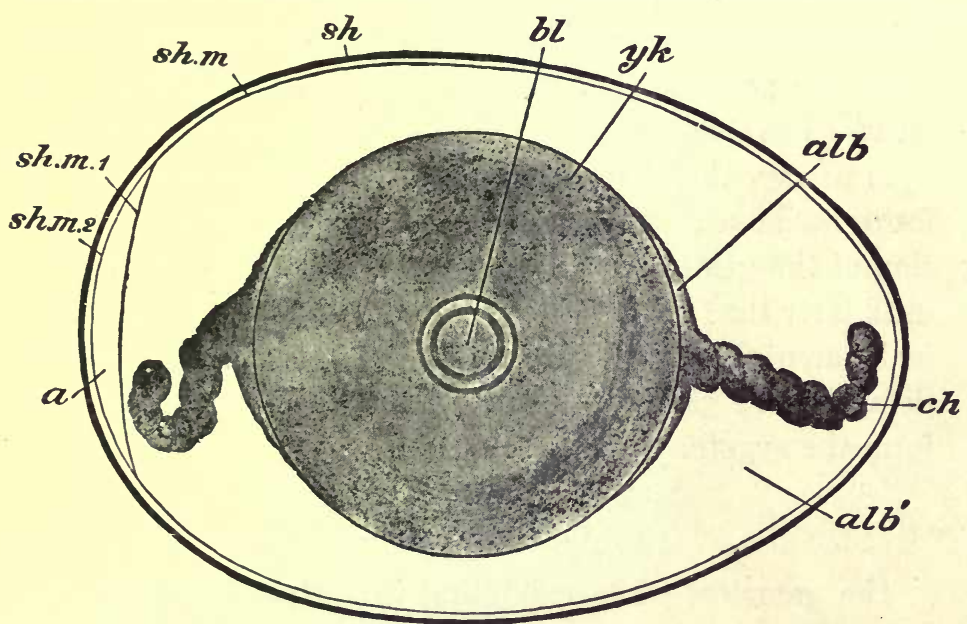

Fig. 128. - Diagram of the egg of the domestic Fowl, before incubation. $a$, air space between two layers of shell membrane; alb, ch, dense albumin (chalaza); $a l b$, more fluid albumin (white of egg); $b l$, point of cytoplasmic concentration from which embryo arises (blastoderm); $8 h$, shell; $8 \mathrm{hm}$, shell membrane. (After Marshall.)

and protective envelopes consisting of the 'white of the egg,' shell membranes, and shell which are formed by secretions from the walls of the oviduct during the passage of the egg to the exterior. On the other hand the eggs of Mammals, for instance of the Rabbit and Man, are very small - the human egg being less than 1/125th of an inch in diameter - since their essentially parasitic method of development in the uterus renders superfluous the storage of any considerable amount of food material in the egg cytoplasm. (Figs. 127-129.) 
With the specialization of the egg along lines which render it non-motile, it has devolved upon the sperm to assume the function of seeking out the egg for fertilization. It does this
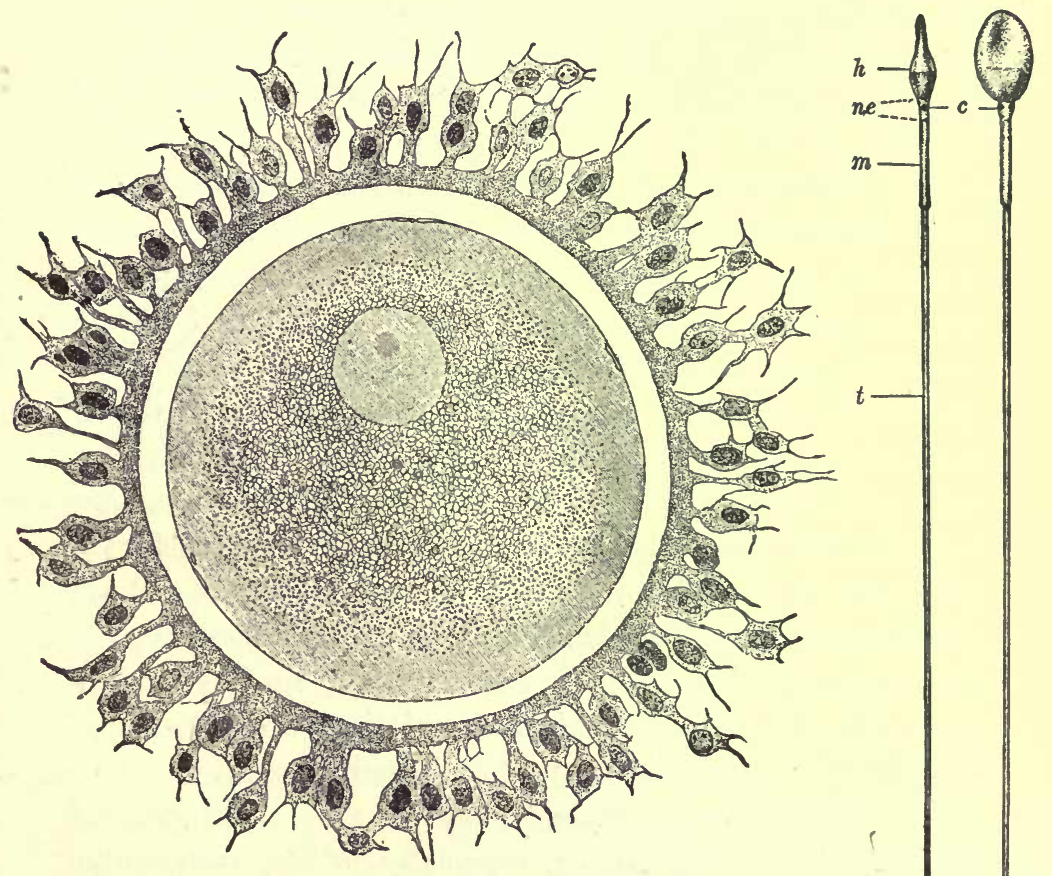

A

FIG. 129. - Human egg cell, $\times 415$, and sperm cell, $\times 2000$. $A$, Egg just removed from the ovary, surrounded by follicle cells of the ovary and a clear membrane. The central part of the egg contains metaplasmic bodies and the large nucleus. Superficially there is a clear ectoplasmic region. (After Waldeyer.) $B$, two views of the human sperm. $c$, centrosome; $h$, 'head' consisting of the nucleus surrounded by a cytoplasmic envelope; $m$, ne, middle piece; $t$, tail or flagellum. (After Retzius.)

in most cases by active lashing of its flagellum. This necessitates a fluid medium in which the sperm can swim, and such is provided by the environment in which the organism lives or, in the case of most higher animals, where fertilization 
takes place within the oviduct, by special fluids secreted for the purpose. In the highest plants, however, it will be recalled that the characteristic motility of the sperm is lost in the excessive specialization attendant upon gametophyte reduction - the sperm nucleus reaching the egg by the growth of the pollen tube down through the tissues of the style.

A question of much interest is how the actual meeting of the gametes is brought about. In many cases it is undoubtedly merely by chance; the random swimming of the sperm sooner or later bringing one in contact with an egg. In other cases the movements of the sperm seem to indicate some definite attraction by the egg. It has been shown, for example, that the sperm of some Mosses and Ferns are attracted by exceedingly dilute solutions of cane sugar and malic acid respectively, traces of which are secreted by the tissues in the vicinity of the egg. Also the sperm of some of the lower animals are attracted by substances eliminated by the egg during maturation. In such instances there can be but little doubt that chemical stimulation of the sperm by specific substances plays a part in bringing the gametes together. This is an example of chemotaxis: a phenomenon of considerable importance, especially in the behavior of free-living cells.

Once a single sperm has come into functional contact with the egg, it initiates a chain of events which constitutes fertilization. Although, as might be expected, the variations in details are legion, they do not obscure the main facts. The first reaction on the part of the egg is to prevent the entrance of other sperm and thereby to insure a free field for the operations of the first arrival. In some of the lower plants this is accomplished by secreting instantly a chemical substance which repels other sperm. Frequently among animals a 
jelly-like layer is formed about the egg, or, if a membrane is already present, this may be rendered impermeable or still another formed. In cases where the egg is surrounded originally by a dense and resistant wall, the tiny opening provided for the entrance of the sperm is closed. However, the accessory wrappings about certain eggs, such as those of Birds, have no relation to the present subject, since they are secreted, not by the egg itself, but by glands in the wall of the oviduct some time after fertilization has occurred.

The reactions of the egg cytoplasm that exclude accessory sperm are overshadowed in importance by others which upset the stable equilibrium of the egg and render its surface permeable, so that extensive osmotic interchanges take place between the cytoplasm of the egg and its surroundings. Most often this is visible merely in a shrinkage of the cytoplasm due to loss of water, but sometimes contractions, amoeboid movements, or flowing of special cytoplasmic materials to definite regions of the egg are visible. In any event it is certain that the cytoplasm undergoes profound changes its organization as a gamete gives place to a reorganization which establishes and determines the general outlines of its subsequent development as an individual. (Fig. 132, A, B.)

Turning now to the nuclei, known as male and female PRONUCLEI, the union of which to form the single fertilization nucleus (synkaryon) is the climax of fertilization. Disregarding the flagellum of the sperm, which disappears as it enters the egg, we find that the sperm nucleus moves through a quite definite path toward the center of the egg where it is met by the egg nucleus. Both the pronuclei now become resolved into chromosomes which lie free in the cytoplasm, while a pair of centrosomes, surrounded by asters, appear and take up positions on either side of the chromosomes to form a 
typical mitotic figure. The two sets of chromosomes form an equatorial plate at the center of the spindle, thus establishing at once not only the mitotic apparatus for the first division of the egg, but also the intimate association on equal terms of chromosomes, with their potentialities from the two parents, to form a common structure - the nuclear complex of the new individual. (Fig. 126, I, II.)

Such are the outstanding facts of fertilization which a host of investigators have brought to light chiefly within the past century. It was not until 1839 that Schwann, with the establishment of the 'cell theory,' recognized the egg as a cell, and sixteen years more before the sperm was similarly understood; while the first realization that fertilization is an orderly amalgamation of two cells to form one came during the seventies of the past century. Then it became evident that in sexual reproduction each individual contributes to the formation of the offspring a single cell, in which must be sought the solution of the problems of sex, fertilization, development, and inheritance. However, the concentration of attention on the cell has not simplified the solution of these fundamental problems; but rather it has contributed to an ever-increasing appreciation of the complexities of cell phenomena and the difficulties of formulating them in general terms.

With a realization of the intricacies of the phenomena involved and that they are cell phenomena, we may turn to a consideration of the significance of fertilization.

\section{Significance of Fertilization}

It may be emphasized again that fertilization is not reproduction. Reproduction, in the final analysis, is division cell division or the detachment of a portion of the substance of a living organism to constitute another. Rather is fer- 
tilization a phenomenon associated with reproduction - so closely associated in nearly all organisms that the two processes, evolving together from relative simplicity to great complexity, have reciprocally influenced one another until in higher forms they seem to be related as cause and effect, and reproduction becomes dependent on fertilization. With this somewhat didactic statement of our viewpoint, we may consider some of the salient features of the almost endless discussion of the significance of fertilization.

Quite naturally the original view, emphasized by Harvey and a long series of successors, was that fertilization fundamentally is a reproductive process, and echoes of this idea are preserved in certain present-day hypotheses, on the basis of such facts as the following. The mature egg pauses in development and usually comes to naught unless fertilized the entrance of the sperm affording a necessary stimulus for the resumption of cell division which is to transform the egg into the adult. Again, the egg typically contains only half the somatic chromosome complex (simplex group, haploid number) and most of the cytoplasm, while the sperm contributes a reciprocal haploid set of chromosomes; in short, seemingly transforms what is essentially a half into a whole.

However, it does not necessarily follow from these facts that fertilization is primarily a reproductive process. The evidence against this conclusion is derived largely from the relations of fertilization and reproduction in the Protista, and trom the development, in certain cases, of eggs without fertilization, or by PARTHENOGENESIS. A single example of each class of facts will suffice.

\section{Protista}

The life histories of nearly all Protozoa and Protophyta which have been carefully studied include a period in which 
fertilization, or syngamy, occurs. Under usual conditions, Paramecium, for instance, reproduces by fission two or three times a day so that in a remarkably short period the one cell is replaced by a host of descendants. Sooner or later, however, the individuals exhibit a tendency to unite temporarily in pairs, or conjugate. In this process complicated changes take place in the nuclei of the cells, during which, after socalled maturation phenomena, two pronuclei are established in each individual of the pair of conjugants. Then one of the pronuclei in each conjugant migrates over and fuses with the stationary pronucleus of the other to form a synkaryon, or fertilization nucleus, in each cell. After this the two Paramecia separate, reconstruct their characteristic vegetative nuclear apparatus, and proceed to reproduce by division as before. (Fig. 130.)

This is fertilization in Paramecium, and it is generally conceded that the primary significance of synkaryon formation must be sought among unicellular forms of which this is an example. Accordingly a large amount of experimental breeding has been carried out on Paramecium and its allies. The earlier results seemed to demonstrate conclusively that Paramecium can divide only a limited number of times, say a couple of hundred, after which the cells die from exhaustion or SENILE DEGENERATION, unless conjugation takes place. In other words, it was believed that periodic REJUVENATION by fertilization is a necessity for the continuance of the life of the race. And therefore, so the natural conclusion ran, protoplasm is unable to grow indefinitely; there is an inherent tendency for the destructive phases of metabolism to gain ascendency over the constructive, and fertilization serves to maintain or restore the youthful condition and thus secure the continuance of the race.

In this connection, the life history of Paramecium from one 

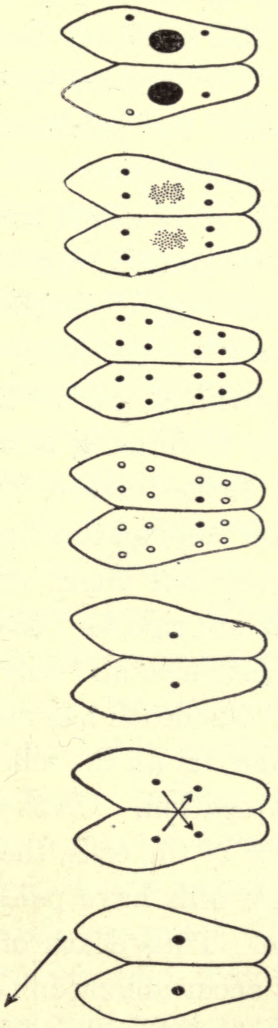

Fig. 130. - Diagram of the nuclear changes during conjugation in Paramecium aurelia. $A$, union of two individuals along the peristomal region; $B$, degeneration of macronucleus and first division of the micronuclei; $C$, second division of micronuclei; $D$, seven of the eight micronuclei in each conjugant degenerate (indicated by circles) and disappear; $E$, each conjugant with a single remaining micronucleus; $F$, this nucleus divides into a stationary micronucleus and a migratory micronucleus - the gametic or pronuclei. The migratory micronuclei are exchanged by the conjugants and fuse with the respective stationary micronuclei to form the synkarya. This is fertilization. $G$, conjugants, with synkarya, separate (only one is followed from this point); $H$, first division of synkaryon to form two micronuclei; $I$, second reconstruction division; $J$, transformation of two micronuclei into macronuclei; $K$. division of micronuclei accompanied by cell division; $L$, typical nuclear condition restored. 
conjugation to the next is often compared to the life of a multicellular organism from its origin as the fertilized egg through youth and adult life to old age, The striking difference is that, in the case of Paramecium, the products of division of the animal which has conjugated (ExconJuGANT) separate as so many independent cells, all of which are alike and, in later generations, capable of conjugation; while all the products of division of the fertilized egg of multicellular forms remain together as a unit and become differentiated for particular functions in the individual, except a few, the germ cells, which retain the power of forming new individuals. Pushing this comparison a little further, if somewhat fancifully, it is stated that after conjugation in Paramecium we have the period of greatest cell vigor, or youth, followed by maturity when the cells are ripe for conjugation again, and in the absence of conjugation - and only then - the onset of old age, and death. Thus death has no normal place in the life history of Paramecium, for all the cells at the period of maturity are capable of conjugation. On the other hand, in multicellular forms only some of the cells, the germ cells, retain this power - the somatic cells have paid the penalty of specialization and must die. Thus death of the individual except by accident does not occur among unicellular forms because fertilization 'rejuvenates' the cell, and the cell and the individual are one and the same. With the origin of multicellular forms, involving the segregation of soma from germ, death became possible, and was established it is the 'price paid for the body.' (Figs. 115, 135.)

Suggestive as is this comparison and contrast - and it is not without some justification - the cardinal fact remains that recent work has demonstrated that Paramecium, under favorable environmental conditions, can continue reproduction indefinitely; at least for fourteen years and some ten 
thousand generations, without conjugation and without any signs of degeneration. In other words fertilization is not a necessary antidote for inherent senescence, and this, taken in connection with other data which point in the same direction, such as the fact that in many plants sexual propagation is seldom if ever resorted to, renders it fairly safe to make the general statement that the need of fertilization is not a primary attribute of living matter. Now, reproduction is such an attribute and therefore the evidence at hand indicates that reproduction and fertilization are intrinsically separate processes which, however, have become closely associated, especially in higher forms.

So far our conclusion is entirely negative - fertilization is not reproduction and is not intrinsically necessary for reproduction. What then is its significance? Though fertilization may not be necessary in the life of simple organisms under favorable conditions, this does not indicate that it may not be a stimulus to protoplasmic activity when it does occur - perhaps a very important factor under special environmental conditions. Indeed there is no doubt that conjugation in certain cases directly results in stimulating all the vital processes of the cell, including reproduction. But it would seem that the essential factor in this stimulation is not the essence of fertilization - synkaryon formation. In Paramecium, for example, an internal nuclear reorganization process known as ENDOMIXIs occurs periodically. Although endomixis is carried on by each cell without the coöperation of another cell, and therefore without synkaryon formation, nevertheless it apparently effects a physiological stimulation similar to that which follows synkaryon formation during conjugation. This is the special aspect which the discussion of the 'dynamic' effect of fertilization in Protista has recently assumed. (Fig. 131.) 
A

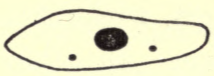

B

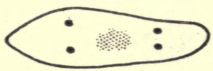

C

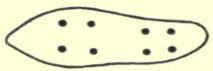

D

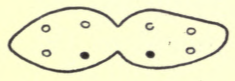

E
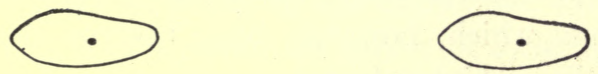

F
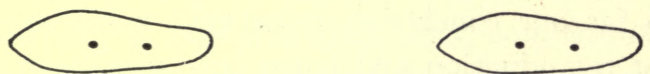

G
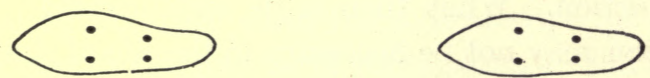

H
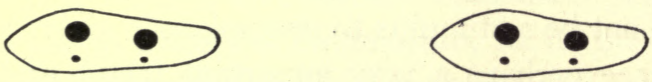

I
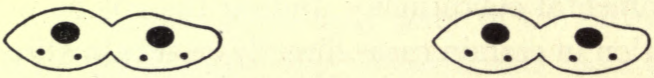

$\mathbf{J}$
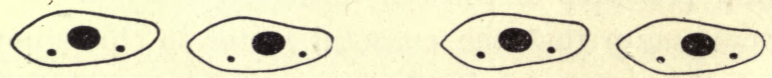

FIg. 131. - Diagram of the nuclear changes during endomixis in Paramecium aurelia. $A$, typical nuclear condition; $B$, degeneration of macronucleus and first division of micronuclei; $C$, second division of micronuclei; $D$, degeneration of six of the eight micronuclei; $E$, division of the cell; $F$, first reconstruction micronuclear division: $G$, second reconstruction micronuclear division; $H$, transformation of two micronuclei into macronuclei; $I$, micronuclear and cell division; $J$, typical nuclear condition restored. 


\section{Metazoa}

Turning from Paramecium and its allies, we may consider some evidence among higher forms in regard to the 'dynamic' influence of fertilization. Although fertilization is usually necessary for the resumption of the series of cell divisions which paused after the maturation divisions, and which are to transform egg into adult, there are many exceptional but entirely normal cases where the egg proceeds to divide of its own accord. Such parthenogenetic eggs are formed like other eggs, though sometimes without synapsis and therefore without chromosome reduction. Thus the eggs of the Honey Bee, to cite the most interesting case, develop either with or without fertilization - fertilized eggs forming females and unfertilized eggs, males. Certain species of Rotifers and Round Worms apparently reproduce solely by parthenogenesis, males not being known. Leaving out of the question the effect on the chromosome complex, it is at once apparent that the mere fact that an egg divides without the influence of a sperm indicates clearly that, in such cases at least, neither structural additions nor physiological influences of the sperm are necessary to initiate development.

It may with justice be urged, however, that such cases of normal parthenogenesis are special adaptations to peculiar conditions in which the egg has usurped, as it were, the usual sperm function, and that therefore the evidence is of little weight in determining the primary significance of fertilization. Accordingly the data from so-called ARTIFICIAL PARTHENOGENESIS are particularly cogent. Within recent years it has been found that the eggs of a considerable number of Invertebrates and even of Vertebrates, such as some Fishes and Frogs, which normally require fertilization, can be induced to start development 'parthenogenetically' by 
various artificial means such as subjection to certain chemicals, unusual temperature changes, shaking, or the prick of a needle - the effective stimulus varying with different species.

Just what happens in the egg as a result of such treatment is open to discussion, but for our purposes it is sufficient to know that the egg begins to divide in normal fashion. This shows conclusively that even eggs which normally require fertilization are intrinsically self-sufficient at least to start to develop, and therefore this strongly indicates that an incidental and not the main function of fertilization is to stimulate cell division.

Restating the evidence in its bearings on the meaning of fertilization, we may say that conjugation, under suitable environmental conditions, is not fundamentally an indispensable event in the life history of the Protozoa, and further that whatever stimulus is associated with fertilization is also provided by endomixis which does not involve synkaryon formation. Similarly in the Metazoa, both normal and artificial parthenogenesis indicate that the egg itself comprises a mechanism which is capable of initiating and carrying on development. From this viewpoint, fertilization may be satisfactorily, interpreted as a means of insuring under special or unfavorable environmental conditions in unicellular organisms, and under usual conditions in the eggs of multicellular forms, a suitable stimulus which otherwise might be un available at the proper time.

Granting then that one aspect of fertilization is 'dynamic,' what is its main significance? Many lines of evidence at present are slowly but surely converging toward the view that the opportunities which fertilization affords for changes in the complex of the germ are of paramount importance. Fertilization establishes new duplex groups of hereditary characters by combining diverse simplex groups from the 
two gametes. Careful studies show, in Paramecium for instance, that variation is greater after than before fertilization, and therefore that the chief significance of the process is to afford new combinations, some of which will more effectually meet - be better adapted to - the exigencies of the environment, and so have a survival value for the organism in the struggle for existence. So whatever the primary meaning of fertilization may be, its importance in establishing the essentially dual nature of every sexually produced organism is settled beyond dispute, and it is the cardinal fact of heredity.

It may seem strange that such a fundamental phenomenon and one so generally distributed throughout the animal and vegetable kingdom should so long have eluded solution. The truth probably is that therein lies the secret of the difficulty. Whatever fertilization may have been originally, it is no longer a simple process, but has undergone evolutionary specialization hand in hand with that of other functions and with the structure of organisms. To-day one or another of its various aspects - rejuvenation, stimulus to development, control of variation, or basis of biparental inheritancemay assume the chief rôle or, at any rate, loom largest in the mind of the student. The popular idea that fertilization is reproduction is solely due to the fact that in higher organisms, if fertilization is to occur at all, it must take place at that period in the life history when the individual is but a single cell detached from the parent - that is, at reproduction.

\section{E. Organization of the Zygote}

The new individual, established by the orderly merging of a cell detached from each parent in sexually reproducing species, has before it first of all the problem of assuming the adult form by a complicated developmental process. As we 
have shown, this involves cleavage of the egg, followed, in the Metazoa, by blastula and gastrula stages during which the primary germ layers are established - the fundament out of which the definitive form, organs, and organ systems of the adult are evolved. The description and comparison of these processes in different organisms constitute the content of one aspect of EMBRYOLOGY. We must be satisfied merely with the realization of the fact that animal development, though it varies widely in producing the immensely diverse body forms, exhibits throughout a thread of similarity in its broader fundamental features. (Figs. 19, 69.)

But embryology is something more than the description of the kaleidoscopic series of stages which seem to melt one into the other as development progresses. It attempts, especially at the present time, to look below and beyond structure to the processes involved, and to determine how the sequence of events is brought about. This is but a repetition of the stages of progress in all science; a passage from the descriptive to the experimental. Although many of the results thus far secured are necessarily largely tentative, they have gone far toward placing the science of biology as a whole on an experimental basis.

From what the pioneer students of embryology during the seventeenth and eighteenth centuries saw, or thought they saw, with simple lens and newly invented compound microscope, there were gradually formulated two opposing views of development which, though long since swept aside in their original form as a result of the increase of knowledge, raised the problem of problems that is still before the embryologist to-day. In brief, one view virtually denied development by maintaining that the adult organism is nearly or completely formed within the germ, either in the egg or the sperm, which marely by expansion, unfolding, and growth gives rise to the 
new generation. In this first crude form tine PRFFORMATION theory demanded the 'encasement' of all future generations one within another in the germ of existing organisms, so that when it was computed that the progenitor of the human race must have contained some two hundred million homunculi (a conservative estimate, to say the least) the reductio ad absurdum was irresistible.

But careful studies on the transformation of the Hen's egg into the chick soon made it clear that the chick is not preformed in the egg. The embryo arises by a gradual process of progressive differentiation from an apparently simple fundament - it is a true process of development or EPIGENESIS. So the upholders of epigenesis versus preformation were before long beyond their depth and in danger of attempting to get something out of nothing - lost in the miraculous!

A statement in such succinct form tends to accentuate the crudities of these two conflicting views - "preformation explaining development by denying it and epigenesis explaining development by reaffirming it" - and it may be well to remark that the early embryologists with the means at their command faced a stupendous task of which only recent work has brought a full appreciation.

The path to progress cleared by the realization that adult structures are not preformed as such in the egg, and that development is not an expansion but the formation - the 'becoming' - by an orderly sequence of events of structures of great complexity out of apparent simplicity, the problem of the embryologist was to determine what the egg structure $i s$ and how related to that of the adult. To trace the development of these studies would involve the history of embryology since the formulation of the cell theory. We must confine ourselves to the bare statement of the new guise in which the 
old theories of preformation and epigenesis confront us today as a result of recent research.

The reader already recognizes the fertilized egg as a cell, with its nucleus comprising a complex of quite definite elements - the chromosomes - contributed jointly by the two gametes. To this extent, then, the nucleus and therefore the egg exhibits a ready-formed structural basis which (as we have already suggested, and will have occasion to elaborate later) seems to be definitely related to characters which appear in the offspring.

Turning to the egg cytoplasm, we are confronted with conditions which are not so uniform but nevertheless highly suggestive. In the first place, before fertilization the egg possesses a definite polarity, expressed, for example, in the position of the nucleus and the distribution of food material (yolk), pigment granules, and vacuoles. This polarity is traceable, in part at least, to the polarity of the oögonia, and through them to the germinal epithelium. In brief, the egg as a whole is organized; the invisible organization of the fundamental matrix of the cytoplasm being revealed, in part, by the disposition of various elements of the cell. Now in some cases this cytoplasmic organization remains essentially undisturbed at fertilization, and persists as that of the zygote, while in others it is superseded sooner or later by a reorganization which establishes that of the new organism. Herein, apparently, is to be sought the explanation of the difference in behavior - in potentialities - of various types of eggs during cleavage stages. Clear-cut examples of the two chief types will serve to bring the main facts before us.

The first type is well illustrated by the egg of a Mollusc, Dentalium, and a primitive Chordate, Cynthia. The egg of the latter shows at the first division five clearly differentiated cytoplasmic regions. For the sake of simplicity these may 


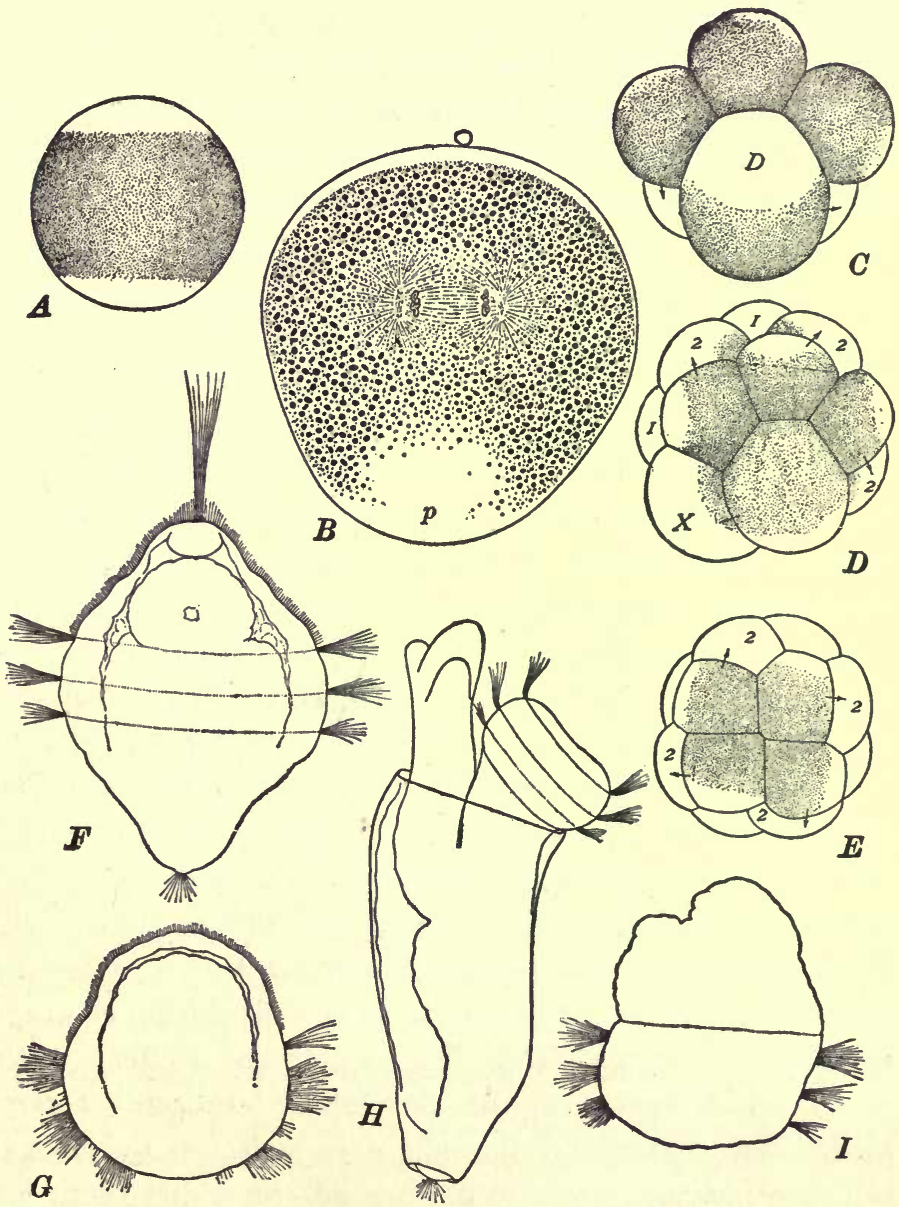

Fra. 132. - Development of a Mollusc (Dentalium), after removal of the 'polar lobe'. $A$, egg, shortly after being extruded and before maturation is completed, showing three differentiated regions. $B$, section through an egg after fertilization, showing cytoplasmic rearrangement involving the segregation of clear 'polar lobe' at $p . \quad C$, normal eight cell stage with 'polar lobe' in cell $D ; D$, normal sixteen cell stage, with materials of polar lobe now in cell $X ; E$, sixteen cell stage, from an egg with the 'polar lobe' removed at the first division; $F$, normal larva at end of twenty-four hours; $G$, larva (abnormal) of same age developed from egg from which 'polar lobe' was removed; $H$, normal larva of seventy-two hours. I, abnormal larva of same age from'lobeless' egg. (From Kellicott, after Wilson.) 
be described as hyaline, light and dark gray, and light and dark yellow. As cleavage proceeds, these substances are distributed with great regularity to definite cell groups, which in turn form special organs or organ systems of the animal. Thus cells which receive the hyaline region form the ectoderm; those which receive the dark gray, the endoderm; while the cells with light or dark yellow form mesodermal structures, and so on. And further, the experimental removal of a cell or cell group in which a certain substance is segregated results in an embryo deficient in the very structures which this normally forms. In other words, the egg cytoplasm seems to be a mosaic of 'organ-forming substances,' which either themselves directly, or through more fundamental conditions of which they are but the visibie expression, have a causal relation to definite adult structures. Just in so far as this is true, the adult is predelineated in bold lines, though not actually preformed, in the egg. (Fig. 132.)

Passing now to the second type, represented by the eggs of Amphioxus and the Sea Urchins, the results which we obtain seem to be diametrically opposite. Although in the egg of the Sea Urchin more or less clearly differentiated cytoplasmic regions appear to exist, the removal of a part of the egg before division, or of one or more cells during cleavage, blastula, or gastrula stages, has no permanent effect on the structural integrity of the developing embryo. Experiments show that each of the cells, even as late as the sixteencell stage, has the power to develop into an embryo complete in every respect, but smaller than the normal. Or, to put it another way: at the sixteen-cell stage, a single cell which normally forms, let us say, one-sixteenth of the embryo, if isolated with two other cells, will form one third of a normal embryo; if isolated with three other cells, will form one quarter; and so on. What now has become of the egg 
organization? Or, if we lean toward a mechanistic interpretation of development or life, what kind of a 'machine' is it which has such potentialities? (Fig. 133.)

At first glance the behavior of these two classes of eggs seems to afford results which are irreconcilable - the former

A

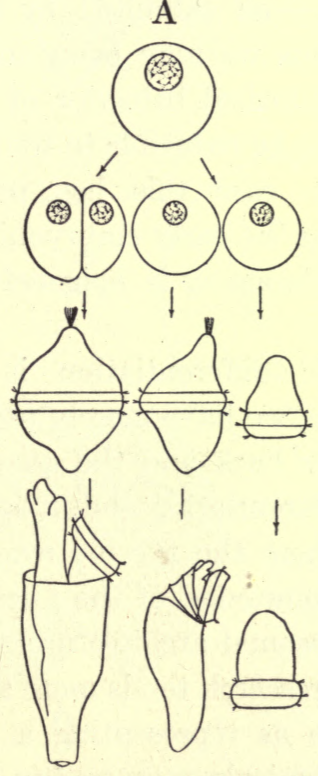

B

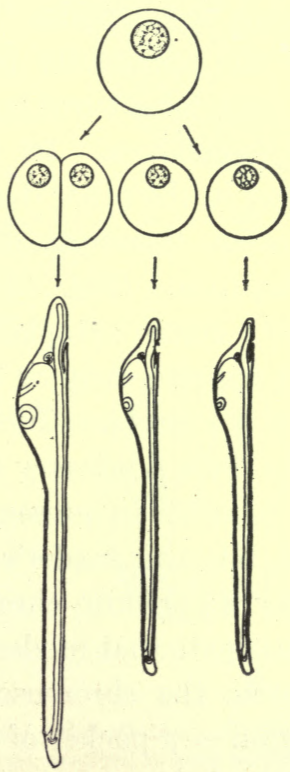

Fig. 133. - Diagram to show development of whole eggs and isolated cells of the two cell stage. $A$, Dentalium; at the left, development of the whole egg; at the right, development of the first two cells, when separated, into two abnormal larvae. $B, A m$ phioxus; identical experiment at the two-cell stage resulting in two perfect small larvae. (From Wilson.)

supporting in a refined form the perennial doctrine of preformation, and the latter its antithesis, epigenesis. But an explanation is not far to seek. The difference apparently depends upon the time when differentiation of the egg cytoplasm is chiefly established. If this occurs before or at fertilization, so that the early divisions give rise to dissimi- 
larly organized cells, then each of the cells is not equipotent and the mosaic type of development results; but if the initial differentiation is delayed until later, or is relatively slight so that the cells of the early stages are all essentially similar, then during this period each cell is totipotent - the whole forms an equipotential system - as exhibited by the early stages of the Sea Urchin. Thus we may bring under one viewpoint the apparently paradoxical behavior of the two classes of eggs, for it turns out to be reducible to the common factor, differentiation. In one case this has progressed further than in the other during the early embryonic stages. In both cases, therefore, development is epigenetic in its obvious features. (Fig. 134.)

However, since cytoplasmic differentiation is a fact whether it appears early or late, we have merely pushed the solution of the problem further back and the question becomes: Is there a primary differentiation and, if so, where? It is not possible to present here the specific evidence on this point, but the reader's knowledge of the nucleus, and particularly its definite chromosomal architecture, will lead him to anticipate that modern research tends more and more to emphasize the chromosome as representing a material configuration - a packet of chemicals, may we say - which is transmitted, in a way, 'preformed' from generation to generation and determines the cytoplasmic characteristics of the cells. As to how the specific physical basis of inheritance, constituting the chromosomes, is related to cytoplasmic organization and to characters which arise later, we can offer no satisfactory explanation or even guess. We must be content with a discussion, in the next chapter, of some of the salient facts of heredity and their definite association with certain chromosome arrangements.

But in so far as the nucleus possesses an organization 
which is definitely related to differentiations of the cytoplasm, 'organ forming substances,' or characters of embryo and adult, we may look upon the chromatin to this extent as

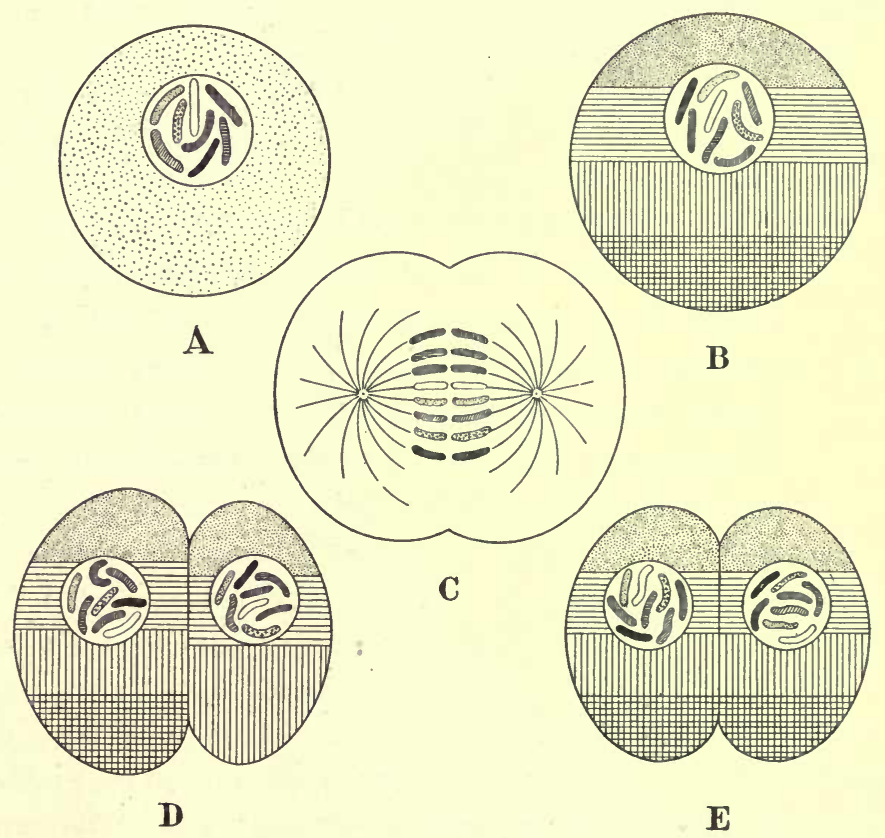

FIG. 134. - Diagram of zones of cytoplasmic differentiation and their distribution at the first division of the egg. $A$, immature egg, assumed to have no definite segregation of cytoplasmic stuffs; $B$, mature egg, with cytoplasmic zones established; $C$, first division of egg; $D$ and $E$, two types of two-cell stages; D, Dentalium or Cynthia type, with one cytoplasmic zone entirely distributed to one of the cells, and therefore each of the two cells, if separated, gives rise to an abnormal larva; E, Echinoderm or Amphioxus type, with equal distribution of the zones to both cells, and therefore, if separated, each of the two cells gives rise to a normal larva. (After Wilson.)

representing a sort of primary preformation which is realized by a process of building up - epigenesis - as one character after another becomes established in the development of the individual. This is the guise in which the old problem of preformation versus epigenesis faces the biologist to-day. 
The early embryologists were right when, watching the egg develop into the chick, they maintained that development is development and not merely an unfolding of an organism already fashioned in more or less definite adult form. But it took two centuries of research to reveal the fact that, below and beyond its superficial aspects, there is a germ of truth in the principle of preformation hidden in the nuclear architecture - that the origin of the individual, though obviously through epigenesis, is fundamentally from a sort of preformed basis. We no longer bother ourselves with the old conundrum as to which is more complex, the hen or the egg, but recognize the fact that each is complex in its waythe simplicity of the egg being more apparent than real as is attested by every endeavor to analyze cytoplasm, nucleus, chromosomes, chromatin, and beyond. 


\section{CHAPTER XVII}

\section{HERITAGE OF THE INDIVIDUAL}

The entire organism may be compared to a web of which the warp is derived from the female and the woof from the male. - Huxley.

THE old adage that 'like begets like' expresses the general fact of HEREDITY. Every one recognizes that parent and offspring agree in their fundamental characteristics or 'belong' to the same 'species.' And every one realizes that the resemblance may be strikingly exact even in details of form or behavior. Family traits crop out. The mere statement of striking resemblances among the individuals of a family is a tacit admission that no two individuals are exactly alike; in other words heredity is "organic resemblance based on descent" - inheritance of the characters exhibited by the parents is not complete, there is VARIATION. Indeed "variation is the most invariable thing in nature," but one must guard against the impression that there is an antithesis between heredity and variation. "Living beings do not exhibit unity and diversity, but unity in diversity. Inheritance and variation are not two things, but two imperfect views of a single process."

We must now address ourselves to the problems of heredity and variation which are at the basis not only of what organisms have been in the past and are at the present, but also of whatever the future may have in store for them. Variations are the raw materials of evolutionary progression or regression. From a broad point of view, the origin of 
species and the origin of individuals are essentially the same question. If we can solve the relations of parent and offspring, the origin of species will largely take care of itself. As a matter of fact, historically the question of species origin was approached first, and through the work of Darwin became of paramount interest in the latter half of the nineteenth century. The twentieth century finds the individual - the genetic relation of parent and offspring - the center of investigation, and it forms the science of genetics. ORGANIC EVOLUTION established the general fact that all organisms are related by descent; GENETICS attempts to show how specific individuals are related.

Even further has the pendulum swung from the general to the particular. To-day the most intense investigation is centered not on the heritage of the individual as a whole, but on particular characters of the individual. The concept has arisen from recent experimental work that, for practical purposes, the individual may be regarded as congeries of UNIT CHARACTERS, both structural and physiological, which are more or less stable, and which are inherited as units. But the analysis does not stop even at this level. There seems to be good reason to believe that each so-called unit character is represented in the chromosomes of the germ ceils by a definite factor, determiner, or, as it is now usually termed, GENE; and whether or not a given character will be present in a tree or a man depends upon whether the gene for this particular character entered into the nuclear complex of the fertilized egg which formed the individual. Therefore, geneticists are busy plotting the relative positions which these genes occupy on certain chromosomes and how they may 'cross-over' from one chromosome to the other of a synaptic pair.

Although at present we are apparently at the threshold of 
great advances in knowledge of the underlying factors of heredity, the data already accumulated are so vast that we can attempt no more than to indicate the character and promise of the principles already discovered.

We may survey the field before us by a concrete example. A score of years ago, just at the opening of the modern concentrated attack on genetic problems, an association of British millers awoke to the fact that some active means must be taken to offset the increasingly great deficiency in quantity and quality of the wheat yield. Accordingly they commissioned a specially trained biologist to investigate the matter. He collected many different varieties of domestic and foreign wheat, each known to have one or more good qualities, and studied how these were inherited. Making use of the data thus secured, in the course of a few years he produced a wheat which combined the good qualities of several varieties; including high content of gluten, beardlessness, immunity to rust, and large yield. And this 'made to order' wheat has proved successful in the British Isles. But with the opening up of new territory in western Canada another obstacle was encountered: the growing season was too short for the finest varieties of wheat. This contingency was quickly met by transferring the quality of early ripening from an inferior grade of wheat to a wheat possessing several valuable characters.

In a similar fashion, a host of workers have performed the impossible of a few years ago. Corn of desirable percentage content of starch or sugar; cotton with long fibers of exotic varieties and quick maturing qualities to escape insect ravages; sheep combining choice mutton qualities of one breed with the fine wool of another and the hornlessness of a third, and so on almost ad infinitum. Furthermore, there is no end in sight of the new stable races of plants and 
animals which are forthcoming as the principles already known are applied, and subsidiary ones are discovered. And last but not least, Man has begun to study himself as a product of breeding and the process of evolution - to determine the distribution of characters in the family, and the consequences of their combinations in the physical and mental make-up of the individual.

\section{A. Heritability of Variations}

What then are the basic principles of heredity which are to-day at the command of the scientific breeder? To answer this question it is necessary to go into some details because no real appreciation of the underlying principles involved is otherwise forthcoming. Most of these details have been acquired through patient investigations madefrom thestandpoint of so-called pure science - one more proof of the indebtedness of the 'practical man of affairs' to the biological laboratory.

In the Protista the problems of heredity confront us in their simplest, though by no means simple, form. Paramecium, as we know, divides into two cells which through growth and reorganization soon are to all intents and purposes replicas of the parent cell. The parent has merged its individuality into that of its offspring. Thus stated, one does not wonder that parent and offspring are alike - each is composed of essentially the same protoplasm. But when we come to multicellular forms in which reproduction is restricted to special germ cells which involve fertilization, confusion is apt to arise unless one keeps clearly in mind and perhaps exaggerates for the sake of concreteness - the distinction between germ and soma which has been previously discussed. Since in higher forms, to which brevity demands that our attention be confined, the sole connection between parent and offspring is through the germ cells, it 
follows that this must be the sole path of inheritance. In other words, whatever characters the body actually inherits must have been represented by genes in the fertilized egg

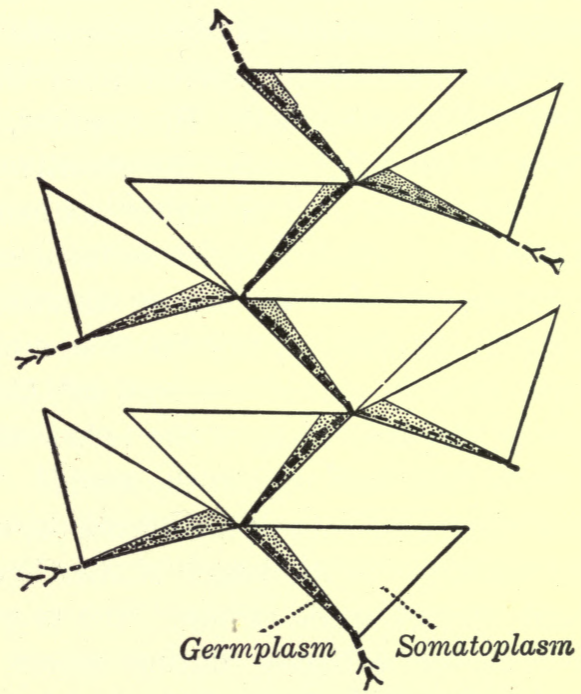

Fra. 135. - Scheme to illustrate the continuity of the germplasm. Each triangle represents an individual composed of germplasm (dotted) and somatoplasm (clear). The beginning of the life cycle of each individual is at the apex of the triangle where both germplasm and somatoplasm are present. In biparental (sexual) reproduction the germplasms of two individuals become associated in a common stream which is the germplasm and gives rise to the somatoplasm of the new generation. This continuity is indicated by the heavy broken line and the collateral contributions at each succeeding generation by light broken lines. (From Walter.)

from which it has arisen: and conversely, any characters which the individual can transmit must be represented in its germ cells. (Figs. 115, 135.)

\section{Modifications}

Every individual organism - a man, for instance - is a mosaic not only of inherited characters but also of MODIFICATIONs of the soma produced by external conditions during 
embryonic development or later. The individual's environment, food, friends, enemies, the world as he finds it, on the one hand, and on the other his education, work, and general reactions to this environment, all have their influence on body and mind and determine to a considerable extent the realization of the possibilities derived from the germ what he makes of his endowment. He acquires, let us say, the strong arm of the blacksmith, the sensitive fingers of the violinist, or the command of higher mathematics. In other words, what he is depends on his heritage and what he does with it. Now, if he does develop an inherited capacity, can he transmit to his offspring this talent in a more highly developed form than he himself received it? Or, must his children begin at the same rung of the ladder at which he started and make their own way in the world? This is the old question of the inheritance of modifications, or so-called ACQUIRED CHARACTERS. Is the length of the Giraffe's neck, to take a classic though crude example, due to a stretching toward the branches of trees during many successive generations, with the result that a slight increment has been gained in each generation and inherited by the following?

We cannot, enter into a discussion of the problem here, but must simply assure the reader that the general consensus of opinion of biologists is certainly to the effect that modifications, or changes in the individual body due to nurture, use and disuse, are not transmitted as such. This conclusion is held chiefly because there is no positive and much negative evidence forthcoming, and also because there is no known mechanism by which a specific modification of the soma can so influence the germ complex that this modification will be reproduced as such or in any representative degree. However, it should be emphasized that biologists in general recognize the potent influence of environment and the organisms' 
reactions to the environment on the destinies of the race, even though they see, at present, no grounds for a belief that any specific modification can enter the heritage and so be reproduced.

In this connection the question of the inheritance of disease will undoubtedly arise in the reader's mind. But this is really not a special case. If the disease is the result of a defect in the germinal constitution, it may be inherited just as any other character, physiological or morphological. But if the disease is a disturbance set up in the body by some exigencies of life or through infections by specific micro-organisms, before birth or later, inheritance does not occur; though it is well known that susceptibility or immunity to disease-producing organisms — the 'soil' for their development — may be inherited. It may, however, be suggested in passing that from the standpoint of the individual born malformed, structurally or mentally, as a result of parental alcoholism or other obliquities, it probably will not appear of the first moment that the sins have been visited otherwise than by actual inheritance.

The whole question of the nonheritability of modifications or acquired characters is a relatively new point of view which has been fostered by an ever-increasing appreciation of the details of the chromosome mechanism of inheritance, and the realization of the essential truth of Weismann's contrast of the soma and germ. Indeed, Lamarck did not question the inheritance of acquired characters and made it the cornerstone of his theory of evolution, while some have even gone so far as to say that either there has been inheritance of acquired characters, or there has been no evolution. But the question is not so serious as that, as will be seen later on; though it obviously is profoundly important from many viewpoints, biological, educational, and sociological. 


\section{Combinations}

Turning from modifications, which are useless to the geneticist, and concentrating attention on characters which represent an expression of germinal factors, we see that, in the final analysis, heredity is germinal resemblance among organisms related by descent - a consequence of the continuity of cells by division. Hereditary differences which appear in offspring are either COMBINATIONs of ancestral characters - apparently new characters which owe their origin to recombinations of the germinal factors of old characters - or MUTATIONs due to fundamental changes in the germinal constitution, possibly in the factors, or genes, themselves.

For didactic purposes we may somewhat arbitrarily classify the obvious hereditary differences following fertilization which are the result of recombinations of parental characters represented in the egg and sperm: that is, cases in which nothing is apparent which is not clearly related to the conditions expressed in the ascendants. In the first place the offspring may exhibit a character, eye color let us say, of one parent to the exclusion of that of the other - the character appearing unmodified. This may be termed alternative inheritance. Or the offspring may seem to be a sort of mosaic of the characters of its progenitors. Here each parent contributes a certain character but without the exclusion of that of the other and without blending - the offspring exhibits MOSAIC inheritance. Sometimes the parental traits seem to fuse so that the progeny exhibit a more or less intermediate and different condition, as in the color of the skin of mulattoes. Such a result is known as BLENDing inheritance. Or again, certain characters are transmitted from males solely to female offspring. This is an example of SEX-LINKED inheritance. In still other instances characters of grandparents which are invisible, or 'latent,' in the parents appear again in 
the progeny. This has long been known as ATAvism. Finally, characters of still more remote ancestors may crop out, and constitute REVERSIONS. (Fig. 136.)

\section{Mutations}

But quite different results now and then occur. Characters which have no place in the ancestry appear and are transmitted to the descendants. Sometimes these new inherited variations are only slight departures from the parental condition, while in other instances they are quite abrupt. However, the studies of deVries and others have led to the realization that there is no fundamental difference between the two classes - it is chiefly one of degree - and so we speak of all heritable variations, which are not the result of recombinations, as mutations, and contrast combinations and mutations sharply with modifications which are not transmitted to

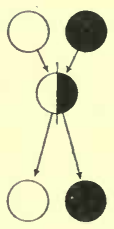

A

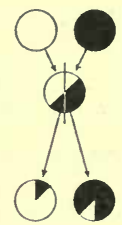

R

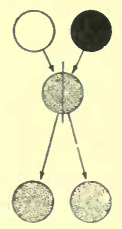

(

Fig. 136. - Diagram to illustrate three types of inheritance which follow recombinations of parental characters. $A$, alternative; $B$, mosaic; $C$, blending. (From Conklin, after Walter.) the offspring and are the results of environing conditions on the soma during embryonic development or later. The importance of this distinction can hardly be overemphasized because it makes comprehensible many of the inconsistencies in earlier work on genetics, as will immediately appear.

\section{B. Galton's 'Laws'}

The studies of Galton, a cousin of Darwin, on the inheritance of definite characters open the modern era of scientific investigations in genetics. In particular, his work on the inheritance of characters in Man, such as stature and. intellectual capacity, is a biological classic judged by the momentous consequences which followed from the discussion it 
evoked. As a result of the statistical treatment of data, Galton formulated two principles of heredity which may be briefly stated as follows:

Law of Ancestral Inheritance. The two parents contribute between them, on the average, one half of each inherited

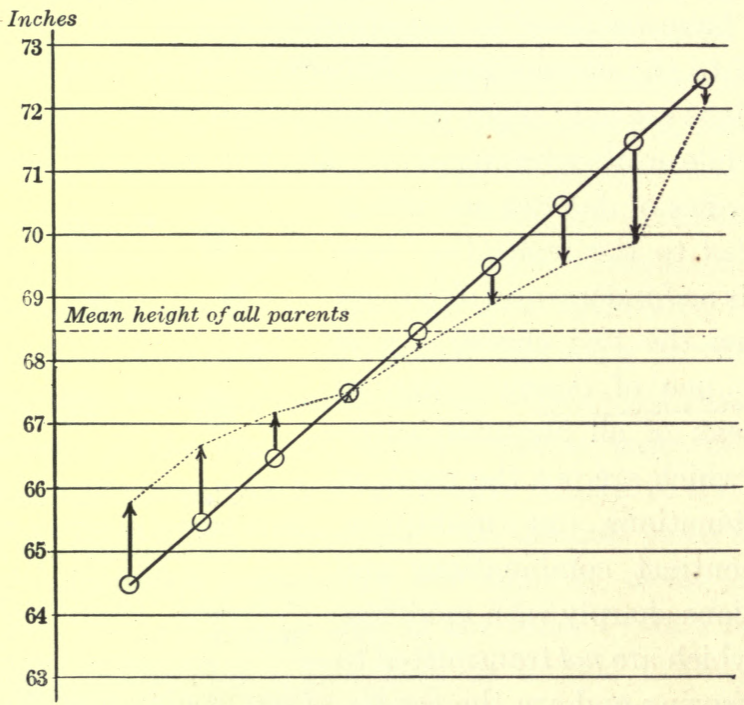

Frg. 137. - Scheme illustrating Galton's law of filial regression, as shown in the stature of parents and children. The circles represent the height of graded groups of parents and the arrow heads show the average heights of their children. The length of the arrows indicates the amount of 'regression' toward mediocrity. (From Walter.)

faculty; each of them contributing one quarter of it. The four grandparents contribute between them one quarter, or each of them one sixteenth; and so on.

Law of Filial Regression. On the average any deviation of the parents from the racial type is transmitted to the progeny in a diminished degree; the deviation from the racial mean being two thirds as great as that of the progenitors. (Fig. 137.) 
These so-called laws taken by and large undoubtedly express general truths - offspring inherit much more from their immediate than from their remote ancestors; and offspring of gifted or deficient parents, judged by the average standard of a mixed population, regress toward mediocrity. But the 'laws' are not particularly helpful in arriving at the fundamental principles involved in heredity because the data upon which they are founded include indiscriminately both heritable variations and modifications. The individual's somatic characters, which form the data, belie in many cases the underlying germinal constitution - what will be transmitted to the progeny. Thus, for instance, experiments show that when the germinal make-up of all the members of a population is the same, the regression is complete, no matter how far the particular parents may diverge somatically from the population average. The somatic divergence represents chiefly modifications which are not inherited. Conversely, when the divergence of the parents from the population average is due to characters which represent expressions of their germinal constitution, then there is no regression.

\section{Mendelism}

It was reserved for Mendel to apply statistical methods to facts observed in the progeny derived from carefully controlled experiments in breeding. In other words, to substitute for 'ancestral generations,' controlled pedigrees - to look forward as well as backward and thus largely to remove the unknown and unknowable quantity which rendered the materials of Galton somewhat delusive. Mendel's studies actually were made a score of years before Galton's, but failed to reach the attention of the biological world engrossed in the evolution theory; in fact were never known to Darwin to 
whom they would have meant so much in his work to secure experimental data in heredity. To-day Mendelism is essentially a science in itself, with its own vocabulary of technical terms. We can attempt no more than to make clear its fundamental features by a few concrete examples; the first from Mendel's own work.

Mendel chose seven pairs of contrasting, or alternative, characters which he found were constant in certain varieties of edible Peas, such as the form and color of the seeds, whether round or wrinkled, yellow or green; and the length of the stem, whether dwarf or tall: and these he studied in the HYBRIDS. One ordinarily thinks of a hybrid as a cross between two species or, at least, two characteristically distinct varieties of animals or plants; but as a matter of fact the offspring of all sexually reproducing organisms are really hybrids because two parents seldom, if ever, are exactly the same in all of their germinal characters. Consequently the offspring are hybrids with respect to the characters in which the parents differ.

\section{Monohybrids}

Mendel found, for example, in the cross between the tall and dwarf varieties of Peas, that all of the progeny in the FIRST FILIAL $\left(F_{1}\right)$ generation were tall like one parent, there being no visible evidence of their actual hybrid character. Accordingly tallness was designated a Dominant (D) and dwarfness a RECESsive (d) character. His next step was to follow the behavior of these characters in succeeding generations. Therefore the tall hybrids $\left(\mathrm{F}_{1}\right)$ were inbred (self-fertilized) and their offspring, the SECOND FILIAL $\left(\mathrm{F}_{2}\right)$ generation, were found to be tall and dwarf in the proportion of three to one (3D:1d). This is now the broadly established MENDELIAN RATro. Of course in dealing with a small number of individ- 
Tall 5 S

$\therefore$

$\mathbf{F}_{1}$

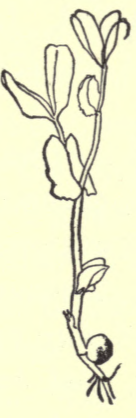

Short 0 O 8

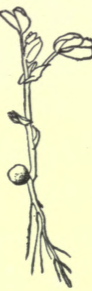

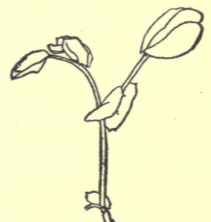

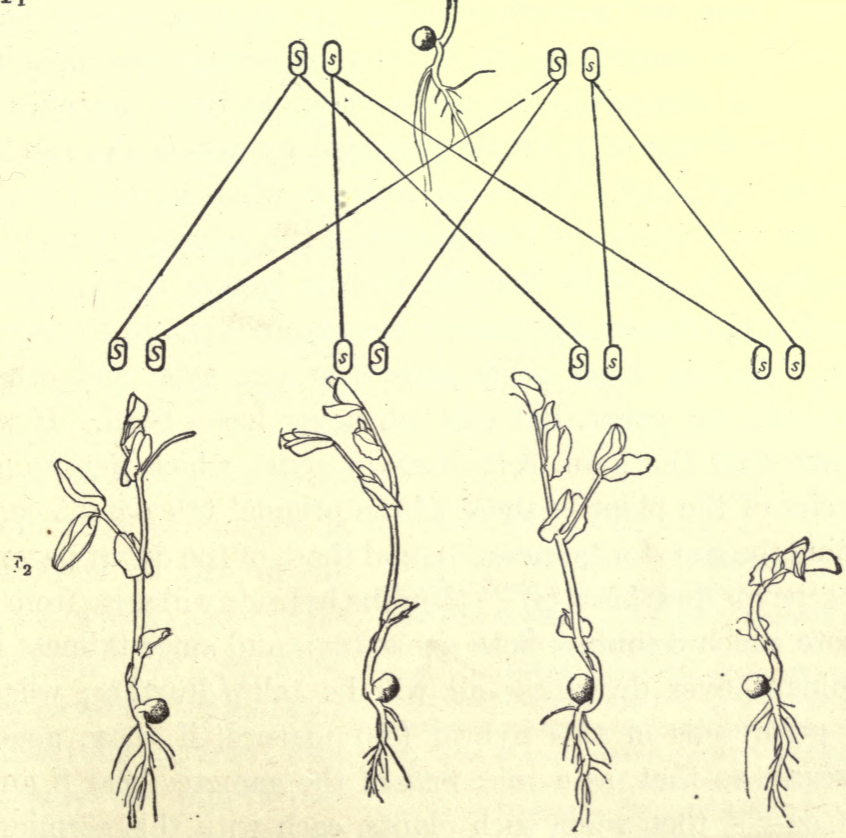

riu. 138. - Inheritance of size in a cross between a tall and a dwarf race of garden Peas. (After Morgan.) 
uals this proportion is merely approximate; the greater the number of offspring, the closer it is approached. In this particular case Mendel obtained 787 dominant and 277 recessive individuals. (Fig. 138.)

Continuing the work, Mendel found that the dwarfs (recessives) when inbred gave only recessives generation after generation, and accordingly were 'pure', or EXTRACTED RECESsives. On the other hand, the tall plants (dominants) when inbred proved to be of two kinds, one third pure EXTRACTED DOMINANTS which bred true indefinitely, and two thirds hybrids like their parents, giving when inbred the same ratio of three dominants to one recessive in the THIRD FILIAL $\left(\mathrm{F}_{3}\right)$ generation.

Aside from his masterly foresight in realizing that success depended on simplifying the problem by dealing with definite contrasting characters, Mendel's claim to fame lies chiefly in his discovery of a simple principle by which the results may be explained. Since the hybrids when inbred always give rise to hybrids and also to each of the parental types in a pure form, it must be that the factors (genes) which determine the characters in question are SEGREGATED in the germ cells. That is, some germ cells bear one gene and other germ cells the other, but one cell never bears both. If we assume that the germ cells contain genes which determine the size of the plant - those of the original tall parent containing the gene for tallness $(\mathrm{S})$, and those of the dwarf parent the gene for dwarfness (s) - then the hybrids will arise from a zygote which combines both genes (Ss), and since tallness is dominant over dwarfness all will be tall.V Further, when the germ cells of this hybrid ( $\mathrm{Ss}$ ) mature, if these genes segregate so that, as a rule, half of the gametes bear $\mathrm{S}$ and half bear s, then when such plants, each with this germinal constitution, are inbred there will be equal chances for 
gametes bearing the same and for gametes bearing different genes to meet in fertilization.

The zygotes are $1 \mathrm{SS}: 2 \mathrm{Ss}: 1 \mathrm{ss}$. But, since $\mathrm{S}$ is dominant, the resulting organisms will be in the proportion of 3 tall to 1 dwarf, which is the familiar 3:1 Mendelian ratio of dominants to recessives in the $\mathrm{F}_{2}$ generation. The important point, however, is that these tall organisms, although they all appear

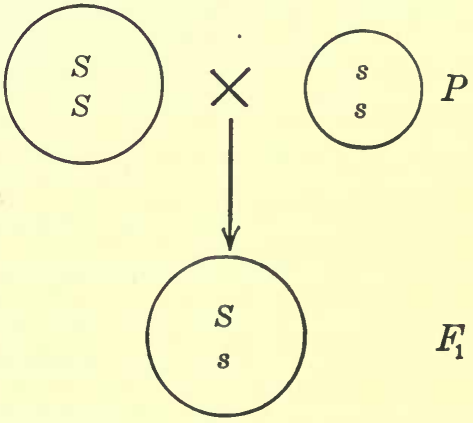
alike or, as we now say, belong to the same PHENOTYPE, are different with respect to their germinal constitution; because one third bear germ cells all of which contain the gene $\mathrm{S}$, and two thirds bear germ cells half of which contain $\mathrm{S}$ and the other half s. Consequently the phenotype is composed of two GENOTYPES which are distinguishable only by what they produce. (Fig. 139.)

It is thus apparent why the pure tall plants (extracted dominants) always breed true, and why

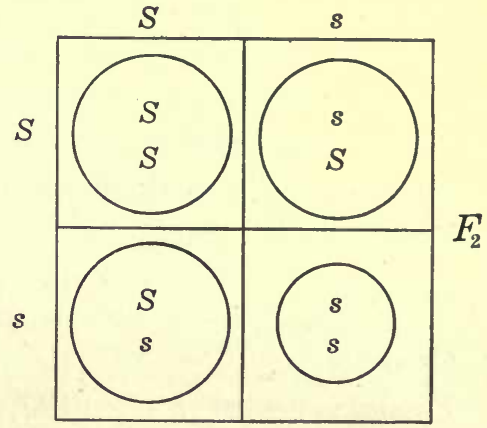

Fig. 139. - Diagram of a Mendelian monohybrid. Results of crossing large size $(S)$ and small (s) Pea plants. The circles represent the zygotes and the characters of the soma (phenotype); the letters within the circles, the germinal constitution (genotype). The letters outside the recombination square represent the gametes. Note that each of the parents $(P)$ represents a different phenotype and genotype; all the $F_{1}$ (one shown) belong to the same phenotype and genotype; while the $F_{2}$ represent two phenotypes and three genotypes. The relative number of individuals composing the $F_{2}$ phenotypes is $3: 1$. 
the pure dwarfs (extracted recessives) do the same - all the germ cells of one bear $\mathrm{S}$ and those of the other,s. The plants are, as we say, HomozyGous with respect to the characters in question. It is also clear why the hybrids give rise to hybrids and extracted dominants and recessives - an equal proportion of the germ cells bear $\mathrm{S}$ and $\mathrm{s}$. The plants are HETEROZYGOUS.

The real difference then between the $\mathrm{F}_{2}$ hybrids (Ss) and the extracted dominants (SS) is that the former are heterozygous and the latter are homozygous. In order to tell which is which, since they are phenotypically the same, it is necessary to breed them. When self-fertilization can be practiced, as in the case of most plants, we get the result directly; that is an individual's progeny are either all dominants or dominants and recessives in $3: 1$ ratio, and thus the gametic constitution of the parent is immediately known. However, in the case of animals, where self-fertilization is impossible, the determination can be made by mating the dominants with recessives, for a homozygous dominant then will give all dominants while a heterozygous dominant will give half dominants and half recessives. Thus:

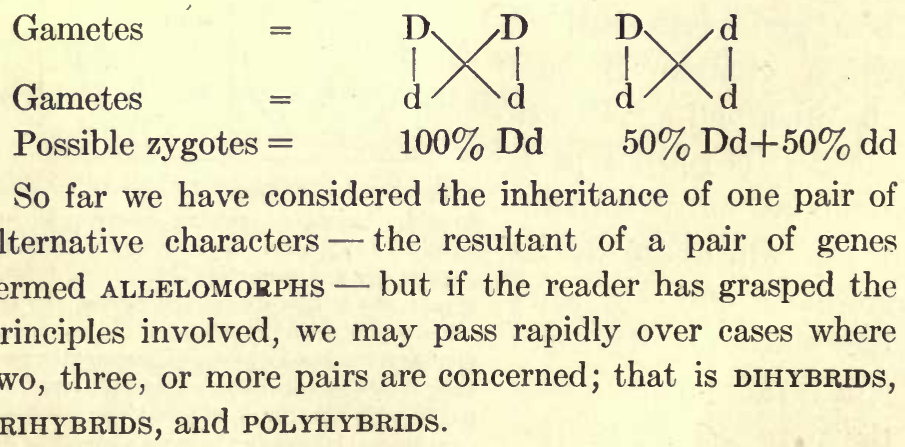

\section{Dihybrids}

Mendel found the solution to heredity in dihybrids by 


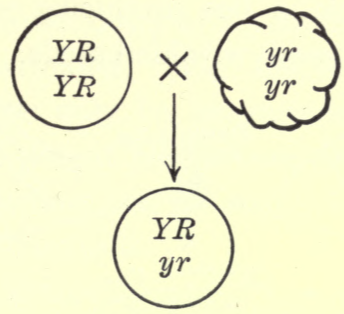

P

$F_{1}$

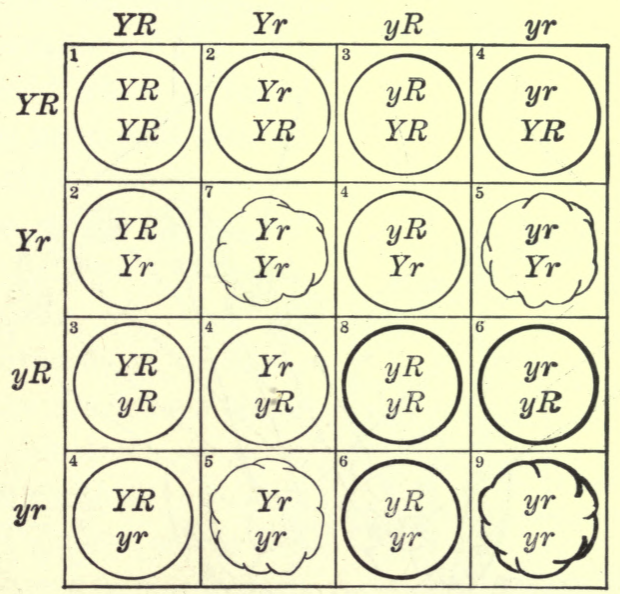

$F_{2}$

Fig. 140. - Diagram of a Mendelian dihybrid - results of crossing yellow round seeded $(Y R)$ Peas with green wrinkled seeded $(y r)$. The circles represent the zygotes and the characters of the soma (phenotype); the letters within the circles, the germinal constitution (genotype). The letter groups outside the recombination square represent gametes. The hybrids of the $\mathrm{F}_{1}$ generation are all yellow round seeded since green and wrinkled are recessive. The $F_{1}$ plants form four types of gametes which affords sixteen possible types of zygotes, representing four phenotypes (shown graphically) and nine genotypes (numbered). There is one pure (extracted) dominant (1) and one pure (extracted) recessive (9). The zygotes numbered 4 are identical with the $F_{1}$ generation. Four are homozygotes $(1,7,8,9)$ and the rest are heterozygotes. The relative number of individuals composing the phenotypes is $9: 3: 3: 1$. 
crossing, for example, a Pea producing yellow round seeds with one producing green wrinkled seeds. The plants in the

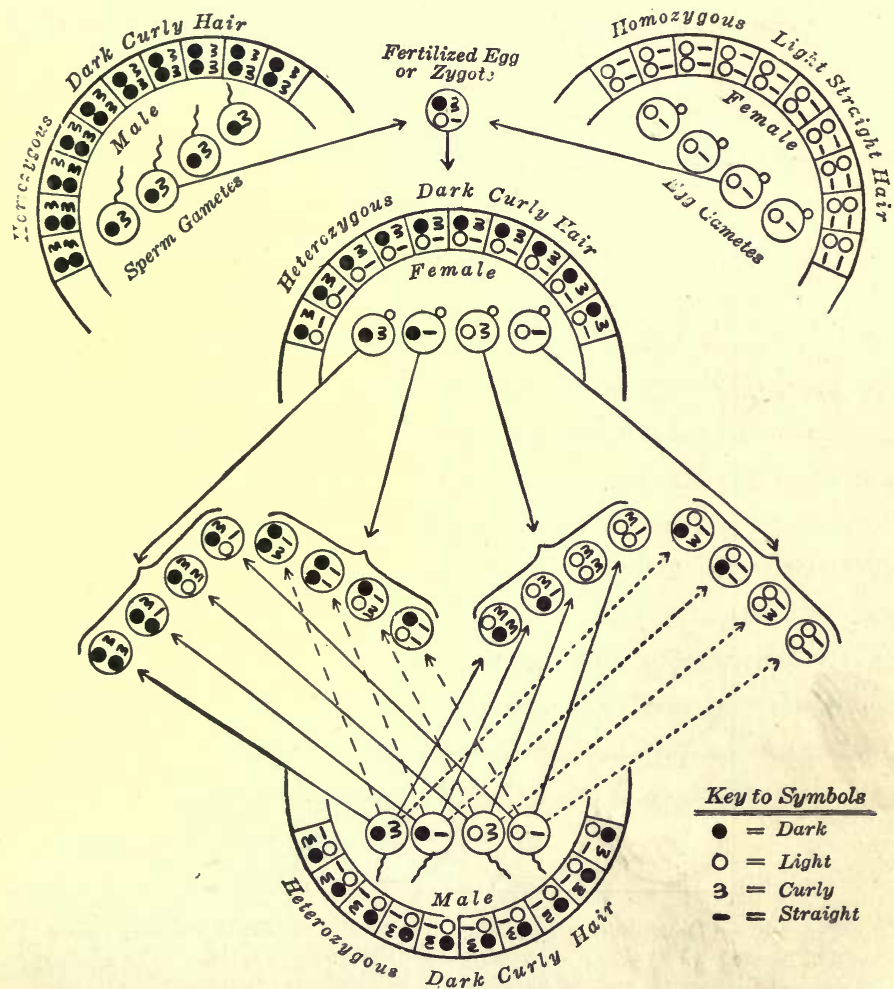

Fra. 141. - Scheme to illustrate the heredity of human hair characters. Mendelian dihybrid. Dark and curly, dominant characters; light and straight, recessive characters. The arcs represent somatic cells of four individuals. The dominant characters are placed on the outer side of the cells, since they represent the visible characters (phenotype). The gametes are placed within the arcs (cf. Fig. 142). (From Walter.)

$\mathrm{F}_{1}$ generations bear only yellow round seeds, and therefore yellow and round are each dominant characters when paired with green and wrinkled. After self-fertilization such hybrid plants produce offspring $\left(\mathrm{F}_{2}\right)$ with seeds showing all the possible combinations of the four characters, and in the 
proportion of 9 yellow round to 3 yellow wrinkled to 3 green round to 1 green wrinkled.

(Fig. 140.)

This logically can only be interpreted as indicating that one of the original parent plants bore germ cells all containing the genes for yellow and for round peas (YR), while the other parent plant bore cells all containing the genes for green and for wrinkled (yr). Such being the case, the resulting zygote is YRyr, and the hybrid which it forms develops germ cells with all the possible combinations of these genes. (except, of course, $\mathrm{Rr}$ and $\mathrm{Yy}$ ) which are $\mathrm{YR}, \mathrm{Yr}, \mathrm{yR}$, and $\mathrm{yr}$. Now, in turn, at fertilization there are sixteen possible combinations of germ cells, since there are four different kinds of sperm and four different kinds of eggs with respect to the characters in question. Accord-

\begin{tabular}{|c|c|c|c|}
\hline $\begin{array}{l}\text { Number } \\
\text { in each } \\
\text { clacs }\end{array}$ & Genotype & Phenotype & $\begin{array}{c}\text { Number } \\
\begin{array}{c}\text { in each } \\
\text { class }\end{array} \\
\text { clase }\end{array}$ \\
\hline 4 & 를 & \multirow{4}{*}{ Dark curly } & \multirow{4}{*}{9} \\
\hline 2 & 3 & & \\
\hline 2 & (2) & & \\
\hline 1 & (3) & & \\
\hline 1 & $\theta$ & \multirow{2}{*}{ Dark straight } & \multirow{2}{*}{3} \\
\hline 2 & 0 & & \\
\hline 1 & 옹 & \multirow[b]{2}{*}{ Light curly } & \multirow[b]{2}{*}{3} \\
\hline 2 & 0 & & \\
\hline 1 & 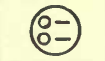 & Light straight & 1 \\
\hline 16 & & & 16 \\
\hline
\end{tabular}

FIg. 142. - Diagram classifying the sixteen possible types of zygotes, shown in the middle of Fig. 141, according to genotypes (nine) and phenotypes (four). (From Walter.) ingly the $\mathrm{F}_{2}$ generation, which is produced by the union of these gametes, is represented by one extracted dominant (YRYR), one extracted recessive (yryr), four (including the former two) homozygotes and twelve heterozygotes. These sixteen individuals form nine genotypes but, since only the dominant character is expressed when dominant and recessive genes combine, they are resolvable into four phenotypes ( $\mathrm{YR}, \mathrm{Yr}, \mathrm{yR}, \mathrm{yr}$ ) in the ratio $9 \mathrm{YR}: 3 \mathrm{Yr}: 3 \mathrm{yR}: 1 \mathrm{yr}$. Thus the $9: 3: 3: 1$ 
Mendelian ratio for two pairs of contrasting characters is merely the monohybrid $3: 1$ expanded. Both rest on the same fundamental assumption that there is an independent assortment of the genes and that those for alternative characters segregate - both members of a pair of allelomorphs can never occur in the same gamete. (Figs. 141, 142.)

\section{Trihybrids}

Similarly, Mendelian trihybrids, for example the cross between tall Peas bearing yellow round seeds and dwarfs bearing green wrinkled seeds, give in the $\mathrm{F}_{2}$ generation 27 genotypes and 8 phenotypes; the relative number of individuals in each phenotype being in the proportion $27: 9: 9$ : $9: 3: 3: 3: 1$. Of course, in nature there are few instances in which parents and offspring differ by only one, two, or three characters, but since characters arising from each pair of allelomorphs can usually be treated singly, expediency demands that the analysis be made with respect to one or two pairs at a time, which accordingly is the usual method of procedure. (Fig. 143.)

\section{General Principles}

Before passing to certain modifications and extensions of Mendelian principles, it may serve to clarify the subject if we restate in slightly different form and then summarize the essential facts thus far discussed on the basis of Mendel's own work.

Every cell of the soma of an individual bears a pair of genes for each 'unit' character (e.g., size in the case of the garden Pea), one member of each pair having been derived from each gamete which contributed to the individual's makeup. When both genes are identical (e.g., either SS or ss) they are expressed in the soma (e.g., the plant is tall or dwarf). The individual is homozygous with respect to size. But when 

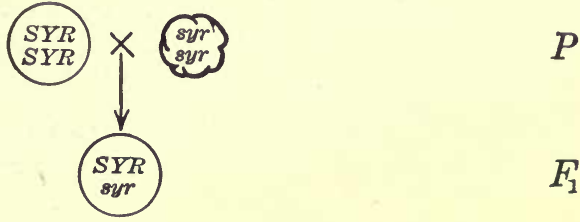

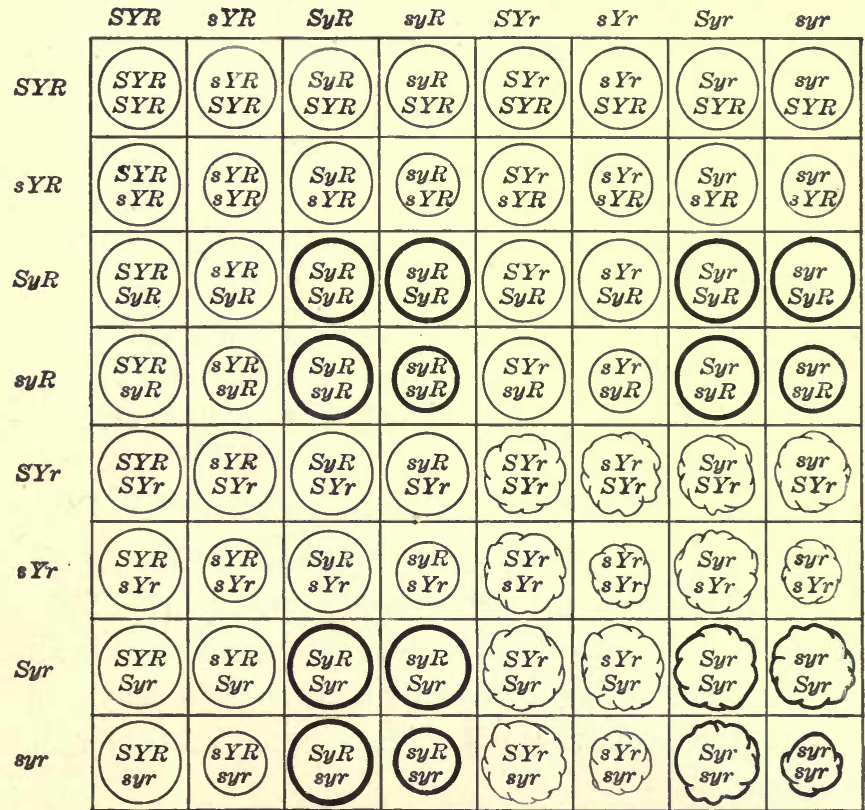

Fig. 143. - Diagram of a Mendelian trihybrid. Results of crossing tall Peas bearing yellow round seeds ( $S Y R$ ) with dwarf Peas bearing green wrinkled seeds (syr). The circles represent the zygotes and the characters of the soma (phenotype); the letters within the circles, the germinal constitution (genotype). The letter groups outside the recombination square represent the gametes. The $F_{1}$ hybrids form eight types of gametes, giving sixty-four possible types of zygotes, representing eight phenotypes (shown graphically) and twenty-seven genotypes. There is one pure (extracted) dominant (upper left corner) and one recessive (lower right corner). Eight are homozygotes (diagonal from upper left to lower right corner) and the rest are heterozygotes. The zygotes in the diagonal from upper right to lower left are identical with the $F_{1}$ generation. The relative number of individuals composing the phenotypes is $27: 9: 9: 9: 3: 3: 3: 1$. 
the two genes are not identical (e.g., S and s), then one, the dominant (S), is expressed in the soma (the plant is tall), while the other, the recessive (s), is not expressed. The individual is heterozygous with respect to the character in question (e.g., size).

At the maturation of the germ cells of the individual, an independent assortment, or segregation, of the genes occurs so that the gametes bear only one gene (e.g., either $\mathrm{S}$ or $\mathrm{s}$ ) for each unit character. Thus the gametes of homozygous individuals are all alike with respect to the gene in question (e.g., all bear $\mathrm{S}$ or $\mathrm{s}$ ), while the gametes of heterozygous individuals are of two numerically equal classes (e.g., half bear $\mathbf{S}$ and the other half bear $\mathrm{s}$ ).

Unit Characters. From the standpoint of heredity an individual organism may be regarded as comprising a complex of single characters, each of which, broadly speaking, behaves essentially as a unit.

Dominance. When the determining genes (allelomorphs) for each of a pair of alternative characters are present in the zygote, one (the dominant) is expressed in the resulting individual; although the other (the recessive) is also present in all of its somatic and in one half of its mature germ cells. In other words, the recessive is not expressed unless it is present in duplicate.

Segregation. The genes for each of a pair of alternative characters are never both present in the same gamete. Therefore the ripe germ cells of hybrids fall into two numerically equal classes: in one the gene of the dominant character and in the other the gene of the recessive character is segregated. This is the so-called purity of the germ cells.

\section{Neo-Mendelism}

It so happens that, as data accumulate, it becomes more 
and more apparent that exceptions which prove the rule make it necessary to revise somewhat our ideas regarding the unity of unit characters and the dominance of dominants, and to accentuate the principle of segregation as the prime Mendelian contribution. A few examples will serve to bring the main facts before us.

The seven pairs of contrasting characters in Peas which Mendel studied showed essentially complete dominance of one character in each pair, and therefore, quite naturally, he laid stress on this principle. As a matter of fact we may say that dominance is hardly the rule because there are innumerable cases in which the hybrid $\left(\mathrm{F}_{1}\right)$ shows a different condition from either of the parents. For instance, on crossing homozygous red and white races of the Four-o'clock, all the progeny in the heterozygous $\left(F_{1}\right)$ generation bear pink flowers, or, we may say, flowers intermediate in color between the two parents. Neither red nor white is dominant. But inbreeding these give an $\mathrm{F}_{2}$ of 1 red, 2 pink, and 1 white. Thus the typical Mendelian $3: 1$ ratio is, so to speak, automatically resolved into the $1: 2: 1$ ratio which, when one character is dominant, is only patent on further breeding. (Fig. 144.)

In the case of the Four-o'clock, only the hybrids are intermediate; segregation occurs as usual and the homozygous progeny show the original parental characters unmodified. But sometimes, with the apparent lack of dominance, segregation seems not to take place. The cross between white and black races of Man is a typical example.

The mulatto $\left(F_{1}\right)$ is intermediate in skin color between the parental types and even in the $\mathrm{F}_{2}$ and later generations rarely gives pure white or black offspring. But an adequate Mendelian explanation is not far to seek. It has been found that both white and black are really composite characters, each made up of varying amounts of black, yellow, and red pig- 
ments. Now, assuming that the full-blooded Negro of Africa bears two sets of genes for black (AABB) which are absent (aabb) in the white race; then, since in the germ cells single genes segregate, the cross of white and black would give only a single set of genes for black $(\mathrm{AaBb})$ and the hybrid $\left(\mathrm{F}_{1}\right)$

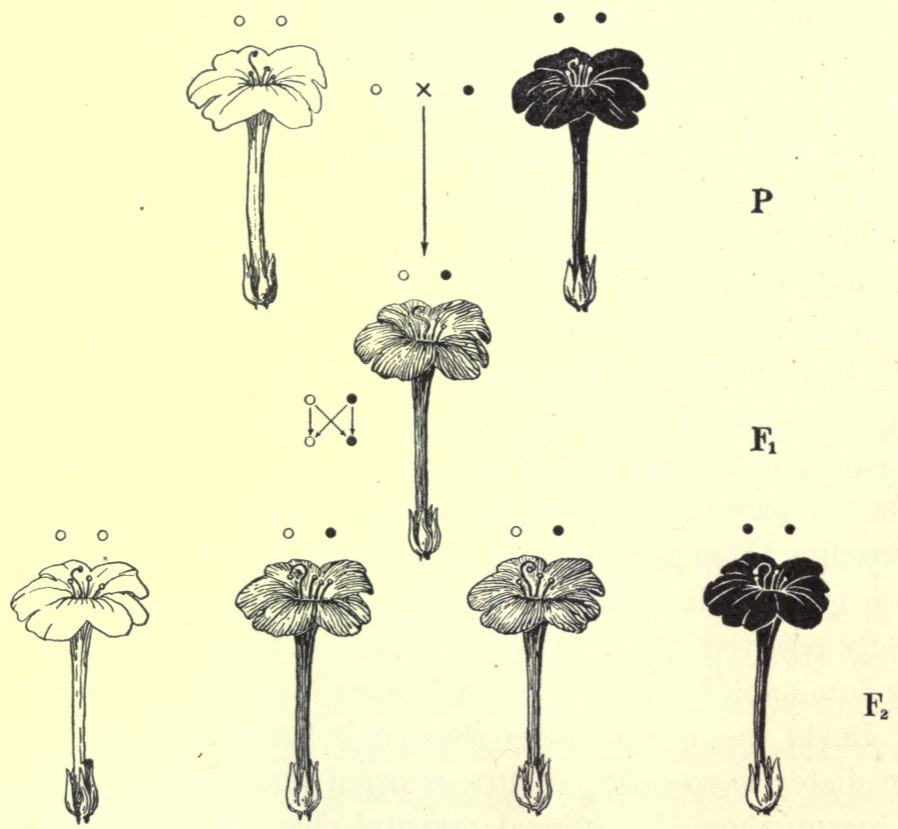

Fig. 144. - Diagram to illustrate the results from crossing white and red flowered races of Four-o'clocks (Mirabilis jalapa). The somatic condition (phenotype) is shown graphically; the small circles represent the genes which are involved.

would be neither black nor white, but intermediate. Again, the progeny of these mulattoes, that is the $\mathrm{F}_{2}$ and subsequent generations, should show different degrees of color, as they actually do, owing to varying combinations of genes; except in the small number of cases of extracted dominants (black) and extracted recessives (white). Therefore the intermediate color of the offspring of black-white crosses is reasonably 
explained, if we regard the character black as the expression of at least two pairs of genes, neither of which alone gives black but only when reinforced by the other. The infrequent appearance of pure whites or blacks in the $\mathrm{F}_{2}$ and later generations is not due to lack of segregation, but to the fact that, since the parental characters have a multiple gene basis, the chances are slight that in segregation all the separate genes

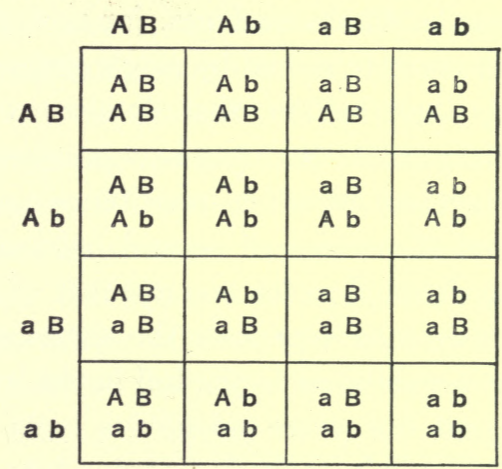

FIG. 145. - Recombination : square showing the result of mating two mulattoes, each having the color factors $A B$ and their absence $a b$ - the latter from their respective white parents. The color of the offspring varies from black (upper left corner) to white (lower right corner). Compare Fig. 140. (After Conklin.)

will be brought together in a single gamete and further that such a gamete at fertilization will meet one similarly endowed. (Fig. 145.)

From experiments with several races of Locusts which breed true for color pattern, it has been found that the hybrids between any two show the entire pattern of each parent, one superimposed upon the other. Thus, again merely by inspection, it is possible to determine the parental components, and since such hybrids give progeny showing the $1: 2: 1$ ratio, it is evident that the mosaic, instead of blended, result is due merely to the fact that each of the 'alternative' characters completely expresses itself. 
From these few examples, selected almost at random from the wealth of data at hand, it is clear that some cases of blending and mosaic inheritance, as well as alternative inheritance, can be satisfactorily interpreted on fundamental Mendelian principles. It is merely necessary to bear in mind that when speaking of unit characters, we mean that the germinal physical basis of characters, that is the genes which condition their development, behave as units, for now we know that some characters are determined by single genes, and some by multiple genes. And further, that dominance is a relation between a pair of genes rather than between their expressions, characters. Therefore blending inheritance may be merely an expression of the action of several pairs of genes, each gene displaying dominance for one member of a pair; while mosaic inheritance may represent the extreme where each gene's influence is exhibited to the full in the hybrid.

Within the past few years geneticists have been able by the MULTIPLE FACTOR hypothesis to bring into line with the Mendelian interpretation the inheritance of a large number of characters, especially in the higher animals. Thus stature, proportions of the parts of the body, build, as well as nearly all of the physiological and mental characteristics in Man, are evidently dependent upon multiple genes. This seems so generally true in the higher animals and plants as to suggest that their characters are genetically relatively complex as compared with those of many of the lower organisms.

So it happens, as is usually the case, the more a problem is studied the more complex it appears to become. Suffice it to say that, although our idea of 'unit characters,' 'dominance,' and even 'segregation' is to-day somewhat broader than Mendel conceived on the basis of his classic experiments, it is evident that he supplied us with fundamental principles which are affording a common denominator for 
an ever-increasing number of facts in genetics. Only the future can determine whether they are universal.

\section{E. Mechanism of Mendelian Inheritance}

With this general outline of the Mendelian principles before us, it is now necessary to bring them into relation with the facts so far known in regard to the structure of the germ cells. In other words, we have assumed germinal factors, or genes, segregation, etc., but has the actual study of cells (cytology) given any evidence of the physical basis of genes and of a segregating mechanism? The reader will at once answer this in the affirmative on the basis of our discussion of the origin and structure of the germ cells and their behavior in fertilization. But all, or nearly all, of these cardinal facts were unknown when Mendel worked and this makes still more remarkable his prevision in interpreting his results in the terms he did.

The essential facts may now be restated from a slightly different viewpoint. The egg and sperm each carry a definite number of chromosomes and consequently after fertilization the zygote contains a double set. For each chromosome contributed by the sperm there is a corresponding, or homologous, chromosome contributed by the egg. In other words, there are two chromosomes of each kind which may be considered as pairs. When division of the zygote takes place each chromosome splits into two chromosomes, so that each daughter cell receives a daughter chromosome derived from each of the original ones. Since all the cells of the organism are lineal descendants by similar mitotic cell divisions, all of its cells contain the double set of chromosomes - half paternal and half maternal; and since the primordial germ cells have a similar origin, they also have a double set of chromosomes. But during the maturation process synapsis occurs: that is, 
homologous chromosomes of paternal and maternal origin unite in pairs - the process of fertilization which gave rise to the individual being consummated in the ripening of its own germ cells. But this union is only temporary; a succeeding mitosis, instead of dividing each chromosome as usual, separates the maternal and paternal chromosomes of each synaptic pair and delivers one of each (though rarely all of the same maternal or paternal set) to the two arising cells. Thus each mature germ cell contains one member of every chromosome pair and the number of chromosomes is reduced one half. ${ }^{1}$ (Fig. 146.)

Mendel postulated that the genes for alternative characters segregate in the formation of the germ cells of hybrids so that a single gamete bears one and not both genes of a pair of allelomorphs. That is the genes, which come together in the zygote which forms the hybrid, separate again in the formation of its own germ cells. This is just what cytological studies show. Chromosome behavior exactly parallels the typical behavior of the Mendelian gene, because in the maturation of the germ cells each chromosome of paternal origin separates from the corresponding chromosome of maternal origin. The genes similarly situated on homologous paternal and maternal chromosomes are allelomorphs and are segregated during maturation. And further, in considering Mendelian dihybrids we found, for instance, that genes for yellow and round, and green and wrinkled seeds were inherited in a fashion which indicated that yellow and round, let us say, are segregated independently of each other, because all possible combinations with green and wrinkled occur. This clearly is

1 It will be recalled that in plants exhibiting an alternation of generations, the chromosome reduction occurs at the formation of the spores. (Fig. 124.) A little thought will convince the reader that this difference is of no importance from the standpoint of the present discussion, because we are interested in inheritance from sporophyte to sporophyte and can neglect the gametophyte which intervenes. 

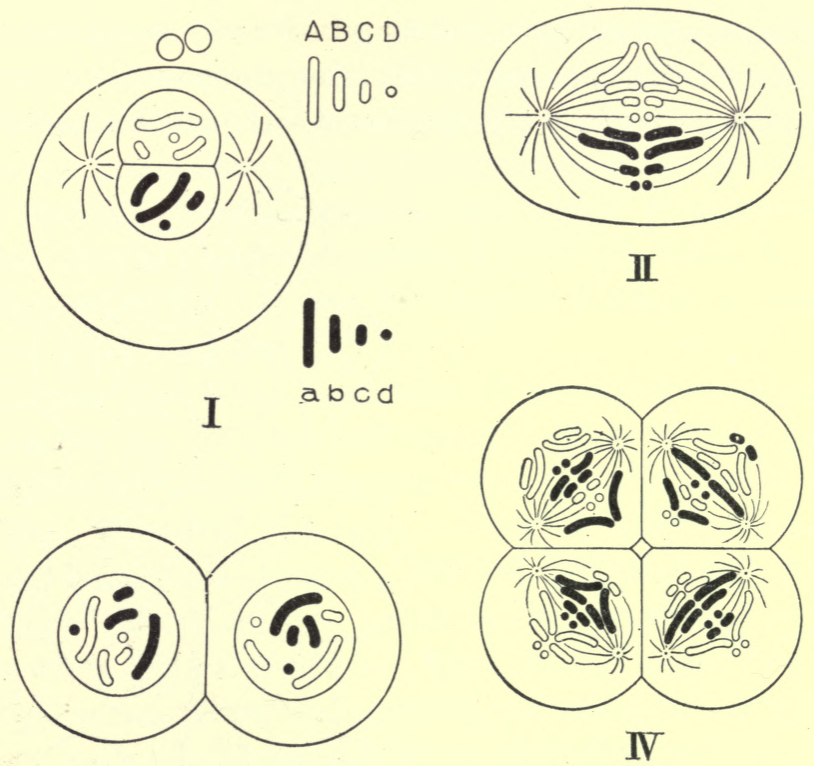

III.

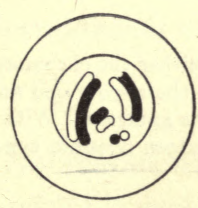

$\mathrm{AaBbCcDd}$

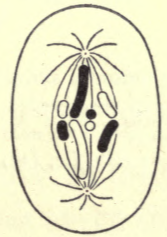

VI

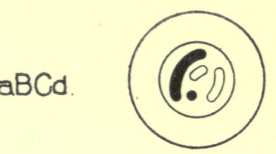

aBCd

$A b c D$

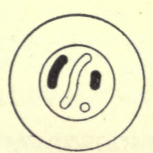

VII

Fig. 146. - Diagram of the chromosome cycle of an animal. Somatic (diploid) chromosome number assumed to be eight. Paternal chromosomes (from sperm) = $A B C D$; maternal (from egg) $=a b c d$. I, union of nuclei of gametes, each with a simplex group (haploid number) of chromosomes, in the zygote at fertilization to form a duplex group (diploid number) of chromosomes. II, III, IV, somatic divisions or divisions of germ cells before maturation (duplex groups of chromosomes). V, synapsis, involving pairing of homologous paternal and maternal chromosomes to give the haploid number of paired chromosomes. VI, reduction division - separation of pairs into single chromosomes again. VII, two gametes, with simplex groups (haploid number) of chromosomes; there are 14 more possible combinations of the chromosomes, or types of gametes, which are not shown. See Fig. 147. (After Wilson, slightly modified.) 
fully accounted for, provided the gene for yellow and the gene for round are not borne by the same chromosome, since in maturation the gametes secure one of each pair of homologous

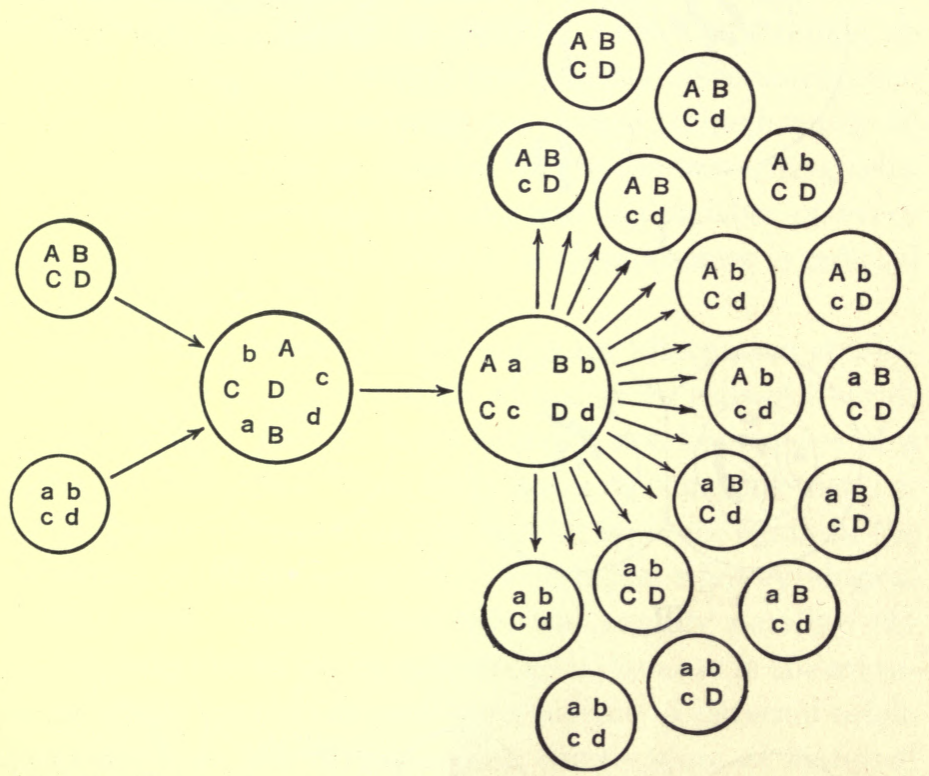

Frg. 147. - Diagram to show the union of simplex groups of either the chromosomes or of the genes of the gametes to form the duplex condition of the zygote and animal body; and then their pairing at synapsis, and segregation in the gametes. With four pairs of chromosomes or of genes $(A a, B b, C c, D d)$ there are sixteen possible types of gametes. (After Wilson.)

chromosomes (a simplex group), but not necessarily all of maternal or paternal origin. (Fig. 147.)

In short, when two gametes unite they each contribute to the zygote two corresponding, simplex groups of genes with the result that the offspring is of a double, or duplex gene, constitution. Similarly, the gametes contribute two simplex chromosome groups so that the zygote is of a duplex chromosome constitution. Thus both the chromosomes and the 
characters (genes) are in the simplex condition in the gametes and duplex in the zygote. This close parallelism of gene and chromosome behavior affords the most cogent evidence that the chromosomes supply the physical basis of inheritance, and that Mendelian segregation and related phenomena are facts. For all practical purposes A, B, C, D, and a, b, c, d, in figures 146 and 147 may be interpreted either as chromosomes or as characters.

Turning now to the inheritance of characters whose genes are borne by the same chromosome: these would seem to be indissolvably linked together; and since the chromosome number is usually not large - there are twenty-three or twenty-four in the gametes of Man - compared with that of heritable characters, we would expect sometimes to find characters linked together. That is, not separately inherited as are yellow and round in our example. In reality many cases are known in which characters are inherited in groups. The inheritance of sex and sex-linked characters will make the main point clear, and at the same time serve to bring before us the essential facts in regard to the determination of sex.

\section{Sex Determination}

The reader will recall that in the general description of cell structure it was stated that every cell of an organism contains a definite even number of chromosomes. As a matter of fact, in most instances the body cells of one sex, usually the male, have one more functional chromosome than the 'regular' set, and therefore an odd number. This extra chromosome, which is commonly designated the $\mathrm{X}$, or sex chromosome, has no mate at synapsis, remains undivided in the reducing maturation division, and passes entire to one of the daughter cells. Thus two classes of sperm are formed, one with and 
the other without the $\mathrm{X}$ chromosome - half of the sperm contain an $\mathrm{X}$ chromosome.

Furthermore, in species in which the male has the $\mathrm{X}$ chromosome, the female has two of them. The female therefore has one more chromosome than the male. Thus during oögenesis the $\mathrm{X}$ chromosomes pair in synapsis just as the other homologous chromosomes, and then one is distributed to each of the daughter cells, so that all of the eggs contain an $\mathrm{X}$ chromosome. For instance, in Man the somatic number of chromosomes apparently is forty-seven in males, or forty-six plus the $\mathrm{X}$ chromosome; while the female somatic number is forty-eight, or forty-six plus two $\mathrm{X}$ chromosomes. Half of the sperm contain 23 and half 24 chromosomes; all the eggs contain 24 chromosomes.

Since there are equal numbers of sperm with and without the $\mathrm{X}$ chromosome, on the average as many eggs will be fertilized by one class of sperm as the other, with the result that half of the zygotes will contain one $\mathrm{X}$ and half two $\mathrm{X}$ chromosomes. Obviously the former will develop into males and the latter into females, since the somatic cells of males have the $\mathrm{X}$ chromosome and therefore the 'sex gene' in simplex condition, and similar cells of females have the duplex condition. So it is possible - it has been accomplished in several species - to ascertain the sex of an embryo by counting the chromosomes in its cells. (Fig. 148.)

Thus there is good eytological evidence that sex inheritance follows the Mendelian formula. The male carries one sex gene (on the single $\mathrm{X}$ chromosome) and the female two sex genes (one on each of the $\mathrm{X}$ chromosomes). At maturation these segregate so that the male is heterozygous and the female is homozygous in regard to sex, and therefore all possible combinations of gametes result in the $1: 1$ ratio of males to females. In passing, we may emphasize that this 
shows that the sex of an individual is usually determined at the time of fertilization, and not subsequently as most of the well-known theories contend. But obviously we must guard against thinking of either the $\mathrm{X}$ chromosome or the 'sex gene' as 'producing' sex. Sex is a complex character whose full development is undoubtedly conditioned by 'sex

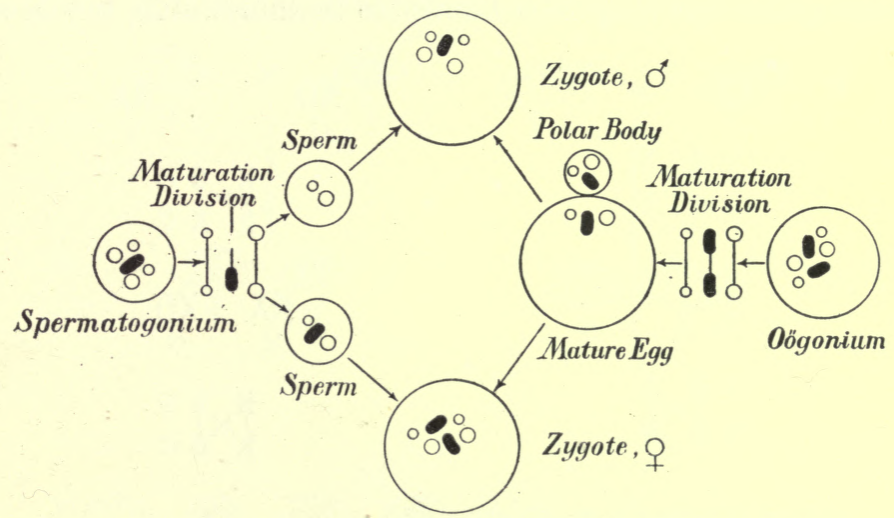

Fig. 148. - Diagram to show the relation of the two classes of sperm in fertilization. The formation of gametes in the male is shown at the left, in the female at the right; fertilization, producing the male or female zygote, in the center. $\mathrm{X}$ chromosome in black. (After Wilson.)

hormones,' etc., but since the $\mathrm{X}$ chromosome is the differential in the sexes, it is to that extent 'sex-determining.'

\section{Linkage}

Since sex is regulated by an internal mechanism which appears to be the same as that which determines the distribution of characters in Mendelian inheritance, it might be supposed that the genes of other characters as well are carried by the $\mathrm{X}$ chromosome. As a matter of fact the behavior in inheritance of certain characters is such that it can only reasonably be explained on this assumption. Accordingly such characters are known as SEX-LINKED. This 
brings us again to the point at which we digressed to consider sex - the discussion of genes associated on the same chromosome. One example must suffice to bring out the main facts.

The common form of color-blindness known as Daltonism, in which the affected individual is unable to distinguish red from green, has long been known to be inheritable, but in a
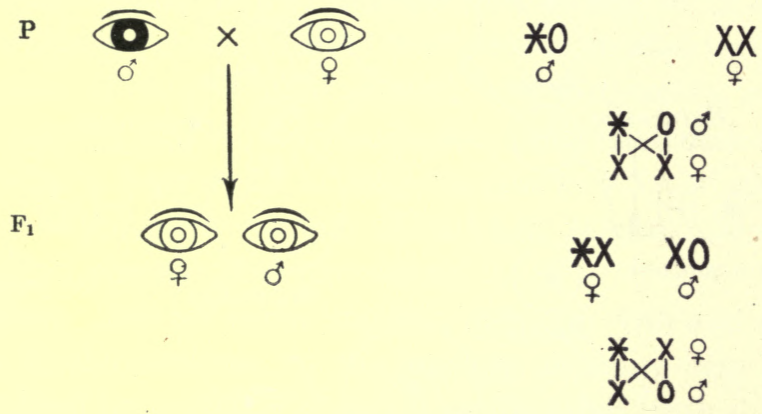

$\mathrm{F}_{2}$

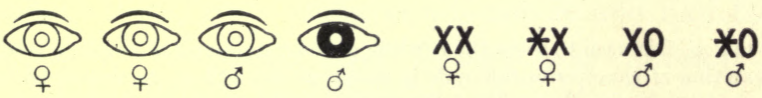

Fig. 149. - Diagram to show the inheritance of color-blindness from the male. A color-blind male (shown in black) transmits the character to half of his grandsons. * indicates the 'sex' chromosome with the gene for color-blindness. (After Morgan.)

peculiar crisscross way. The condition is transmitted from a color-blind man through his daughters, who are normal, to half of his grandsons; and from a color-blind woman to all of her sons and none of her daughters. This behavior is readily accounted for if we assume that the gene for colorblindness is associated, when present, with the gene for sex on the $\mathrm{X}$ chromosome, and that color-blindness develops in males, just as 'maleness,' when it is simplex or from one parent, and develops in females when it is duplex, or from both parents. (Figs. 149, 150.) 
Color-blindness thus serves to illustrate the association of genes of different characters on the same chromosome and the association later of their respective characters in the adult. But the presence of separate genes on the same chromosome by no means indicates that the genes must always be distributed together, for there is considerable evidence that during synapsis genes may reciprocally cross-

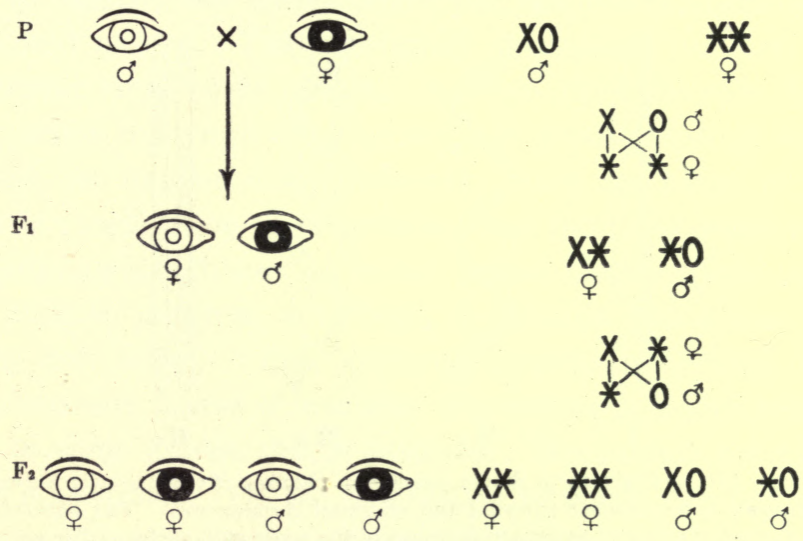

Fig. 150. - Diagram to show the inheritance of color-blindness from the female. A color-blind female (shown in black) transmits the character to all of her sons, and to half of her grandsons, and to half of her granddaughters. (After Morgan.)

over from one synaptic mate to the other and thus become separated from their former gene associates on the same chromosome. This crossing-over removes the limitations which, at first glance, would seem to confine the possible number of characters capable of independent segregation in Mendelian inheritance to that of the chromosome number, and renders invalid any objections to the universality of Mendelism which are based on the chromosome mechanism as at present understood. And further, the crossing-over gives an opportunity to determine the relative positions of different genes on a chromosome - if it is assumed that the 
distance between two genes is proportional to the percentage of crossing-over which these genes show. (Fig. 151.)

\section{F. Nature versus Nurture}

From one viewpoint, then, the individual may be considered as a composite of very many unit characters which behave in a definite way in inheritance. "Expressed otherwise, and

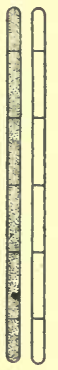

I

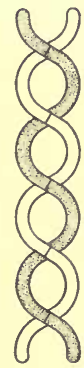

II $a$

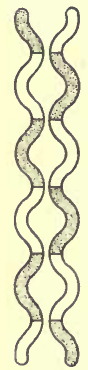

II $b$

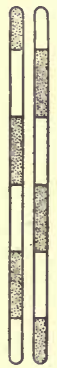

II $c$

Fig. 151. - Diagram to show a possible mechanism of crossing-over during synapsis of homologous paternal and maternal chromosomes. The segments indicate the assumed linear arrangement of the genes with allelomorphic genes opposite each other. I, pair of chromosomes which have entered and emerged from the synaptic state without any crossing-over; II $a$, chromosomes winding about each other at synapsis; II $b$, separation of these chromosomes, involving breaking at the points of crossing; II $c$, their emergence from synapsis with the members of the pairs of allelomorphic genes interchanged. (After Wilson.)

somewhat fancifully, individuals are simply temporary kaleidoscopic combinations of the various determiners (genes) belonging to the species; the act of reproduction, especially the reduction division and subsequent fusion, providing the . new turn of the kaleidoscope." But since the life of an organism is one continuous series of reactions with its surroundings, it follows that nurture plays an immensely important part in molding the individual on the basis of its heritage. This is especially true in the case of Man. Development is a form of behavior, and how a child develops 
physically and mentally is determined not by its heritage alone nor by its environing conditions alone, but by both in intricate combination. Although apparently we do not inherit the effects on our forebears of their surroundings and training, nevertheless we are the heirs to their mores, which entails added responsibilities as well as opportunities for each succeeding generation. Thus 'social heredity' bids fair to outstrip our conservative and essentially unchanging inherited nature. The EUTHENIST emphasizes nurture, the EUGENIST emphasizes nature. As is so often the case, however, when doctrines are opposed, the truth combines both; though we cannot doubt, knowing what we know of the genetic constitution of organisms, that from the standpoint of permanent advance - racial rather than individual the path to progress is through EUGENICS, the science of being well born. "This distinction between heritage and acquirements leaves a fatalistic impression in many minds, and to some extent this is justified. We cannot get away from inheritance. On the other hand, although the organism changes slowly in its heritable organization, it is very modifiable individually; and this is Man's particular secret - to correct his internal organic inheritance by what we may call his external heritage of material and spiritual influences." (Thomson.) (Fig. 152.)

It is therefore clear that the problem of human improvement has two aspects: in the first place, the effects of culture on the individual which, though not inherited, are cumulative from generation to generation through training; and secondly, racial betterment through breeding the best. But the reader may well ask: What is the possibility of anything much better than the present best if heredity is essentially a recombination of the characters of our forebears - a turn of the kaleidoscope? 
Although we are wofully ignorant of the cause of variations, the difficulty is more apparent than real and arises from our absolute ignorance of what genes really are. We may conceive them to be chemical molecules, and if so they can change only by an alteration of their chemical constitution. And for all we know, this may occur. Or, without any change in the genes themselves, their expression - the

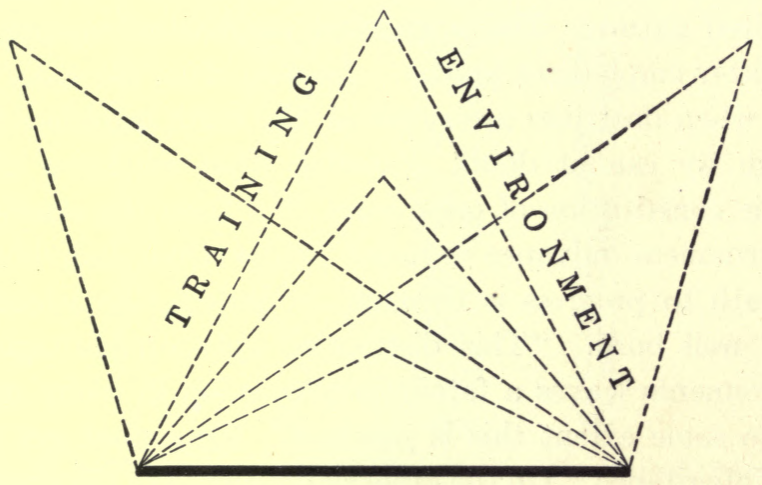

H E R I T A G E

Fig. 152. - Scheme to illustrate the contributions of nature and nurture to the makeup of the individual. The triangles represent various types of individuals which may be produced by the same germ cells (heritage) if environment and training are variable. The foundation of the "triangle of life" is heritage. (After Conklin.)

chemical effects which they produce - may change by the alteration of other substances with which they react. If we interpret such phenomena as recombinations, they are profoundly more subtle and far-reaching than are called to mind by our simile of a kaleidoscope. They may be essentially infinite in number and infinite in potentialities for variations in the germ plasm and therefore for heritable variations expressed in the soma. Again it is possible, perhaps probable, that inheritable variations are often the result of chromosomes 'accidentally' losing or gaining one or more genes during 
synapsis. That is, one member of a pair of synaptic mates leaves with the other member certain genes for which it gets none in return: only half of the crossing-over process occurs. Such a phenomenon would probably profoundly modify the constitution of both chromosomes involved and accordingly the organisms to which they contribute. And all such types of mutations must be important raw materials for evolution.

\section{G. Selection}

For more than half a century selection has been something to conjure with - a sort of creative principle to explain the progressive changes in plants and animals. It was assumed that the SELECTION of a certain type of individual for breeding would result in a gradual and continuous transformation of the race or species in the direction of the selection. But Darwin recognized that selection in itself can produce nothing - its efficacy depends on the materials afforded by variation. He did not and, in fact, could not make the modern sharp distinction between modifications, combinations, and mutations, but accepted all variations as at the disposal of selection. But recent work indicates that selection of certain types of variations effects only an apparent and not a real change. An example will make this clear. (Fig. 153.)

Take, say, a quart of beans and sort them into groups according to the weight of each bean. Then put each group into a separate cylinder and arrange the cylinders in a series according to the weight of the enclosed beans. Now if we imagine a line connecting the tops of the bean piles in each cylinder, it takes the form of a typical curve of probability, or frequency polygon. A similar figure would be obtained by the statistical treatment of nearly all fluctuating characters among the members of any large group of organisms, or of the size of the grains in a handful of sand, or the deviations of 
shots from the bull's-eye in a shooting match. Therefore the variations with respect to a given character very closely ap-

\section{Pure Line}

1

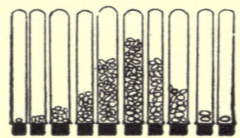

2

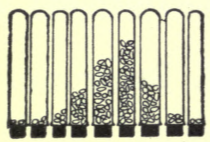

8

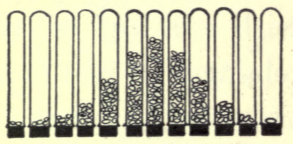

4

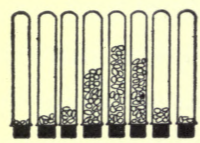

5
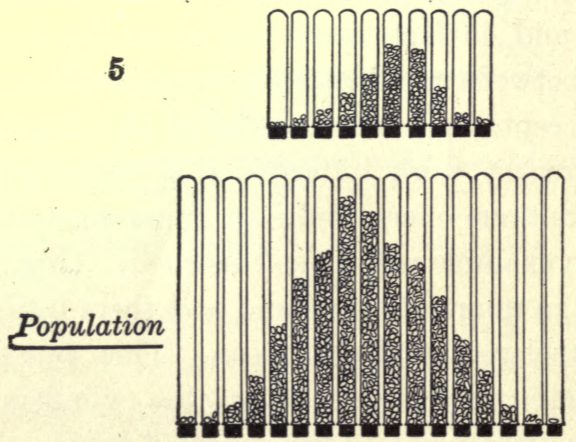

Fig. 153. - Diagram to illustrate a population of beans and its five component pure lines. The beans are assorted according to weight. Tubes containing beans of the same weight are placed in the same vertical row. The population represents the quart of beans discussed in the text. (From Walter, after Johannsen.)

proximate the expectation from the mathematical theory of probability, or chance, and the reasonable conclusion is that the FLUCTUATIONS are a resultant of a large number of factors 
each of which contributes its slight and variable quota to the expression in a given individual. (Figs. 154, 155.)

The question is, what results are obtained by breeding from individuals which exhibit such a fluctuating variation to, let us say, a greater degree than that of the mean of a mixed population? The reader with Galton's theory of filial regres-

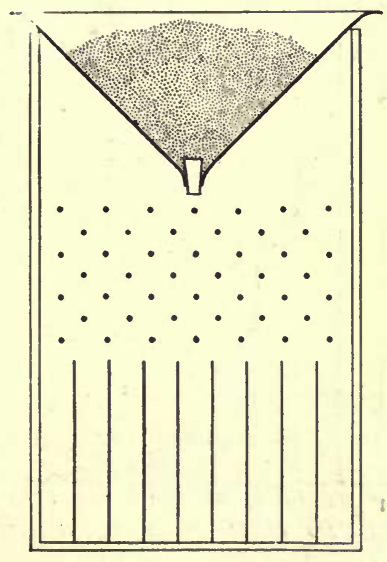

A

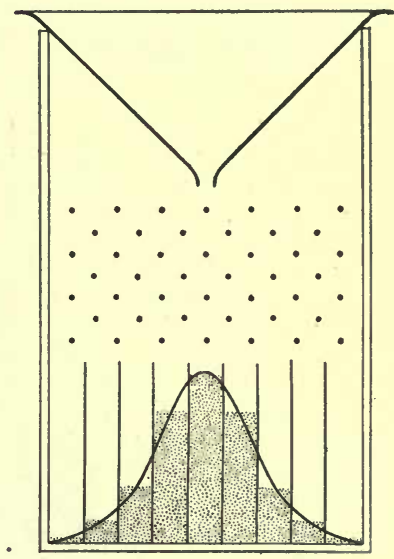

B

FIG. 154. - Model to illustrate the law of probability, or chance. $A$, shot held in the funnel at the top of the board; $B$, the shot, released by opening the mouth of the funnel, have fallen through the series of hazards (pins), and been deflected by 'chance' into the vertical compartments at the bottom. The curve connecting the tops of the columns of shot is the normal probability, or frequency, curve. (After Kellicott.)

sion in mind will naturally expect, and rightly, that the offspring usually will exhibit the character to a less degree than the parents but to a greater degree than the population. The top (mode) of the curve will have moved, so to speak, slightly in the direction of selection. Now, by continuing generation after generation to select as parents the extreme individuals, is it possible, with due allowance for some regression, to take one step after another indefinitely, or until the character in question is expressed to a degree which did not exist previ- 
ously? The experience of practical breeders gives a partial answer, since the continual selection of the best animals for mating and the best plants for seed has been a profitable procedure. But it has long been known that after a certain amount of selection has been practiced it ceases to be so

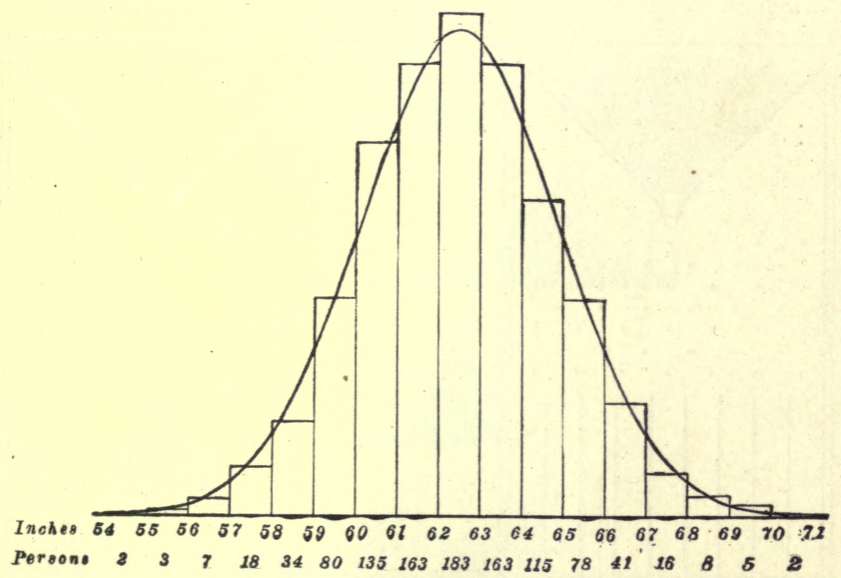

Fig. 155. - Normal frequency curve. Plotted measurements of the height of 1,052 women. The height of each rectangle is proportional to the number of individuals of each given height. (Cf. Figs. 153, 154.) (From Kellicott, after Pearson.)

effective, and thenceforth serves chiefly to keep the character at the higher level attained. (Fig. 156.)

The crux of the matter is in regard to exactly what the fluctuations are. Modifications (non-heritable) and frequently combinations (heritable) give a normal variability curve, and both may be included in fluctuations. This mixture of heritable and non-heritable variations is what makes confusion. If we rule out combinations, by inbreeding or by self-fertilization of homozygous individuals - establish PURE LINES - then the fluctuations are all modifications and selection is ineffectual with characters which are not inherited. 


\section{Pure Lines}

The importance of this point was discovered by careful experiments on the inheritance of characters in single pure lines; particularly those of Johannsen on inheritance in a brown variety of the common garden Bean. For example, by keeping the progeny of each individual bean separate from that of all the rest, he was able to isolate a number of pure lines which differed in regard to the average weight of the

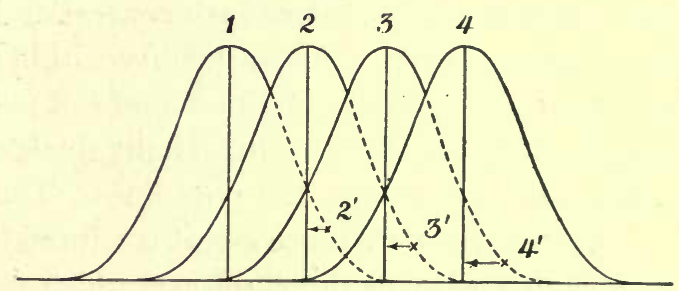

FIG. 156. - Schematic representation of the effect of selection from the viewpoint. of Galton's 'law of filial regression.' (1) Mode before selection; 2, 3, 4, new (successive) modes, the results of selections of individuals at $2^{\prime}, 3^{\prime}, 4^{\prime}$. The mode has been shifted in the direction of selection (toward the right). But there has been each time an amount of regression indicated by the length of the arrows.

beans. Selection did nothing but resolve the species, or the bean 'population' with which he began, into its constituent 'weight types,' or lines, each of which exhibited a characteristic variability curve of its own with a mode departing more or less from that of the population. But when Johannsen selected within a pure line (ruled out combinations) nothing at all resulted; he was unable to shift the mode because he was dealing with nonheritable characters. In other words, the effect of selection is one of isolation and not creation. As a rule it sorts out pre-existing pure lines (lines with homogeneous germinal constitution) from a population and then stops - though if selection is stopped the isolated lines usually soon merge again into the original population. A mutation 
must occur in a pure line for selection to be effective - and then, ipso facto, the single pure line becomes two. (Fig. 153.)

The trend of present work certainly seems to indicate that these conclusions are of general application and that the explanation of the long-accepted feeling that selection is 'creative' is to be found in the fact that variations are of three sorts: modifications which are not heritable and combinations and mutations which are heritable. Most of the variations within pure lines apparently are the result of environmental influences recurrent in each generation, but the germ plasm is homogeneous. The variability within a population is the composite variability of its component pure lines, but the germ plasm is not the same in all individuals - these may be segregated into groups, the pure lines. Thus, very liberally interpreted, the pure line concept is a formal expression of the fact that most of the variations which we recognize are either somatic or the result of recombinations of diverse parental genes. Accordingly when the genes of the gametes are identical (as in pure lines) the latter source of variation does not exist, and selection is powerless except when comparatively rarely mutations occur. (Fig. 157.)

However, some recent work indicates that under certain conditions selection appears to be effective, at least to a limited degree, within a pure line. We have previously seen that certain characters are the expression of multiple genes. In some such cases one gene is, so to speak, the determining gene for the character as a whole, while associated with this gene there is a galaxy of modifying genes which themselves do not find expression without the presence of the determining gene, but merely serve to alter the character expression of the latter. Under such conditions it is possible to modify the character by selection - to add or subtract or otherwise change the relationships of the modifying genes to the pri- 
mary gene. It would seem however that the effectiveness of selection of this sort should be relatively limited in any particular case, and, in any event, the data thus far secured do

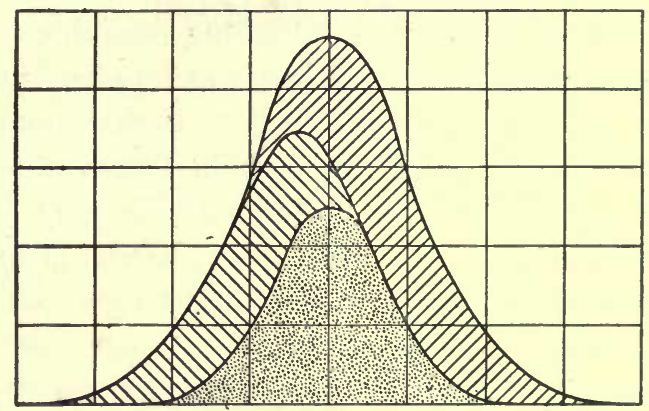

A

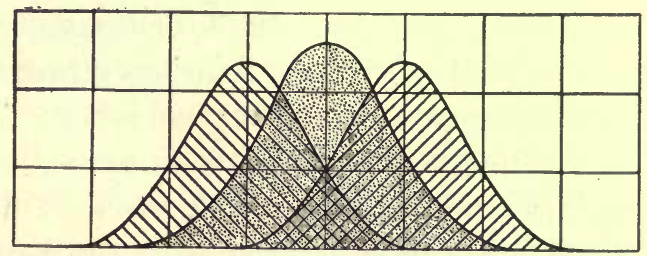

is

FIG. 157. - Curves illustrating the relation between pure lines and populations or species. $A$, a population or 'species' curve, comprising three pure lines; $B$, the separate elements (pure lines) of $A$, each with its own average and variability. (After Kellicott.)

not fundamentally alter the general importance of the pure line concept.

When all is said, it is clear that the realization of certain categories of variations, taken in connection with the pure line concept, has given new content to the problem of selection. The appreciation of its limitations has but accentuated its possibilities. Selection is not shorn of its importance either practical or theoretical. Artificial selection is useful in 
separating one line from another, as is attested by practical breeders everywhere, and in taking advantage of mutations when they occur. Most of the 'new creations' in horticulture and animal breeding are the result of hybridization and the rigid selection of individuals exhibiting desirable new combinations and sometimes mutations which hybridizing seems to induce. Natural selection, in a quite similar manner, may act as a 'sieve' and sort out new combinations and mutations presented - leave the fit and eliminate the unfit - and so afford a natural explanation of the adaptation of organisms to their environing conditions. (Fig. 194.)

\section{Summary}

Before leaving the subject a brief summary of the most important general principles which the study of genetics has thus far afforded may be helpful. In the first place, it appears clear that the basis of inheritance is in the germinal rather than in the somatic constitution of the individual. A character to be inherited must be innate in the germ cells, and there is no satisfactory evidence that modifications of the body, 'acquired characters,' can be transferred to the germ and so inherited. Secondly, characters or groups of characters are usually, if not universally, inherited as definite units. These follow Mendelian principles of segregation and recombination in the formation of the germ cells of an individual, so that paternal and maternal contributions are readjusted in all the combinations which are mathematically possible. And finally, the germinal factor basis (genes) of unit characters is remarkably constant. Selection is apparently powerless to alter it, but merely sorts out what is already there, or, taking advantage of such changes (mutations) as do occur, determines their survival value for their possessor in the struggle for existence. 


\section{CHAPTER XVIII}

\section{ADAPTATION OF ORGANISMS}

Every creature is a bundle of adaptations. Indeed, when we take away the adaptations, what have we left?

-Thomson and Geddes.

Organisms are systems dependent for their maintenance and operation upon energy liberated by chemico-physical processes in protoplasm, and therefore any and all influences which induce changes in the structure or functions of an organism must initially modify the underlying phenomena which are responsible therefor. In a word, organic response is a problem of metabolism. Although it is highly important that this cardinal fact be clearly grasped, the science of biology to-day is not in a position to interpret the responses of organisms in these fundamental terms, and we shall merely present some representative instances to illustrate the fact that the response of organisms, as exhibited in active adjustment-adaptation - of internal and external relations, overshadows in uniqueness all other characteristics of life and at one stroke differentiates even the simplest organism from the inorganic.

Overwhelmingly striking as is the fitness of organisms to their physical surroundings, we must not lose sight of the fact that the environment itself presents a reciprocal fitness. This results from the "unique or nearly unique properties of water, carbonic acid, the compounds of carbon, hydrogen, and oxygen. ... No other environment consisting of primary constituents made up of other known elements, or lacking water 
and carbonic acid, could possess a like number of fit characteristics, or in any manner such great fitness to promote complexity, durability, and active metabolism in the organic mechanism which we call life." (Henderson.)

\section{A. Adaptations to the Physical Environment}

In any consideration of the reciprocal relations which must exist between organisms and their surroundings, of first importance is the inconstancy of the latter. Uncertainty is the one certainty in nature and accordingly the response of living things - their adaptability to environmental exigencies is at once the most striking and indispensable adaptation.

\section{Adaptations Essentially Functional}

Although the changes of the environment are almost inconceivably complex - witness the kaleidoscopic series of events exhibited in the hay infusion microcosm - there are certain general conditions which every environment must supply, and without which life cannot exist. These are food, including water and oxygen, certain limits of temperature and pressure.

Food. As we know, food represents the stream of matter and energy which is demanded for the metabolic processes of living matter. And each and every element which forms an integral part of protoplasm must be available. Since all protoplasm consists chiefly of a dozen chemical elements, these, of course, must be present; and further, since protoplasm is a colloidal complex in which water plays a fundamental rôle, life processes without water are impossible. But the old adage that what is food for one is another's poison has a broader content than is immediately apparent. Although it is true there are general 'food-elements' which all life demands, it is equally true that the combinations in 
which these elements must be presented to the organism, in in order to be available for its metabolic processes, are subject to the widest variation.

We have emphasized and contrasted the nutrition of a typical animal, green plant, and colorless plant, and have seen the reciprocal part which they play in the circulation of the elements in nature, so it is only necessary, with these facts in mind, to cite special cases in order to illustrate the adaptation of special groups of organisms to special condi-
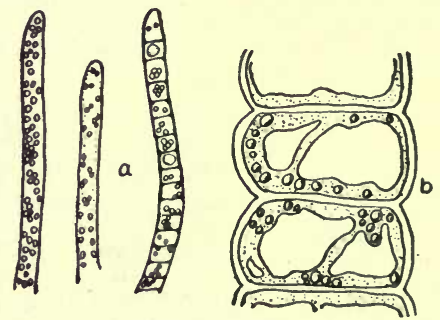

Fig. 158. - Portion of filaments of Beggiotoa alba (a), and two cells of Beggiotoa mirabilis $(b)$ showing enclosed sulfur granules. (From Buchanan.)

tions of existence. The demands of the so-called Sulfur Bacteria and the Yeasts are in point.

The Sulfur Bacteria (Beggiotoa) live in water containing sulfuretted hydrogen, from which, by oxidation, they obtain energy and store up within the protoplasm free sulfur in the form of tiny granules. And then by further oxidation they transform the sulfur into sulfuric acid and excrete it. Thus a gas which is poisonous to nearly all organisms is for Beggiotoa a necessary life condition. (Fig. 158.)

The Yeasts include a host of microscopic colorless plants which play an important part in the simplification of organic compounds. (Fig. 159.) Being devoid of chlorophyll, Yeasts of course lack photosynthetic powers, though like many other colorless plants they are not dependent upon 
proteins for nitrogen but obtain it in less complex forms. But the essential fact of interest at present is the chemical changes associated with Yeast metabolism - the transformation of a large proportion of the sugar content of the medium in which they live into alcohol and carbon dioxide. This process of alcoholic fermentation may be approximately expressed by the formula:

$$
\mathrm{C}_{6} \mathrm{H}_{12} \mathrm{O}_{6} \text { (sugar) +yeast }=2 \mathrm{C}_{2} \mathrm{H}_{5} \mathrm{OH}(\text { alcohol })+2 \mathrm{CO}_{2}
$$

The explanation is not far to seek. Deprived of an adequate supply of air, Yeasts resort to the energy released when, with the decomposition of the sugar, the carbon and oxygen unite

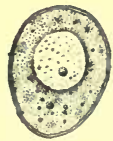

A

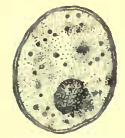

B

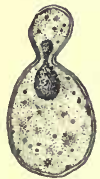

C

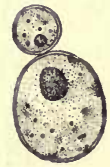

D

Fıg. 159. - Yeast cells, very highly magnified. $A$, cell showing granular cytoplasm and a large vacuole; $B$, showing nucleus; $C$, cell budding; $D$, mother cell and bud after division is completed.

as $\mathrm{CO}_{2}$. The formation of alcohol by the remnants of the sugar molecules is, from the standpoint of the Yeasts, a mere incidental factor which is, so to speak, unavoidable. On the other hand, from the broad viewpoint, the waste products of the action of the Yeast plants' enzymes represent an important phase in the general simplification of organic compounds in nature. And Man turns to account in numerous ways both products of the Yeasts' destructive powers - the alcohol and the carbon dioxide.

Thus the Yeasts are practically independent of free oxygen and in this they agree with many kinds of Bacteria as well as some animals, chiefly parasitic worms, which are able to secure the necessary oxygen by the rearrangement of the atoms within a molecule or the disruption of the molecule 
itself. Indeed, certain species of Bacteria not only do not need free oxygen at all, but are killed when it is present in any considerable amount. All such organisms are termed ANAERoBes. A common example is Bacillus tetani which inhabits garden soil and street dust and produces tetanus, or lockjaw, in Man and certain domesticated animals when it gains entrance to the tissues.

Temperature. Although protoplasmic activity is restricted to ranges of temperature which do not seriously interfere with the chemico-physical processes involved, it is a commonplace that various species are adapted to different degrees of temperature. The great majority of organisms, however, find their optimum temperature between $20^{\circ} \mathrm{C}$. and $40^{\circ} \mathrm{C}$., though species inhabiting the polar and tropical regions show adaptations to the temperature extremes of their surroundings. As a matter of fact, it is not possible to state the upper and lower limits beyond which active life is suspended, but some Algae and Protozoa are known to multiply in the water of hot springs, certainly at temperatures higher than $50^{\circ} \mathrm{C}$., and others in water until freezing actually occurs.

But many of the lower forms of life, such the Bacteria and Protozoa, have the power of developing, particularly under unfavorable surroundings, protective coverings of various sorts about themselves and of assuming a resting condition in which all the metabolic processes characteristic of active life are reduced to the lowest ebb. (Fig. 160.) In this spore or encysted state they are immune to extremes of temperature and of desiccation to which they readily succumb during vegetative life. Thus some types of Bacteria can successfully withstand a temperature of nearly $-200^{\circ} \mathrm{C}$. for six months, and about $-250^{\circ} \mathrm{C}$. for shorter periods, which is a temperature approaching closely that at which no 
chemical reactions are known to occur. Again, the spores of other Bacteria can endure a temperature as high as $120^{\circ} \mathrm{C}$. for a short time.

It is clear that the great majority of organisms are at the mercy of environmental temperatures. This is true of all except the higher Vertebrates, the Birds and Mammals. These so-called warm-blooded, or HомотнERMAL, animals possess a highly complex mechanism which maintains their

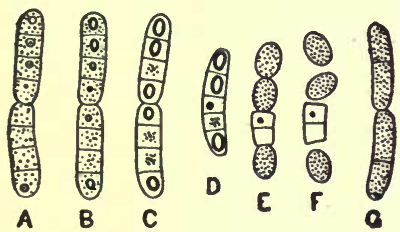

Frg. 160. - Spore formation and germination in Bacteria. $A, B, C$, a pair of rods forming spores, drawn at one hour intervals; $D$, a five-celled rod, with three fully-formed spores, which was allowed to dry for several days and then placed in a nutrient medium; $E, F$, the same spores at one and three hours later; $G$, a pair of typical vegetative rods. (From Sedgwick and Wilson, after De Bary.)

body temperature practically constant; e.g., in Man at $37^{\circ} \mathrm{C}$. $\left(98.6^{\circ} \mathrm{F}\right.$.).

The heat regulatory mechanism represents, so to speak, the culmination of the assembling and elaborating, during Vertebrate evolution, of elements, the genesis of which is found among the Fishes. In the Mammals it comprises insulating material in the skin, a closed blood vascular system, power of rapid oxidation, endocrinal and other glandular products, evaporation surface of the lungs and skin, 'trophic' and 'temperature' nerves, coördinating centers, etc., - the whole complex rendering its possessors largely independent of the surrounding temperature and making possible a carrying on of the various bodily functions with such nicety as the life of these forms demands. 
Pressure. The metabolism of organisms, in common with chemical processes in general, is influenced by the surrounding mechanical pressure. Therefore it is evident that the pressure of either the water or air plays an important part in the carrying on of the life functions. We find organisms adapted to the greatest depths of the ocean where the water pressure is several hundred atmospheres - so great that some forms burst when rapidly brought to the surface; while others are adapted to live at high altitudes where the air pressure is relatively low. And again, the higher Vertebrates present an adaptive mechanism which renders them less dependent on a constant barometric pressure.

These few examples must suffice to emphasize the general environmental conditions which are necessary for life, as we know it, to exist, and to suggest that within these broad limits organisms are adapted to special environmental conditions so that there is scarcely a niche in nature untenanted.

\section{Adaptations Essentially Struclural}

We may now broaden our view of the plasticity of organisms by a brief consideration of adaptations which are essentially structural. But here as elsewhere it is absolutely impossible to divorce structure and function which, obviously, are only reciprocal aspects of the fitness of living creatures.

Adaptive Radiation of Mammals. In the group of Eutherian Mammals, forms are to be found which are extraordinarily modified in adaptation to the most diverse environmental conditions. From a more or less primitive type, or focus, there radiate, as it were, types which are specialized for different habitats and modes of life. (Fig. 161.) We may select a small Malayan insectivorous animal known as Gymnura, which is allied to the Hedgehogs, as 
most similar among living Mammals to the generalized or focal type of terrestrial Mammal. Gymnura has relatively short pentadactyl limbs with the entire palms and soles

Cursorial-

Unguligrade

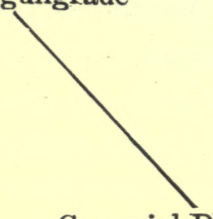

Cursorial-Digitigrade

(Terrestrial)

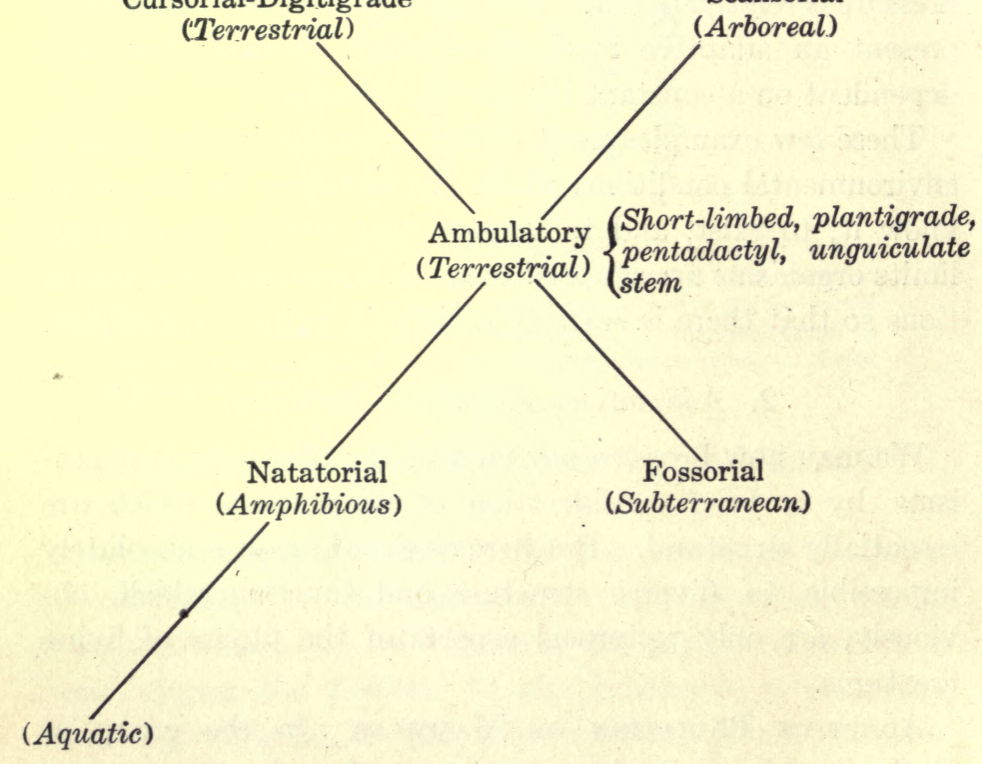

Frg. 161. - Diagram of the adaptive radiation of Eutherian Mammals as exhibited in limb structure. (From Lull.)

resting flat upon the ground (PLANTIGRADE) and therefore essentially adapted for comparatively slow progression. (Fig. 162.)

Radiating from this focus, adaptations for rapid running (cursorial adaptations) are chiefly evident in a lengthening 
of the limbs. Thus, for example, in the Dogs, Foxes, and Wolves, the effective limb length is increased by raising the wrist and heel from the ground and walking merely upon the digits (Digitigrade); while in Antelopes, Horses, and hoofed runners in general, the chief limb bones themselves are lengthened, subsidiary ones are suppressed, and the wrist and ankle are raised still further from the ground, so that merely the tips of one or two digits of each limb support the animal (UNGULIGRAdE). Thus the typical cursorial

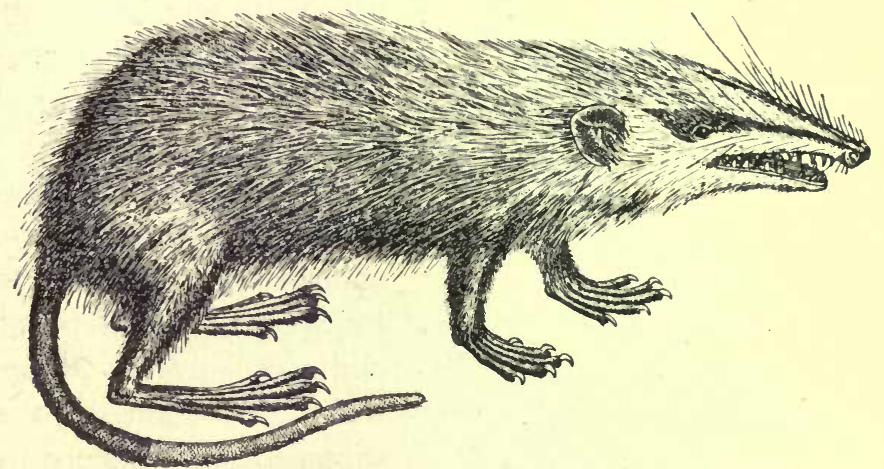

Fig. 162. - Gymnura. (From Lull, after Horsfield and Vigors.)

forms represent the culmination of Mammalian adaptation to plains and steppes; regions in which long distances must frequently be traversed in quest of food, and safety is to the swift. (Fig. 163.)

Another line of adaptive radiation is presented by the tree dwellers: arboreal forms which make their own the world of foliage high above the ground. Such are, for instance, the Sloths (Fig. 164), which are really tree climbers that walk and sleep upside down suspended from branches; the Man-like Apes that swing among the boughs chiefly by their arms; and the Squirrels that scamper along the branches. Some Squirrels and the so-called Flying Lemurs 


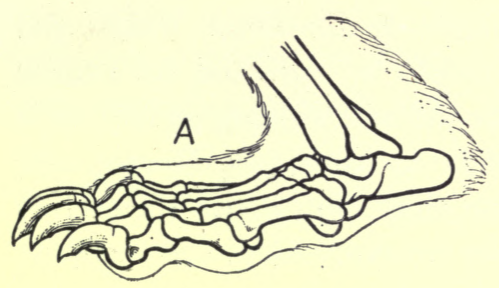

take long soaring leaps supported by wide folds of skin between the sides of the body and the extended limbs. (Fig. 167.) But the Mammals have not left the air untenanted, for truly volant forms are

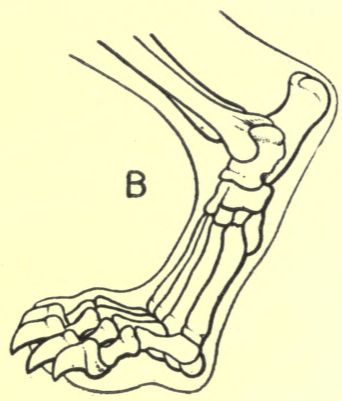
represented by the Bats in which the fore limbs with greatly elongated fingers form the framework of true wings: (Fig. 168.)

Passing below the surface of the earth, fossorial animals are found such as the Woodchucks, Gophers, and especially the Moles, which are adapted to a subterranean existence by

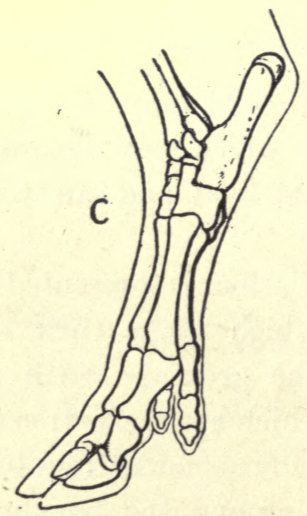
bodily modifications which facilitate digging. (Fig. 165.) The gap between terrestrial and aquatic Mammals is bridged by the Muskrats, Beavers, Otters, and Seals which are more or less equally at home on land and in the water.

The truly aquatic Mammals are the Porpoises and

Frg. 163. - Foot postures of Mammals. $A$, plantigrade; $B$, digitigrade; $C$, unguligrade. (From Lull, after Pander and D'Alton.) Whales which have completely abandoned the 
land of their ancestors of the geological past and to-day approach, in adaptations to a marine life, the general contour of the primitively adapted aquatic Vertebrates, the Fishes. (Fig. 166.)

Thus the various lines of adaptive radiation of the Mammals from a generalized terrestrial type, such as Gymnura, have provided Mam-

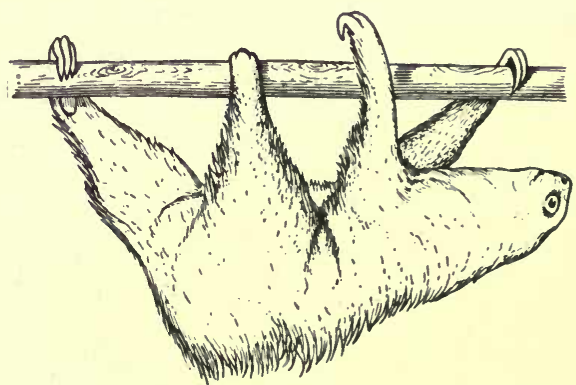

Fra. 164. - A Sloth, Choloepus, walking suspended from a branch. (After Allen.) mals fitted for all sorts and conditions of the environment - representatives are competing with members of other

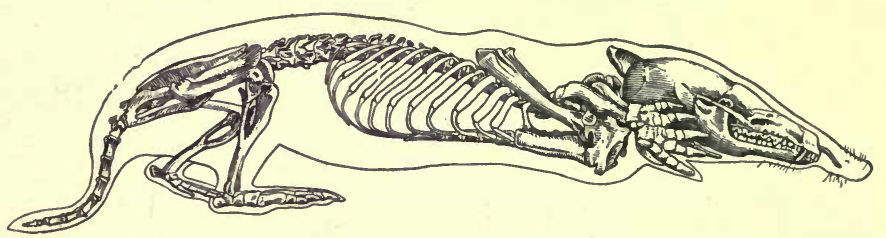

Fig. 165. - Skeleton of a Mole, Talpa europaea. (After Pander and D'Alton.)

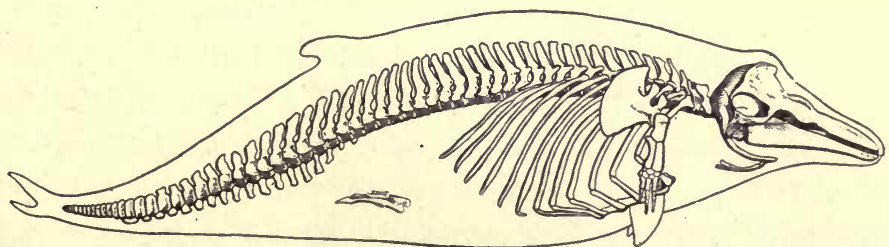

Fra. 166. - Skeleton of a Porpoise. The vestigial pelvic bones are shown imbedded in the flesh. (After Pander and D'Alton.)

groups beneath, on, and above the earth and in the water. Somewhat similar adaptative radiations are traceable in other animal and plant groups, though there seems no doubt that 


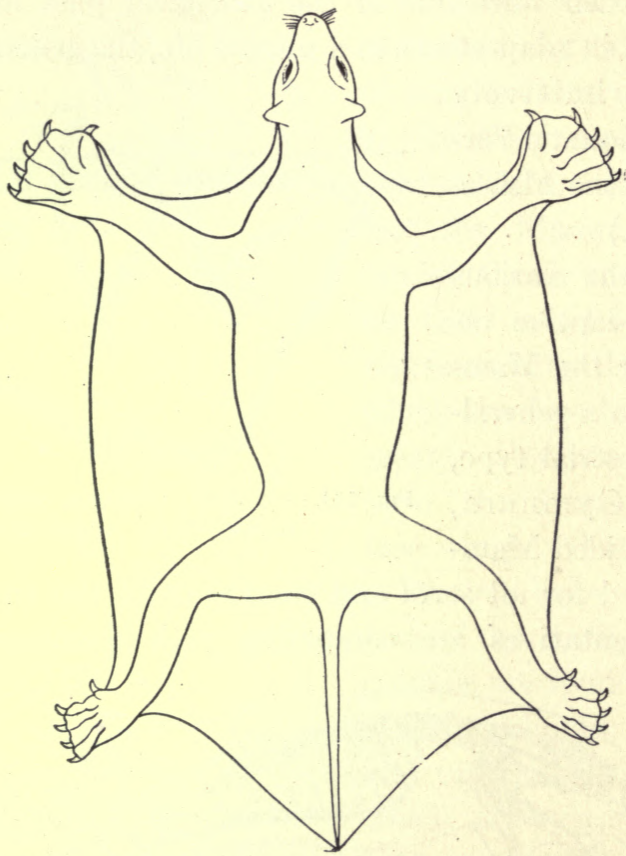

Fig. 167. - 'Flying Lemur,' Galeopithecus volans. (After Lull.)

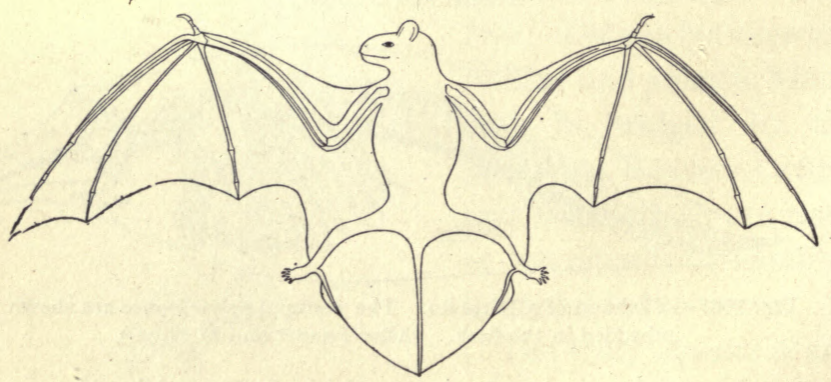

Fig. 168. - A Bat, Vespertilio noctula. (After Lull.) 
the adaptability of the Mammal stock - its potential of evolution - is in no small degree responsible for the dominant position which the Mammals hold in the animal world of to-day. Man is a Mammal.

Animal Coloration. Perhaps the most generally striking characteristic of organisms is their color and color pattern. Among plants this applies chiefly to the flowers and fruit of the higher forms, though here and there through-

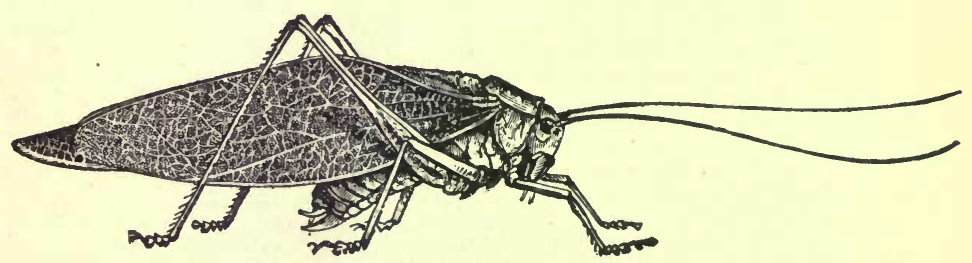

FIG. 169. - The common green Katydid (Microcentrum). (After Riley.)

out the plant series the typical green color is replaced or rendered inconspicuous by others. But the absence of photosynthetic pigments in animals and their relatively active life have permitted more latitude in body color, and accordingly it is in the animal world that color adaptations are more numerous and varied. Some colors and color patterns are, of course, merely incidental to the chemical composition of the whole or parts of the body. Others, however, irresistibly arouse our interest and seem to demand a less simple explanation because they are apparently of special service to their possessors. A few examples will serve to bring the problem before us and indicate the class of facts involved.

The color and color patterns of many animals are such that they harmonize or fuse with the usual surroundings of the creatures and render them practically indistinguishable from their immediate environment. Every frequenter of the open 
knows innumerable instances. The song of the green Katydid readily guides one to its immediate vicinity, but it is quite another matter to distinguish its leaf-green wings among the foliage of its retreat. (Fig. 169.) One is attracted by the

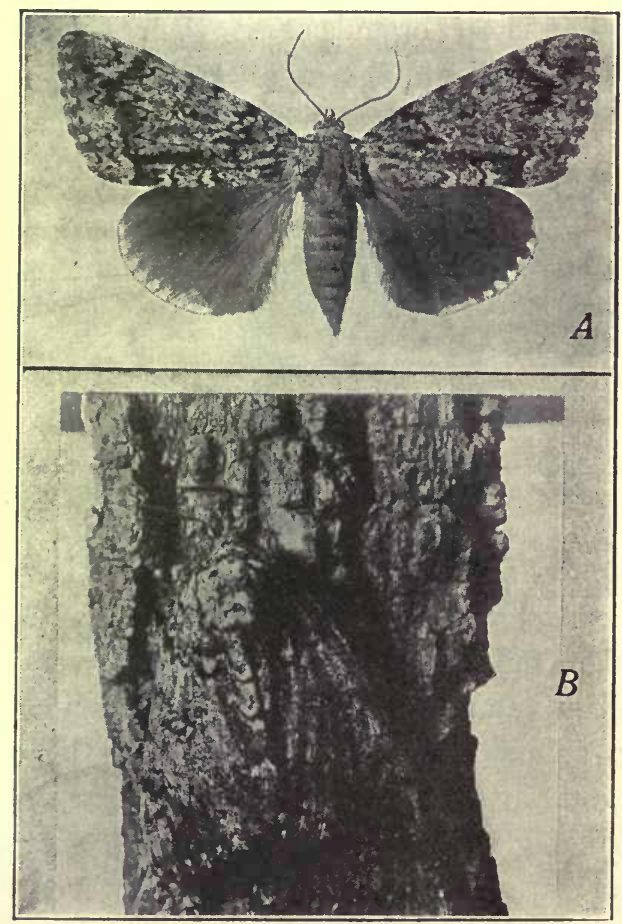

Fra. 170. - Catocala lacrymosa; $A$, wings expanded, exposing the highly colored hind-wings; $B$, resting on bark. (From Folsom.)

striking colors of an Underwing Moth (Catocala) while in flight, but is at a loss to find the insect when scarlet or orange is obscured by the overlapping grayish-mottled fore-wings blending with the tree trunk where it has come to rest.

(Fig. 170.) 
The white of the Foxes, Hares, and Owls of alpine and arctic regions; the green color of foliage-dwelling Insects and Frogs; the tendency toward fawn and gray of desert Insects, Reptiles, Birds, and Mammals; the olive upper surface of the bodies of brook Fishes; the steel gray above and white below of sea Birds which harmonize with sea and sky when viewed from above and below respectively the number of such cases is legion. Gazelles living on the lava fields of volcanic regions are dark gray, while those of the great stretches of sand plains are white - the same species exhibiting regional variations in color which blend with the surroundings. Furthermore, the same individual may vary in color with the seasonal changes in its environment, or present different color schemes in different localities. Thus the

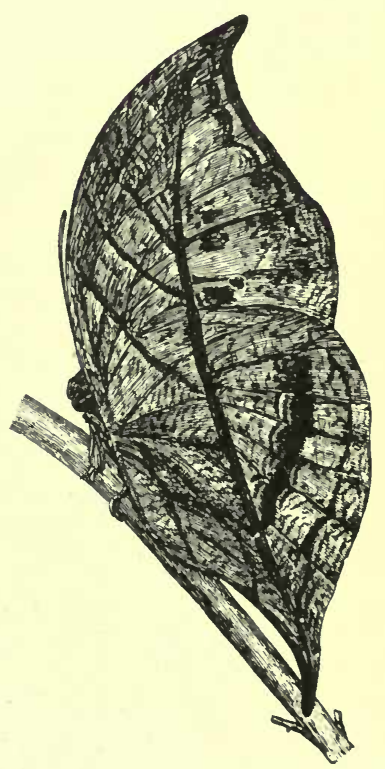

Frg. 171. - Dead-leaf Butterfly, Kallima paralecta. (After Weismann.)

summer coat colors of the Arctic Fox and the Weasel harmonize with the browns of rocks; and the winter coat of white with snow-clad nature. And the Chameleons are by no means unique in their ability to change color very rapidly in response to that of their immediate surroundings.

But confusion is worse confounded when to harmonizing color is added harmonizing form, striking examples of which are the Dead-leaf Butterfly (Kallima) of the East Indian region, the familiar Walking-sticks (Diapheromera), and the caterpillars of Geometrid Moths. (Figs. 171, 172, 173.) 
Although the general tendency in nature is for sympathetic coloration - indeed, it is frequently possible to infer from

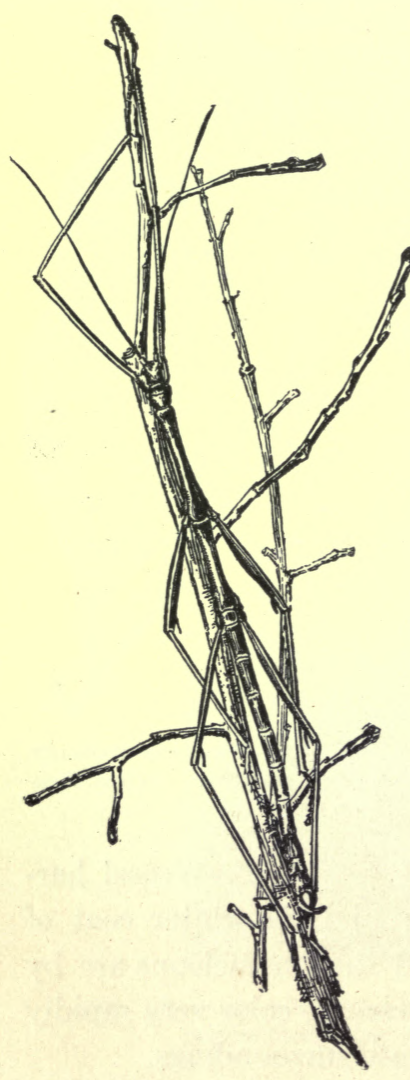

Frg. 172. - A Walking-stick Insect, Diapheromera femorata, on a twig. (From Jordan and Kellogg.)

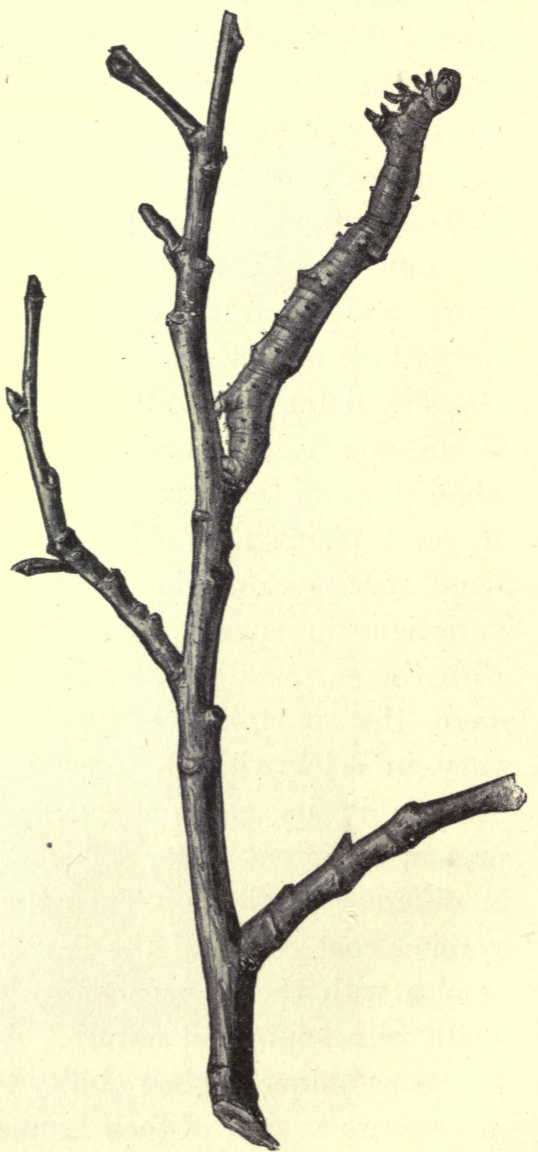

Frg. 173. - Larva of a Geometrid Moth resting extended from a twig. (From Jordan and Kellogg.)

the color of an animal its habitat - there are numerous cases in which the colors and color schemes seem to be in striking 
contrast with the animal's usual background. Sometimes, however, the contrast which is so striking with the bird in the hand, proves to be 'obliterative' with the bird in the bush - a conspicuous color pattern, expressing gradations of light and shadow, and counter shading, fuses with a background of light and shadow afforded by foliage.

But examples of color patterns which by the most liberal stretch of the imagination cannot be interpreted as harmoni-

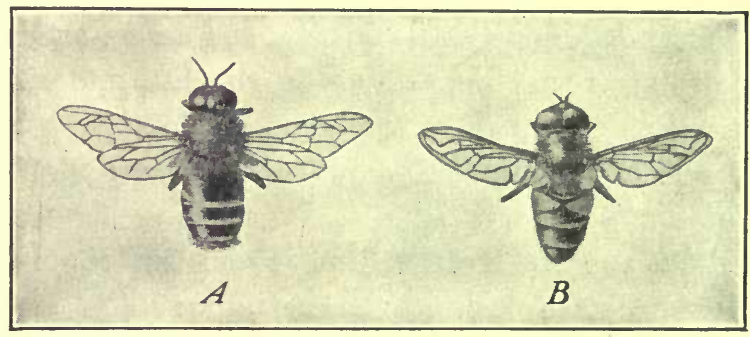

Frg. 174. - 'Protective Mimicry.' $A$, drone Honey Bee; $B$, a Bee-fly, Eristalis tenax. (From Folsom.)

ous with the animal's usual surroundings are not far to seek. Brilliant yellows and reds render, for instance, many Wasps, Bees, Butterflies, and various species of Snakes actually conspicuous. And it is suggestive that very many of these forms are provided with special means of defense, such as poison glands and formidable jaws, or special secretions which render them unpalatable. Moreover, what is still more interesting, many animals possessing this 'protective conspicuousness' which renders them easily identified and advertises that they are to be avoided by their foes, are frequently ' mimicked' in color pattern and form by defenseless creatures. Thus commonly associating with the various species of Bees hovering about flowers are defenceless Flies which are so bee-like in appearance that they are usually mis- 
taken for Bees, and avoided accordingly by human and presumably by other enemies also. (Fig. 174.)

Now, what is the significance of such phenomena of animal coloration and form which are so universal in nature? The problem appears by no means so simple to-day as it did a generation ago, and biologists are not so ready to interpret individual cases as 'protective,' 'aggressive,' 'alluring,' 'confusing,' or 'mimetic.' But it is beyond dispute that nowhere else is the plasticity - adaptability - of organisms better illustrated, and that, taken by and large, such adaptations are of crucial importance in the life and strife of species. Whatever may be the origin of adaptive variations, natural selection is undoubtedly responsible for their accumulation and preservation.

The Legs of the Honey Bee. From time immemorial the Honey Bee (Apis mellifica) has been the subject of wonder and study, and to-day there is no more interesting and instructive example of adaptation than that exhibited by the Bee in relation to the highly specialized community life of the hive.

An average hive comprises some 65,000 Bees of which one is a QUEEN, several hundred are DRONES, and the rest wORKERs. The queen is the only fertile female and accordingly she is the mother of nearly all the other members of the hive. Throughout her life of about three years she is tended and fed by her numerous offspring. The drones, or males, contribute nothing to the life of the hive in which they live, but at the swarming of the Bees, one of them mates with a virgin queen, which thenceforth becomes the queen of a new hive. Thus the queen and the drones represent an adaptation of the colony to communal life - a physiological division of labor in the hive which involves a specialization of a class solely for reproduction, while the daily work and strife of the colony devolves upon the workers. The latter 
are sexually undeveloped females which do not lay eggs but spend their time carrying water, collecting nectar and pollen, secreting wax, building the comb, preparing food, tending the young, and cleaning, airing, and defending the hive. (Fig. 175.)

The worker is a 'bundle of adaptations' for its varied duties. Indeed, when we take away the adaptations there is little left! The primitive insect appendages have become specialized in the worker Bee so that collectively they constitute a battery of tools adapted with great nicety to the

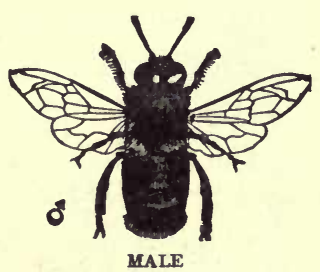

MALE

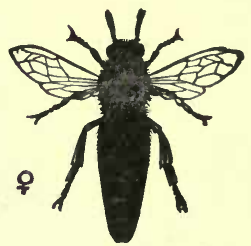

FEMALE

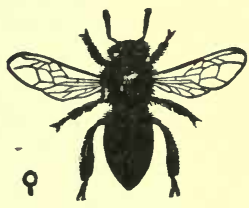

WORKER

Fig. 175. - The Honey Bee, Apis mellifica. (After Shipley and MacBride.)

uses for which they are employed. This applies to all of the appendages of the insect's body, but we shall neglect those of the head (Fig. 176) and consider only the specializations of the three pairs of legs. These, as in all Insects, arise from the THORAX; the anterior pair from the first segment of the thorax (prothorax); the second, or middle, pair from the second thoracic segment (mesothorax); and the posterior pair from the third and last thoracic segment (metathorax). A typical insect leg consists of several parts: the coxA, which forms the junction with the body, followed in order by the TROCHANTER, FEMUR, TIBIA, and five-jointed TARSUS, or foot. (Fig. 177.)

The worker Bee's PRothoracic LEGs show the following specializations. The femur and tibia are covered with long, 
branched FEATHERY HAIRS which aid in gathering pollen when the Bee visits flowers: the tibia, near its junction with

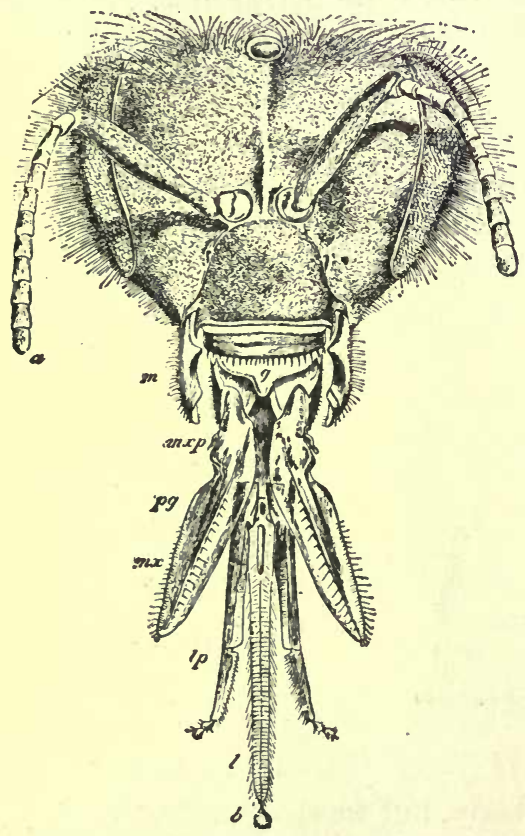

Fig. 176. - Head of a worker Honey Bee. $a$, antenna; $b$, bouton; $g$, epipharynx; $l$, hypopharynx; $l p$, labial palpus; $m$, mandible; $m x$, maxilla; $m x p$, maxillary palpus. (After Cheshire.) the tarsus, bears a group of stiff bristles (POLLEN BRUSH) which is used to brush together the pollen grains that have been dislodged by the hairs of the upper legsegments. On the opposite side of the leg is a composite structure, the ANTENNA CLEANER, formed by a movable plate-like process (VELUM) of the tibia which fits over a circular notch in the upper end of the tarsus. The notch is provided with a series of bristles which form the teeth of the antenna сомв. The antennae, or 'feelers,' which are important sense organs of the head, are cleaned by being placed in the toothed notch and, after the velum is closed down, drawn between the bristles and the edge of the velum. On the anterior face of the first segment of the tarsus is a series of bristles (EYE BRUSH) which is used to remove pollen and other particles adhering to the hairs on the head about the large compound eyes and interfering with their operation.

The terminal segment of the tarsus of each leg is provided 


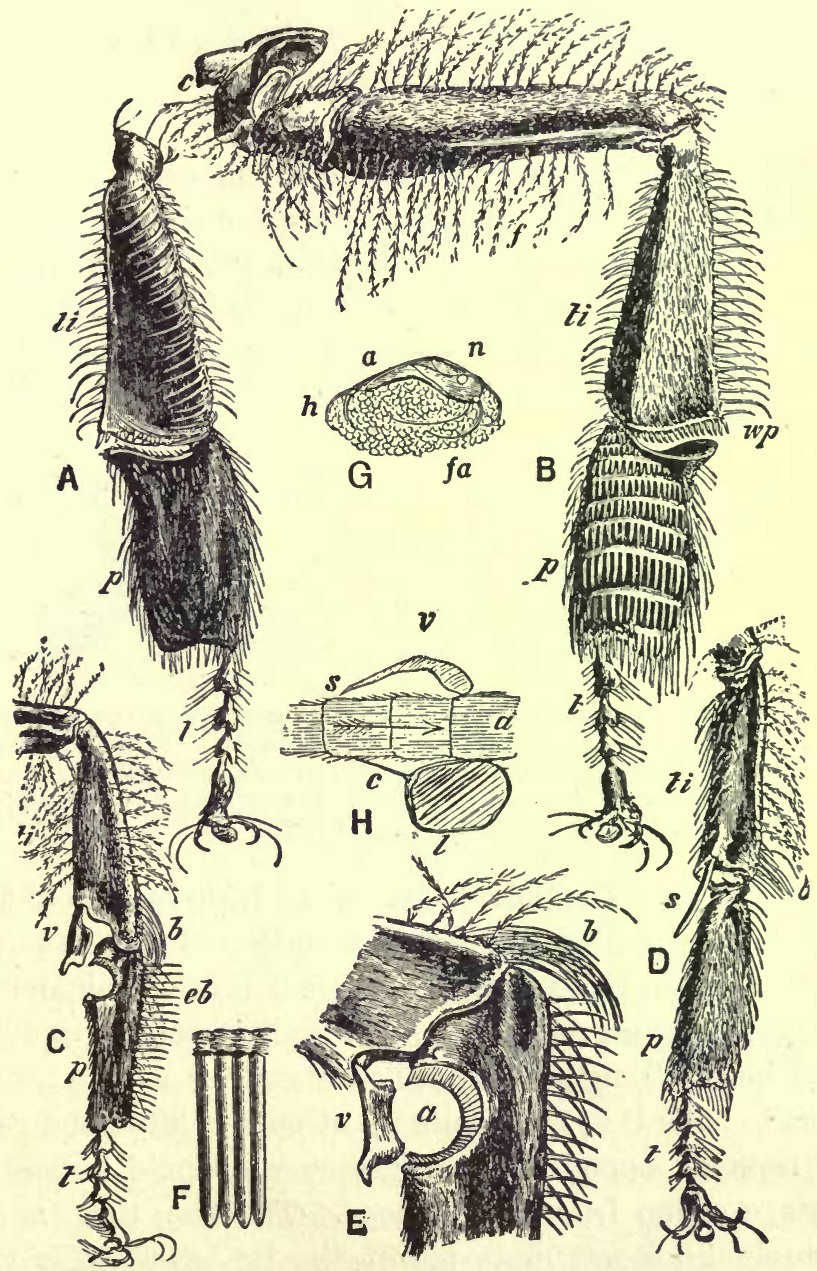

Fig. 177. - Legs of the worker Honey Bee. A, outer side of metathoracic leg: $p$, metatarsus (first segment of tarsus); $t$, tarsus; $t i$, tibia. $B$, inner side of metathoracic leg: $c$, coxa; $p$, metatarsus; $t$, tarsus; $t i$, tibia; $t r$, trochanter; $w p$, pecten and auricle. $C$, prothoracic leg: $b$, pollen brush; $e b$, eye brush; $p$, metatarsus; $t$, tarsus; $t i$, tibia; $v$, velum. $D$, mesothoracic leg: lettering as in $C ; s$, pollen spur. $E$, joint of prothoracic leg: lettering as in $C$. $F$, teeth of antenna comb. $G$, transverse section of tibia through pollen basket: $a$, antenna; $f a$, pollen; $h$, holding hairs; $n$, nerve. $H$, antenna in process of cleaning: $a$, antenna; $c$, antenna comb; $l$, section of leg; $s$, scraping edge of $v$, velum. (From Hegner, after Cheshire.) 
with a pair of notched CLAWs, a sticky pad (PULVILLUs) and TACTILE HaIRs. (Fig. 178.) When the Bee is walking up a rough surface, the points of the claws catch and the pulvillus does not touch, but when the surface is smooth, so that the claws do not grip, they are drawn beneath the foot. This change of position applies the pulvillus, and it clings to the smooth surface. Thus the character of the surface automatically determines whether claw or pulvillus shall be used. But there is another adaptation equally

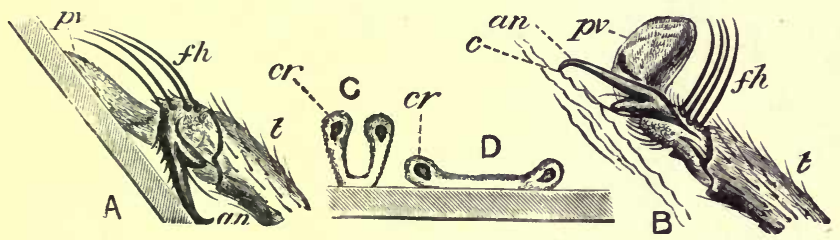

Fig. 178. - Foot of the Honey Bee in the act of climbing, showing the 'automatic' action of the pulvillus. $A$, position of foot on a slippery surface. $f h$, tactile hairs; $p v$, pulvillus; $t$, last segment of tarsus; $a n$, claw. $B$, position of foot in climbing on a rough surface. an, $c$, claw. $C$, section of a pulvillus just touching a flat surface; $c r$, curved rod. $D$, the same applied to the surface. (From Packard, after Cheshire.)

remarkable. "The pulvillus is carried folded in the middle, but opens out when applied to a surface; for it has at its upper part an, elastic and curved rod, which straightens as the pulvillus is pressed down. The flattened-out pulvillus thus holds strongly while pulled along the surface by the weight of the Bee, but comes up at once if lifted and rolled off from its opposite sides, just as we should pull a wet postage stamp from an envelope. The Bee, then, is held securely till it attempts to lift the leg, when it is freed at once; and, by this exquisite yet simple plan, it can fix and release each foot at least twenty times per second." (Cheshire.)

The characteristic structures of the middle (MEsothoRAcic) legs of the Bee are a small POLLEN BRUSH and a long spine, or 
SPUR, which is employed in removing the pollen from the pollen baskets on the metathoracic legs, and also in cleaning the wings.

The METATHoracic LEgS exhibit four remarkable adaptations to the needs of the insect known as the POLLEN COMBS, peCten, AURICle, and pollen basket. The pollen combs comprise a series of rows of bristle-like hairs on the inner surface of the first segment of the tarsus: the pecten is a series of spines on the distal end of the tibia which is opposed by a concavity, the auricle, on the proximal end of the tarsal segment; while the pollen basket is formed by a depression on the outer surface of the tibia which is arched over by rows of long curved bristles arising from its edges.

Thus the worker is fully equipped. Flying from flower to flower for nectar, the Bee brushes against the anthers laden with pollen, some of which adheres to the hairs on its body and legs. While still in the field, the pollen combs are first brought into play to comb the pollen from the hairs, while the pectens scrape the pollen from the combs. Then the auricles are manipulated so that the accumulating mass of pollen is pushed up into the bristle-covered pollen baskets. This process is repeated until the baskets are full and then the insect returns to the hive, where the contents of the pollen baskets are removed by the aid of the spurs with which the mesothoracic legs are provided.

Moreover, the structural adaptations of the worker Bee are but one aspect of a reciprocal fitness. Many of the flowers which the Bee visits show remarkable adaptations for the reception of the Bee and for dusting it with pollen, because Bees are effective agents in transferring pollen from flower to flower and thus insuring crossfertilization. 


\section{B. Adaptations to the Living Environment}

We have now discussed the close reciprocal relationship between organism and environment, putting emphasis upon adaptations to the non-living surroundings, and must turn more specifically to some striking interrelations of organism with organism, in order to make possible an appreciation of the devious means to which they have recourse - to what extent the strands of the web of life become entangled - in the competition for a livelihood.

The mutual biological interdependence of organisms is, in the final analysis, the result of the primary demands of all creatures-proper food, habitat, reproduction, defense against enemies and the forces of nature. The web of life is an expression of the coöperation, jostling, and strife of individual with individual, and species with species for these primary needs; and the activities which follow from them form the foundations of life in the lowest as well as the highest. There is a struggle for existence. A common food Fish, the Squeteague, captures the Butter-fish or the Squid, which in turn have fed on young Fish, which in their turn have fed on small Crustacea, which themselves have utilized microscopic Algae and Protozoa as food. Thus the food of the Squeteague is actually a complex of all these factors, and such a 'nutritional chain' is no stronger than its single links. Circumstances which modify or suppress the food and thereby reduce the abundance of the microflora and microfauna of the sea are reflected in correlative changes in the abundance of economically important food Fishes. And this same principle is true throughout living nature, though only occasionally is it possible to trace it. "Nature is a vast assemblage of linkages." 


\section{Communal Associations}

Perhaps the simplest organismal associations are represented by GREGARIous animals, such as Wolves which hunt in packs, and Buffaloes and Horses which herd for protection. Here the association is more or less temporary and there is no division of labor between the members, other than leadership by one animal.

Communal animals, however, exhibit highly complex associations in which the members merge, as it were, their individuality in that of the community. This is well exhibited, for example, among the Ants, in which all of the various species, about 5000 in number, are communal, and in the Wasps and Bees in which all gradations exist from solitary to hivedwelling species. And, as has been mentioned in the case of the Bees, the division of labor has developed to the extent that structural differentiations have given rise to classes of individuals specially adapted for the performance of certain functions in the economy of the hive.

It is in Man, however, that we find the highest expression of communal coöperation, because increased intelligence, in particular, makes flexible the stereotyped life as exhibited in the lower forms - the human individual being adaptable to the various community tasks.

But associations are not confined to members of the same species, nor are all an expression of coöperative adaptations. All gradations occur from those which are mutually beneficial to the parties in the pact, to those in which one member secures all the advantage at the expense of the other.

\section{Symbiosis}

The most intimate associations in which the organisms involved are mutually benefited, if not absolutely necessary 
for each other's existence, are termed syмвіотіс. A familiar illustration is the common green Hydra (Hydra viridis) which owes its characteristic color to the presence of a large number of unicellular green plants which live in its endoderm cells. The products of the photosynthetic activity of the plant cells are at the disposal of the Hydra and the latter

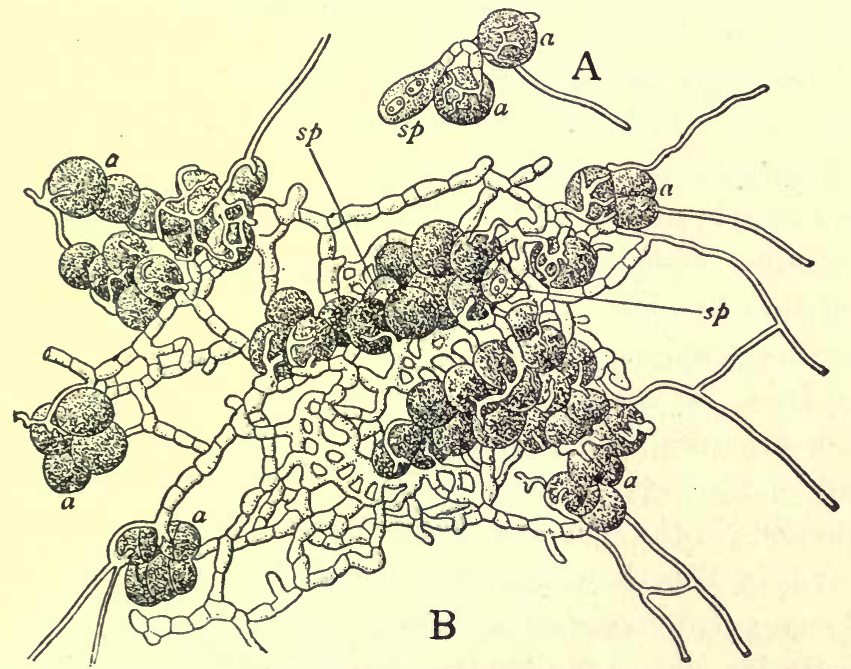

Fra. 179. - The formation of a Lichen, Physcia paratina, by the combination of an Alga and a Fungus. $A$, germination of a Fungus spore $(s p)$, whose filaments are surrounding two cells (a) of the unicellular Alga, Cystococcus humicola. B, later stage in which spores have formed a web of filaments (mycelium), enveloping many algal cells. Magnified about 400 times. (From Abbott, after Bonnier.)

in return affords a favorable abode and the material necessary for the life of the plant.

A far more striking example of symbiosis is afforded by Lichens which represent intimate combinations of various species of Fungi and Algae. (Fig. 179.) In each case the Fungus supplies attachment, protection, and the raw materials of food, while the green Alga performs photosynthesis. Each can live independently under favorable conditions, but 
in partnership they are superior to vicissitudes with which many other plants cannot cope, and thus some forms become the vanguard of vegetation in repopulating rocky, devastated areas.

From the practical standpoint of agriculture the symbiotic nitrogen-fixing Bacteria are of first importance. It will be

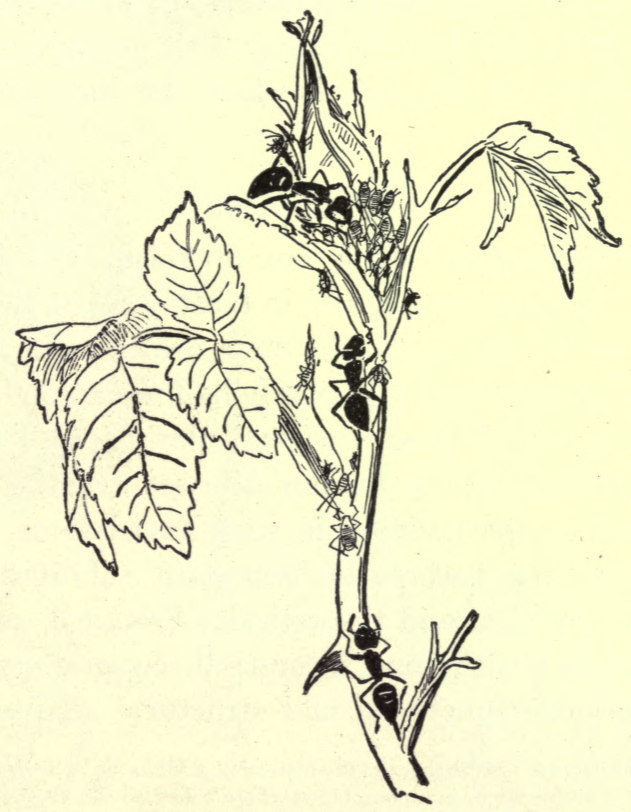

Frg. 180. - Rose Aphids visited by Ants. (After Kellogg.)

recalled that these Bacteria form small tubercles on the rootlets of higher plants and make atmospheric nitrogen available to the latter. Thus in return for an abode and certain food elements, such nitrogen-fixing Bacteria render their symbiotic associate largely independent of soil nitrogen. Again in the higher animals, including Man, evidence is accumulating which indicates that certain kinds of Bacteria 
find their normal habitat in the digestive tract, where, incidental to getting their own living, they bring about chemical changes in the food of their host which is an important factor in the digestive processes of the latter.

Still another type of association in which both partners profit is represented by the relation that occurs between Ants and Aphids. The defenseless Aphids are protected, herded and 'milked' by the Ants to supply their demand for honeydew, a secretion of the Aphids which the Ants greedily devour. (Fig. 180.)

\section{Parasitism}

But associations in which one organism, the PARASITE, secures the sole advantage, and in most cases at the expense of the helpless second party, the HOST, are far more numerous - it has been estimated that nearly half the animal kingdom are parasites. And these are particularly forced upon our attention because many human diseases are the result of Man's unwilling partnership in such associations. Indeed, PARASITOLOGY has become an important subdivision of biology, both practical and theoretical. Practical, as a corner stone of public health; and theoretical, because many of the most remarkable functional and structural adaptations are

Fig. 181. - Diagram illustrating the life history of a Malarial Parasite. The stages above the line of dashes occur in human blood; those below, in the body of a Mosquito. I-V and 6-10 show asexual multiplication (schizogony) in human red blood corpuscle following introduction of a parasite (XIX) by a Mosquito. This may continue by the parasites (10) entering other corpuscles until a large number of the latter are destroyed. Sooner or later sexual forms arise. VI-XIII, the sexual generation involving the differentiation of male $(\hat{b})$ and female $(q)$ gametes which unite (XI) to form a zygote (XII). The rygote becomes motile (XIII), works its way into the wall of the stomach of the Mosquito, and encysts (XIV). Within the cyst a number of small cells (XVI, $s p . b l$.) arise by division, and these, in turn, give rise to a multitude of motile cells (XVIII) termed sporozoites. The sporozoites are liberated (XIX) from the cyst, make their way to the salivary glands of the Mosquito where they are ready to be inoculated into the human body, and so gain entrance to a red blood corpuscle (I). The production of the sporozoites from the zygote is known as sporogony. $n$, nucleus of the parasite: $p$, pigment and waste products of the parasites; $f l$, long slender male gametes. (From Minchin, in Iankester's Treatise.) 


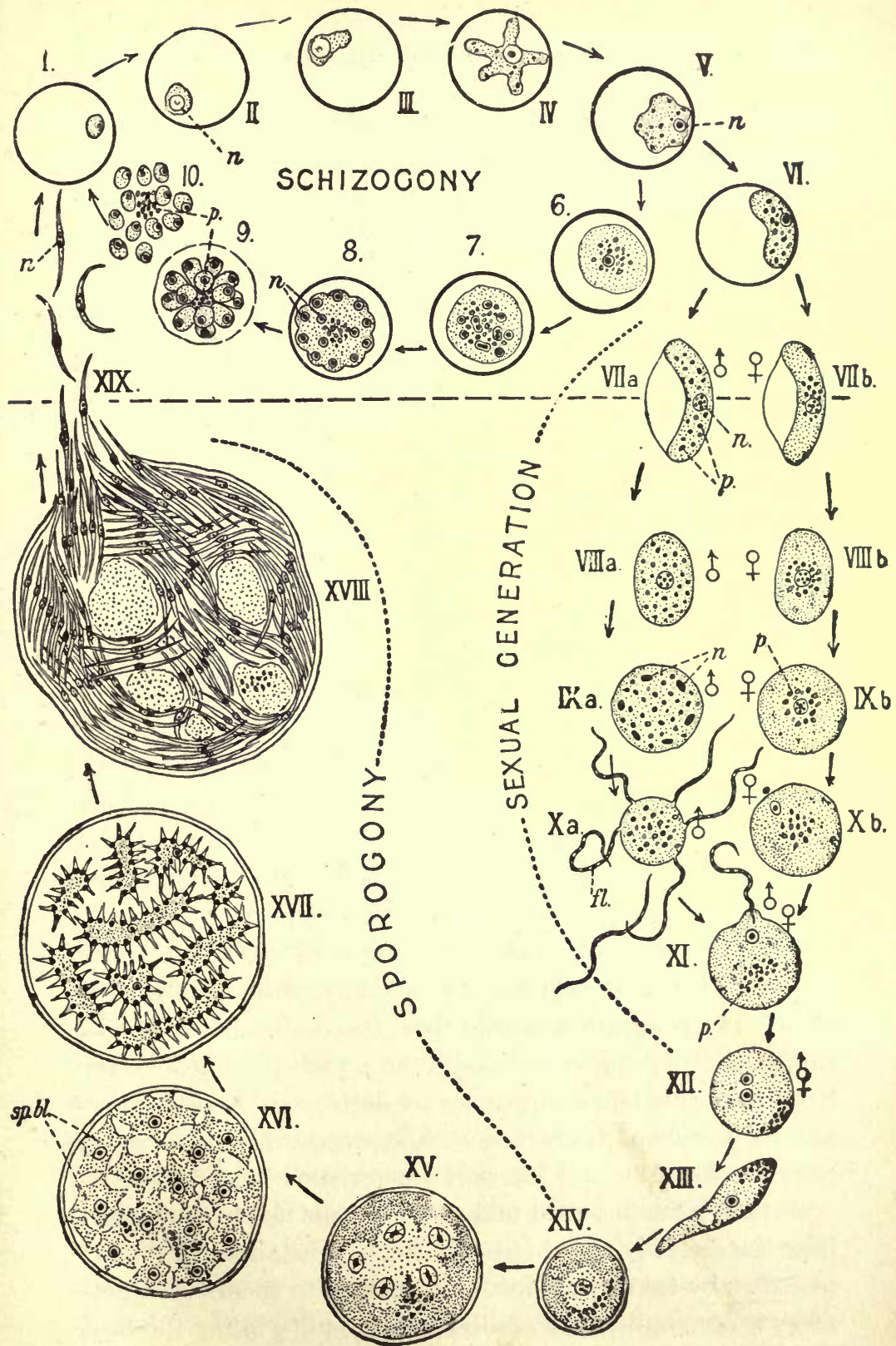

FIg. 181. 
exhibited by parasites in becoming fitted for this apparently highly successful method of gaining a livelihood, and by the hosts in bearing the burden with the least outlay. Generally speaking, the effect on the parasite consists in a simplification of the various organs of the body devoted to foodgetting, locomotion, etc., since their duties are foisted upon the host; while the organs and methods of reproduction are highly specialized and elaborated, owing to the necessity of producing enough offspring to compensate for the hazards involved in reaching a proper host. For in the majority of cases a parasite is adapted to live in a specific host, and death ensues if this is not attained at the proper time.

Probably the most generally interesting example of parasitism is the cause of the disease known as MaLARIA. Man is subject to at least three types of malaria, each the result of infection by a different malarial organism. The malarial parasites are all unicellular animals, Protozoa, with complicated life histories which are adaptations to the specific exigencies of their parasitic existence. (Fig. 181.) One part of the life history, the asexual, is passed in the red blood corpuscles of Man; while the other, the sexual, occurs in the digestive tract of certain species of Mosquitoes. A single parasite inoculated into the human system by the bite of an infected Mosquito enters a red blood corpuscle and multiplies. The progeny, liberated from the destroyed corpuscle, similarly attack other corpuscles and multiply until a very large number of blood corpuscles are destroyed. And the liberation of poisonous products of the life processes of the parasites provoke the chills and fevers characteristic of the disease.

But the parasites must make their escape before the human host successfully combats the toxic substances, kills the parasites by taking quinine, or succumbs to them. The getaway is accomplished, if at all, by a Mosquito biting the host 
and taking with the blood certain sexual stages of the parasite which can develop in the cold-blooded insect. And now the Mosquito is the host. In its stomach the sexual phase of the life history of the malarial parasite takes place, fertilization occurs, and finally the numerous products of the zygote work their way to the mouth parts of the Mosquito, where they await an opportunity to enter the human blood.

The life history of malarial parasites exhibits a continuous series of adaptations to parasitic life: the nicety of the ad-

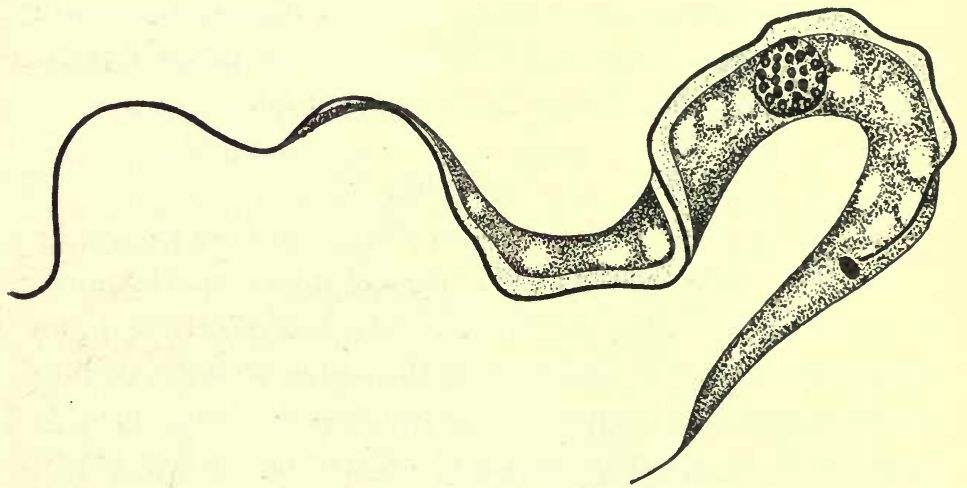

Fig. 182. - A trypanosome (Trypanosoma theileri) from the blood of cattle. Magnified about 3000 times. (After Lühe.)

justment being especially well illustrated at the transfer from Man to Mosquito, since all the parasites which enter the stomach of the latter are digested except those sexual forms which are ready to initiate the sexual part of the cycle in the new host.

But the acme of parasitic associations is only attained when the adaptations of parasite and host have become so complete that the latter 'pays the price' without any untoward results. Thus the Antelopes and similar Mammals of certain regions of Africa harbor in their blood various species of Protozoan parasites, known as TRYPANosomes, 
without any apparent discomfort. But if the intermediate hosts, which are biting Flies, transfer for example Trypanosoma brucei to imported Horses or Cattle, a serious disease results which is usually fatal. Indeed, the opening up of certain regions of Africa has been greatly retarded by the ravages of this Trypanosome in new hosts to which it is not adapted. Generally speaking, pathogenic species may be regarded as aberrant forms which are not yet adapted to their hosts or are not in their normal hosts. And these are the parasites which are forced upon our attention, though there are few organisms without their specially adapted parasites - the parasites themselves not excepted.

\section{Immunity}

At best, however, the part played by the host cannot be regarded as ideal, and devious types of adaptations against parasites exist which, insofar as they are effective, bring about IMMUNITY. Usually among the higher animals, including Man, immunity to pathogenic Bacteria seems to have its foundations in specific chemical substances in the blood, termed ANTIBodiEs. These either modify the activities of certain cells of the body, chiefly the white blood corpuscles, or act directly upon the invaders themselves and the poisons (Toxins) which they produce. The white blood corpuscles have been called the 'policemen of the body' because, under the influence of invading organisms and of certain antibodies called opsonins, some of them make their way through the walls of the capillaries in the region of the infection and, in amoeboid fashion, engulf and digest the intruders. When acting in this capacity the corpuscles are referred to as PHAGOCYTES.

Among the various classes of antibodies are also the ANTIToxINs which neutralize the poisonous products of Bacteria, 
and the сүтотохіNs which actually destroy the foreign cells. Various specific antibodies may be naturally present in the blood - a part of the heritage - so that an individual is immune to certain diseases due to pathogenic organisms. Or the antibodies may be produced in response to the parasites themselves, and the individual acquires immunity only after undergoing the disease. Finally, immunity may be artificially acquired by various means, such as VACCINATION, which stimulate the production of antibodies so that the individual is fore-armed, as it were, in the event of an infection. But the subject of immunity has become a science in itself within the past few years - a science which has as its basis the exploitation of the marvelous power of adaptation of protoplasm as exemplified in coping with disease-producing parasites.

\section{Individual Adaptability}

We may now turn to a survey of the highest expression of adaptation evolved by nature, which is revealed in relatively simple form in the behavior of the lower organisms, gains definiteness and content as we ascend the animal series, and becomes the basis of the intelligence and all that the mental life of Man involves. It is the adaptation which renders Man essentially superior to adaptation - enables him to a large extent to control, instead of being controlled by, his environment. "It seems that nature, after elaborating mechanisms to meet particular vicissitudes, has lumped all other vicissitudes into one and made a means of meeting them all" - the nervous mechanism.

That organisms respond to environmental changes, we are well aware. Life itself is the result of - in fact, is - a continuous flow of physico-chemical actions, interactions, and reactions with the surroundings. But by the behavior of 
the organism we refer specifically to the reactions of the organism as a unit, rather than to the internal processes in the economy of its life. And surveyed from a broad viewpoint, there is discernible in the behavior of animals, just as in their structure in general and in their nervous system in particular, from the lowest to the highest, a gradual increase in the complexity of behavior. The behavior of Amoeba or Paramecium is an expression of the primary attributes of proto-
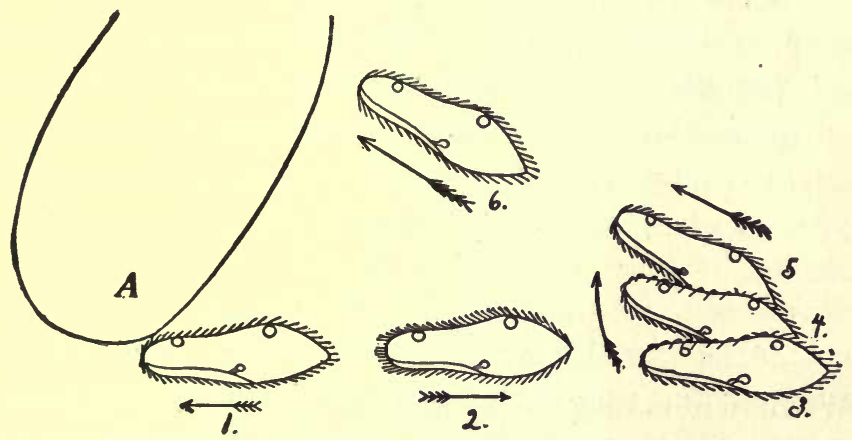

Fig. 183. - Diagram to illustrate the avoiding reaction of Paramecium. $A$, a solid object or other source of stimulation. 1-6, successive positions taken by the animal. The rotation on its long axis is not indicated. See Fig. 184. (After Jennings.)

plasm-irritability, conductivity, and contractility. So is the behavior of Hydra and Earthworm, in which special cells constitute a definite coördinating, or nervous, system. And so is the complex behavior of the higher animals, including Man, with their elaborate series of sense organs and highly developed sensorium, or brain.

"Let us now try to form a picture of the behavior of Paramecium in its daily life under natural conditions. An individual is swimming freely in a pool, parallel with the surface and some distance below it. No other stimulus acting, it begins to respond to the changes in distribution of its internal contents due to the fact that it is not in line with gravity. 
It tries various new positions until its anterior end is directed upward, and continues in that direction. It thus reaches the surface film. To this it responds by the avoiding reaction (Fig. 183), finding a new position and swimming along near the surface of the water. . . . Swimming forward here, it approaches a region where the sun has been shining strongly into the pool, heating the water. The Paramecium receives some of this heated water in the current passing from the anterior end down the oral groove. (Fig. 184.) Thereupon it pauses, swings its anterior end about in a circle, and finding that the water coming from one of the directions thus tried is not heated, it proceeds forward in that direction. This course leads it perhaps into the region of a fresh plant stem which has lately been crushed and has fallen into the water. The plant juice, oozing out, alters markedly the chemical constitution of the water. The Paramecium soon receives some of this altered water in its ciliary current. Again it pauses, or if the chemical was strong, swims backward a dis-

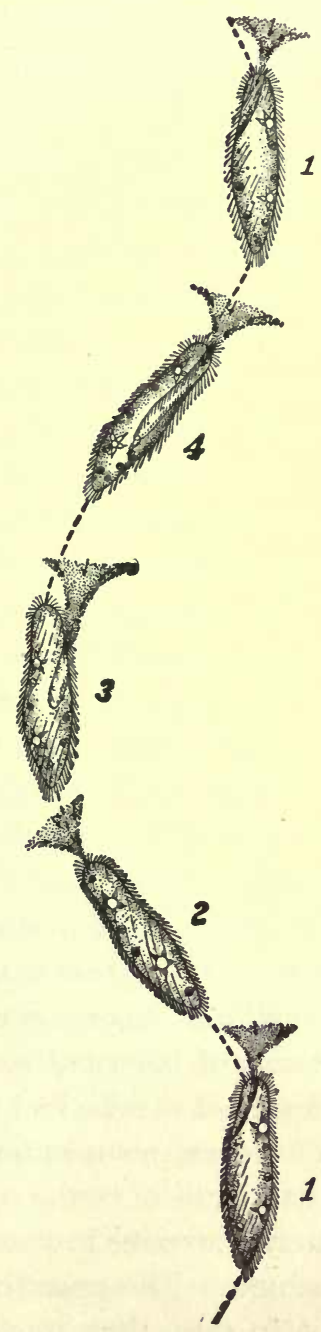

Fia. 184. - Diagram to show the rotation on the long axis, and the spiral path of Paramecium. 1-4, successive positions assumed. The dotted areas with small arrows represent the currents of water drawn from in front. (After Jennings.) 
tance. Then it again swings the anterior end around in a circle till it finds a direction from which it receives no more of this chemical; in this direction it swims forward. . .

"In this way the daily life of the animal continues. It constantly feels its way about, trying in a systematic way all sorts of conditions, and retiring from those that are harmful. Its behavior is in principle much like that of a blind and deaf person, or one that feels his way about in the dark. It is a continual process of proving all things and holding to that which is good." (Jennings.)

The behavior of Paramecium leaves one with the impression that the animal is largely at the mercy of its surroundings - that the environment rather than the organism itself is the dominant factor, but this is true only to a limited degree. Paramecium is not merely an automaton. Its behavior is modifiable and, in the long run, is adapted to the usual changes of its surroundings. That the reactions are adequate for the simple life and methods of reproduction of Paramecium is attested by the fact that it is one of the most common and widely distributed animals.

In such simple beginnings, then, must be sought the largely automatic responses of animals to the exigencies of external conditions, known as REFLExes and INSTINCTS. Both are the result of inherited nervous structure and therefore may be regarded as inherited behavior - just as truly characteristics of the organism as form of body or method of reproduction. And increase in the complexity of life processes has involved a synchronous increase in the number and complexity of instincts. The primitive reflexes and instincts of Hydra lead it to seize with its tentacles small organisms within reach and pass them to its mouth: the Earthworm, to swallow decaying leaves as it burrows through the soil: the Crayfish, 
to grasp its prey with its large claws, tear it into pieces by means of certain appendages about the mouth which are adapted just for the purpose - and so on to the higher Vertebrates where the feeding instincts reach their maximum of complexity. The marvelous behavior of Ants and Bees is essentially a complex of instincts. Turn the hive around and the homing instinct of the Bees proves abortive - they cannot find the entrance. Moreover, instincts of fear, selfdefense, play, care of the young, etc., render a considerable part of the behavior of even the higher organisms more 'automatic' than is perhaps, at first thought, apparent. (Fig. 101.)

But just as the behavior of Paramecium and its allies is modifiable, so instincts which seem the most stereotyped show at least a slight degree of adaptability to unusual conditions. And it is this ever-present modicum of modifiability, which is in Man called 'choice,' that leavens the whole and becomes the dominant factor in the behavior of the highest animals; while reflex action and instinct are relegated to a subsidiary though by no means unimportant rôle.

The power of such more or less conscious 'choice' of responses to external conditions affords a gradual and illdefined transition from instincts to intellectual processes, or reason. The foundations of both are to be sought in simple reflex actions and oft-repeated voluntary actions which gradually become habits - relegated to the level of reflex actions. Indeed a large part of the education of Man consists in establishing adaptive reflexes which relieve the conscious life of innumerable simple factors of behavior, and leave it more or less free for the higher intellectual processes. Although it is necessary to emphasize that mind and intelligence, in the biological sense, are expressions for that integration of nervous states and actions which makes possible 
a nicety of adaptation of behavior to environmental conditions that otherwise would be impossible - that it is our chief means of adaptation - "it is a grave mistake to minimize the importance of the great gulf between Man's nature and that of the most highly developed of the lower animals. In no respect are these differences more marked than in the various forms of learning that, taken together, form the means of education." (Cameron.)

Thus it is clear that, with all the variations in structure and function, organisms all possess irritability in common: they all exhibit adaptive responses which enable them to exist in spite of surrounding changes. "Adaptability appears to be the touchstone with which nature has tested each kind of organism evolved; it has been the yard-stick with which she has measured each animal type; it has been the counterweight against which she had balanced each of her productions . . . the general course of evolution has been always in the direction of increasing adaptability or increasing perfection of irritability." (Mathews.) The individual's heritage affords the cumulative result of the adaptations of the race - including adaptability. 


\section{CHAPTER XIX \\ THE ORIGIN OF SPECIES}

Thoughtful men, once escaped from the blinding influences of traditional prejudice, will find in the lowly stock whence Man has sprung, the best evidence of the splendor of his capacities; and will discern in his long progress through the Past, a reasonable ground of faith in his attainment of a nobler Future.

-Huxley.

Everyone recognizes not only that there are many kinds of animals and plants, but also that many individuals are essentially the same. Groups may be formed of individuals which differ less among themselves in the sum of their characters than they do from the members of any other group of individuals. And further, the members of a group produce other individuals which are essentially similar. Such a group of similar individuals is termed by the biologist a species. It will be noted, therefore, that a species is merely a concept of the human mind - the only reality in nature is the individual, and an understanding of the differences between individuals gives us the key to the differences between species. This seemingly obvious point of view has but relatively recently been clearly emphasized by biologists, and the species rather than the individual has loomed large in the discussions of how plants and animals came to be what they are to-day.

From the time of the Greek natural philosophers there always have been men who have sought a naturalistic explanation of the origin of the diverse forms of animals and plants, 
and who have suggested that the present ones arose from earlier forms by a process of descent with modification, or EvoLUTION. But with the revival of natural history studies after the Middle Ages, the Mosaic account of creation led the majority, perhaps almost unconsciously, to assume that there are as many kinds of organisms as issued from the Ark. And this is not so strange, as might.at first glance appear, when one considers that all of the important facts which we have reviewed in the preceding pages were then absolutely unknown, and that the number of known kinds of animals totalled but a thousand or so, instead of upward of a million, as to-day.

The pioneer work of the early Renaissance naturalists consisted principally of collecting and describing animals and plants. This involved making a catalog of the different kinds - classifying them in some way - and consequently some basis of classification was sought. Thus attention was focused on the kinds of species and for practical, if for no other, reasons, the species assumed a prominence which overshadowed the individuals which composed it. As a matter of fact during the eighteenth century the greatest student of plant and animal classification, Linnaeus, emphasized the idea that each species represents a distinct thought of the Creator and that the object of classification is to arrange species in the order of the Creator's consecutive thoughts. This viewpoint is somewhat whimsically expressed by the old naturalist who, finding a beetle which did not seem to agree exactly with any species in his collection, solved the difficulty by crushing the unorthodox individual under his foot. (See page 391.)

We may consider that the consensus of opinion up to the middle of the last century was overwhelmingly on the side of SPECIAL CREATION and FIXITY OF SPECIES, and there- 
fore against the idea occasionally advanced by men, as it now appears, ahead of their times, that DESCENT wITH MODIFICATION is the explanation of the origin of the diverse forms of plants and animals. But, as nearly every one knows, a complete reversal of opinion has occurred since 1860 - today professional scientists and most educated laymen accept organic Evolution. And we have accepted it in the preceding sections of this work; but if this appears to have been prejudging the question, the explanation is that the genetic connection of organisms is the guiding principle of all biology - and the mere fact that an unbiased presentation of the data seems to prejudge the question is the most cogent presumptive evidence for evolution. It is true that there are wide differences of opinion among biologists in regard to the factors which have brought about the evolutionary change but there are none in regard to the fact of evolution itself. It will be convenient, therefore, first to summarize the evidences of evolution and then to discuss modern views in regard to the methods of evolution. (See Glossary, 'evolution.')

\section{A. Evidences of Organic Evolution}

To one who has thoughtfully followed the preceding pages there must immediately occur many facts which are readily and reasonably interpreted from the point of view of descent of one species from another, but which are entirely enigmatical from that of the special creation of species. For instance, one will recall the cellular structure of all organisms; the method of origin and the fate of the germ layers in animals; the interrelationship of the urinary and reproductive systems in the Vertebrates; the comparative anatomy of the vascular and skeletal systems of Vertebrates; the similarity of the physical basis of inheritance in animals and plants; the gradual dominance of the sporophyte over the 
gametophyte from the lower to the highest plants; and so on.

In general, such is the nature of the data which support the evolution theory. Although the evidence, from the nature of the case, must be indirect, it is none the less cogent chiefly because the facts for evolution are from such diverse sources and all converge toward the same conclusion. The theory of evolution reaches the highest degree of probability, since in every branch of botany and zoölogy all the data are most simply and reasonably explained on the basis of 'descent with modification,' and not a single fact points toward special creation. It is a cardinal principle of science to accept the simplest conceptions which will embrace all the facts.

We may now summarize some of the most striking evidence from taxonomy, comparative anatomy, paleontology, embryology, physiology, and distribution of animals. But, as will soon appear, it is impossible to arrange the facts in hard and fast groups under these headings - the evidence from one merges into that from another, and in the final analysis nearly all are based on comparative anatomy in the broadest sense of the term.

\section{Taxonomy}

When the serious study of classification was well under way, biologists found increasing evidence of the similarity, or affinity, of various sPECIES of animals and plants. Not only is it possible to arrange animals, for example, in an ascending series of increasingly complex forms, but also in many cases it is difficult or impossible to decide just where one species ends and the next begins. That is, the most aberrant individuals within a given species frequently approach those of a closely similar species. There are intergrades. 
Again, it is found that species themselves can be naturally arranged in more comprehensive groups to which the name Genus is applied. For example, the common Gray Squirrel represents the species carolinensis, and the Red Squirrel, the species hudsonicus. Both are obviously Squirrels, and therefore both species are grouped under the genus Sciurus. Accordingly, each animal is given a name composed of two words: the first, generic and the second, specific. The Gray Squirrel is Sciurus carolinensis and the Red Squirrel is Sciurus hudsonicus. Thus to give a scientific name to an animal or plant is really to classify it, because the first word of the name indicates that it possesses some fundamental characteristics in common with the other species of the genus in fact, is more like them than it is like any other group of organisms.

But again, the members of the genus Sciurus have many characteristics in common with other animals which obviously are not true squirrels. The Chipmunks or Ground Squirrels, for instance, differ not only in certain obvious features, but in the possession of internal cheek pouches, etc. This dissimilarity and similarity is expressed by placing them in a different genus, Tamias, but in the same FAMILY, Sciuridae. The familiar eastern Chipmunk is Tamias striatus.

Moreover, while the Beaver (Castor americana) differs still more from the Squirrels than do the Chipmunks, and therefore is placed in a distinct family, the Castoridae, it nevertheless agrees with both in many fundamental ways, so that it is placed in the ORDER Rodentia, which also includes the Squirrels and Chipmunks, as well as many other families and genera. Other orders, such as the Ungulata (Horses, Cattle, etc.) and the Carnivora (Cats, Dogs, Bears, etc.), while they differ widely from the Rodents, still agree with 
them in possessing hair, and milk glands for suckling the young. This basic likeness is expressed by including all under the CLAss Mammalia.

The Mammals in turn are readily distinguished from Birds, Reptiles, Amphibians, and Fishes (each of which forms a separate class), but nevertheless are constructed on the same fundamental plan, comprising a dorsal central nervous system surrounded by skeletal elements forming the skull and spinal column. Therefore, all are comprehended in the larger group Vertebrata, in contrast with the Invertebrate groups which include Hydra, Earthworm, Crayfish, etc. (See pp. 116, 146, 414.) The classification of the Gray Squirrel, Sciurus carolinensis, (Fig. 86.) may be outlined as follows:

\section{SUBPHYLUM - Vertebrata.}

Class - Mammalia.

ORDER - Rodentia.

FAMILY - Sciuridae.

Genus - Sciurus.

SPECIES - S. carolinensis.

This classification of the Gray Squirrel, although it incidentally serves to illustrate the general method of classification of all organisms, is important because it places concretely before us the fact that organisms show such fundamental similarities with obvious dissimilarities. In short, the mere fact that animals and plants naturally arrange themselves, as it were, in classes, orders, families, genera, species, etc., raises the question of the origin of species. Is special creation implying fixity of species, or is descent with modification the more plausible explanation?

The unavoidable answer is, descent with modification evolution - because the principle in accordance with which the groups of increasing comprehensiveness are formed is 
solely the greater or less similarity in the structural features of the organisms. It is much more reasonable to assume that the thread of fundamental similarity which runs through all the Vertebrates, for instance, is the result of inheritance, while the differences of orders, families, genera, etc., are due to changes brought about under different unknown conditions, than it is to assume that each is the result of a special creative act. Especially so when we realize that in a very large number of cases it.is difficult or impossible to decide the limits of a species, owing to variations among the individuals comprising it, and it is necessary to resort to subspecies and varieties in.classification. And further, among genera, intergrading forms demand subgenera; among orders, suborders; among classes, sub-classes; and so on. If we admit the origin by descent with modification of the subspecies and varieties, there is no logical reason for denying the same origin of species, orders, and higher groups. The difference is one of degree and not of kind. Before the recognition of evolution classification was a groping after an elusive ideal arrangement which naturalists felt but were unable to express except in artificial form and in transcendental terms. Under the influence of the evolution theory classification became the natural expression of biological pedigrees.

\section{Comparative Anatomy}

The evidence from taxonomy is, as has just been seen, really evidence from comparative anatomy, since modern classifications are based chiefly on anatomical characters. The various groups - classes, orders, families, genera, species, etc. - are founded not on a single difference, nor on several differences, but on a large number of similarities. For instance, the differences exhibited throughout the five classes of the Vertebrates are relatively slight in comparison with 


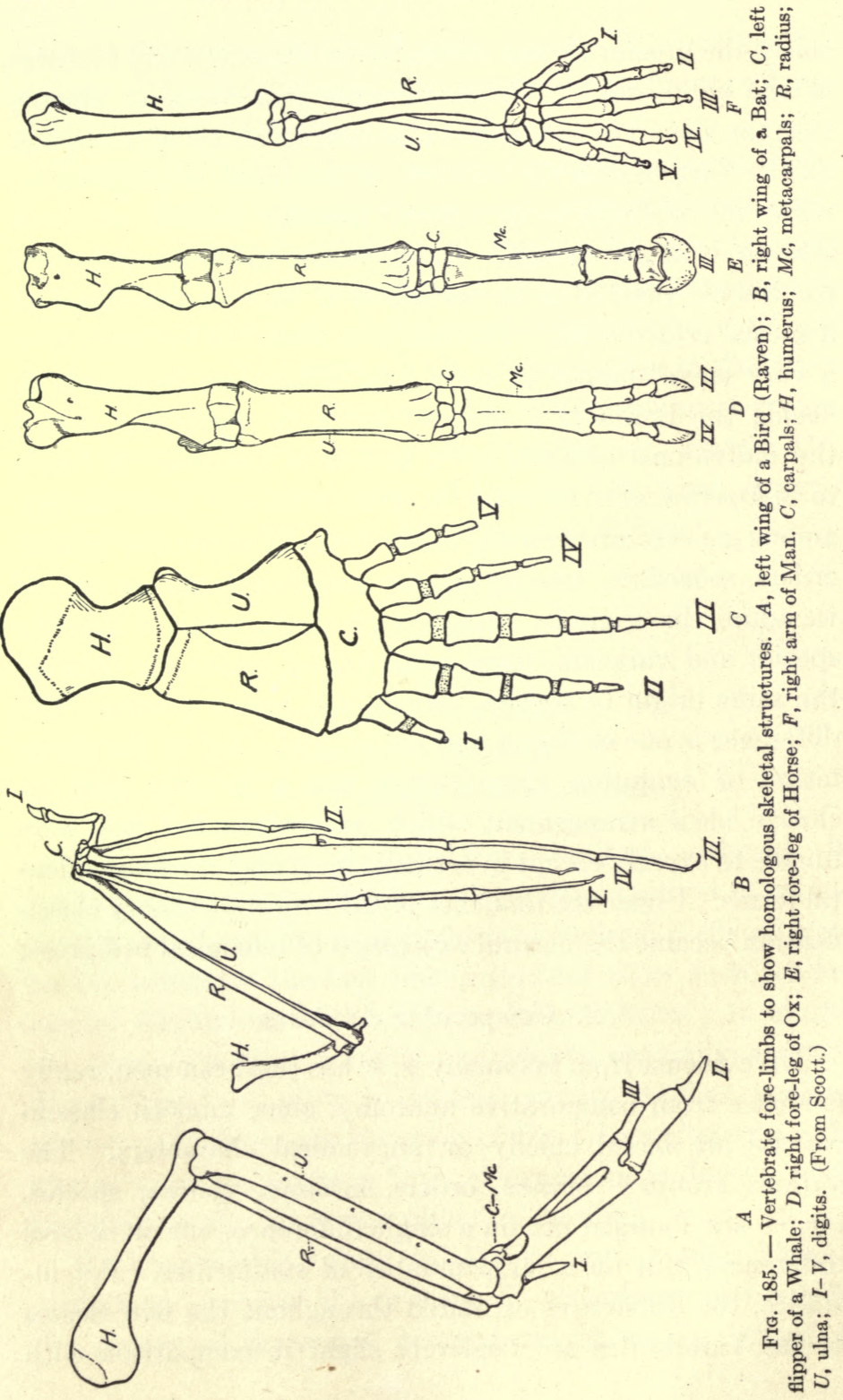


the fundamental resemblances. This similarity in dissimilarity is brought out by the science of comparative anatomy. A few concrete examples, some of which we are already familiar with, will serve to bring the main facts clearly before us.

The fore-legs of Frogs and Lizards, the wings of Birds, the fore-legs of the Horse, and the arms of Man are built on the same basic plan. (Figs. 80, 81, 185, 186.) The same is true of the hind-limbs. Clearly all are homologous structures, such variations as exist being brought about chiefly by the modification or absence of one part or another. In short, all the chief parts of both the fore-limbs and the hind-limbs are homologous throughout the series. All are composed of the same fundamental materials disposed in practically the same way - nearly all the bones, muscles, blood vessels, and nerves are homologous. Or compare the digestive systems of the same forms, or the excretory and reproductive systems. One has but to recall that, on an earlier page, it was possible to describe in general terms these systems as they exist throughout the Vertebrate series - in forms as obviously different as Fish and Man. They are all fundamentally the same. (Figs. 82-87, 97.)

Turning to the Invertebrates, we may remind the reader that all the appendages of the Crayfish are built on the same simple biramous plan as exhibited in the swimming legs (swimmerets) of the abdomen. The highly specialized walking legs, great claws, jaws, and feelers (antennae and antennules) are all reducible to modifications of the simple swimmeret type. (Fig. 72.) In short, all are homologous structures, though differing widely in function. This is a most striking example of SERIAL HOMOLOGY, though we have seen the same principle exhibited in the Vertebrates where the fore-limbs and the hind-limbs of each animal are homolo- 

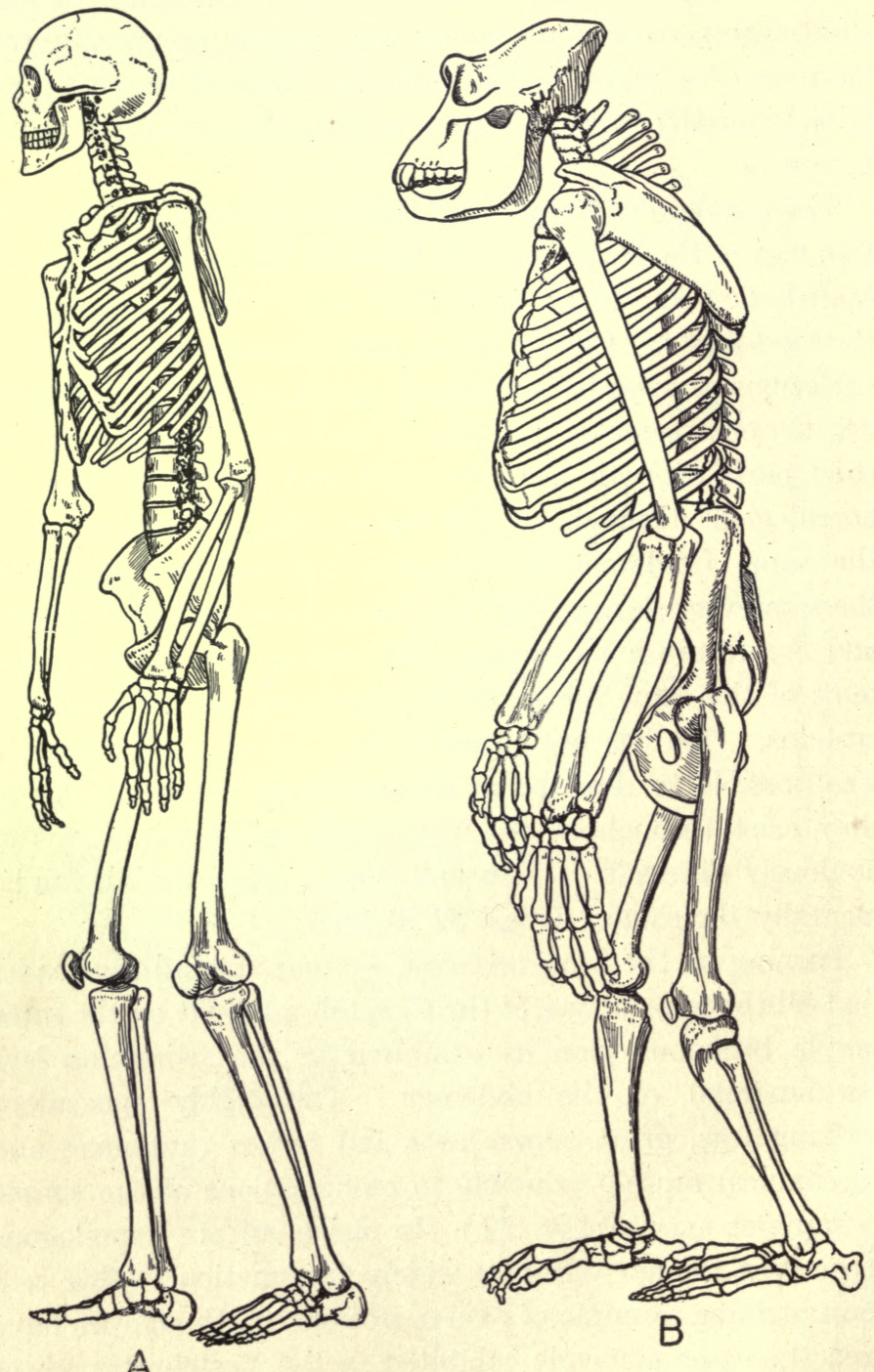

Frg. 186. - Skeletons of Man and of Gorilla. (From Lull.) 
gous. Moreover, the appendages of the Crayfish are not only serially homologous among themselves, but are also homologous with the appendages of all the other members of the class Crustacea - just as the limbs of one Vertebrate are homologous with those of all other Vertebrates.

Another class of facts presented by comparative anatomy is derived from the so-called vestigial organs. In Man there are nearly a hundred structures which at best are useless and sometimes are harmful. One thinks at once of the VERMIFORM APPENDIX of the large intestine, a remnant of an organ which serves a useful purpose in the vegetablefeeding (herbivorous) Mammals. (Fig. 88.) But equally suggestive are the muscles of the ear, which in some individuals are sufficiently developed to move the external ear; the so-called third eyelid at the inner angle of the eye which corresponds to the lid (Nictitating MEMbrane) that moves laterally across the eye in Bird and Frog; or the terminal vertebrae (COCCYx) of the human spinal column which are remnants of the tail of lower Vertebrates. (Fig. 87.)

Other animals are likewise replete with such structures. Porpoises possess vestiges of hind-limbs enclosed within the body, and certain species of Snakes have tiny useless hind-legs. The 'splint bones'. of

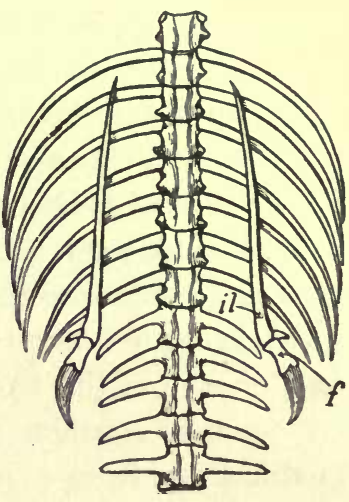

FIG. 187. - Vestigial hindlimbs of a Snake, Python. $f$, femur or thigh bone; $i l$, ilium or hip bone. (From Romanes.) the Horse are remnants of lost toes. Among plants, it will suffice to mention the functionless remnant of the pistil which sometimes is present in 'male' (staminate) flowers. (Figs. 166, 187, 189.) 
In another class of cases, the organs, or remnants of organs, of a lower form are altered or completely made over, as it were, into new organs of the higher form. During the embryonic life of all Vertebrates there are gill slits, all of which soon vanish except one, which remains as an opening (EUstachiaN TUBE) connecting the middle ear with the pharynx. (Fig. 110.)

Gill arches, which function as supports for the gills in the aquatic Vertebrates, persist in highly modified form as skeletal structures associated with the tongue and entrance to the lungs (LARYNX) in terrestrial forms. The milk glands of Mammals are transformed sebaceous glands of the skin, while the poison glands of Snakes are specialized salivary glands of the mouth. Finally, in this connection the reader will recall the transformations of the blood vessels in the Vertebrates which occur with the substitution of lungs for gills, and also the variations and interrelationships of the excretory and reproductive systems in the ascending series of Vertebrate classes. (Figs. 95, 97.)

One may, of course, conclude from all these facts that Fish, Frog, Lizard, Bird, and Man have each been independently created according to the same preconceived plan - and likewise all the great numbers of orders, families, genera, species, etc., of each of the five classes that these forms represent. Or, one may conclude, that all have arisen by descent with modification from a primitive Vertebrate organism which possessed the fundamental similarities exhibited from Fish to Man. The latter is the conclusion accepted unreservedly by biologists to-day.

\section{Paleontology}

Huxley once said that if zoölogists and embryologists had not put forward the theory of evolution, it would have been 
necessary for paleontologists to invent it. What then are the main facts offered by the study of the fossil remains of extinct animals and plants?

In the first place it must be made clear that geologists are able to determine, with remarkable accuracy in most cases, the sequence in time, or CHRONOLOGICAL SUCCESSION, of the rock strata composing the Earth's surface. The main outline of this scheme of geological chronology was understood long before the evolution of organisms was a crucial question; so that we may consider the evidence which it affords of the chronological succession of the fossil remains exhibited by the various strata, as impartial testimony to the order of appearance on the Earth of the different types of animals and plants.

The following geological time-table summarizes the panoramic succession of life as it is seen by the paleontologist. It is useless to attempt to state the absolute duration of geologic time, because we have little more than guesses to depend on, though there are fairly reliable data in regard to the relative length of the various eras. Perhaps the conservative estimate of $500,000,000$ years - at least half of which was before the Permian period - will serve to spell the Earth's unfathomable past. 


\section{THE GEOLOGICAL TIME-TABLE ${ }^{1}$}

PRESENT TIME.

Psychozolc Era. age of man or age of Reason.

Includes the present or 'Recent time,' and the time during which Man attained his highest civilization, estimated to be probably less than 30,000 years.

GEOLOGIC TIME.

Cenozoic Era. age of mammal dominance.

Glacial or Pleistocene time. Last great ice age.

Late Cenozoic or Pliocene and Miocene time. Primates changing into Apes and Man.

Early Cenozoic or Oligocene and Eocene time. Rise of higher

Mammals, including Primates.

Mesozoic Era. age of Reptile dominance.

Cretaceous period. Rise of primitive Mammals.

Comanchian period. Rise of Flowering Plants and higher Insects.

Jurassic period. Rise of Birds and flying Reptiles.

Triassic period. Rise of Dinosaurs, and Mammalian stock.

Paleozolc Era. age of Fish dominance.

Permian period. Rise of Reptiles. Another great ice age.

Pennsylvanian period. Rise of Insects and first time of marked coal accumulation.

Mississippian period. Rise of marine Sharks.

Devonian period. First known marine Fishes, and Amphibians.

Silurian period. First known land floras.

Ordovician period. First known fresh-water Fishes.

Cambrian period. First abundance of marine fossils, and dominance of Trilobites.

Proterozoic Era. age of invertebrate dominance.

An early and a late ice age.

Archeozolc Era. ORIGIN OF PROTOPLASM ANd OF SIMPLEST LIFE.

COSMIC TIME:

Formative Era. BIRTh aNd GRowth of the EARTh oUt of the SPIRAL NEBULA OF THE SUN.

Beginnings of the atmosphere and hydrosphere, and of continental platforms and oceanic basins. No known geological record.

' From The Earth's Changing Surface and Climate by Professor Charles Schuchert. See Bibliography. 
Even a casual survey of this history - natural history of the Earth and its inhabitants cannot but impress one with the fact that, taken all in all, there has been a continuous, though not always a uniform, advance in the complexity of organisms from the most ancient times, and that the older types seem gradually to melt into modern forms as the remoter geological eras merge into the more recent. "Only the shortness of human life allows us to speak of species as permanent entities." Invertebrates appear in the Proterozoic Era; Fishes and Amphibia in the Paleozoic; Reptiles, Birds, and Primitive Mammals in the Mesozoic; higher Mammals and Man in the Cenozoic. Mosses and Ferns arise before Conifers and the latter before the familiar Flowering Plants. "Just in proportion to the completeness of the geological record is the unequivocal character of its testimony to the truth of the evolutionary theory." For the sake of concreteness we may select two examples from the wealth of material offered by the paleontologist.

At first glance there seems to be little but contrasts between a typical Reptile and a typical Bird; between a cold-blooded, scaly-skinned Lizard, let us say, and a warmblooded, feathered Pigeon. And yet the zoölogist is convinced that Birds have evolved from a reptilian stock, because, in spite of superficial dissimilarities, there are fundamental structural resemblances not only between adult Reptiles and Birds, but also between their developmental stages. And further, because, the fossil remains of a very primitive Bird, Archaeopteryx, have been found which form, in many ways, a connecting link between the Reptiles and Birds as we know them to-day.

Archaeopteryx was undoubtedly a bird about the size of a Pigeon, but one with jaws supplied with many small teeth; with a long lizard-like tail formed of many vertebrae, each 
bearing a pair of quill feathers; with a four-fingered reptilian hand; and so on. In brief, just such a creature as the imagination of an evolutionist would picture for a primitive Birc has been disclosed by the lithographic stone quarries of
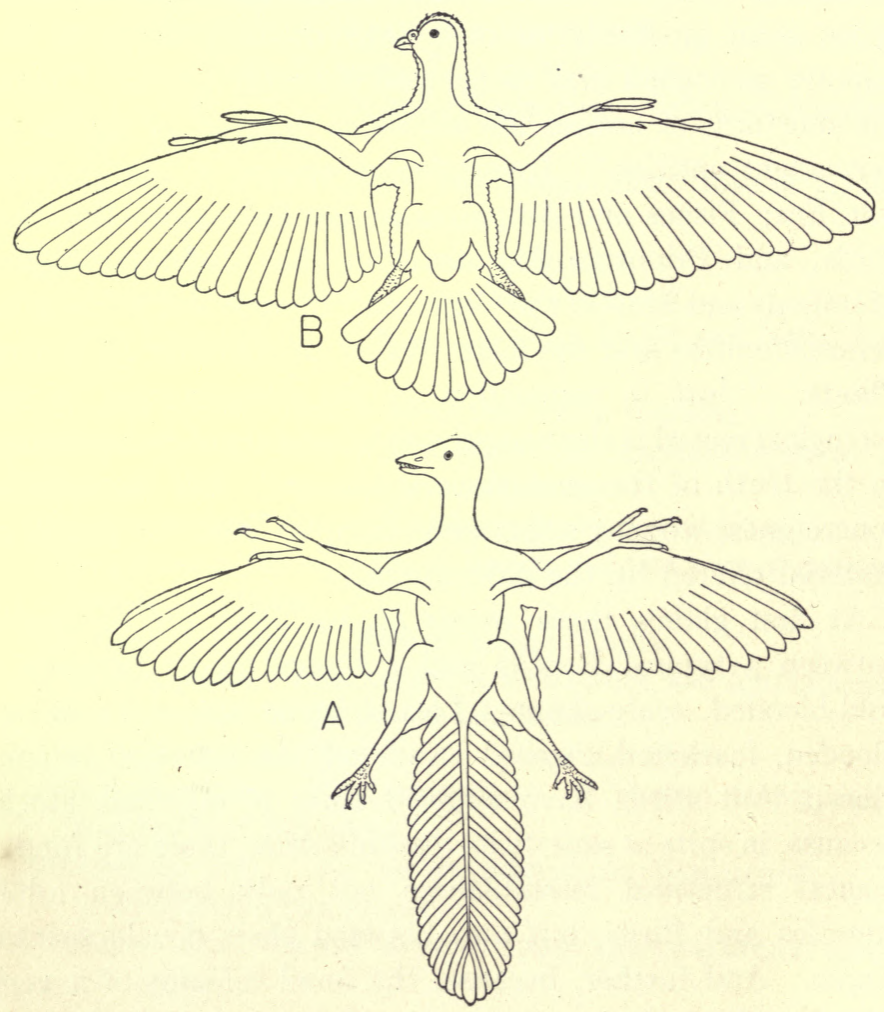

Fig. 188. - Reptilian Bird, Archaeopteryx, (A), compared with Pigeon, Columba livia $(B)$. (From Lull.)

Bavaria, representing the later Jurassic period. (Fig. 188.)

The ancestry of the modern Horse has been the most impressive 'fossil pedigree,' ever since Professor Marsh collected the famous series of fossil skeletons from the western United 
States and arranged them in the Yale Museum. The essential facts are these. Horse-like animals probably arose from an extinct group known as the Condylarthra which had five toes on each foot and a large part of the sole resting on the ground. However, the first unquestionably horselike form found in North America is a little animal less than a foot in height, known as Eohippus, from rocks of the Eocene age. The fore-foot of Eohippus has four complete toes (digits 2, 3, 4, and 5) and a vestige of the first digit in the form of a splint bone. The hind-foot has three toes (digits 2,3 , and 4) with a remnant of the fifth digit. Later in the Eocene we find Protorohippus with the same functional digits but lacking the vestiges. Coming to the Oligocene, Mesohippus appears. This animal is about the size of a sheep and still has three toes (digits 2,3 , and 4 ) on the hindfoot, but only three complete toes (digits 2, 3, and 4) and the vestige of a fourth (digit 5) on the fore-foot. Also the middle toe (digit 3 ) is now much larger than the side toes, which barely touch the ground. Then during the late Miocene and early Pliocene we find Protohippus, an animal about three feet tall, with three toes on each foot, but with only one reaching the ground, and with no vestiges of other digits. Finally, toward the end of the Pliocene, appears the genus Equus which includes the modern horse, Equus caballus, with one functional toe (digit 3 ) on each foot and the remnants of two more (digits 2 and 4 ) in the splint bones. (Fig. 189.)

In this outline of what must be interpreted as the fossil ancestors of the Horse of to-day, we have merely selected several representative forms to emphasize changes in foot structure. But the reader will realize that many other equally significant changes were involved in the transformation of an Eohippus type into that of Equus. This much 


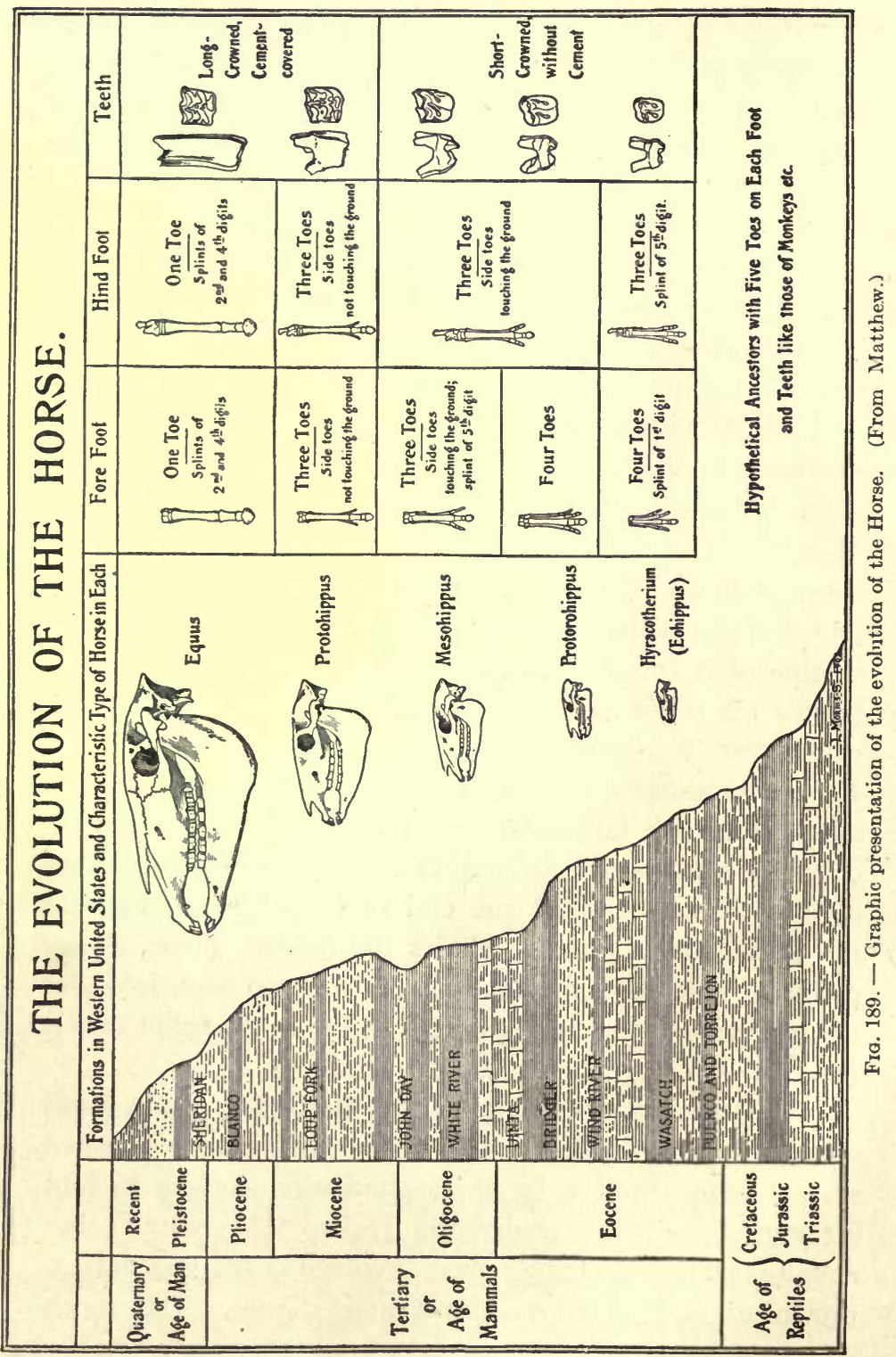




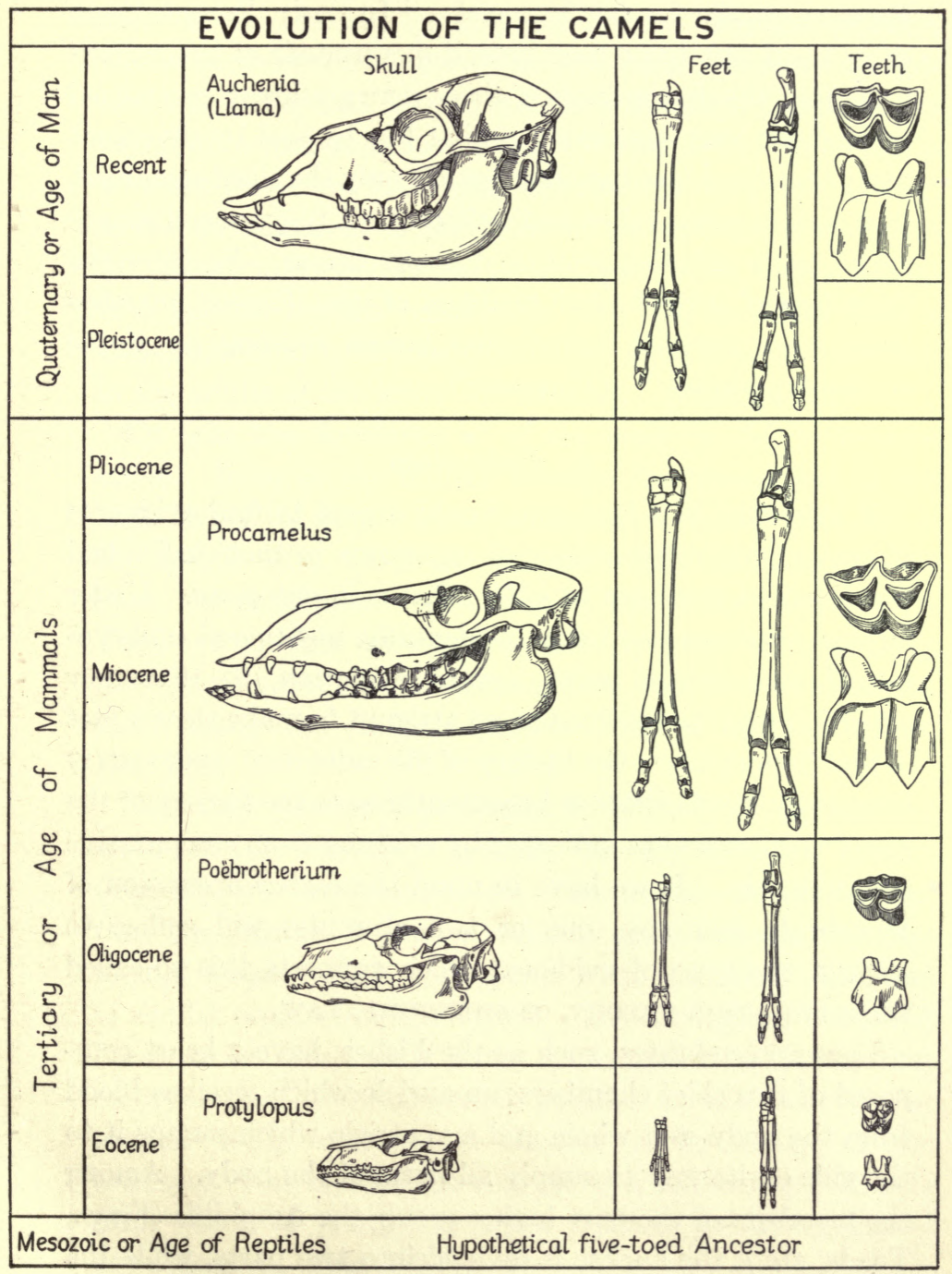

Frg. 190. - Graphic presentation of the evolution of the Camel. (From Lull, after Scott.) 
appears certain to the biologist: "In early Eocene times there lived small five-toed hoofed quadrupeds of generalized type, that the descendants of these were gradually specialized throughout long ages along similar but by and by divergent

- lines, that they lost toe after toe till only the third remained, that they became taller and swifter, that they gained longer necks, more complex teeth and larger brains. So from the short-legged splay-footed plodders of the Eocene marshes there were evolved light-footed horses running on tiptoe on the dry plains." (Thomson.)

\section{Embryology}

If evolution is a fact, one would expect to find evidences of the genetic relationships of organisms in their individual development from egg to adult, that is in ontogeny. Under former headings we have incidentally mentioned embryological data which point toward evolution, so that now attention may be confined to an attempt to make clear a fact of first importance- the history of the individual (ONTOGENY) frequently corresponds in broad outlines to the history of the race (PHYLOGENY) as indicated by evidence from comparative anatomy, etc. If we have in mind the earlier discussion of Vertebrate anatomy, one or two examples will suffice to suggest the type of evidence which supports this so-called RECAPITULATION THEORY, Or BIOGENETIC LAW.

Lower Vertebrates, such as the Fishes, have a heart composed of two chief chambers: an auricle which receives blood from the body as a whole and a ventricle which pumps it to the gills on its way to supply all parts of the body. Among the members of the next higher group, the Amphibia (Frogs, Toads, etc.), the auricle is divided into two parts, while the ventricle remains as before. Thus these forms have a threechambered heart. Passing to the Reptiles, we find that 
most of the Lizards, Snakes, and Turtles have the ventricle partially divided into two chambers, while the more specialized Crocodiles and Alligators have a complete partition and therefore a four-chambered heart. This is the condition in all adult Birds and Mammals, but the significant fact is that, in the development of the heart of the individual Bird and Mammal, embryonic stages succeed each other which parallel in a general though remarkable way this sequence from a two-chambered to a four-chambered condition as exhibited in the adults of the lower Vertebrates. (Figs. 91, 92.)

Or take the development of the brain in the Vertebrate series. Even in the human embryo the fundament of the brain arises by simple transformations of the anterior end of the neural tube, which at first are nearly indistinguishable from the conditions which exist in the lowest Vertebrates. Then the changes become progressively more complex along lines broadly similar to those occurring from Fish to Mammal, until finally the complex human brain is formed. (Figs. 104, 105.)

The same picture is presented by a study of the development of the excretory system, the reproductive system (Fig. 97), the skull, and so on. One cannot avoid the fact that the organs of higher animals pass through developmental stages which correspond with the adult condition of similar organs in lower forms. The correspondence is not exact, to be sure, but it is not an exaggeration to say that embryological development is parallel to that which anatomical study leads us to expect. A knowledge of the anatomy of an animal actually gives a sound basis of facts from which to predict in broad outlines its embryological development. (Fig. 191.)

What are the bearings of these facts on the evolution theory? It is perfectly logical to conclude that it is an 
'architectural necessity,' let us say, for the four-chambered heart to arise from a two- and three-chambered condition and undoubtedly if this were the only example of 'ontogeny repeating phylogeny' the conclusion might be justified. But when one considers the widespread general correspond-
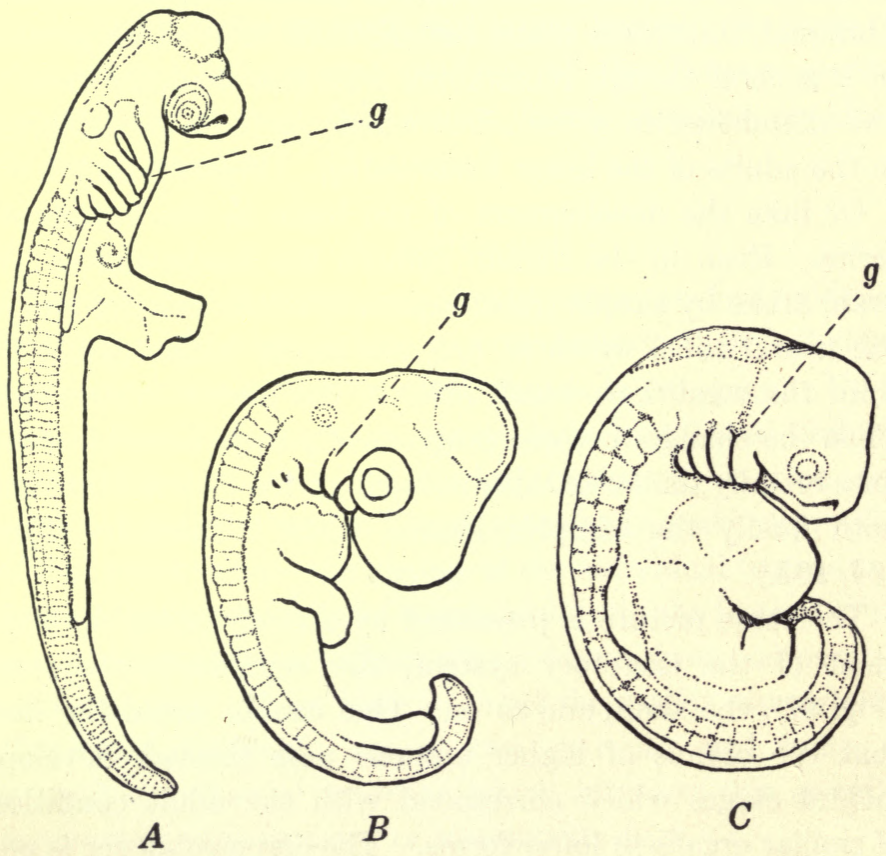

FIG. 191. - Embryos in corresponding stages of development. A, Fish (Shark); $B$, Bird; $C$, Man. $g$, gill slits. (From Scott.)

ence of the developmental stages in higher forms with conditions as they exist in the adults of lower forms, the facts almost overwhelmingly force us to go further and conclude that the similarity has its basis in inheritance, in actual blood relationship between the higher and lower forms, in descent with modification - evolution. 


\section{Physiology}

Fundamental structural similarities throughout a series of organisms implies fundamental physiological similarities structure and function go hand in hand, each being an expression of the other. But the physiological evidence is less readily presented in brief form, so we may confine attention to one striking example on the borderline.

It has been known for a long time that there are important chemical differences - not determinable by ordinary chemical analysis - between the blood even of closely related species, because the transfusion of the blood of one species into another is usually attended by physiological disturbances and often by death. It has been found by innumerable transfusions and also by so-called precipitation tests of the blood in vitro, that is outside the body, that the degree of the 'reaction' is in many cases proportional to the degree of relationship of the species involved, as indicated by their classification on the basis of anatomical criteria.

Thus, as one would expect, human blood shows closer chemical relationships with the blood of the Man-like Apes than it does with that of the Old World Monkeys; closer relationships with the blood of the latter than it does with that of the New World Monkeys; and closer with the blood of these than with that of the Lemurs; and so on. Or, descending to the Reptiles: paleontology indicates that there is a close relationship between Lizards and Snakes and also between Turtles and Crocodiles, while the reptilian ancestor of the Birds was probably more closely allied with the latter than the former groups. These same relationships are indicated by blood tests.

Thus aside from a few startling exceptions, which further study perhaps may bring into line, all the data warrant the conclusion that the chemical similarities of the blood are 
almost as constant as the structural similarities of the blood vessels, or, in evolutionary terms, "a common property has persisted in the bloods of certain groups of animals throughout the ages which have elapsed during their evolution from a common ancestor." Blood relationship is a fact.

\section{Distribution}

Every one recognizes that the fauna and flora are not the same in all regions of the Earth. There is a characteristic life on mountain, plain, and seashore, and in the sea - as well as in pond and puddle - and also in the Arctic, Temperate, and Torrid zones. But the problem of animal and plant distribution is by no means so simple as this statement might seem to imply, because the study involves the investigation of both the relations of the various organisms to the general environing conditions, and also the interrelations of the species with each other. It forms a part of the sciences of plant and animal ECOLOGY.

Confining attention merely to the geographical distribution of animals - which forms the science of zoöGEOGRAPHY - let us take a couple of clear-cut examples and see whether special creation or evolution is the more reasonable explanation of the facts.

At the present time a characteristic family of Mammals, known as the Tapirs, is represented by distinct species in two widely separated regions, Central and South America and Southern Asia and adjacent islands. But paleontological studies show that in the Pliocene period Tapirs were distributed over nearly all of North America, Europe, and Northern Asia, and thereafter gradually became extinct so that by the close of the Pleistocene period the remnants were distributed as we find them to-day. In brief, the present discontinuous distribution represents the remnants of a world-wide Tapir 
population, and the differences between the existing species are such as one might expect to find among the members of a genus long isolated in different environments by geographical barriers. We know, for example, that a litter of European Rabbits was introduced on the small island of Porto Santo during the fifteenth century and by the middle of the last century its descendants had become so distinct from the parent form that it was described as a 'new species.'

As a matter of fact the characteristic fauna of islands was what impressed Darwin with the need of some interpretation other than special creation. During his famous three years' voyage around the world on the "Beagle," he stopped at the Galapagos Islands, situated about 600 miles off the west coast of South America, and was astonished to find that although the fauna as a whole resembled fairly closely that of the mainland, nevertheless the species for the most part not only were different, but even those of the separate islands were distinct - the islands nearest to each other having species most similar. Darwin wrote, "My attention was first thoroughly aroused by comparing together the numerous specimens, shot by myself and several others on board, of Mocking Thrushes, when, to my astonishment, I discovered that all those from Charles Island belonged to one species (Mimus trifasciatus); all from Albemarle Island to M. parvulus; and all from James and Chatham Islands (between which two other islands are situated as connecting links) belonged to $M$. melanotis."

Darwin's observations of such facts as these have been corroborated in the Galapagos and extended to isolated island faunas and floras all over the world. And further, his explanation of the phenomena is the most plausible extant. Continental islands secure their life from the mainland before they are cut off, and Oceanic islands after their formation by 


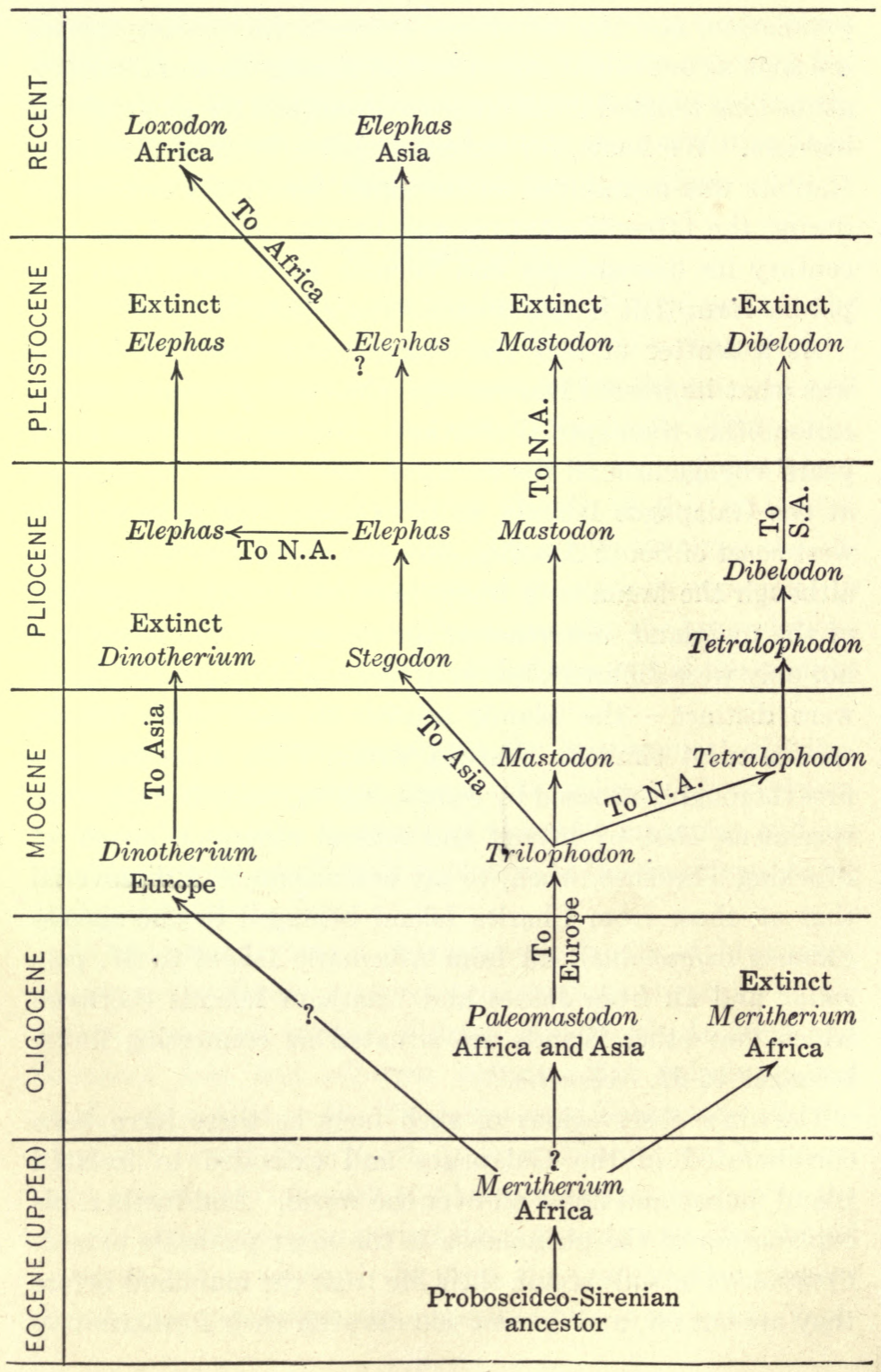

FIG. 192. - Chart of the phylogeny of the Elephants, showing their geological and geographical distribution. (After I,ull.) 

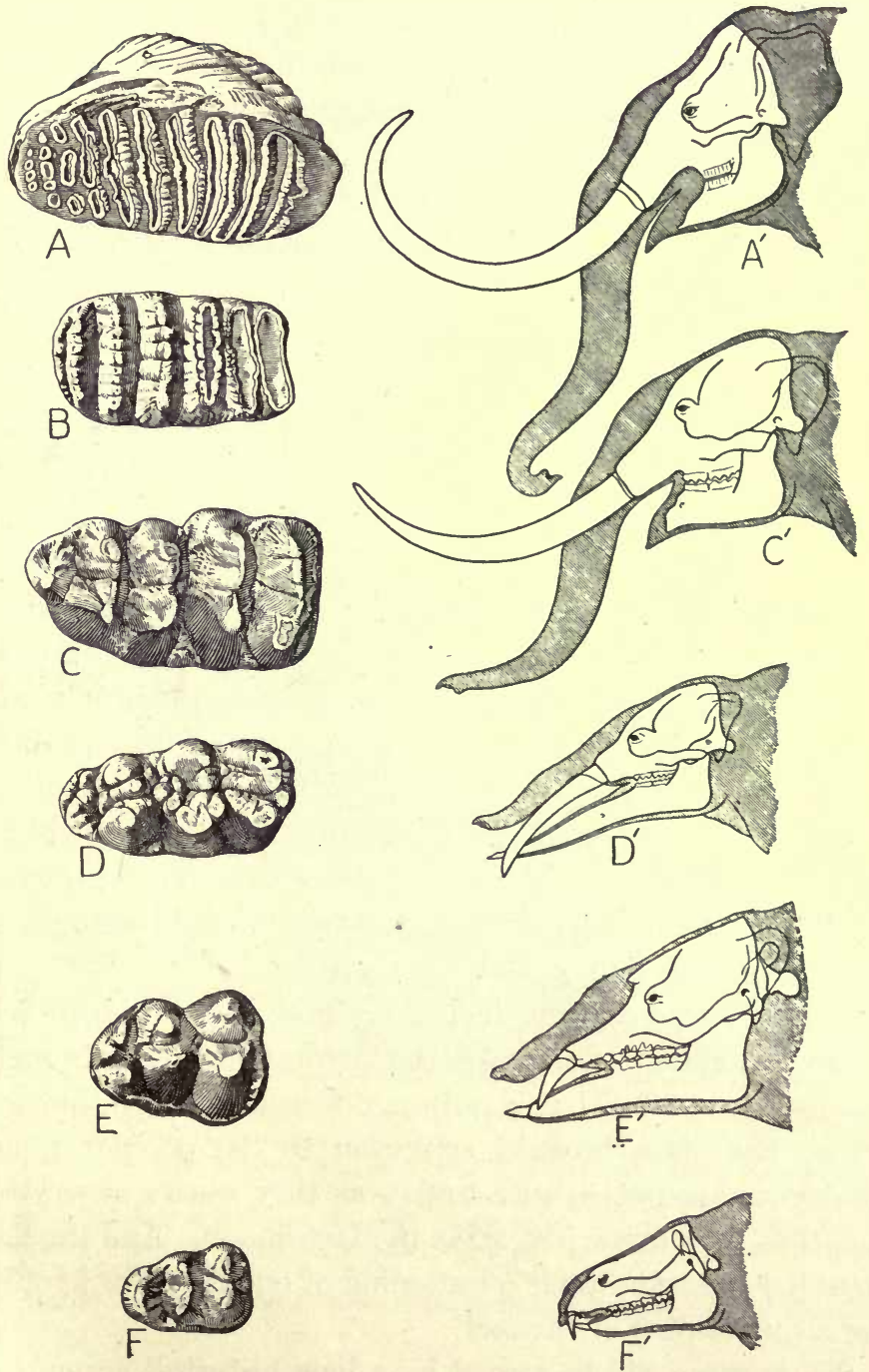

Fig. 193. - Evolution of the head and molar teeth of Elephants. A, A', Elephas, Pleistocene; $B$, Stegodon, Pliocene; $C, C^{\prime}$, Mastodon. Pleistocene; $D, D^{\prime}$, Trilophodon, Miocene; $E, E^{\prime}$, Palaeomastodon, Oligocene; $F, F^{\prime}$, Moeritherium, Eocene. (After Lull.) 
volcanic action alone or aided by coral growth. In either event the organisms are isolated from the main stock of the species, and in proportion to the length of time and the degree of isolation the insular forms diverge until separate races and species arise. Each species peculiar to each isolated island has not arisen by a special act of creation but by descent with modification.

\section{B. Factors of Organic Evolution}

We have now summarized a few concrete examples of the chief types of evidence that organisms - species - have come to be what they are to-day through a long process of descent with modification. This evidence, taken with that presented, so to speak, on and between the lines throughout this work, should place the reader in a position to form a more or less independent judgment of the question. It is only necessary to remind him again that, since the evidence, from the nature of the case, must inevitably be indirect, its cogency is tremendously increased by its amount. And the overwhelming impressiveness of all the concordant evidence for organic evolution the reader, with only a very limited amount of the data before him, cannot appreciate.

Taking for granted the fact of evolution - as we have had to do throughout - what are the factors which have brought evolution about? That is quite a different question, but one which has often brought confusion to the popular mind. Biologists are not so sure to-day as they were a generation ago that they know just what the factors are. And the layman has mistaken their questioning of one factor or another for a questioning of the fact.

No purpose will be served by a long historical account of - the origin of the present-day point of view. Suffice it to say that the evolution idea is a generalization which has erept 


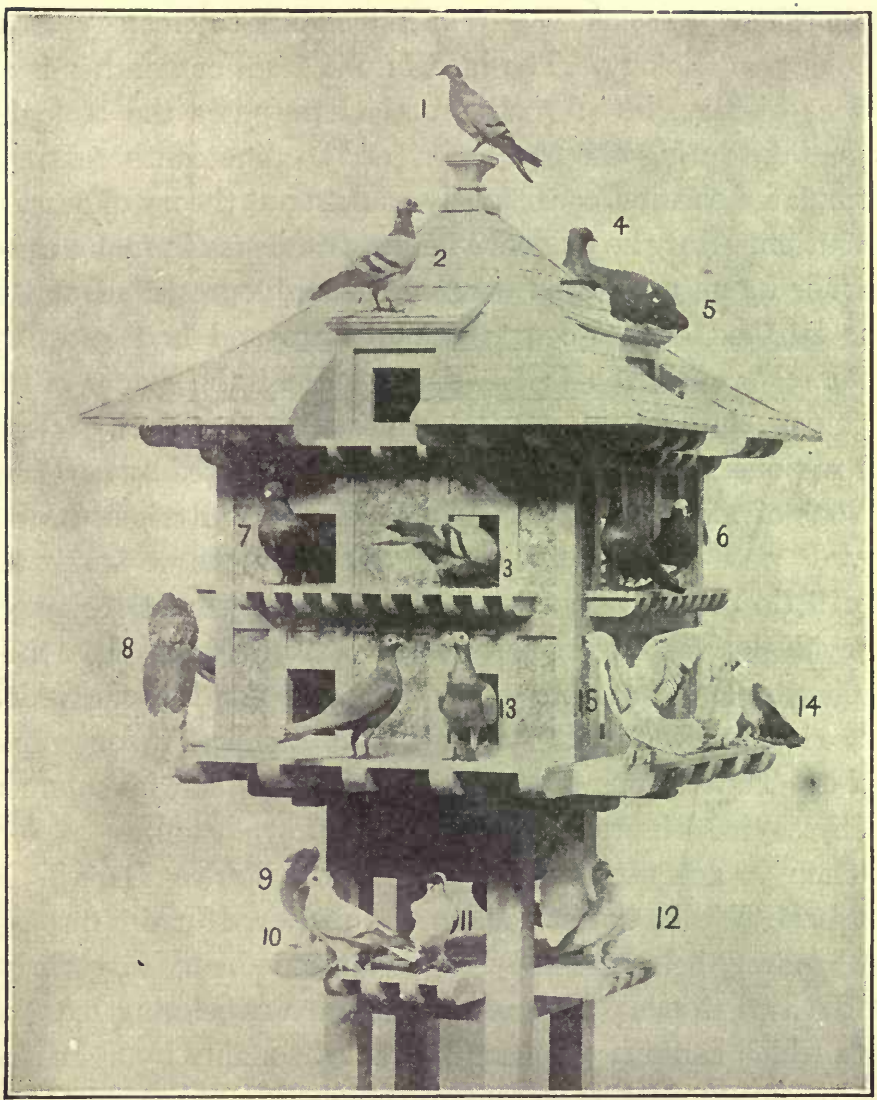

Fig. 194. - A few varieties of domestic Pigeons. Over one hundred and fifty different breeds have been derived by selection from the wild Blue-rock Pigeon, some of which "differ fully as much from each other in external characters as do the most distinct natural genera." (Darwin.) 1, Blue-rock Pigeon, Columba livia, ancestral form; 2, homing; 3, common mongrel; 4, archangel; 5, tumbler; 6, bald-headed tumbler; 7 , barb; 8 , pouter; 9 , Russian trumpeter; 10, fairy swallow; 11, blackwinged swallow; 12, fantail; 13 , carrier; 14, 15, bluetts; bird between 14 and 15, a tailed turbit. (From photograph of an exhibit in the United States National Museum.) 
from science to science - from Astronomy to Geology, from Geology to Biology. The idea in one form or another is as old as history, but for all practical purposes the biologist Lamarck, during the early part of the nineteenth century, formulated the first consistently worked out theory of organic evolution. But the evidence he presented was in many cases neither happily selected nor convincingly presented and it was laughed out of court by biologists and laymen alike. Lamarck's evolution factor was essentially the change of the organism through the use and disuse of parts, the physiological response of the organism to new needs offered by new conditions of life. And these changes, somatic in origin, he believed were transmitted to the progeny. As we know, today little or no value is placed on such somatic changes as evolution factors, because there is no evidence that they are heritable. But this weak point was not the one which caused the rejection of the theory by Lamarck's contemporaries. The various antagonistic influences can be summed up by saying, the time was not ripe for evolution.

Then a generation later appeared Charles Darwin in England. With a better background prepared for him through the headway being made by the evolution theory in geology, he did two things. He presented an overwhelming mass of data which could be explained most reasonably by assuming the origin of existing species by descent with modification from other species. And he offered as an explanation of the origin of species the theory of "NATURAL SELECTION, or the preservation of favoured races in the struggle for life." It was the combination of the facts and the theory to account for the facts which won the thinking world to organic evolution.

What, in brief, was the theory? In the first place, without discussing the cause of variations, Darwin showed the great amount of variation in nature. And any and all kinds of 
variation were, broadly speaking, equally important - he made no sharp distinction between somatic and germinal. The universality of variations established, Darwin emphasized the fact that the power of reproduction of organisms far exceeds space for them to live in and food for them to eat. Some recent facts will illustrate this point. A single microscopic Paramecium possesses the potentiality to eat, grow, and reproduce - to transform the materials of its environment into Paramecium protoplasm - at the rate of 3000 generations in five years. And all the descendants (if they actually existed) would equal 2 raised to the 3000 th power, or a volume of protoplasm approximately equal to $10^{1000}$ times the volume of the Earth!

Something must inhibit the inherent power of each species to overpopulate the Earth, and Darwin emphasized the struggle for existence between the individuals of species. Since the struggle is so keen, a variation, however slight, which fits - adapts - an individual better to its surroundings than its neighbors are adapted, will, more often than not, give its possessor an advantage in the struggle, and accordingly the latter will survive to pass on the favorable variation to its progeny. Thus is brought about, in Spencer's phraseology, "the survival of the fittest" - the survival of those individuals, and therefore species, which are adapted to the peculiar conditions of their environment and mode of life. And note, this offers an explanation of the fact of adaptation itself - the most striking phenomenon which organisms exhibit.

This is all so simple from one point of view and so confusingly complex from others that it may well be restated in a couple of sentences by Darwin himself: "As many more individuals of each species are born than can possibly survive, and as, consequently, there is frequently recurring struggle for existence, it follows that any being, if it vary however 
slightly in any manner profitable to itself, under the complex - and sometimes varying conditions of life, will have a better chance of surviving, and thus be naturally selected. From the strong principle of inheritance any selected variety will tend to propagate its new and modified form."

Nothing succeeds like success, and once started Darwin's theory gradually swept all opposition away, and some of its exponents out-Darwined Darwin. Then, as was to be expected, the reaction came. Acquired characters are not heritable; variations are swamped by interbreeding; large variations and not small fluctuating variations are crucial; and so on. But it is not necessary to obscure the main issue by entering into these controversies. What is the status of the theory of natural selection to-day?

Evolution is not a closed book - an event which has been completed in the past - but a process which is actively going on now. "Nothing endures save the flow of energy and the rational order that pervades it." And there is every reason to believe that the factors involved in present evolution are the same as those which have operated in the past. The uniformitarian doctrine has proved productive in explaining the evolution of the Earth, and there is every reason to think that this viewpoint will prove - is proving - equally valuable in understanding the origin of the diverse inhabitants of the Earth. We have come to realize that evolution is a bird's-eye view of the results of heredity, since the origin of life - the facts of inheritance hold the key to the factors of evolution. Therefore in a previous chapter we discussed the relations of recent discoveries in genetics to the evolution problem, some of which may be restated now with special reference to the origin of the fitness of organisms.

In the first place we have seen that though variations are the rule and not the exception, some are of importance for 
evolution and some are not. All the evidence indicates that the effective variations are germinal and not somatic. Changes arising in the soma - acquired characters - are unable so specifically to modify the germ that they are 'born again' and evolution must be brought about by the evolution of the germ itself. Accordingly selection must operate to eliminate the 'unfit' germ plasm rather than the unfit soma, though as a matter of fact the fitness of an individual is determined largely by its somatic characters. This apparently is the crux of the matter and presents a complication of the mental picture of the operations of selection which did not exist when we thought of soma producing germ and germ producing soma again. Since individuals frequently belie their germinal condition - what they will pass on to their progeny - selection has, so to speak, a more devious though not less sure path.

Secondly, how does the germ plasm change? Developed characters are the result of the activities of one or more genes. Of course, a gene is not a character. It is not even an undeveloped character. Characters in many cases arise from the interaction of several genes, though, since one gene determines whether the gene complex will give rise to a certain character, it is really the determining factor - for example, the so-called sex gene on the so-called sex chromosome. Such being the case, characters may be changed by alterations of the gene complex. (Cf. p. 298.) This may be from the influence of changes within the soma itself or from the environment of the organism, but here particularly we are on debated ground. On the whole, it may be said that mutations - germinal changes other than those arising from recombinations - seem to be infrequent compared with non-heritable changes of somatic origin.

These facts from genetics, taken in connection with 
the data from geographical distribution, the succession of types in the geologic past, and the great diversities in 'breeds' in nature, etc., give us the modern background for attempt-' ing to form an opinion of the method of evolution. The consensus of opinion seems to be that natural selection in some form is the guiding principle in the establishment of the 'adaptive complexes' of organisms. Evolution is the result of germinal variations, largely independent of environing conditions. Many of these variations give rise to characters which neither increase nor decrease the adaptation of the organism, and consequently are neutral from the standpoint of its survival. With regard to such characters natural selection is essentially inoperative. Other germinal variations arise which produce adaptive structures and here natural selection is effective - it sifts them out, as it were, from the unadaptive and neutral variations and in this way makes possible their survival value in the struggle for existence.

So, it will be noted, this is essentially a clarified Darwinism. Instead of all variations being heritable - some are inherited and some are not. Instead of all heritable variations being important-some are and some are not. The important ones are the heritable adaptive variations and these form the raw materials for natural selection. Natural selection is still the only natural explanation of that coördinated adaptation which pervades every form of life, but it is probable - indeed, positive - that there are more factors involved than are dreamt of in our philosophy. 


\section{CHAPTER XX}

\section{EPOCHS IN BIOLOGICAL HISTORY}

History must convey the sense not only of succession but also of evolution.

Sоме knowledge of hunting, agriculture, and husbandry was one of the early acquirements of prehistoric Man, and at the dawn of history, nearly 5000 years ago, systems of medicine apparently found a place in Egyptian and Babylonian civilizations. So, on the practical side, biology has a very ancient beginning. But biology as the science of life in which emphasis is transferred to the philosophical - to the study of vital phenomena for their own sake - really begins with the Greeks.

Science reaching Greece from the South and East fell upon fertile soil, and in the hands of the Hellenic natural philosophers was transformed into coherent systems through the realization that nature works by fixed laws - a conception foreign to the Oriental mind and the corner-stone of all future scientific investigation. It is not an exaggeration to say that to all intents and purposes the Greeks laid the foundations of the chief subdivisions of natural science and, specifically, created biology.

\section{A. Greek and Roman Science}

Aristotre (384-322 B.c.), the most famous pupil of Plato and dissenter from his School, represents the highwater mark of the Greek students of nature and is justly called the Father of Natural History. Although Aristotle's 
contributions to biology are manifold, perhaps of most significance is the fact that he took a broad survey of the existing data and welded them into a science. He did this by relying, to a considerable extent, on the direct study of organisms and by insisting that the only true path of advance lies in accurate observation and description. The observa-

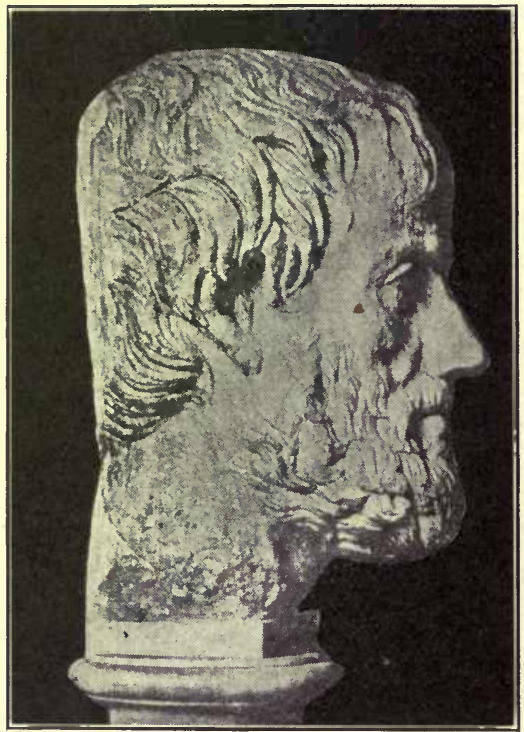

FIG. 195. - Aristotle.

tional method and its very modern development, the laboratory method of biological study, find their first great exponent in Aristotle. But mere observation without interpretation is not science. Aristotle's generalizations based on the facts accumulated and his elaboration of broad philosophical conceptions of organisms give to his biological works their perennial significance.

While Aristotle's biological investigations were devoted 
chiefly to animals, his pupil and co-worker, Theophrastus (370-286 в.c.), made profound studies. on plants. Theophrastus not only laid the foundations but also gave suggestions of much of the superstructure of botany; an achievement which entitles him to rank as "the first of real botanists in point of time."

Before leaving the Greeks we must mention Hippocrates

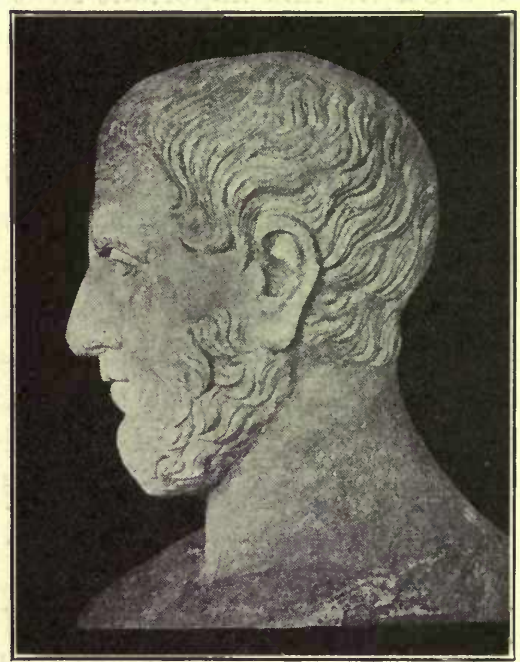

FIG. 196. - Theophrastus of Eresus.

(460-370 B.c.), the Father of Medicine. Writing a generation before Aristotle, at the height of the Age of Pericles, Hippocrates crystallized the knowledge of medicine into a science, dissociated it from philosophy, and gave to physicians "the highest moral inspiration they have."

The history of medicine and of biology as a so-called pure science are so inextricably interwoven that consideration of the one involves that of the other. Indeed the physicians form the only bond of continuity in biological history be- 
tween Greece and Rome. The chief interest of the Romans lay in technology, and it is but natural that the practical advantages to be gained from medicine should ensure its advance. As it happens, however, two Greek physicians were destined to have the most influence: Dioscorides, an army surgeon under Nero, and Galen, physician to the Emperor Marcus Aurelius.

Dioscorides wrote the first important treatise on applied botany. This was really a work on the identification of plants for medicinal purposes but, gaining authority with age, it became the standard 'botany' for fifteen centuries.

GaLen (131-201) was the most famous physician of the Roman Empire and his voluminous works represent both a depository for the anatomical and physiological knowledge of his predecessors, rectified and worked over into a system, and also a large amount of original investigation. Galen was at once a practical anatomist and the first experimental physiologist, inasmuch as he described from dissections and insisted on the importance of vivisection and experiment. Galen gave to medicine its standard 'anatomy' and 'physiology' for fifteen centuries.

Any consideration of the biological science of Rome would be incomplete without a reference to the vast compilation of fact and fancy indiscriminately mingled made by PLINY the Elder (23-79). It was aside from the path of biological advance, but long the recognized Natural History, passing through some eighty editions after the invention of printing.

\section{B. Medieval and Renaissance Science}

For all practical purposes we may consider that biology at the decline of the Roman Empire was represented by the works of Aristotle, Theophrastus, Dioscorides, Galen, and Pliny. Even these exerted little influence during the Middle 
Ages, being saved from total loss for future generations chiefly by Arabian scientists, and the monasteries of Italy and Britain. In so far as science was taught at all, it was from small compilations of corrupt texts of ancient authors interspersed with anecdotes and fables. Under theological influence there arose the oft-quoted PHysiologus, found in many forms and languages, which is at once a collection of natural history stories, and a treatise on symbolism and the medicinal use of animals. The centaur and phoenix take their place with the Frog and Crow in affording illustrations of theological texts and in pointing out more or less evident morals.

So low had science fallen that the scientific Renaissance may be said to owe its origin to the revival of classical learning - to the translation and study of the writings of Aristotle, and other authors we have mentioned. These were so superior to the existing science that, in accord with the spirit of the time, Aristotle and Galen became the bible of biology. The first works were merely commentaries on the writings of these authors, but as time went on more and more new observations were interspersed with the old. In short, the climax of the scientific Renaissance involved a turning away from the authority of Aristotle and an adoption of the Aristotelian method of observation and induction.

Botany was the first to show visible signs of the awakening, probably because of the dependence of medicine on plant products. "All physicians professed to be botanists and every botanist was thought fit to practice medicine." In the HERBaLs published in Germany during the sixteenth century we can trace the evolution of plant description and classification from mere annotations on the text of Dioscorides to well-illustrated manuals of the flora of western Europe. 
During the same century zoölogy made abortive attempts to emerge as a science, but the less immediate utility of the subject, combined with the difficulty of collecting material and therefore the necessity of more dependence on travelers' tales, contributed to retard its advance. One group of naturalists, the ENCYCLOPAEDISTS, so-called from their endeavor to

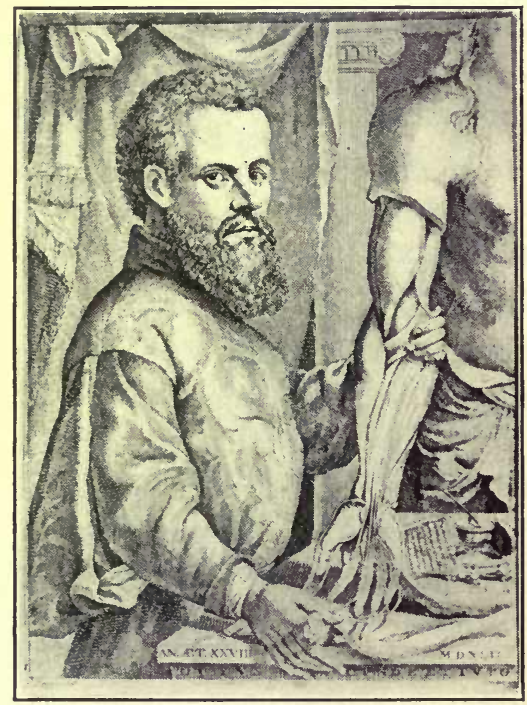

FIG. 197. - Andreas Vesalius.

gather all available information of living things, attempted the impossible. Gleaning from the ancients and adding such materials as they could gather, led to the publication of huge volumes of fact and fiction whose value bore no just proportion to the vast expenditure of labor - even in the case of the best, Gesner's History of Animals.

Although Gesner (1516-1565) of Switzerland was without doubt the most learned naturalist of the period and probably the best zoölogist who had appeared since Aristotle, the direct 
path to progress was blazed by men whose plans were less ambitious. Contemporaries of Gesner, who confined their treatises to special groups of organisms which they themselves investigated, really instituted the biological monograph which has proved to be the effective method of scientific publication.

While the herbalists, encyclopaedists, and monographers at work in natural history were making brave endeavors to develop the powers of independent judgment, which were oppressed to such an extent during the Middle Ages that the very activity of the senses seemed stunted, the emancipator of biology from the traditions of the ancients appeared in the Belgian anatomist, Andreas Vesalius (1514-1564). Disgusted with the anatomy of the time, which consisted almost solely in interpreting the works of Galen by reference to crude dissections made by barbers' assistants, Vesalius attempted to place human anatomy on the firm basis of exact observation. The publication of his great work On the Structure of the Human Body made the year 1543 the dividing line between ancient and modern anatomy, and thenceforth anatomical as well as biological investigation in general broke away from the yoke of authority and men began to trust their own eyes.

The work of Vesalius was on anatomy, and physiology was treated somewhat incidentally. The.complementary work on the functional side came in 1628 with the publication of the epoch-making monograph on the Motion of the Heart and Blood in Animals by William Harvey (1578-1657) of London. No rational conception of the economy of the animal organism was possible under the influence of Galenic physiology, and it remained for Harvey to demonstrate by a series of experiments, logically planned and ingeniously executed, that the blood flows in a circle from heart back to 
heart again, and thus to supply the background for a proper understanding of the dynamics of the organism as a whole. With the work of Vesalius and Harvey, biologists had again laid hold of the great scientific tools - observation,

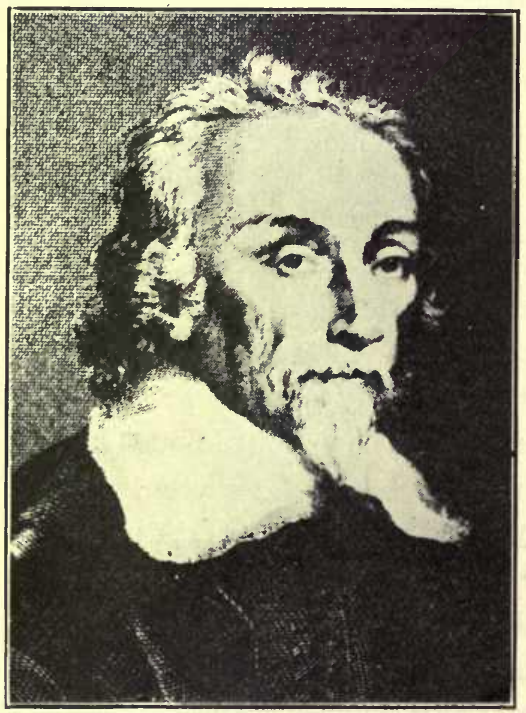

Fıg. 198. - William Harvey.

experiment, and induction - which since then have not slipped from their grasp.

\section{The Microscopists}

Even while the marshalling of accurate descriptions of plants and animals was getting under way, and the study of macroscopic anatomy and physiology was making rapid strides forward, an event occurred which was destined to make possible modern biology. This was an adaptation of the principle of the spectacles - the invention, probably by Roger Bacon, of the simple microscope. Then came the 
compound microscope as a development of the telescope at the hands of Galileo about 1610, and by the middle of the century simple and compound microscopes were being made by opticians in the leading centers of Europe.

The earliest clear appreciation of the importance of studying nature with instruments which increase the powers of the senses in general and of vision in particular is found in

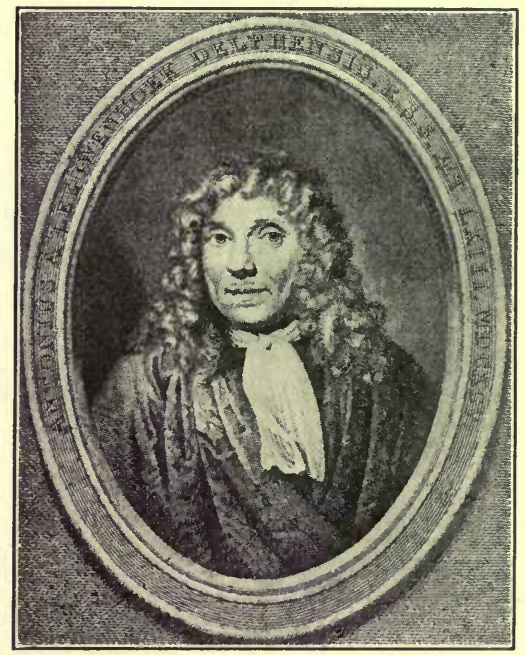

Fra. 199. - Antony van Leeuwenhoek.

a remarkable book, by Hooke (1635-1703) of London, published in 1665. Using his improved compound microscope, Hooke clearly observed and figured for the first time the "little boxes or cells" of organic structure, and his use of the word cell is responsible for its application to the protoplasmic units of modern biology.

Microscopical work was a mere incident among the varied interests of Hooke, while LeEuWENHOEK (1632-1723) of Holland spent a long life studying nearly everything which 
he could bring within the scope of his simple lenses. With an unexplored field before him, all of his observations were discoveries. Bacteria, Protozoa, Hydra, and many other organisms were first revealed by his lenses. But Leeuwenhoek's discovery of the sperm of animals created the most astonishment. His imagination, however, outstripped his observations for he thought he saw evidence of the organism preformed within the sperm and so came to regard it as the true germ which had only to be hatched by the female.

The patience of Leeuwenhoek would have been strained to the breaking point by the studies on insect anatomy made by Swammerdam (1637-1680) of Holland. Instigated largely by the desire to refute the current notion that insects and similar lower animals are without complicated internal organs, Swammerdam spent his life in studies on their structure and life histories. Revealing, as he did, by the most delicate technique in dissection, the finest details observable with his lenses, Swammerdam not only set a standard for minute anatomy which was unsurpassed for a century, but also dissipated for all time the conception of simplicity of structure in the lower animals. He thus, quite naturally, added one more argument to those of the Italian REDI (16261698) and others against spontaneous generation.

Malpighi of Bologna and Grew of London, contemporaries of Hooke, Leeuwenhoek, and Swammerdam, may be considered as the pioneer histologists. GRew (1641-1712) devoted all his attention to plant structure, while MALPIGHI (1628-1694), in addition to botanical studies which paralleled Grew's, made elaborate investigations on animals.

The versatility as well as the genius of Malpighi is shown by his studies on the anatomy of plants, the function of leaves, the development of the plant embryo, the embryology of the chick, the anatomy of the silkworm, and the structure of 
glands. Skilled in anatomy but with prime interest in physiology, his lasting contribution lies in his dependence upon the microscope for the solution of problems where structure and function, so to speak, merge. This is well illustrated by his ocular demonstration of the capillary circulation in the lungs, which is not only his greatest discovery but also the first

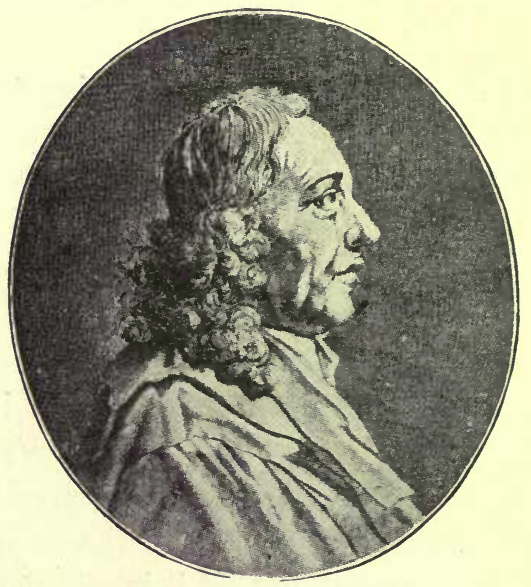

Fıc. 200. - Marcello Malpighi.

of prime importance ever made with a microscope, since it completed Harvey's work on the circulation of blood.

D. The Development of the Subdivisions of Biology The microscopists taken collectively created an epoch in the history of biology, so important is the lens for the advancement of the science. Broadly speaking, we find that its development along many lines during the eighteenth and particularly the nineteenth century went hand in hand with improvements in the compound microscope itself and in microscopical technique. Again, the microscopists in general and Malpighi in particular opened up so many new paths of 
advance that from this period on it is not possible, even in the most general survey, to discuss the development of biology as a whole. The composite picture must be formed by emphasizing and piecing together various lines of work, such as taxonomy, comparative anatomy of animals, embryology, physiology of plants and animals, genetics, and evolution.

\section{Taxonomy}

Taxonomy has as its object the bringing together of organisms which are alike and the separating of those which are unlike; a problem of no mean proportions when a conservative estimate to-day shows upward of a million species of animals and plants - leaving out of account the myriads of forms represented only by fossil remains.

Naturally the earliest classifications were utilitarian or more or less physiological, but as knowledge increased emphasis was shifted to the anatomical criterion of specific differences, and thenceforth classification became an important aspect of natural history - a central thread both practical and theoretical. Practical, in that it involved the arranging of living forms so that a working catalog was made which required nice anatomical discrimination, and therefore the amassing of a large body of facts concerning animals and plants. Theoretical, because in this process botanists and zoölogists were impressed, almost unconsciously at first, with the 'affinity' of various types of animals and plants, and so were led to problems of their origin.

From Aristotle, who emphasized the grouping of organisms on the basis of structural similarities, we must pass over some seventeen centuries, in which the only work of interest was done by the herbalists and encyclopaedists, to the time of RAY (1628-1705) of England and Linnaeus (1707-1778) of Sweden. Previous to Ray the term species was used some- 
what indefinitely, and his chief contribution was to make the word more concrete by applyịng it solely to groups of similar individuals which seem to exhibit constant characters from generation to gezeration. This paved the way for the great taxonomist, Linnaeus.

Linnaeus was first and foremost a botanist who gave plant students at once a practical classification of Flowering Plants,

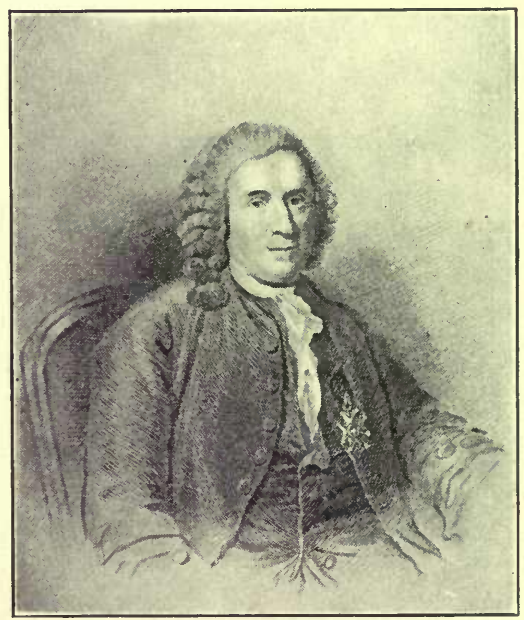

Frg. 201. - Carolus Linnaeus.

based chiefly on the number and arrangement of the stamens; and at the same time insisted on brief descriptions and the scheme of giving each kind of organism a name of two words, generic and specific, thereby establishing the system of BINOMIAL NOMENCLATURE. Linnaeus' success with botanical taxonomy led him to extend the principles to animals and even to the so-called mineral kingdom: the latter showing at a glance his lack of appreciation of any genetic relationship between species. Although the terms genus and species to Linnaeus expressed a transcendental affinity, since he 
believed that species, genera, and even higher groups represented distinct acts of creation, nevertheless his greatest works, the Species Plantarum and Systema Naturae, are of outstanding importance in biological history and by common consent the base line of priority in botanical and zoölogical nomenclature.

\section{Comparative Anatomy}

Owing to the less marked structural differentiation of plants in comparison with animals, plant anatomy lends

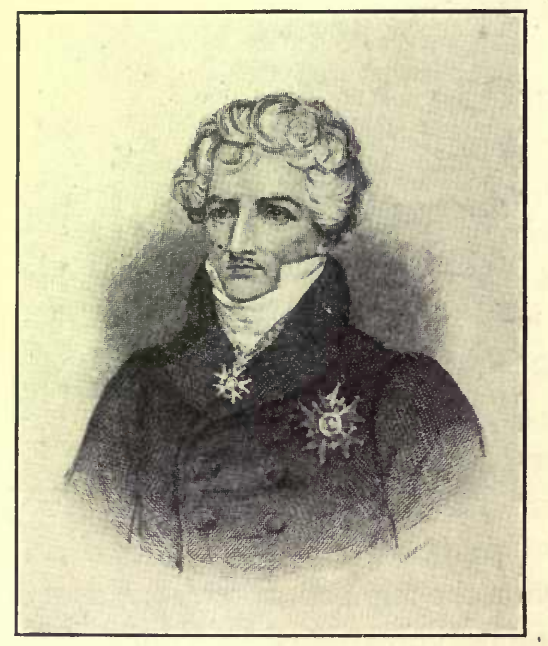

IIG. 202. - Georges Cuvier.

itself less readily to descriptive analysis, so that an epoch in the study of comparative anatomy is not so well defined in botany as in the sister science, zoölogy. Therefore, we shall confine our attention to the comparative anatomy of animals.

Comparative anatomy as a really important aspect of zoölogical work, in fact as a science in itself, was the result of the life-work of Cuvier (1769-1832) of Paris. It is true

$$
\text { In farour with the Court. }
$$


that some of his predecessors had reached a broad viewpoint in anatomical study, but Cuvier's claim to fame rests on the remarkable breadth of his investigations - his grasp of the comparative anatomy of the whole series of animal forms. And not content merely with the living, he made himself the

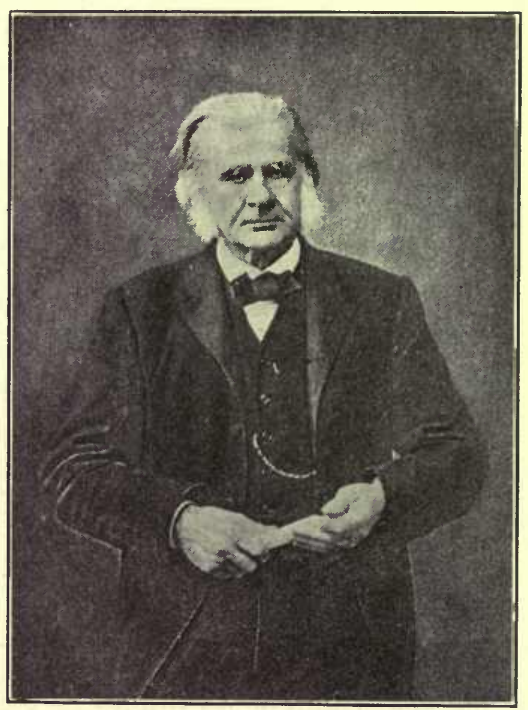

FIg. 203. - Thomas Henry Huxley.

first real master of the anatomy of fossil Vertebrates as was his contemporary, Lamarck, of fossil Invertebrates.

Cuvier's grasp of anatomy was due to his emphasizing, as Aristotle had done before him, the functional unity of the organism: that the interdependence of organs results from the interdependence of function: that structure and function are two aspects of the living machine which go hand in hand. Cuvier's famous principle of correlation - "Give me a tooth," said he, "and I will construct the whole animal" is really an outcome of this viewpoint. Every change of 
function involves a change in structure and, therefore, given extensive knowledge of function and of the interdependence of function and structure, it is possible to infer from the form of one organ that of most of the other organs of an animal. But Cuvier undoubtedly allowed himself to exaggerate his guiding principle until it exceeded the bounds of facts.

Among Cuvier's immediate successors, OwEN (1804-1892) of London perhaps demands special mention. Owen spent a long life dissecting with untiring patience and skill a remarkable series of animal types, as well as reconstructing extinct forms from fossil remains. Aside from the facts accumulated, probably his greatest contribution was making concrete the distinction between homologous and analogous structures, which has been of the first importance in working out the pedigrees of plants as well as of animals; though Owen himself took an enigmatical position in regard to organic evolution - quite different from that of his great English contemporary comparative anatomist, HuXLEY (1825-1895).

\section{Physiology}

The functions of organisms were discussed by Aristotle with his usual insight, though, as might be expected since physiology is more dependent than anatomy upon progress in other branches of science, with less happy results. Similarly Galen was hampered in his attempt to make physiology a distinct department of learning, based on a thorough study of anatomy, and the corner stone of medicine; though fate foisted upon uncritical generations through fifteen centuries his system of human physiology. The worst of it was not that it was nearly all wrong, but that to question Galen's physiology or anatomy became little less than sacrilege until the studies of Vesalius and Harvey brought a realization that Galen had not quite finished the work. 
Neither Vesalius nor Harvey made an attempt to explain the workings of the body by appeal to so-called physical and chemical laws; and for good reason. Chemistry had not yet thrown off the shackles of alchemy and taken its legitimate place among the elect sciences, while during Harvey's lifetime, under the influence of Galileo, the new physics was born. But by the end of the seventeenth century both physics and chemistry had forced their way into physiology and split it into two schools. The physical school was founded by BoreluI (1608-1679) of Italy, who, employing incisive physical methods, attacked a series of problems with brilliant results; while the chemical school developed from the influence of Franciscus Sylvius (1614-1672) of Holland as a teacher rather than as an investigator.

This awakening brought a host of workers into the field and the harvest of the century was garnered and enriched by HALLER (1708-1777) of Geneva. In a comprehensive treatise which at once indicated the erudition and critical judgment of its author, Haller established physiology as a distinct and important branch of biological science. It was no longer a mere adjunct of medicine. Perhaps the most significant advance in Haller's century consisted in setting the physiology of nutrition and of respiration - both of which awaited the work of the chemists - well upon the way toward their modern form.

Reaumur (1683-1757) of Paris and Spallanzani (17291799) of Pavia may be singled out for their exact studies of gastric digestion, which showed solution of the food to be the main factor in digestion - though it was not clear how these changes differ from ordinary chemical ones. It was left for nineteenth-century investigators to establish the fact that food in passing along the digestive tract runs the gauntlet of a series of complex chemical substances, each of which has 
its part to play in putting the various constituents of the food into such a form that they can pass to the various cells of the body where they are actually used.

On the side of respiration, a closer approach was made toward a true understanding of the process. In France LAvoisier (1743-1794) made it clear that the chemical changes taking place in respiration involve essentially a process of combustion, and it only remained for later work to show that this takes place in the tissues rather than in the lungs.

Enough perhaps has been said to indicate the trend of physiology away from the maze of Galenic "spirits" in which science lost itself, toward the modern viewpoint of science which assumes as its working hypothesis that life phenomena are an expression of a complex interaction of physicochemical laws which do not differ fundamentally from the so-called laws operating in the inorganic world, and that the economy of the organism is in accord with the law of the conservation of energy - probably the most far-reaching generalization attained by science during the past century.

Most of the firm foundation on which the physiology of animals rests to-day has been built up by the work on Vertebrates. But since the middle of the nineteenth century, when the versatile MüLLER (1801-1858) of Germany emphasized the value of studying the physiology of higher and lower animals alike, there has been an ever-increasing tendency to focus evidence, in so far as possible, from all forms of life on general problems of function. This has culminated in the science of COMPARATIVE PHYSIOLOGY.

The less obvious structural and functional differentiation of plants retarded progress in plant physiology as it did in plant anatomy. Probably of most historical and certainly of most general interest is the development of our knowledge 
of the nutrition of green plants. Aristotle's notion that the plant's food is prepared for it in the ground was still prevalent during the seventeenth century when Malpighi, from his studies on plant histology, gave the first hint of supreme importance - the crude sap enters by the roots and is carried to the leaves where, by the action of sunlight, evaporation, and some sort of a fermentation, it is elaborated and distributed as food to the plant as a whole.

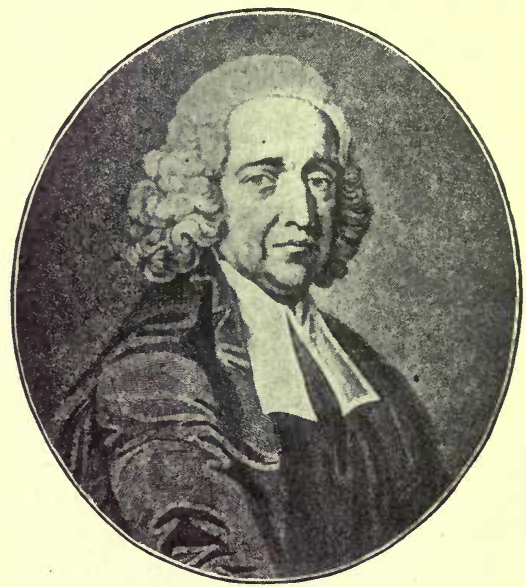

Fra. 204. - Stephen Hales.

It is Stephen Hales (1677-1761) of England, however, to whom the botanist looks as the Harvey of plant physiology, because in his Vegetable Statics (1727) he laid the foundations of the physiology of plants by making "plants speak for themselves" through his incisive experiments. For the first time it became clear that green plants derive a considerable part of their food from the atmosphere, and also that the leaves play an active rôle in the movements of fluids up the stem and in eliminating superfluous water by evaporation. Still the picture was incomplete, and so it 
remained until the biologist had recourse to further data from the chemist. In 1779, Priestley (1733-1804) of England, the discoverer of oxygen, showed that this gas under certain conditions is liberated by plants. This fact was seized upon by a native of Holland, Ingenhousz (17301799), who demonstrated that carbon dioxide from the air is reduced to its component elements in the leaf during exposure to sunlight. The plant retains the carbon and returns the oxygen - this process of carbon-getting being quite distinct from that of respiration in which carbon dioxide is eliminated. It remained then for DE SAUSsure (1767-1845) in Geneva to show that, in addition to the fixation of carbon, the elements of water are also employed, while from the soil various salts, including combinations of nitrogen, are obtained. But it was nearly the middle of the last century before the influence and work of LIEBIG (1803-1873) at Giessen led to a elear realization of the fundamental part played by the chlorophyll of the green leaf in making certain chemical elements available to animals. The establishment of the cosmical function of green plants the link they supply in the circulation of the elements in nature - is a landmark in biological progress.

\section{Histology}

Studies on the physiology of plants and animals naturally involved the progressive analysis of the physical basis of the phenomena under consideration, but the Aristotelian classification of the materials of the body as unorganized substance, homogeneous parts or tissues, and heterogeneous parts or organs, practically represented the level of analysis until the beginning of the eighteenth century. In fact it was not until the revival of interest in embryology early in the last century that the cell became a particular object of 
study, and attention began gradually to shift from more or less superficial details to cell organization. This culminated in the classic investigations of two German biologists, the botanist Schleiden (1804-1881) and the zoölogist ScHwanN (1810-1882), published in 1838 and 1839. Together these studies clearly showed that all organisms are composed of

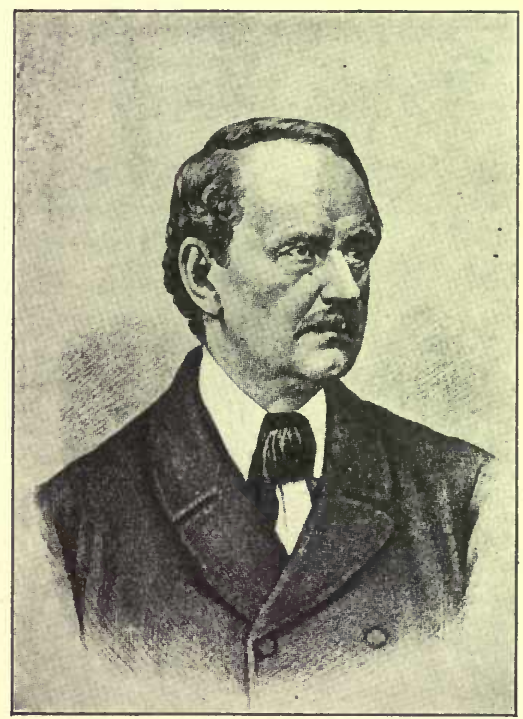

Frg. 205. - Matthias Jacob Schleiden.

units, or cells, which are at once structural entities and the centers of physiological activities. And further that the development of animals and plants consists in the multiplication of an initial cell to form the multitude of different kinds which constitute the adult. Unquestionably the cell concept represents one of the greatest generalizations in biology, and it only needed for its consummation the full realization that the viscid, jelly-like material which zoölo- 
gists interpreted as the true living matter of animals, and the quite similar material which botanists considered the true living part of plants are practically identical. This viewpoint was crystallized in the early sixties by Schultze (18251874) of Germany in the formulation of the protoplasm concept and thenceforth not only morphological elements -

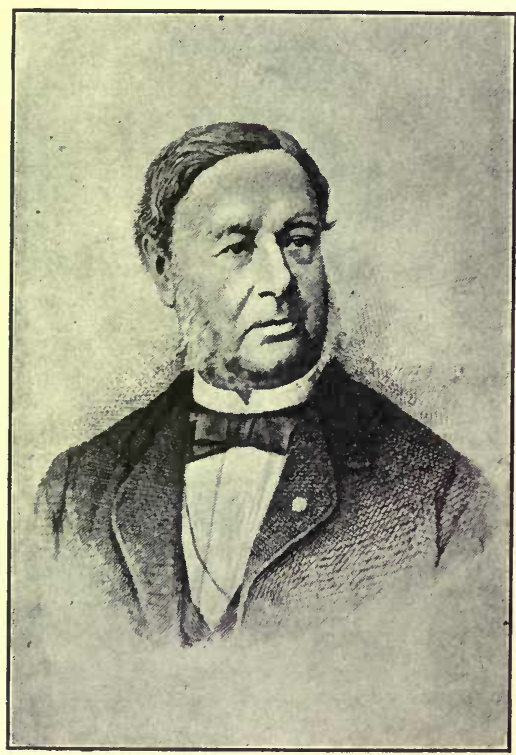

Fig. 206. - Theodor Schwann.

cells - but also the material of which they are composed protoplasm - were recognized as fundamentally the same in all living beings. Indeed, the realization of a common physical basis of life in both plants and animals - a common denominator to which all vital phenomena are reducible gave content to the term biology and created the science of life in its modern form. 


\section{Embryology}

The enunciation of the cell theory came, as we have seen, from combined studies on the adult structure and on the development of plants and animals from the germ or egg, and accordingly implies that the science of embryology has a history of its own. As a matter of fact, Aristotle discussed the wonder of the beating heart in the hen's egg after three days' incubation, but there the subject rested until FABRICIUS (1537-1619) at Padua, early in the seventeenth century, published a treatise which illustrated the obvious sequence of events within the hen's egg to the time of hatching. This beginning was built upon by a pupil of Fabricius, the celebrated Harvey, who added many details of interest, though little progress in embryology was possible without the microscope. This was first turned on the problem by the versatile Malpighi in two treatises published in 1672, and at one step animal development was placed upon a plane so advanced that for over a century it was unappreciated. One conclusion of Malpighi, however, was seized upon by contemporary biologists. Apparently, unbeknown to him, some of the eggs which he studied were slightly incubated, so that he thought traces of the future organism are preformed in the egg. This error contributed to the formulation of the preformation theory, which gradually became the dominant question in embryology.

As a matter of fact the time was not ripe for theories of development. The preformationists were wrong, but so were Aristotle, Harvey, and others who went to the opposite extreme and denied all egg organization and therefore tried to get something out of nothing. It remained, as we know, for the present generation of embryologists to work out many of the details of the origin and organization of the germ cells, 
and to reach a level of analysis deep enough to suggest how "the whole future organism is potentially and materially implicit in the fertilized egg cell" and thus that "the preformationist doctrine had a well-concealed kernel of truth within its thick husk of error."

The next great advance came in the accurate and comprehensive studies of the Russian, von BAER (1792-1876), pub-

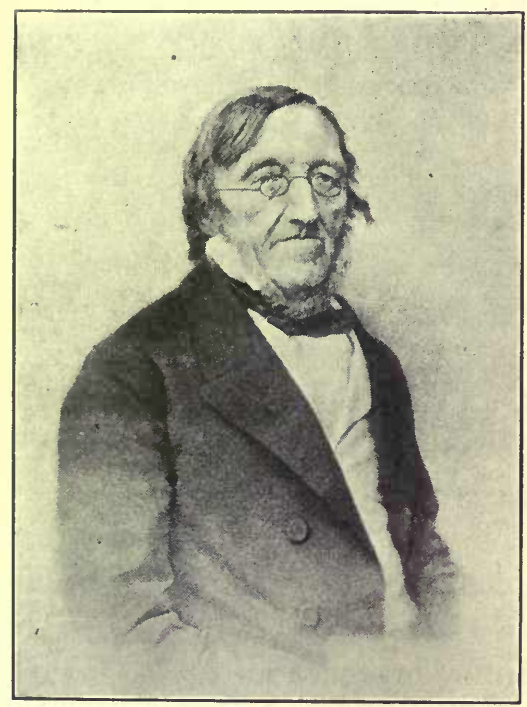

Frg. 207. - Karl Ernst von Baer.

lished in the thirties of the last century. Taking his material from all the chief groups of higher animals, von Baer founded COMPARATIVE EMBRYOLOGY. Among his achievements may be mentioned: the clear discrimination of the chief developmental stages, such as cleavage of the egg, germ layer formation, tissue and organ differentiation; the insistence on the importance of the facts of development for classification; and the discovery of the egg of Mammals. His observations on the 
origin and development of the germ layers, which afforded the key to many general problems of the origin of the bodyform (morphogenesis), and his emphasis on the resemblance of certain embryonic stages of higher animals to the adult stages of lower forms, were crystallized by his successors, under the influence of the evolution theory, as the germ layer theory and the recapitulation theory.

From every point of view von Baer created an epoch in embryology synchronous with the formulation of the cell theory by Schleiden and Schwann, and it thenceforth became the problem of the embryologist to interpret development in terms of the cell. It is unnecessary to follow historically the establishment of the fact that the egg and the sperm are really single nucleated cells; that fertilization consists in the fusion of egg and sperm and the orderly arrangement of their chief nuclear contents, or chromosomes; that the new generation is the fertilized egg, since every cell of the body as well as every chromosome in every cell is a lineal descendant by division from the zygote, and so from the gametes which united at fertilization to form it. Such, however, are the chief results of cytological study since von Baer. But embryologists have not been content to employ merely the descriptive method, and the dominant note of the most modern research is physiological - the experimental study of the significance of fertilization, the dynamics of cell division, the basis of differentiation, the influence of environmental stimuli, and so on.

\section{Genetics}

The study of inheritance could be little more than a groping in the dark until embryology, under the influence of the cell theory, afforded a body of facts which clearly indicated that typically the fertilized egg is the sole bridge of continuity 
between successive generations. Indeed, the present science of genetics has a history largely confined to this century.

Although clearly intimated by a number of workers, the conception of the continuity of the germ cells was first forced upon the attention of biologists and given greater precision by Weismann (1834-1914) of Germany in a series of essays culminating in 1892 in his volume entitled The Germ Plasm. He identified the chromatin material which constitutes the chromosomes of the cell nucleus as the specific bearer of hereditary characters, and emphasized a sharp distinction between germ cells and somatic cells.

While this viewpoint had been gradually gaining content and precision, the science of genetics had been advancing not only by exact studies on the structure and physiology of the germ cells, but also by statistical studies of the results of heredity - the various characters of animals and plants as exhibited in parents and offspring. The studies of this typc which first attracted the attention of biologists were made by GaLton (1822-1911) of England. In the eighties and nineties of the last century, he amassed a great volume of data in regard to, for example, the stature of children with reference to that of their parents, and formulated his well-known 'laws' of inheritance. But the work which eventually created the science of genetics was that of Gregor Mendel (1822-1884) of Austria. Mendel combined in a masterly manner the experimental breeding of pedigree strains of plants and the statistical treatment of the data thus secured in regard to the inheritance of sharply contrasting characters, such as the form and color of the seeds in Peas. Mendel's work was published in 1863 in an obscure natural history periodical, and he abandoned teaching and research to become the Abbot of his monastery. Thus terminated prematurely the productive work of one of the epochmakers of 
biology, and the now famous Mendelian laws of inheritance were unknown to science until 1900 , when other biologists, coming to similar results, unearthed his forty-year-old paper. We have already seen that the fundamental principle of the segregation of the genes of 'alternative' characters in the germ cells, which Mendel's work indicated, has been ex.

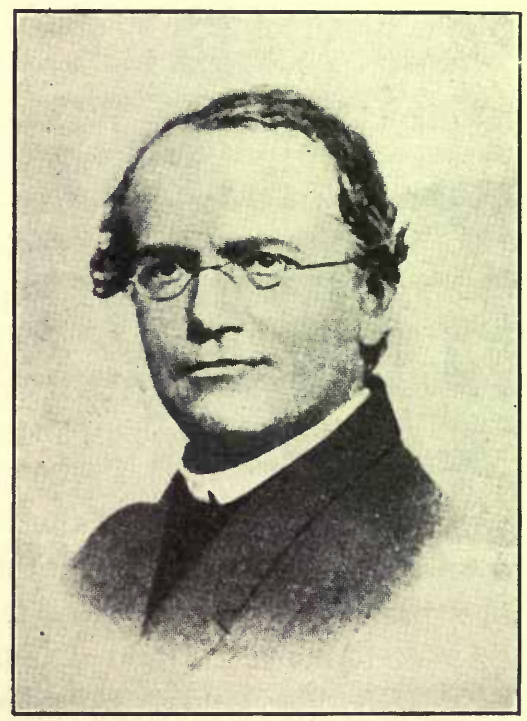

Frg. 208. - Gregor Johann Mendel.

tended to other plants and to animals, and that instead of being, as at first thought, a principle of rather limited application, has come to be the key to all inheritance. And the present results are extremely convincing because cytological studies on the architecture of the chromosome complex of the germ cells keep pace with and afford a picture of the physical basis of inheritance - the mechanism by which the segregation and distribution of characters by the 
Mendelian formula takes place. Such is the deeply hidden modicum of truth in the old preformation theories!

\section{Organic Evolution}

A question which has interested and perplexed thinking men of all times is how things came to be as they are to-day. The historian of human affairs attempts to trace the sequence and relationship of events from the remote past to the present. Similarly, the geologist endeavors to formulate the history of the Earth; and the biologist, the history of plants and animals on the Earth. All recognize that the present is the child of the past and the parent of the future, and that past, present, and future, though causally related, are never the same. It was the Greek natural philosophers who projected this idea of history into science and attempted to substitute a naturalistic explanation of the Earth and its inhabitants for the established theogonies, and thus started the uniformitarian trend of thought which culminated in the establishment of organic evolution during the past century.

Aristotle held substantially the modern idea of the evolution of life from a primordial mass of living matter to the higher forms, and placed Man at the head of animal creation. "To him belongs the God-like nature. He is preëminent by thought and volition. But although all are dwarf-like and incomplete in comparison with Man, he is only the highest point of one continuous ascent." And evolution is still going on - the highest has not yet been attained. In looking for the effective cause of evolution Aristotle rejected the hypothesis of EMPEdocles (495-435 B.c.), which embodied in crude form the idea of the survival of the fittest, and substituted secondary natural laws to account for the apparent design in nature. This was a sound induction by Aristotle from his necessarily limited knowledge of nature, but had he 
accepted the idea of the survival of the fittest to account for adaptations in organisms, he would have been "the literal prophet of Darwinism."

The thread of continuity in evolutionary thought is not broken from Aristotle to the present, but from the strictly biological viewpoint two Frenchmen, Buffon and Lamarck,

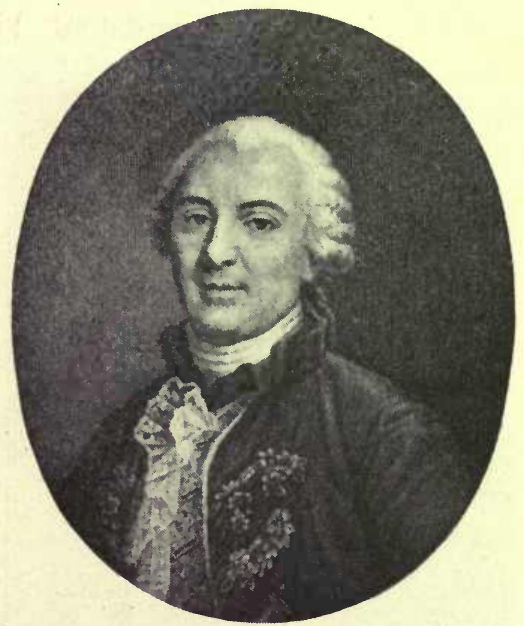

Fra. 209. - Comte de Buffon.

and two Englishmen, Erasmus Darwin and his grandson, Charles Darwin, stand preëminent.

BUFFon (1707-1788) was a peculiarly happy combination of entertainer and scientist who found expression in each new volume of his great Natural History. And it was largely, so to speak, between the lines of this work that Buffon's evolutionary ideas were displayed; beyond the reach, he hoped, of the censor and dilettante. It is not strange, therefore, that it is often difficult to decide just how much weight is to be placed on some of his statements; though certainly it is not exaggerating to ascribe to him not only the recogni- 
tion of the factors of geographical isolation, struggle for existence, artificial and natural selection in the origin of species, but also the propounding of a theory of the origin of variations - that the direct action of the environment brings about alterations in the structure of animals and plants and these are transmitted to the offspring.

When Buffon's influence had passed its zenith, Erasmus DARWIN (1731-1802) expressed consistent views on the

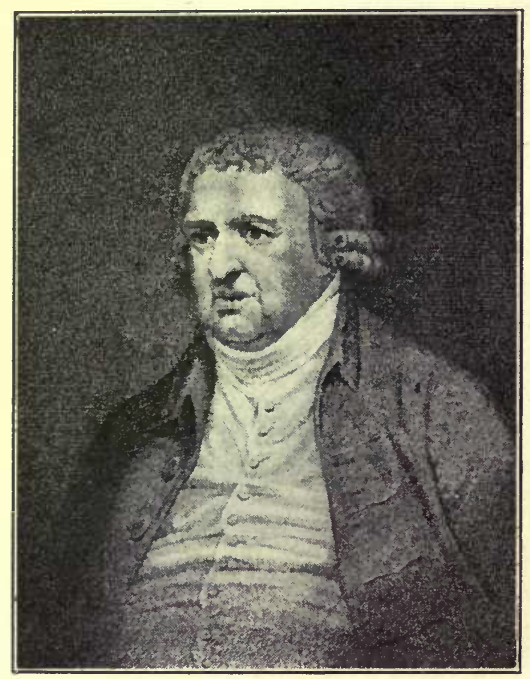

Frg. 210. - Erasmus Darwin.

evolution of organisms, in several volumes of prose and poetry, which lead biologists to-day to recognize him as the anticipator of the Lamarckian doctrine that somatic variations arise through the reaction of the organism to environmental conditions. "All animals undergo transformations which are in part by their own exertions, in response to pleasures, and pain, and many of these acquired forms or propensities are transmitted to their posterity." 
LAMARCK (1744-1829) developed with great care the first complete and logical theory of organic evolution and is the one outstanding figure in biological uniformitarian thought between Aristotle and Charles Darwin. "For nature," he writes, "time is nothing. For all the evolution of the Earth and of living beings, nature needs but three elements, space, time, and matter." In regard to the factors of evolution,

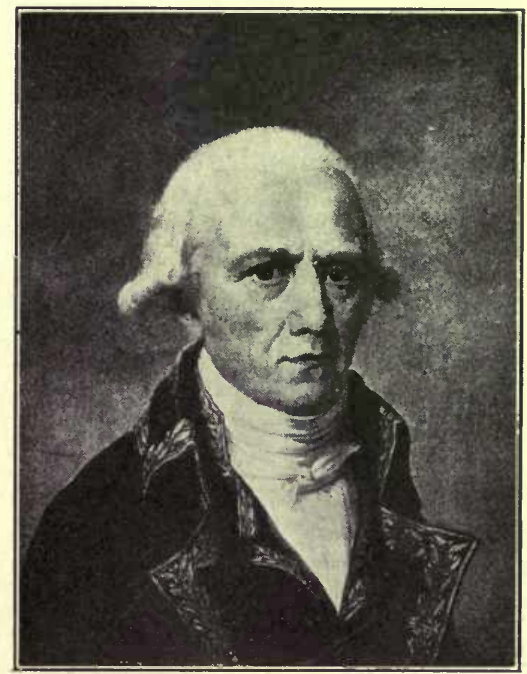

Frg. 211. - Jean-Baptiste Lamarck.

Lamarck put emphasis on the indirect action of the environment in the case of animals, and the direct action in the case of plants. The former are induced to react and so adapt themselves, as it were; while the latter, without a nervous system, are molded directly by their surroundings. And, so Lamarck believed, such changes, somatic in origin acquired characters - are transmitted to the next generation and bring about the evolution of organisms. 
Through the relative weakness of Lamarck's successors the French school of evolutionists dwindled to practical extinction; while in Germany, Gozthe (1749-1832), the greatest poet of evolution, and Treviranus (1776-1837) "brilliantly carried the argument without carrying conviction," for the man and the moment must agree. Then in England the uniformitarian ideas of HuTToN (1726-1797), elaborated by LyELL (1797-1875) in his Principles of Geology (1830-1833), established evolution in geology, and the way was paved for Charles Darwin (1809-1882) to do the same for the organic world. It is true that "the idea of development saturated the intellectual atmosphere - nevertheless the elaborate and toilsome labor of thinking it through for the endless realm of nature was to be done" and Darwin did it in his Origin of Species which appeared in 1859. By his brilliant, scholarly, open-minded, and cautious marshalling of the facts pointing toward the universality of variations and the mutability of species; and by the theory of natural selection on the basis of slight adaptive variations resulting in the survival of the fittest in the struggle for existence - which, strange to say, Darwin and Wallace (1822-1913), reached simultaneously and independently Darwin "made the old idea current intellectual coin."

To-day, as we know, no representative biologist questions the fact of evolution - "evolution knows only one heresy, the denial of continuity" - though in regard to the factors involved there is much difference of opinion. It may well be that we shall have reason to depart widely from Darwin's interpretation of the effective principles at work in the origin of species, but withal this will have little influence on his position in the history of biology. The great value which he placed upon facts was exceeded only by his demonstration that this "value is due to their power of guiding the mind to a 
further discovery of principles." The Origin of Species brought biology into line with the other inductive sciences, recast practically all of its problems, and instituted new ones. Darwin beautifully and conservatively expressed this new outlook on nature in the historically important concluding paragraph of his epoch-making work:

"It is interesting to contemplate a tangled bank, clothed with many plants of many kinds, with birds singing on the bushes, with various insects flitting about, and with worms crawling through the damp earth, and to reflect that these elaborately constructed forms, so different from each other, and dependent upon each other in so complex a manner, have all been produced by laws acting around us. These laws, taken in the largest sense, being Growth with Reproduction; Inheritance which is almost implied by reproduction; Variability from the indirect and direct action of the conditions of life, and from use and disuse: a Ratio of Increase so high as to lead to a Struggle for Life, and as a consequence to Natural Selection, entailing Divergence of Character and the Extinction of less-improved forms. Thus, from the war of nature, from famine and death, the most exalted object which we are capable of conceiving, namely, the production of the higher animals, directly follows. There is a grandeur in this view of life, with its several powers, having been originally breathed by the Creator into a few forms or into one; and that, whilst this planet has gone cycling on according to the fixed law of gravity, from so simple a beginning endless forms most beautiful and most wonderful have been, and are being evolved." 


\section{APPENDIX}

\section{A BRIEF SYNOPTIC CLASSIFICATION OF PLANTS AND ANIMALS}

\section{A. PLANTS}

Phylum 1. THALLOPHYTA: Thallus plants.

Series of the ALGAE. (1500 species.)

Class I. Cyanophyceae: Blue-green Algae. Oscillatoria.

Class II. Chlorophyceae: Green Algae.

Order 1. Protococcales: Unicellular Green Algae. Pleurococcus, Sphaerella.

Order 2. Confervales: Confervas and Sea Lettuces: Ulothrix, Oedogonium, Ulva.

Order 3. Conjugales: Pond Scums, Desmids, and Diatoms. Spirogyra, Closterium, Navicula.

Order 4. Siphonales: Tubular Algae. Vaucheria.

Order 5. Charales: Stoneworts. Chara.

Class III. Phaeophyceae: Brown Algae. Kelps and Rock-

Weeds. Laminaria, Fucus, Sargassum.

Class IV. Rhodophyceae: Red Algae. Rhodomela.

Series of the FUNGI. (65,000 species.)

Class V. Schizomycetes: Bacteria.

Class VI. Phycomycetes: Alga-like Fungi. Molds.

Class VII. Ascomycetes: Sac Fungi. Mildews, Morels, Truffles, Yeasts, (Lichens).

Class VIII. Basidiomycetes: Basidia Fungi. Smuts, Rusts, Toadstools, Mushrooms.

Phylum 2. BRYOPHYTA: Liverworts and Mosses. (17,000 species.)

Class I. Hepaticae: Liverworts. Marchantia. 
Class II. Musci: Mosses.

Order 1. Sphagnales: Peat Mosses. Sphagnum.

Order 2. Bryales: Common Mosses. Polytrichum, Bryum. Phylum 3. PTERIDOPHYTA: Ferns and their allies. (4500 species.)

Class I. Filicineae: Common Ferns and Water Ferns. Aspidium, Marsilia.

Class II. Equisetineae: Horsetails. Equisetum.

Class III. Lycopodineae: Lycopods. Selaginella.

Phylum 4. SPERMATOPHYTA: Seed Plants. Flowering Plants. Subdivision 1. GYMNOSPERMAE: Cycads and Conifers. Pines. (600 species.)

Subdivision 2. ANGIOSPERMAE: The familiar 'flowering plants.'

Class I. Monocotyledoneae: Grasses, Palms, Lilies, Orchids. (25,000 species.)

Class II. Dicotyledoneae: Elms, Buttercups, Pitcher Plants, Roses, Beans, Flax, Cacti, Daisies. (110,000 species.)

\section{B. ANIMALS}

Phylum 1. PROTOZOA. (10,000 species.)

Class I. Sarcodina: Amoeba, the Foraminifera.

Class II. MAstigophora: Flagellates. Euglena, Volvox, Trypanosoma.

Class III. SporozoA: Plasmodium malariae.

Class IV. Infusoria: Paramecium, Vorticella.

Phylum 2. PORIFERA: Sponges. (2500 species.)

Phylum 3. COELENTERATA. (4500 species.)

Class I. Hydrozoa: Hydra, Obelia, Gonionemus.

Class II. ScyphozoA: Jellyfish.

Class III. Anthozon: Sea Anemones, Corals.

Class IV. Ctenophora: Sea Combs.

Phylum 4. PLATYHELMINTHES: Flatworms. (5000 species.)

Class I. Turbellaria: Planaria.

Class II. Trematoda: Liver Flukes.

Class IIf. Cestoda: Tape Worms. 
Phylum 5. NEMATHELMINTHES: Round Worms. Ascaris, Trichina. (1500 species.)

Phylum 6. TROCHELMINTHES: Rotifers. (500 species.)

Phylum 7. MOLLUSCOIDA: Polyzoans and Brachiopods. (2000 species.)

Phylum 8. ECHINODERMATA: (4000 species.)

Class I. Asteroidea: Starfishes.

Class II. Ophiuroidea: Serpent Stars.

Class III. Echinoidea: Sea Urchins.

Class IV. Holothuroidea: Sea Cucumbers.

Class V. Crinoidea: Feather Stars, Sea Lilies.

Phylum 9. ANNELIDA. Segmented Worms. (4000 species.)

Class I. Archiannelida: Polygordius.

Class II. Chaetopoda: Earthworms, Clamworms.

Class III. Hirudinea: Leeches.

Phylum 10. MOLLUSCA. (60,000 species.)

Class I. Lameluibranchiata: Oysters, Clams, Scallops, Shipworm.

Class II. Amphineura: Chiton.

Class III. Gastropoda: Snails.

Class IV. SCaphopoda: Dentalium.

Class V. Cephalopoda: Squid, Octopus, Nautilus.

Phylum 11. ARTHROPODA.

Class I. Crustacea: Barnacles, Crayfishes, Lobsters, Crabs, Trilobites (extinct). (16,000 species.)

Class II. ONychophora: Peripatus.

Class III. Mrriapoda: Centipedes, Millipedes.

Class IV. Insecta: Locusts, Bugs, Flies, Butterflies, Beetles, Ants, Bees, Wasps. (400,000 species.)

Class V. Arachnida: Scorpions, Spiders. (16,000 species.)

Phylum 12. CHORDATA.

Subphylum A. ENTEROPNEUSTA: Dolichoglossus.

Subphylum B. TUNICATA: Tunicates. Cynthia. species.)

Subphylum C. CEPHALOCHORDA: Amphioxus. 
Subphylum D. VERTEBRATA.

Class I. Cyclostomata: Lampreys.

Class II. Elasmobranchir: Sharks. Dogfish. $\}(15,000$

Class III. Pisces: Cod, Trout, Perch. $\}$ species.)

Class IV. Amphibia: Frogs, Toads, Salamanders. (1400 species.)

Class V. Reptilia: Lizards, Snakes, Tortoises, Turtles, Crocodiles, Dinosaurs (extinct). (3500 species.)

Class VI. Aves: Birds. (13,000 species.)

Subclass 1. Archaeornithes: Archaeopteryx (extinct).

Subclass 2. Neornithes.

Division A. Ratitae: Apteryx, Ostrich.

Division B. Carinatae: All familiar birds.

Class VII. Mammalia. (3500 species.)

Subclass 1. Prototheria: Duck-bill, Echidna.

Subclass 2. Metatheria: Opossums, Kangaroos.

Subclass 3. Eutheria: Sloths, Whales, Porpoises, Horses, Tapirs, Camels, Cats, Hedgehogs, Bats, and the Primates including Monkeys, Apes, Man. 


\section{BIBLIOGRAPHY}

Some easily available works in English which are suitable for reference and collateral reading.

\section{CHAPTER I}

Colton, H. S. $\quad$ A List of Selected Readings for Students in Elementary College Zoölogy. University of Pennsylvania, 1915.

Gregory, R. A. Discovery, or the Spirit of Service of Science. The Macmillan Co., 1919.

Henderson, I. F. and Henderson, W. D. A Dictionary of Scientific Terms: Pronunciation, Derivation, and Definition of Terms in Biology, Botany, Zoology, Anatomy, Cytology, Embryology, Physiology. Oliver \& Boyd, 1920.

Huxuey, T. H. "Educational Value of the Natural History Sciences." Collected Essays, Vol. Science and Education. D. Appleton \& Co.

Huxuey, T. H. "On our Knowledge of the Causes of the Phenomena of Organic Nature." Collected Essays, Vol. Darwiniana.

Huxuex, T. H. "On the Study of Biology." Collected Essays, Vol. Science and Education.

Mulls, John. Realities of Modern Science. Introduction for the Modern Reader. The Macmillan Co., 1919.

Pearson, Karl. The Grammar of Science. 3d edition. A. \& C. Black, 1911.

SANFORD, Fernando. The Scientific Method: Its History and Its Value. The Macmillan Co., 1921.

Thомson, J. A. An Introduction to Scrence. H. Holt \& Co., 1911.

Westaway, F. W. Scientific Method. Blackie \& Son, 1912. 


\section{CHAPTER II}

Bayliss, W. M. Principles of General Physiology. 3d Edition. Longmans, Green \& Co., 1921.

Euler, Hans. General Chemistry of the Enzymes. John Wiley \& Sons, 1912.

Harrow, Benjamin. Vitamines: Essential Food Factors. E. P. Dutton \& Co., 1921.

Huxley, T. H. " "On the Physical Basis of Life." Collected Essays, Vol. Method and Results. D. Appleton \& Co.

Loeb, Jacques. The Dynamics of Living Matter. Columbia University Press, 1906.

Sherman, H. C. Chemistry of Food and Nutrition. 2d Edition. The Macmillan Co., 1918.

Slosson, E. E. Creative Chemistry. The Century Co., 1920.

TAYlor, W. W. The Chemistry of Colloids and some Technical Applications. Longmans, Green \& Co., 1915.

Underhill, F. P. Physiology of the Amino Acids. Yale University Press, 1915.

\section{CHAPTER III}

Agar, W. E. Cytology, with Special Reference to the Metazoan Nucleus. The Macmillan Co., 1920.

Doncaster, L. An Introduction to the Study of Cytology. Cambridge Univ́ersity Press, 1920.

Sharp, L. W. Introduction to Cytology. McGraw-Hill Book Co., 1921.

Thompson, D'Arcy W. On Growth and Form. Cambridge University Press, 1917.

Wilson, E. B. The Cell in Development and Inheritance. Columbia University Press, 1900:

\section{CHAPTER IV}

Dendy, Arthur. Outlines of Evolutionary Biology. D. Appleton \& Co., 1911.

Duggar, B. M. Plant Physiology, with Special Reference to Plant Production. The Macmillan Co., 1911. 
Ganong, W. F. Textbook of Botany for Colleges. The Macmillan Co., 1917.

Peebles, Florence. "Life History of Sphaerella lacustris." Centralblatt für Bakteriologie, 1909.

Thatcher, R. W. The Chemistry of Plant Life. McGraw-Hill Book Co., 1921.

\section{CHAPTER V}

Calkins, G. N. Protozoölogy. Lea and Febiger, 1909.

Huxley, T. H. "On the Border Territory between the Animal and Vegetable Kingdoms." Collected Essays, Vol. Discourses Biological and Geological.

Minchin, E. A. Introduction to the Study of the Protozoa. Arnold, 1912.

Sedgwick, W. T. and Wilson, E. B. General Biology. Henry Holt \& Co., 1895.

\section{CHAPTER VI}

Buchanan, E. D. and Buchanan, R. E. Bacteriology. Revised Edition. The Macmillan Co., 1921.

Frost, W. D. and McCampbell, E. F. Textbook of General Bacteriology. The Macmillan Co., 1910.

Muir, Robert and Ritchie, James. Manual of Bacteriology. 4th Edition. The Macmillan Co., 1907.

\section{CHAPTER VII}

Büнm, A. A. and von Davidoff, M. A Textbook of Histology, Including Microscopic Technic. Edited by G. Carl Huber. 2d Edition. W. B. Saunders Co. 1914.

Chamberlain, C. J. Methods in Plant Histology. 3d edition. University of Chicago Press, 1915 ,

Dahlgren, Ulric and Kepner, W. A. Principles of Animal Histology. The Macmillan Co., 1908.

Guxer, M. F. Animal Micrology. Practical Exercises in Zoological Micro-technique. 2d edition. University of Chicago Press, 1917.

Kellicott, W. E. General Embryology. H. Holt \& Co., 1913. 
Stevens, W. C. Plant Anatomy from the Standpoint of the Development and Functions of the Tissues. P. Blakiston's Sons \& Co., 1911.

\section{CHAPTERS VIII and IX}

Bergen, J. Y. and Caldwell, O. W. Practical Botany. Ginn \& Co., 1911.

Bergen, J. Y. and Davis, B. M. Principles of Botany. Ginn \& Co., 1906.

Campbell, D. H. A University Textbook of Botany. The Macmillan Co., 1907.

Coulter, J. G. Plant Life and Plant Uses. American Book Co., 1913.

Coulter, J. M. The Evolution of Sex in Plants. University of Chicago Press, 1914.

Coulter, J. M., Barnes, C. R. and Cowles, H. C. Textbook of Botany. American Book Co., 1910.

Densmore, H. D. General Botany. Ginn \& Co., 1920.

GAGER, C. S. Fundamentals of Botany. P. Blakiston's Son \& Co, 1916.

Ganong, W. F. Textbook of Botany for Colleges. The Macmillan Co., 1917.

Gray, Asa. Manual of Botany. 7th edition. American Book Co., 1908.

Strasburger's Textbook of Botany. 5th English Edition. The Macmillan Co., 1921.

\section{CHAPTERS X-XV}

Beddard; F. E. Earthworms and their Allies. Cambridge University Press, 1901.

Cambridge Natural History. Ten volumes. S. F. Harmer and A. E. Shipley, Editors. The Macmillan Co., 1895.

Conn, H. W. and Budington, R. A. Physiology and Hygiene. Silver, Burdett \& Co., 1909.

Drew, G. A. Invertebrate Zoölogy. 3d edition, revised. W. B. Saunders Co., 1920. 
Hegner, R. W. Introduction to Zoölogy. The Macmillan Co., 1913.

Hegner, R. W. College Zoology. The Macmillan Co., 1914.

Holmes, S. J. Biology of the Frog. The Macmillan Co., 1914.

Hough, T. and Sedgwick, W. T. The Human Mechanism. Revised edition. Ginn \& Co., 1918.

Howell, W. H. Textbook of Physiology. W. B. Saunders Co., 7th edition. 1920.

Huxley, T. H. The Crayfish. 1880.

Huxley, T. H. Lessons in Elementary Physiology. 6th edition. The Macmillan Co., 1915.

Hyman, L. H. A Laboratory Manual for Comparative Vertebrate Anatomy. University of Chicago Press, 1922.

Keith, Arthur. The Engine of the Human Body. J. B. Lippincott Co., 1920.

Kingsley, J. S. Comparative Anatomy. P. Blakiston's Sons \& Co., 1912.

KingsLey, J. S. Vertebrate Zoology. H. Holt \& Co., 1899.

LANkester, E. R. (editor), Treatise on Zoology. Eight volumes. The Macmillan Co.

Lillie, F. R. "The Free-Martin; A Study of the Action of Sex Hormones in the Foetal Life of Cattle." Jour. Exp. Zool., Vol. $23,1917$.

Linville, H. R. and Kelly, H. A. Textbook in General Zoology. Ginn \& Co., 1906.

Marshall, F. H. A. The Physiology of Reproduction. Longmans, Green \& Co., 1910.

Martin, H. N. The Human Body. 10th edition. H. Holt \& Co., 1917.

Newman, H. H. Vertebrate Zoology. The Macmillan Co., 1920. Osborn, Herbert. Economic Zoology. An Introductory Textbook in Zoology. The Macmillan Co., 1912.

Parker, G. H. The Elementary Nervous System. J. B. Lippincott Co., 1919.

Parker, T. J. and Haswell, W. A. Textbook of Zoology. 3d edition. The Macmillan Co., 1922. 
Petrunkevitch, Alexander. Morphology of Invertebrate Types. The Macmillan Co., 1916.

Pratt, H. S. A Manual of the Common Invertebrate Animals, Exclusive of Insects. A. C. McClurg \& Co., 1916.

Reynolds, S. H. The Vertebrate Skeleton. 2d edition. Cambridge University Press, 1913.

Shipley, A. E. and MacBride, E. W. Zoology. The Macmillan Co., 1901.

Walter, H. E. The Human Skeleton. The Macmillan Co., 1918. WARD, H. B. and Whipple, G. C. Fresh-Water Biology. John Wiley \& Sons, 1918.

Wilder, H. H. History of the Human Body. H. Holt \& Co., 1909.

\section{CHAPTER XVI}

Calkins, G. N. Biology. H. Holt \& Co., 1917.

Child, C. M. Senescence and Rejuvenescence. University of Chicago Press, 1915.

Conklin, E. G. Localization of Morphogenetic Substances in the Egg. J. B. Lippincott Co., 1922.

Driesch, Hans. Science and Philosophy of the Organism. Gifford Lectures, 1907-08. A. \& C. Black.

Geddes, P. and Thomson, J. A. Sex. H. Holt \& Co., 1914.

Hegner, R. W. The Germ-cell Cycle in Animals. The Macmillan Co., 1914.

Huxley, T. H. "Biogenesis and Abiogenesis." Collected Essays, Vol. Discourses Biological and Geological.

Jennings, H. S. Life and Death, Heredity and Evolution in Unicellular Organisms. Gorham Press, 1920.

Kellicott, W. E. Chordate Development. H. Holt \& Co., 1913. Lillie, F. R. Problems of Fertilization. University of Chicago Press, 1919.

Morgan, T. H. Regeneration. Columbia University Press, 1901. Weismann, August. The Germ Plasm. Chas. Scribner's Sons, 1892. Wirson, E. B. "The Problem of Development." Science, 1905. Woodrufr, L. L. "The Origin of Life," in the Evolution of the 
Earth and its Inhabitants, R. S. Lull, editor. 3d edition. Yale University Press, 1922.

\section{CHAPTER XVII}

Babcock, E. B. and Clausen, R. E. Genetics in Relation to Agriculture. MeGraw-Hill Book Co., 1918.

Bateson, William. Materials for the Study of Variation. The Macmillan Co., 1894.

Bateson, William. Problems of Genetics. Yale University Press, 1913.

Castle, W. E. Genetics and Eugenics. Revised edition. Harvard University Press, 1921.

Conkuin, E. G. Heredity and Environment in the Development of Men. 4th edition. Princeton University Press, 1922.

Coulter, J. M. and Coulter, M. C. Plant Genetics. University of Chicago Press, 1918.

Cunningham, J. T. Hormones and Heredity. The Macmillan Company, 1922.

Davenport, C. B. Heredity in Relation to Eugenics. H. Holt \& Co., 1911.

East, E. M. and Jones, D. F. Inbreeding and Outbreeding; their Genetic and Sociological Significance. J. B. Lippincott Co., 1919. Galton, Francis. Natural Inheritance. 1889.

Goddard, H. H. The Kallikak Family. A Study in the Heredity of Feeble-mindedness. The Macmillan Co., 1912.

Guyer, M. F. Being Well-born. Bobbs Merrill Co., 1916. Jennings, H. S. "Heredity and Personality." Science, 1911. Kellicotr, W. E. The Social Direction of Human Evolution. D. Appleton \& Co., 1911.

Morgan, T. H. Heredity and Sex. Columbia University Press, 1913. Morgan, T. H. The Physical Basis of Heredity. J. B. Lippincott \& Co., 1919.

Mотт, F. W. Nature and Nurture in Mental Development. London, 1914.

Pearl, Raymond. Modes of Research in Genetics. The Macmillan Co., 1915. 
Popenoe, P. and Johnson, R. H. Applied Eugenics. The Macmillan Co., 1918.

Punnett, R. C. Mendelism. 6th edition. The Macmillan Co., 1919. Thomson, J. A. Heredity. 2d edition. Henry Holt \& Co., 1916. Walter, H. E. Genetics. 2d edition. The Macmillan Co., 1922.

\section{CHAPTER XVIII}

Adams, C. C. A Guide to the Study of Animal Ecology. The Macmillan Co., 1913.

Cameron, E. H. Psychology and the School. The Century Co., 1921.

Chandere, A. C. Animal Parasites and Human Disease. John Wiley \& Sons, 1918.

Cheshire, F. R. Bees and Bee-Keeping. London, 1886.

Crile, G. W. Man-An Adaptive Mechanism. The Macmillan Co., 1916.

Darwin, Charles. The Fertilization of Orchids. The Various Contrivances by which Orchids are Fertilized by Insects. 1862 . HaLdane, J. S. Organism and Environment. Yale University Press, 1917.

Henderson, L. J. The Fitness of the Environment. The Macmillan Co., 1913.

Henderson, L. J. The Order of Nature. Harvard University Press, 1917.

Holmes, S. J. The Evolution of Animal Intelligence. H. Holt \& Co., 1911.

Jeñnings, H. S. Behavior of the Lower Organisms. Columbia University Press, 1906.

LLoyd, R. E. What is Adaptation? Longmans, Green and Co., 1914.

Loeb, JACques. The Organism as a Whole. New York, 1916. Loeb, JACQUes. Forced Movements, Tropisms, and Animal Conduct. J. B. Lippincott, 1918.

Longley, W. H. "Studies upon the Biological Significance of Animal Coloration." I. Journ. of Exper. Zoology, Vol. 23, 1917. II. American Naturalist, Vol. 51, 1917. 
Mace, H. A Book about the Bee. E. P. Dutton \& Co., 1921.

Morgan, T. H. Evolution and Adaptation. The Macmillan Co., 1903.

Needham, J. G. and Lloyd, J. T. Life of Inland Waters. Comstock Publishing Co., 1916.

Roosevelt, Theodore. "Revealing and Concealing Coloration in the Birds and Mammals." Bull. Amer. Museum Nat. Hist., XXX, 1911.

Sumner, F. B. "Adaptation and the Problem of 'Organic Purposefulness." ' American Naturalist, 1919.

Symposium on Adaptation. Papers by M. M. Metcalf, B. E. Livingston; G. H. Parker, A. P. Mathews and I. J. Henderson. American Naturalist, Vol. 47, 1913.

Thayer, G. H. Concealing Coloration in the Animal Kingdom. The Macmillan Co., 1909.

Tromson, J. A. The Study of Animal Life. 4th edition. John Murray, 1917.

Thomson, J. A. The System of Animate Nature. H. Holt \& Co., 1920.

Van Beneden, P. J. Animal Parasites and Messmates. D. Appleton \& Co., 1876.

Washburn, M. F. The Animal Mind. A Textbook of Comparative Psychology. The Macmillan Co., 2d edition, 1917.

Zinsser, Hans. Infection and Resistance, $2 \mathrm{~d}$ edition. The Macmillan Co., 1918.

\section{CHAPTER XIX}

Allen, J. A. "The Geographical Distribution of Mammals." Bulletin U. S. Geological Survey, 1878.

BARRELl, Joseph. "The Origin of the Earth," in the Evolution of the Earth and its Inhabitants. R. S. Lull, editor. 3d edition. Yale University Press, 1922.

Bergson, Henri. Creative Evolution. English translation, 1911. Campbell, D. H. Plant Life and Evolution. H. Holt \& Co., 1911. Conklin, E. G. Direction of Human Evolution. Chas. Scribner's Sons, 1921. 
Crampton, H. E. The Doctrine of Evolution, its Basis and its Scope. Columbia University Press, 1911.

Darwin, Charles. Voyage of the Beagle. (A Naturalist's Voyage.) London, 1839.

Darwin, Charles. The Origin of Species. London, 1859. 6th edition, 1880.

Darwin, Charles. The Descent of Man. London, 1871.

Darwin, Charles. Variation in Animals and Plants under Domes. tication. London, 1868.

Fifty Years of Darwinism: Modern Aspects of Evolution. Centennial Addresses in honor of Charles Darwin before the American Association for the Advancement of Science, 1909.

Gadow, Hans. The Wanderings of Animals. Cambridge University Press, 1913.

Geddes, P. and Thomson, J. A. Evolution. H. Holt \& Co., 1911. Hardy, M. E. An Introduction to Plant Geography. Oxford University Press, 1913.

Holmes, S. J. The Trend of the Race. Harcourt, Brace \& Co., 1921.

Johnstone, James. The Philosophy of Biology. Cambridge University Press, 1914.

Jordan, D. S. and Kellogg, V. L. Evolution and Animal Life. D. Appleton \& Co., 1907.

Kellogg, V. L. Darwinism To-day. H. Holt \& Co., 1907.

Lull, R. S. Organic Evolution. The Macmillan Co., 1917.

Newman, H. H. Readings in Evolution, Genetics, and Eugenics. University of Chicago Press, 1921.

Nuttall, G. H. F. Blood Immunity and Blood Relationships. Cambridge University Press, 1904.

Osborn, H. F. The Origin and Evolution of Life. Chas. Scribner's Sons, 1917.

Reichert, E. T. and Brown, A. P. "The Differentiation and Specificity of Corresponding Proteins and Other Vital Substances in Relation to Biological Classification and Organic Evolution. The Crystallography of Hemoglobins." Carnegie Institution of Washington, Publication 116, 1909. 
Schuchert, Charles. "The Earth's Changing Surface and Climate," in the Evolution of the Earth and its Inhabitants, R. S. Lull, editor. 3d edition. Yale University Press, 1922.

Scotr, W. D. The Theory of Evolution. The Macmillan Co., 1911. DeVries, Hugo. Species and Varieties. Their Origin by Mutation. 3d edition. Open Court Publishing Co., 1912.

Wallace, A. R. Darwinism. 3d edition, The Macmillan Co., 1905.

Wallace, A. R. The Geographical Distribution of Animals. London, 1876.

Wallace, A. R. Island Life. 2d edition, The Macmillan Co., 1892.

Wells, H. G. The Outline of History, Chapters I-XII. The Macmillan Co., 1920.

Yale Sigma Xi Lectures: Evolution of the Earth and its Inhabitants, 3d edition, 1922; Evolution of Man, 1922. Yale University Press.

\section{CHAPTER XX}

Butler, Samuel. Evolution Old and New. Revised edition, E. P. Dutton \& Co., 1911.

Foster, Michael. History of Physiology during the 16th, 17th, and 18th Centuries. Cambridge University Press, 1901.

Garrison, F. H. History of Medicine. 3d edition. W. B. Saunders Co., 1921.

Green, J. R. History of Botany, 1860-1900. Oxford University Press, 1909.

Huxuey, T. H. "The Progress of Science, 1837-1887." Collected Essays, Vol. Methods and Results. D. Appleton \& Co.

Judd, J. W. The Coming of Evolution. The Story of a Great Revolution in Science. Cambridge University Press, 1910.

Locy, W. A. Biology and Its Makers. 3d edition. H. Holt \& Co., 1915.

Merz, J. T. History of Scientific Thought in the Nineteenth Century. W. Blackwood \& Sons, 1903-1914.

Miali, L. C. History of Biology. G. P. Putnam's Sons, 1911. 
Ossorn, H. F. From the Greeks to Darwin. An Outline of the Development of the Evolution Idea. Columbia University Press, 1894.

von Sachs, Julius. History of Botany, 1530-1860. (English translation.) Oxford University Press, 1890.

Thompson, D'Arcy W. On Aristotle as a Biologist. Oxford University Press, 1913.

Thomson, J. A. The Science of Life. An Outline of the History of Biology. Blackie \& Son, Ltd., 1900.

White, A. D. A History of the Warfare of Science with Theology. D. Appleton \& Co., 1896.

Woodward, H. B. History of Geology. G. P. Putnam's Sons, 1911.

Yale Gamma Alpha Lectures: History of the Sciences. Yale University Press, 1922. 


\section{GLOSSARY}

Abiogenesis. The abandoned idea that living matter may arise from non-living without the influence of the former. See Biogenesis.

Absorption. The passage of nutritive and other fluids into living cells.

Acoelomate. Not possessing a coelom, or body cavity. E.g., Hydra. Acquired Character. A modification of body structure or function which arises during individual life as a result of environmental influences.

Adaptation. The reciprocal fitness of organism and environment; a structure or reaction fitted for a special environment; the process by which an organism becomes fitted to its surroundings. Adrenals. Suprarenal bodies. Ductless glands situated near the kidneys. Secretion supplies a hormone known as adrenin. Adventitious. Not in the usual position, e.g., aerial roots. Aerobe. An organism requiring free oxygen. See Anaerobe. Afferent Root. Dorsal, or posterior, root of certain cranial and all spinal nerves through which sensory nerve impulses enter the brain and spinal cord. See Efferent Root.

Algae. A heterogeneous group of lower plants in which the body is unicellular or consists of a thallus; e.g., Sphaerella, Spirogyra, Seaweeds.

Alimentary Canal. The digestive tract.

Allelomorphs. Genes similarly situated on homologous chromosomes which produce 'alternative,' or 'contrasting,' characters. Alternative Inheritance. Typical Mendelian inheritance.

Amino AcID. Components of proteins. Organic acids in which one hydrogen atom is replaced by the amino group $\left(\mathrm{NH}_{2}\right)$. Monoamino acids, e.g., Glycine $\left(\mathrm{CH}_{2} \mathrm{NH}_{2} \cdot \mathrm{COOH}\right)$. Diamino acids, e.g., Lysine $\left(\mathrm{H}_{2} \mathrm{NCH}_{2} \cdot \mathrm{CH}_{2} \cdot \mathrm{CH}_{2} \cdot \mathrm{CH}_{2} \cdot \mathrm{CHNH}_{2} \cdot \mathrm{COOH}\right)$. 
Амоввогd. Usually applied to the flowing movements of a cell, as in the Protozoön, Amoeba.

Aмphimixis. The mingling of the germ plasm of two gametes in the zygote.

Anabolism. The constructive phase of metabolism. See Katabolism.

Anaerobe. An organism not requiring free oxygen; e.g., certain Bacteria and parasitic Worms. See Aerobe.

ANAlogy. Structural resemblance due to similarity of function. See Homology.

ANaphase. Period in mitosis during which the daughter chromosomes move toward the respective centrosomes. See Telophase. Anatomy. The structure of organisms, especially as revealed by dissection.

Anther. The part of the stamen which contains the pollen sacs (microsporangia) in Flowering Plants.

Antheridium. The organ in plants, such as the Mosses and Ferns, in which the male gametes arise.

Avus. Terminal orifice of the alimentary canal. Opening of the large intestine either on the surface of the body (Man) or into the cloaca (Frog).

Aorta. A great trunk artery carrying blood away from the heart. See Dorsal Aorta.

Aortic Arches. Arteries arising from the ventral aorta and supplying the gills in aquatic Vertebrates. Undergo many modifications in the ascending series of air-breathing Vertebrates. ApHIDs. Small sucking Insects; e.g., the green 'Plant Lice' of garden shrubs.

Archegonium. The organ in plants, such as the Mosses and Ferns, in which the female gamete (egg) arises.

Arthropoda. Phylum of Invertebrates. Includes the Crustacea, Insecta, Arachnida, etc.

Aster. Radiations surrounding the centrosome during cell division.

Atavism. Appearance of grandparental characters in an individual. See Reversion. 
Autonomic System. System of outlying ganglia and nerves which communicates with the central nervous system via the roots of the spinal and cranial nerves. Innervates chiefly the involuntary muscles of blood vessels, digestive organs, etc. Sympathetic system.

Axon. A nerve fiber conducting impulses away from the cell body.

Dendrites conduct toward the cell body. See Neuron.

BAST. The phloem portion of a vascular bundle.

Biennial. A plant which completes its life history in two years, usually reproducing in the second.

Bile Duct. Tube which conveys the secretions (bile) of the liver to the small intestine. Usually unites with the pancreatic duct to form a common duct which enters the intestine.

Binary Fission. The division of a cell, especially a unicellular organism, into two daughter cells; e.g., in Paramecium.

Binomial Nomenclature. The accepted scientific method of designating organisms by two Latin or Latinized words, the first indicating the genus and the other, the species. E.g., the Dog, Canis familiaris; Man, Homo sapiens.

Brogenesis. The established doctrine that all life arises from preexisting living matter. See Abiogenesis.

Bıology. The study of the manifestations of matter in the living state.

Biparental. Derived from two progenitors, male and female, e.g., in sexual reproduction. See Uniparental.

Blastocoel. The cavity within the blastula. Segmentation cavity. BLASTOPORE. The opening to the exterior from the enteric pouch of a gastrula.

Blastula. The stage following cleavage when the cells are arranged in a single layer to form a hollow sphere.

BLENding Inheritance. Apparent fusion of parental characters in the offspring so that a more or less intermediate condition arises. E.g., skin color of mulattoes.

Blood Corpuscles. Detached cells present in the fluid plasma of the blood. Two principal kinds, red and white.

Buccal Cavity. Mouth cavity. 
BuD. Growing point of shoot. An undeveloped branch. Leaf buds form stem and leaves; mixed buds, both leaves and flowers; flower buds, flowers only.

Calciferous Glands. Glands opening into the oesophagus of the Earthworm which secrete calcium carbonate, probably to neutralize acidity of food.

Calyx. The outer whorl of modified leaves composing a typical flower. Usually green.

CAmbium. Layer of actively dividing cells which, in the highest Flowering Plants, is situated between xylem and phloem of vascular bundles, and forms a thin cylinder between wood and bark.

Carbohydrates. Compounds of carbon with hydrogen and oxygen, the hydrogen and oxygen being in the same proportion as in water $\left(\mathrm{H}_{2} \mathrm{O}\right)$.

CARPEL. One of the innermost whorl of floral leaves which bear the megaspores. A simple pistil or an element of a compound pistil. A megasporophyll.

CATALYsis. The acceleration of a chemical reaction by a substance which itself remains unchanged (e.g., an enzyme).

CELL. A structural and physiological unit mass of protoplasm, differentiated into cytoplasm and nucleus.

Cell SaP. Water, with solutes, under pressure in a large vacuole in the cytoplasm of certain types of plant cells. Effects cell turgor.

Cellulose. A carbohydrate which characteristically forms the walls of plant cells.

Centrosome. A minute body situated in the center of the aster and active during cell division.

Cheliped. The first thoracic appendages, or walking-legs, in the Crayfish and its allies. The 'pincer.'

Chemosynthesis. Manufacture (synthesis) of food material from water and carbon dioxide, through energy derived from chemical changes involving oxidation instead of directly from sunlight. Restricted to special groups of Bacteria.

Chemotaxis. Movements of cells (e.g., Paramecium) in response to chemical stimuli. 
Chlorenchyma. The chlorophyll-bearing tissue of plants.

Chlorophyll. The characteristic green coloring matter of plants through which photosynthesis takes place.

Chioroplastid. The special protoplasmic bodies in which chlorophyll, or functionally similar pigments, resides.

Chordate. An animal whose primary axial skeleton consists temporarily or permanently of a notochord. All Vertebrates are Chordates.

Chromatin. A deeply staining substance characteristic of the nucleus, forming chromosomes, etc. See Germ Plasm.

Chromomere. A chromatin granule of the linear series which constitute a chromosome.

Chromosome. One of the deeply staining bodies into which the chromatic network of the nucleus becomes visibly resolved during mitosis. See Germ Plasm.

Cinia. Delicate protoplasmic projections from a cell, which lash in unison and propel the cell in the water (e.g., Paramecium), or move particles over the cell surface (e.g., cells lining various tubes in multicellular forms).

Class. In classification, a main subdivision of a phylum. See Order.

Cleavage. The divisions which transform the egg into the blastula stage during development.

Cloaca. A cavity at the posterior end of the Vertebrate body, into which the intestine, urinary, and reproductive ducts open. Not present in most Mammals.

Cochlea. The portion of the ear, in communication with the sacculus, which is the essential organ of hearing in the higher Vertebrates.

Coelom. The body cavity, lying between the digestive tract and the body wall. Lined with mesodermal tissue.

Coelomate. Possessing a coelom, or body cavity; as in all the chief groups of animals above the Coelenterates. The latter are acoelomate.

Coelomic Epithelium. See Peritoneum.

Colloid. A state of matter in which a substance is finelv divided 
into particles larger than one molecule and suspended in another substance.

Colony. An aggregation, or intimate association of several or many individuals to form a superior unit.

Combination. Heritable variation due to recombinations of genes at maturation or fertilization.

Conjugation. The temporary union of two cells during which sexual phenomena occur; e.g., in Paramecium. See Endomixis. Conservation of Energy. The 'law' that the total energy of the universe is constant, none being created or destroyed but merely transformed from one form to another.

Contractile Vacuole. A reservoir in unicellular organisms (e.g. Paramecium) in which water and waste products of metabolism collect and are periodically expelled to the exterior.

Conm. A solid bulb-like expansion of a plant stem below the surface of the ground. A bulb is an underground storage leaf bud.

Corolla. The whorl of modified leaves immediately within the calyx of a flower. The petals collectively.

Cortex. The cylinder between the outer and central cylinder in root and stem of the higher plants.

Cotyledon. A seed leaf. The first leaf (in monocotyledons) or pair of leaves (in dicotyledons) of the young sporophyte within the seed.

Cranial Nervess. Nerves which arise from the brain.

Cranium. The protective case enclosing the brain.

Crossing-over. The rearranging of linked characters as a result of the exchange of genes during synapsis of chromosomes.

Crura Cerebri. Thickenings of ventral surface of mid-brain. Crustacea. A group of Arthropoda, including Crayfish, Crabs, etc. Cuticle. The outermost lifeless layer of organisms.

Cyst. A resistant envelope formed about an organism (e.g., many Protozoa) during unfavorable conditions or reproduction.

Crtology. The science of cell structure and function.

Cytoplasm. The protoplasm of a cell exclusive of the nucleus.

DECAY. Chemical decomposition involving putrefaction or other types of fermentation. 
Denitrifying Bacteria. Types of Bacteria which break down compounds of nitrogen and set free the nitrogen.

Dermal. Pertaining to the skin. The dermis is the inner layer of the Vertebrate skin. See Epidermis.

Differentiation. A transformation from relative homogeneity to heterogeneity, involving the production of specific substances or parts from a general substance or part. Specialization.

DIнYвRID. The progeny of parents differing in regard to two given characters.

Diploid. The maximum or full (duplex) number of chromosomes which occurs during the life-history of a given species. See Haploid.

Division of LABor. Allocation of special functions to special parts which coöperate toward the unity of the whole.

Dominant Character. One of a pair of alternative characters which appears to the exclusion of the other (recessive) character.

Dorsal Aorta. Chief artery distributing pure blood to the body. Ventral aorta carries blood from heart to gill-arteries in Fishes.

Ductless Gland. An organ whose function is to elaborate and secrete a hormone directly into the blood. An endocrine gland.

Ecologr. The study of the relations of the organism to environing conditions, organic and inorganic.

ECTODERM. The primary tissue comprising the surface layer of cells in the gastrula; its derivatives in subsequent stages forming the outer part of the skin, nervous system, etc. See Germ Layer. Ectoplasm. Modified surface layer of cytoplasm of a cell. See Endoplasm.

EFFERENT Root. Ventral, or anterior, root of certain cranial and all spinal nerves through which motor nerve impulses leave the brain and spinal cord. See Afferent Root.

EGG. The female gamete. Ovum.

Embryology. The study of the early development of individual organisms.

Embryo Sac. Megaspore of the Flowering Plants.

EMULSoID. A state in which one liquid is divided into very fine droplets and suspended in another liquid with which it is immiscible. 
Encystment. The formation of a resistant covering, or cyst wall, about an organism.

Endocrine Guand. See Ductless Gland.

ENDoderm. The primary tissue comprising the inner layer of cells in the gastrula, and in subsequent stages forming the lining of the essential parts of the digestive tract and its derivatives. See Germ Layer.

Endomixis. A nuclear reorganization process in Protozoa, e.g., Paramecium, which does not involve the coopperation of two cells (as in conjugation) and therefore is without synkaryon formation.

Endoplasm. The inner cytoplasm surrounding the nucleus; e.g., in Paramecium. See Ectoplasm.

Endopodite. The inner of the two distal parts of the typical biramous Crustacean appendage. See Protopodite and Exopodite. Endoskeleton. An internal living skeleton affording support and protection, as well as levers for the attachment of muscles. Characteristic of Vertebrates.

Endosperm. A tissue, containing reserve food materials, formed within the embryo sac.

ENTERIC Cavity. The digestive cavity of the gastrula stage, and of simple Metazoa, e.g., Hydra.

Enzymes. Complex chemical substances of organisms which bring about by catalytic action many of the chemical processes of the body; e.g., digestion.

EPIDERmis. The outer cellular layer of the skin.

Epigenesis. Development from absolute or relative simplicity to complexity. See Preformation.

Epithelium. A layer of cells covering an external or internal surface, including the essential secreting cells of glands.

Equation Division. A typical division of the nucleus involving division of the chromosomes. See Reduction Division.

Equatorial Plate. The equator of the spindle with its group of chromosomes during the metaphase of mitosis.

EugEnICS. The system of improving the human race by breeding the best. "The science of being well born." See Euthenics. 
Eustachian Tube. Passage connecting the Vertebrate middle ear with the pharynx. Remnant of the most anterior gill slit, represented in present-day Sharks by the 'blow-hole,' or spiracle.

Euthenics. The system of improving the human race by good environment. See Eugenics.

Eutheria. The highest of the three subclasses of Mammals, including all the familiar forms. See Appendix I, Classification. Evolution, Organic. The accepted theory that present-day organisms are the result of descent with modification, or change, from those of the past. The word 'modification' is not used in the technical sense employed in genetics. See Modifications.

Excretion. The elimination of waste products of metabolism. The waste products themselves. See Secretion.

Exopodite. The outer of the two distal parts of the typical, biramous, Crustacean appendage. See Protopodite and Endopodite.

Exoskeleton. A non-living external skeleton chiefly for protection. The characteristic skcleton of Invertebrates, e.g., Crayfish.

External Receptors. Sense organs upon the surface of the body. See Internal Receptors.

Extracted Dominant. A homozygous individual, exhibiting the dominant character, derived from heterozygous (hybrid) parents.

Extracted Recessive. An individual exhibiting the recessive character, necessarily homozygous, derived from heterozygous (hybrid) parents.

Family. In classification, a main subdivision of an order. See Genus.

Fats. One of the chief groups of foodstuffs. Organic salts consisting of the glycerol radical $\left(\mathrm{C}_{3} \mathrm{H}_{6}\right)$, the basic part, combined with a fatty acid. E.g., mutton tallow is chiefly the fat Stearin $\left(\mathrm{C}_{57} \mathrm{H}_{110} \mathrm{O}_{6}\right)=$ Glycerin plus Stearic acid.

Fermentation. The transformation of organic substances chiefly through the activity of ferments, or enzymes, derived from living organisms. See Putrefaction.

Fertilization. The union of male and female gametes, especially 
their nuclei (pronuclei), by which the chromatin complex of each is arranged to form the composite nucleus of the zygote.

Flagellum. A whip-like prolongation of the cytoplasm, the movements of which usually effect the locomotion of the cell; e.g., Sphaerella.

FLower. A group of sporophylls and accessory structures, as in the Flowering Plants.

Fluctuations. Relatively slight variations always found in organisms; may be either modifications or combinations.

Foetal Membrane. The embryo of the higher Mammals before birth lies in the uterus of the mother enclosed in a series of membranes the outer one of which is in intimate contact with the uterine wall at one or more points to form the placenta.

Fovea Centralis. A slight depression at the posterior end of the optical axis of the eyeball. The center of distinct vision. Frond. Fern leaf, usually both vegetative and spore-producing.

Fruit. The ripened ovule case and contents, together with any structures which by adhesion become an integral part of it.

Gall Bladder. Receptacle near the liver for the temporary storage of bile.

Gametangium. A gamete-producing organ, especially in the lower plants.

Gamete. A cell which unites with another at fertilization to form a zygote. Egg or sperm.

Gametophyтe. The sexual, gamete-bearing generation in plants.

Ganglion. A group of nerve cells, chiefly the cell bodies, with supporting cells.

Gastric Vacuole. A droplet of fluid enclosing ingested food, in which digestion occurs; e.g., in Paramecium.

Gastroliths. Calcareous bodies found at certain times in the lateral walls of the stomach of the Crayfish. Probably represent the storage of material for the exoskeleton.

Gastrula. A stage in animal development in which the embryo consists of a two-layered sac, ectoderm and endoderm, enclosing the enteric cavity which opens to the exterior by the blastopore. GEL. A colloid which is more or less rigid. 
GENE. A factor or element in the chromosomes of the germ cells which conditions a character of an organism.

Genetics. The science of heredity.

GENotype. The fundamental hereditary constitution of an organism or group of organisms. The gene complex of an organism. See Phenotype.

Genus. In classification, a main subdivision of a family. See Species.

Germinal Continuity. The concept of an unbroken stream of germ plasm from the beginning of life, from which each generation is derived.

Germ Layer. A primary tissue (ectoderm, endoderm, or mesoderm) in the embryo from which the tissues and organs of the adult animal develop.

Germ Layer Theory. The doctrine that the germ layers are fundamentally similar throughout the Metazoa and that homologous structures in various animals are derived during ontogeny from the same germ layer.

Germ Plasm. The physical basis of inheritance. The chromatin which forms the specific bond of continuity between parent and offspring. Contrasted with soma or somatoplasm.

GiLl Surrs. Paired lateral openings leading from the anterior end of the alimentary canal to the exterior for the exit of the respiratory current of water. Permanent or embryonic characters of Vertebrates. Branchial clefts.

GLAND. One cell or a group of many epithelial cells which elaborate certain materials and then secrete the product for the use of the organism.

GLotris. The opening from the pharynx into the tube (trachea) leading to the lungs.

GoNaD. An organ in which the germ cells develop. Ovary or testis.

Green Glands. Excretory organs (nephridia) of the Crayfish and its allies.

Haploid. The reduced (one-half) number (simplex group) of chromosomes. See Diploid. 
Hadstoria. Sucker-like absorbing organs of parasitic plants; e.g., Dodder.

Hepatic Portal System. Non-oxygenated but food-laden blood from digestive tract to the liver via hepatic portal vein. Oxygenated blood reaches liver via hepatic artery. All leaves via hepatic vein. Thus there is a double blood supply to liver in all Vertebrates.

Heredity. The transmission of characters from parent to offspring through the germ cells.

Hermaphrodite. An organism bearing both male and female reproductive organs; e.g., Hydra and Earthworm.

Heterospory. The condition of producing two kinds of spores, megaspores and microspores, as in the higher plants.

Heterozygous. Producing gametes which fall into two numerically equal classes with respect to the genes (allelomorphs) for a pair of alternative characters. See Homozygous.

Histology. The science which treats of animal and plant tissues. Microscopic anatomy.

HoLophyтic. Type of nutrition involving photosynthesis. Characteristic of green plants. See Holozoic and Saprophytic.

Holozorc. Type of nutrition involving the ingestion of solid food. Characteristic of animals. See Holophytic and Saprophytic.

Homologous Chromosomes. The members of a pair of chromosomes, of a duplex group, one paternal and the other maternal in origin, which bear the same or allelomorphic genes. See Synaptic Mates.

Homologous Genes. Genes similarly situated on homologous chromosomes. See Allelomorph.

Homology. Fundamental structural similarity, regardless of function, due to descent from a common form.

Hoмothermal. Animals provided with a mechanism which maintains the body at a practically constant temperature, usually higher than that of the environment. E.g., the 'warm-blooded' animals, or Birds and Mammals.

Homozygous. Producing gametes all of which bear the gene for one of a pair of alternative characters. See Heterozygous. 
Hormone. An internal secretion, usually from a ductless gland, which is distributed by the blood and influences the activities of one or more parts of the body.

Hyauine. Pellucid or glassy.

HYBRID. The progeny of parents which differ in regard to one or more characters.

HYDRoIDs. A group of animals allied to Hydra, exhibiting alternation of generations.

Immunity. Resistance of the body to infection by disease-producing organisms. Exemption from disease.

INFUNDIBULUM. A funnel-like outgrowth from the ventral wall of the diencephalon. See Pituitary Body.

Intercellular Digestion. Digestion by the secretion of enzymes into a digestive cavity; e.g., in Earthworm and Man. See Intracellular digestion.

Internal Receptors. Sense organs within the body. See External receptors.

Internal SeCretion, See Hormone and Ductless Gland.

INTESTINE. Portion of the alimentary canal from pyloric end of stomach to anus. Divided into small and large intestine.

Intracellular Digestion. Digestion of food within the cell itself; e.g., in Paramecium and to some extent in the endoderm cells of Hydra. See Intercellular digestion.

INTUSSUSCEPTION. Interstitial growth by the addition of new particles throughout the whole mass of protoplasm. Contrasted with growth by accretion, or the deposition of particles on the surface as in crystals.

Invagination. Sinking or growing in of a portion of the surface of a hollow body; e.g., during transformation of blastula to gastrula. INVERTEBRATE. An animal without a notochord or a vertebral column. IRRITABILITY. The power of responding to stimuli, exhibited by all protoplasm.

KARYOLYMPH. The more fluid material of the nucleus in contrast with the linin and chromatin.

KARYOSOME. An aggregation of part of the chromatin material within the nucleus. A 'net-knot'. See Nucleolus. 
Katabolism. The destructive phase of metabolism. See Anabolism.

Kinetic ENERGy. Energy possessed by virtue of motion. E.g., union of $\mathrm{C}$ with $\mathrm{O}_{2}$ transforms chemical potential energy into kinetic energy, i.e., heat, etc. See Potential Energy.

LAMina. The blade of a leaf.

LARVA. An immature stage in the life history of certain animals, usually active and differing widely in appearance from the adult. E.g., caterpillar of a Butterfly, tadpole of Frog.

LENTICELS. Openings on the outer surface of the bark which permit a slight amount of gaseous interchange. Arise as stomata in the young shoot.

Lisis. The material of the reticulum of the nucleus, upon and through which the chromatin appears to be distributed in the resting cell. The representative within the nucleus of the general cytoplasmic reticulum.

LiNKage. Tendency for certain characters to be inherited in groups, probably because the genes for the characters are closely associated on the same chromosome.

LYMPH. Essentially plasma and white blood corpuscles which have passed through the capillary walls to supply the milieu of the tissue cells.

MaCronucleus. The large 'vegetative' nucleus in Infusoria with dimorphic nuclei; e.g., in Paramecium. See Micronucleus.

MANDIBLES. Jaws. The third pair of appendages of the head of the Crayfish.

Maturation. Final stages in the formation of the germ cells, involving chromosome reduction.

MAXILLIPEDS. The three posterior pairs of appendages of the head of the Crayfish.

Mechanism. The doctrine that the phenomena of life are interpretable in terms of the laws of matter and energy which hold in the realm of the non-living. See Vitalism.

Medusa. Sexual, gonad-bearing generation of hydra-like animals, the Hydroids.

Megasporangium. A sporangium which bears megaspores. 
Megaspore. The large spore which in heterosporous plants forms a female gametophyte.

Megasporophyll. A modified leaf of a heterosporous sporophyte which produces megaspores. A carpel.

Meristem. Formative tissue with rapidly dividing cells, as in cambium and growing points of plants.

Mesoderm. A primary tissue, or germ layer, of animals which develops between ectoderm and endoderm. See Germ Layer.

Mesogloea. The non-cellular layer between ectoderm and endoderm in Hydra and other Coelenterates.

MesophylL. Tissue of the leaf, between upper and lower epider- mis, exclusive of the vascular bundles (veins).

Metabolism. The sum of the chemical processes in organisms, involving the building up and breaking down of the living matter. See Anabolism and Katabolism.

Metagenesis. Alternation of generations, as in Obelia.

Metamere. One of the series of similar parts, or segments, of the body; e.g., in the Earthworm and Crayfish and, in highly modified form, throughout the Vertebrates.

Metamorphosis. A more or less abrupt transition from one developmental stage to another. E.g., in Insects.

Metaphase. Climax of mitosis involving the separation of the halves of the longitudinally split chromosomes arranged in the equatorial plate. See Anaphase.

Metaphyta. Multicellular plants.

Metaplasm. Lifeless inclusions in cytoplasm; e.g., yolk granules, etc.

Metazoa. Multicellular animals.

Micronucleus. The small 'germinal' nucleus in Infusoria with dimorphic nuclei; e.g., Paramecium caudatum has one, and $P$. aurelia and $P$. calkinsi have two micronuclei. See Macronucleus.

Microsporangium. A sporangium which bears microspores; e.g., pollen sacs in anther of stamen.

Microspore. The small spore, of heterosporous plants, which forms a male gametophyte. A pollen grain. 
Microsporophyll. A modified leaf, of a heterosporous sporophyte, which produces microspores. A stamen.

Mitosis. The typical process of cell division.

Modifications. In genetics: changes in the soma due to environmental influences; so-called acquired characters are modifications. In evolution: signifies 'change'; no technical connotation. MoNoнYвRID. The progeny of parents differing in regard to one given character.

MoRPHOGENESIS. The origin of the form and structure of an organism during ontogeny.

MoRphology. The science of the form of animals and plants.

Mosaic INHERITANCE. Inheritance of a character in part from each parent but without blending.

Mutation: A heritable variation due to a fundamental change in the constitution of the germ plasm, independent of the normal processes of segregation and crossing-over.

Мүотомеs. Muscle segments in body wall of lower Vertebrates and embryos of higher forms.

Natural Selection. The processes occurring in nature which result in the "survival of the fittest" individuals and the elimination of those less adapted to the conditions imposed by their environment and mode of life.

NEPHRIDIUM. An excretory organ; e.g., in Earthworm.

Nephrostome.' Coelomic opening or funnel of a nephridium.

Nerve. Essentially a group or cable of parallel nerve fibers bound together. See Axon.

Neural Canal. The tube in which the brain and spinal cord lie. Formed by the neural arches and centra of the vertebrae.

Neural Tube. A tube derived from the ectoderm and forming the brain and spinal cord in Vertebrates.

Neuron. A nerve cell, comprising cell body and cytoplasmic processes. See Axon.

Nitrifying Bacteria. Types of Bacteria which, in the process of their nutrition, change ammonia $\left(\mathrm{NH}_{3}\right)$ into compounds with the $\mathrm{NO}_{2}$ radical (nitrites), and change nitrites into compounds with the $\mathrm{NO}_{3}$ radical (nitrates.) 
Nitrogen-fixing Bacteria. Types of Bacteria which take free atmospheric nitrogen and combine it with oxygen so that nitrates available for green plants are formed. Found in the soil and in tubercles on rootlets of various leguminous plants.

NотосновD. An axial cord of cells about which the backbone is formed. Gradually replaced by the centra of the vertebrae in the ascending series of Vertebrates.

NucEllus. The megasporangium of Flowering Plants. See Ovule and Embryo sac.

Nucleolus. A spherical body of achromatic material within the nucleus. Plasmosome. See Karyosome.

Nucleus. A specialized protoplasmic body in all typical cells. Most characteristic element is chromatin.

Oesophagus. Narrow tube leading from pharynx to stomach.

Olfactory. Relating to the sense of smell.

Ontogeny. The developmental history of the individual. See Phylogeny.

OöCYTE. The ovarian egg before maturation.

OöGENEsis. The development of the mature egg from a primordial germ cell.

Optic LoBEs. Thickenings of the dorsal surface of the mid-brain. Order. In classification, a main subdivision of a class. See Family. Organ. A complex of tissues for the performance of a certain function; e.g., the heart.

Osmosis. Diffusion of dissolved substances through a semi-permeable membrane. Osmotic pressure may be considered as a result of the inhibited power of diffusion of a dissolved substance - inhibited because the membrane is semi-permeable. The physical phenomena of diffusion and osmosis are complicated in living cells by the fact that their limiting surfaces may function now as permeable and again as semi-permeable membranes, i.e., permitting water but not the substance in solution to pass through.

Osteology. The study of the Vertebrate skeleton.

Ovary. The definitive female reproductive organ in which the gametes (eggs) develop. 
Ovule. The body which after fertilization of the egg becomes a seed. The ovule consists of protective envelopes (integument) enclosing the nucellus (megasporangium) with the embryo sac (megaspore).

Ovule Case. The base of the pistil in which ovules arise. "Ovary."

Ovum. Egg. Female gamete.

Oxidation. The combination of any substance or its constituent parts with oxygen.

Paleontology. The science of extinct animals and plants represented by fossil remains.

Parasite. An organism which secures its livelihood directly at the expense of another living organism, on or in whose body it lives. Parthenogenesis. Development of an egg without fertilization.

Pathogenic. Disease-producing, especially in regard to the relation of a parasite to its host.

Peduncle. Stalk of a flower; represents the floral branch.

Pentadactyl. Having five fingers or toes; typical Vertebrate limb.

Perianth. Collective term for calyx and corolla.

Pericardium. Peritoneum lining the pericardial cavity containing the heart.

Peristalsis. Rhythmical contractions of the wall of the alimentary canal which forces the food along.

Peritoneum. Membrane lining coelom of Vertebrates. Consists of an outer layer of connective tissue next to the muscles of body wall and an inner layer of coelomic epithelium which forms the innermost layer of body wall.

Petal. One of the leaves of the corolla of a flower.

Petiole. A leaf stalk.

Pharynx. Region of alimentary canal between buccal cavity, or mouth, and oesophagus. Throat.

PhenotyPe. The somatic, or expressed, characters of an organism or group of organisms irrespective of those potential in their germ cells. See Genotype.

Phloem. The outer part of a vascular bundle. 'Inner bark.' 
Pнотоsynthesis. Process by which complex compounds are built up from simple elements through the energy of sunlight absorbed by chlorophyll, or a functionally similar pigment.

Phylogeny. The ancestral history of the race. See Ontogeny.

Phylum. In classification, a main subdivision of the animal or plant kingdom. See Class.

Physiology. The study of the functions of animals and plants. The mechanical and chemical engineering of organisms.

Pineal Body. An outgrowth from the upper wall of the diencephalon. The vestige of an additional pair of eyes possessed by the ancestors of existing Vertebrates. Fcssibly functions as an endocrine gland in Mammals. Brow-spot of Frog.

Pistil. Organ of the flower, composed of ovule case, style, and stigma. See Carpel.

Pitr. Middle part of the central cylinder of a plant shoot. Functions largely for the storage of water and food.

Рiтh Rays. Extensions of the pith which radiate between the vascular bundles to the bark. Medullary rays.

Pituitary Body. An ingrowth of the ectodermal tissue above the mouth and the tip of the infundibulum from the ventral wall of the diencephalon unite to form a gland-like structure (pituitary body or hypophysis).

Placenta. A Mammalian organ adapted for the interchange of all nutritive, respiratory, and excretory materials between the embryo (foetus) and mother. It also serves as an organ of attachment. In the higher Mammals it is composed of both foetal and maternal tissues. See Umbilical Cord.

Plasma. Liquid portion of the blood.

Plexus. Intercommunication of the fibers from one nerve with those of another to form a network of nerves; e.g., branchial and sciatic plexus.

Polar Bodies. Tiny abortive cells arising, by division, from the egg during maturation.

Pole Cells. Two cells which give rise to the mesoderm in the development of the Earthworm and its allies.

Pollen. The microspores of Flowering Plants. 
Pollination. The transference of pollen to the stigma of the pistil in higher Flowering Plants.

PoLyнyBRID. The progeny of parents which differ in regard to more than three given characters.

Polymorphism. Occurrence of several types of individuals during the life history, or composing a colony; e.g., in some Hydroids. Potential Energy. Energy possessed by virtue of stresses, i.e., two forces in equilibrium. Criterion is work done against any restoring force; e.g., kinetic energy of sunlight through agency of chlorophyll separates $\mathrm{CO}_{2}$ into $\mathrm{C}$ and $\mathrm{O}_{2}$ and thereupon is represented by an equal amount of chemical potential energy. Restoring force is here chemical affinity. Similarly a raised weight possesses gravitational potential energy in amount equal to kinetic energy expended in raising it. See Kinetic Energy and Conservation of Energy.

Preformation. The abandoned doctrine that development is essentially an unfolding of an individual ready-formed in the germ. See Epigenesis.

Pronephros. Primitive kidney of Vertebrates.

Pronuclei. The nuclei of the male and female gametes ready to unite at fertilization.

Prophase. Preparatory changes during mitosis leading to the disposition of the chromosomes in the center of the cell (equatorial plate) ready for division. See Metaphase.

Prostomium. A lobe which projects from the first segment of the body of the Earthworm and forms an upper lip.

Protein. A class of complex chemical molecules, containing nitrogen, which form the chief characteristic constituent of protoplasm.

Prothallus. The gametophyte of Ferns.

Protista. Protophyta and Protozoa; all unicellular organisms.

Protonema. A filamentous growth from a Moss spore which gives rise to the leafy Moss plant.

Protophyta. Unicellular plants. See Protista.

Protoplasm. The physical basis of life. Living matter.

Protoplast. The cell exclusive of the cell wall, especially in plants. 
Protopodite. The basal portion of the typical Crustacean appendage from which arise the endopodite and exopodite.

Protozos. Unicellular animals.

Pure Line. A group of individuals bearing identical genes, derived from a common homozygous ancestor.

Putrefaction. The simplification of nitrogenous compounds, such as proteins, chiefly through the action of enzymes of living organisms. See Fermentation.

Pyloric Valve. Muscular constriction between stomach and small intestine.

Recapitulation Theory. Doctrine that individual development (ontogeny) repeats in abbreviated and modified form the development of the race (phylogeny). So-called biogenetic law.

Recessive Character. See Dominant character.

Reduction. The halving of the chromosome number during maturation. Transformation of duplex into simplex group.

Reduction Division. The division during spermatogenesis and oögenesis which separates synaptic mates and reduces the chromosome number one half. The mechanism of segregation.

REFLEXES. Relatively simple and essentially automatic responses. Merge into instincts which are the most complex reactions made without learning.

REgEneration. The power of replacement of parts which have been lost through mutilations or otherwise.

Renal Portal System. Blood ('impure') from posterior part of the body to kidneys via renal portal vein. Oxygenated blood to kidneys via renal artery. Thus in animals with the renal portal system there is a double blood supply to the kidneys. Present in Fishes, Amphibians, and Reptiles; vestigial in Birds; absent in Mammals.

REPRoduction. The power of living matter to reproduce itself. Protoplasmic growth resulting in cell division.

RESPiRATion. Essentially the securing of energy from food, involving the exchange of carbon dioxide for oxygen by protoplasm.

RESPONSE. Any change in the activity of protoplasm, and therefore of an organism as a whole, as the result of a stimulus. 
Resting Cell. One which is not undergoing mitosis.

Retina. Actual percipient part of the eye by virtue of a sensory layer which is stimulated by light rays.

REversion. The appearance of a distant ancestral character in an individual. See Atavism.

RHizord. A root-like filament in lower plants; e.g., in Mosses and prothallus of Ferns.

Rhizome. Prostrate underground stem; e.g., in sporophyte of common Ferns.

Rоот HAIRs. Prolongations of epidermal cells just above the growing point of roots which afford surface for intake of water and solutes.

Rostrum. The anterior pointed extension of the exoskeleton of the Crayfish and its allies.

RotiferA. Microscopic, aquatic, multicellular animals. Wheel animalcules.

Rusts. Fungi which are destructive parasites of the higher plants; e.g., the Wheat Rust.

Sacculus. The anterior sac of the labyrinth of the ear, a derivative of which becomes the cochlea in higher Vertebrates.

SAPROPHYTIC. Type of nutrition involving the absorption of complex products of organic decomposition; e.g., in many groups of Bacteria and other Fungi, as well as various species of lower animals. See Holozoic and Holophytic.

Sebaceous Glands. Glands which elaborate a fatty substance (sebum) and secrete it in the hair follicles.

Secretion. A substance elaborated by glandular epithelium; or the process involved. See Gland and Excretion.

Seed. An embryo sporophyte supplied with food and protective envelopes.

Segregation. The distribution of contrasting genes (allelomorphs) to separate cells during the maturation of the germ cells in a heterozygous individual (hybrid).

Semicircular Canals. Portion of the Vertebrate ear devoted to equilibrium.

Seminal Receptacles. Globular sacs within the body cavity of 
the Earthworm, which receive the sperm from another worm and retain them until fertilization is to occur.

Sepal. A leaf of the calyx of a flower.

SEPTA. The partitions which divide the coelom of the Earthworm into a series of chambers, or metameres.

Serial Homology. Homology of a structure of an organism with another of the same organism; e.g., appendages of the Crayfish, fore- and hind-limbs of Vertebrates.

SetaE. Bristle-like structures which protrude from the body wall of the Earthworm and aid in locomotion.

Sex Chromosome. The odd, $\mathrm{X}$, or accessory chromosome which bears the differential gene for sex.

SeX-Linked Characters. Characters represented by genes on the sex chromosomes.

Sноот. Stem and leaves as contrasted with the root.

Simplex Character. The result of a determiner, or gene, from one parent only.

SoL. A colloid which is highly fluid.

Soma. Body tissue (somatoplasm) in contrast with germinal tissue. Special Creation. Abandoned doctrine that each species was specially created. Implies fixity of species. See Evolution.

Species. In classification, the main subdivision of a genus. A group of individuals which do not differ from one another in excess of the limits of "individual diversity," actual or assumed.

Sperm. Male gamete. Spermatozoön.

SPERmatid. Male germ cells after the final maturation division but before assuming the typical form of the ripe sperm.

Spermatocytes. Cells arising from the spermatogonia. Primary spermatocyte arises by growth from the last generation of spermatogonia. Primary divides to form two secondary spermatocytes.

Spermatogenesis. The development of the sperm from a primordial germ cell.

Spermatophytes. Plants bearing true seeds. Seed Plants. Flowering Plants. Phanerogams. 
Spindle. The 'fiber-like' apparatus between the centrosomes during mitosis.

SPIREme. The linear arrangement of the chromosomes frequently observed during mitosis.

SpleEN. A vascular ductless organ of most Vertebrates, usually situated near the stomach, which produces certain changes in the blood.

Spontaneous Generation. See Abiogenesis.

Sporangium. A spore-producing structure on a sporophyll.

Spore. A cell, liberated from the parent, which gives rise without fertilization to a new individual. The resistant phase assumed by certain unicellular organisms; e.g., Bacteria.

SPOROPHYLL. A leaf which bears sporangia.

Sporophyte. Spore-bearing (asexual) generation in plants exhibiting alternation of generations.

Sporulation. Occurrence of several simultaneous divisions by which a unicellular organism is resolved into many smaller cells. Stamen. The pollen-bearing organ in Flowering Plants. A.microsporophyll. See Anther.

STELE. The central cylinder of root and stem, formed of united vascular bundles, in the highest Flowering Plants.

Stigma. The tip of the pistil adapted to receive the pollen and provide for its germination.

Stimulus. Any condition which calls forth a response from living matter.

Stipules. Pair of appendages frequently occurring at the point (leaf base) where the petiole joins the stem.

Stomata. Openings through the epidermis of a leaf for the interchange of gases and exit of water vapor. The 'stomatic apparatus' comprises the stoma and its guard cells.

Strle. An elongation of a pistil which bears the stigma.

Symbiosis. The association of two species in a practically obligatory and mutually advantageous partnership; e.g., Lichens. Sympathetic Nervous System. See Autonomic.

SyNAPSE. The contact of one nerve cell with another, which makes possible the conduction of a nervous impulse from cell to cell. 
Synapsis. The pairing of homologous chromosomes during maturation of the germ cells.

Synaptic Mates. Homologous chromosomes of maternal and paternal origin paired in synapsis.

Syngamy. The union of gametes to form a zygote.

Synkaryon. The composite nucleus formed by the union of the nuclei of two gametes. Male and female pronuclei united to form the fertilization nucleus. See Zygote.

TAPIR. A large herbivorous Mammal, having short stout limbs and flexible proboscis with the nostrils near the end. New World species are brownish-black, those of the Old World are black and white.

TAхоNомy. The science of classification.

Telophase. Final phase of mitosis during which the two daughter nuclei are reformed and cytoplasmic division is completed. See Prophase.

Testis. The definitive male reproductive organ in which the gametes (sperm) develop.

Thallus. A relatively simple plant body, not differentiated into root, stem, and leaf; e.g., in Seaweeds and other multicellular Algae

Thorax. The anterior chamber of the coelom in Mammals, containing lungs and heart. The middle portion of the body in the Arthropoda; e.g., in all Insects. In the Crayfish the head and thorax are fused to form the cephalothorax.

Thrmus. A glandular structure in the pharyngeal region of Vertebrates. Disappears during early life in Man. Function unknown.

THYRoID. A glandular structure in the pharyngeal region of Vertebrates. Supplies an important hormone.

Tissue. An aggregation of similar cells for the performance of a certain function. See Organ.

Tracheids. Elongated cells which form water-conducting vessels in the vascular bundles of higher plants.

Transpiration. The exhalation of water vapor, particularly through the stomata of higher plants.

Trichocysts. Minute bodies, arranged in the outer part of the 
ectoplasm of certain Infusoria (e.g., Paramecium), each of which upon proper stimulation is transformed into a thread-like process protruding from the cell surface. Apparently defensive structures.

TRIHYBRID. The progeny of parents differing in regard to three given characters.

Trilobites. Crustacea dominant during the early Paleozoic era. Extinct.

Turgor. Outward pressure of the cell, largely due to the absorption of water, which distends the cell wall. The turgidity of the individual cells results in the semi-rigid position of many plants. Wilting results from a lowering of the turgidity of the cells.

Typhlosole. A median dorsal invagination along the entire length of the intestine of the Earthworm. Increases the area of the digestive and absorptive surface.

Umbilical Cord. A Mammalian structure, commonly known as the navel cord, by which the embryo is attached to the placenta. The blood vessels from the embryo to the placenta pass through it. See Placenta.

Unguiculate. Provided with claws.

Uniformitarian Doctrine. An interpretation of the present condition of the Earth on the assumption of similarity of factors at work during past ages and to-day.

Uniparental. Derived from a single progenitor; e.g., in asexual reproduction. See Biparental.

Unit Characters. Characters which behave more or less as units in heredity.

UreA. Nitrogenous waste product of animal metabolism. Formed as such in the liver, removed from the blood by the kidneys and eliminated from the body chicfly in urine.

UnETER. A tube carrying urine from kidney to the cloaca or to the urinary bladder.

Urogenital. Relating to the urinary and reproductive systems.

UTERUS. Lower portion of the oviduct (or oviducts) modified for the retention of the eggs temporarily (Frog) or until development has proceeded a considerable way and 'birth' occurs (Man). 
Utriculus. The posterior sac of the labyrinth of the ear into which the semicircular canals open.

Vascular Bundle. Composite of xylem, cambium, phloem, and bundle sheath. Except for the cambium, essentially a system of tubes for conducting water and food. A fibro-vascular bundle. See Stele.

VAso-Motor Nerves. Nerves which regulate the calibre of small arteries by bringing about relaxation or contraction of the muscular layer of their walls.

Vermiform APPEndix. Blind outpocketing of the large intestine near its origin from the small intestine. Vestigial end of the caecum. Found only in Apes and Man.

Vertebra. One of the series of elements forming the backbone, or vertebral column.

Vertebrate. An animal with a backbone, or vertebral column.

Vitalism. The doctrine which attributes at least some of the phenomena of life to an interplay of matter and energy which transcends the so-called laws'operable in the inorganic world. See Mechanism.

Vitamines. Indispensable accessory food substances whose importance has but recently been realized. Chemical composition is as yet practically unknown.

Working Hypothesis. A basic assumption to guide the study of a subject, and to be proved or disproved by facts accumulated.

$\mathrm{X}$ Chromosome. The 'accessory' or 'sex-chromosome.'

XYLEM. The inner woody part of a vascular bundle.

YEAST. A group of unicellular colorless plants (Fungi) which are chiefly responsible for alcoholic fermentation.

YoLk. Food material stored within the cytoplasm of an egg. See Metaplasm.

ZOÖGEOGRAPHY. The science of the geographical distribution of animals.

ZYGoTE. The composite cell formed by the union of male and female gametes. See Synkaryon. 


$$
\text { - } \div
$$




\section{INDEX}

[Figures in italics designate pages on which illustrations occur.]

\section{A}

Abdomen, 130, 153

Abdominal cavity, 140

Abdominal pores, 207

Abdominal vein, 165

Abiogenesis, 209, 210, 388

Absorption, 87, 156, 158

Accessory chromosome (see $\mathrm{X}$ chromosome)

Acoelomates, 121

Acquired character, 266, 297, 306, $377,408,409$

Adam's apple, 153, 356

Adaptability, individual, 339-344

Adaptation, 11, 17, 18, 307-344, 375 ; functional, 308-313; to living environment, 330-339; physical environment, 308-329; structural, 313-329

Adaptive radiation of Mammals, 313-319

Adaptive variation, 378

Adrenal body, 152

Adventitious roots, 67

Aerial roots, 66, 67

Afferent nerve, 192

Air bladder, 148

Air spaces, 83,84

Alcoholism, 267

Algae, classification, 413

Alimentary canal, 121, 123, 131, 137, 148-156; derivatives, 160 Alimentary system, 116

Allelomorphs, 276, 280, 282, 288 Alligator, brain, 189
Alternation of generations, 54, 100-114, 218-220, 229

Alternative inheritance (see Inheritance)

Amines, 36, 87

Amino acids, 13, 42, 158

Amoeba, 9, 19, 116, 340

Amphibian, 117, 136, 149, 189 (see Frog)

Amphioxus, 146, 259, 415; development, 257; egg, 256

Anabolism, 16

Anaerobe, 311

Analogous structures, 63, 130, 199 Anaphase, 225

Anatomy, 4; comparative, 132, 351-356; history, 393, 394

Ancestral inheritance, law of, 270 Animal body, 115-153; versus plant body, 115

Animal, chief groups, 116, 117; circulation, 161-174; classification, 116, 117, 414-416; coloration, 319-324; coördination, 181-202; excretion, 175-180; metabolism, 39-43; nutrition, 154-160; reproduction, 203208 ; respiration, 161-174; sessile, 115; unicellular, 39

Annual plant, 66

Antenna, 131, 132; cleaner, 326; comb, 326

Antennule, 131, 132

Anther, 108, 110, 112

Antheridium, 101, 104 
Antibody, 338

Antitoxin, 338

Antlers, 206

Ants, instincts, 343; associated with Aphids, 333

Anus, 121, 153

Aorta (see Dorsal and Ventral aorta)

Aortic arches, 171

Aphids and Ants, 333

Apis (see Bee)

Aqueous humor, 201

Arabian scientists, 383

Archaeopteryx and Pigeon, 360

Archegonium, 101, 104

Aristotle, 2, 15, 209, 379, 380, 383,

$390,394,398,401,406$

Arterial system, 166

Arteries, 163-165; pulmonary,

$150,151,152$

Arterioles, 163

Arthropoda, 129; classification,

415; structure of primitive, 130

Artificial parthenogenesis, 249

Ash, 80

Asparagine, 36

Asparagus, 70

Aspidium, 103, 104

Associations, communal, 331

Aster, 225

Atavism, 269

Auditory capsule, 145

Auditory nerve, 197, 198

Aurelius, Marcus, 44, 382

Auricle, 163, 172 (see Cireulation)

Autonomic nervous system, 186,

191,192

Azalea, 75

\section{B}

Babylonian science, 379

Bacillus tetani, 311

Bacon, R., 386
Bacteria, 44-53; discovery, 388; chief types, 45 ; denitrifying, 49 ; as food, 42 ; nitrate, 48 ; nitrogen-fixing, 49, 333; nutrition, 50 ; reproduction, 46; sulfur, 309 ; types of flagellation, 46

von Baer, 1, 402

Balanced aquarium, 53

Barberry, 72

Bark, 88

Barley, 80

Barnacle, 115

de Bary, 7

Bat, 318; wing skeleton, 352

Beagle, voyage of, 369

Bean, 66; inheritance in, 300 ; section of stem, 81

Beaver, 349

Bee, 325, 415; head, 326; instincts, 343; legs, 324-329; parthenogenesis, 249; pollination by, 330

Bee-fly, 323

Beggiotoa, 309

Bernard, 91

Bibliography, 417-428

Biennial plant, 67

Bilateral symmetry, 124

Bile duct, 197, 148, 151, 152, 155

Binomial nomenclature, 391

Biochemistry, 5

Biogenesis, 210, 388

Biogenetic law, 364, 403

Biological sciences, 5

Biology, 1; divisions of, 4; history, $379-411$; and medicine, 381 ; scope of, 1-5

Biophysics, 5

Biparental inheritance, 251 (see Inheritance)

Biramous appendage, 132

Bird, 117, 136; brain, 189 ; circulation, 165; dissection of, 151; 
egg, 238; embryo, 366; versus Reptile, 359; skeleton of wing, 352

Birth, 208

de Blainville, 15

Blastocoel, 57

Blastoderm, 238

Elastopore, 57, 58, 127

Blastostyle, 218

Blastula, 57, 58, 126, 252

Blending inheritance, 268, 283, 286

Blood, 163; capillary circulation discovered, 389; circulation demonstrated, 385; corpuscles, 163, 338; pressure, 173; rate of flow, 172; relationships, 367; specific differences, 367 ; transfusion, 367

Body, animal, 115-153; plant, $61-90$

Body plan of Earthworm, 122

Rody plan of Vertebrates, 136-138

Body temperature, 174, 176, 312

Bone (see Skeleton)

Borelli, 395

Botany, 3, 4

Brain, 134, 137, 148-152; evolution of, 365 ; human, 153 ; ventricles, 188

Branchial arteries, 165, 166

Branchial clefts, 164 (see Gill slits)

Bryales, 101, 414

Bryophyta, 101, 112, 413

Bud, 81, 82; winter, 72

Budding, 113, 119, 213

Buffon, 407

Bulb, 70

Buttress root, 67

Cactus, 70

Calciferous gland, 128

Calyx, 75, 107
Cambarus (see Crayfish)

Cambium, 60, 76, 81

Camel, evolution of, 368

Cameron, E. H., 344

Capillaries, 163, 173; of lungs 165; network, 159, 389

Carbohydrates, 13, 14, 35, 42, 157

Carbon cycle, 48

Carnivora, 349

Carotid artery, 164, 165, 171

Carpal, 144, 145

Carpel, 75, 107, 108, 112

Cartilage, 25, 140

Castor, 349

Catalyzer, 14

Cat, brain, 189; skeleton, 145

Catocala, 320

Caudal artery and vein, 164

Cell, 21; ciliated, 25 ; defined, 23 ; diagram of, 26 ; discovery, 387 ; division, 29, 225, 227; doctrine, 399; epithelial, 59; forms of, 23-29; nerve, 25; origin, 28 ; plant, generalized, 77 ; sap, 26. 80,84 ; theory, 242 ; wall, 27 . $7 y$

Cell cycle, 214, 215

Cellulose, 13, 31

Cenozoic era, 358

Central cylinder, 76,79

Central nervous system, 186 (see Nervous system)

Central spindle, 226

Centrosome, 26, 27, 225

Centrum, 141, 143, 145 .

Cephalothorax, 131

Cerebellum, 153, 187, 189

Cerebral ganglion, 123, 131, 134

Cerebral hemispheres, 153, 18\%, 188,189

Chameleon, 321

Characters, acquired, 266, 297 $306,377,408$, 409; alternative, 
405; dominant, 272; linked, $268,291,293$; recessive, 272 ; unit, 262, 280, 282, 286

Cheliped, 131

Chemical coördination, 181-183

Chemistry, origin of, 395

Chemosynthesis, 50

Chemotaxis, 240

Cheshire, F. R., 328

Chipmunk, 349

Chlorenchyma, 77, 83

Chlorophyll, 22; chemical composition of, 35

Chloroplastid, 35, 84

Choloepus, 317

Chordate, 146, 415

Choroid, 201

Chromatin, 28; knot, 26; network, 26

Chromomere, 234

Chromosome, 225, 242, 296; accessory, 292; combinations, 290; diploid number, 235, 289; distribution, 236; division, 226; duplex groups, 231, 235, 289; haploid number, 235, 289; homologous, 234, 235, 287, 289; individuality, 227; in Man, 237, 291, 292; maternal, 234, 235, 287; pairs, 236; paternal, 234, 235, 287 ; reduction, 228; segregation, 290; sex, 292, 295, 377; simplex groups, 231, 235, 289; synapsis, 235; X, 292-295, 377

Chromosome cycle, 233-237; in animals, 229, 289; diagram of, 235 ; in plants, 229,288

Cilium, 19, 25, 40

Circulation, in animals, 116, 122, 131, 161-174; in Flowering Plants, 85-88

Class, 350

Classification, animals, 116, 117,
414-416; Algae, 413; Arthropoda, 415; Eutherian Mammals, 416; Ferns, 414; Flowering Plants, 414; Fungi, 413; history of, 390; Mammals, 416; Mosses, 413, 414; plants, 413, 414; Protozoa, 414; Vertebrates, 416

Clavicle, 141, 144

Claws, 138

Cleavage, 55

Cloaca, 137, 149, 156

Clover, 80

Clustered roots, 65

Coccyx, 153, 355

Cochlea, 196

Coelenterata, 118, 414 (see Hydra and Obelia)

Coeliac artery, 164

Coelom, 120, 137, 140, 153

Coelomate, 121

Coelomic fluid, 162, 177

Collar bone, 144

Colloidal, 8

Colony, 213

Coloration, animal, 319-324

Color-blindness, inheritance of, 294, 295

Colorless plants, $43-53$

Columba (see Pigeon)

Combinations, 268, 269, 302, 377

Comparative anatomy (see Anatomy)

Conduction, 18, 183

Condylarthra, 361

Conjugation, 41, 214, 244, 250; diagram of, 245

Conjunctiva, 201

Connective tissue, 142

Conservation of energy, 396

Contractile vacuole, 9,40

Contractility, 33

Conus arteriosus, 165, 166 
Coördination in animals, 181-202; chemical, 181-183; by nervous system, 183-193

Copulatory organs, 132, 152, 205

Coracoid, 141, 144

Corm, 70

Cornea, 201

Corolla, 75, 107

Correlation of structure and function, 393

Cortex, 60, 77, 79, 81

Cortical system, 76

Cotyledons, 66,87

Cranial nerves, 188, 190

Cranium, 148-153

Crayfish, 129-135, 169, 415; appendages, 132,353 ; circulatory system, 131; copulatory organs, 132, 205; dissection of, 131; feeding instincts, 342

Cretin, 182

Crop, of Earthworm, 123; of Bird, 151

Crossing-over, 262; mechanism 296

Crura cerebri, 188

Crustacea, 117, 415 (see Crayfish)

Cursorial, 314

Curve of probability, 299-305

Cutaneous senses, 195

Cuvier, 392-394

Cyclostomes, 179, 416

Cynthia, 254, 259, 415

Cytology, 4, 287, 403

Cytoplasm, 24-27

Cytoplasmic differentiation, 257, 258 , 259; organization, 254; zones, 259

Cytotoxin, 339

Dahlia, 65

D

Daltonism, 294

Dandelion, 65
Darwin, C., 262,271, 299,369, 374$376,378,410,411$, frontispiece

Darwin, E., 209, 408

Darwinism, present status, 378

Dead-leaf Butterfly, 321

Dentalium, 254, 259, 415; development, 257

Dermal system, 76

Dermis, human, 139

Descent with modification (see Evolution)

Dextrin, 13

Diapheromera, 322

Diaphragm, 140, 153, 155

Dicotyledons, 82, 414

Diencephalon, 187, 188

Digestion, 42, 87, 157-160, 395

Digitigrade, 316

Digits, 144,361

Dihybrid, 276-280

Dinosaur, 116, 416

Dioscorides, 382

Diploid number, 229, 234, 235

Disease, inheritance of, 267

Distribution, 368-372; discontinuous, 368

Division of labor, physiological, $28,57,117,324$

Dodder, 68

Dogfish, 164, 416

Dominance, 272, 282, 286; incomplete, 283; lack of, 283

Dorsal aorta, 137, 150, 151, 166

Dorsal root, 192

Ductless glands, 159

Ducts, of glands, 151, 155, 158; in plant stem, 86

Dujardin, 7

Duplex group, 234

\section{E}

Ear, 196-198

Earth, age of, 357 
Earthworm, 121-129, 159, 162, 415; body plan, 122; circulatory system, 122; dissection of, 123; excretion, 177; feeding instinct, 342 ; nerve cells, 194; nerve cord, 184; reflex are, 184; regeneration and grafting, 222; reproductive organs, 204; sensory and motor neurons, 184; transverse section, 124

Echinoderm, 259, 415 (see Sea Urchin)

Ecology, 4, 368

Ectoderm, 22, 57, 119, 126, 185, 215

Ectoplasm, 27, 40

Education (see Man)

Efferent nerve (see Nerve)

Egg, 101, 104, 106, 112, 236, 253; of Cat, 25; changes at fertilization, 241; human, 239; Mammal, 238, 239, 402; membrane, 241 ; organization of, 236,254 , 255

Egyptian science, 379

Elements, cycle of, 43, 46-50, 309 Elephants, evolution of, 371; geological and geographical distribution, 370 .

Elodea, 82

Embryo, 112; Fish, Bird, Man, 205, 366

Embryology, 4, 252, 364-366; comparative, 402; of Earthworm, 125-129; experimental, 255,403 ; history of, 401-403

Embryo sac, 108, 112

Empedocles, 406

Emulsoid, 8

Encyclopaedists, 384

Endocrine, 312; glands, 159 (see Thyroid and Chemical coördination)
Endocrinology, 182

Endoderm, 22, 57, 119, 126, 215

Endomixis, 41, 247, 250; nuclear changes, 248

Endoplasm, 27, 40

Endopodite, 132

Endoskeleton, 140 (see Skeleton)

Endosperm, 110, 111, 112

Energy, conservation of, 396 ; from sun, 37, 38; transformation of, 15, 38 (see Kinetic and Potential energy)

Enteric cavity, 57, 119

Enteron, 22

Environment, fitness of, 307; influence of, 266, 267, 296-298, 409 (see Adaptation)

Enzymes, 14, 37, 156, 158, 310

Eohippus, 361, 362

Epencephalon, 188 (see Cerebellum)

Epidermis, 22; 60, 77, 79, 81, 139

Epigenesis, 253, 257, 259, 401

Epithelium, 156

Epochs in biological history, 379411

Equation division, 231, 232

Equatorial plate, 225, 226, 242

Equipotent, 258

Equus (see Horse)

Eristalis, 323

Eugenics, 297

Eustachian tube, 149, 150, 198, 356

Euthenics, 297

Evaporation, 89

Evolution, 4, 129, 185, 251, 262, 267, 345-378; of Camel, 363; of Elephant, 371; evidences of, $347-372$; factors of, 372 378 ; and heredity, 376 ; of Horse, 361, 362; history of, 406-411 
Exconjugant, 245

Excretion, 16; in animals, 43, 175-180

Excretory system, 116; evolution of, 179,365

Exopodite, 132

Exoskeleton, 140, 146

Experimental biology, 252

External receptor, 193

Extracted dominant, 274

Extracted recessive, 274

Eye, of Arthropod, 199; of Cuttlefish, 199; development of, 200; human, diagram of, 201; Invertebrate, 199; optic stalk, 199; origin of, 198-200; rods and cones, 201; Vertebrates vs. Invertebrates, 200

\section{F}

Fabricius, 401

Factors, multiple, 286

Faeces, 156, 175

Fallopian tubes, 205 (see Oviduct)

Fats, 13, 14, 42, 157, 158

Fat body, 149

Feather, 138

Fermentation, 47; alcoholic, 310

Ferns, classification of, 414; fertilization in, 240; life history, $103,104,107$

Fertilization, 34, 113, 114, 214, 231, 235, 237-242, 245, 249-251; Protista, 243-248; significance of, 242-251

Fibrous root, 65

Fibula, 144

Fig, 67

Filial regression, law of, 270, 301, 303

Fins, 138, 141

Fish, 117, 136; brain, 189; circulation, 164, 165, 171; classifi- cation, $117,135,416$; dissection of, 148; embryo, 366; respiratory current, 170; skeleton, 141

Fission, binary, 212; multiple, 212 Fixity of species, 346

Flagellum, 33

Flatworm, 414; fission, 217 ; regeneration, 223

Flax, 110

Flexures, cranial, 188

Floral parts, 75, 107, 108

Flower, 107, 112; staminate, 355 ; vertical section, 110

Flowering plants, 61, 105; classification, 414; life history, 107-114; physiology, 84-90; structure, 65-84

Fluctuations, 300, 302

'Flying Lemur,' 318

Foetal membranes, 205

Food, 157, 158, 308-311; of animal and green plant contrasted, 42; stuffs, 14, 42 ; utilization, Flowering Plants, 89, 90

Fore-brain, 186, 187, 188, 189

Four-o'clock, 283, 284

Fovea centralis, 201

Fragmentation, 113

Frequency curve, 299-305

Frog, brain, 189; circulation, 165; dissection of, 149 ; section of intestine, 59 (see Amphibian)

Frond, 39, 103, 104

Fructose, 13, 36

Fruit, $66,110,112$

Fucus, 62

Fungi, classification of, 413 (see Bacteria)

G

Galen, 382, 394, 396

Galeopithecus, 318 
Galileo, 387

Gallapagos Islands, 369

Gall bladder, 148, 149, 155

Galton, 301, 303, 404

Galton's Laws, 269-271, 303

Gamete, 54, 112, 228-230，236; formation, 94-96; evolution of, 237 (see Egg and Sperm)

Gametophyte, 64, 101, 105; female, 106, 110; male, 106, 110

Ganglion, 133, 185, 191

Ganong, W. F., 61, 111

Gastric juice, 157, 158

Gastric vacuole, 40

Gastroliths, 131

Gastrula, 57, 58, 156, 252

Geddes, P., 307

Gel, 8

Gene, 236, 280, 286, 377; alteration of, 298; modifying, 304; multiple, 285, 286; segregation of, 290

Genetics, 4, 261-306; history of, 403-406

Genital duct, 137

Genotype, 275, 277, 279, 281

Genus, in classification, 349

Geological time table, 356

Geometrid Moth, larva, 322

Germ cells, 215, 229; origin, 223242 ; primordial, 224

Germ layer, 58, 128; theory, 403

Germ plasm, 222, 265, 377, 404

Germinal continuity, 216, 222, $264,265,377,404$

Gesner, 384

Gill, 175; pouches, 155, 169; slits, $137,147,164,366$

Giraffe, 266

Gizzard, of Earthworm, 123; of Bird, 151

Gland, Cowper's, 152; diagram of, 159; ductless, 159; endo- crine, 159 ; oil, 151; prostate, 152; salivary, 159; sebaceous, 139; sweat, 139, 176; thymus, $150,152,155,159$; thyroid, $152,155,159,182$; unicellular, 59,158

Glossary, 429-455

Glottis, $149,150,151$

Glucose, 13, 36

Glycerine, 14

Goethe, 410

Goitre, 182

Gonad, 137, 164, 179, 203 (see Ovary and Testis)

Gorilla, skeleton of, 354

Grafting, 221

Grape, 70

Grape sugar, 87

Grass, 65, 70

Greek natural philosophers, 345406

Greek science, 2, 379-382

Green gland, 131

Green plants, $30-38$

Gregarious animals, 331

Grew, 388

Growing point, 76, 79, 81, 82, 87

Growth, by accretion, 16; by intussusception, 11, 16, 19

Growth zone, 78

Guard cells, 22, 83

Gulfweed, 63

Gullet, 40

Gymnura, 315

H

Hair, 139; character, inheritance of, 278

Hales, 397

Haller, 395

Haploid number, 229, 234, 235

Harvey, 161, 243, 385, 386, 389, 394, 401 
Haustoria, 68

Hay infusion microcosm, 50-51

Head, 130, 190; of Honey Bee, 326

Heart, 131, 137, 148-151, 153, 163, 165,172 ; evolution of, 365 ; work of, 172

Heat, animal, 15(see Temperature)

Hedgehog, 313, 416

Hematochrome, 35

Henderson, L. J., 308

Hen's egg, 238, 253

Hepatic artery and vein, 164,165 , 167

Hepatic portal system, 150, 165, 167,168

Herbalists, 385

Herbals, 383

Heredity, 251; and evolution, 376 ; 'social,' 297 (see Inheritance)

Heritage of the individual, 261306

Hermaphrodite, 204

Hertwig, O., 21

Heterospory, 106

Heterozygote, 27\%, 279, 281

Heterozygous, 276

Hickory, 72

Hind-brain, 186 (see Brain)

Hippocrates, 381

Histology, 4; history of, 398-400; plant, 75-84 (see Tissue)

History, of biology, 379-411; comparative anatomy, 392-394; embryology, 401-403; genetics, 403-406; histology, 398-400; organic evolution, 406-411; physiology, 394-398; taxonomy, 390-392

Holdfast, 63

Homologous chromosome (see Chromosome)

Homologous organs, 130, 352
Homology, serial, 353

Homothermal, 174, 176, 312

Homozygote, $277,279,281$

Homozygous, 276, 302

Honey Bee (see Bee)

Hoofs, 138

Hooke, 387

Hormone, 181, 206 (see Endocrine)

Horns, 138

Horse Chestnut bud, 72

Horse, evolution, 361, 362; skeleton of leg, 352

Host, 334

Human, body, chemical composition, 11; median section, 153; ear, 198; egg, 239; eye, 201; kidney, 180; skeleton, 354; sperm, 239 (see Man)

Humerus, 144

Hutton, 410

Huxley, 30, 54, 211, 261, 345, 356, 393, 394

Hybrid, 272, 306 (sce Heterozygote)

Hydra, 118-121，157，169, 194, $219,332,414$; asexual reproduction, 217; discovery of, 388; feeding instinct, 342; longitudinal section, 119; nerve cell, 183; receptor-effector system, 184; regeneration and grafting, 221; reproductive organs, 204; transverse section, 22, 120

Hydranth, 218; comparison with medusa, 219

Hydrochloric acid, 157

Hydroid, 115, 117, 145; colony, 218; life history, 218

I

Iliac artery and vein, 164

Ilium, 144, 145, 354 
Immunity, 338, 339

Incus, 198

Indian Corn, 67, 263

Individual, adaptability, 339-344; origin of, 209-260; heritage of, 261-306

Infundibulum, 187-189

Ingenhousz, 398

Inheritance, 261, 403; alternative, 268, 405; blending, 268, 283,286 ; of human hair characters, 2r8; mosaic, 268; sexlinked, 268; of size in Peas, 273

Insects, 117, 415; traps, 73

Instincts, 342

Integumentary system, 116

Intercellular digestion, 156

Internal receptor, 193

Intestine, 123, 131, 137, 148, 156; nerve supply, 186; section of, 59

Intracellular digestion, 156

Invertebrates, 117, 414, 415

Invertebrate eye, 199, 200

Iris, 201

Irritability, 18, 181, 183

Ischium, 144, 145, 354

Islands, continental, 369; coral, 372

Island faunas and floras, 369

Ivy, 67

\section{J}

Jaws, 143

Jennings, H. S., 342

Johannsen, 303

Jugular vein, 164, 165

Jurassic period, 358

\section{K}

Kallima, 321

Karyolymph, 27

Karyosome, 26, 28
Katabolism, 16

Katydid, 819

Kelley, H. A., 148-152

Kelp, 63

Kidney, 137, 153, 175, 180

Kinetic energy, 6, 35, 42

\section{L}

Labyrinth, 196

Lacteals, 168

Lagena, 197

Lamarck, 3, 39, 267, 374, 393, 409

Lamina, 71

Lamprey, 416; egg and sperm, 236

Laplace, 15

Larynx, 153, 356

Latent character, 268

Lateral line organs, 195

Lavoisier, 15, 396

Law of probability, 299-305

Leaf, $65,71-75,82-84,112$; air spaces, 83 ; base, 71 ; development, 82; epidermis, 83; palisade layer, 83 ; section of, 83 ; vein, 83 ; vertical section, 22

Leeuwenhoek, 387, 388

Legs of Bee, 327

Lens, 201

Lichen, 332

Liebig, 398

Life, 6, 19; definition, 15; origin, 28,209 ; physical basis, 6,400 ; 'triangle' of, 298; web of, 330

Limb, pentadactyl, 144 (see Skeleton)

Linin, 26, 27

Linkage, 293-296

Linnaeus, 346, 390-392

Linville, H. R., 148-152

Liver, 137, 148, 149, 156, 168, 175

Living matter, adaptation, 17-18; characteristies of, 10-20; chemi- 
cal composition, 11-14; organization, 18, 19

Lizard, dissection of, 150

Lockjaw, 311

Loiseleuria, 75

Lumbricus (see Earthworm)

Lungs, 150, 153, 161, 175

Lyell, 410

Lymph, 156, 163, 168, 173

\section{M}

Macronucleus, 40, 41, 245, 248

Malaria, 336

Malarial Parasite, life history, 385

Malleus, 198

Malpighi, 388, 389, 401

Mammal, 117, 136; adaptive radiation of, 313-319; brain, 189; circulation, 165; copulatory organs, 152; classification of, 416; dissection of, 152; egg of, 238, 239; Eutherian, 313, 416 .

Mammary glands, 206

Man, body temperature, 312; digestion, 158; education, 297, 344 ; embryo, 366 ; inheritance in, 297; skeleton, 354; skeleton of arm, 352 (see Human)

Mandible, 132, 145

Marsilia, 106

Mastodon, 370

Mathews, A. P., 181, 344

Matter, non-living and living associated, 7

Maturation, 288 (see Oögenesis and Spermatogenesis)

Maxilla, 132, 145

Maxilliped, 131, 132

Mechanism, 257

Medicine and biology, 381

Medieval science, 382, 383

Medulla, 153, 187, 189 (see Brain)
Medusa, 218, compared with hydranth, 219

Megasporangium, 108, 112

Megaspore, 106, 107, 110, 112

Megasporophyll, 106, 108, 112

Mendel, 271-274, 404, 405

Mendelism, 271-306; general principles, 280-282; in Man, 278; mechanism of, 287-296, 405; laws rediscovered, 405; ratio, 272 (see Monohybrid, Dihybrid, and Trihybrid)

Meristem, 77, 78, 79

Mesenteric artery, 164

Mesentery, 137, 149

Mesoderm, 57, 126, 215; bands, 126; somatic, 126; splanchnic, 126

Mesogloea, 118, 120, 219

Mesohippus, 361, 362

Mesonephric duct, 148, 179

Mesonephros, 137, 148, 179

Mesozoic era, 358

Metabolism, 15, 16, 175, 181, 307; animals, 39-43; Bacteria, 4453; colorless plants, 44-53; green plants, 34-38

Metagenesis, 220

Metamere, 121-123, 190

Metamerism, 121, 124, 127, 130, 191

Metanephric duct, 179

Metanephros, 150, 151, 152, 153, 179

Metaphase, 225

Metaphyta, 54

Metaplasm, 26

Metazoa, 54, 116

Metencephalon (see Medulla)

Microcentrum, 319

Micronucleus, 40, 41, 245, 248

Microscope, 7; invention of, 386, 387 
Microscopists, 386-389

Microsporangium, 108, 110, 112

Microspore, 106, 107, 110, 112

Microsporophyll, 106, 112

Mid-brain, 186 (see Brain)

Millipede, 129, 415

Mimicry, protective, 323

Mirabilis, 284

Mistletoe, 68

Mitosis, 29, 224-228; typical stages in, 225

Mitral valve, 165,172

Modifications, 265-267, 302, 304, 444

von Mohl, 7

Mole, 317

Mollusc, 117, 415; development of, 255 ; nerve cells, 194

Monads, 52

Monographers, 385

Monohybrid, 272-276

Morphogenesis, 403

Morphology, 3

Mosaic inheritance, 268

Mosquito, 336

Moss, 105; classification, 413, 414; fertilization, 240; life history, 100-103

Motor nerve, 191

Mouth, 41, 119, 121

Movement, amoeboid, 19; ciliary, 19; power of, 19

Mulatto, 283-285; recombination square, 285

Müller, 396

Muscles, 18, 138, 139; cells, 59, 183; involuntary, 139; smooth, 25; striated, 25; voluntary, 139; of eye, 201

Muscular system, 116

Mutations, 269, 298, 306, 377

Mycelium, 332

Myotome, 139
Myrsiphyllum, 71

Myxedema, 182

\section{$\mathrm{N}$}

Nails, 138

Nares (see Nostrils)

Natural history, 2

Natural philosophy, 3

Natural selection, 306, 374-376, 378,411

Nature versus nurture, 296-299

Neo-Mendelism, 282-306

Nephridium, 122, 123, 124, 131, 17\%, 207

Nephrostome, 124, 177, 208

Nerve, 191; afferent and efferent, 192; auditory, 197; cranial, 152, 188; motor, 191; optic, 152; sensory, 191; sensory ending, 139; spinal, 188, 190; temperature, 312; trophic, 312; vagus, 190 ; vasomotor, 174,312

Nerve cells, differentiation, 185

Nerve cord, 123, 134, 190

Nerve fibers, 185

Nerve net, 184, 186

Nerve plexus, $186,190,191$

Nervous impulse, 191, 193, 194

Nervous systtem, 116, 133; coördination by, 183-193; Crayfish, 134; Earthworm, 134; Frog, 190

Neural arch, 137, 143

Neural canal, 137, 143, 153

Neural groove, 186

Neural tube, 186, 18\%, 190

Neuro-muscular mechanism, 183

Neuron, 184-186, 193, 194

Nictitating membrane, 355

Nitrates, 36, 43

Nitrogen cycle, 49

Nitrogen-fixing Bacteria, 49, 333

Nitrogenous wastes, 43

Nomenclature, Binomial, 391 
Nostrils, 149, 152, 153

Notochord, 137, 142,146

Nucleolus, 26

Nucleus, 9, 26, 27, 28, 77; during conjugation, 245 ; during endomixis, 248

Nurture versus nature, 296-299

Nutrition of animals, 154-160

Nutritional chain, 330

\section{$\mathrm{O}$}

Obelia, 414; life history, 218

Oedogonium, 97, 98

Oesophagus, 123, 131, 148-155

Oil, 14; gland, 151

Olfactory, bud, 196; lobe, 14y, $187,189,190$; pouches, 196; sense, 196

Oligocene period, 358

Onion leaf, 72

Onoclea, 74

Ontogeny, 364 (see Embryology)

Oöcytes, primary and secondary, 231

Oögenesis, 231-233

Oögonium, 224, 232

Operculum, 141

Opsonin, 338

Optic capsule, 141,145 ; cup, 199 ; lobes, 188, 189; nerve, 152, 190; stalk, 199

Order, in classification, 349

Organ, 59; organ-forming substances, 256, 259

Organic evolution, 262 (see Evolution)

Organisms, adaptation of, 307344 ; colonial, 55 , 56 ; microcosm, 20; structure of multicellular, 54-60

Organization, 11, 18

Organ systems, 60,116

Origin of the germ cells, 223-242
Origin of the individual, 209-260

Origin of species, 345-378, 410, 411

Osmosis, 86, 88

Osteology, 140 (see Skeleton)

Ovary, 119, 123, 148, 203

Oviduct, 123, 179, 205, 208

Ovule, 110, 112

Ovule case, 108

Owen, 394

Ox, skeleton of leg, 352

Oyster, 135, 415

\section{$\mathrm{P}$}

Pain, sense of, 195

Paleontology, 4, 356-364, 393

Palm, 67

Pancreas, 149, 152, 155, 158

Pancreatic duct, 151, 155

Paramecium, 39, 52, 116, 157, 169; aurelia, 40, 244; behavior, 340, 341 ; calkinsi, 40; caudatum, 40 ; conjugation, 41, 245; contractile vacuole, 40; digestion, 42; division, 41; ectoplasm, 40; endomixis, 41, 248; endoplasm, 40; excretion, 43; focd taking, 42; gastric vacuole, 40; gullet, 40; heredity in, 264; irritability, 194; macronucleus, 40, 41, 245, 248; metabolism, 41-43; micro-nuclei, 40, 41, 245, 248; mouth, 40, 41; neuromotor apparatus, 40; peristome, 40; power of reproduction, 375 ; reproduction, 212,246 ; respiration, 43 ; species, 40,414 ; structure and life history, 39-41; trichocysts, 40

Parasitism, 68, 220, 334-338

Parencephala, 188 (see Cerebral hemispheres)

Parthenogenesis, 243, 249

Pasteur, 210 
Patella, 145

Peas, inheritance in, 272-282

Pectoral girdle, 141, 144, 145, 354

Peduncle, 107

Pelvic bones, 317, 144, 153

Perea, 141, 148

Perch, dissection, 148

Pericardial cavity, 140

Peripheral nervous system, 186

Peristalsis, 157

Peristome, 40

Peritoneum, 59, 137

Permian period, 358

Perspiration, 176

Petal, 75, 107, 108, 112

Petiole, 71

Phagocyte, 338

Pharynx, 123, 152, 153, 155

Phenotype, 275, 277, 279, 281

Phloem, 60, 76, 81, 87

Phosphates, 36

Photosynthesis, 35, 87, 332; chemical equation, 36

Phylogeny, 364

Physcia, 332

Physical basis of life, 7-10, 400

Physical sciences, 1

Physies, origin of,' 395

Physiological division of labor (see Division of labor)

Physiologus, 383

Physiology, 3, 4, 367; comparative, 396; Flowering Plant, 8490; history, 394-398

Pigeon, compared with Archaeopteryx, 360; brain, 189; dissection of, 151; domestic varieties, 373

Pineal body, 187, 188, 189

Pinna, 152, 198

Pistil, 75, 107; compound, 108

Pitcher-plant, 73
Pith, 60, 76, 81, 87

Pituitary body, 183, 447

Placenta, 205

Planaria, 223

Plant, body, 61-90; classification, 413,414 ; chromosome reduction, 228; colorless, 38; evolution, 105, 112-114; food, 397; green, 30 ; gross structure, 6575; histology, 75-84; ideal vertical section, 76 ; physiological activities, 87 ; reproduction, 91-114; stem, 81; unicellular, 30,39

Plantigrade, 316

Plasma, 163

Plastid, 26, 27

Plexus, nerve, 190, 191

Pliny the Elder, 382

Pliocene period, 358

Polar body, 231, 233

Polar lobe, 255

Pole cells, 126

Pollen, 110, 112; basket, 329; brush, 326; combs, 329; grain, 108; tube, 109, 110

Pollination, 111

Polygon, frequency, 299-305

Polyhybrid, 276

Polymorphism, 218

Polytrichum, 101

Pond Scum, 92, 413

Population and pure lines, 300

Porpoise, 317, 416

Portal vein, $150,167,168$

Porto Santo Rabbits, 369

Potato, 66, 70

Potential energy, 6, 15, 35, 42

Precaval vein, 164

Preformation, 253, 257, 259, 401, 406

Pressure, 313

Prickly Pear, 70 
Priestley, 398

Primary cylinder, 76

Primates, 358, 416

Pronephric duct, 179

Pronephros, 179

Pronuclei, 241

Prophase, 225

Prosencephalon, 187, 188

Prostomium, 123

Proteins, 12, 14, 36, 42, 87, 157

Proterozoic era, 358

Prothallus, 103, 104

Protista, 214, 216; fertilization in, 243-248

Protohippus, 361, 362

Protonema, 101, 102

Protophyta, 39, 214

Protoplasm, 4, 7-10, 19; alveolar structure, 10; appearance, 8; chemical composition, 11 ; concept, 400; and environment, 9, 17

Protoplast, 31

Protopodite, 132

Protozoa, 39, 116, 214; classification, 414; discovery, 388 ; fertilization in, 335 ; malarial parasite, 335 ; maturation in, 233 (see Paramecium)

Pseudopodium, 9

Psychology, 4

Psychozoic era, 358

Pteridophyta, 103, 112, 414

Pubis, 144, 145, 354

Pulmonary artery and vein, 150$153,165,171,172$

Pulvillus, 328

Pupil, 201

Pure lines, 300, 302-306; versus population, 300,305

Purkinje, 7

Pyloric, caecum, 148; valve, 156

Python, 355
$\mathrm{R}$

Rabbits, Porto Santo, 369

Radial symmetry, 118

Radius, 144

Rana, 149 (see Frog)

Ray, 390

Reaumur, 395

Recapitulation theory, 364, 403

Receptor-effector system, 183,184

Receptor, external, 193; internal, 193 (see Sense organs)

Recessive character (see Character)

Recombinations, 268

Rectum, 155

Redi, 210, 388

Reducing division, 231 (see Oögenesis and Spermatogenesis)

Reduction, 228, 229

Reflex action, 193

Reflex arc, 184

Reflexes, 342

Regeneration, 217; in Crayfish, Earthworm, Flatworm, Paramecium, Salamander, Snail, 221; and grafting in Hydra, 221

Rejuvenation, 244

Renaissance science, 346, 384-386

Renal artery, 180

Renal portal system, 164, 165, 167

Reproduction, 11, 17, 212-222;

in animals, 203-208; asexual,

113; biparental, 54; versus fertilization, 243, 251; in plants, 91-114; uniparental, 54

Reproductive organs, 98-100; Crayfish, 131; Earthworm, 204; Hydra, 204; system, 116; evolution of, 179, 208, 365; Vertebrate, 137, 148-152

Reptile, 117, 136; versus Bird, 359; brain, 189; dissection of, 150 
Respiration, $37,87,89,396$; in animals, 43, 161-174; chemical equation, 37 ; in Invertebrates, 169; in Vertebrates, 169

Respiratory, currents, paths of, 170; membranes, 175; system, 116

Response, 18; organic, 307 (see Adaptation)

Retina, 200, 201

Reversion, 269

Rhinencephala, 188 (see Olfactory lobes)

Rhizoids, 104

Rhizome, 70, 74, 103

Rib, 137, 141

Ricinus, 81

Rockweed, 62, 63

Rodentia, 349

Rods and cones, 201

Roman science, 382

Root, 65-69, 76, 78-80, 112; cap, 79; hair, 80; primary, 65; tip, 79,87

Rostrum, 131

Rotifer, 135; parthenogenesis in, 249

Round Worms, parthenogenesis in, 249,415

Runners, 70; of Strawberry, 69

\section{$\mathrm{S}$}

Sacculus, 196, 197

Salivary glands, 155, 157, 159

Sap cavity, 77

Saprophytic, 51

Sarcode, 7

Sargassum, 64

de Saussure, 398

Scales, 72

Scapula, 141, 144

Sceloporus, 150

Schizogony, 335
Schlciden, 399

Schuchert, C., 358

Schultze, 7, 400

Schwann, 242, 399, 400

Scientific method, 2

Sciurus, 152, 349

Sclerotic coat, 201

Sea Lettuce, 63

Sea Urchin, 135, 259, 415; development, 58; egg, 256

Seaweeds, 62, 63

Sebaceous gland, 139

Secondary root, 66

Secretion, 158

Seed, $66,110,111,112$; coat, 111; plants, 61

Segregation, 274, 280-283, 286, 290, 306

Selaginella, 107

Selection, 299-306, 377; artificial, 373 ; natural, 306, 324, 374, 376, $378,410,411$; in population, 300; in pure lines, 300

Semicircular canals, 196-198

Seminal fluid, 152, 207

Seminal vesicle, 123,151

Senile degeneration, 244

Sense, auditory, 196; cutaneous, 195; cells, differentiation of, 194; organs, 116, 193-202; pain, 195; sight, 198; smell, 196; taste, 195; temperature, 195

Sensitive Fern, 74

Sensory nerve, 191

Sepal, 107, 112

Septa, 121

Setae, 124

Sex, 34, 113; chromosome, 292295, 377; determination, 291293; differentiation, 96-98; linked characters, 268, 291, 293; origin, 94,95 
Sexual characters, secondary, 206 Shark, 164, 416

Sheep, 263

Shoot, 65, 76, 81

Simplex group, 234

Sinus venosus, 165,166

Skeleton, appendicular, 143; axial, 143; Bat's wing, 352; Bird's wing, 352; Cat, 145; Fish, 141; Gorilla, 354; Horse's leg, 352; Man, 354; Man's arm, 352; Ox's leg, 352; Vertebrate, 140146; Vertebrate limbs, 352; Whale's flipper, 352

Skin, 138, 175; human, 139

Skull, 141, 143; bones, 145; evolution, in Camel, 363; evolution, in Horse, 362

Sloth, 317

Smell, sense of, 196

'Smilax,' 70

Snake, 416; hind limbs, 355

'Social heredity,' 297

Sociology, 4

Sol, 8

Somatic cells, 229, 246 (see Germ plasm and Germinal continuity)

Somatoplasm, 265

Somite (see Metamere)

Sorus, 104

Spallanzani, 395

Special creation, 210, 346

Species, 262, 345; classification, 391 , 392 ; concept, 390 ; mutcbility, 410

Specific form, 11

Spencer, 15, 114, 115, 375

Sperm, 101, 104, 106, 112, 236;

discovery, 388; human, 239;

Snake, 25

Spermatic fluid, 152, 207

Spermatid, 231
Spermatocytes, primary, secondary, 231

Spermatogenesis, 230-232; diagram of, 231

Spermatogonia, 224

Spermatophytes, 61, 112, 414

Sphaerella, 30-38, 52, 169, 413

Spider, 129, 415

Spinal cord, 137, 142, 152, 153;

paths of nervous impulses, 193

Spinal nerves, 188, 190, 193

Spines, 72

Spireme, 225

Spirogyra, 61

Spleen, 137, 148, 149, 150, 152

Splint bones, 355, 361, 362

Spondylomorum, 55

Sponges, 115, 117, 414

Spontaneous generation, 209, 210, 388

Sporangium, 65, 74, 112

Spore, 31, 101-113; formation, 92, 93, 312, 332

Sporogony, 335

Sporophyll, 65, 74, 106, 112

Sporophyte, 64, 101, 104, 105

Sporulation, 213, 335

Squeteague, food of, 330

Squid, 330, 415

Squirrel, 349; classification, 350; dissection, 152

Stamen, 10\%, 108, 112

Staminate flower, 355

Stapes, 198

Starch, 13, 36

Starfish, 221, 415

Statolith, 131

Stele, 76

Stem, 60, 65, 69-71, 81, 103, 112

Sternum, 145, 151, 153

Stigma, 108

Stimulus, 18

Stipule, 71 
Stoma, 22, 83

Stomach, 137, 148-153, 155

Storage root, 67

Struggle for existence, 330, 375, 411

Style, 108

Subclavian artery, 171 ; vein, 164 Subgenus, 351

Suboesophageal ganglion, 122, 123, 130,131

Suborder, 351

Subspecies, 351

Sugar, 13, 36, 158

Sulfates, 36

Sulfur Bacteria, 309

Sundew, 73

Survival of the fittest, 375,406

Swammerdam, 388

Sweat gland, 139, 176

Swimming foot, 131, 132

Sylvius, 395

Symbiosis, 331-334; Alga and Fungus, 332

Symmetry, bilateral, 124; radial, 118

Sympathetic nervous system, 186, 192

Synapse, 185

Synapsis, 231, 234, ,235, 287, 289, 290, 296

Synaptic mates, 232

Syngamy, 244 (see Fertilization)

Synkaryon, 241, 244, 250

Systems, of organs, 116

\section{$\mathrm{T}$}

Tactile corpuscle, 195

Talpa, 317

Tamias, 349

Tap root, 65

Tapeworm, 135, 414

Tapirs, distribution of, 368

Tarsus, 144,145
Taste, sense of, 195

Taxonomy, 4, 348-351, 390-392

Teeth, 138; evolution, in Camel, 363; evolution, in Horse, 362

Telophase, 225

Temperature, body, 174; limits for life, 311, 312; regulation, 174, 312; sense, 195

Tendril, 70, 72

Tennyson, 203

Tentacles of Hydra, 119

Testis, 119, 123, 131, 149-152, 203 .

Tetanus, 311

Thallophytes, 112, 413

Thallus, 62, 63, 112, 113

Theophrastus, 2, 381 .

Thistle, 72

Thomson, J. A., 6, 154, 297, 307, 364

Thoracic duct, 168

Thorax, 130, 140, 153

Thrush, 369

Thymus gland, 150, 152, 155, 159

Thyroid gland, 152, 155, 159, 182

Tibia, 144, 145, 354

Time, geologic, 358; cosmic, 358

Tissue, 59; connective, 59, 142; systems, 60,116

Tonsils, 155

Totipotent, 258

Toxin, 338

Trachea, 149, 153, 155

Tracheid, 86

Transpiration, 87,88

Transverse process, 137,143

Treviranus, 3,410

Trichocyst, 40

Tricuspid valve, 165,172

Trihybrid, 280, 281

Trillium, 70

Trypanosome, 337, 338, 414

Tunicate, 146, 415

Turgor, 84 
Turnip, 66

Tympanic membrane, 197, 198

Typhlosole, 124

\section{$\mathrm{U}$}

Ulna, 144, 145, 352, 354

Ulothrix, $61,94,95,96,413$

Ulva, 63, 413

Umbilical cord, 205

Underwing Moth, 320

Ungulata, 349

Unguligrade, 316

Uniformitarian doctrine, 376, 406

Unit character, 262, 280, 282, 286, 306

Urea, 43,176

Ureter, 148-153, 179, 180

Urinary bladder, 137, 148-153, 179

Urinary and reproductive systems, interrelationship, 179, 207

Urogenital canal, 207; pore, 148; system, 207; system of Vertcbrates, 179

Uropod, 132

Urostyle, 149

Uterus, human, 205

Utriculus, 196

\section{V}

Vaccination, 339

Vacuole, 26, 77 ; contractile, 9, 40; food, 9; gastric, 40

Valves, 163, 165, 172

Variation, 237, 261; adaptive, 378 ; fluctuating, 301; heritability of, 264-269; universality of, 410

Varieties, 351

Vascular bundle, 77, 78, 83

Vascular plants, 64, 103

Vascular system (see Circulation)
Vaso-motor nerves, 174

Vein, 163; of leaf, 77 (see Circulation)

Veinlets, 163

Vena cava, 152

Venous system, 166 (see Circulation)

Ventral aorta, 164, 171

Ventral root, 192

Ventricle, 163

Vermiform appendix, 153, 155, 355

Vertebra, 137, 141, 145, 153; human, 143

Vertebral column, 1/41

Vertebrates, 117, 135-153; body plan, 136-138; brains of, 189; characters, 146, 147; circulation and respiration, 161-174; classification, 350, 416; coelom, 140; labyrinth, diagram of, 197; limb, plan of, 144; longitudinal section, 137; skeleton, 140-146; skin, 138; transverse section, 137; urogenital system, 179

Vesalius, 384, 385, 394

Vespertilio, 318

Vestigial organs, 317, 355, 361, 362

Violet seed, 111

Vitamines, 14

Vitreous humor, 201

Vocal organ of Bird, 151

Volant, 316

Volvox, 55, 56, 217

de Vries, 269

\section{W}

Walking-stick, 322

Wallace, 410

Warm-blooded animals, 176 (see Homothermal)

Waste, nitrogenous, 43; and repair, 10 
Water Lily, 108

Weismann, 267, 404

Whale, 116; skeleton of flipper, 352

Wheat, 263

Wood, 88

Working hypothesis, 5, 396

$\mathrm{X}$

$\mathrm{X}$ chromosome, 292, 293, 377

Xylem, 60, 76, 81, 87

Yeast, 213, 310

Yolk, 238

Z

Zoögeography, 368

Zoölogy, 3, 4

Zygote, 32, 95, 98; chromosomes in, 289, 290, 293; in genetics, 275-284; organization of, 251260 
sto. 

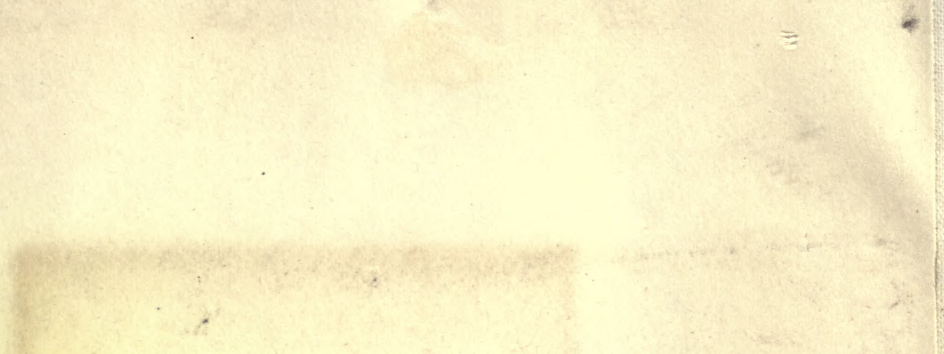


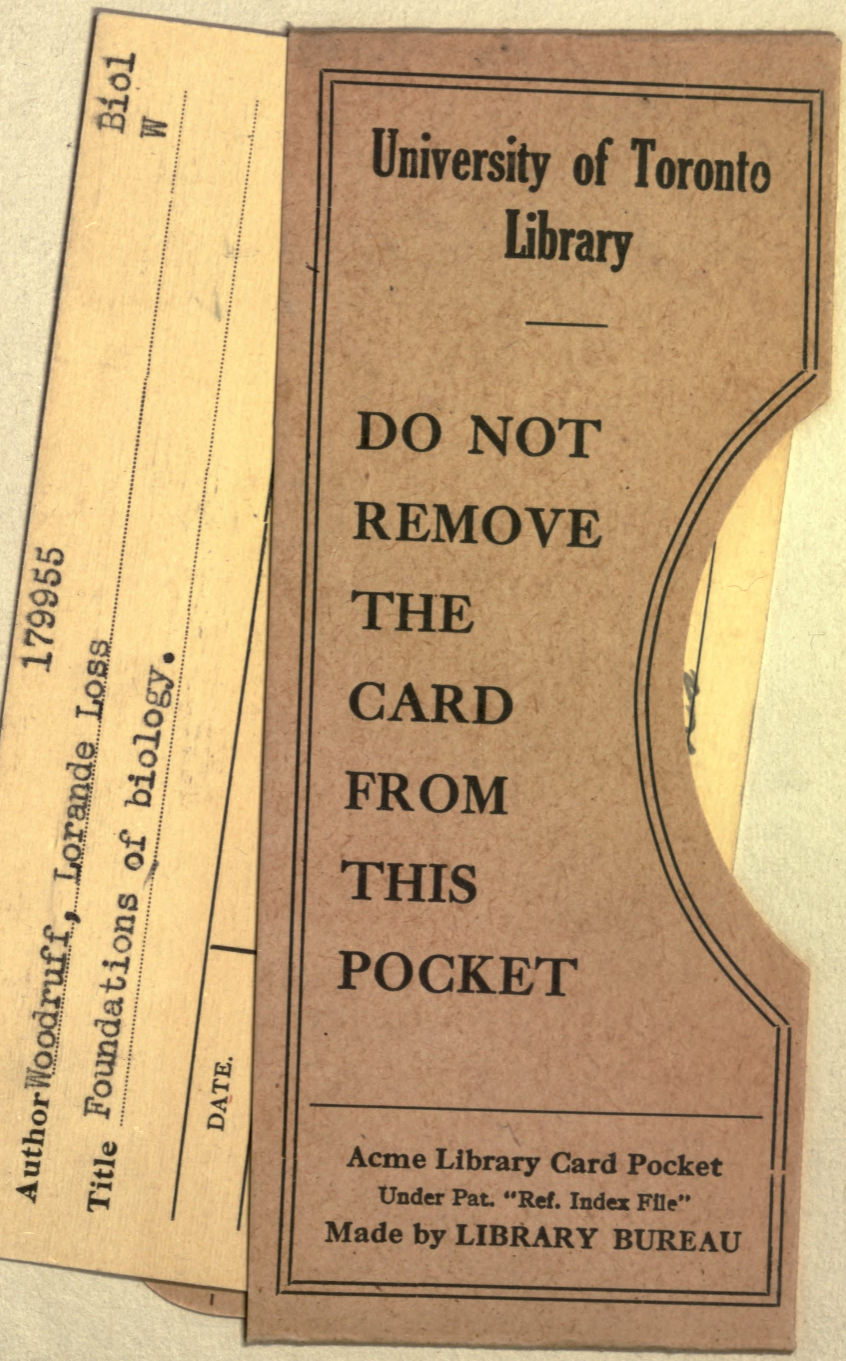



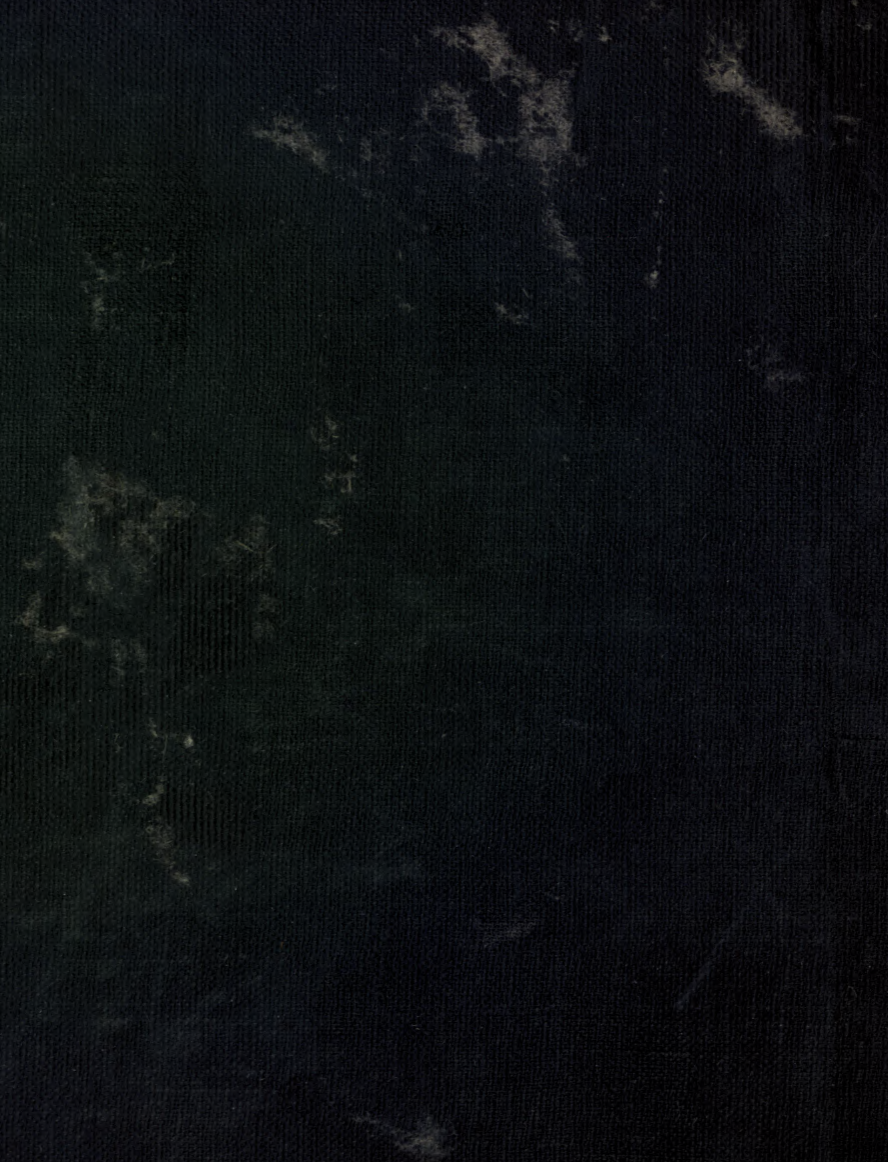